LATE CRETACEOUS (MAESTRICHTIAN)

CALCAREOUS NANNOPLANKTON BIOGEOGRAPHY

With Emphasis on Events Immediately Preceding the Cretaceous/Paleocene Boundary

by

Thomas Wolfgang Ehrendorfer

Magister rer. nat., University of Vienna, Austria

SUBMITTED IN PARTIAL FULFILLMENT OF THE

REQUIREMENTS FOR THE DEGREE OF

DOCTOR OF PHILOSOPHY

at the

MASSACHUSETTS INSTITUTE OF TECHNOLOGY

and the

WOODS HOLE OCEANOGRAPHIC INSTITUTION

February 1993

(c) Copyright Thomas W. Ehrendorfer, 1993. All rights reserved.

The author hereby grants to MIT and WHOI permission to reproduce and distribute copies of this thesis document in whole or in part.

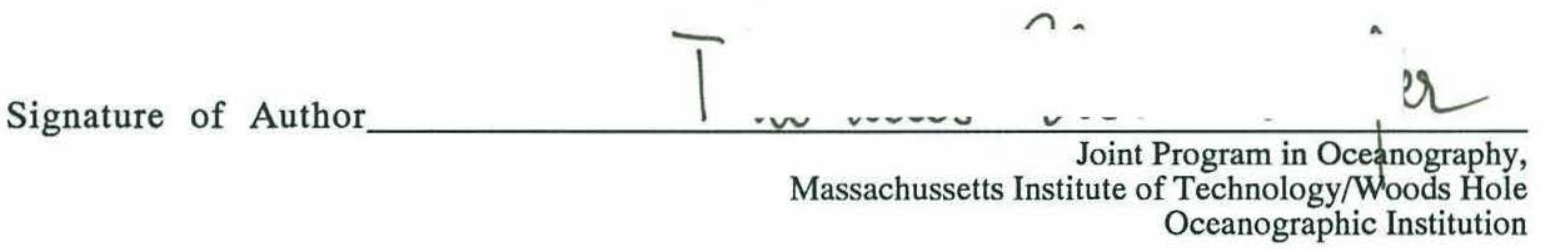

Certified by

u

William A. Berggren

Thesis Supervisor

Accepted by

\begin{tabular}{|c|}
\hline $\begin{array}{l}\text { MAEUAE } \\
\text { BIOLOGIOAL } \\
\text { LABORATOYY }\end{array}$ \\
\hline LBRAGY \\
\hline $\begin{array}{c}\text { WoODS HOE, MASS. } \\
\text { W. H. O. }\end{array}$ \\
\hline
\end{tabular}

Marcia McNutt Massachusetts Institute of Technology/Woods Hole Oceanographic Institution 
This work is dedicated to my parents. 


\title{
LATE CRETACEOUS (MAESTRICHTIAN) \\ CALCAREOUS NANNOPLANKTON BIOGEOGRAPHY \\ With Emphasis on Events Immediately Preceding the \\ Cretaceous/Paleocene Boundary
}

by Thomas Wolfgang EHRENDORFER

\author{
Submitted to the \\ Department of Earth, Atmospheric, and Planetary Sciences, \\ Massachusetts Institute of Technology \\ and the \\ Department of Marine Geology and Geophysics, \\ Woods Hole Oceanographic Institution \\ on February 8, 1993 \\ in partial fulfillment of the requirements \\ for the Degree of Doctor of Philosophy
}

\begin{abstract}
The Maestrichtian biogeography of calcareous nannoplankton is investigated in order to characterize paleoenvironmental conditions in the marine photic zone during the latest Cretaceous. Different theories explaining the biospheric turnover at the Cretaceous/Paleocene $(\mathrm{K} / \mathrm{P})$ boundary have alternatively suggested or denied substantial environmental perturbations during the last $\sim 500 \mathrm{ky}$ of the Cretaceous. The purpose of this study is to determine whether evidence from calcareous nannoplankton supports a gradual (or stepwise) decline of the photic zone environment presaging the $\mathrm{K} / \mathrm{P}$ boundary.

In order to achieve this goal a detailed quantitative study of the biogeography of calcareous nannoplankton was carried out in three time slices from early and late Maestrichtian. Well preserved material was investigated from five sections: Ocean Drilling Program Site 690 in the Atlantic sector of the Southern Ocean represents the Maestrichtian high southern nannoplankton province. Indian Ocean Sites 217 and 761, South Atlantic Site 528 and the land based, epicontinental section from Millers Ferry, Alabama, represent the Maestrichtian mid-/low latitudinal bioprovince. Quantitative counts were performed on settling slides under the light microscope. Occasionally scanning electron microscopy was employed to resolve taxonomic uncertainties.

A pronounced turnover from early to late Maestrichtian occurred in the nannoplankton in high southern latitudes. Numerous taxa (Biscutum boletum, B. coronum, B. dissimilis, $\underline{B}$. magnum, Misceomarginatus spp., Monomarginatus spp., Neocrepidolithus watkinsii, Nephrolithus corystus, Octocyclus magnus, Phanulithus obscurus, Psyktosphaera firthii, and Reinhardtites spp.) that are restricted to (or most abundant in) high southern latitudes became extinct in the latest early and earliest late Maestrichtian (between $\sim 72.4$ and $70.4 \mathrm{Ma}$ ), resulting in a loss of about one third of the early Maestrichtian
\end{abstract}


nannoplankton (corresponding to $\sim 20-25 \%$ of the assemblage). It is argued that the extinctions are not a consequence of temperature changes alone. Instead they may be a consequence of increased surface water fertility (and only secondarily due to a temperature decrease).

In addition to the extinctions, about another third of all taxa present (Biscutum constans, B. notaculum, Biscutum sp. 1, Chiastozygus garrisonii, $\underline{C}$. amphipons, Discorhabdus ignotus, Rhombolithion rhombicum, Scapholithus fossilis, Staurolithites laffittei, Watznaueria barnesae, Zygodiscus compactus, and $\underline{Z}$. diplogrammus) disappeared from high southern latitudes during the same time interval ( 72.4 and $70.4 \mathrm{Ma})$ but persisted until the end of the Maestrichtian in lower latitudes. These geographic restrictions are interpreted as a consequence of global cooling. No comparable changes were recorded in mid- and low latitudes in the early Maestrichtian, but this may represent an artifact of sampling.

While previous speculations on the paleoenvironmental preferences of some nannofossil taxa have been confirmed, several commonly accepted interpretations of the biogeographic significance of other taxa are contradicted. Micula staurophora seems to be a warm water indicator and abundance peaks of this species cannot be attributed exclusively to diagenetic effects. The biogeographic evolution of the high latitude taxon Ahmuellerella octoradiata does not correlate with temperature trends suggested from stable isotope studies implying that this taxon is not a cold water indicator. Abundance changes of other high latitude taxa (e.g. Nephrolithus frequens, Cribrosphaerella? daniae, Kamptnerius magnificus, and Gartnerage spp.) correlate roughly with temperature changes, but seem to respond only beyond a certain threshold.

No gradual or stepwise extinctions were observed during the last $500 \mathrm{ky}$ of the Maestrichtian. Environmental perturbations as indicated by stable isotope studies (e.g. warming pulse, circulation changes) led to abundance fluctuations of a few taxa, but did not result in any extinctions. This supports previous observations that the extinctions of the calcareous nannoplankton at the $\mathrm{K} / \mathrm{P}$ boundary were not presaged during the Maestrichtian.

Thesis Supervisor: Dr. William A. Berggren, Senior Scientist 


\section{ACKNOWLEDGEMENTS}

My thanks go first and foremost to my parents for their love and support during my studies here in the United States.

Special thanks go to the members of my thesis committee, particularly to my supervisors Marie-Pierre Aubry and Bill Berggren for their inexhaustible support during all parts of my graduate studies. This thesis would have never been written without their constant scientific and personal advice, encouragement, and help. I am grateful to Dick Norris for all our discussions on scientific as well as personal matters. I am also thankful for the advice and support from my other committee members, Ed Boyle, Lloyd Keigwin, and Pat Lohmann.

Discussions with Tim Bralower and Steve D'Hondt have helped me focus on specific research questions; their advice is gratefully acknowledged. Special thanks are due to Rindy Ostermann for helping me with the carbonate content analyses. Colleen Hurter and the library staff must be commended for their invaluable help in tracking down hard-to-find literature. I want to thank the staff at the Center for Data Processing of the University of Agriculture in Vienna, Austria, for their help with various statistical questions. My acknowlegements also go to the staff of the Core Repositories of the Ocean Drilling Program at Lamont, College Station, and La Jolla for their friendly support during my sampling trips.

I thank El Uchupi for serving on a moment's notice as chairman at my

General Examination, and for his continual help and support as student advisor. I am grateful to Jake Peirson, Abbie Jackson, and Stella Callagee in the Education Office for their help in all matters ranging from registration and exhausted student accounts to technical details regarding the preparation of this document. Thanks are also due to Pam Foster, Roy Smith and Janet Johnson for their friendly help.

I was fortunate to have met friends like Mike and Danusia Kaminski, Peter Schweitzer, Luc Beaufort, Bernward and Felicita Hay, Niall Slowey, JoAnn Muramoto, Carol Arnosti, and Rick Krishfield. Special thanks go to my office mate of the last two years, Javier Escartin, not only for his help in programming, but, more importantly, for his companionship and cheerfulness.

Special thanks are due to my fiancée, Lee Goodell, for her love, patience and understanding during periods when my work absorbed me completely. I also want to thank her parents and her uncle's family for their warm hospitality.

I gratefully acknowledge receiving a Graduate Research Assistantship from the Woods Hole Oceanographic Institution during most of my tenure in the Joint Program. Additional funding from the following sources is also appreciated: a travel grant from the Austrian-American Educational Commission (Fulbright Commission); a Grant-in-Aid from the American Association of Petroleum Geologists (1990); a grant from the Ocean Ventures Fund at W.H.O.I. (1991); a Research Grant-in-Assistance from the Paleontological Society/Margaret C. Wray Trust (1991); a Grant-in-Aid of Research from the Sigma Xi Society (1992). 


\section{TABLE OF CONTENTS}

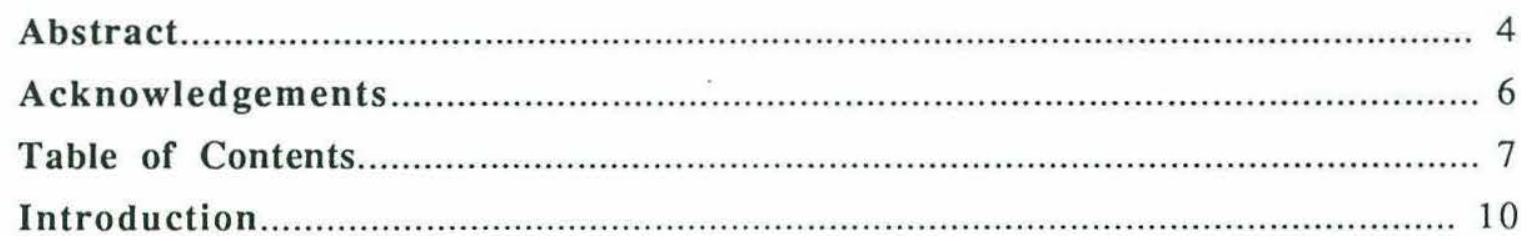

Chapter 1. Maestrichtian Climate and Oceanography.................. 12

1) Global Temperature Gradients.................................................................. 12

2) Biospheric Changes at the Cretaceous/Paleocene Boundary and

Extinction Hypotheses....................................................................... 14

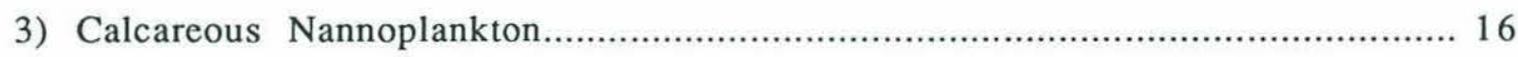

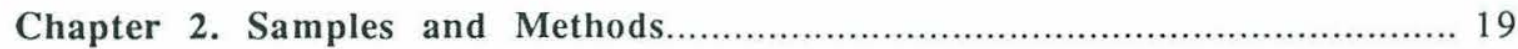

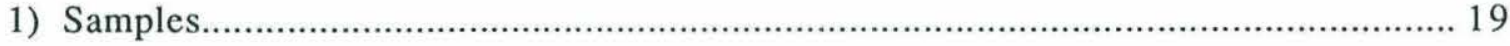

(A) Sections Investigated in This Study.................................................. 19

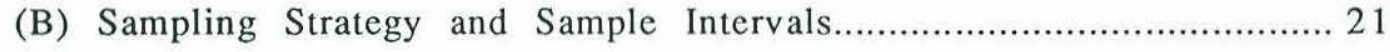

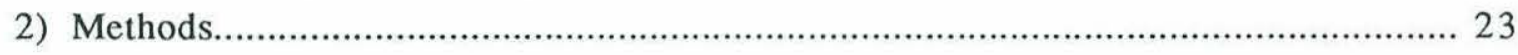

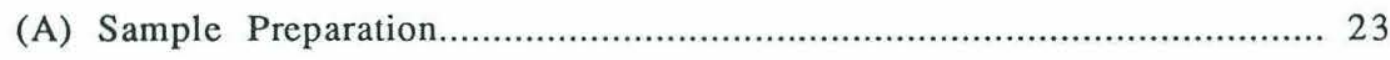

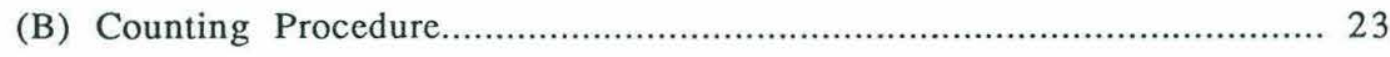

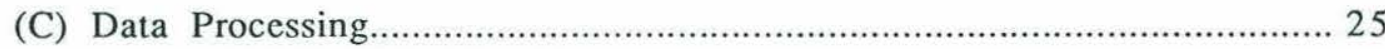

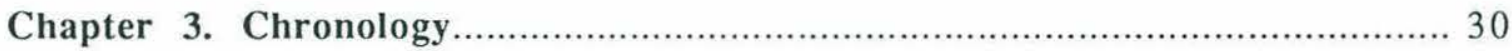

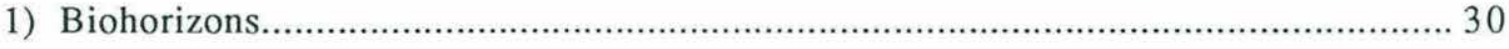

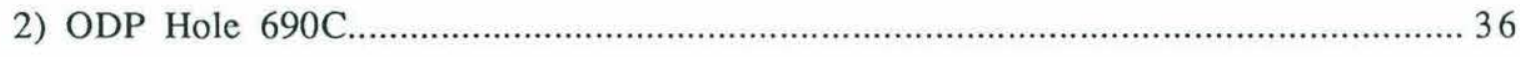

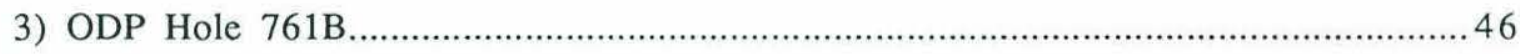

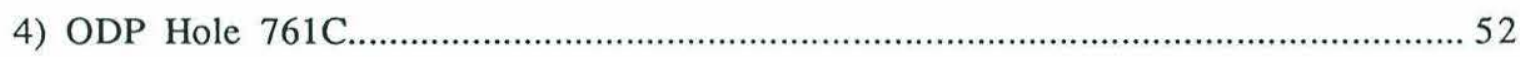

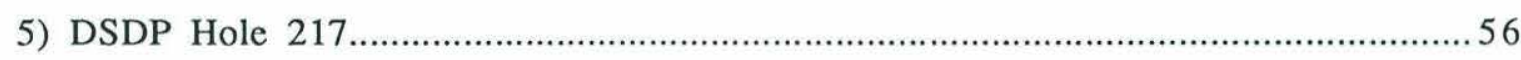

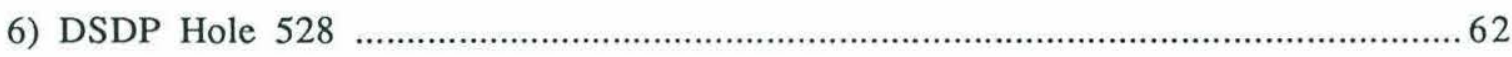

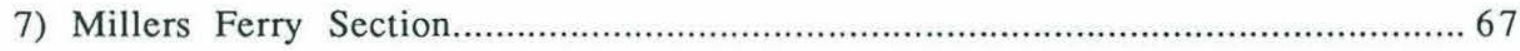

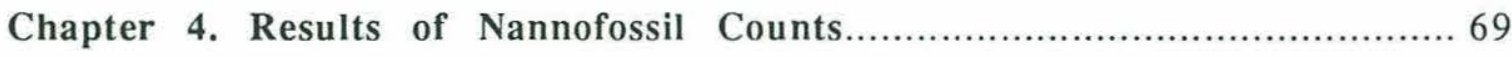

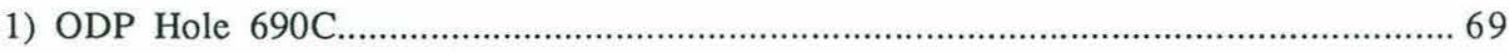

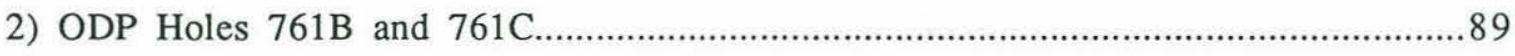

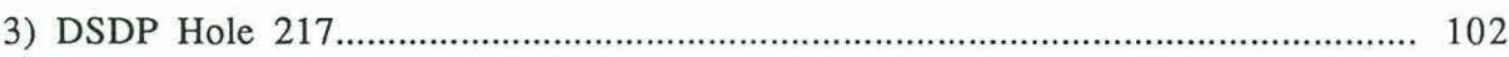

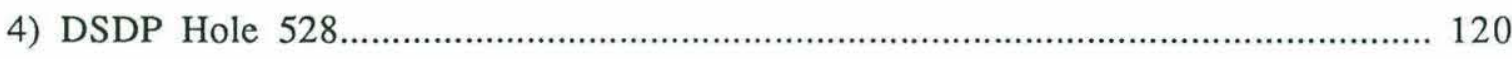


Chapter 5. Discussion.

1) Maestrichtian Evolutionary and Biogeographic Events

at High Latitudes............................................................................... 145

(A) Evolutionary Changes........................................................... 145

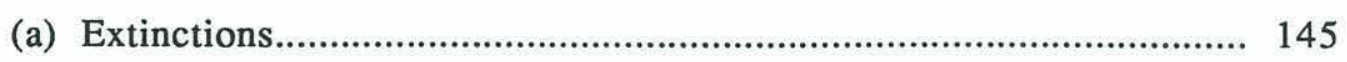

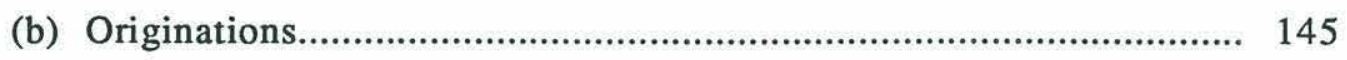

(B) Biogeographic Changes.......................................................... 149

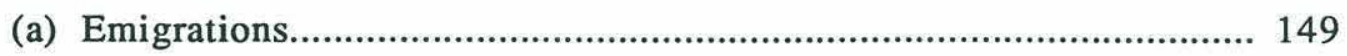

(b) Abundance Changes................................................................ 149

2) Maestrichtian Evolutionary and Biogeographic Events

in Mid/Low Latitudes........................................................................ 154

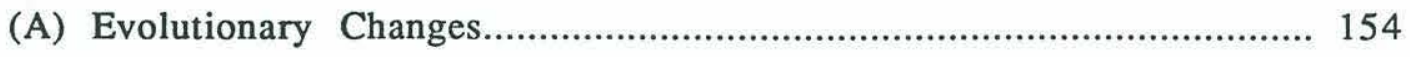

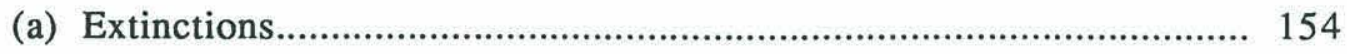

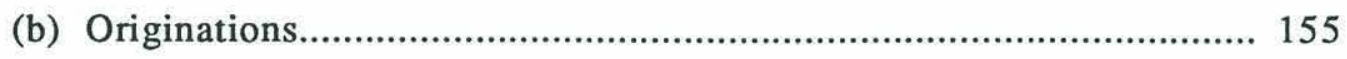

(B) Biogeographic Changes and Abundance Changes...................... 155

3) Maestrichtian Nannoplankton Evolution................................................ 159

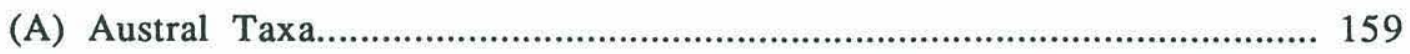

(a) Which are the "austral" taxa? ................................................. 159

(b) Paleogeographic distribution of austral taxa...........................160

(c) Why did austral calcareous nannoplankton species become

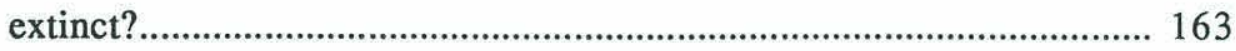

(B) Nannoplankton Response to Environmental Perturbations

During the Last $500 \mathrm{ky}$ of the Cretaceous (66.9 to $66.4 \mathrm{Ma}) \ldots \ldots \ldots \ldots \ldots \ldots . . . . . .171$

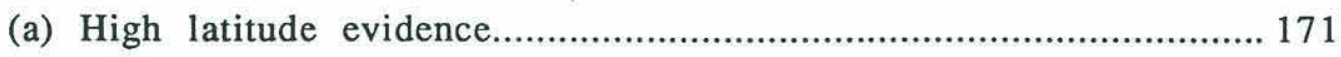

(b) Mid-latitude trends................................................................. 177

(C)Paleoenvironmental Significance of Selected Nannoplankton

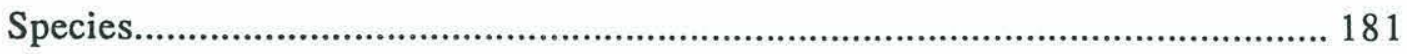

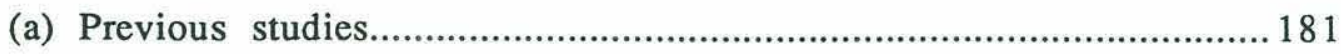

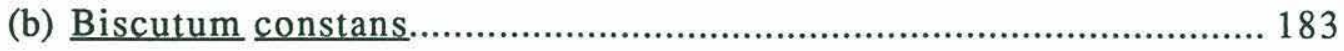

(c) Discorhabdus ignotus...................................................................... 186

(d) Nephrolithus frequens and other high latitude taxa................ 186

(e) Ahmuellerella octoradiata ........................................................ 190

4) Implications of High Resolution Biogeographic Studies ........................ 190

5) Implications for the Extinctions at the K/P Boundary............................ 192 


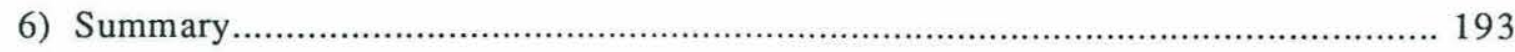

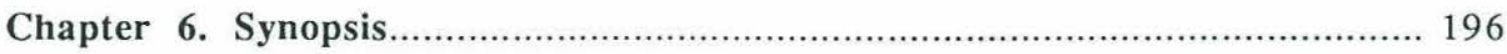

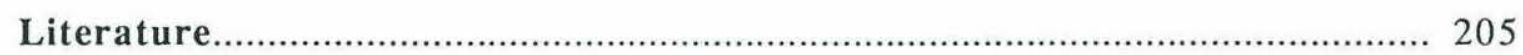

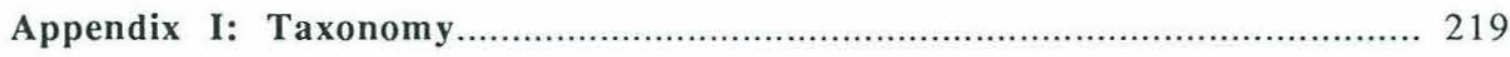

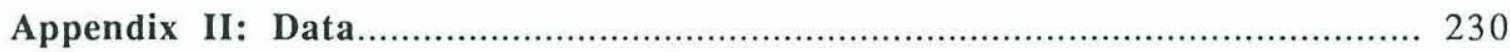

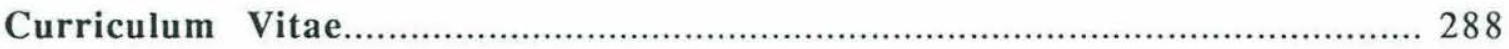




\section{INTRODUCTION}

The Maestrichtian represents the last $8.1 \mathrm{~m} . \mathrm{y}$. of the Cretaceous (74.5 Ma - 66.4 Ma; Kent and Gradstein, 1985; Berggren et al., 1985). Its end (at $66.4 \mathrm{Ma}$; Berggren et al., 1985) corresponds to the Cretaceous/Paleocene (K/P) boundary, when one of the most severe extinctions of life on Earth occurred (e.g. Russell, 1977; Raup and Sepkoski, 1984). Pronounced changes of the climate, surface water circulation, and stratification of the photic zone during the Maestrichtian have been proposed (e.g. Douglas and Savin, 1975; Huber and Watkins, 1992). Little micropaleontologic evidence is available to assess how these changes affected the marine micro- and nannoplankton. Some authors have concluded that stable ecological conditions prevailed in the photic zone during the last 15 m.y of the Cretaceous (e.g. Thierstein, 1981). Others have argued that environmental perturbations and long term climate shifts were responsible for gradual extinctions in some groups of organisms (inoceramids, dinosaurs; see Kauffman, 1984, for a review) during the Maestrichtian.

The extinction event at the end of the Cretaceous is one of the most severe of the Phanerozoic (Raup and Sepkoski, 1984) but the mechanisms causing the extinctions are still vehemently debated. The impact of an asteroid (Alvarez et al., 1980) or of a comet (Hsü, 1980) has been proposed to explain the abruptness of the $\mathrm{K} / \mathrm{P}$ extinctions in numerous groups of organisms. Progressive cooling (Stanley, 1984), possibly linked to massive volcanic eruptions (Courtillot et al., 1986), and changes in the ocean circulation (deep water formation) as a consequence of sea level fall (Brinkhuis and Zachariasse, 1988) have been proposed as alternative mechanisms. Paleontologic evidence in support of either mechanism has been presented (e.g. Thierstein, 1982; Kauffman, 1984).

In this study I investigate the Maestrichtian biogeographic evolution of the calcareous nannoplankton in order to determine how the changes in the oceanic surface water habitat affected them. Biogeographic changes, migrations, and extinctions of calcareous nannoplankton species are documented and their causal relation to environmental perturbations are explored. The biogeographic patterns observed in the early and midMaestrichtian are compared to those of the last $\sim 500 \mathrm{ky}$ of the Maestrichtian in order to assess whether increased environmental stress could be documented. 
Calcareous nannoplankton are well suited to study the effect of proposed oceanic environmental perturbations on the marine plankton for several reasons. 1) The ubiquitous presence of fossil remains of calcareous nannoplankton in calcareous marine sediments allows worldwide sample coverage and comparisons between different paleoenvironments. 2) Due to the small size and abundance of calcareous nannofossils, samples can be very closely spaced, allowing high temporal resolution; only very little material is necessary to conduct quantitative studies. 3) In contrast to previous synoptic studies (Thierstein, 1981), material from high southern latitudes recovered by the Ocean Drilling Project during the past few years is included in this investigation. It is essential to include high and low latitudes sites in a biogeographic study of Maestrichtian calcareous nannoplankton, because of the pronounced bioprovincialism that has been documented (e.g Wind, 1979a, b; Wise, 1988). 


\section{CHAPTER 1 MAESTRICHTIAN CLIMATE AND OCEANOGRAPHY}

\section{1) Global Temperature Gradients}

Geological and paleontological evidence indicate that the Cretaceous period was considerably warmer than today, with strongly reduced latitudinal and vertical temperature gradients in the oceans (reviewed by Savin, 1977; compare also Barron et al., 1981). Polar ice caps did not exist (Miller and Fairbanks, 1987) and ocean surface temperatures in low latitudes were between $17^{\circ}-20^{\circ} \mathrm{C}$ (similar to today), while bottom water temperatures ranged from $5^{\circ}-8^{\circ} \mathrm{C}$ (Douglas and Savin, 1971, 1973, 1975; Saito and Van Donk, 1974; Savin, 1977; Saltzman and Barron, 1982) or $6.5^{\circ}-10^{\circ} \mathrm{C}$ according to Shackleton and Boersma (1984), which is much warmer than today's $1-3^{\circ} \mathrm{C}$.

Latitudinal temperature gradients were lower than today: high southern latitude surface water temperatures were $\sim 4.5^{\circ}-10.5^{\circ} \mathrm{C}$ (Barrera et al., 1987). Studies of plant fossils from the North Slope of Alaska led Parrish and Spicer (1988) to estimate that mean annual Arctic temperatures were $2^{\circ}-8^{\circ} \mathrm{C}$.

\section{Cooling Trend}

Oxygen isotope analyses of planktonic and benthic foraminifera, of fine fraction carbonate (primarily calcareous nannofossils), and of well preserved macrofossils (inoceramids) imply a general cooling trend during the Late Cretaceous (Albian to Maestrichtian, Douglas and Savin, 1975).

A temperature decrease in the early Maestrichtian of bottom and surface waters was reported by Douglas and Savin (1975), Margolis et. al. (1977), and Boersma (1984b) in low and mid-latitudes. Clauser (1987) reported a cooling peak straddling the late Campanian/early Maestrichtian boundary from a section near Bidart (southwest France). No temperature changes are reported during the middle Maestrichtian (Boersma, 1984b). While Margolis et al. (1977) reported a slight decline of surface- and bottom water temperatures during the late Maestrichtian, Douglas and Savin (1975) reported a temperature increase in the early Danian. Shackleton and Boersma (1984) indicated "somewhat higher mean surface temperatures" in the Paleocene than in the Maestrichtian in the South Atlantic (Walvis Ridge, paleolatitude of about $40^{\circ} \mathrm{S}$ ). Zachos et al. (1989) reported cooling beginning in the latest Cretaceous (about $200 \mathrm{ky}$ before the $\mathrm{K} / \mathrm{P}$ boundary) and a warming peak in the 
early Paleocene ( 600 ky after the K/P boundary). Barrera and Huber (1990) presented stable isotope evidence from the high southern Atlantic Ocean (Maud Rise) indicating that surface and deep waters cooled throughout the Maestrichtian.

\section{Latest Maestrichtian Warming Pulse}

Stott and Kennett (1990b) reported a brief warming pulse $\left(\sim 2^{\circ} \mathrm{C}\right)$ in the latest Maestrichtian (between $\sim 66.9$ and $66.6 \mathrm{Ma}$; i.e. this pulse did not straddle the K/P boundary). Land plant evidence from the western interior of North America (Wyoming and North Dakota) also suggest a brief warming trend during the last $350 \mathrm{ky}$ (from early Subchron C29R) of the Maestrichtian (Johnson, 1992).

\section{Deep Water Formation}

Ocean bottom waters were much warmer than they are today (see above). Two hypotheses exist for deep water formation in the Cretaceous oceans: 1) formation of dense, saline waters on subtropical shelves where evaporation exceeded precipitation (Brass et al., 1982); and 2) deep water formation due to cooling in high latitudes (e.g. Barrera et al., 1987). Brinkhuis and Zachariasse (1988) speculated that the regression at the K/P boundary led to the cessation of deep water formation; the resulting interruption of deep ocean circulation and upwelling of nutrients from the deep ocean caused the collapse of the marine ecosystem at the K/P boundary. This hypothesis, however, does not explain the extinctions of terrestrial organisms.

\section{Maestrichtian Sedimentary Cycles}

Cyclic variations of carbonate content (expressed visually as red and white color cycles) occur in Upper Cretaceous - lower Cenozoic sediments in the South-Atlantic. Herbert and D'Hondt (1990) interpreted these variations as resulting from precessional climate cycles. It has been shown that certain calcareous nannofossil species fluctuate in response to orbital forcing (e.g. Chepstow-Lusty et al., 1989; Beaufort and Aubry, 1990; Erba et al., 1992). This has not yet been demonstrated for the Maestrichtian. The identification of such taxa would be very valuable for paleoclimatic as well as stratigraphic investigations (see discussion in Herbert and D'Hondt, 1990). 


\section{Sea level changes}

Haq et al. (1987) have reported a sea level fall at the early/late Maestrichtian boundary as well as at the K/P boundary. Huber (1992a) speculated that the mid-Maestrichtian sea level fall led to significant changes in the ocean circulation and ended the isolation of the austral planktonic foraminiferal province. Brinkhuis and Zachariasse (1988) speculated about the consequences of the sea level fall at the K/P boundary (see above).

\section{2) Biospheric Changes at the Cretaceous/Paleocene boundary and Extinction Hypotheses}

Biospheric Changes at the K/P boundary

Extinction or significant reduction of species diversity at the K/P boundary are documented for groups as diverse as marine calcareous plankton (foraminifera: Loeblich and Tappan, 1957; Luterbacher and Premoli-Silva, 1964; coccolithophorids: Bramlette and Martini, 1964), marine macrobenthos (bivalves, brachiopods, bryozoans, echinoderms; see review by Hallam and Perch-Nielsen, 1990) and marine nekton (belemnites: Christensen, 1976; ammonites: Cobban and Scott, 1972, Wiedmann, 1964), as well as land vertebrates (dinosaurs: Van Valen and Sloan, 1977; for an overview see Kauffman, 1984). A major extinction event was also documented for land plants (Johnson and Hickey, 1990). Some of these groups disappeared rather abruptly (most calcareous marine plankton), others had already been on the decline prior to the end of the Cretaceous (inoceramids, and dinosaurs; see Kauffman, 1984, for a review). Theoretical considerations by Signor and Lipps (1982) and findings of recent fieldwork (summarized by Kerr, 1991) challenge this view of gradual attrition and claim that the apparently gradual extinctions may be sampling artifacts resulting from the increasing scarcity of macrofossils in the strata below the boundary.

In contrast to the extinctions, some groups of organisms were little affected by the K/P boundary event(s). These included some phytoplankton groups, such as organic walled dinoflagellates (Brinkhuis and Zachariasse, 1988) and siliceous diatoms (Kitchell et al., 1986) as well as some macroinvertebrates (nautiloids: Kauffman, 1984), and vertebrates (turtles: Hutchison and Archibald, 1986; snakes, crocodilians: Kauffman, 1984) and mammals. 
Cretaceous/Paleocene Boundary Hypotheses

In addition to the biological changes, chemical and mineralogical anomalies in sediments on both sides of the K/P boundary are well known. Assuming a causal connection between the chemical and mineralogical anomalies on one hand, and the extinctions on the other hand, Alvarez et al. (1980) proposed the impact of a $10-\mathrm{km}$-diameter asteroid at the $\mathrm{K} / \mathrm{P}$ boundary (for a review see Alvarez, 1986). Other workers suggested the impact of a comet (Hsü, 1980) or several simultaneous impacts (Smit, 1990). Among others, a circular subsurface structure near Chicxulub on the Yucatán Peninsula (Mexico) was proposed as the site of the $\mathrm{K} / \mathrm{P}$ boundary impact (Hildebrand et al., 1991).

In contrast to extraterrestrial causes of the $\mathrm{K} / \mathrm{P}$ extinctions, Courtillot et al. (1986) claimed that extended intense volcanism associated with the formation of the Deccan Traps could explain the biospheric changes and the mineralogical/chemical signatures more readily (see also Officer et al., 1987). Other researchers have claimed that earthbound, environmental changes (e.g global cooling: Stanley, 1984) during the Late Cretaceous were sufficient to explain the $\mathrm{K} / \mathrm{P}$ extinctions.

The basic differences between the extraterrestrial and the earthbound extinction hypotheses are the timing and duration of their respective influences on the biosphere. The flood basalt volcanism of the Deccan Traps straddled the K/P boundary and lasted about 0.5 to 1 m.y. (paleomagnetic and paleontologic data indicate that the bulk of the Deccan Traps were extruded during Chron 29R, the oldest and the youngest flood basalts were extruded during times of normal polarity; Courtillot et al., 1986; Courtillot, 1990). In contrast, the impact of an extraterrestrial body is an instantaneous event. Paleontologists have pointed out that a discrepancy exists between the instantaneous, severe, and non-selective extinctions expected by the impacthypothesis, and the actual changes in fossil assemblages occurring prior to and extending across the K/P boundary, as pointed out above (Clemens et al., 1981). 


\section{3) Calcareous Nannoplankton}

Remains of calcareous nannoplankton are ubiquitous in marine calcareous sediments. Their small size and great abundance in the sediments permit quantitative investigations of abundance changes of individual taxa. Cores drilled by the Deep Sea Drilling Project (DSDP) and the Ocean Drilling Program (ODP) in the world's oceans provide an unprecedented opportunity to study these changes at very high resolution at almost all latitudes.

\section{Previous Studies: Paleoprovincialism and Biogeographic Changes}

Only few studies have investigated biogeographic changes of calcareous nannofossils during the Maestrichtian. Yet several observations are well documented.

Provincialism: Maestrichtian provincialism of calcareous nannoplankton was first pointed out by Worsley and Martini (1970) who showed that the late Maestrichtian marker species Micula murus and Nephrolithus frequens were largely restricted to low and high latitudes, respectively. Worsley (1974), Thierstein (1976, 1981) and Wind (1979a, b) conducted superregional studies and confirmed that numerous species had pronounced latitudinal abundance gradients in the Maestrichtian. This latitudinally-defined provincialism was in contrast to the conditions in the mid-Cretaceous (Barremian to Cenomanian; Roth and Bowdler, 1981) when latitudinal provincialism was weak, but oceanic versus neritic provincialism well developed (Roth and Bowdler, 1981). Wise (1988) argued that the increase of latitudinal provincialism of calcareous nannofossils during the Late Cretaceous reflected the global cooling that progressed during the same time (compare e.g. Douglas and Savin, 1975). Similarly, Wind (1979a) speculated that some high latitude taxa (B. magnum and $\underline{B}$. coronum) were indicative of cool surface water temperatures, whereas others (such as e.g. $\underline{B}$. constans) were characteristic of warmer water temperatures.

Biostratigraphy: The latitudinal provincialism during the Late Cretaceous is also reflected in the fact that nannofossil taxa that have been used for stratigraphic purposes in low latitudes (e.g. Bukry, 1973) were absent from mid- and high latitudes. For this reason, different zonations have been developed for different latitudinal zones.

Geographic and Temporal Changes: Thierstein (1981) performed semiquantitative analyses of late Campanian to early Paleocene calcareous 
nannoplankton associations. His study includes sections from all ocean basins and from high as well as from low latitudes. Only one site was from very high southern latitudes (DSDP Hole 327A) and its stratigraphic range was misinterpreted ${ }^{1}$. In addition to latitudinal bioprovincialism (see above) Thierstein (1981) concluded in particular that (i) nannofossil abundances did not change significantly during late Campanian through Maestrichtian, indicating stable oceanic surface environments, (ii) that no gradual or stepwise extinctions of Cretaceous taxa occurred prior to the $\mathrm{K} / \mathrm{P}$ boundary and (iii) that the persistent taxa (i.e. those that "survive" the K/P extinctions; Percival and Fischer, 1977) occurred mainly at high latitude sites possibly indicative of their adaptation to higher seasonality of temperature, salinity or light.

Doeven (1983) investigated abundance changes of calcareous nannoplankton taxa from Campanian to Maestrichtian in the northwest Atlantic Ocean (Canadian Atlantic Margin). He interpreted the abundance

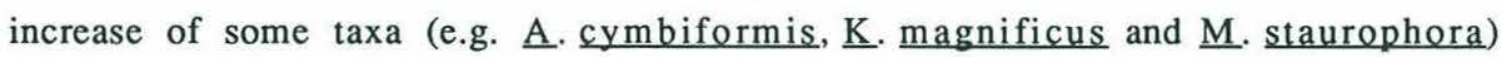
and the decrease of $\underline{W}$. barnesae as indicative of cooling of surface waters in the early Maestrichtian, possibly as a consequence of circulation changes caused by early seafloor spreading in the Labrador Sea.

The resolution in both of these studies was very low: Thierstein's (1981) sample spacing throughout most of the late Campanian and Maestrichtian was $\sim 1-5 \mathrm{~m}(\sim 100-200 \mathrm{ky})$, but increased significantly (sample spacing $<10 \mathrm{~cm}: \sim 5-10$ ky) immediately below $(\sim-1 \mathrm{~m})$ the K/P boundary. Doeven (1983) investigated one (or two) samples in each of the five Campanian to Maestrichtian nannofossil zones in nine drillholes (29 samples total).

In addition, both studies only reported on the abundance trends of the most abundant taxa present ( $>2 \%$ of the assemblage), since the authors believed that abundance changes of rarer taxa were unreliable.

\footnotetext{
${ }^{1}$ Thierstein (1981) thought that the age of Cores $327 \mathrm{~A}-10$ to $327 \mathrm{~A}-12$ was late Maestrichtian (while in fact it was early Maestrichtian), most likely because he mistook the early Maestrichtian species Nephrolithus corystus for the late Maestrichtian marker species $\underline{N}$. frequens. The same mistake was made in the original core descriptions (Shipboard Scientific Party, 1977; Wise and Wind, 1977). It was only in 1979 that Wind (1979a) had recognized the taxonomic and stratigraphic differences between $\underline{N}$. corystus and $\mathbf{N}$. frequens.
} 
$\underline{\text { K/P Boundary Studies of Calcareous Nannoplankton Associations }}$

Calcareous nannoplankton associations have been studied extensively in $\mathrm{K} / \mathrm{P}$ boundary sections all over the world (e.g Percival and Fischer, 1977; papers in Christensen and Birkelund, 1979; Perch-Nielsen et al., 1982;

Thierstein, 1981; Jiang and Gartner, 1986). Most studies concentrated on the abrupt extinctions at the $\mathrm{K} / \mathrm{P}$ boundary and the recovery of the calcareous nannoplankton in the early Paleocene. No quantitative, high resolution studies exist that documented abundance changes of all calcareous nannofossil taxa during the last $500 \mathrm{ky}$ of the Cretaceous. 


\section{CHAPTER 2 SAMPLES AND METHODS}

\section{1) Samples}

\section{(A) SECTIONS INVESTIGATED IN THIS STUDY}

Three sites (ODP Holes 690C, 761B and DSDP Hole 217) were selected for detailed study based on 1) their latitude during the Maestrichtian (high southern and mid-latitudes; Figure 1; see also site descriptions in Chapter 3), 2) the completeness of their Maestrichtian sedimentary record, and 3) the high quality of calcareous nannofossil preservation. In addition, three sections were selected (ODP Hole 761C, DSDP Hole 528, and Millers Ferry Section) to study calcareous nannoplankton biogeographic evolution in detail during the last several $100 \mathrm{ky}$ prior to the $\mathrm{K} / \mathrm{P}$ boundary (Figure 1).

Hole $690 \mathrm{C}\left(\sim 65^{\circ} \mathrm{S}\right)$ is one of the few Maestrichtian sections in calcareous facies recovered in high southern latitudes to date. Its Maestrichtian latitude was very similar to its present latitude (see Chapter 3). This hole represents southern high latitudes and the austral province in this study.

Hole $761 \mathrm{~B}$ is located at $16^{\circ} \mathrm{S}$ on the northwestern Australian margin (Wombat Plateau, Indian Ocean); its Maestrichtian location was in (high) mid latitudes $\left(\sim 40^{\circ} \mathrm{S}\right.$; see Chapter 3$)$. Hole $761 \mathrm{C}$ was included in this study because the $\mathrm{K} / \mathrm{P}$ boundary section in this hole appears to be continuous, whereas an unconformity occurred in Hole 761B (see Chapter 3).

Hole 217 is presently located at $8^{\circ} \mathrm{N}$ (Ninetyeast Ridge, Bay of Bengal, Indian Ocean). This site was originally included in this study to represent tropical latitudes, but results from recent ODP Legs in the Indian Ocean indicate that the Maestrichtian latitude of this site was $\sim 30^{\circ} \mathrm{S}$ (see Chapter 3).

DSDP Hole 528 is located on Walvis Ridge in the South Atlantic Ocean $\left(28^{\circ} \mathrm{S}\right)$. Its Maestrichtian latitude was $\sim 35^{\circ} \mathrm{S}$ (Chave, 1984). This site was included in order to investigate nannofossil changes associated with the pronounced sediment color variation at this site.

The section at Millers Ferry (Alabama) represents the only section from the northern hemisphere investigated in this study. It was located in (low) mid-latitudes during the Maestrichtian $\left(\sim 30-35^{\circ} \mathrm{N}\right)$. It also represents the only epicontinental section studied herein. 


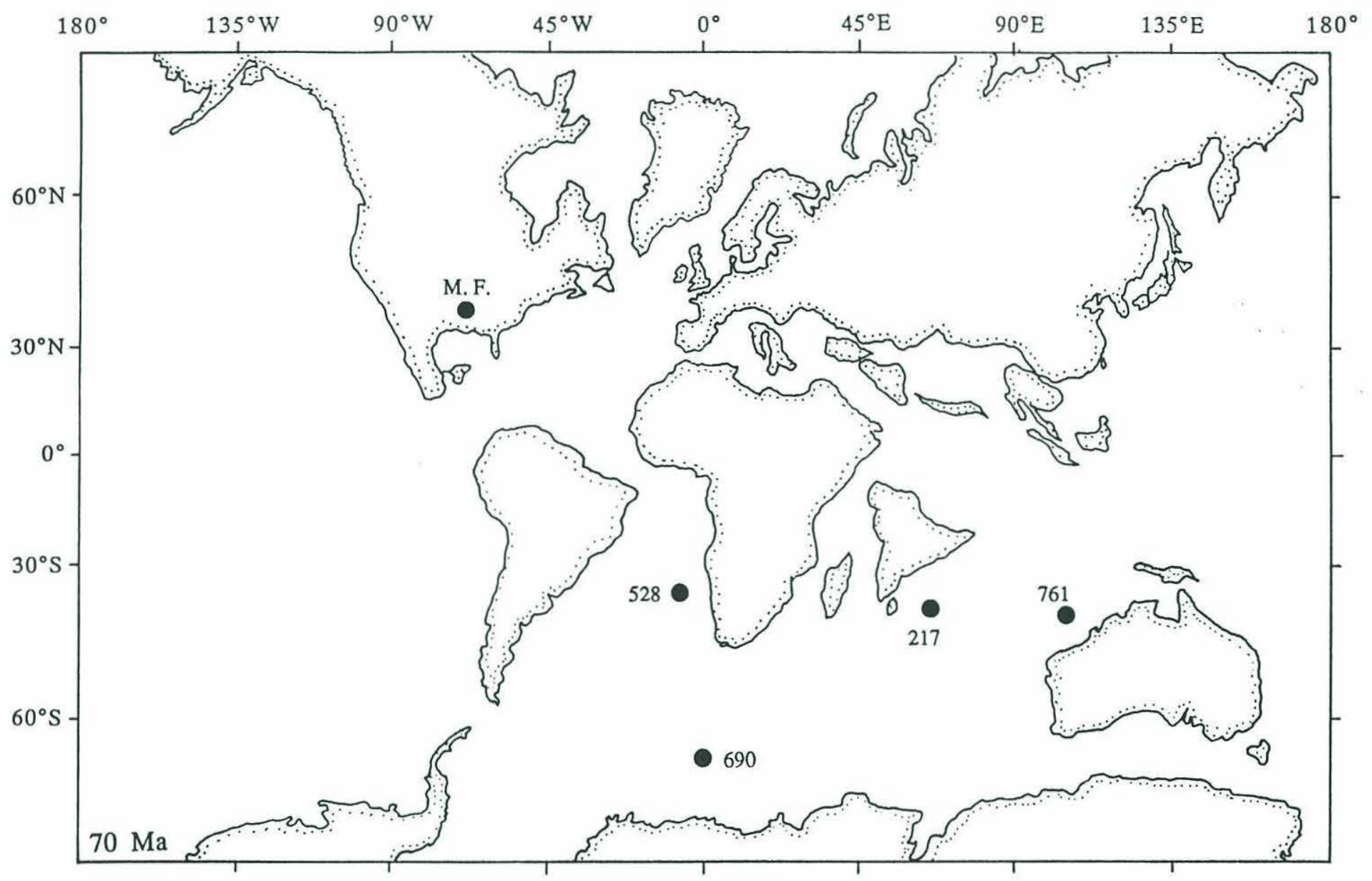

Figure 1: Maestrichtian locations of the sections investigated in this study. Numbers indicate DSDP and ODP Sites, M. F. indicates the Millers Ferry Section. Paleocontinental reconstruction of the mid-Maestrichtian (70 Ma) after Coffin et al. (1992). 
(B) SAMPLING STRATEGY AND SAMPLE INTERVALS

In order to investigate the response of calcareous nannoplankton to short term environmental perturbations as well as their biogeographic evolution through the Maestrichtian, different degrees of temporal resolution (through different sampling density) were used in different parts of the sections studied (see Figure 2).

Herbert and D'Hondt (1990) showed that the carbonate content varied cyclically in Upper Cretaceous-lower Cenozoic marine sediments over 20 m.y. in the South Atlantic. They interpreted this carbonate content cyclicity as a response to precessional climatic cycles and calculated a mean absolute period of $23.5 \pm 4.4 \mathrm{ky}$. To avoid the problem of aliasing, a minimum of two samples per cycle is required (Blackman and Tukey, 1958) but Ledbetter and Ellwood (1976) suggested that at least four samples per cycle should be analyzed in order to increase the reliability of the results. Following Ledbetter and Ellwood (1976) I attempted to obtain a chronologic resolution of $\sim 5 \mathrm{ky}$ in order to investigate whether calcareous nannofossil fluctuations occur in cycles of $\sim 20 \mathrm{ky}$ : very closely spaced samples (every $\sim 3 \mathrm{~cm}$ ) were taken in the uppermost $2.7 \mathrm{~m}$ of the Cretaceous in Hole 690C (representing the last $\sim 60 \mathrm{ky}$ of the Maestrichtian) and every $\sim 5 \mathrm{~cm}$ in the uppermost $7.5 \mathrm{~m}$ in Hole 528 (representing the last $\sim 75 \mathrm{ky}$; stippled intervals in Figure 2). A temporal resolution of $\sim 3$ ky was thus achieved in both holes.

The remainder of the "latest Maestrichtian interval" (cross hatched interval prior to the K/P boundary in Figure 2) represented in Holes $690 \mathrm{C}$ and 528 was investigated at slightly lower temporal resolution (only $\sim 10 \mathrm{ky}$ in Hole $690 \mathrm{C}$, corresponding to sample intervals of $\sim 10 \mathrm{~cm} ; \sim 20 \mathrm{ky}$ in Hole 528, corresponding to sample intervals of $\sim 20 \mathrm{~cm}$ ). Similar resolution (between $\sim 10$ $20 \mathrm{ky}$ ) was also achieved for the latest Maestrichtian interval represented in Holes 761B, 761C, and 217.

In order to assess whether nannoplankton changes during the last $\sim 500$ ky of the Maestrichtian were inherently different from those earlier in the Maestrichtian, control intervals with a temporal resolution of $\sim 10-20$ ky were selected (cross hatched intervals in the early and mid-Maestrichtian in Figure 2). 


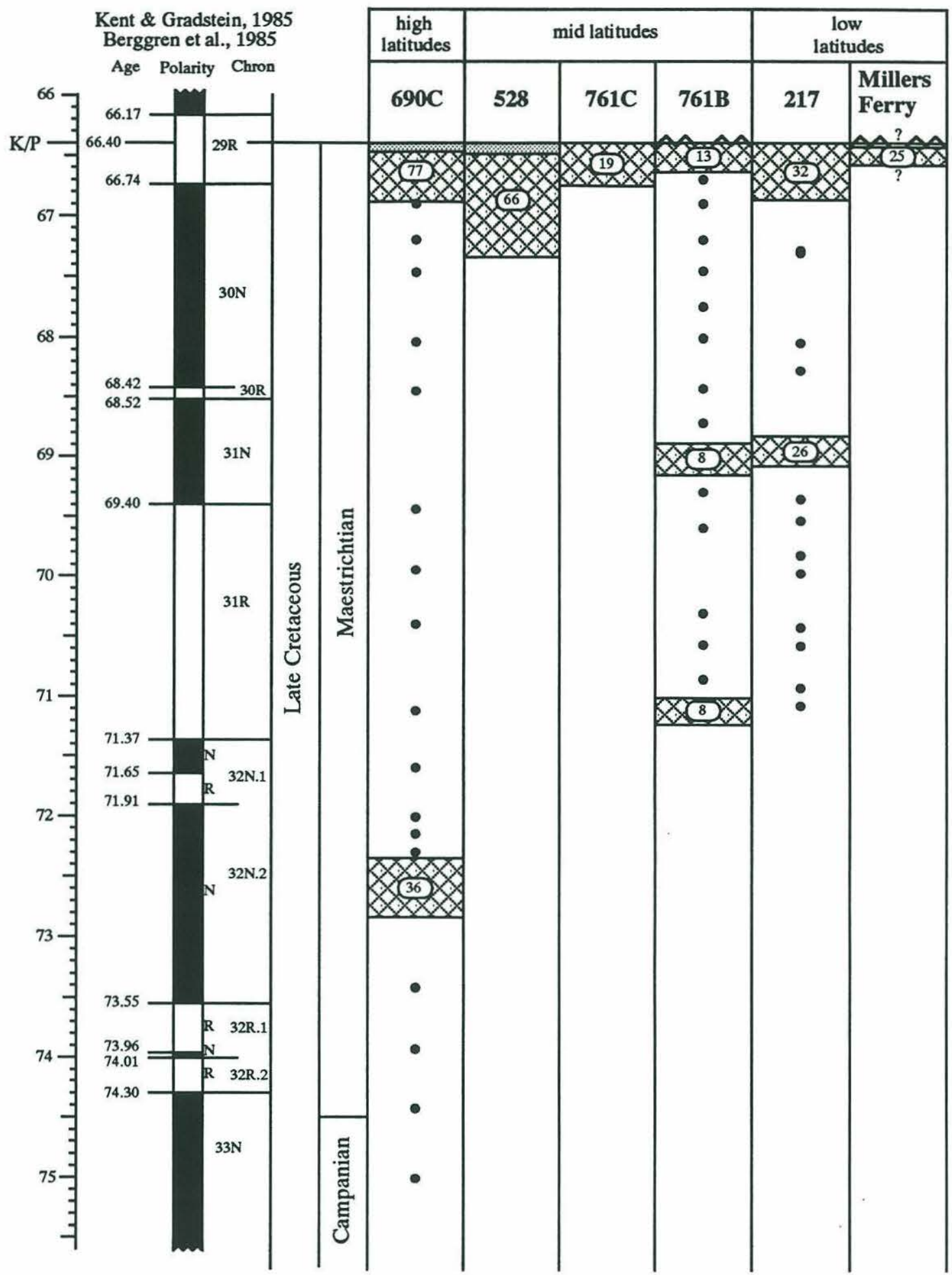

Figure 2: Schematic representation of the samples investigated in this study. The cross hatched and stippled patterns indicate intervals of high sample resolution. The numbers in each interval are the number of samples studied. The black dots represent the widely spaced samples between the intervals of high temporal resolution. 
The portions between the intervals of very high resolution (cross hatched intervals in Figure 2) were investigated at much lower resolution (about one sample every $500 \mathrm{ky}$; black dots in Figure 2).

\section{2) Methods}

\section{(A) SAMPLE PREPARATION}

Counts were performed on settling slides for DSDP Holes 217 and 528, ODP Holes 690C, 761B and 761C. Smear slides were used for the section at Millers Ferry. The settling slides were prepared following Beaufort (1991) with slight modifications. Tap water was used to disaggregate the sediment and to prepare the nannofossil suspension. As tap water was slightly acidic having very noticeable etching effects on the calcareous nannofossils, the water was alkalinized by adding Ammoniumhydroxide $\left(\mathrm{NH}_{4} \mathrm{OH}\right)$ which has the advantage of dissociating and evaporating in the heater oven without leaving a precipitate on the nannofossils. The largest problem encountered during sample preparation was that as the water degassed in the drying oven tiny gas bubbles accumulated under the cover slips and frequently lifted them from the platforms on which they were resting. It was not unusual to lose a quarter of the samples in a batch during the last step of sample preparation because of this phenomenon. This problem was avoided by weighing down the cover slip with a small amount of plasticine held above the suspension by four toothpicks (Figure 3).

\section{(B) COUNTING PROCEDURE}

All counts for this study were performed using a Zeiss Axiophot light microscope. Three hundred specimens were selected as the minimum number to be counted because with this sum there is a $95 \%$ probability of encountering at least one specimen of a taxon whose true abundance in the assemblage is $1 \%$. Because of the predominance of one species in most samples (P. stoveri in Hole 690C, M. staurophora in Holes 217, 528, 761B, 761C, and at Millers Ferry), counting was usually performed in two steps: first, all specimens were counted until a sum of $\sim 300$ was reached. Then, all taxa were counted except the single most abundant one until the sum of these (rarer) taxa was at least 300. In most samples the sum of all taxa exclusive of the dominant one was $>500$. Only when preservation was poor were fewer than 300 specimens counted. In samples 


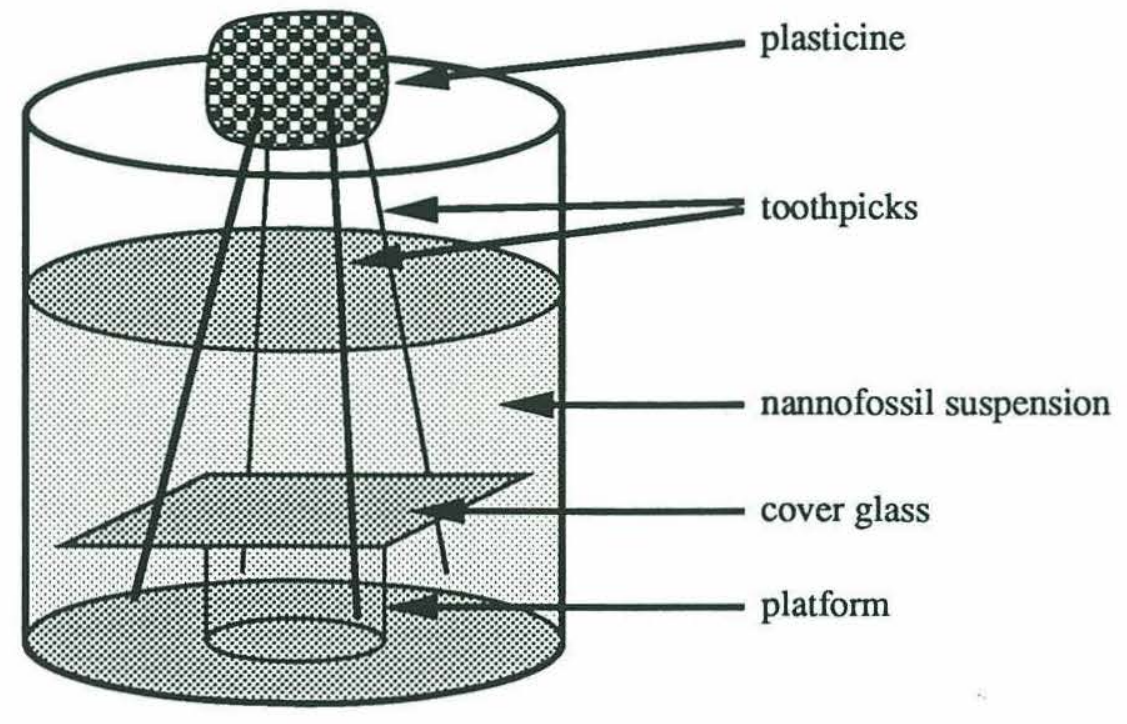

Figure 3: Toothpicks were used to hold a piece of plasticine (modelling compound) above the nannofossil suspension in order to hold the cover glass in place during the evaporation period in the heater oven. 
with a preponderance of $\underline{\mathrm{P}}$. stoveri or $\underline{\mathrm{M}}$. staurophora all taxa were counted in at least 20 viewfields. If the sum of all taxa exclusive of the dominant one was $<300$ after examination of 20 viewfields, counting was continued.

Samples located near zonal boundaries or samples with very good preservation were scanned in addition to the counts. Any taxa that were observed during this additional scanning and had not been recorded previously are noted in the data tables (Appendix II) with an asterisk $\left(^{*}\right)$ or a 'P'. For calculation purposes an abundance of 0.5 "specimens" was assigned to these rare taxa.

\section{(C) DATA PROCESSING}

Percent of nannofossil taxa were calculated exclusive of the most abundant taxon because the dominance of one species ( $\underline{\mathrm{P}}$. stoveri or $\underline{\mathrm{M}}$. staurophora) would have suppressed the percentages of all other taxa to such a degree that genuine abundance variations would have been obscured.

Absolute abundances: By counting on settling slides it is possible to estimate the number of specimens per gram sediment using the following equation (Beaufort, 1991):

$$
X_{\text {sed }}=\frac{A}{G \times N} \times \frac{V_{d} \times r^{2} \pi}{S \times\left(V_{b}+V_{p}-r^{2} \pi \times H\right)}
$$

where

$\mathrm{X}_{\text {sed }}=$ number of specimens per gram sediment

$\mathrm{A}=$ number of specimens counted

$\mathrm{G}=$ weight of sediment used to prepare the slide (in gram)

$\mathrm{N}=$ number of viewfields counted

$\mathrm{V}_{\mathrm{d}}=$ volume of dilution $=1000 \mathrm{ml}$

$r=$ radius of beaker $=2.65 \mathrm{~cm}$ for $150 \mathrm{ml}$ beaker $=2.32 \mathrm{~cm}$ for $100 \mathrm{ml}$ beaker

$\mathrm{S}=$ area of one viewfield $=1.65 \times 10^{-4} \mathrm{~cm}^{2}$ (at $1250 \mathrm{x}$ mag.)

$\mathrm{V}_{\mathrm{b}}=$ volume of suspension $=100 \mathrm{ml}$ for $150 \mathrm{ml}$ beaker poured in beaker. $=80 \mathrm{ml}$ for $100 \mathrm{ml}$ beaker

$\mathrm{V}_{\mathrm{p}}=$ volume of platform $=3.4 \mathrm{~cm}^{3}$

$\mathrm{H}=$ height of platform $=2.69 \mathrm{~cm}$ 
Two different kinds of beakers were used to prepare the settling slides of the uppermost Maestrichtian samples in Hole 690C: the different radii of the beakers and the different volumes of suspension used in the sample preparations for Hole $690 \mathrm{C}$ were taken into account in the calculations. The constants that were used to calculate the numbers of specimens per gram sediment in each of the two cases are given below (they are listed as "Beaker Constant" for all samples of Hole 690C in the data tables, Appendix II):

$$
\begin{aligned}
& X_{\text {sed }}=\frac{A}{G \times N} \times 3.0 \times 10^{6} \text { for } 150 \mathrm{ml} \text { beakers and } \\
& X_{\text {sed }}=\frac{A}{G \times N} \times 2.7 \times 10^{6} \text { for } 100 \mathrm{ml} \text { beakers. }
\end{aligned}
$$

Only the smaller beakers were used for the preparations of samples from all other sites.

In order to take the changing carbonate content into consideration the number of specimens per gram carbonate, rather than per gram sediment have to be compared. They are calculated using the following equation:

$$
\mathrm{X}_{\mathrm{CO}_{3}}=\frac{\mathrm{X}_{\text {sed }}}{\left[\mathrm{CO}_{3}\right] / 100}=\frac{\mathrm{A}}{\mathrm{G} \times\left(\left[\mathrm{CO}_{3}\right] / 100\right) \times \mathrm{N}} \mathrm{x} \text { const. }
$$

Fluxes: The flux of coccoliths and nannoliths (number of specimens per $\mathrm{cm}^{2}$ per kiloyear) was calculated using the following formula:

$$
\text { Flux }=\left(\mathrm{X}_{\mathrm{CO}_{3}}\right) \times(\mathrm{W}-(\mathrm{P} / 100) 1.01) \times \mathrm{SR}
$$

where

$\mathrm{X}_{\mathrm{CO}_{3}}=$ number of nannofossil specimens per gram carbonate $\mathrm{W}=$ wet bulk density $\left(\mathrm{g} / \mathrm{cm}^{3}\right)$

$\mathrm{P}=$ porosity $(\%)$

$\mathrm{SR}=$ sedimentation rate $(\mathrm{cm} / \mathrm{ky})$ 
The values for wet bulk density and for porosity were taken from DSDP and ODP Initial Reports and the sedimentation rates used are given in Chapter 3 "Chronology".

Accumulation rates of carbonate and of insolubles: The carbonate accumulation rate (CAR) was calculated using the following formula:

$$
\mathrm{CAR}=\left(\left[\mathrm{CO}_{3}\right] / 100\right) \times(\mathrm{W}-(\mathrm{P} / 100) \times 1.01) \times \mathrm{SR}
$$

where $[\mathrm{CO} 3]=$ carbonate content in $\%, \mathrm{~W}=$ wet bulk density, $\mathrm{P}=$ porosity, and $\mathrm{SR}$ $=$ sedimentation rate. The accumulation rate of insolubles was calculated in a similar way, but the first term in the equation above was replaced by $\left(1-\left[\mathrm{CO}_{3}\right] / 100\right)$.

Reproducibility: On several slides multiple counts were performed to test whether the results were reproducible. Multiple counts of four samples were tested for homogeneity at the Center for Data Processing, University of Agriculture, Vienna, Austria, and the results are given in Table 1. Only the more abundant taxa in the samples were tested. Each field in Table 1 contains the numbers of specimens counted in the top row. In the lower row of each field the calculated $\chi^{2}$ value as well as an indication of its significance are given (n.s. = not significant; $\left(^{*}\right)=$ significant at the $99 \%$ level; $*=$ significant at the $95 \%$ level). Generally, these results imply homogeneity among different counts on the same slide, since one or two significant values among 60 are expected at a 0.05 probability level (i.e. one significant value out of 20).

Reliability: In the graphs in Chapter 4 ("Results of Nannofossil Counts") the data are plotted without further statistical treatment. These 1) reveal an apparent short term variability and 2) show the distribution of very rare taxa. These raw data may contain valuable information. However, when statistical treatments as described below are applied, some of the changes are not significant at the $95 \%$ confidence level. Thus, only major long term trends should be deduced from the raw data. In order to assess the significance of relatively small abundance changes $(<\sim 5 \%)$ and short term trends (i.e. $\sim 100-500$ ky) the following calculations were performed on data included in the discussion in Chapter 5: in order to reduce the short term variability of the 


\begin{tabular}{|c|c|c|c|c|c|c|c|c|c|}
\hline Hole & $690 \mathrm{C}$ & & $690 \mathrm{C}$ & & $690 \mathrm{C}$ & & $690 \mathrm{C}$ & & \\
\hline Core-Section & $16-1$ & & $15-\mathrm{CC}$ & & $15-6$ & & $15-5$ & & \\
\hline \multirow[t]{2}{*}{ cm-interval } & $21-22$ & & $19-20$ & & $40-41$ & & $79-80$ & & \\
\hline & count 1 & count 2 & count 1 & count 2 & count 1 & count 2 & count1 & count 2 & count 3 \\
\hline \multirow[t]{2}{*}{ Number of Fields counted } & 30 & 37 & 30 & 11 & 30 & 26 & 30 & 34 & 33 \\
\hline & 0.012 & n.s. & 0.006 & n.s. & 0.145 & n.s. & 2.61 & n.s. & \\
\hline \multirow[t]{2}{*}{ L. cayeuxii } & 18 & 23 & 5 & 0 & 2 & 2 & 24 & 33 & 50 \\
\hline & 0.005 & n.s. & 0.603 & n.s. & 0.248 & n.s. & 0.914 & n.s. & \\
\hline \multirow[t]{2}{*}{ A. octoradiata } & 2 & 3 & 5 & 3 & 13 & 10 & 0 & 2 & 3 \\
\hline & 0.094 & n.s. & 0.172 & n.s. & 0.191 & n.s. & 0.572 & n.s. & \\
\hline \multirow[t]{2}{*}{ Arkhangelskiella spp. } & 14 & 14 & 24 & 5 & 12 & 12 & 5 & 3 & 13 \\
\hline & 0.3 & n.s. & 0.586 & n.s. & 0.04 & n.s. & 2.524 & n.s. & \\
\hline \multirow[t]{2}{*}{ C.? daniae } & 22 & 35 & 46 & 8 & 21 & 11 & 10 & 9 & 17 \\
\hline & 0.365 & n.s. & 2.709 & n.s. & 2.742 & $(*)$ & 0.192 & n.s. & \\
\hline \multirow{2}{*}{ C. ehrenbergii } & 6 & 4 & 11 & 2 & 3 & 4 & 1 & 4 & 6 \\
\hline & 0.576 & n.s. & 0.233 & n.s. & 0 & n.s. & 0.833 & n.s. & \\
\hline \multirow[t]{2}{*}{ Cretarhabdus spp. } & 11 & 13 & 12 & 4 & 10 & 1 & 6 & 3 & 10 \\
\hline & 0.003 & n.s. & 0.083 & n.s. & 5.982 & $*$ & 1.073 & n.s. & \\
\hline \multirow[t]{2}{*}{ E. turriseiffeli } & 9 & 8 & 9 & 2 & 5 & 0 & 2 & 2 & 1 \\
\hline & 0.328 & n.s. & 0.03 & n.s. & 3.248 & $(*)$ & 0.235 & n.s. & \\
\hline \multirow[t]{2}{*}{ Gartnerago spp. } & 6 & 4 & 4 & 4 & 4 & 1 & 1 & 2 & 3 \\
\hline & 0.576 & n.s. & 1.531 & n.s. & 0.816 & n.s. & 0.058 & n.s. & \\
\hline \multirow[t]{2}{*}{ G. fessus } & 3 & 12 & 6 & 4 & 15 & 20 & 5 & 5 & 3 \\
\hline & 2.486 & n.s. & 0.549 & n.s. & 0.474 & n.s. & 1.268 & n.s. & \\
\hline \multirow[t]{2}{*}{ K. magnificus } & 20 & 41 & 74 & 20 & 40 & 36 & 17 & 10 & 18 \\
\hline & 2.588 & n.s. & 0.597 & n.s. & 0.154 & n.s. & 2.576 & n.s. & \\
\hline N. frequens & 42 & 42 & 87 & 24 & 30 & 51 & 48 & 55 & 64 \\
\hline (multiperforate) & 1.546 & n.s. & 0.614 & n.s. & 5.796 & . & 2.215 & n.s. & \\
\hline N. frequens & 24 & 22 & 20 & 6 & 12 & 14 & 8 & 7 & 8 \\
\hline (biperforate) & 1.266 & n.s. & 0 & n.s. & 0.036 & n.s. & 0.578 & n.s. & \\
\hline \multirow[t]{2}{*}{ P. fibuliformis } & 1 & 3 & 12 & 4 & 13 & 17 & 0 & 1 & 1 \\
\hline & 0.054 & n.s. & 0.083 & n.s. & 0.306 & n.s. & 0.176 & n.s. & \\
\hline \multirow[t]{2}{*}{ P. cretacea } & 26 & 39 & 43 & 20 & 28 & 29 & 19 & 22 & 31 \\
\hline & 0.181 & n.s. & 1.363 & n.s. & & n.s. & 0.007 & n.s. & \\
\hline \multirow[t]{2}{*}{ P. spinosa } & 11 & 8 & 9 & 3 & 9 & 9 & 5 & 11 & 11 \\
\hline & 1.163 & n.s. & 0.111 & n.s. & 0.054 & n.s. & 1.213 & n.s. & \\
\hline Total & 236 & 310 & 421 & 140 & 250 & 251 & 162 & 181 & 265 \\
\hline
\end{tabular}

Table 1: Results of test of homogeneity between different counts on the same slide. 
data and to recognize underlying trends a five-point running average was calculated after the following method:

$$
\mathrm{p}_{\mathrm{i}}=\frac{\sum_{\mathrm{i}=-2}^{2} \mathrm{x}_{\mathrm{i}}}{\sum_{\mathrm{i}=-2}^{2} \operatorname{sum}_{\mathrm{i}}}
$$

where $x_{i}$ is the number of specimens of a particular species counted in sample $i$ and $\operatorname{sum}_{i}$ is the sum of all species in this sample (exclusive of the most abundant species). The age assigned to the five-point average was the mean of all five sample ages. In order to assess the reliability of the abundance variations observed in the curves of the five-point running average, approximate $95 \%$ confidence intervals were calculated following the method described by Mosimann (1965: p. 643).

$$
\mathrm{p}_{\mathrm{L}}=\frac{\mathrm{p}+[3.84 /(2 \mathrm{n})] \pm 1.96 \sqrt{[\mathrm{p}(1-\mathrm{p}) / \mathrm{n}]+\left[3.84 /\left(4 \mathrm{n}^{2}\right)\right]}}{1+(3.84 / \mathrm{n})}
$$

where the larger value obtained is the upper limit and the smaller value is the lower limit. 


\section{CHAPTER 3 \\ CHIRONOLOGY}

\section{1) Biohorizons}

In this chapter I present a discussion of the Maestrichtian biohorizons (calcareous nannofossils and planktonic foraminifera) used to construct the sedimentation rate curves. Age estimates of these biohorizons are based on calibration against magnetostratigraphy in sections with a reliable paleomagnetic record, using the magnetochronology of Berggren et al. (1985). The depth-levels of the biohorizons in each section were compiled from the literature and were calculated as the average between the highest/lowest sample in which the taxon was present, and the subsequent higher/lower sample where it was absent. In all cases several different age estimates of the same biohorizon were obtained from different sections (Figure 4). For some biohorizons the age estimates cluster fairly tightly, whereas for others they show considerable spread. The reliability of the different estimates is discussed as well as the age (and error) ultimately assigned to a particular biohorizon. Generally, the age assigned to any biohorizon is the average of all the ages listed here, the error assigned to each age estimate is the difference to the extreme values listed.

First Appearance Datum (FAD) of Micula prinsii: $66.63 \mathrm{Ma}(+0.38 ;-0 \quad 17)$

Hole Age (Ma)

527

66.46

$525 \mathrm{~A}$

577

66.57

$577 \mathrm{~A}$

66.63

524

67.01

Except for Hole 524 the lowest occurrence of $\underline{M}$. prinsii lies in the Maestrichtian portion of Chron C29R. Thus the level of the K/P boundary and the Chron C29R/30N reversal boundary were used as tiepoints to estimate the age of this biohorizon. Because the Maestrichtian portion of Chron C29R is quite short (only about 0.34 m.y.; Berggren et al., 1985) even a short hiatus at the $\mathrm{K} / \mathrm{P}$ boundary could lead to a significant underestimate of the sedimentation rate. A complete sequence of biozones in the early Paleocene 


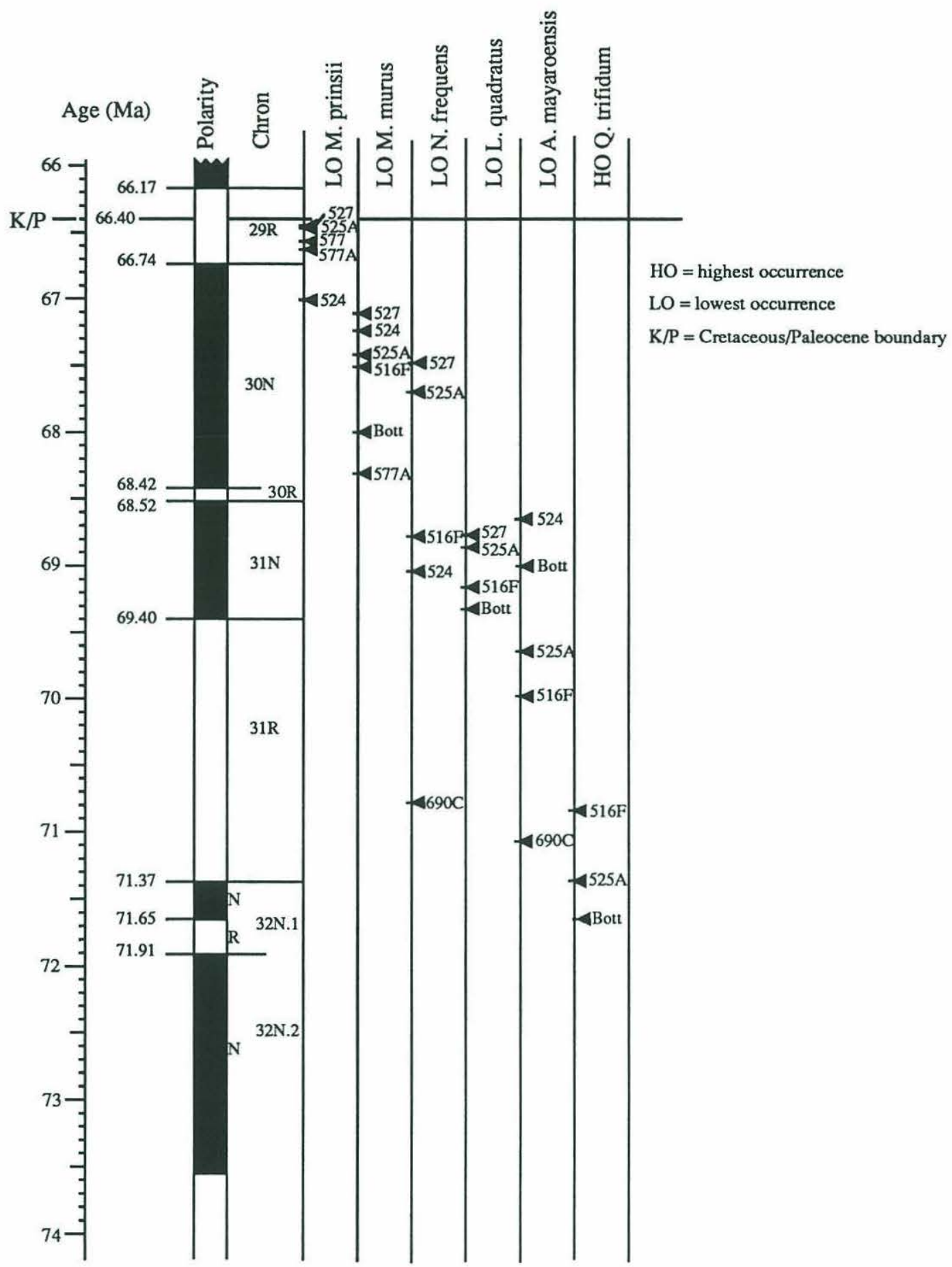

Figure 4: For each species the highest/lowest occurrences in different DSDPand ODP Holes, and in the Bottacione Section (Bott), Italy, are plotted against magnetostratigraphy (after Berggren et al., 1985). For literature used to compile this chart see text. 
and the presence of an iridium enrichment in Hole 524 (Percival, 1984; Hsü et al., 1982) and in Hole 577B (iridium was not measured in Holes 577 and 577A; Michel et al., 1985) suggest that these sections are indeed complete. In Holes $525 \mathrm{~A}$ and 527 no iridium enrichment was reported, but based on biostratigraphy the K/P boundary sequences (calcareous nannofossils: Manivit, 1984; planktonic foraminifera: Boersma, 1984a) in these holes appear to be continuous.

The lowest occurrence of $\underline{M}$. prinsii is most precisely delineated in Holes 577 and 577A (within 30 and $50 \mathrm{~cm}$, respectively; Monechi, 1985).

In Holes 525A and 527 the lowest occurrence of $\underline{M}$. prinsii is not very well constrained: Micula prinsii was reported only from one sample in each hole (Manivit, 1984).

The lowest occurrence of $\underline{\mathrm{M}}$. prinsii in Hole 524 is an exception insofar as it occurs in Chron C30N (Percival, 1984). Percival does not discuss his species concept of $\underline{\mathrm{M}}$. prinsii, and he does not report any peculiarities associated with it.

The age assigned to the FAD of $\underline{\mathrm{M}}$. prinsii is $66.63 \mathrm{Ma}(+0.38 ;-0.17 \mathrm{~m} . \mathrm{y}$.) when all available sections are included. If the outlier of Hole 524 is disregarded the FAD of $\underline{\mathrm{M}}$. prinsii is at $66.53 \mathrm{Ma}(+0.1 ;-0.07)$.

First Appearance Datum of Micula murus: $67.60 \mathrm{Ma}(+0.71 ;-0.49)$

$\begin{array}{ll}\text { Hole/Section } & \text { Age (Ma) } \\ 527 & 67.11 \\ 524 & 67.24(68.39 ?) \\ 525 \mathrm{~A} & 67.42 \\ 516 \mathrm{~F} & 67.51\end{array}$

Bottacione Section 68.00

$577 \mathrm{~A} \quad 68.31$

The calcareous nannofossils in Hole 524 were studied by Percival (1984) who presented a range chart in which $\underline{M}$. murus occurred continuously from the $\mathrm{K} / \mathrm{P}$ boundary to $524-22-\mathrm{CC}$ (228.0 mbsf; corresponding to $67.24 \mathrm{Ma}$ ). Below this sample no specimen of $\underline{M}$. murus was recorded until sample 524-26-5, 39-40 cm (262.89 mbsf; corresponding to $68.39 \mathrm{Ma}$ ) where $\underline{\mathrm{M}}$. murus was observed again very rarely. Percival (1984) used this isolated, lowermost occurrence of $\underline{\text { M. murus }}$ to delineate the lowest occurrence of $\underline{\mathrm{M}}$. $\underline{\text { murus. }}$. I believe that it is more appropriate to use the base of the continuous occurrence of $\underline{M}$. murus as 
the level of its lowest occurrence; therefore the age estimate of $67.24 \mathrm{Ma}$ is preferred for the lowest occurrence of $\underline{\mathrm{M}}$. murus in Hole 524.

It appears that the six ages estimated for the lowest occurrence of $\underline{\mathbf{M}}$. murus fall into two groups: the South-Atlantic Holes (516F, 524, 525A, 527:

Shipboard Scientific Party, 1983; Percival, 1984; Manivit, 1984) have values between 67.11 and $67.51 \mathrm{Ma}$, whereas the tropical hole 577A (Monechi, 1985) and the Tethys-section (Bottacione Section: Monechi and Thierstein, 1985) have values of 68.31 and 68.00 , respectively. Micula murus is the low latitude marker species of the late Maestrichtian, and it is possible that this form occurs earlier in tropical latitudes than at middle latitudes.

The average of all values listed for the lowest occurrence of $\underline{M}$. murus is $67.60 \mathrm{Ma}(+0.71 ;-0.49)$. If the paleolatitude of a section is very well known, it may be permissible to use a value of $67.32 \mathrm{Ma} \pm 0.2$ for mid latitude sites, or of $68.15 \mathrm{Ma} \pm 0.15$ for tropical/tethyan sections.

$\begin{array}{ll}\text { First Appearance } & \text { Datum of Nephrolithus frequens } \\ \text { Hole } & \text { Age (Ma) } \\ 527 & 67.48 \\ \text { 525A } & 67.70 \\ 516 \mathrm{~F} & 68.78 \\ 524 & 69.04 \\ \text { 690C } & 70.78\end{array}$

The diachrony of this biohorizon is very apparent in Figure 4 (compare also Pospichal and Wise, 1990a: fig. 6). Whereas the lowest occurrence of $\underline{\mathrm{N}}$.

frequens in Hole 690C lies in the lower half of Chron C31R (Pospichal and Wise, 1990a; Hamilton, 1990), it lies within C31N in Holes 524 (Percival, 1984; Tauxe et al., 1984) and 516F (Shipboard Scientific Party, 1983; Hamilton et al., 1983), and in Chron C30N in Holes 525A and 527 (Manivit, 1984; Chave, 1984). It is not strictly correlated with latitude, or else the lowest occurrences of this species in the Walvis Ridge Sites (latitude and paleolatitude within five degrees of each other: 524, 525A, 527) should be clustered more tightly, which is not the case. In fact, the temporal difference in the lowest occurrence between Hole 524 and 527 (1.56 m.y.) is almost as large as the difference between Hole 524 and 690C (1.74 m.y.)! Still, it is intriguing that the lowest occurrences of $\underline{N}$. frequens in the Walvis Ridge sites occurs progressively from the more southern to the northern sites (i.e. earliest first occurrence in Hole 524, then 
in 525A, then in 527). It has been suggested (Pospichal and Wise, 1990) that the diachronous lowest occurrences of $\underline{N}$. frequens in different sections reflects the equatorward spreading of high latitude water mass properties (e.g. cooler temperatures) throughout the Maestrichtian. If this is correct, then this spreading did not proceed at a constant pace from high latitude Site 690 to the equator. It took $\underline{\mathrm{N}}$. frequens roughly the same amount of time to conquer all the Atlantic Ocean between Antarctica (Hole 690C) and the Walvis Ridge (Hole 524) as it needed to cross the Walvis Ridge itself (from Hole 524 to Hole 527).

As a consequence of the highly diachronous first occurrences of $\underline{N}$. frequens no average age is assigned to this biohorizon. The list given above may help, though, to estimate an approximate age of the lowest occurrence of $\underline{N}$ frequens in a sections of which the paleolatitude is known.

First Appearance Datum of Abathomphalus mayaroensis: $69.67 \mathrm{Ma}(+1.4 ;-1.02)$ Hole/Section Age (Ma) $524 \quad 68.65$

Bottacione Section $\quad 69.00$

$525 \mathrm{~A} \quad 69.64$

$516 \mathrm{~F} \quad 69.98$

690C $\quad 71.07$

The lowest occurrence of this planktonic foraminifer varies considerably between the sections included in this compilation, occurring in different magnetochrons in different sections: in Hole 524 (Smith and Poore, 1984) and in the Bottacione Section its lowest occurrence lies in Chron C31N (Luterbacher and Premoli Silva, 1964), whereas in Holes 516F (Weiss, 1983), 525A (Boersma, 1984a), and 690C (Huber, 1990) it lies in Chron C31R. No clear correlation of this diachrony of the lowest occurrence with paleolatitude is apparent, other than its earliest first occurrence in southern high latitude Site 690 (see also discussion in Huber and Watkins, 1992). The age estimate of this biohorizon is fairly poorly constrained: $69.67 \mathrm{Ma}(+1.4 ;-1.02)$. 
First Appearance Datum of Lithraphidites quadratus: $69.03 \mathrm{Ma}(+0.29 ;-0.26)$

Hole/Section Age (Ma)

527

68.77

$525 \mathrm{~A}$

68.86

$516 \mathrm{~F}$

69.16

Bottacione Section

69.32

The ages estimates for this biohorizon in different sections cluster fairly tightly compared with other biohorizons. The lowest occurrence of $\underline{L}$. quadratus in all sections lies in Chron C31N (calcareous nannofossil results from Shipboard Scientific Party, 1983; Manivit, 1984; Monechi and Thierstein, 1985; paleomagnetic results from Alvarez et al., 1977; Hamilton et al., 1983;

Chave, 1984). The average age is $69.03 \mathrm{Ma}(+0.29 ;-0.26)$.

Last Appearance Datum of Quadrum trifidum: 71.28 Ma $(+0.34 ;-0.44)$

$516 \mathrm{~F}$ 70.84

$525 \mathrm{~A}$ 71.36

Bottacione Section 71.65

Age estimates of this biohorizon cluster fairly tightly around the boundary between Chrons C31R and C32N (calcareous nannofossil results from Shipboard Scientific Party, 1983; Manivit, 1984; Monechi and Thierstein, 1985; paleomagnetic results from Alvarez et al., 1977; Hamilton et al., 1983; Chave, 1984). The average age assigned to this biohorizon is $71.28 \mathrm{Ma}(+0.37 ;-0.44)$. 


\section{2) ODP Hole $690 \mathrm{C}$}

\section{Location}

ODP Hole 690C was drilled on the southwestern flank of Maud Rise in the Atlantic Sector of the Antarctic Ocean (Weddell Sea) at $65^{\circ} 9.621^{\prime} \mathrm{S}, 1^{\circ} 12.285^{\prime} \mathrm{E}$ in 2914 m waterdepth (Shipboard Scientific Party, 1988). This site was included in this study because it represents one of the southernmost Maestrichtian sections in calcareous facies drilled to date. It contains a biostratigraphically complete $\mathrm{K} / \mathrm{P}$ boundary section with an iridium enrichment.

\section{Lithology}

About $70 \mathrm{~m}$ of Upper Cretaceous (upper Campanian/lower Maestrichtian to $\mathrm{K} / \mathrm{P}$ boundary) sediment were penetrated (sediment/basement contact at $317.0 \mathrm{mbsf}$; K/P boundary at $247.79 \mathrm{mbsf}$ ). The sediment was divided into two lithologic units, based on the calcareous nannofossil content (Shipboard Scientific Party, 1988; Figure 5): in the lower unit (unit V: 317.0 to $281.1 \mathrm{mbsf}$ ) foraminifera and terrigenous quartz and clay constitute the dominant components of the sediment, in the upper unit (unit IV: 281.1 to $137.8 \mathrm{mbsf}$ ) calcareous nannofossils dominate; the boundary between these lithologic units coincides approximately with the boundary between the middle and upper Maestrichtian.

The relative abundances of different sedimentary components vary widely throughout the Maestrichtian (Figure 5). Calcareous nannofossils fluctuate considerably $(10-40 \%)$ in the uppermost Campanian to middle Maestrichtian; they constitute about $50 \%$ of the upper Maestrichtian sediment. In the Paleocene they increase to values $>80 \%$. Foraminifera attain peak abundances of $30-35 \%$ in the uppermost Campanian/lowermost Maestrichtian.

They fluctuate between 2-20\% throughout the middle and upper Maestrichtian; in the uppermost Maestrichtian (about $4 \mathrm{~m}$ below the $\mathrm{K} / \mathrm{P}$ boundary) foraminifera reach a peak of $25 \%$. Quartz and clay constitute $10-20 \%$ of the sedimentary components in the uppermost Campanian/lowest Maestrichtian, reach peak abundances over $80 \%$ in the middle Maestrichtian, and decrease to very low values $(<10 \%)$ in the lowest Paleocene. Mica content increases throughout the Maestrichtian from $<10 \%$ in the uppermost Campanian/lower Maestrichtian to almost $20 \%$ in the upper Maestrichtian. About $4 \mathrm{~m}$ below the $\mathrm{K} / \mathrm{P}$ boundary mica decreases to ca. $5 \%$ and remains at this level through the 


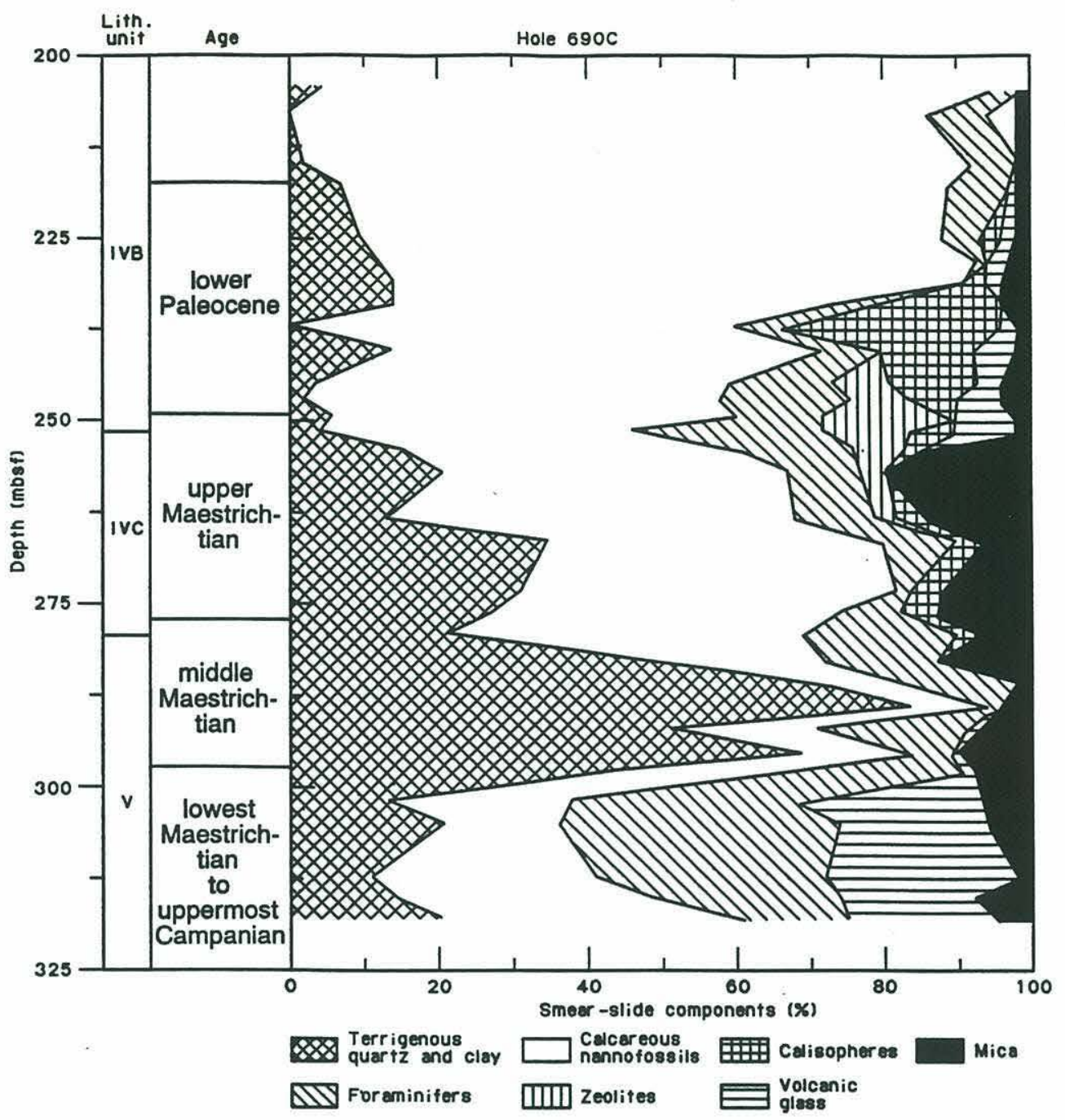

Figure 5: Lithologic composition of Maestrichtian and lower Paleocene sediments in Hole 690C (from Shipboard Scientific Party, 1988: p. 191). 
lower Paleocene. Volcanic glass is an important sedimentary component (2025\%) below ca. 300 mbsf (uppermost Campanian to lowermost Maestrichtian). A light greenish ash-layer occurs at $314.38 \mathrm{mbsf}$. Volcanic glass is virtually absent in most of the middle and upper Maestrichtian sediments, but reoccurs towards the top of the Maestrichtian (ca. $4 \mathrm{~m}$ below the $\mathrm{K} / \mathrm{P}$ boundary) where it reaches values of ca. $10 \%$ and declines to $0 \%$ during the lower Paleocene. Zeolites are present only in upper Maestrichtian and lower Paleocene sediments; they reach their peak abundance (almost 20\%) in the immediate vicinity of the $\mathrm{K} / \mathrm{P}$ boundary. Calcispheres occur as minor sediment components $(<5 \%)$ in the upper part of the middle and in the upper Maestrichtian. In the lowermost Paleocene they reach peak abundances of almost $30 \%$. Pale brown and yellowish brown chert fragments and layers occur sporadically in the lowermost sediments at this site.

Bioturbation is minor to strong throughout the Upper Cretaceous section, often obscured by drilling disturbance in the uppermost Campanian/lowest Maestrichtian sediments.

\section{Cretaceous/Paleocene boundary:}

The change of Cretaceous to Paleocene assemblages of planktonic foraminifera and of calcareous nannofossils occurs in section 690C-15-4, between about 50 and $30 \mathrm{~cm}$ (Stott and Kennett, 1990a; Pospichal and Wise, $1990 \mathrm{~b}$; personal observation). Also in the immediate vicinity of the $\mathrm{K} / \mathrm{P}$ boundary (Section 690C-15-4, between ca. 60 and $30 \mathrm{~cm}$ ) occurs a very distinct, but heavily bioturbated lithology- and color-change from white nannofossil chalk below to pale-brown nannofossil mud above. The carbonate content of the sediment in this interval decreases from $80-90 \%$ in the white chalk to $<50 \%$ in the pale-brown sediment (Figure 6). The peak abundance of zeolites (which are the product of diagenetic alteration of volcanogenic sediments) and the presence of moderate amounts (ca. 10\%) of volcanic glass support the argument of Shipboard Scientific Party (1988) that the darker color of the sediment above the contact may be due to volcanic influence.

Pospichal and Wise (1990b) showed that the white nannofossil chalk contains typical Cretaceous nannofossil assemblages, whereas the pale-brown sediments contain approximately $20 \%$ persistent and incoming taxa. They argue therefore that the $\mathrm{K} / \mathrm{P}$-boundary should be drawn at the top of the highest autochthonous white chalk clast (690C-15-4, between 41.5 and $41.8 \mathrm{~cm}$; 


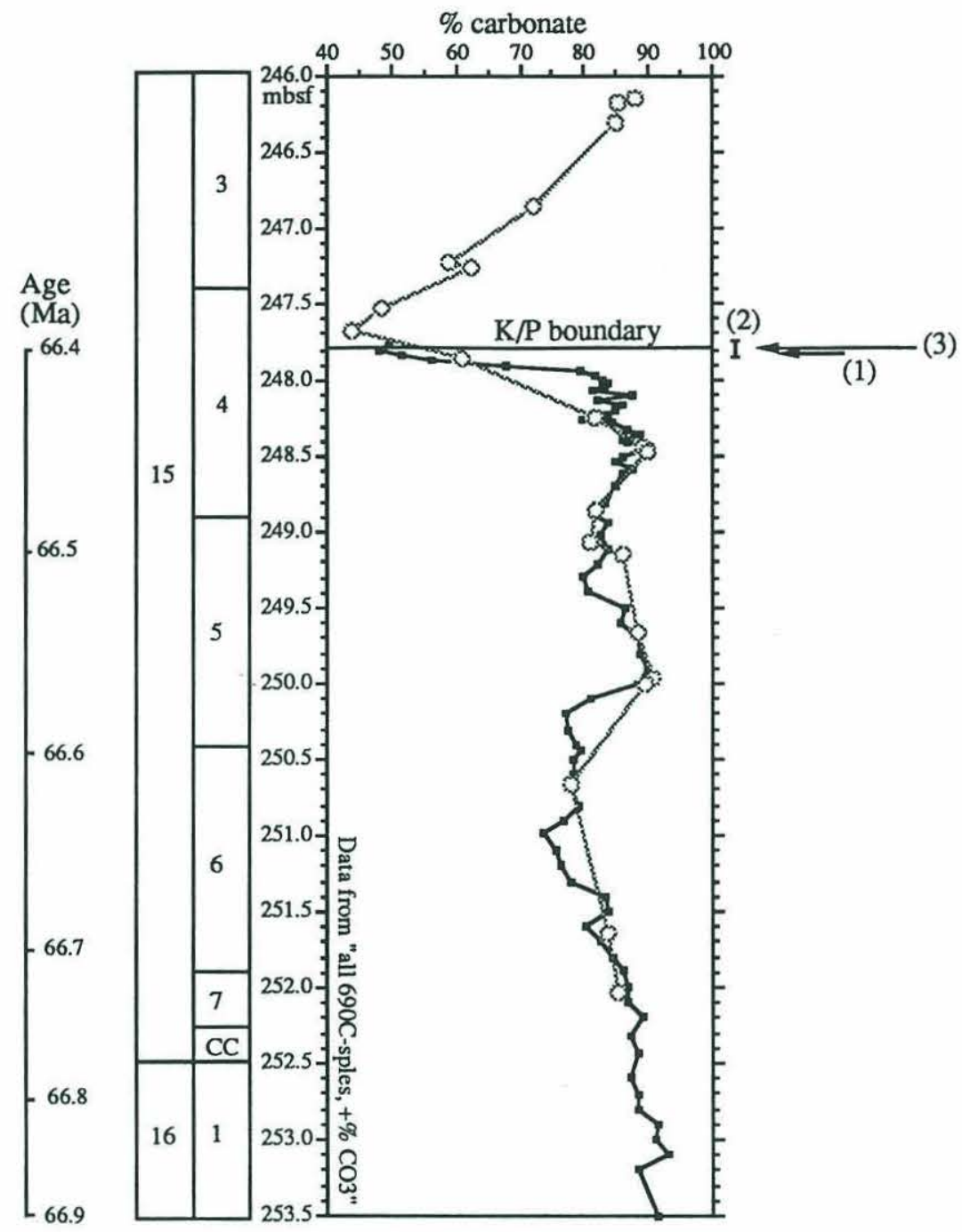

Figure 6: Decrease in carbonate content at the Cretaceous/Paleocene boundary (black squares: this study; open circles: Stott and Kennett, 1990b).

(1) Level where Pospichal and Wise (1990b) place the K/P boundary (based on calcareous nannofossils).

(2) Interval of planktonic foraminiferal turnover from Maestrichtian to Paleocene assemblages (Stott and Kennett, 1990b).

(3) Peak of iridium enrichment (Michel et al., 1990). 
247.815 and 247.817 mbsf; Pospichal and Wise, 1990b). This approach - which differs from the definition of the $\mathrm{K} / \mathrm{P}$ boundary as the "level of extinction of most Upper Cretaceous species" (Cepek and Hay, 1969) - was justified by the fact that no extinction horizon is apparent in this section, due to reworking (or survival) of Cretaceous species into the Paleocene.

In the planktonic foraminifera there is no well defined extinction horizon at the $\mathrm{K} / \mathrm{P}$ boundary. Cretaceous taxa are replaced by Cenozoic taxa over a $10-\mathrm{cm}$ interval (between samples $690 \mathrm{C}, 15 \mathrm{X}-4,45-47 \mathrm{~cm}$ and $15 \mathrm{X}-4,35-37$ $\mathrm{cm}, 247.85$ and $247.75 \mathrm{~cm}$, respectively; Stott and Kennett, 1990a). Stott and Kennett place the K/P boundary at the level where Paleogene species become dominant $(>50 \%)$ over Cretaceous species. It must be stressed, that this is not the proper definition of the K/P boundary in planktonic foraminifera biostratigraphy (i.e. the extinction horizon of Cretaceous taxa) but rather an attempt to circumvent the problem of intensive reworking in this section.

An iridium-enrichment occurs in Core $690 \mathrm{C}-15 \mathrm{X}$ with a well-defined peak at 15X-4, 39-40cm (247.79 mbsf; Michel et al., 1990).

Benthic foraminifera show only minor changes at the $\mathrm{K} / \mathrm{P}$ boundary (Thomas, 1990), whereas calcareous dinoflagellates show a dramatic turnover (Fütterer, 1990).

Because bioturbation makes it impossible to draw the $\mathrm{K} / \mathrm{P}$ boundary unambiguously with nanno- and microfossils, the level of the Ir-enrichment is used as the level of the $\mathrm{K} / \mathrm{P}$ boundary in this study.

\section{Paleoenvironment during the Maestichtian}

The Maestrichtian latitude of Site 690 was about $70^{\circ} \mathrm{S}$ based on paleocontinental reconstructions of Firstbrook et al. (1979) and of Smith et al. (1977).

The Upper Cretaceous and Cenozoic sediments at Site 690 were laid down in a pelagic, open-ocean environment (Shipboard Scientific Party, 1988, p. 236). Paleontological (benthic foraminifera; Thomas, 1990) as well as geochemical evidence ( $\mathrm{Mn} / \mathrm{Fe}$ ratios; Robert and Maillot, 1990) suggest that bottom waters were well oxygenated. Water depth estimates were based on comparison of benthic foraminiferal assemblages at Site 690 (Thomas, 1990) with results from benthic foraminifera studies in the South Atlantic (Katz and Miller, 1990). Estimates of water depth are tenuous and indicate middle to lower bathyal depths (1000-2500m) during the Late Cretaceous and early Paleocene, 
and subsequent deepening to upper abyssal depths $(2500 \mathrm{~m}$ or deeper) for the remainder of the Cenozoic (Shipboard Scientific Party, 1988, p. 213).

\section{Paleoclimate}

Smectite dominates the clay mineral fraction from the Upper Cretaceous through the upper Eocene in sediments of Sites 689 and 690 (65-100\%; Robert and Maillot, 1990). This indicates warm climatic conditions with alternating periods of humidity and aridity in Antarctica, the source area of the clay minerals. Starting in the Paleocene kaolinite is present at Site 690 indicating increased humidity on Antarctica at this time (Robert and Maillot, 1990).

Stable isotope results $\left(\delta^{18} \mathrm{O}\right)$ from Maestrichtian planktonic and benthic foraminifera indicate long term cooling throughout the entire Maestrichtian with a short warming event during the last 0.5 m.y. before the K/P boundary (Barrera and Huber, 1990; Stott and Kennett, 1990b; see Chapter 5 for discussion).

\section{Nannofossil Biostratigraphy}

The initial sampling was based on the nannofossil biostratigraphy of Pospichal and Wise (1990a) which was subsequently refined in the course of this study. The following problems were encountered:

First occurrence of Nephrolithus frequens: This species evolves in the late Maestrichtian, possibly from Nephrolithus corystus (Pospichal and Wise, 1990a). Consequently there are many forms close to the first occurrence of $\underline{N}$. $\underline{\text { frequens }}$ that are intermediate between a typical $\underline{\mathrm{N}}$. corystus and a typical $\underline{\mathrm{N}}$. frequens. Pospichal and Wise report that $\underline{\mathrm{N}}$ frequens is absent in sample 19X-1, $130-132$ (282.41 mbsf), that it is questionably present at $18 \mathrm{X}, \mathrm{CC}(281.10 \mathrm{mbsf})$ and that it occurs 'commonly' in sample 18X-5, 36-38 cm (277.76 mbsf). My own investigations showed that $\underline{N}$. frequens occurs commonly in sample $18 X-5,54$ $\mathrm{cm}$ (277.94 mbsf), where it constitutes about $22 \%$ of the assemblage. In sample $19 \mathrm{X}-1,107 \mathrm{~cm}$ intermediate forms between $\underline{\mathrm{N}}$. frequens and $\underline{\mathrm{N}}$. corystus occur infrequently. These forms do not bear a central stem, they have a comparatively narrow margin, they are smaller and have fewer perforations than the 'typical', stem-bearing specimens of $\underline{N}$. corystus in this sample. In addition, these forms mostly have a distinct kidney-shaped outline, whereas $\underline{\mathrm{N}}$. corystus often has an almost elliptical outline. At this time it is impossible to assign these intermediate forms unambiguously to either species because the 
structural differences of the central area - which are the only pertinent criteria to distinguish $\underline{N}$. frequens from $\underline{N}$. corystus - are not visible under the light microscope. Until these questions can be resolved in a subsequent study on the SEM the first (certain) occurrence of $\underline{\mathrm{N}}$. frequens is recorded in sample 690C-18-5, $54 \mathrm{~cm}$ (277.94 mbsf); $\underline{\mathrm{N}}$. frequens is (probably) absent in 690C-19-1, $107 \mathrm{~cm}$ (282.17 mbsf).

Last occurrence of Nephrolithus corystus: The last occurrence of this species lies in an interval where preservation of calcareous nannofossils is very poor. Unquestionable specimens are present up to $690 \mathrm{C}-18-2,60-61 \mathrm{~cm}$ (273.5 mbsf). In overlying samples from sections 18-2 and 18-1 no specimens of $\mathrm{N}$. corystus were observed; only the most dissolution resistant taxa are present in this interval. In sample $690 \mathrm{C}-17-\mathrm{CC}, 20-21 \mathrm{~cm}(271.4 \mathrm{mbsf})$ the preservation of calcareous nannofossils improves and one specimen was found after extremely careful search in a sample where large forms were enriched by centrifuging. Nephrolithus corystus is absent in the remainder of Core 690C-17. Due to the poor preservation of calcareous nannofossils in the interval where $\underline{N}$. corystus disappears (between $690 \mathrm{C}-18-2,60-61 \mathrm{~cm}$ and $690 \mathrm{C}$ 17-CC) it is not possible to establish whether $\underline{N}$. corystus is present continuously through sections $690 \mathrm{C}-18-2$ and $-18-1$, or whether the occurrence in 690C-17-CC should be discarded as an artifact of reworking.

Last occurrence of Biscutum magnum: This species disappears between samples 690C-18-CC, 15-16 cm (281.10 mbsf) and 690C-18-5, $54 \mathrm{~cm}$ (277.94 mbsf). No sediment was recovered between these sections. These observations agree with Pospichal and Wise's (1990a) practice of drawing the boundary between the $\underline{\mathrm{B}}$. magnum Zone and the $\underline{\mathrm{N}}$. corystus Subzone (i.e. LO of $\underline{\mathrm{B}}$. magnum, Pospichal and Wise, 1990a) at the same level, despite the observation of one specimen in sample 690C-18-5, 36-38 cm (277.76 mbsf; Pospichal and Wise, 1990a).

Last occurrence of Biscutum coronum: The last occurrence of this species was observed in sample 690C-20-1, $136 \mathrm{~cm}$ (292.16 mbsf), it is absent in sample 690C-20-1, $133 \mathrm{~cm}$ (292.13 mbsf). This level is a little higher than previously reported by Pospichal and Wise (1990a).

Last occurrence of $\underline{\mathrm{R}}$ levis: This species was observed in sample 690C-185 , $54 \mathrm{~cm}$, albeit very rarely. According to Pospichal and Wise (1990a) $\underline{\mathrm{R}}$. levis is absent in sample $690 \mathrm{C}-18-5,36-38 \mathrm{~cm}$ (277.76 mbsf). 


\section{Magnetostratigraphy}

High resolution paleomagnetic data of high quality were obtained from Upper Cretaceous sediments of Holes 690C and 689B (Hamilton, 1990). Hamilton (1990) indicated that the combined results from both holes yielded sufficient evidence to decipher the Upper Cretaceous magnetostratigraphy of Maud Rise. Due to the high latitude of Maud Rise in the Late Cretaceous (not significantly different from its present day location; Hamilton, 1990) it was acceptable to use the inclination of the remanent magnetization vector as a reliable index of magnetic polarity. Normal magnetization overprint of most samples could be satisfactorily removed through magnetic cleaning. The high rate of recovery allowed high resolution sampling and yielded a sharp definition of the polarity record in Hole 690C (Hamilton, 1990).

The polarity record as well as the magnetostratigraphic interpretation (after Hamilton, 1990) are shown in Figure 7.

All biostratigraphic zones around the $\mathrm{K} / \mathrm{P}$ boundary which occurs in Chron C29R were identified (Pospichal and Wise, 1990b; Stott and Kennett, 1990a). Interestingly, in Hole 690C this boundary occurs closer to the top of 29R than in other pelagic sections (Herbert and D'Hondt, 1990). This may be due to a very low sedimentation rate in the earliest Paleocene, or may indicate the presence of a hiatus within $\mathrm{CP} 1 \mathrm{a}$ or at the $\mathrm{CP} 1 \mathrm{a} / \mathrm{CP} 1 \mathrm{~b}$ zonal boundary (Pospichal and Wise, 1990b). The fact that Cruciplacolithus primus and $\underline{\mathrm{C}}$. tenuis appear at about the same level (Pospichal and Wise, 1990b) supports the possibility of a hiatus between these two subzones. Poor preservation of planktonic foraminifera (R. D. Norris, oral comm.) in the lowermost Paleocene may indicate partial carbonate dissolution; no similar preservational pattern is reported in the calcareous nannofossils (Pospichal and Wise, 1990b).

Sedimentation rates: Sedimentation rates in the Maestrichtian of Hole 690C are based on the paleomagnetic results of Hamilton (1990). Magnetochron boundaries are very well constrained (Figure 7) except for the C32R/33N boundary, which occurs between samples that are more than six meters apart. The sedimentation rate of the overlying interval (Chron $\mathrm{C} 32 \mathrm{~N}$ ) is extended to the bottom of the section. The data used are tabulated in Table 2 , the results included in Figure 7. 
Table 2: The depth assignments of the magnetozone boundaries are taken from Hamilton (1990), the K/P boundary was placed at the level of the iridium-peak (Michel et al., 1990). Numerical ages were assigned to these boundaries according to Kent and Gradstein (1985) and Berggren et al. (1985).

\begin{tabular}{llll} 
Boundary & $\begin{array}{c}\text { Depth } \\
\text { (mbsf) }\end{array}$ & Age (Ma) & $\begin{array}{c}\text { Sedimentation Rate } \\
(\mathrm{m} / \mathrm{m} . \mathrm{y} .)\end{array}$ \\
\hline $29 \mathrm{~N} / 29 \mathrm{R}$ & 247.55 & 66.17 & $0.24 \mathrm{~m} / 0.23 \mathrm{~m} \cdot \mathrm{y} .=1.04$ \\
$\mathrm{~K} / \mathrm{P}$ boundary & 247.79 & 66.40 & $4.49 \mathrm{~m} / 0.34 \mathrm{~m} \cdot \mathrm{y} .=13.21$ \\
$29 \mathrm{R} / 30 \mathrm{~N}$ & 252.28 & 66.74 & $19.97 \mathrm{~m} / 2.66 \mathrm{~m} \cdot \mathrm{y} .=7.51$ \\
$31 \mathrm{~N} / 31 \mathrm{R}$ & 272.25 & 69.40 & $11.14 \mathrm{~m} / 1.97 \mathrm{~m} \cdot \mathrm{y} .=5.65$ \\
$31 \mathrm{R} / 32 \mathrm{~N}$ & 283.39 & 71.37 & $19.39 \mathrm{~m} / 2.18 \mathrm{~m} \cdot \mathrm{y} .=8.89$ \\
$32 \mathrm{~N} / 32 \mathrm{R}$ & 302.78 & 73.55 &
\end{tabular}




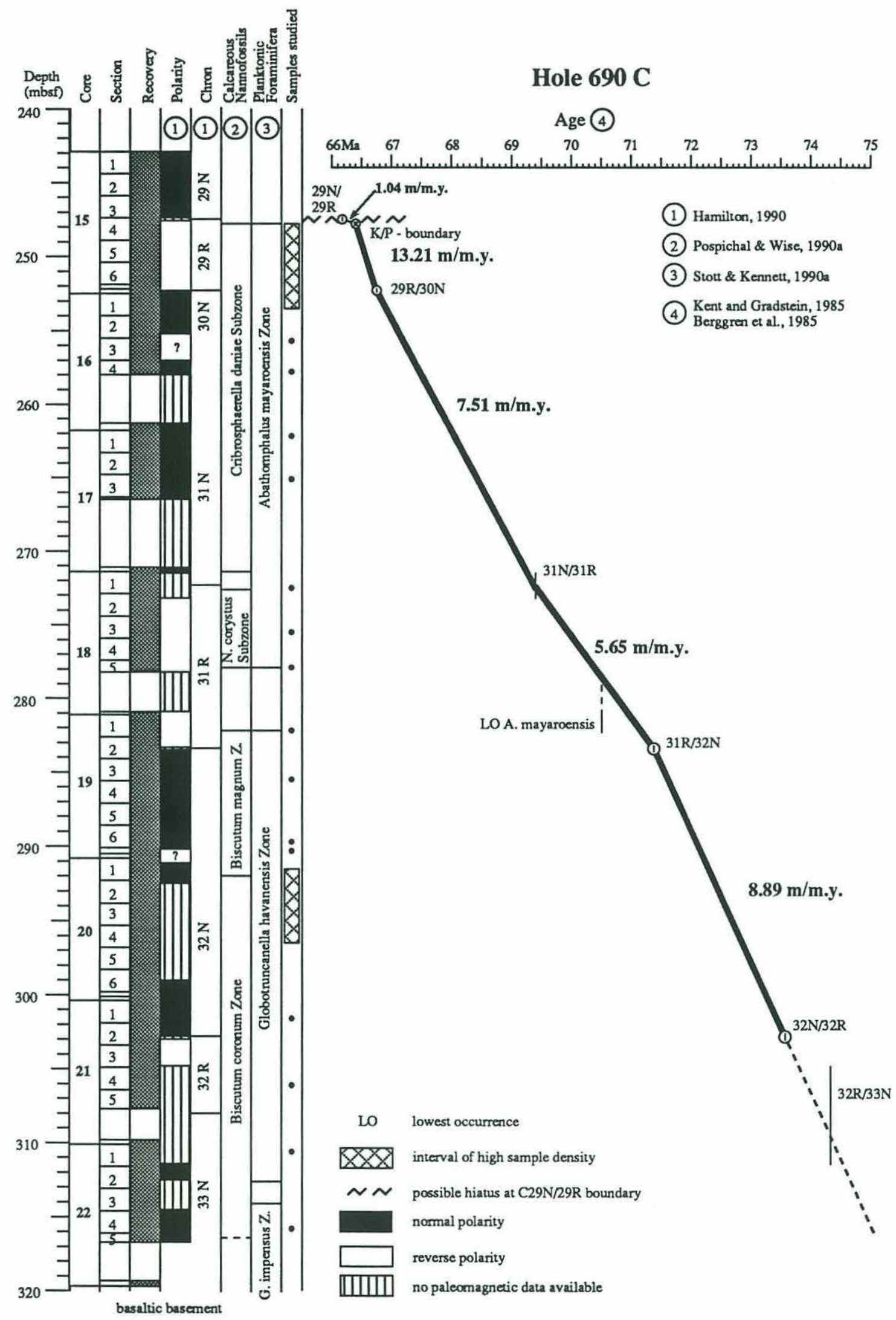

Figure 7: Sedimentation rate curve for the Maestrichtian section in Hole 690C. 


\section{3) ODP Hole 761B}

\section{Location}

Hole $761 \mathrm{~B}$ is located in the eastern Indian Ocean on the central part of Wombat Plateau $\left(16^{\circ} 44.23^{\prime} \mathrm{S}, 115^{\circ} 32.10^{\prime} \mathrm{E}\right)$ about $400 \mathrm{~km}$ off the Australian coast in $2167.9 \mathrm{~m}$ waterdepth (Shipboard Scientific Party, 1990). The paleolatitude of this site during the Maestrichtian was about $40-45^{\circ} \mathrm{S}$ according to Firstbrook et al. (1979), and about $30-40^{\circ} \mathrm{S}$ according to the paleocontinental reconstructions of Smith and Briden (1977).

\section{Lithology}

The Maestrichtian sediments in this Hole are light-colored nannofossil chalks with foraminifera (lithologic unit II; Shipboard Scientific Party, 1990); this unit was divided into three subunits based on changing abundances of biogenic and lithologic components. Subunit IIA (175.9-198.7 mbsf) consists of fairly pure, extensively bioturbated nannfossil chalk, with $<10 \%$ foraminifera and usually $<2 \%$ detrital mica. Yellowish brown porcellanite chert nodules are present but rare. The top of this subunit coincides with the K/P boundary where a distinct color and lithologic change occurs.

In Subunit IIB (198.7-240.0 mbsf) foraminifera increase to $10-25 \%$ and zeolite constitutes up to $5 \%$ of the sediment in core 761B-24X. Inoceramus shell fragments are common throughout this subunit, particularly abundant in core 761B-25X. Bioturbation is extensive throughout; sediment colors are very pale brown, light gray, and white. Brownish yellow chert nodules are present but rare. The base of this lithologic subunit is early to middle Albian.

\section{The K/P boundary}

Calcareous Nannofossils: The $\mathrm{K} / \mathrm{P}$ boundary is a drilling contact and coincides with a conspicuous lithologic and colour change, from light-gray, clay-rich Paleocene chalk to white late Maestrichtian nannofossil chalk at 761B-21-4, $126 \mathrm{~cm}$ (175.96 mbsf; Shipboard Scientific Party, 1990). A hiatus is present at the K/P boundary as the lowermost Paleocene nannofossil zone (NP1) is missing. Cruciplacolithus primus and $\underline{\mathrm{C}}$. tenuis both are present together in 761-21-4, $125 \mathrm{~cm}$ (Shipboard Scientific Party, 1990). The uppermost Maestrichtian at 761B belongs to the $\underline{\text { Murus }}$ Zone. 
Planktonic Foraminifera: The hiatus at the $\mathrm{K} / \mathrm{P}$ boundary is also recognized by planktonic foraminifera as the lowermost Paleocene assemblages indicate Zone P1C (Shipboard Scientific Party, 1990).

\section{Biostratigraphy}

Calcareous Nannofossils: The uppermost Maestrichtian marker fossil, $\underline{\mathbf{M}}$. prinsii, was not observed in this hole, nor in the more complete hole 761C (Bralower and Siesser, 1992). The reason for its absence may be a short hiatus in Hole 761B or paleoceanographic exclusion. The latter explanation is favored because $\underline{M}$. prinsii is also absent in Hole $761 \mathrm{C}$ where an iridium enrichment at the K/P boundary (Rocchia et al., 1992) and a complete sequence of upper Maestrichtian and (condensed) Paleocene nannofossil zones indicate that the $\mathrm{K} / \mathrm{P}$ transition is complete. On the other hand, the absence of $\underline{\mathrm{M}}$. prinsii at Site 761 cannot be strictly a function of paleolatitude, since this species is present in the Walvis Ridge sites (e.g. 528) which have a very similar paleolatitude to Site 761 in the Upper Cretaceous.

The upper Maestrichtian marker fossils $\underline{M}$. murus and $\underline{N}$. frequens are both present in this section. The lowest sample where unquestionable specimens of $\underline{\mathrm{M}}$. murus were observed is 761B-22-1, $80 \mathrm{~cm}$ (180.50 mbsf). Specimens very similar to $\underline{M}$. murus but with slightly shorter arms were observed in sample $761 \mathrm{~B}, 22-2,80 \mathrm{~cm}$ (182.0 mbsf). Micula murus is absent in sample $761 \mathrm{~B}, 22-3,80 \mathrm{~cm}$ (183.50 mbsf) and below. Specimens intermediate

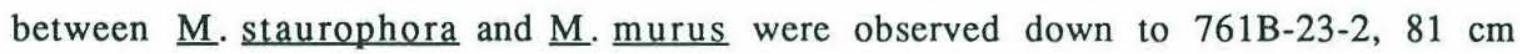
(191.51 mbsf). These forms have a compact, square center with the extinction pattern of $\underline{M}$. staurophora in cross polarized light, and elongate arms reminiscent of $\underline{M}$. murus. The lowest occurrence of $\underline{M}$. murus observed here is considerably higher in the section than reported by Bralower and Siesser (1992; 23-1, 81-83 cm; $190.01 \mathrm{mbsf}$ ). The reason for this discrepancy is unclear.

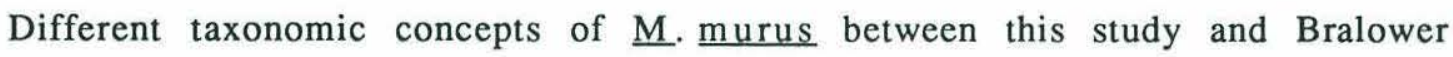
and Siesser's inverstigation cannot be invoked, since Bralower and Siesser (1992) were aware of the intermediate forms between $\underline{M}$. staurophora and $\underline{M}$. murus (compare their illustrations: plate 7, figures 1-6). It should be noted that the lowest occurrence of $\underline{\mathrm{M}}$. $\underline{\text { murus }}$ as reported by Bralower and Siesser (1992) is unusually low compared with the level of this biohorizon in other sections (see Chapter Biohorizons). 
Nephrolithus frequens occurs continuously down to sample 761B-23-1, $81 \mathrm{~cm}$ (190.01 mbsf). This agrees well with Bralower and Siesser's (1992) observation of the lowest occurrence of $\underline{N}$. frequens in $761 \mathrm{~B}-23-1,81-83 \mathrm{~cm}$. The isolated occurrence in sample 761B-23-3, 90cm $(193.10 \mathrm{mbsf}$; see data table for Hole 761B) is unexplained (bioturbation? truly discontinuous occurrence?). It is not taken as the level of the lowest occurrence of $\underline{N}$. frequens since careful inspection of smear slides could not verify the presence of $\underline{\mathrm{N}}$. frequens in the samples between.

The lowest occurrence of $\underline{L}$. quadratus was reported in 761B-23-3, 40-41 cm (192.60 mbsf; Bralower and Siesser, 1992) at which level this species occurs frequently (Bralower and Siesser, 1992). In my count data the lowest occurrence of $\underline{L}$. quadratus is in sample 761B-23-3, $150 \mathrm{~cm}(193.70 \mathrm{mbsf}$; see data table for Hole 761B).

The highest occurrence of $\underline{\mathrm{R}}$. levis was found in 761B-24-1, 39-40 cm (199.09 mbsf; Bralower and Siesser, 1992).

A very low sedimentation rate or a hiatus in the lower Maestrichtian is indicated by the very close (or concomitant) occurrence of the following three nannofossil biohorizons. The highest occurrence of $\underline{E}$. eximius lies in 761B-24-CC (208.2 mbsf, Bralower and Siesser, 1992). Bralower and Siesser (1992) report the highest occurrence of B. parca constricta from 761B-24-5, 34$35 \mathrm{~cm}$ and use this level as the highest occurrence of $\underline{B}$. parca. This is not followed here, since the highest occurrence in 761B-24-5, 34-35 is discontinuous from the other levels where this species was observed; in addition, section 761B-24-5 does not exist in the barrel sheets of the core description (Shipboard Scientific Party, 1992; p. 506) and was not present in the ODP core repository in College Station, Texas, where I took my samples. Therefore the highest occurrence of $\underline{B}$. parca is placed in $761 \mathrm{~B}-25-1,41-42 \mathrm{~cm}$ (208.61 mbsf), which is the higest level of continuous occurrence of B. parca parca and B. parca constricta in 761B (Bralower and Siesser, 1992). The highest occurrence of $\underline{Q}$. trifidum was also reported from 761B, 25-1, 41-42 cm (208.61 mbsf). The presence of a hiatus in the lower Maestrichtian in 761B is indicated in the sedimentation rate curve supplied by Shipboard Scientific Party (1990). In contrast, Bralower and Siesser (1992) indicate that the Maestrichtian is complete (at least as far as nannofossil biostratigraphy indicates), but that the Campanian portion is condensed. 
Cretaceous planktonic foraminifera indicate that only the upper to middle Maestrichtian are fully developed (Wonders, 1992), the remainder of the Upper Cretaceous (lower Maestrichtian to Coniacian/upper Turonian) is condensed. The lowest occurrence of A. mayaroensis was reported in 761B-241 , 56-58 cm (199.28 mbsf; absent in 761B-24-2, 63-65cm; 200.85 mbsf; Wonders, 1992) and defines the bottom of the $\underline{A}$. mayaroensis Zone.

The middle Maestrichtian $\underline{C}$. contusa Zone was recognized between 761B24-2, 63-65 cm (200.85mbsf) and 761B-24-4,61-63 cm (203.83 mbsf; Wonders, 1992), underlain by the H. rajagopalani Zone: 761B-25-1, 59-62 cm (208.82 mbsf) to 761B-25-5, 59-62 cm (214.82 mbsf; Wonders, 1992). The bottom of this zone (lowest occurrence of $\underline{\mathrm{H}}$. rajagopalani) is of late Campanian age (within the G. calcarata Zone, according to Nederbragt, 1990; Wonders, 1992).

\section{Magnetostratigraphy}

Paleomagnetic data are available from Upper Cretaceous sediments of Hole 761B (Galbrun, 1992; Table 3). Thermal cleaning, alternating field demagnetization, or both, revealed a stable remanent component of normal or reverse polarity in most samples (Galbrun, 1992). The magnetic polarity sequences were correlated with the standard magnetic polarity time scale with the aid of calcareous nannofossil biostratigraphy (Galbrun, 1992). Above the $\mathrm{K} / \mathrm{P}$ boundary where sedimentation rates are low, some polarity zones were indicated by single samples only (e.g. C29N, C28). For this reason these chrons were not included in Figure 8. It is a striking, but unexplained feature of the NRM intensity curve that the intensities show a minimum in the upper Maestrichtian and lower Paleocene (Galbrun, 1992: figure 4). No correlation between variation of NRM intensity and of lithology was noted (Galbrun, 1992). 
Table 3: Fixpoints used to calculate sedimentation rates in the Maestrichtian of Hole 761B.

$\begin{array}{llll}\begin{array}{l}\text { Boundary } \\ \text { K/P boundary }\end{array} & \begin{array}{l}\text { Depth } \\ (\mathrm{mbsf})\end{array} & \begin{array}{l}\text { Age } \\ (\mathrm{Ma})\end{array} & \begin{array}{c}\text { Sed. Rate } \\ (\mathrm{m} / \mathrm{m} . \mathrm{y} .)\end{array} \\ 29 \mathrm{R} / 30 \mathrm{~N} & 175.96 & 66.40 & 5.21 \mathrm{~m} / 0.34 \mathrm{~m} . \mathrm{y} .=15.32 \\ 31 \mathrm{~N} / 31 \mathrm{R} & 181.17 & 66.74 & 13.77 \mathrm{~m} / 2.66 \mathrm{~m} . \mathrm{y} .=5.18\end{array}$




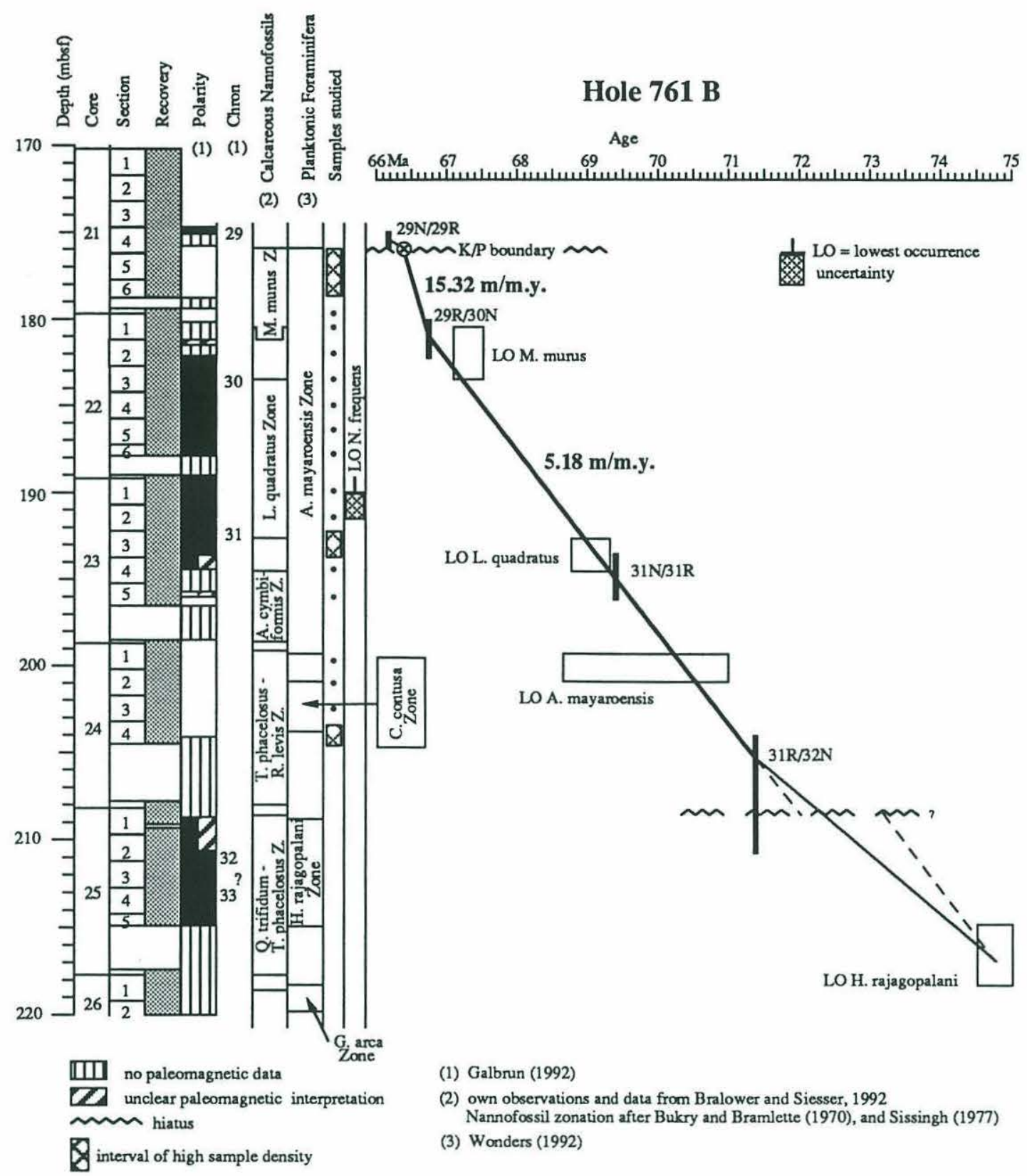

Figure 8: Sedimentation rate curve for the Maestrichtian section in Hole 761B. 


\section{4) ODP Hole 761C}

This hole was drilled $20 \mathrm{~m}$ north of Hole $761 \mathrm{~B}$ and contains a more complete $\mathrm{K} / \mathrm{P}$ sequence than Hole $761 \mathrm{~B}$.

A gap in recovery of about $1 \mathrm{~m}$ was reported in section 761C-3R-2 (Shipboard Scientific Party, 1990). However, for calculation of the sample depths by ODP and in papers included in ODP Volume 122, Scientific Reports, this gap was ignored (i.e. section 761C-3R-2 was considered to be only $0.5 \mathrm{~m}$ long). Sample depths included in the following discussion were calculated in the same manner (i.e. the gap in section 761C-3R-2 is ignored) in order to facilitate comparison between this study and previous publications.

\section{The K/P boundary}

A distinct lithologic and color change occurs in core 761C-3R-3, between 75 and $77 \mathrm{~cm}$. The contact is sharp and inclined (Figure 9), with white nannofossil chalk below and greenish-grey nannofossil chalk above. Bioturbation is common in both lithologies, but is more conspicuous in the darker, overlying sediment. The carbonate content decreases from about 85$90 \%$ in the white sediment to about $70 \%$ in the greyish chalk (Figure 10a). Two pieces of chert are present about $1 \mathrm{~cm}$ below the sharp color contact; another piece of chert lies about $12 \mathrm{~cm}$ higher in the section (at 761C-3-3, 66$67 \mathrm{~cm}$; Figure 9). At both chert layers the section is apparently drilling disturbed.

The lowest occurrence of $\underline{B}$. sparsus was observed in sample 761C-3-3, 70 $\mathrm{cm}$ (Figure 10b). The next lower sample available to me is from the white chalk at 761C-3-3, $75 \mathrm{~cm}$ and contains a typical upper Maestrichtian nannofossil assemblage (without $\underline{B}$. sparsus) indicating that the $\mathrm{K} / \mathrm{P}$ boundary should be placed between these two samples.

An iridium enrichment with a well defined peak was reported by Rocchia et al. (1992; Figure 10c). It coincides with the sharp color contact at 761C-3R-3, $75 \mathrm{~cm}$ (Figure 9).

Based on nannofossil, sedimentological and geochemical evidence the $\mathrm{K} / \mathrm{P}$ boundary is thus placed between $761 \mathrm{C}-3 \mathrm{R}-3,75$ and $77 \mathrm{~cm}(172.45-172.47$ mbsf).

In contrast, Pospichal and Bralower (1992) placed the K/P boundary about $9 \mathrm{~cm}$ higher in this section (between samples $761 \mathrm{C}-3-3,66-68 \mathrm{~cm}, 172.36$ - 


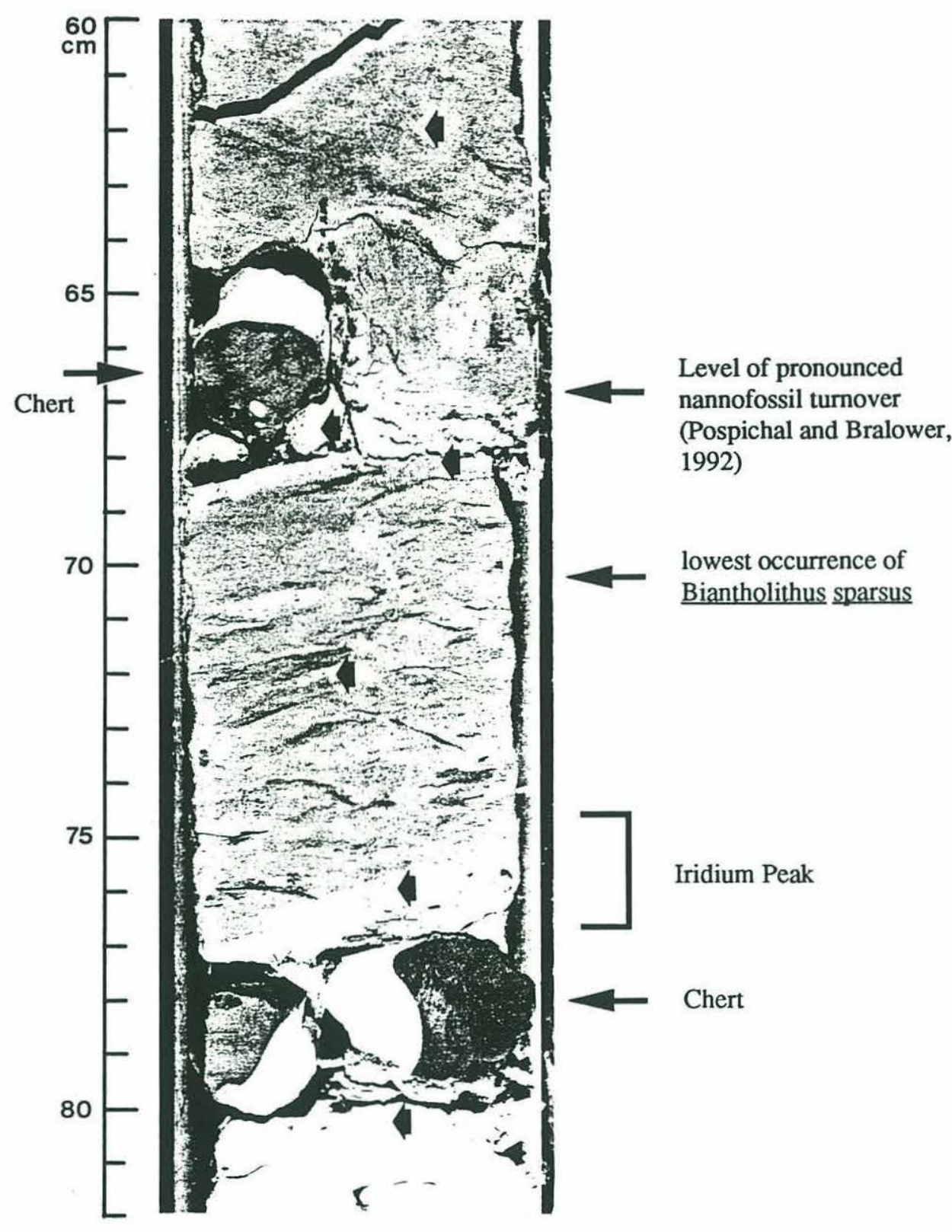

Figure 9: The lithology in the vicinity of the K/P boundary in Hole 761C (Section 761C-3R-3, 60-82 cm; from Pospichal and Bralower, 1992). The short fat arrows indicate levels where Pospichal and Bralower (1992) took samples. 
(a)

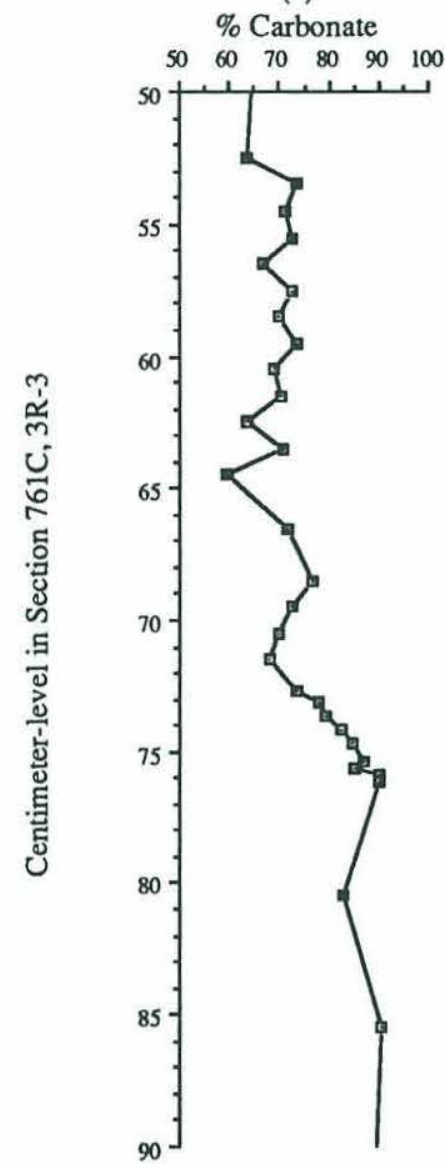

(b)

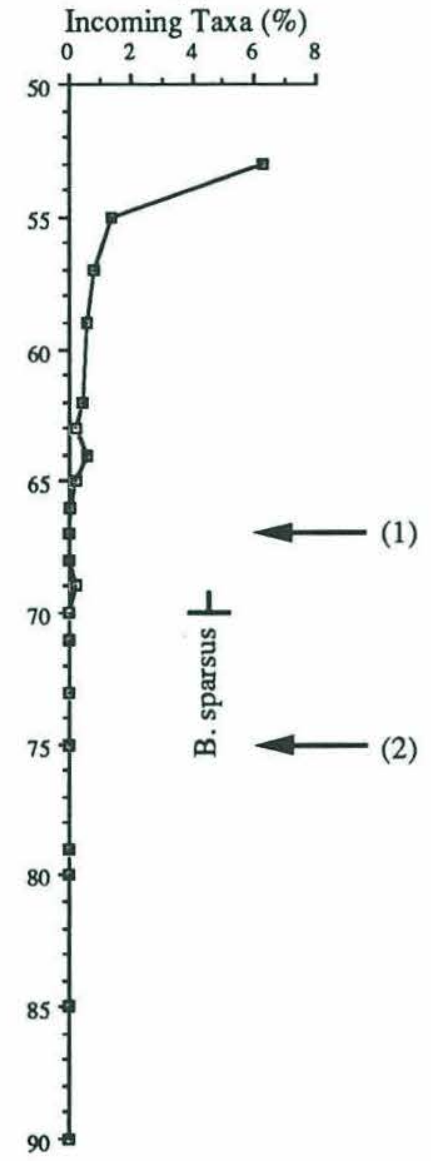

(c)

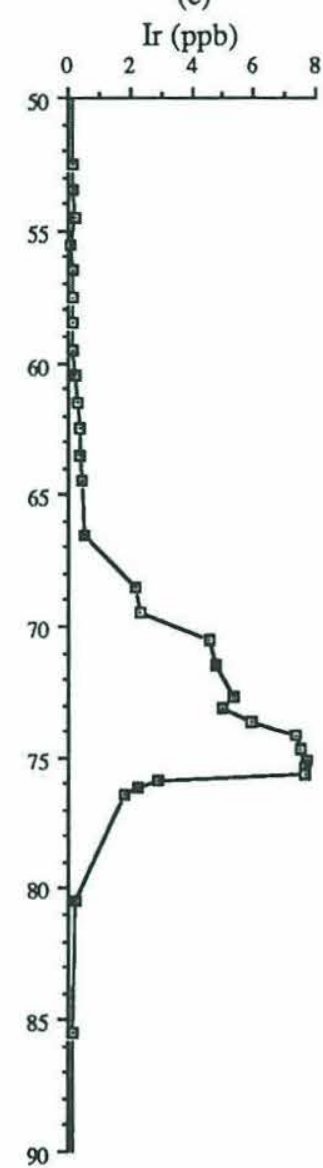

(d)

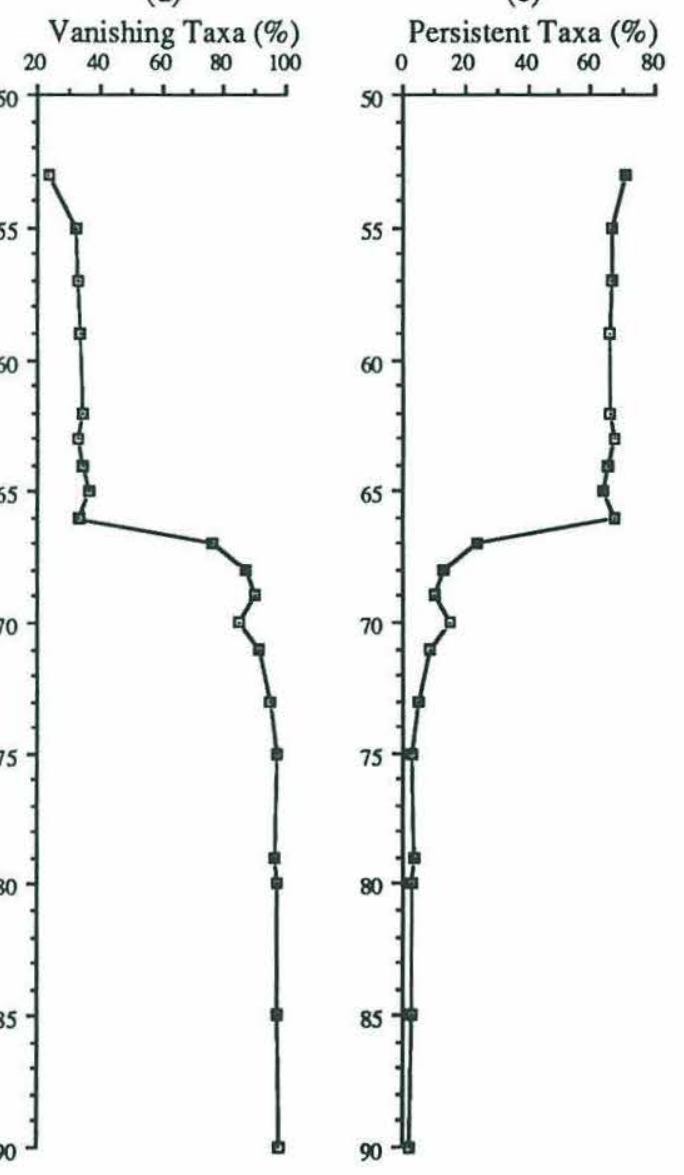

Figure 10: The K/P boundary interval in Hole 761C. (a) Carbonate content (Rocchia et al., 1992). (b) Abundance distribution of incoming calcareous nannofossil taxa (Pospichal and Bralower, 1992) and level of the first occurrence of Biantholithus sparsus (this study). (1) denotes the location of the K/P boundary after Pospichal and Bralower, 1992. (2) shows the level where the K/P boundary was placed in this study. (c) Iridium content in the sediment (Rocchia et al., 1992). (d) and (e) Abundance distribution of vanishing and incoming calcareous nannofossil taxa (Pospichal and Bralower, 1992). 
$172.38 \mathrm{mbsf}$ ), based on the pronounced change in the calcareous nannofossil assemblages at this level (compare Figure 10b, d, e); the vanishing taxa decrease from $>80 \%$ to about $40 \%$ of the assemblage, whereas the persistent taxa (dominated by Cyclagelosphaera spp.) increase from $<20 \%$ to about $60 \%$. Pospichal and Bralower (1992) found one specimen of $\underline{B}$. sparsus in sample $761 \mathrm{C}-3-3,69 \mathrm{~cm}$ which they considered as reworked and disregarded it in their placement of the K/P boundary; this interpretation is not supported by my own observations (see above). The pronounced turnover of calcareous nannofossil assemblages at the level where Pospichal and Bralower place the boundary may be due to a hiatus: a lithologic discontinuity is indicated by subtle color differences of the sediment below and above this level. In addition, the sediment below this horizon is more conspicuously mottled and bioturbated than the sediment above. Unfortunately, the exact nature of the sediment contact is obliterated by the drilling disturbance caused by the chert pebble (Figure 9) at this level.

No data on planktonic foraminifera were available to delineate the level of the $\mathrm{K} / \mathrm{P}$ boundary in this hole.

\section{Magnetostratigraphy}

Paleomagnetic data are available from Core 761C-3 (Rocchia et al, 1992) indicating that the $\mathrm{K} / \mathrm{P}$ boundary occurs in a reverse polarity interval (C29R). The boundary between Chrons C29R and C30N was not encountered since the lowest sample analyzed (761C-3-6, $83 \mathrm{~cm} ; 177.05 \mathrm{mbsf})$ was still of reversed polarity.

\section{Sedimentation Rate}

According to Berggren et al. (1985) the age of the K/P boundary is 66.40 $\mathrm{Ma}$, the base of Chron C29R occurs at $66.74 \mathrm{Ma}$. With the $\mathrm{K} / \mathrm{P}$ boundary at $761 \mathrm{C}$ 3-3, $75-77 \mathrm{~cm}$ (172.46 mbsf) the Maestrichtian portion of $\mathrm{C} 29 \mathrm{R}$ is at least $4.59 \mathrm{~m}$ long. This corresponds to a sedimentation rate of at least $13.50 \mathrm{~m} / \mathrm{m} . \mathrm{y}$. for the latest Cretaceous. The same sedimentation rate as calculated for the uppermost Maestrichtian in Hole 761B is also used in Hole 761C. 


\section{5) DSDP Hole 217}

\section{Location}

Hole 217 is located at $8^{\circ} 55.57^{\prime} \mathrm{N}, 90^{\circ} 32.33^{\prime} \mathrm{E}$ on the northernmost portion of Ninetyeast Ridge in $3010 \mathrm{~m}$ waterdepth, just south of the flat turbidite sediments of the Bengal Fan (Shipboard Scientific Party, 1974). The paleolatitude of this site during the Maestrichtian was about $>30^{\circ} \mathrm{S}$ according to the paleocontinental reconstructions of Smith and Briden (1977). A much lower paleolatitude during the Maestrichtian $\left(\sim 15^{\circ} \mathrm{S}\right)$ was indicated by Firstbrook et al. (1979; compare their reconstruction of the southern hemisphere at $70 \mathrm{Ma}$ ) apparently due to the fact that they did not place Hole 217 on the Indian Plate. Information obtained through recent ODP Legs (Leg 116 - 121) in the Indian Oceans (see detailed discussion in Royer et al., 1991) supports Smith and Briden's reconstruction which is also used in this study.

\section{Lithology}

The Maestrichtian sediments (421 to about $530 \mathrm{mbsf}$ ) were divided into two lithologic subunits, 2c and 2d (Shipboard Scientific Party, 1974). From the $\mathrm{K} / \mathrm{P}$ boundary between cores 17 and 16 (421 mbsf) to about $480 \mathrm{mbsf}$ the sediment consists of light grey to light brown nannofossil chalk with moderate to intense bioturbation (subunit $2 \mathrm{c}$ ).

Lithologic subunit 2d (420-600 mbsf) ranges from middle Maestrichtian to Campanian. The Maestrichtian portion of this subunit consists of carbonate siltstone (480 to about $500 \mathrm{mbsf}$ ) and micarb chalk (about 510-555 mbsf); concurrent with the change to micarb chalk occurs a prominent increase in shell fragments of Inoceramus, oysters and other unidentified large molluscs (Shipboard Scientific Party, 1974). Foraminifera constitute about $3-5 \%$ of the sediment, clay minerals about $5-10 \%$. Trace amounts of pyrite, glauconite, and volcanic glass are also present. The presence of oyster shells, glauconite, and of microfossils with shallow-water affinities led Shipboard Scientific Party (1974) to the conclusion that the paleo-waterdepth during the Late Cretaceous was less than about $500 \mathrm{~m}$.

\section{The K/P boundary}

Calcareous nannofossils: Calcareous nannofossil assemblages in samples $217-16-6,76-77 \mathrm{~cm}$ and $217-16-6,128-129 \mathrm{~cm}$ are moderately to poorly 
preserved and are dominated by fragments of Thoracosphaera spp. and by $\underline{\mathrm{P}}$.

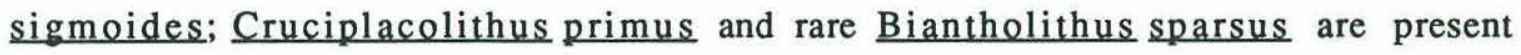
and indicate an age of early Paleocene (upper part of Biochron NP1). In addition, uppermost Maestrichtian calcareous nannofossils (e.g. $\underline{M}$. murus) are present. Gartner (1974) reported that the nannofossils in 217-16-CC are "Maestrichtian in age, though admixed with some Danian forms". In the range chart he recorded an isolated occurrence of Cruciplacolithus tenuis in sample 217-16-CC (Gartner, 1974) which would indicate nannofossil Zone NP2 (Martini, 1971). My own observations do not corroborate the presence of $\underline{C}$. tenuis in the lowermost samples of Core 217-16-6. Furthermore, the base of the continuous occurrence of $\underline{C}$. tenuis lies only in 217-15-CC (Gartner, 1974). Consequently, the lowermost nannofossil zone identified in 217-16-6, 128-129 is (the upper part of) NP1. No samples of 217-16-CC are available to me. Based on my observations in section 217-16-6, and on the isolated occurrence of $\underline{C}$. tenuis in 217-16-CC, Gartner's observation of mixed Danian and Maestrichtian nannofossils in 217-16-CC are interpreted here as constituting Danian assemblages with admixed Cretaceous taxa.

Sample 217-17-1, 18-19 cm contains a moderately to well preserved, typical upper Maestrichtian assemblage, including the marker species $\underline{M}$. $\underline{\text { murus }}$ and $\underline{\mathrm{N}}$. frequens. Forms very close to $\underline{\mathrm{M}}$. prinsii (elongate, curved arms, but no distinct bifurcation) were also observed. Paleocene forms were not encountered. Based on own observations and on Gartner's (1974) results the $\mathrm{K} / \mathrm{P}$ boundary is placed between cores 217-16 and 217-17. There may be a short hiatus at the $\mathrm{K} / \mathrm{P}$ boundary since the lowermost Paleocene sediment is assigned to the upper part of NP1 (or, possibly, NP2).

\section{Planktonic Foraminifera: Typical Danian forms (Eoglobigerina,} Chiloguembelina) were observed in core 217-16 (McGowran, 1974). The lower Paleocene subzone P1b was identified tentatively in sample 217-16-6, 148-150 cm (McGowran, 1974); subzone P1a was indicated in 217-16-CC (on the barrel sheets of the core description; Shipboard Scientific Party, 1974). Accordingly, the Danian biostratigraphic record is almost complete (McGowran, 1974). In sections 217-16-6 and 217-16-CC large specimens of the Maestrichtian planktonic foraminifer Hedbergella monmouthensis occur abundantly (McGowran, 1974). A typically diverse, tropical Maestrichtian assemblage occurs in section 217-17-1 (McGowran, 1974). The K/P boundary is placed 
between cores 217-16 and 217-17 at $421.0 \mathrm{mbsf}$, on the tenuous evidence that the Maestrichtian foraminifera in 217-16-CC represent upward reworking rather than downhole contamination (McGowran, 1974).

\section{Biostratigraphy}

Calcareous Nannofossils: In agreement with Wind (1979a) but contrary to Shipboard Scientific Party (1974) the upper Maestrichtian marker species Micula murus and Nephrolithus frequens are both present in Hole 217. Bukry (1974) reported the presence of "Micula murus Zone assemblages" in cores 21717 and 217-18 but does not indicate whether the marker species is present.

Forms very similar to Micula prinsii are present throughout core 21717. They have elongate, curved arms, but do not have the bifurcation at the ends of their arms which is characteristic of $\underline{M}$. prinsii. I consider these forms as intermediate between $\underline{M}$. murus and $\underline{\mathrm{M}}$. prinsii, possibly representing early morphotypes of $\underline{M}$. prinsii.

The lowest occurrence of Micula murus lies between 217-18-CC ( $\underline{M}$. murus still present) and 217-19-3, $100 \mathrm{~cm}$ (ㅆ. $\underline{\text { murus }}$ absent; Wind, 1979a), indicating the base of the $\underline{M}$. murus Zone (Bukry and Bramlette, 1970).

The high-latitude marker species of the latest Maestrichtian, $\underline{\mathrm{N}}$. frequens, is also present in Hole 217. It is rare and was not observed in all samples; its lowest occurrence was observed in 217-24-CC, which is very close to the top of the $\underline{Q}$. trifidum Zone. Because of its anomalous low occurrence, $\underline{N}$. frequens is not used in the biostratigraphic zonation of this hole.

The lowest continuous occurrence of $\underline{L}$. quadratus was observed in 217 20-CC, it was absent in 217-21-2, $101 \mathrm{~cm}$ (Wind, 1979a). An isolated occurrence of this species was reported in 217-21-5, $100 \mathrm{~cm}$ (Wind, 1979a; dotted square in Figure 11). The lowest occurrence of this species indicates the base of the $\underline{L}$. quadratus Zone (Cepek and Hay, 1969) which corresponds to the base of Zone CC25c (highest part of the A. cymbiformis Zone, Sissingh, 1977).

The highest occurrences of $\underline{R}$. levis, of $\underline{T}$. phacelosus, and of $\underline{B}$. parca were observed in 217-24-1, 49-50 cm (these forms were absent in 23-4, 53-54 $\mathrm{cm})$. The highest occurrence of $\underline{\mathrm{R}}$ levis indicates the base of the $\underline{\mathrm{A}}$. cymbiformis Zone (CC 25, Sissingh, 1977); the other two species are used to delineate the base of the $\underline{\mathrm{R}}$ levis Zone (CC24) and to subdivide the $\underline{\mathrm{T}}$. phacelosus Zone (CC23), respectively. Further biostratigraphic refinement is required to distinguish these boundaries or to determine whether a hiatus is present. For 
this reason these biohorizons were not included in the construction of the sedimentation rate curve. Because of the absence of Reinhardtites anthophorus cores $217-24$ to $217-26$ were assigned to the lower part of the $\mathrm{T}$. phacelosus Zone (CC23a, Sissingh, 1977).

The highest occurrence of $\underline{Q}$. trifidum was observed in 217-25-CC, but could not be identified confidently in 217-24-CC. Wind (1979a) reported the highest occurrence of this form in 217-25-2, $76 \mathrm{~cm}$ (absent in 24-6, $125 \mathrm{~cm}$ ). Thus the highest occurrence of $\underline{\text { Q }}$ trifidum is placed between $217-25-2,76 \mathrm{~cm}$ and 217-24-CC. This agrees with Bukry (1974), but is in contrast to Gartner (1974) who places this biohorizon about $10 \mathrm{~m}$ lower in Hole 217. According to Perch-Nielsen (1983) the highest occurrence of $\underline{Q}$. trifidum should be above that of B.parca, which is not the case in this hole. The highest occurrence of Q. trifidum seems to be a temporally narrowly defined biohorizon (compare chapter "Biohorizons"; see also Monechi and Thierstein, 1985) and therefore it was used as the lowest point in the construction of the sedimentation rate curve for Hole 217.

Planktonic Foraminifera: The upper Maestrichtian $\underline{A}$. mayaroensis Zone ranges from core $217-23$ to the $\mathrm{K} / \mathrm{P}$ boundary. The lowest occurrence of $\underline{\mathrm{A}}$. mayaroensis was reported in 217-23-CC (487.5 mbsf; McGowran, 1974); it is absent in sample 217-24-1, 80-82 cm (488.3 mbsf; Pessagno and Michael, 1974). In the top part of core 217-24 Abathomphalus intermedius is still present, possibly indicating the mid-Maestrichtian Gansserina gansseri Zone (Shipboard Scientific Party, 1974). The planktonic foraminiferal zonation of the remainder of the Upper Cretaceous is problematic because of the lack of zonal marker species. The presence of Bolivinoides draco miliaris in core 21727 indicates upper Campanian to lower Maestrichtian, the presence of Globotruncana of the arca/rosetta group in core 217-36 suggests a Campanian age (Shipboard Scientific Party, 1974).

\section{Age Model}

Since no paleomagnetic data are available for DSDP Hole 217, the age model relies on nannofossil and planktonic foraminiferal biostratigraphy. The biohorizons available to construct the sedimentation rate curve are discussed in the previous chapter and are listed in Table 4. The results are plotted in Figure 11. The depth assigned to each biohorizon is the average between the 
lowest/highest occurrence and the subsequent sample in which the species was not observed.

All five biohorizons can be connected with one straight line. Since the $\mathrm{K} / \mathrm{P}$ boundary and the LO $\underline{Q}$. trifidum are the best constrained datum points available, they were used to calculate the sedimentation rate $(15.81 \mathrm{~m} / \mathrm{m} . \mathrm{y}$.).

Table 4: Biohorizons used to construct the sedimentation rate curve of Hole 217 (HO $=$ highest occurrence, $\mathrm{LO}=$ lowest occurrence). For age assignments see chapter "Biohorizons". The depth determination of each biohorizon is described in the previous chapter.

\begin{tabular}{|c|c|c|c|c|}
\hline $\begin{array}{l}\text { Boundary/ } \\
\text { Biohorizon }\end{array}$ & Sample (mbsf) & $\begin{array}{l}\text { average } \\
\text { Depth }\end{array}$ & Age & $\begin{array}{l}\text { Sed. rate } \\
(\mathrm{m} / \mathrm{m}, \mathrm{y} .)\end{array}$ \\
\hline $\mathrm{K} / \mathrm{P}$ boundary & $\begin{array}{l}16-\mathrm{CC} \quad(421.0) \\
17-1 \quad(421.0)\end{array}$ & 421.00 & 66.40 & \\
\hline LO $\underline{\mathrm{M}}$. murus & $\begin{array}{l}18-C C \quad(440.0) \\
19-3,100 \mathrm{~cm}(444.0)\end{array}$ & 442.0 & 67.60 & \\
\hline LO $\underline{L}$. quadratus & $\begin{array}{l}20-C C \quad(459.0) \\
21-2,101 \mathrm{~cm} \quad(461.51\end{array}$ & 460.26 & 69.03 & \\
\hline LO $\underline{\text { A. mayaroensis }}$ & $\begin{array}{l}23-C C \quad(487.5) \\
24-1,80-82 \mathrm{~cm} \quad(488.3)\end{array}$ & 487.90 & 69.67 & \\
\hline LO $\underline{\text { Q. trifidum }}$ & $\begin{array}{l}24-\mathrm{CC} \quad(497.0) \\
25-2,76 \mathrm{~cm} \quad(499.26)\end{array}$ & 498.13 & 71.28 & \\
\hline
\end{tabular}




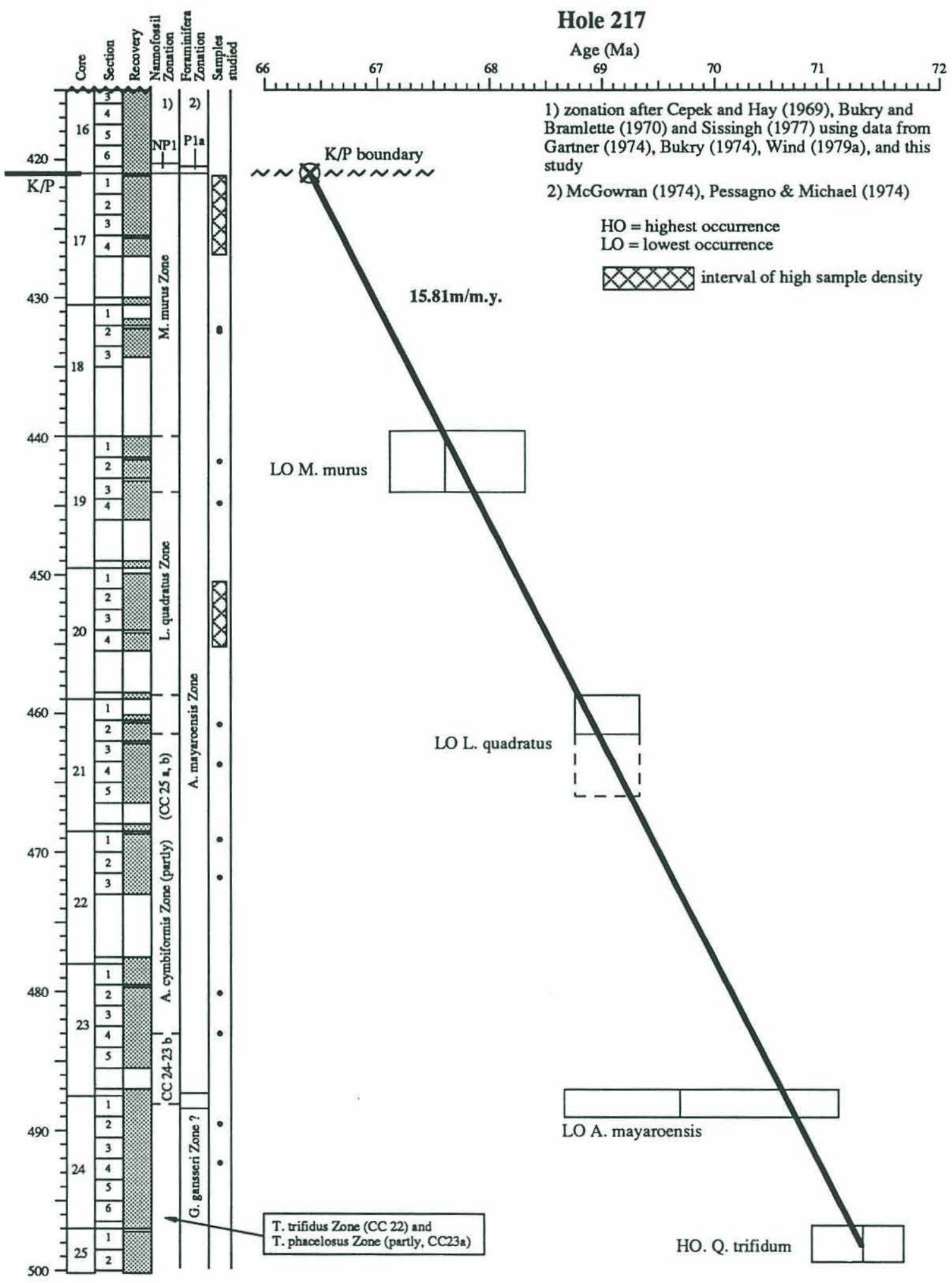

Figure 11: Sedimentation rate curve for the Maestrichtian section in Hole 217. 


\section{6) DSDP Hole 528}

\section{Location}

DSDP Hole 528 is located on the north western slope of Walvis Ridge in the South-Atlantic $\left(28^{\circ} 31.49^{\prime} \mathrm{S} ; 2^{\circ} 19.44^{\prime} \mathrm{E}\right)$ in $3800 \mathrm{~m}$ waterdepth (Shipboard Scientific Party, 1984). The latitude of Walvis Ridge during the late Maestrichtian was $36^{\circ} \mathrm{S} \pm 1^{\circ}$ (Chave, 1984). Because this hole reached basement in the A. cymbiformis Zone only the uppermost Maestrichtian interval was investigated in detail in this study.

A conspicuous cyclical alternation of reddish-brown and white sediment-layers occurs in the Maestrichtian in Hole 528 (Borella, 1984); the individual layers are about 0.3 to $0.5 \mathrm{~m}$ thick. It has been argued that these color cycles are a record of Late Cretaceous precessional climate cyclicity, because the mean absolute period of the color cycles $(23.5 \pm 4.4 \mathrm{kyr})$ is similar to the predicted Late Cretaceous precessional period $(20.8 \mathrm{kyr}$; Herbert and D'Hondt, 1990). One of the reasons that Hole 528 was included in this study was to ascertain whether and in which way calcareous nannofossil assemblages change in response to the proposed climatic cycles.

Four samples that were counted are assigned to the lowermost Paleocene because at the beginning of the study of this hole, the exact location of the $\mathrm{K} / \mathrm{P}$ boundary (within 528-31-CC, or between Cores 528-31 and 528-32) was unclear.

\section{Lithology}

About $63 \mathrm{~m}$ (Cores 528-32 to 528-38) of upper Maestrichtian sediment were penetrated in DSDP Hole 528. The sediment consists of foraminiferal nannofossil chalk interbedded with volcanoclastic turbidite sandstone (lithologic unit III, Shipboard Scientific Party, 1984). Turbidite sediments occur most abundantly in Cores 528-37 and 528-38 (lithologic subunit IIIC). Fining upward volcanoclastic sequences with varying clay content $(10-78 \%$, Shipboard Scientific Party, 1984) alternate irregularly with nannofossil chalks. Parallel laminations, normal and reversed graded bedding, and flaser bedding are common in the sandstone layers. Scoured contacts between the volcanoclastic and the chalky layers resulted from turbidity currents. Volcanoclastic turbidites occur also in Cores 528-32 to 528-37, but they are much rarer and thinner. The turbidite beds as reported in the core description of Hole 528 (Shipboard Scientific Party, 1984) are shown in Figure 12. Two 
slumps occur in Core 528-31 corroborating geophysical evidence for reworking and erosion on the slope of Walvis Ridge. The lower slump (528-316, $90-150 \mathrm{~cm}$ ) occurred within Chron $\mathrm{C} 29 \mathrm{R}$ and had to be subtracted for the calculation of the lowest Paleocene sedimentation rate.

Cores 528-39 to 528-47 penetrated basaltic basement rocks with interbedded upper Maestrichtian sediment (lithologic unit IV; Shipboard Scientific Party, 1984).

\section{The $K / \mathbf{P}$ boundary}

In agreement with Manivit (1984) the K/P boundary occurs between Cores 528-31 and 528-32. The sediments at the very top of Core 528-32 (sample $528-32-1,8 \mathrm{~cm}$ ) contain a moderately well preserved uppermost Maestrichtian assemblage, including the markers $\underline{M}$. prinsii, $\underline{M}$. murus and $\underline{N}$. frequens which indicate the upper part of the $\underline{N}$ frequens Zone (Perch-Nielsen, 1979). In contrast, the nannofossil assemblages in 528-31-CC are poorly preserved and dominated by fragments of Thoracosphaera. Other persistent taxa ( $\underline{P}$. sigmoides, Neocrepidolithus spp., $\underline{B}$. constans, $\underline{M}$. inversus) are much more abundant than in the underlying core. Biantholithus sparsus, the first truly Cenozoic calcareous nannofossil taxon, was encountered in sample 528-31-7, $58-59 \mathrm{~cm}, 0.3 \mathrm{~m}$ above the boundary between Cores 528-32 and -31 . Manivit (1984) reported $\underline{B}$. sparsus from sample 528-31-CC, and the first occurrence of C. primus in $528-31-5,150 \mathrm{~cm}(405.00 \mathrm{~m})$, indicating that the lower part of NP1 is present between 528-31-CC and $-31-5,150 \mathrm{~cm}(407.0-405.0 \mathrm{mbs})$. Thus calcareous nannofossils indicate that the $\mathrm{K} / \mathrm{P}$ boundary is complete in Hole 528 (i.e. all nannofossil zones are present).

Planktonic foraminifera indicate that the $\mathrm{K} / \mathrm{P}$ boundary occurs between Cores 528-31 and -32 (Boersma, 1984) in agreement with the calcareous nannofossil boundary. A very thin $(0.5-1 \mathrm{~cm})$, blue-tinged, fine-grained sediment layer occurs at the very top of the Maestrichtian at all Walvis Ridge Sites, containing a unique foraminiferal fauna (528-32-1, $1 \mathrm{~cm}$; Boersma, 1984): small individuals, typical of the upper Maestrichtian A. mayaroensis Zone together with Hedbergella monmouthensis and heavily costate Pseudoguembelina excolata characterize this layer. Substantial amounts of pyrite were present in the foraminifera tests (Boersma, 1984). The $\underline{\text { P. eugubina }}$ Zone (lowermost Paleocene) occurs in Core 528-31-CC to -31-7, $24 \mathrm{~cm}$ (Boersma, 1984). The sediment contains volcanic glass and less pyrite than below the 
boundary. Inverse to the trend in nannofossil preservation, foraminiferal preservation is better above the boundary than below (moderately well versus poor). Based on comparison of planktonic foraminiferal biohorizons (LADs, FADs) in this section with those in more expanded, epicontinental K/P sections (Brazos River and El Kef) MacLeod and Keller (1991) argue that a hiatus of 100 to $250 \mathrm{kyr}$ exists at the $\mathrm{K} / \mathrm{P}$ boundary in Hole 528 ; it is unclear if this hiatus occurs exclusively in the Paleocene or if it extends into the Maestrichtian.

\section{Magnetostratigraphy}

Paleomagnetic measurements were performed on samples taken at 30-60 $\mathrm{cm}$ intervals in undisturbed cores (Chave, 1984). Demagnetizing fields of 15-30 $\mathrm{mT}$ were sufficient in most cases to remove any magnetic overprint. All samples were measured, demagnetized, and measured again (Chave, 1984). The natural remanence of the sediments proved to be very strong and yielded essentially the same stratigraphic interpretation as the demagnetized results (Chave, 1984). Walvis Ridge Holes 525A and 527 have better recovery and therefore more complete paleomagnetic records than 528. Comparison of the paleomagnetic record of 528 with those of $525 \mathrm{~A}$ and 527 and integration of micropaleontological data yielded consistent paleomagnetic interpretation of the four Walvis Ridge Sites.

The following magnetochrons were identified in Hole 528 (Figure 12): the K/P boundary occurs close to the top of a reverse interval (Chron C29R). The boundary to the underlying normal interval is very sharp (Chave, 1984); it occurs between Sections 528-32-4 and -5. Micula murus first occurs in the upper half of this long normal interval indicating Chron C30N (Monechi and Thierstein, 1985). The normal interval extends down to the base of Core 528-37. Very low values of inclination ocurred in the top half of Core 528-33 (ca. 417420.5 mbsf; Chave, 1984). Lithraphidites quadratus was observed to have its first occurrence very close to the base of the long normal interval (Manivit, 1984), indicating Chron C31N (Monechi and Thierstein, 1985). The short reverse Chron C30R was not identified in Hole 528. The boundary with the underlying reverse interval could not be established precisely, because of turbiditic sediments in the upper two sections of Core 528-38. The lowermost sediments above the uppermost basalts of Hole 528 (lower half of Core 528-38) are of reverse polarity, representing Chron C31R. 


\section{Age Model (Table 5 and Figure 12)}

The sedimentation rate of the lowermost Paleocene was calculated using the K/P boundary and the $29 \mathrm{~N} / 29 \mathrm{R}$ boundary.

Two paleomagnetic boundaries $(29 \mathrm{R} / 30 \mathrm{~N}$ and $31 \mathrm{~N} / 31 \mathrm{R})$, the $\mathrm{K} / \mathrm{P}$ boundary and two biohorizons (lowest occurrence of $\underline{\mathrm{M}}$. murus, LO $\underline{\mathrm{L}}$. quadratus) are available to construct the sedimentation rate curve for the upper Maestrichtian. The age estimate assigned to the lowest occurrence of $\underline{M}$. murus is an average calculated from the four South Atlantic sites listed in chapter "Biohorizons" (see discussion there). The K/P boundary, the 29R/30N boundary and the lowest occurrence of $\underline{M}$. murus can be connected with a straight line, corresponding to a sedimentation rate of $19.56 \mathrm{~m} / \mathrm{m} . \mathrm{y}$. The age of the lowest occurrence of $\underline{\mathrm{M}}$. murus thus obtained $(67.4 \mathrm{Ma})$ is used as the upper tie-point for the sedimentation rate in the lower portion of the section which is about $20 \mathrm{~m} / \mathrm{m} . \mathrm{y}$.

Table 5: Sedimentation Rates in the lowermost Paleocene and Upper Cretaceous in Hole 528.

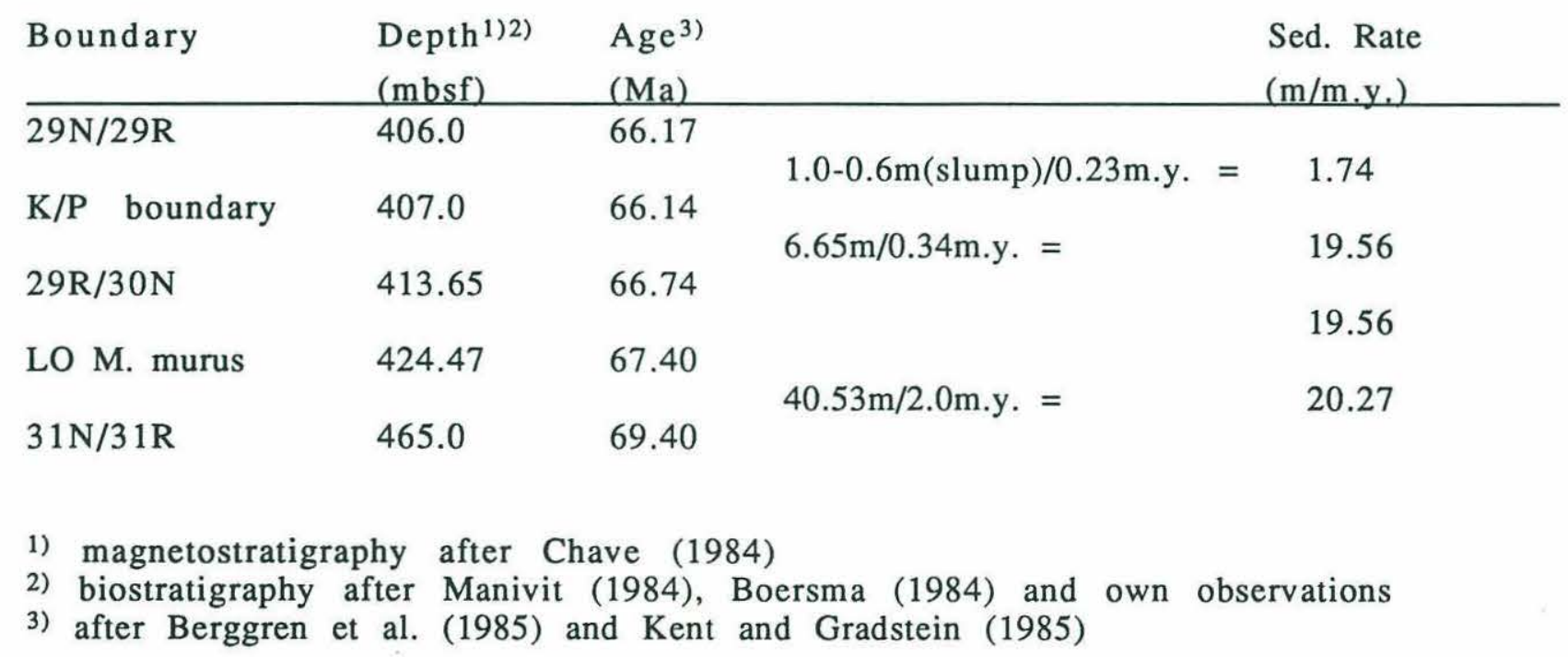




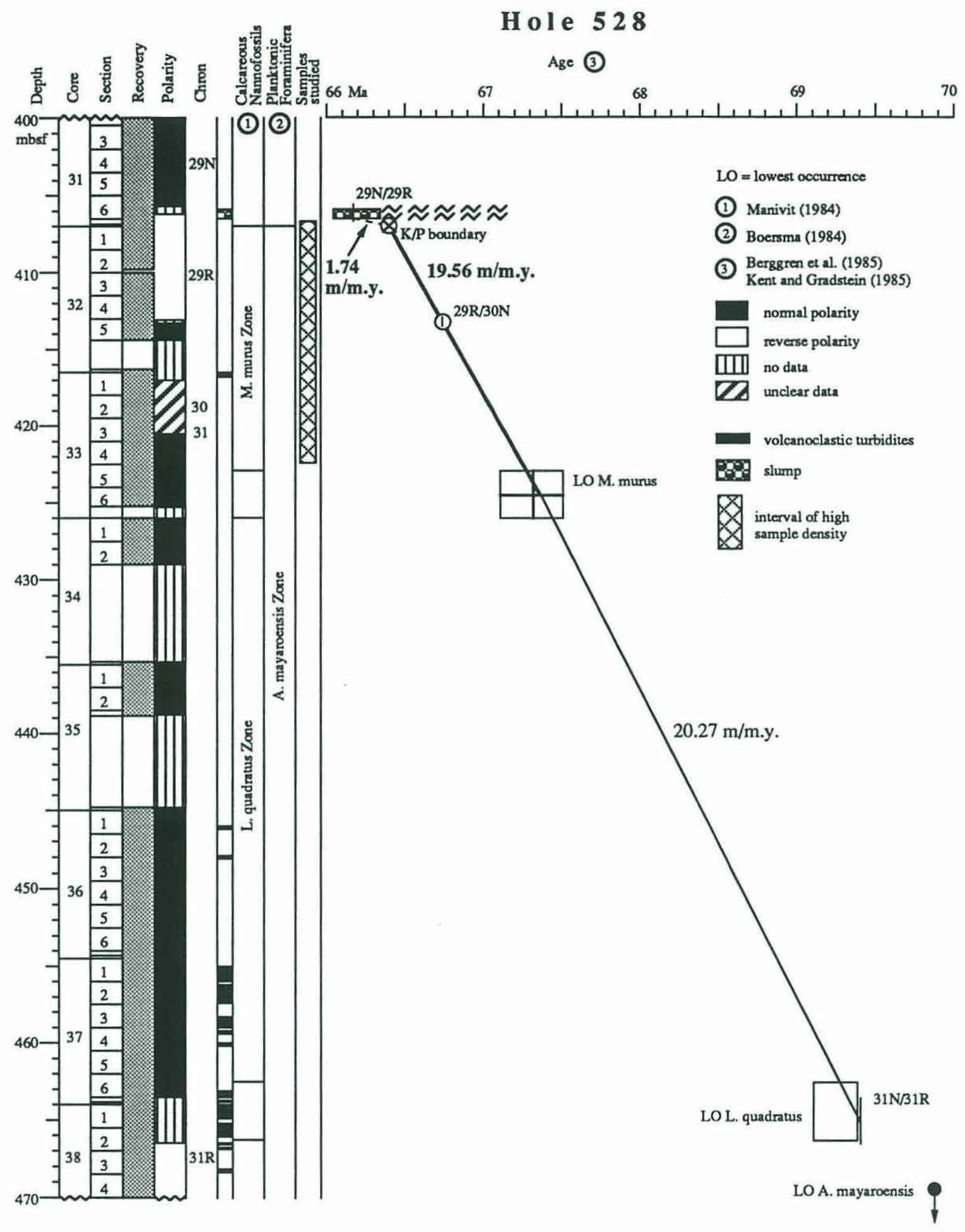

Figure 12: Sedimentation rate curve for the Maestrichtian section in Hole 528. 


\section{7) Miller's Ferry Section (Hole 226), Alabama}

The Cretaceous/Paleocene sequence near Millers Ferry (Alabama) was cored by the U.S. Army Corps of Engineers during the construction of the Millers Ferry Dam on the Alabama River. The samples included in this study are from one of the boreholes drilled (Hole 226) and were supplied by R. K. Olsson (Rutgers University). This core represents a low latitude, epicontinental section. Its latitude in the latest Cretaceous was about $30^{\circ}-35^{\circ} \mathrm{N}$ (paleocontinental reconstructions of Smith and Briden, 1977, and of Firstbrook et al., 1979). The sequence recovered in Millers Ferry Hole 226 consists of Upper Cretaceous chalk of the Prairie Bluff Formation and of lower Paleocene sandstone, siltstones, and marls of the Pine Barren Member (Clayton Formation). Planktonic foraminifera in this section were investigated by Liu (1992) who placed the K/P boundary at the top of the Prairie Bluff Chalk, a level where Guembelitria cretacea increases in relative abundance. The upper Maestrichtian marker species $\underline{A}$. mayaroensis is absent in Millers Ferry (e.g. Mancini et al, 1989). Liu (1992) reports that the lowermost planktonic foraminiferal zone (P0) is missing in Hole 226, indicating a short hiatus at the $\mathrm{K} / \mathrm{P}$ boundary.

Investigation of the calcareous nannofossils in Hole 226 showed that the uppermost Maestrichtian marker fossils of low latitudes, Micula murus and Micula prinsii, as well as the high latitude marker species Nephrolithus frequens are present (Olsson et al, 1992). Consequently, the absence of $\underline{A}$. mayaroensis must be explained as environmental exclusion and not as the consequence of a hiatus. Immediately above the level where Liu (1992) placed the K/P boundary there is a conspicuous increase of Cyclagelosphaera spp., similar to ODP Hole 761C, but Cretaceous (vanishing) nannofossil taxa still dominate the assemblage in the lowermost Paleocene samples. The lowest occurrence of Biantholithus sparsus was observed in sample \#5, $4 \mathrm{~cm}$ above the $\mathrm{K} / \mathrm{P}$ boundary.

\section{Age Model}

Few constraints exist in the Maestrichtian portion of this section to estimate the sedimentation rate. Paleomagnetic data are not available; the zonal boundary between the $\underline{M}$. prinsii Zone and the $\underline{M}$. murus Zone is not present in the core, $\underline{M}$. prinsii occurs throughout; a hiatus is present in this 
hole in the lowermost Paleocene (planktonic foraminiferal zone PO is absent: Liu, 1992) and it is unclear whether this hiatus is restricted to the Paleocene or whether it extends down into the Maestrichtian. Because of these uncertainties only a minimum estimate of the sedimentation rate can be given based on the fact that $\mathrm{M}$. prinsii is present throughout the section. The average duration of the $\underline{M}$. prinsii Zone is $0.23 \mathrm{~m} . \mathrm{y}$. (see chapter Biohorizons), leading to an estimated minimum sedimentation rate of $10.2 \mathrm{~m} / \mathrm{m} . \mathrm{y}$. This figure is comparable to the sedimentation rates of upper Maestrichtian chalks in the other sites included in this study (12.7-19.6 m/m.y; Holes 217 and 528, respectively).

In comparison, a sedimentation rate of $5.1 \mathrm{~m} / \mathrm{m}$.y. was reported for the upper Maestrichtian section near Braggs, Alabama (Channell and Dobson, 1989). But the presence of (at least) one hiatus of unknown duration (minimum 80000 years, Channell and Dobson, 1989) in the Braggs section, as well as different lithology (predominantly clastic; Copeland and Mancini, 1986) make a direct comparison of sedimentation rates between the two sections difficult.

For this study a sedimentation rate of $10 \mathrm{~m} / \mathrm{m} . \mathrm{y}$. is adopted to estimate sample ages in the Millers Ferry section and I assume that the hiatus in the lowest Paleocene does not extend into the Maestrichtian. 


\section{CHAPTER 4 RESULTS}

\section{1) ODP Hole $690 \mathrm{C}$}

\section{(A) Differences between the early and the late Maestrichtian}

The number of taxa recorded in each sample decreased from about 30-40 taxa per sample in the early Maestrichtian to less than 25 taxa per sample in the late Maestrichtian (Figure 13a). The anomalously low values at about 72.1 $\mathrm{Ma}$ and at about $75 \mathrm{Ma}$ were recorded in poorly preserved samples and are not considered to reflect a genuine diversity decrease at these levels. The diversity decrease occurred rather abruptly between 71.1 and $70.4 \mathrm{Ma}$. There is a slight decrease in preservation between these two samples (from moderate preservation at $71.1 \mathrm{Ma}$ to moderately poor preservation at $70.4 \mathrm{Ma}$ ) but I consider it too small to cause the diversity decrease from 34 to 19 taxa.

The species that shows the most pronounced abundance increase from the early to the late Maestrichtian is Prediscosphaera stoveri (Figure 13b). This species constituted $<10 \%$ of the assemblage in most samples in the lower Maestrichtian. After $\sim 70 \mathrm{Ma}$ the abundance of this species increased rapidly; it constituted $40-60 \%$ of the entire assemblage during most of the latest Maestrichtian (67-66.4 Ma) with a peak value of $>80 \%$. The relative abundances given for $\underline{\mathbf{P}}$. stoveri are percentages of the entire nannofossil assemblage. In contrast, the abundances given for all other taxa were calculated exclusive of

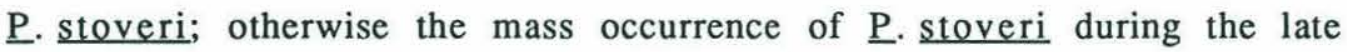
Maestrichtian would have largely obscured the abundance fluctuations of other taxa.

The majority of nannofossils that disappeared close to the early/late Maestrichtian boundary are representatives of typical austral taxa that were either unknown or extremely rare at middle and low latitudes. They include Biscutum magnum, Chiastozygus garrisonii, Monomarginatus spp., Misceomarginatus spp., Neocrepidolithus watkinsii, Nephrolithus corystus, Phanulithus obscurus, Psyktosphaera firthii and Reinhardtites spp. (Figure 14a - h). All of these taxa are common or abundant in the early Maestrichtian. The following taxa were present as minor components (less than about 2\%) during the early Maestrichtian, but were absent during the late Maestrichtian: Biscutum boletum, Biscutum coronum, Biscutum dissimilis, Biscutum sp. 1, Biscutum sp. 2, Chiastozygus amphipons, Chiastozygus sp. 1, Octocyclus magnus, 
(a) Taxon Richness

(number of taxa per sample)

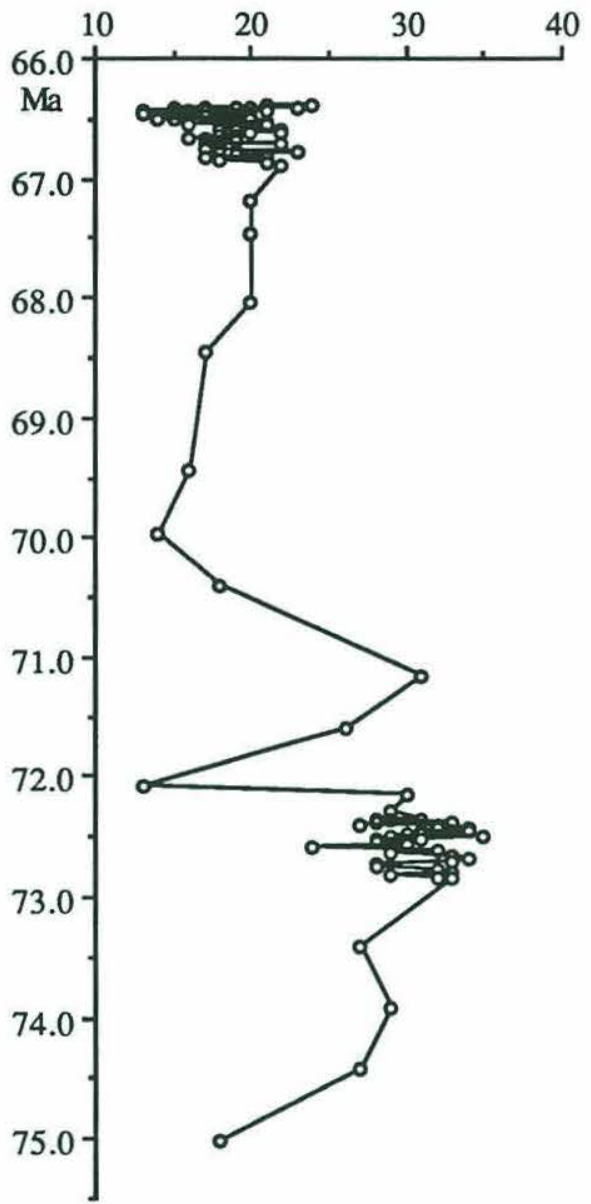

(b)

P. stoveri

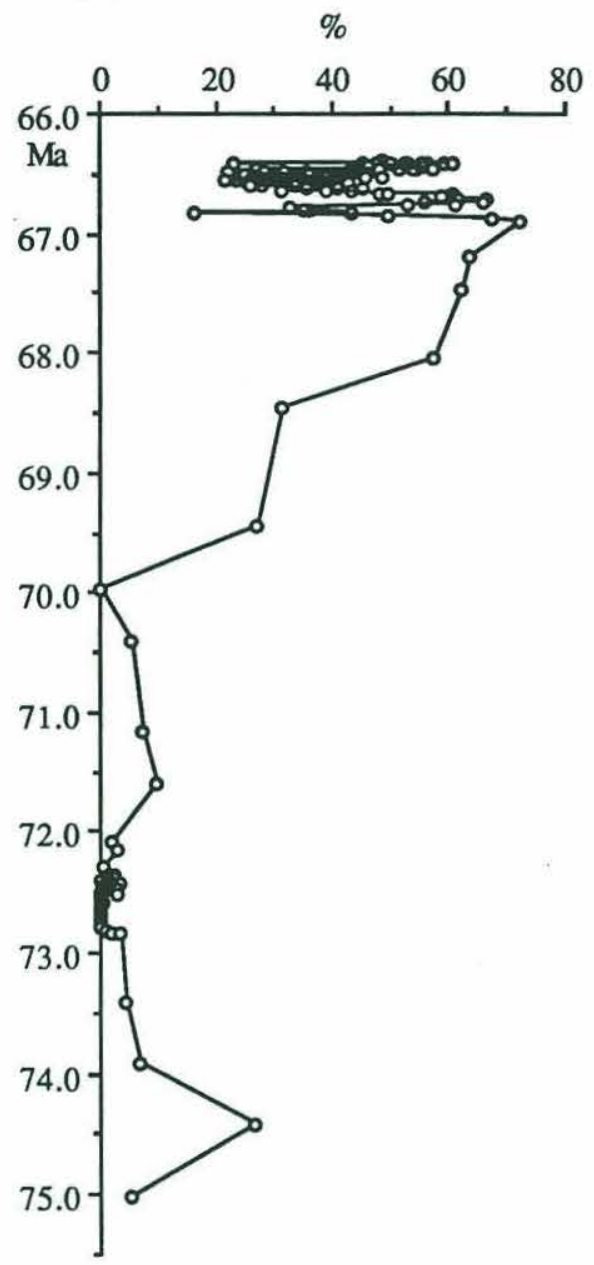

Figure 13: (a) Taxon richness in Hole 690C plotted against age. Note the pronounced abundance decrease between $\sim 71$ - 70 Ma. (see text for discussion). (b) Relative abundance of Prediscosphaera stoveri in Hole 690C. This species becomes very abundant in the late Maestrichtian. 

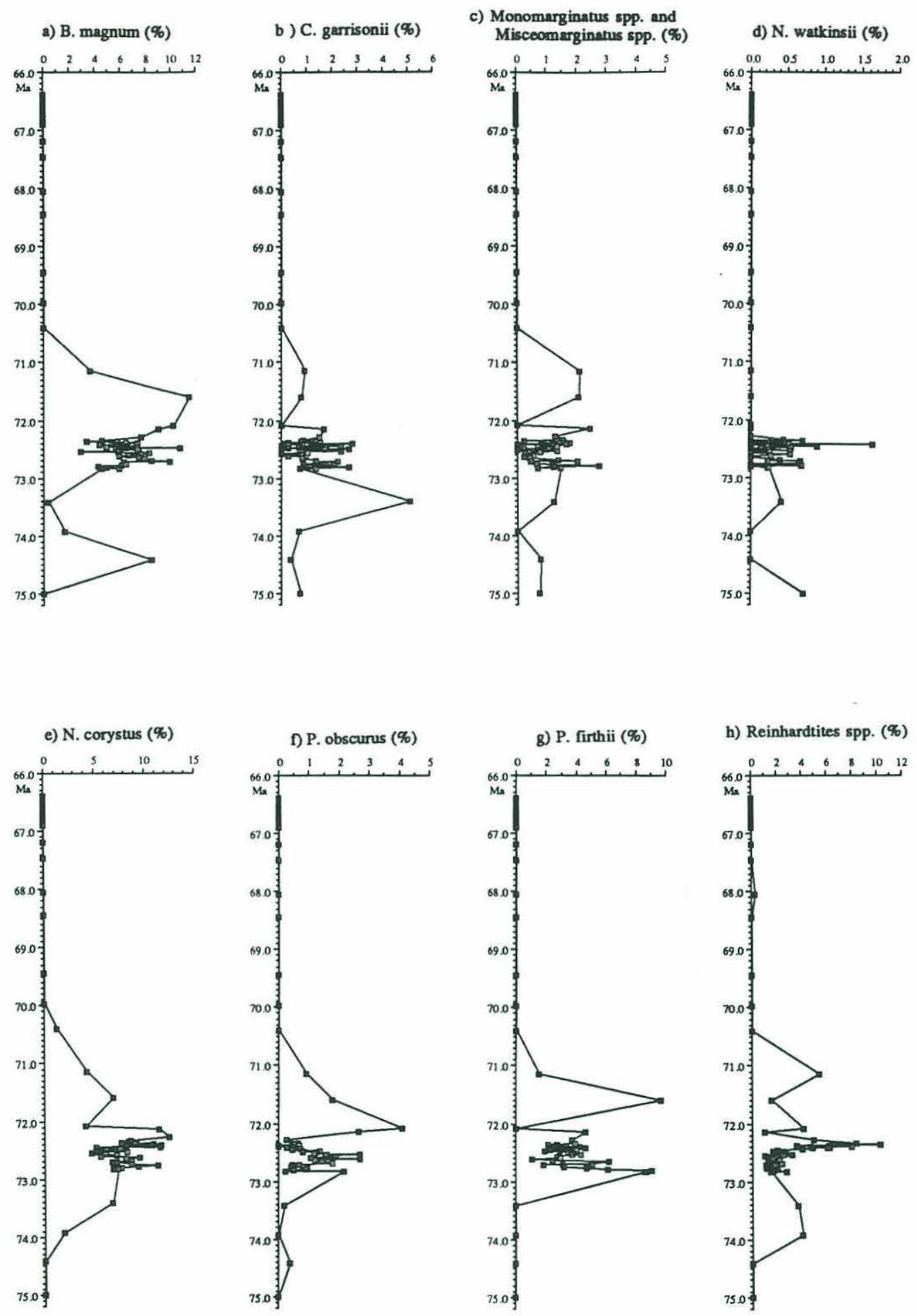

Figure 14: Relative abundances (\%) of nannofossil taxa which decrease in abundance during the Maestrichtian in Hole 690C. (Percent were calculated exclusive of $\underline{P}$. stoveri.) 


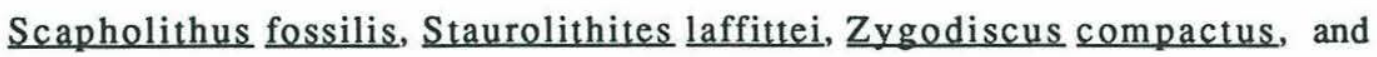
Zygodiscus diplogrammus (Figure 15a - h; Figure 16a - d).

Several taxa displayed higher relative abundances in the early than in the late Maestrichtian assemblages. Biscutum notaculum (Figure 16e) shows this trend most pronouncedly: it reached peak values of almost $40 \%$ during the early Maestrichtian, drops to less than $5 \%$ between $71.1 \mathrm{Ma}$ and $70.4 \mathrm{Ma}$ (which is coeval with the diversity decrease) and was absent from the counts in almost the entire upper Maestrichtian interval (Figure 16e). A very similar trend was observed for the group $\underline{A}$. octoradiata and $\underline{\text {. }}$ regularis (Figure 16f): while common to abundant during the early Maestrichtian and up to $71.1 \mathrm{Ma}$ (about $10-15 \%$ ) this group drops to almost $0 \%$ at $70.4 \mathrm{Ma}$ and remains at values below $5 \%$ during most of the late Maestrichtian. Other taxa that occurred commonly or rarely during the early Maestrichtian but were extremely rare or absent during the late Maestrichtian include Biscutum constans, Discorhabdus ignotus, Placozygus bussonii, Prediscosphaera arkhangelskyi, Rhombolithion rhombicum, and Watznaueria barnesae (Figure 17a - f). Thoracosphaera spp. and Vagalapilla spp. decrease in abundance between the early and the late Maestrichtian, but are common to rare in both intervals (Figure17g, h).

Nephrolithus frequens (Figure 18a) is the only taxon that evolved during the late Maestrichtian. This species was absent prior to $\sim 71 \mathrm{Ma}$, but constituted over $20 \%$ of the assemblage where it was first observed (at about $70.4 \mathrm{Ma}$ ). During the late Maestrichtian this species constituted up to $40 \%$ of the entire assemblage. Two other taxa are almost completely absent during the early Maestrichtian, but are important assemblage elements during the late Maestrichtian: Cribrosphaerella(?) daniae (Figure 18b) increased from about $1 \%$ at $71.1 \mathrm{Ma}$ to $>15 \%$ at $70.4 \mathrm{Ma}$, dropped again to values $<5 \%$ between about 69.5 $\mathrm{Ma}$ and $68.4 \mathrm{Ma}$, and reached abundances of up to $>10 \%$ in the latest Maestrichtian (67-66.4 Ma). Similarly, G. fessus (Figure 18c) was absent in most samples prior to about $70 \mathrm{Ma}$, it was present in low abundances $(<1 \%)$ between about 70 and $68 \mathrm{Ma}$, and reached values up to almost $8 \%$ in the latest

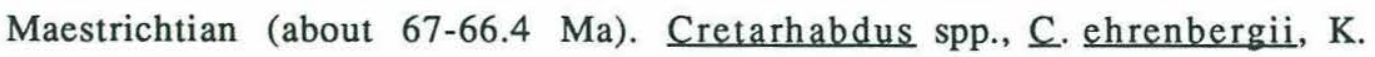

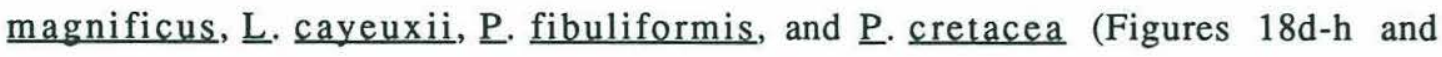
19a) were common to abundant during the entire Maestrichtian and showed a slight abundance increase from the early to the late Maestrichtian. 

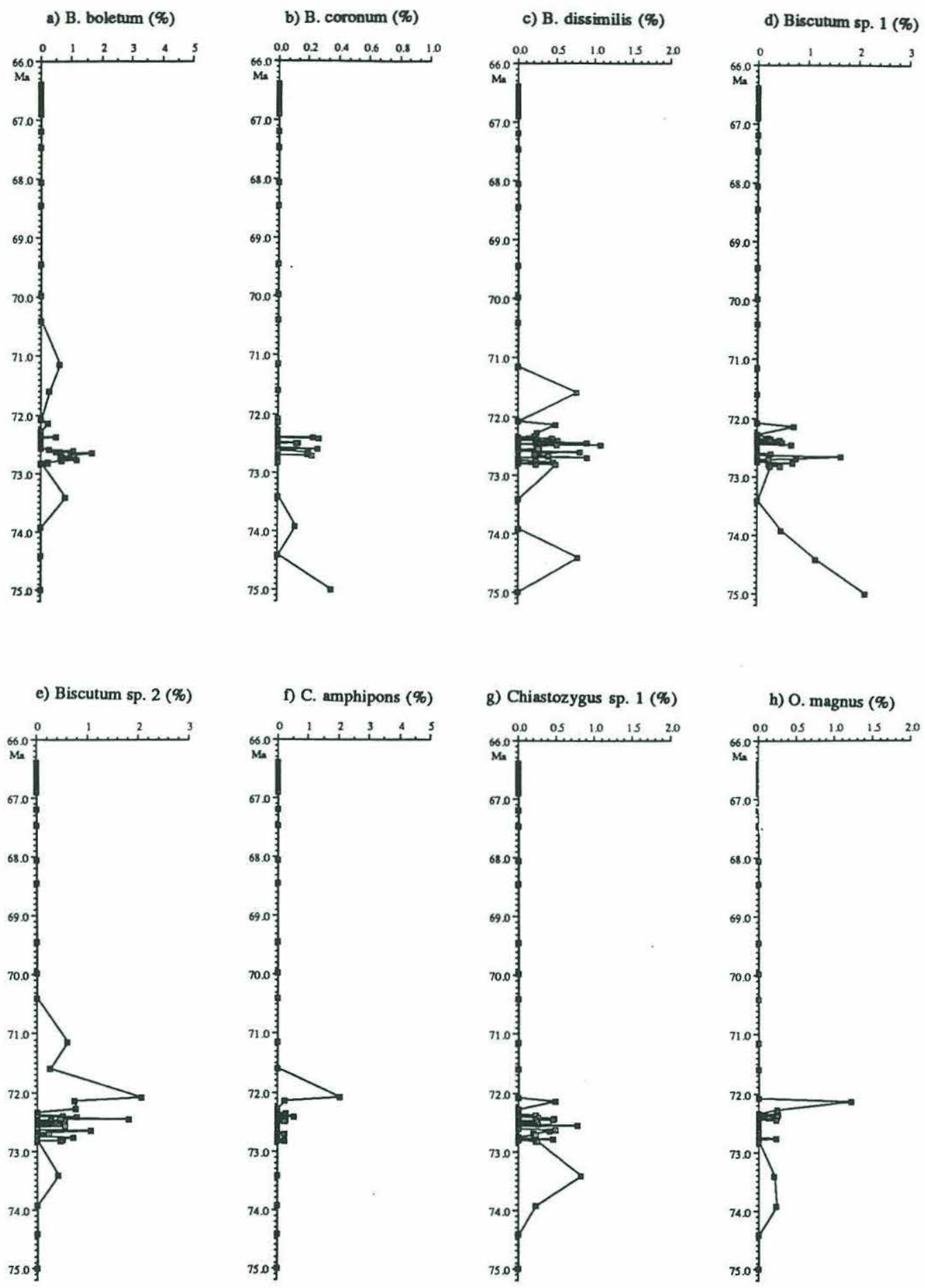

Figure 15: Relative abundances (\%) of nannofossil taxa which decrease in abundance during the Maestrichtian in Hole 690C. (Percent were calculated exclusive of $\underline{P}$. stoveri.) 

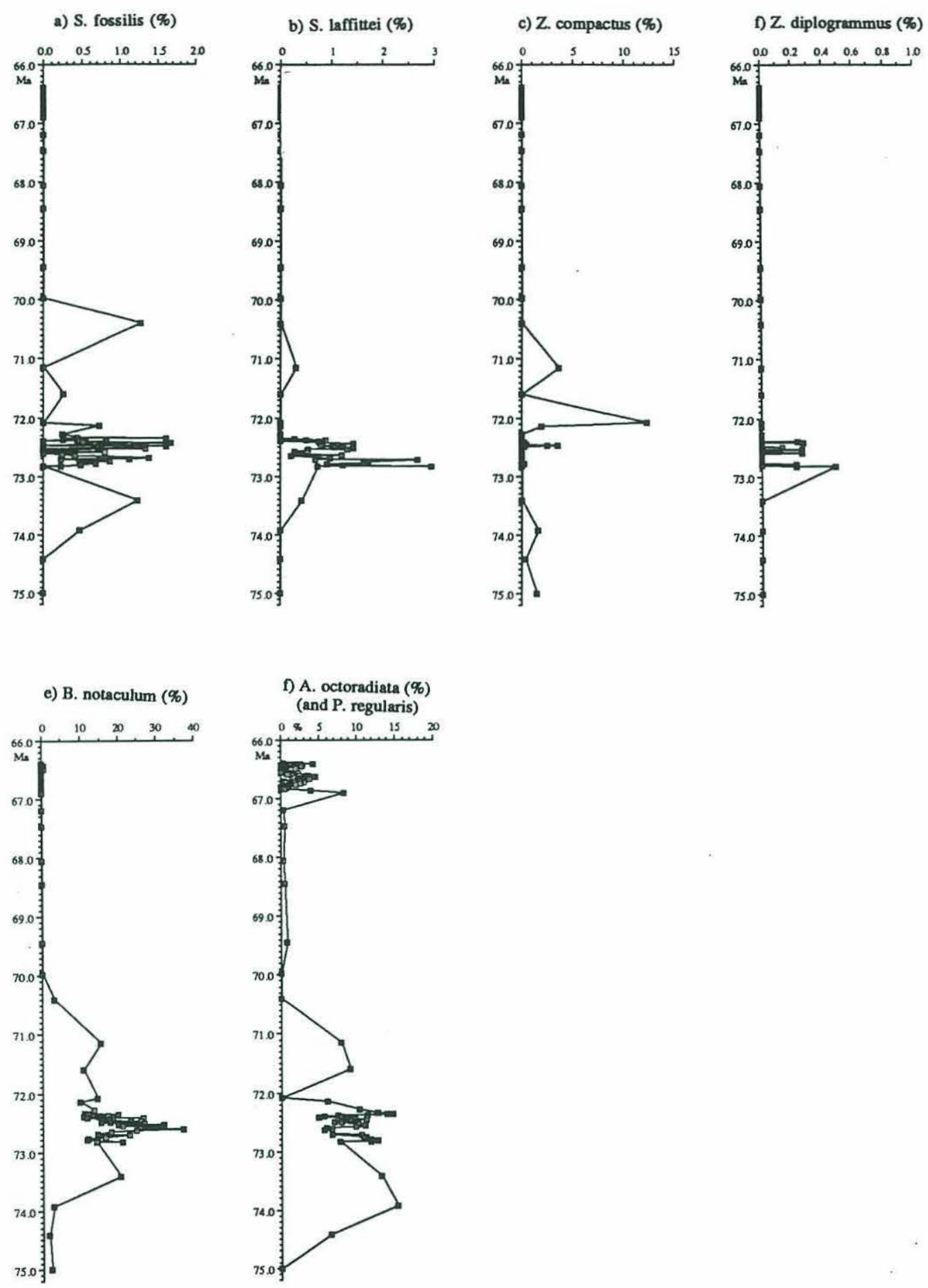

Figure 16: Relative abundances (\%) of nannofossil taxa which decrease in abundance during the Maestrichtian in Hole 690C. (Percent were calculated exclusive of $\underline{P}$. stoveri.) 

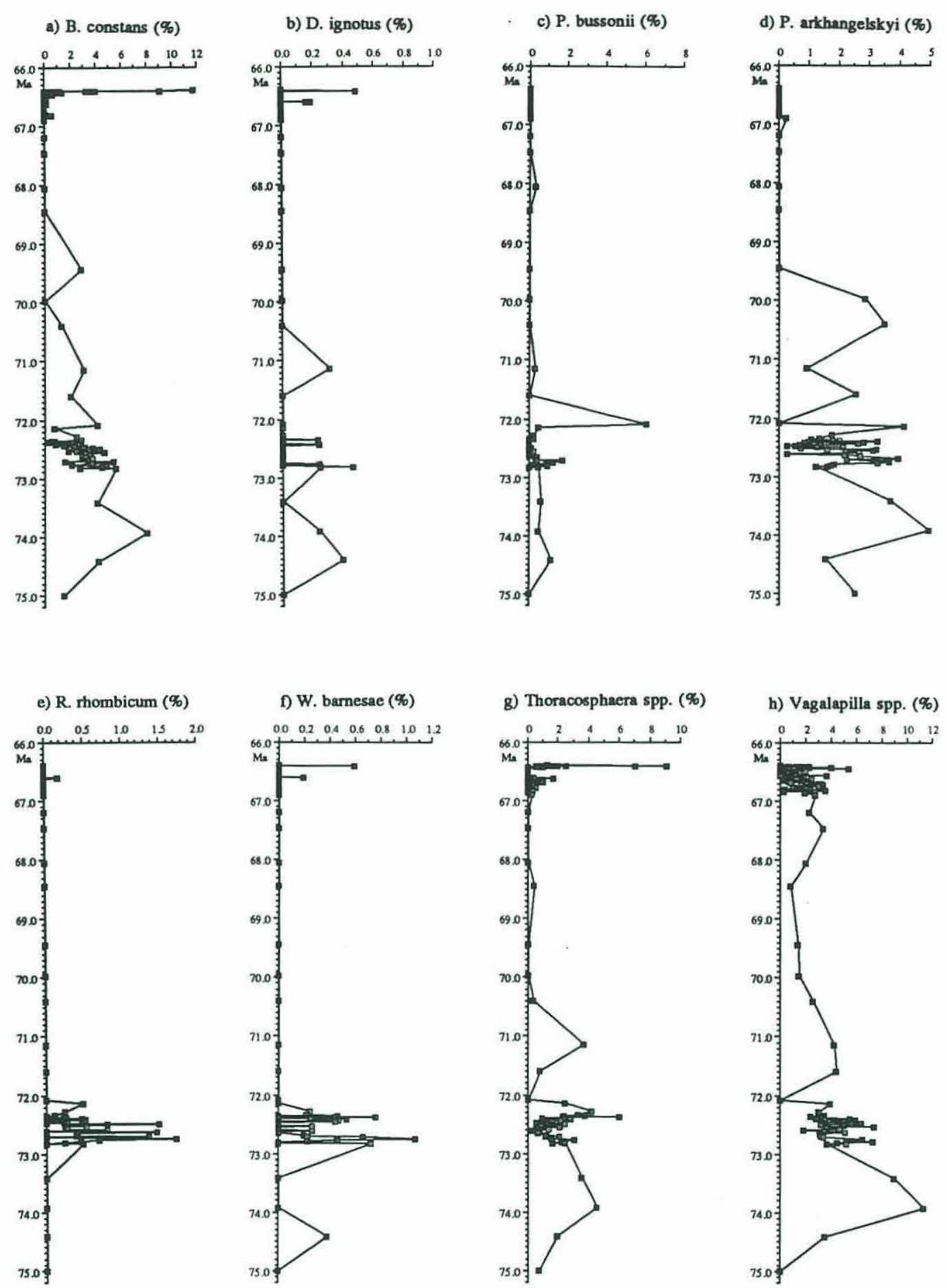

Figure 17: Relative abundances (\%) of nannofossil taxa which decrease in abundance during the Maestrichtian in Hole 690C. (Percent were calculated exclusive of $\underline{P}$. stoveri.) 

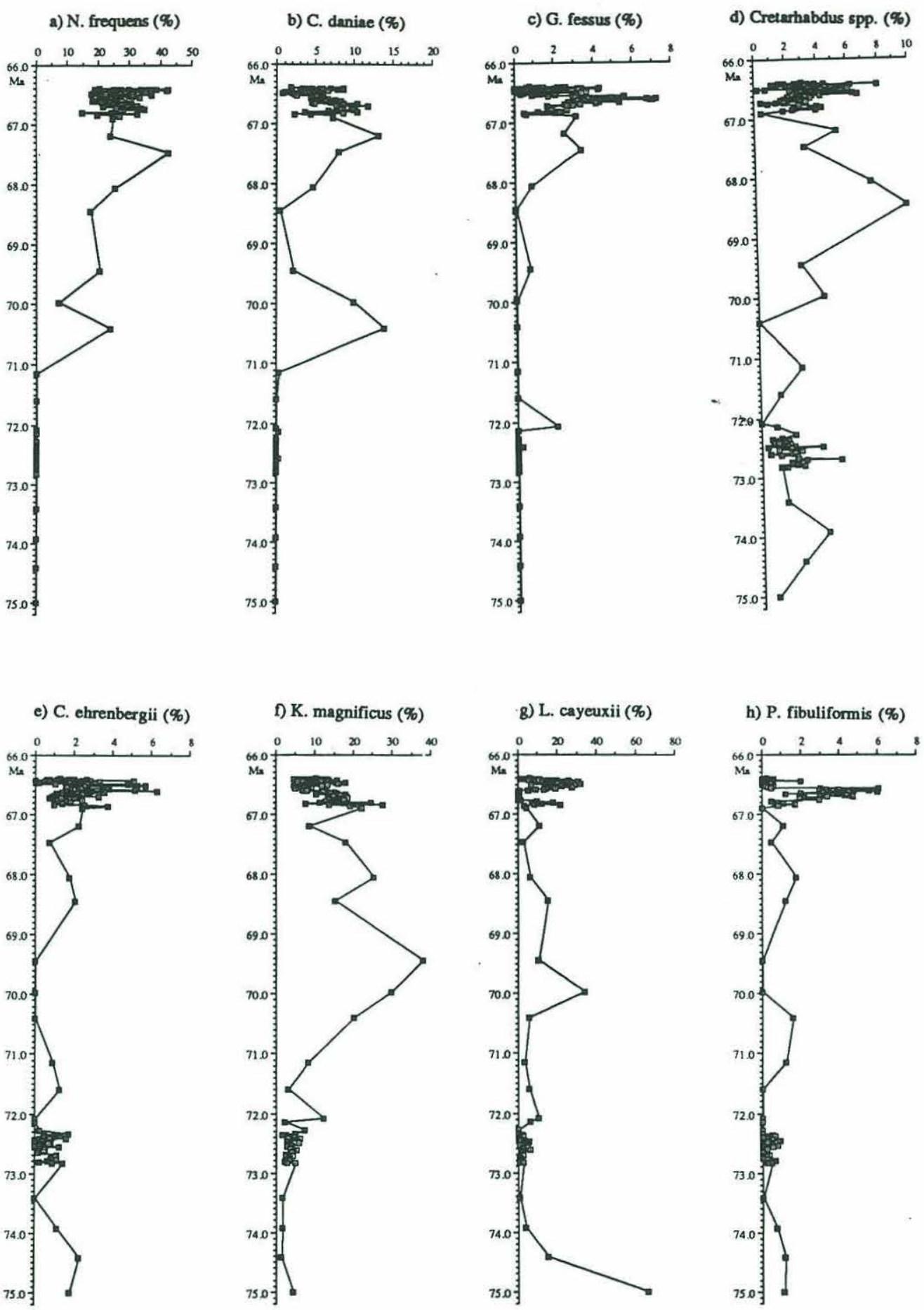

Figure 18: Relative abundances (\%) of nannofossil taxa in Hole 690C. (Percent were calculated exclusive of $\underline{P}$. stoveri.) 
Hardly any changes between the abundances in the early and the late Maestrichtian are apparent in Arkhangelskiella spp. and Broinsonia spp. (possibly a slight increase?), E. turriseiffeli (possibly slight decrease?),

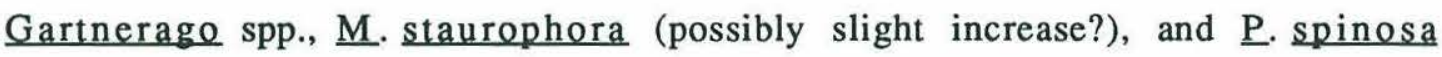
(possibly slight decrease; Figure 19b-f); all of these taxa are common to abundant throughout the Maestrichtian, except for $\underline{M}$. staurophora which is rare $(<3 \%$, Figure $19 \mathrm{e})$.

\section{B) Abundance Changes of Calcareous Nannofossils Between 66.90 and $66.40 \mathrm{Ma}$ \\ Taxon Richness: Taxon richness remained essentially constant during} most of the latest Maestrichtian (16-21 taxa; Figure 20a). A slight diversity decrease is discernible around $66.45 \mathrm{Ma}$, possibly due to dissolution effects in several poorly preserved samples around this level. A diversity increase followed these low values and continued up to the K/P boundary; in two samples immediately preceding the $\mathrm{K} / \mathrm{P}$ boundary the highest diversity values of the latest Maestrichtian interval were recorded (23 taxa, Figure 20a). These high values are due to increasing abundances of the persistent taxa ( $\underline{B}$.

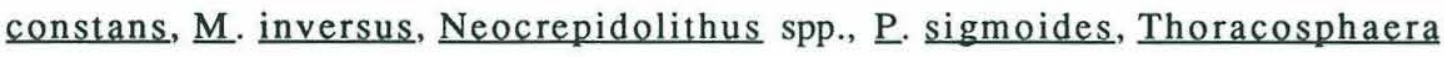
spp.; Figure 20b-f) resulting in their constant recognition in the counts performed. In addition, typical incoming species (Hornibrookina, Cruciplacolithus) were encountered in several samples before the $\mathrm{K} / \mathrm{P}$ boundary and artificially increased the diversity; their presence is interpreted as a consequence of heavy bioturbation of the $\mathrm{K} / \mathrm{P}$ boundary interval (see also the discussion in Pospichal et al., 1990).

Relative abundance: Several taxa show very conspicuous abundance variations during the latest Maestrichtian. Lucianorhabdus cayeuxii displays the most pronounced abundance changes (Figure 20g): it is common to abundant between about 66.78 and $66.90 \mathrm{Ma}$, but is virtually absent between $\sim 66.76$ and $66.61 \mathrm{Ma}$; it increases in abundance again after $66.60 \mathrm{Ma}$ and constitutes up to $>30 \%$ of the assemblage during most of the last $200 \mathrm{ky}$ of the Maestrichtian. However, a constant decline begins at about $66.44 \mathrm{Ma}$ and continues until the $\mathrm{K} / \mathrm{P}$ boundary; in the youngest samples investigated this species constitues $<5 \%$ of the entire assemblage. 


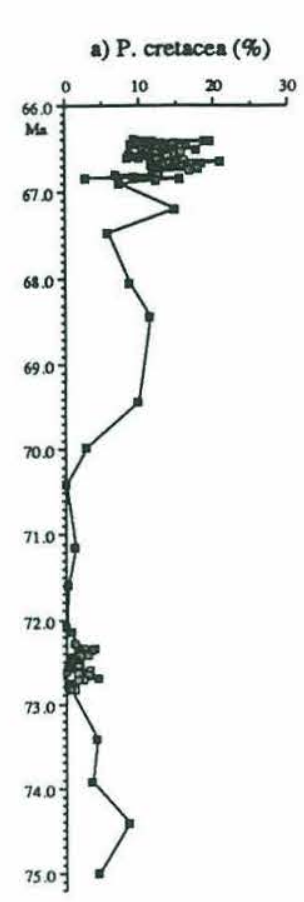

b) Arkhangelskiella spp.

c) E. turriseiffeli (\%)

d) Gartnerago spp. (\%)
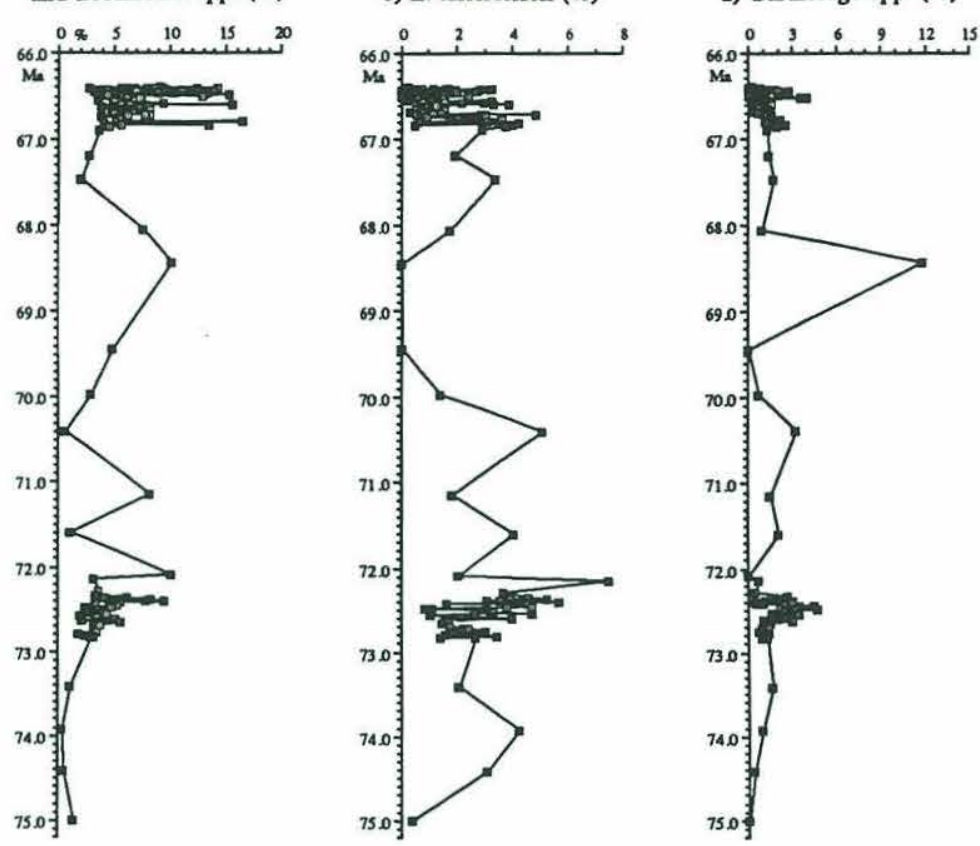

e) M. staurophora (\%)

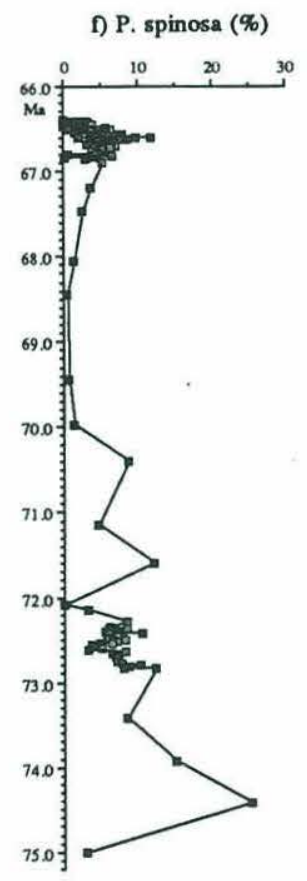

Figure 19: Relative abundances (\%) of nannofossil taxa in Hole 690C. (Percent were calculated exclusive of $\underline{P}$. stoveri.) 

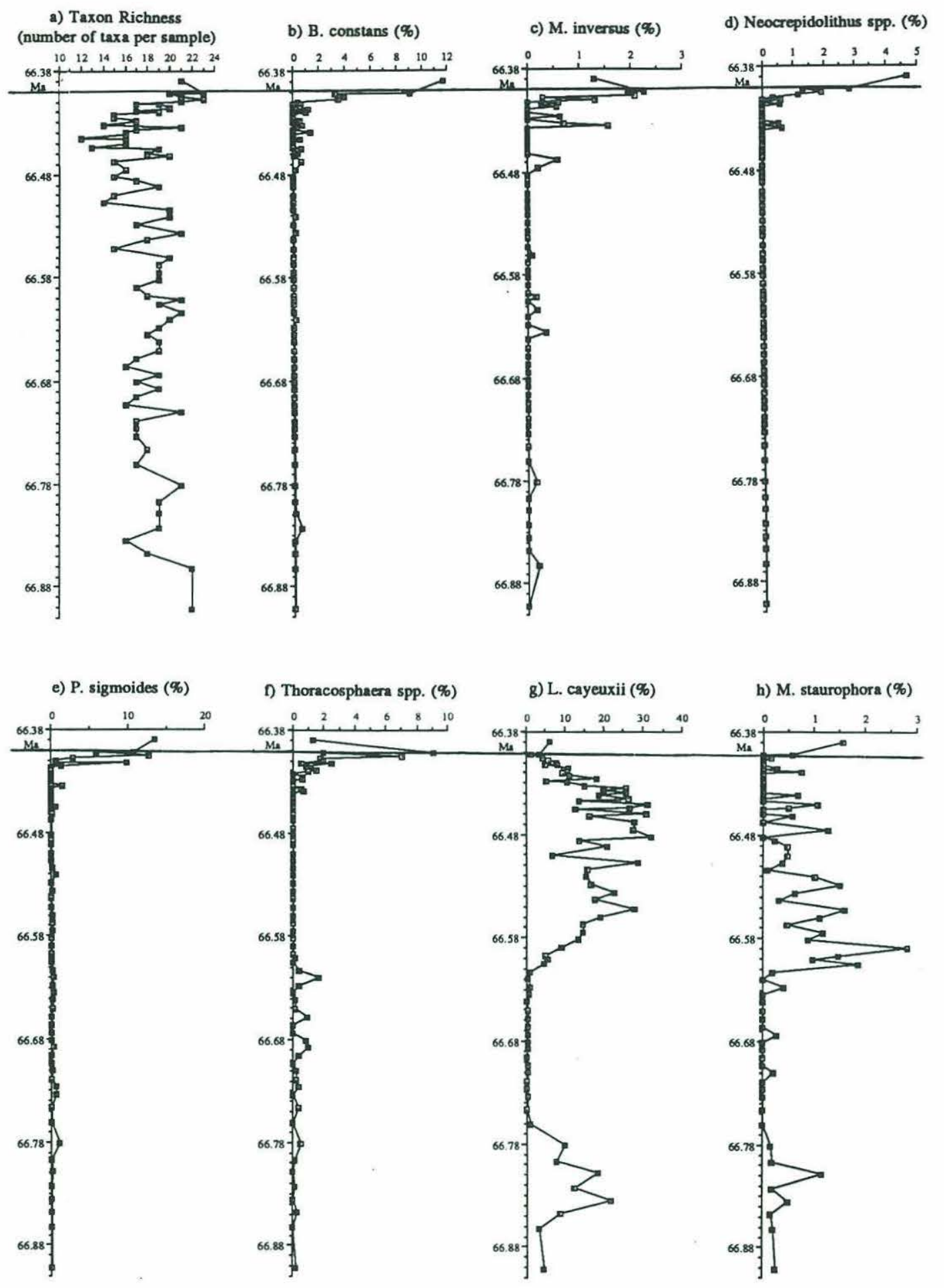

Figure 20: Relative abundances (\%) of nannofossil taxa in the latest Maestrichtian ( 66.4 - 66.9 Ma) in Hole 690C. The K/P boundary lies at $66.4 \mathrm{Ma}$. (Percent were calculated exclusive of $\underline{\mathrm{P}}$. stoveri.) 
Micula staurophora is an order of magnitude rarer than $\underline{L}$. cayeuxii but shows similar abundance variations (Figure $20 \mathrm{~h}$ ). It is rare $(<1 \%)$ prior to about $66.78 \mathrm{Ma}$, virtually absent between about 66.78 and $66.62 \mathrm{Ma}$, and comparatively more abundant (up to $3 \%$ ) between $\sim 66.78 \mathrm{Ma}$ and $66.52 \mathrm{Ma}$. After $\sim 66.52 \mathrm{Ma}$ it is very rare again (virtually always $<1.5 \%$ ) and was not encountered during the counts in many samples.

Placozygus fibuliformis (Figure 21a) displays abundance variations that are almost exactly opposite to those of $\underline{L}$. cayeuxii: Placozygus fibuliformis increases in abundance from $<2 \%$ to $2-6 \%$ between 66.78 and $66.76 \mathrm{Ma}$. At about $66.58 \mathrm{Ma}$ it reaches its peak abundance $(>6 \%)$, and then drops precipituously to very low values $(<1 \%)$ at about $66.56 \mathrm{Ma}$; $\underline{\mathrm{P}}$ f fibuliformis remained a minor component in the latest Maestrichtian assemblage.

Microrhabdulus decoratus, a very rare species (always $<1 \%$; Figure $21 \mathrm{~b}$ ) was more often encountered during the interval when $\underline{P}$. fibuliformis showed increased abundance.

It must be pointed out that $\underline{\mathrm{L}}$. cayeuxii and $\underline{\mathrm{M}}$. staurophora on one hand, and $\underline{\mathrm{P}}$. fibuliformis (and $\underline{\mathrm{M}}$. decoratus) on the other, are not mutually exclusive; all four taxa occur together between about 66.60 and $66.57 \mathrm{Ma}$. This overlap cannot result from bioturbation since $\underline{\mathrm{P}}$. fibuliformis and $\underline{\mathrm{M}}$. staurophora show very sudden abundance changes, whereas bioturbation would tend to smear out abrupt changes.

Glaukolithus fessus increases in abundance from about $66.85 \mathrm{Ma}(<2 \%)$ to about 66.63 Ma (almost 8\%; Figure 21c). High, but strong fluctuations (4-8\%) occur between $\sim 66.63$ and $66.58 \mathrm{Ma}$ after which a fairly abrupt abundance decrease occurred (between 66.58 and $66.56 \mathrm{Ma}$ ) to values $<1 \%$. This decrease was coeval with the abundance decrease in $\underline{\mathrm{P}}$. fibuliformis. Strongly fluctuating abundance values (between 0 and $>4 \%$ ) occur in this species during the last $150 \mathrm{ky}$ of the Maestrichtian (66.55 to $66.40 \mathrm{Ma}$ ).

Ahmuellerella octoradiata and $\underline{P}$. regularis (Figure 21d) were grouped together at this site, because these species could not be differentiated consistently in all samples due to poor preservation in some samples. However, I believe that almost all specimens included in this group belong to $\underline{\mathrm{A}}$. octoradatia. During most of the latest Maestrichtian this group represents $<5 \%$ of the assemblage. The abundance variations are similar to those of $\underline{\mathrm{G}}$. fessus: an abundance increase occurs between $\sim 66.80$ and $66.63 \mathrm{Ma}$ where maximum 

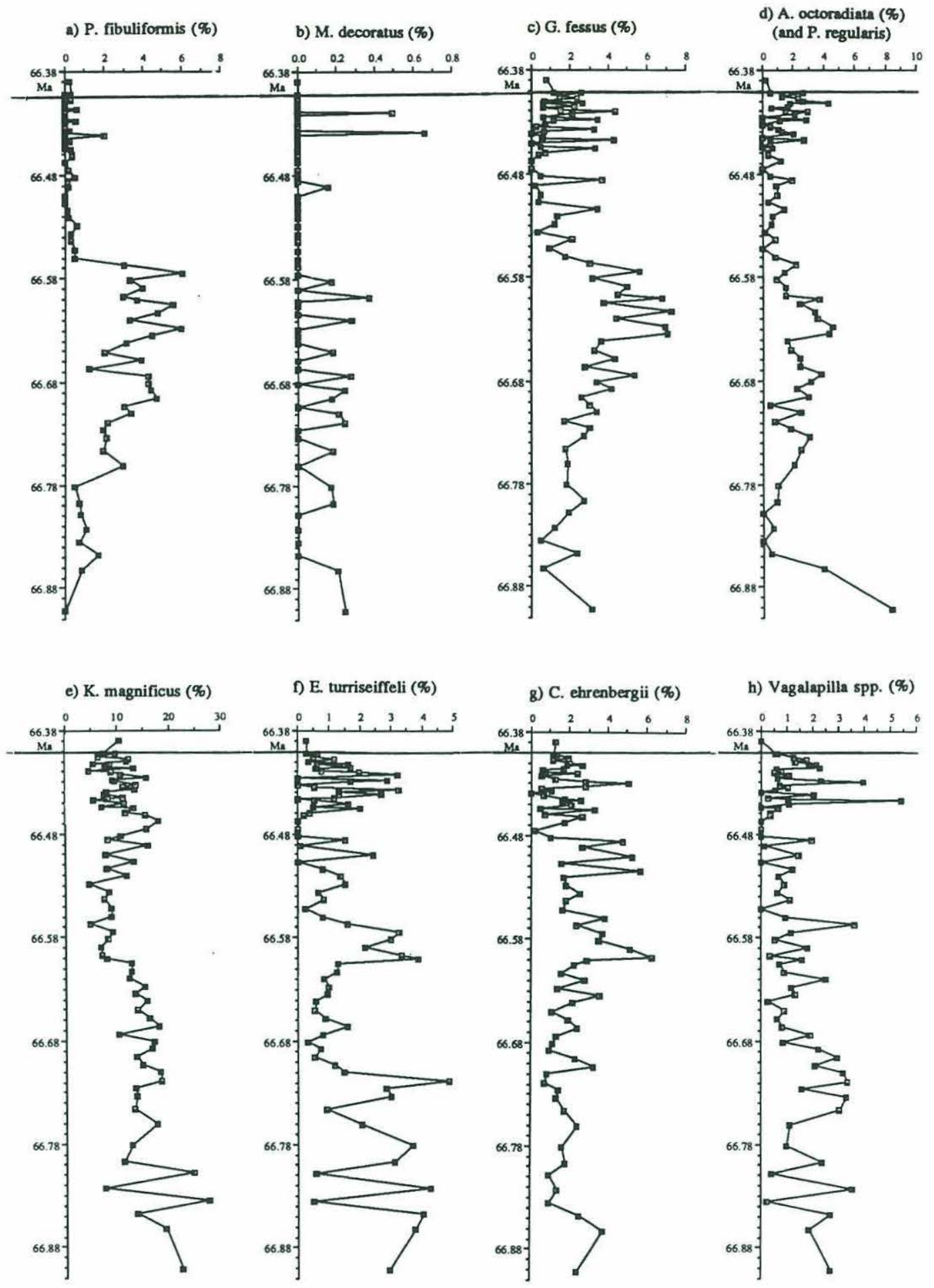

Figure 21: Relative abundances (\%) of nannofossil taxa in the latest Maestrichtian $(\sim 66.4-66.9 \mathrm{Ma})$ in Hole $690 \mathrm{C}$. The K/P boundary lies at $66.4 \mathrm{Ma}$. (Percent were calculated exclusive of $\underline{P}$. stoveri.) 
values of $>4 \%$ were recorded. Subsequently values decreased again to about $1 \%$ or less at $66.55 \mathrm{Ma}$ and remained low for the remainder of the Maestrichtian. During the very latest part of the Maestrichtian (66.40 to $66.46 \mathrm{Ma}$ ) high abundance fluctuations occurred (between 0 and $4 \%$ ).

Kamptnerius magnificus reached two abundance maxima in the early part of the latest Maestrichtian (at $\sim 66.84$ and at $66.81 \mathrm{Ma}$ ) when this species constituted between 25 and $30 \%$ of the entire assemblage (Figure 21e). Apart from these isolated peak values, the abundance of $\underline{\mathrm{K}}$ magnificus changed only little during the last $0.5 \mathrm{~m} . \mathrm{y}$. of the Maestrichtian. A slight decrease in abundance occurred at $\sim 66.60 \mathrm{Ma}$ (from values around $13 \%$ to $<10 \%$ ). This is at the time when $\underline{L}$. cayeuxii and $\underline{M}$. staurophora increased in abundance; it is possible that this decrease of $\underline{\mathbf{K}}$. magnificus is only an effect of the closed sum of the calculation of percentages. At $\sim 66.52 \mathrm{Ma}$ abundance values increased again and between this time and the K/P boundary values fluctuated between 5 and $15 \%$.

Eiffellithus turriseiffeli varied considerably in relative abundance during the latest Maestrichtian (Figure 21f): very low values $(<1 \%)$ occur at $\sim 66.84$ and at $66.81 \mathrm{Ma}$. An abundance peak of about $5 \%$ occurred at $\sim 66.72 \mathrm{Ma}$; after this maximum values decreased to about $1 \%$ and remained low until about 66.61 Ma. Eiffellithus turriseiffeli became more abundant ( 2-4\%) between about 66.60 and $66.57 \mathrm{Ma}$. This is also the time when $\underline{\mathrm{P}}$ fibuliformis and $\underline{\mathrm{L}}$. cayeuxii occurred together. Close to $66.57 \mathrm{Ma}$ the abundance ot E. turriseiffeli declined to low values (about 1\%). As $\underline{G}$. fessus, E. turriseiffeli displayed somewhat higher and highly variable abundance during the last $150 \mathrm{ky}$ of the Maestrichtian (between about 66.55 and $66.40 \mathrm{Ma}$ ).

Cribrosphaerella ehrenbergii constituted about $2 \%$ of the assemblage during the early part of the latest Maestrichtian (between about 66.91 and $66.60 \mathrm{Ma}$; Figure 21g). It reached a peak abundance of $>6 \%$ at $\sim 66.595 \mathrm{Ma}$ and decreased again to lower values $\sim 2 \%$. Fairly variable values were recorded between about 66.55 and $66.40 \mathrm{Ma}$.

Vagalapilla spp. displayed very low abundances at 66.835 and at $66.81 \mathrm{Ma}$ (Figure 21h); between 66.75 and $66.69 \mathrm{Ma}$ relative abundance values of this group of species lay between 2 and $3 \%$; subsequently they decreased and fluctuated around $1 \%$ while isolated peaks occurred at $66.57 \mathrm{Ma}(>3.5 \%)$, at 66.45 Ma $(5.5 \%)$ and at $66.43 \mathrm{Ma}$ (about $4 \%$ ). 
The abundance of Gartnerage spp. decreased gradually throughout most of the latest Maestrichtian (Figure 22a) from about $2.5 \%$ at $66.91 \mathrm{Ma}$ to $<1 \%$ at $\sim 66.55$ Ma. A peak abundance of $3.5-4 \%$ occurred between 66.54 to $66.53 \mathrm{Ma}$. During the latest Maestrichtian (66.40 to $66.46 \mathrm{Ma}$ ) abundance values of species of this genus displayed considerable variability $(0-\sim 3 \%)$.

During most of the latest Maestrichtian the relative abundance of $\underline{\mathrm{N}}$. frequens (Figure 22b) remained constant around 25\% ( $\pm \sim 5 \%$ ). However, its abundance increased to values between $30-40 \%$ during the very latest Maestrichtian (between about 66.43 and $66.41 \mathrm{Ma}$ ).

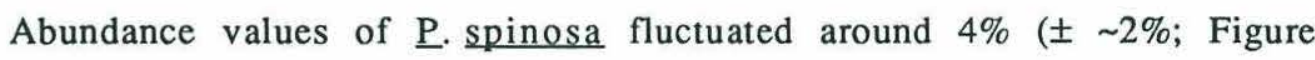
22c) during most of the latest Maestrichtian ( $66.91-66.48 \mathrm{Ma})$; after about $66.48 \mathrm{Ma}$ its abundance decreased to values averaging $1 \%(0-4 \%)$.

The relative abundance of the group of Arkhangelskiella spp. and Broinsonia spp. remained fairly constant throughout the late Maestrichtian (Figure 22d). Abundance peaks were recorded at $\sim 66.84$ and at $\sim 66.81 \mathrm{Ma}$, and at $\sim 66.605 \mathrm{Ma}$. This group displayed conspicuous abundance variations during the latest Maestrichtian (between about 66.46 and $66.40 \mathrm{Ma}$ ).

Prediscosphaera cretacea was among the more abundant taxa (Figure $22 \mathrm{e}$ ), constituting on average around $10 \%$ of the late Maestrichtian assemblage. Lower abundance values occurred at $\sim 66.84$ and at $\sim 66.81 \mathrm{Ma}$, and an abundance peak of almost $10 \%$ above the longterm average (i.e. $>20 \%$ vs. $\sim 10 \%$ ) occurred between $\sim 66.67$ and $66.63 \mathrm{Ma}$.

Prediscosphaera stoveri predominated in the latest Maestrichtian assemblage. This species constituted about $70 \%$ of all calcareous nannofossils prior to $\sim 66.85 \mathrm{Ma}$ (Figure 22f), its abundance decreased sharply at $\sim 66.84 \mathrm{Ma}$, but recovered subsequently and reached an unprecedented peak of almost $80 \%$ at about $66.73 \mathrm{Ma}$. Afterwards the abundance of $\underline{\mathrm{P}}$. stoveri decreased to $\sim 50 \%$ (at $\sim 66.67 \mathrm{Ma}$ ) and remained close to this abundance during the remainder of the latest Maestrichtian (Figure 22f).

Abundance values of Cretarhabdus spp. changed little during the latest Maestrichtian (Figure 22g). Only around $66.50 \mathrm{Ma}$ two very low values were recorded. During the very latest part of the late Maestrichtian ( 66.48 to 66.40 Ma) the abundance values of the species of Cretarhabdus displayed a higher intersample variability than throughout the earlier part. 

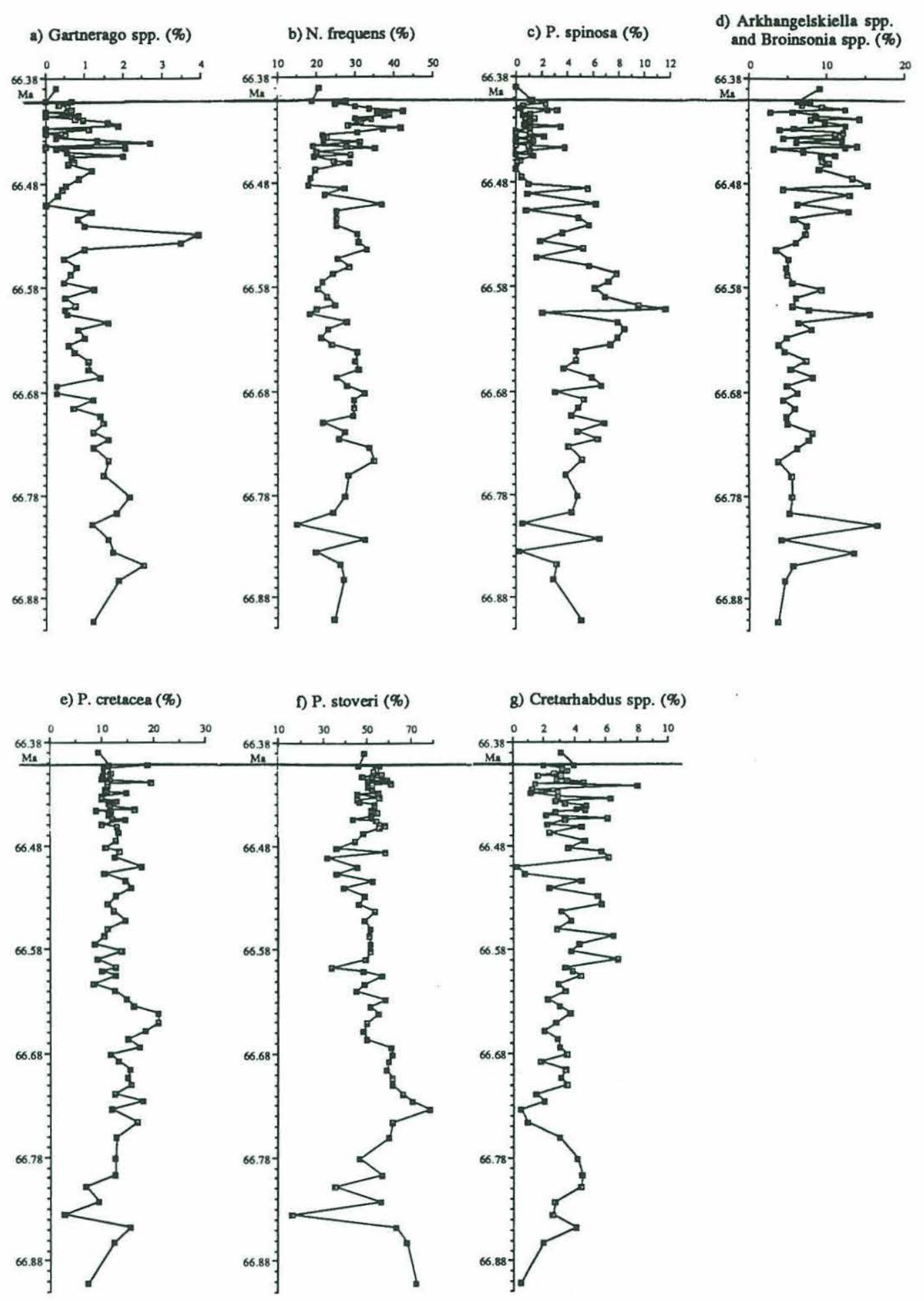

Figure 22: Relative abundances (\%) of nannofossil taxa in the latest Maestrichtian ( 66.4 - 66.9 Ma) in Hole 690C. The K/P boundary lies at $66.4 \mathrm{Ma}$. (a) to (e) and (g): Percent were calculated exclusive of $\underline{P}$. stoveri. 
Absolute abundance and fluxes: The number of coccoliths and nannoliths (exclusive of the placoliths $\underline{P}$. stoveri) that were observed per viewfield are plotted in Figure 23a. High values prior to $\sim 66.84 \mathrm{Ma}$ are followed by a pronouncedly lower values between $\sim 66.84$ and $66.78 \mathrm{Ma}$. Subsequently, values increased again and reached maxima between $\sim 66.75$ - $66.66 \mathrm{Ma}$.

Between $~ 66.66-66.55 \mathrm{Ma}$ the numbers of placoliths per viewfield decreased steadily, and remained at a constant level between $\sim 66.55$ and $66.40 \mathrm{Ma}$. A similar trend was observed in the abundance variations of the number of placoliths of $\underline{\mathrm{P}}$. stoveri between 66.90 and $66.40 \mathrm{Ma}$ (Figure 24a).

In the curve of coccoliths and nannoliths per viewfield (Figure 23a) low values occur at $\sim 66.83 \mathrm{Ma}, \sim 66.81 \mathrm{Ma}$ and at $\sim 66.74 \mathrm{Ma}$. These correspond to a reduction of nannofossil specimens of $80 \%$ and $70 \%$, respectively. Micarb (microcrystalline carbonate) is much more abundant in these samples than in the adjacent ones. This, as well as the relative enrichment of dissolution resistant taxa (according to Thierstein, 1980) at these levels (L. cayeuxii, $\underline{\mathrm{K}}$. magnificus, Arkhangelskiella spp. and Broinsonia spp.; Figures 20g, 21e, 22d) and the massive reductions of dissolution susceptible taxa (e.g. G. fessus, E.

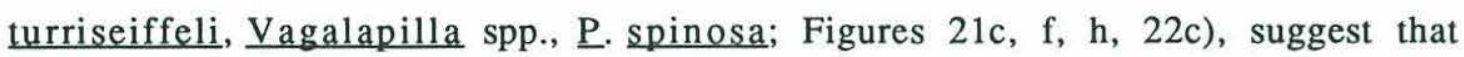
the low values of calcareous nannofossils per viewfield do not correspond to a primary signal but reflect extensive dissolution. The older two outlier values are also apparent in the curve of $\underline{P}$. stoveri (Figure 22f), but the value at 66.74 $\mathrm{Ma}$ is not unusually low.

The long term abundance reduction of $\underline{P}$. stoveri as well as of the sum of all other coccoliths and nannoliths after $\sim 66.70 \mathrm{Ma}$ is considered to be a genuine signal rather than an artifact of deteriorating preservation: examination of the preparations did not reveal long term trends of changing preservation or increasing micarb content upsection; relative abundances of dissolution resistant taxa do not increase in concert with the falling "specimens-per-viewfield" curves (‥ cayeuxii, Figure 20g; $\underline{\text { K. magnificus, }}$ Figure 21e; Arkhangelskiella and Broinsonia, Figure 22d), nor do dissolution susceptible taxa display systematic decreases (e.g. E. turriseiffeli, Figure 21f; Vagalapilla spp., Figure 21h; $\underline{\text {. }}$ spinosa, Figure 22c).

The numbers of coccoliths and placoliths per gram sediment and per gram carbonate as well as the fluxes derived from these data are plotted in Figure 23b-e). The same calculations were performed for $\underline{P}$. stoveri and the 
(a)

number of coccoliths and nannoliths per viewfield (b)

number of coccoliths and nannoliths per gram sediment (c)

flux of coccoliths and nannoliths

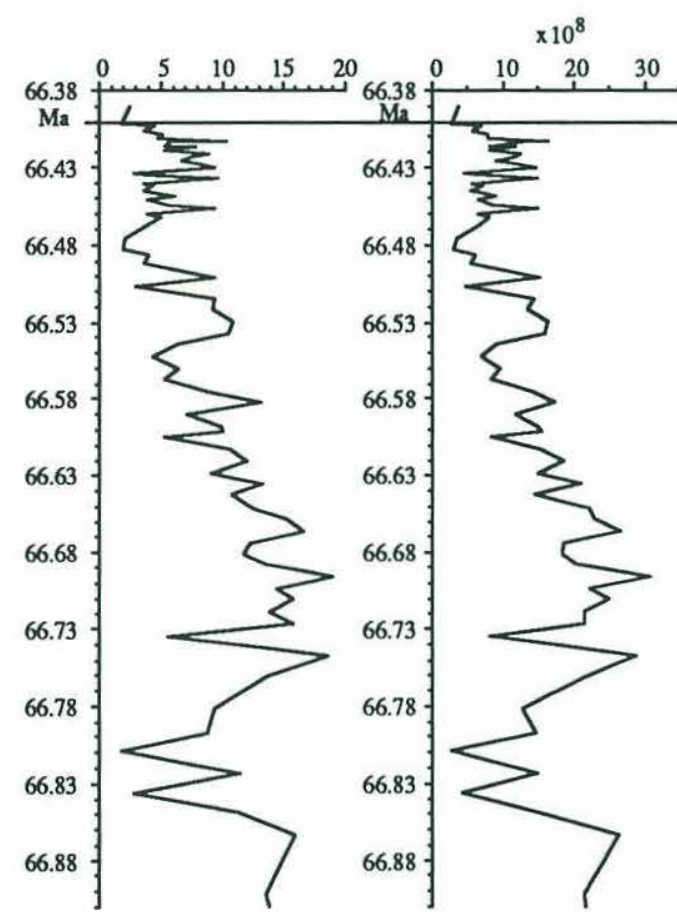

$\times 10^{8}$

(d)

number of coccoliths

and nannoliths

per gram carbonate (e) flux of coccoliths

and nannoliths

nomalized to

specimens/cm2/ky

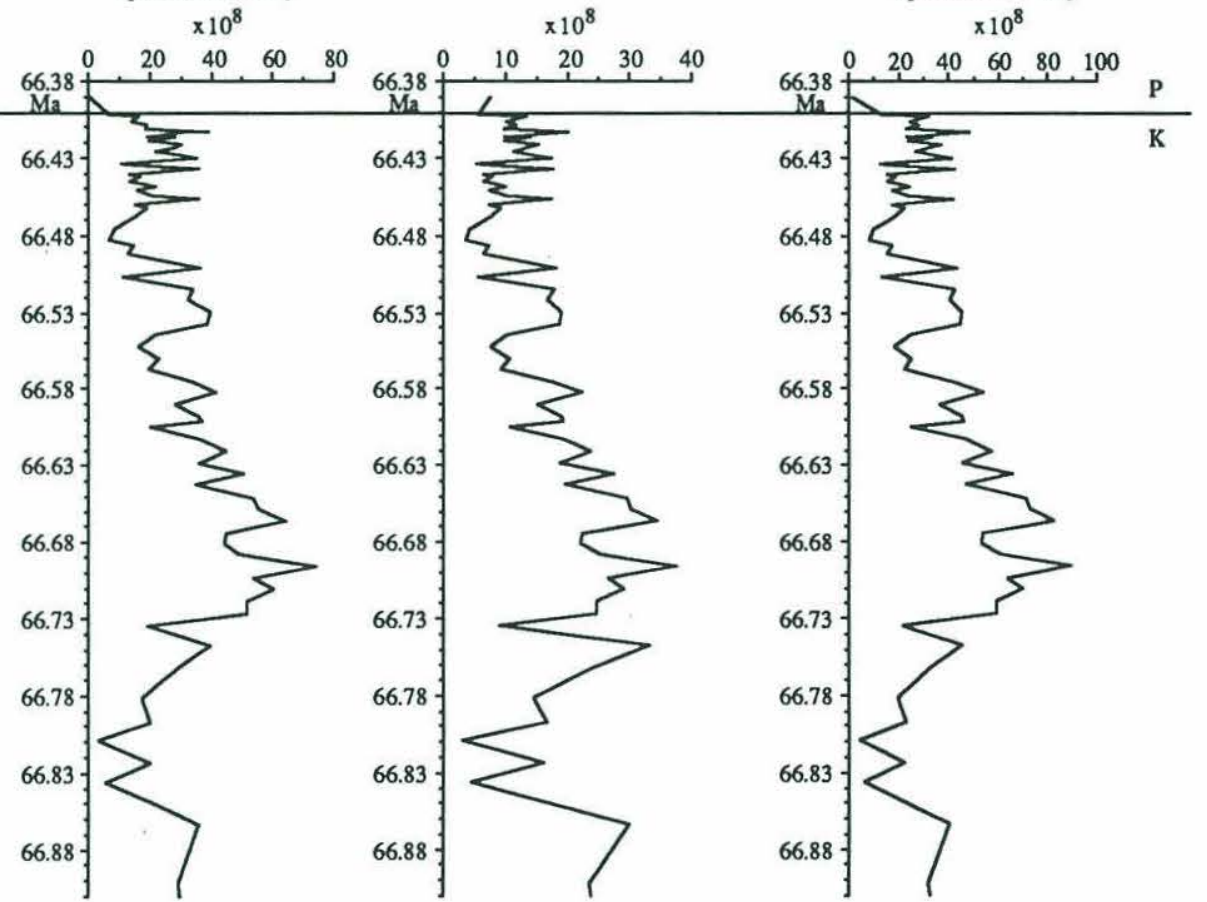

Figure 23: Abundance fluctuations of coccoliths and nannoliths during the latest Maestrichtian in Hole 690C. All data exclusive of $\underline{\mathrm{P}}$. stoveri. 
(a)

number of placoliths of Prediscosphaera stovea per viewfield

(b)

number of placoliths of Prediscosphaera stoveri per gram sediment (c)

flux of placoliths of Prediscosphaera stover

specimens/cm $2 / \mathrm{ky}$ (d)

number of placoliths of Prediscosphaera stover per gram carbonate (e) flux of placoliths of Prediscosphaera stoveri carbonate conten

specimens/cm2/ky

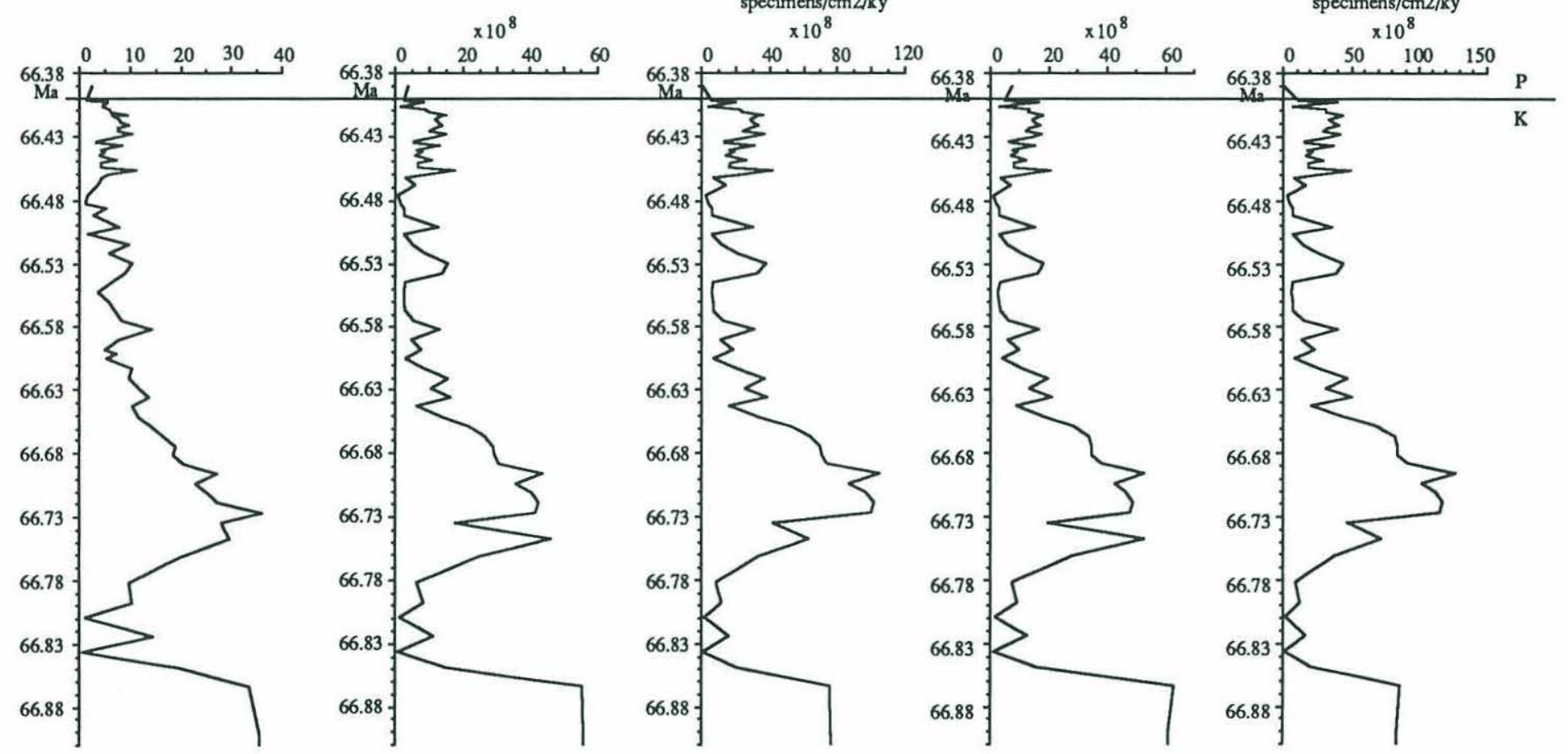

Figure 24: Absolute abundance fluctuations of $\underline{\mathrm{P}}$. stoveri during the latest Maestrichtian. 
data plotted in Figure 24b-e. These plots reiterate the trends observed in the curves of specimens per viewfields as discussed above. The graphs of the fluxes of calcareous nannofossils (Figure $23 \mathrm{c}$ and e) indicate that the elevated values between about 66.72 and $66.60 \mathrm{Ma}$ represent a brief excursion over lower background values $\left(60-80 \times 10^{8}\right.$ versus $20-40 \times 10^{8}$ specimens $\left./ \mathrm{cm}^{2} / \mathrm{ky}\right)$. Also the flux of $\underline{\mathrm{P}}$. stoveri shows a pronounced increase in about the same interval (Figure 24e).

The decrease of absolute abundances of calcareous nannofossils during the latest Maestrichtian is not reflected in a similar decrease of the carbonate content. The discrepancy between these two curves is most likely accounted for by the increase of foraminifera as a sedimentary component during this time interval (compare Figure 5 in Chapter 3 on page 37). 


\section{2) ODP Hole 761B and ODP Hole 761C}

\section{(A) Long term trends: Hole 761B}

The taxon richness recorded in all samples in Hole $761 \mathrm{~B}$ is plotted against age in Figure 25. An increase in species richness from about 30-35 taxa per sample to values between about 40-45 occurs throughout the entire section investigated. This increase is more pronounced between about 71-69 Ma than afterwards.

All relative abundances that are discussed below were calculated exclusive of $\underline{M}$. staurophora.

Lithraphidites quadratus and $\underline{L}$. praequadratus both were beyond the detection limit prior to about $69.5 \mathrm{Ma}$. After that both taxa increased in abundance (Figure 26a, b); this increase was very abrupt and pronounced in $\underline{\mathrm{L}}$. praequadratus, which remained at about the same abundance level $(\sim 3 \%)$ for the remainder of the Maestrichtian. In contrast, $\underline{L}$ quadratus was always rarer (hardly ever exceeding $1 \%$ ), but increased steadily in relative abundance between $69 \mathrm{Ma}$ and the K/P boundary. Tranolithus macloedae (Figure 26c) was absent prior to about $69.5 \mathrm{Ma}$. Subsequently it was encountered in most samples but remained a minor component of the nannofossil assemblages $(<2 \%)$.

Biscutum constans (Figure 27a) is one of the taxa displaying more or less constant abundances (around 5\%) throughout the late Maestrichtian, but displays an abrupt and drastic abundance decrease at about 67 Ma. During the late Maestrichtian this species constituted $<1 \%$ of the nannofossil assemblage.

A pattern that is almost inverse to that of $\underline{B}$. constans was recorded for Biscutum sp. 1 (Figure 27b): this species constituted $<5 \%$ during most of the late Maestrichtian, but increased in abundance during between $\sim 67.5 \mathrm{Ma}$ and 66.4 Ma (to $7 \%$ ). A similar pattern was recorded for Corollithion exiguum: this species was so rare that it was beyond the detection limit prior to $66.5 \mathrm{Ma}$; after $\sim 66.5 \mathrm{Ma}$ this species was still rare $(<1 \%)$, but it was recorded almost consistently between 66.5 - $66.4 \mathrm{Ma}$ (Figure 27c). The abundance distribution of Cribrosphaerella(?) daniae (Figure 27d)was very similar to that of $\underline{C}$. exiguum: C. daniae was rare $(<1.5 \%)$ but recorded almost consistently between $\sim 66.5-66.4$ $\mathrm{Ma}$, whereas prior to $\sim 66.5 \mathrm{Ma}$ this species was almost always absent. Cylindralithus gallicus (Figure 27e) was rare during most of the late 


\section{Taxon Richness}

Hole 761B

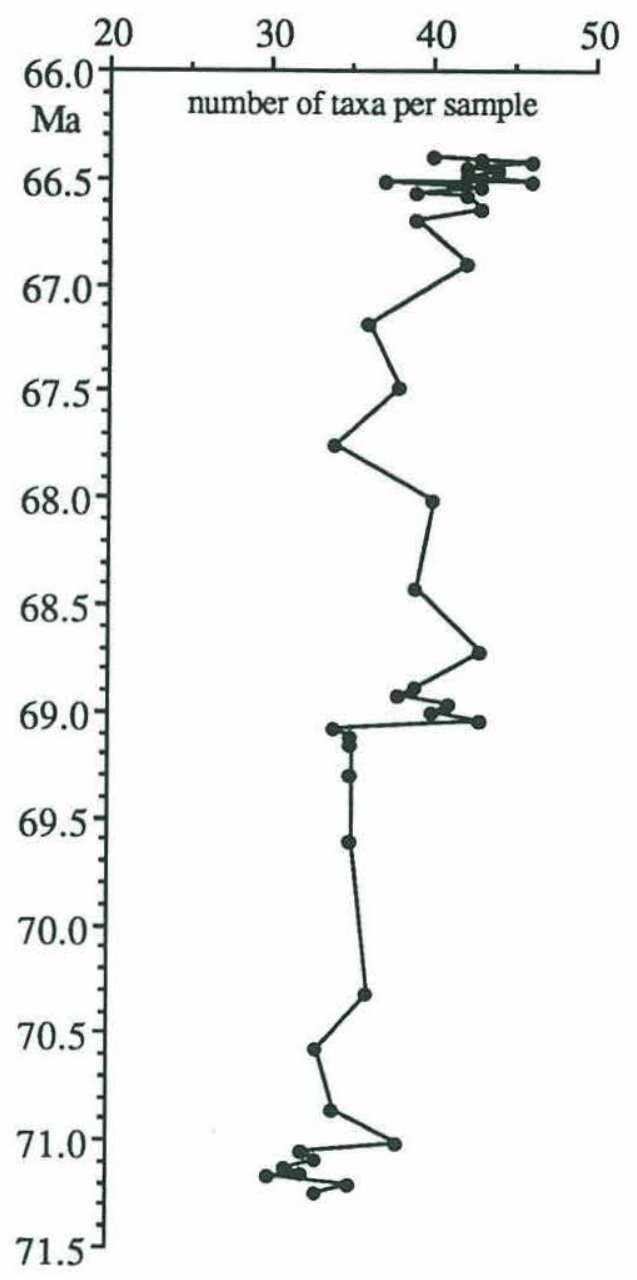

Figure 25: Plot of taxon richness (number of taxa per sample) versus age. The taxon richness increased slightly during the late Maestrichtian, no gradual or stepwise decline prior to the $\mathrm{K} / \mathrm{P}$ boundary (at $66.40 \mathrm{Ma}$ ) is discernible. 

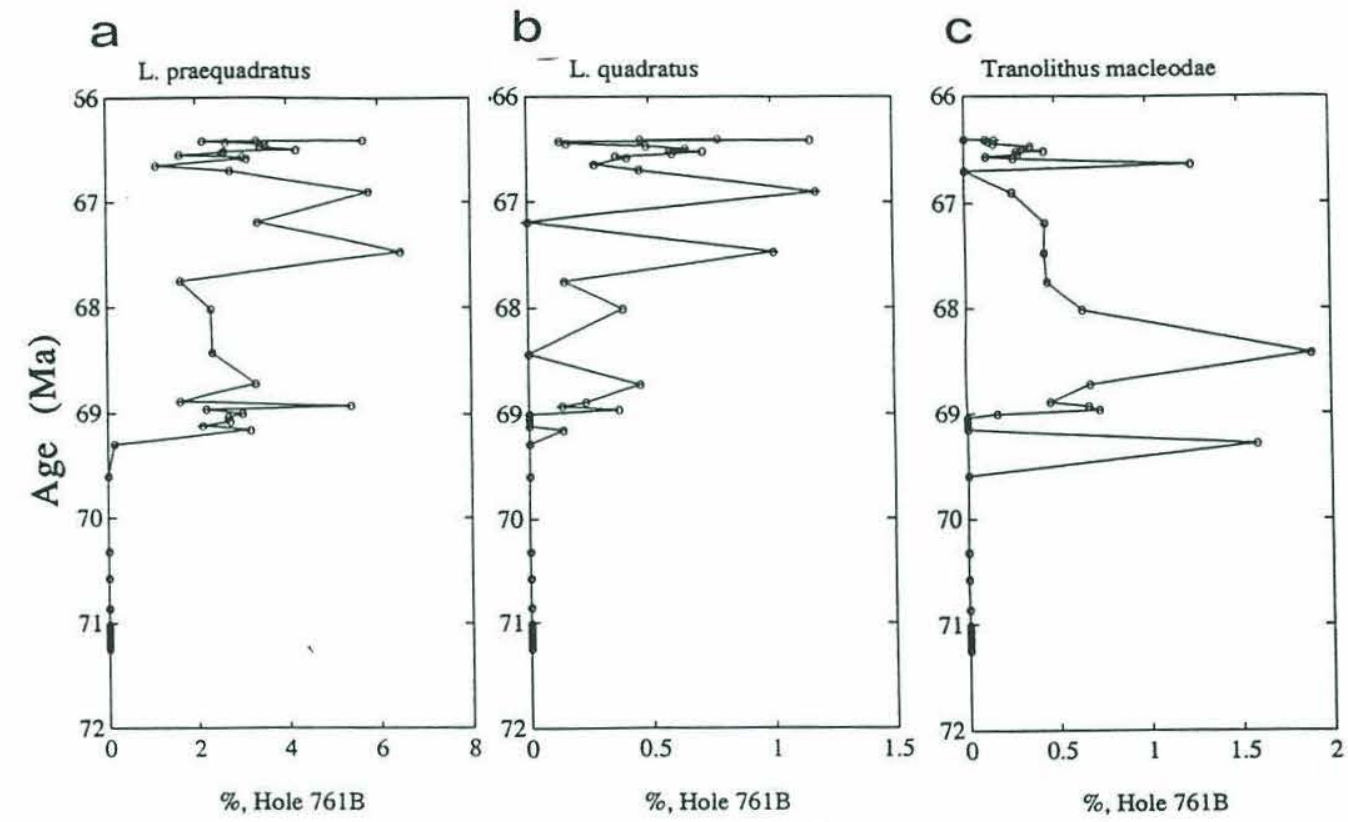

Figure 26: Relative abundance plots of selected taxa in Hole 761B during the late Maestrichtian. The data were calculated exclusive of $\underline{M}$. staurophora. 

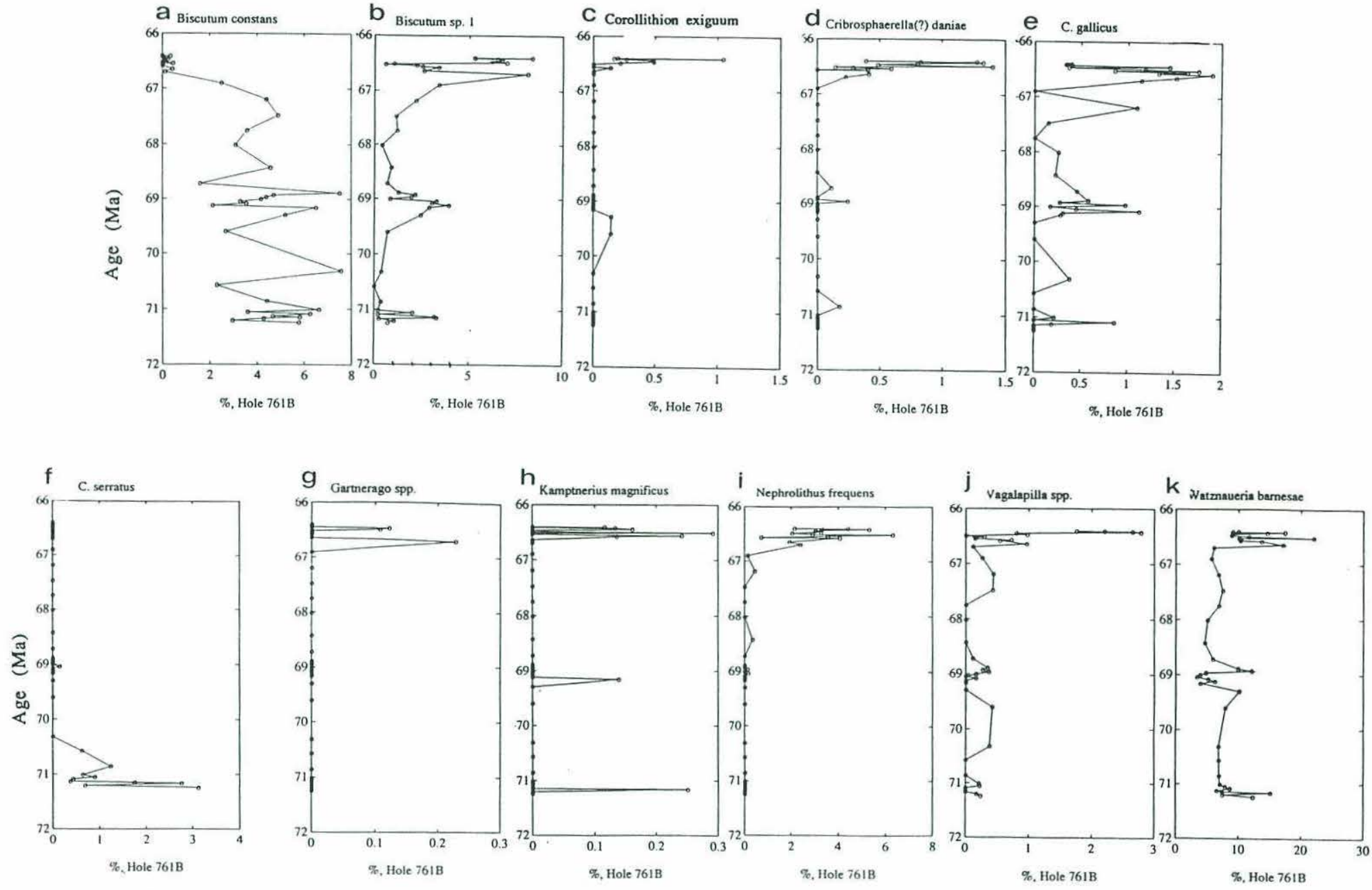

Figure 27: Relative abundance plots of selected taxa in Hole 761B during the late Maestrichtian. The data were calculated exclusive of $\underline{M}$. staurophora. 
Maestrichtian $(<1 \%)$ but its abundance increased abruptly to values $>1.5 \%$ after $\sim 67$ Ma. After peak values $(\sim 2 \%)$ had been reached at $\sim 67 \mathrm{Ma}$, relative abundance of $\underline{\mathrm{C}}$. gallicus decreased again between $\sim 67 \mathrm{Ma}$ and $66.4 \mathrm{Ma}$.

Cylindralithus serratus was encountered commonly prior to $\sim 70.5 \mathrm{Ma}$ (Figure 27f) when it reached relative abundance peaks of $>3 \%$. Between $\sim 70.5$ $\mathrm{Ma}$ and $66.4 \mathrm{Ma}$ this species was recorded only once. Zygodiscus sp. 1 was very rare $(<1 \%)$ prior to about $68 \mathrm{Ma}$ (Figure 28a). Between about $68 \mathrm{Ma}$ and $66.7 \mathrm{Ma}$ this species increased gradually in abundance (to $\sim 1-2 \%$ ). Between $\sim 66.7$ to 66.4 Ma this species first decreased in abundance $(<0.5 \%$ between about 66.6 and $66.5 \mathrm{Ma}$ ), but then increased again to values between 1.5 and $3 \%$ during the last $50 \mathrm{ky}$ of the Maestrichtian. Ceratolithoides sp. cf. $\underline{\text { C. aculeus }}$ was common (2-5\% in most samples) prior to $\sim 66.6 \mathrm{Ma}$; between $\sim 66.6$ and $66.4 \mathrm{Ma}$ this taxon was always very rare $(<1 \%$; Figure $28 \mathrm{~b})$.

The relative abundance of $\mathrm{G}$. fessus increased gradually throughout the late Maestrichtian (Figure 28c). It constituted between about 1-2\% around 71 $\mathrm{Ma}$ and increased to values close to $5 \%$ after $\sim 66.8 \mathrm{Ma}$. An unusually high value $(>10 \%)$ was recorded around 69 Ma. Manivitella pemmatoidea was recorded consistently prior to about $69 \mathrm{Ma}$, although the relative abundances decreased between 71.1 - $69 \mathrm{Ma}$ from about $1 \%$ to $<0.5 \%$ (Figure 28d). After about $69 \mathrm{Ma}$ this species was very rare and recorded only intermittently. An almost reverse trend was recoded for $\underline{\mathrm{M}}$. belgicus, which was absent or very rare $(<0.5 \%)$ prior to about $69 \mathrm{Ma}$, but subsequently increased in abundance and was recorded consistently between about $69 \mathrm{Ma}$ and the K/P boundary (Figure 29e). The relative abundances of $\underline{\mathrm{P}}$. stoveri increased from $\sim 2 \%$ to values $>10 \%$ between about 71.2 and $68 \mathrm{Ma}$.

Watznaueria barnesae was one of the major constituents of the Maestricthian nannofossil assemblages in Hole 761B (Figure 27k); in contrast to most other abundant taxa its relative abundances did not fluctuate very much but essentially remained between 5-10\%. At about $66.65 \mathrm{Ma}$ the relative abundances of $\underline{W}$. barnesae increased fairly abruptly to values between $\sim 10$ and $15 \%$ at which level it remained until $66.4 \mathrm{Ma}$. The relative abundances of Arkhangelskiella spp. were $<5 \%$ in most samples (Figure 28g); between about 71 and $70 \mathrm{Ma}$ the abundances were higher, between 5 and $10 \%$. Cribrosphaerella ehrenbergii (Figure 28h) displayed abundance variations similar to Arkhangelskiella spp. in so far as this species was rarer around 69 

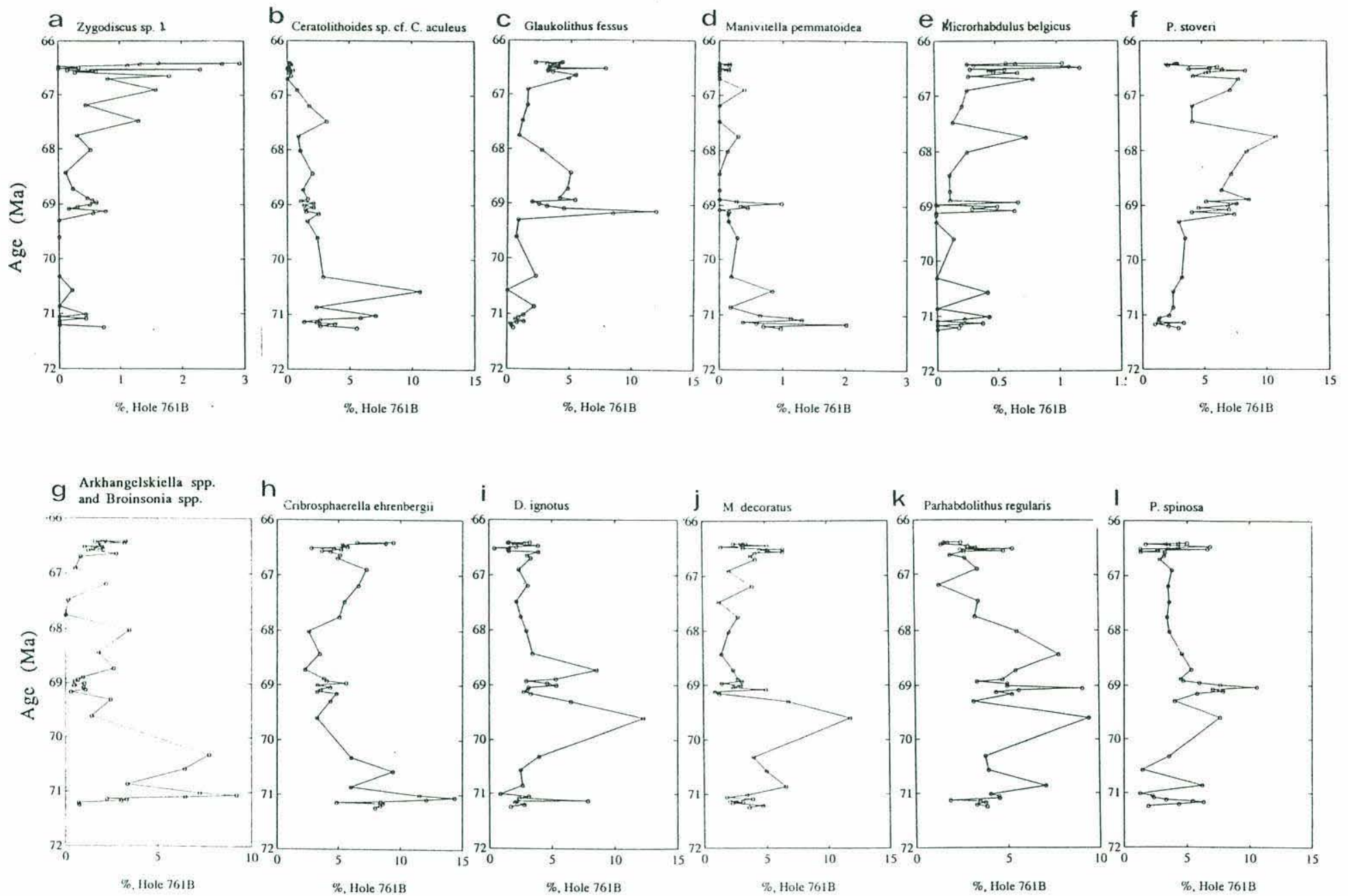

Figure 28: Relative abundance plots of selected taxa in Hole 761B during the late Maestrichtian. The data were calculated exclusive of $\underline{M}$. staurophora. 
Ma than either before or after this interval. Discorhabdus ignotus displayed only minor long term trends during the Maestrichtian (Figure 28i): its abundance was highest between $\sim 70.3$ and 68.5 Ma. The relative abundance of

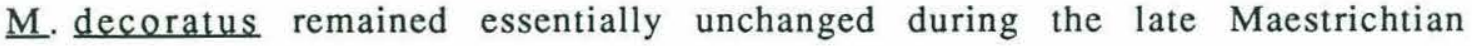
(Figure 28j); an abundance peak of $>10 \%$ was recorded at $\sim 70 \mathrm{Ma}$.

Parhabdolithus regularis constituted between $1-10 \%$ of the assemblage during the late Maestrichtian (Figure 28k); slightly higher values were recorded around $69 \mathrm{Ma}$ than either before or after. The relative abundance of $\underline{\mathrm{P}}$. spinosa was highest $(\sim 5-10 \%)$ between $\sim 69.5$ - $68.5 \mathrm{Ma}$, whereas lower vlaues ( 3-5\%) were recorded prior to and after this increase (Figure 281).

Ahmuellerella ectoradiata was rare in Hole 761B (Figure 29a). Its abundance in most samples is $<0.5 \%$. Although rare, this species was recorded in most samples prior to $\sim 68 \mathrm{Ma}$, but was not observed in any sample thereafter. Highly variable abundance data were recorded for $\underline{\mathrm{P}}$. fibuliformis (Figure 29b). In the earliest five samples recorded the data fluctuate from 4 $11 \%$ between adjacent samples, reminiscent of the abundance fluctuations of M. staurophora. Between about 71.1 and $69.3 \mathrm{Ma}$ comparatively low values were recorded (around 2\%). After that the relative abundances increased abruptly to values slightly $>5 \%$ and remained at this level until about $66.8 \mathrm{Ma}$ (with two lower values around $67 \mathrm{Ma})$. During the latest part of the Maestrichtian (66.7 $\mathrm{Ma}-66.4 \mathrm{Ma})$ the relative abundances of $\underline{\mathrm{P}}$ fibuliformis decreased from $\sim 8 \%$ to 2\% (Figure 29b). Placozygus sp. displayed low (between $\sim 0.5$ and $1 \%$, Figure 29c) but fairly constant relative abundances during most of the late Maestrichtian: somewhat higher values (between 1 and 2\%) were recorded prior to $71 \mathrm{Ma}$ as well as during the last $\sim 50 \mathrm{ky}$ of the Maestrichtian. The relative abundances of $\underline{P}$. cretacea varied widely during the Maestrichtian (Figure 29f). At about $71 \mathrm{Ma}$ adjacent samples yielded values of $15 \%$ and almost $30 \%$. The average relative abundances remained approximately constant between 20-25\% between about 71.2 and $67 \mathrm{Ma}$. Between $67 \mathrm{Ma}$ and the $\mathrm{K} / \mathrm{P}$ boundary the relative abundances of $\underline{P}$. cretacea were slightly lower and varied between $\sim 15-20 \%$. The abundance of Rhagodiscus splendens (Figure $29 \mathrm{~d}$ ) increased from values $<0.5 \%$ around $71 \mathrm{Ma}$ to $\sim 1 \%$ at about $69 \mathrm{Ma}$; subsequently its abundance decreased again to low values $(<0.5 \%)$ immediately preceding the K/P boundary. Stephanolithion spp. (Figure 29e) were very rare prior to $71 \mathrm{Ma}$ and increased throughout the late Maestrichtian to values 

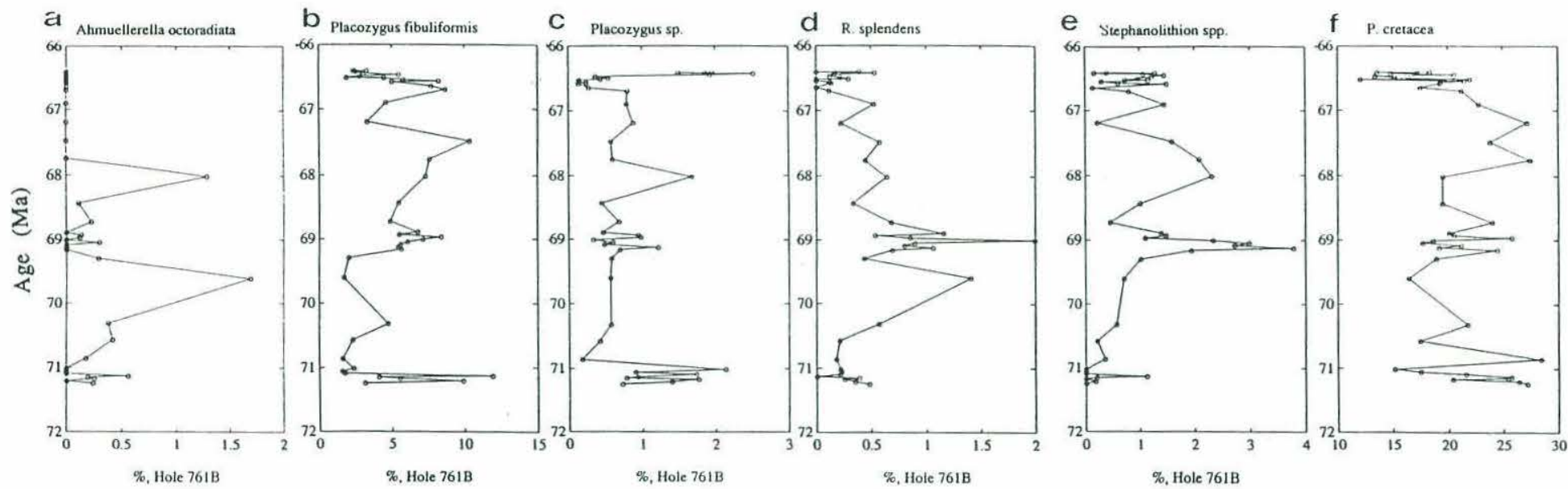

Figure 29: Relative abundance plots of selected taxa in Hole 761B during the late Macstrichtian. The data were calculated exclusive of $\underline{M}$. staurophora. 
around $1 \%$ at $\sim 66.4 \mathrm{Ma}$. Comparatively very high values (between 2-3\%) were recorded at about $69 \mathrm{Ma}$ and $68 \mathrm{Ma}$.

\section{B) The latest Maestrichtian: Holes $761 \mathrm{~B}$ and $761 \mathrm{C}$}

Subtle changes in the calcareous nannofossil assemblages in Hole 761B occurred during the last $500 \mathrm{ky}$ of the Maestrichtian. In both holes, 761B and $761 \mathrm{C}$, the relative abundance of $\underline{\mathrm{P}}$ fibuliformis decreased between $\sim 66.7$ and 55.4 Ma (Figure 30j). The magnitude of the decrease was similar in both holes (around $8-9 \%$ at about $66.7 \mathrm{Ma} ; 2-3 \%$ at the $\mathrm{K} / \mathrm{P}$ boundary). The decrease proceeded more or less gradually in both holes, except for isolated outlier values that seem to be associated with poorer preservation in some instances (e.g. unusually low values around $66.5 \mathrm{Ma}$ in Hole 761B where $\mathrm{M}$. staurophora showed increased abundance values).

Several taxa that were important components of the nannofossil assemblages in high southern latitude Hole 690C appeared or increased in abundance during the latest part of the Maestrichtian in Hole 761B. These taxa

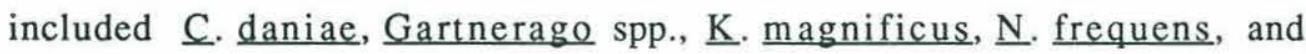
Vagalapilla spp (Figure 30c, i; 31c, d). Species of the genus Gartnerage were absent from most samples in Hole 761B, but were recorded in three samples between 66.7 and $66.4 \mathrm{Ma}$. Kamptnerius magnificus was always very rare - $(<0.5 \%)$. Prior to $\sim 67 \mathrm{Ma}$ it was recorded only in isolated samples. Between $\sim 67$ $\mathrm{Ma}$ and $\sim 66.4 \mathrm{Ma}$ its abundance increased slightly and it was encountered in several samples. Nephrolithus frequens displayed one of the most conspicuous abundance increases at about $67 \mathrm{Ma}$ : this species was recorded as early as at $\sim 69$ $\mathrm{Ma}$, but between about 69 and $67 \mathrm{Ma}$ it was very rare. After $\sim 67 \mathrm{Ma}$ the relative frequency of $\underline{\mathrm{N}}$. frequens increased abruptly from values $<0.5 \%$ to values between 2 and $4 \%$ (with a maximum value $>6 \%$ ). Species of Vagalapilla were rare $(<0.5 \%)$ throughout most of the Maestrichtian studied in Hole $761 \mathrm{~B}$ but increased in abundance $\sim 50 \mathrm{ky}$ before the K/P boundary and reached abundance values between 2-3\%. All of these taxa are characteristic components of high latitude assemblages.

Also $\underline{C}$. ehrenbergii (Figure 30d) which was present during the entire Maestrichtian in Hole $761 \mathrm{~B}$ increased in relative abundance during the last 350 ky of the Maestrichtian. 

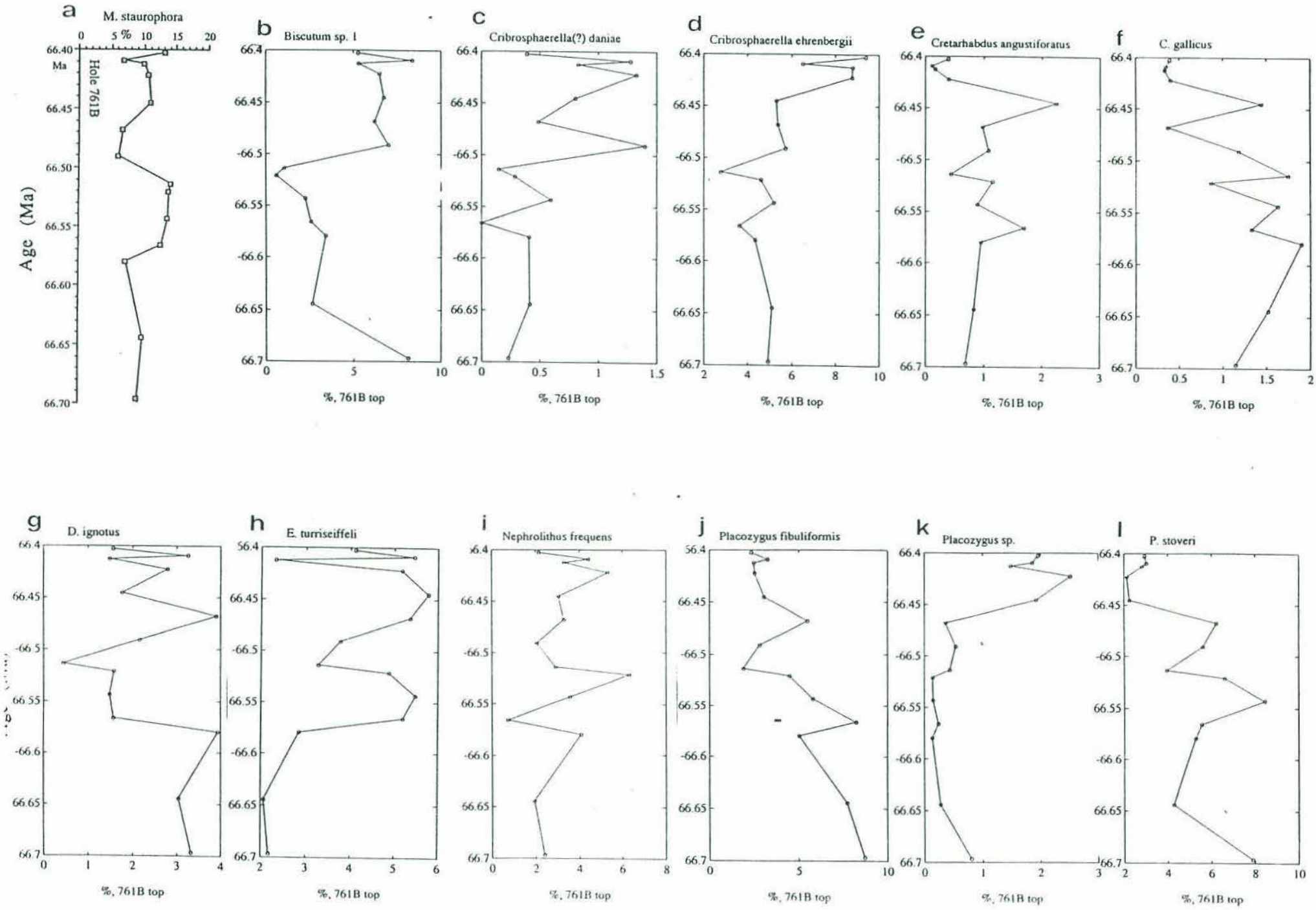

Figure 30: Relative abundance plots of selected taxa versus age (Hole 761B). Only the latest Maestrichtian is represented. (Abundances calculated excl. of M. staurophora). 


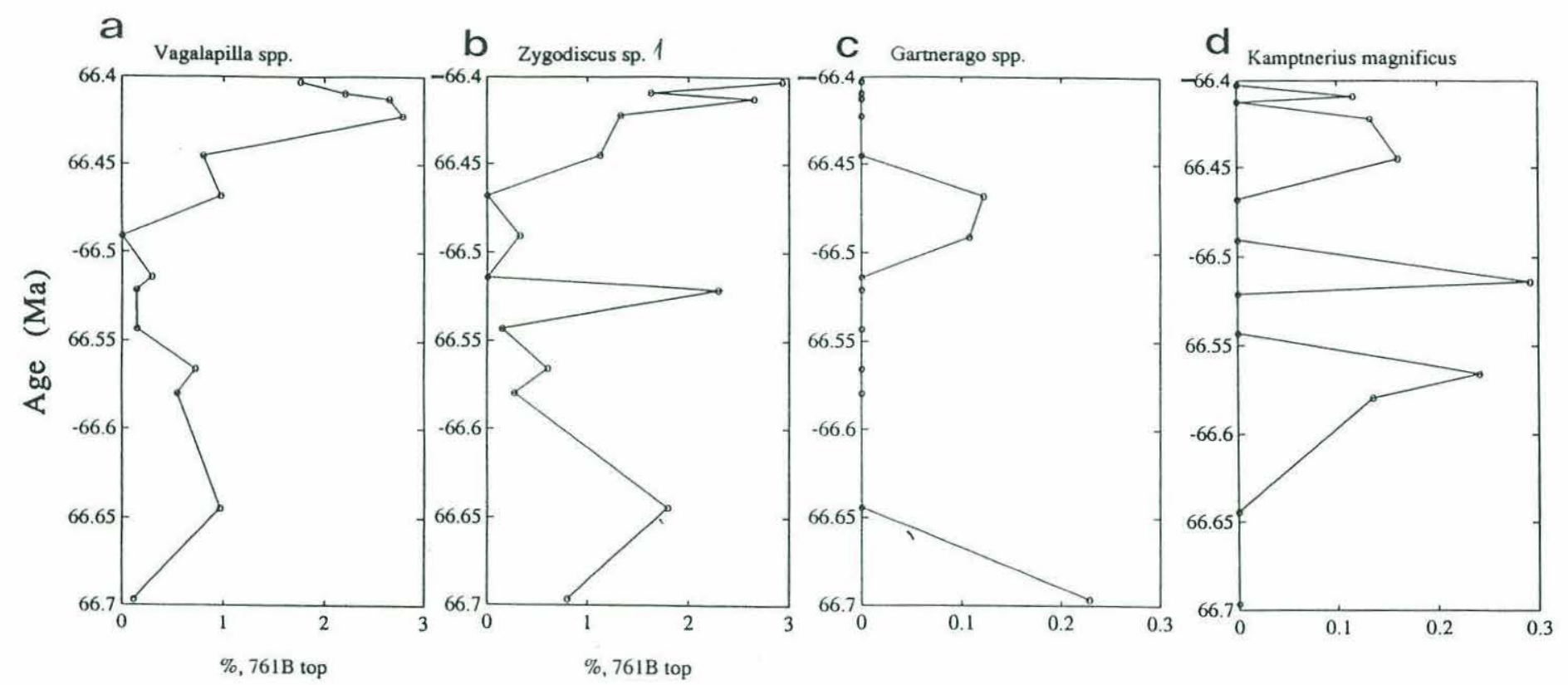

Figure 31:Relative abundance plots of selected taxa versus age (Hole 761B).

Only the latest Maestrichtian is represented. (Abundances calculated excl. of

M. staurophora). 


\section{C) Assessment of Preservation}

The influence of dissolution on the nannofossil assemblages was investigated at Site 761 by comparing the abundance variations of dissolution resistant and dissolution susceptible taxa: nannofossil assemblages that were modified by increased dissolution should be enriched in the former group and depleted in the later group. Following Thierstein (1980) four taxa were included in the dissolution resistant group: Arkhangelskiella spp., Broinsonia spp., $\underline{\mathrm{K}}$. magnificus, and $\underline{\mathrm{W}}$. barnesae. The last taxon is by far the most abundant one and controls the pattern of the shape of the curve of the dissolution resistant group. Included in the dissolution susceptible group were

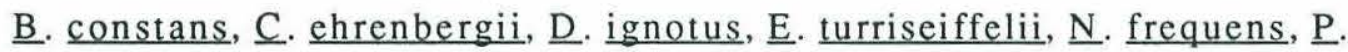

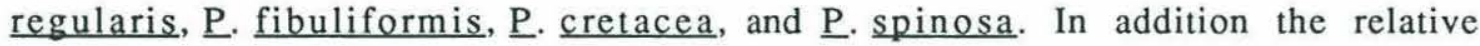
abundances of $\underline{M}$. staurophora was used as an additional very dissolution resistant indicator. The graphs are presented in Figure 32. One sample at around 66.51 was identified where all three 'dissolution indices' indicated increased dissolution (circled in Figure 32a, b, c). In all other samples there is no unambiguous signal indicating increased dissolution and consequently all other data points are considered to represent genuine abundance variations. In some of the older samples (prior to about $70.5 \mathrm{Ma}$ ) very high fluctuations in the relative abundances of the dissolution susceptible group as well as of $\underline{M}$. staurophora were recorded. Since there were no corresponding abundance variations in the dissolution resistant group, these samples were not considered to be extensively modified by increased dissolution; however, this possibility could not be completely ruled out and the samples in question were marked with a circle and a question-mark (Figure 32d, e, f). 


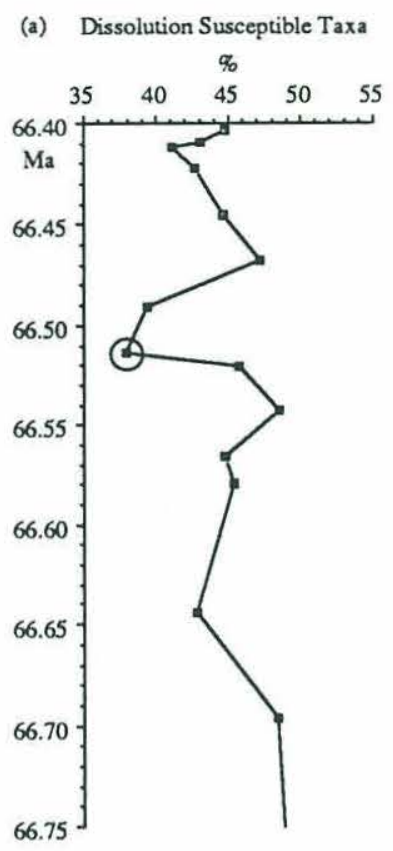

(b) Dissolution Resistant Taxa, 761B

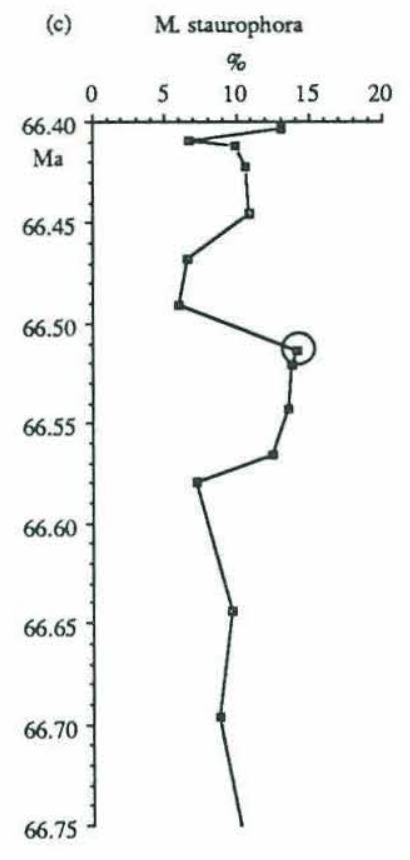

(d) Dissolution Susceptible Taxa
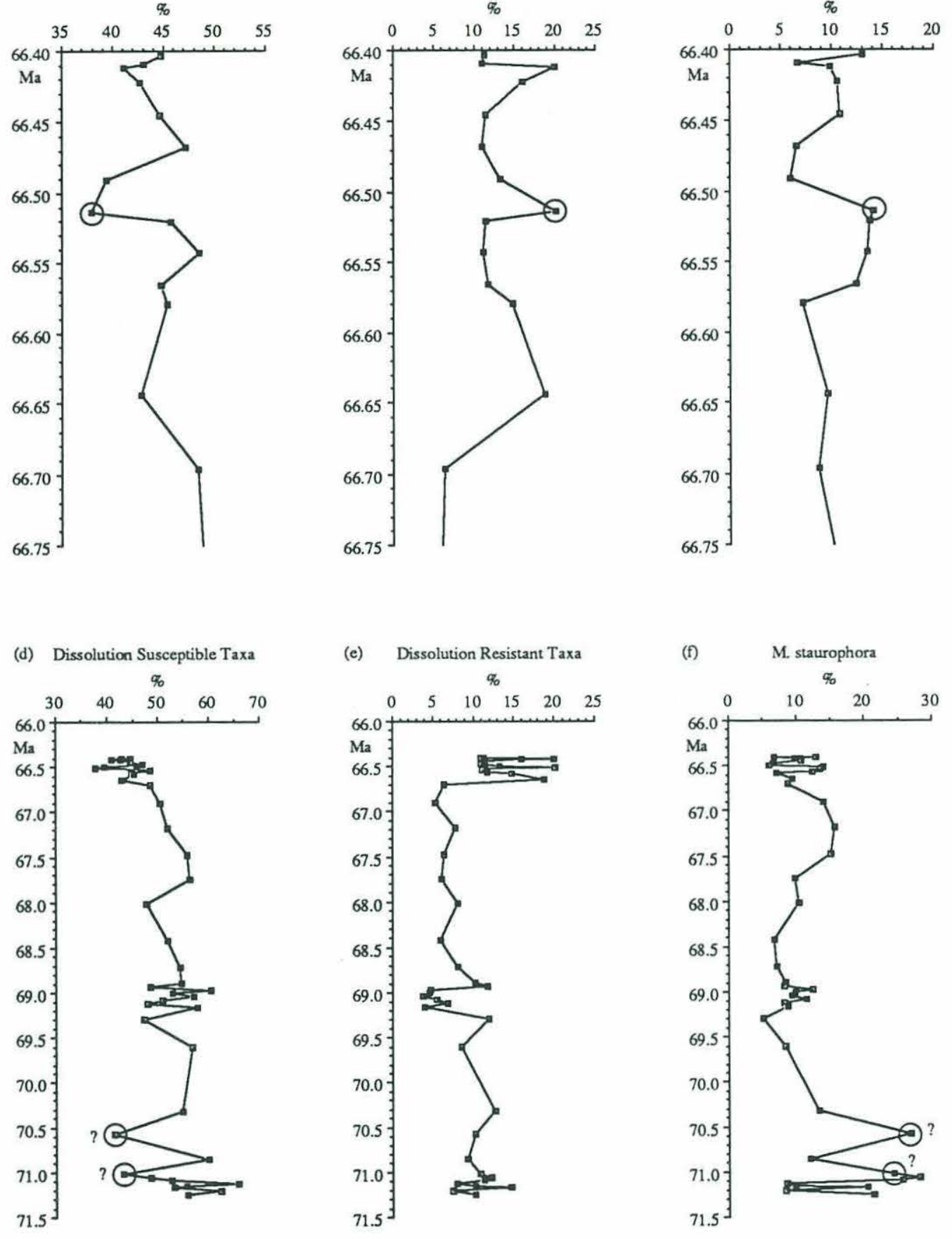

Figure 32: Plots of dissolution susceptible and dissolution resistant taxa, as well as of $\underline{M}$. staurophora versus age. The graphs on top represent the latest Maestrichtian only, while those below represent the entire Maestrichtian section investigated. The data points that are circled are most likely modified due to increased dissolution. The $\mathrm{K} / \mathrm{P}$ boundary lies at $66.40 \mathrm{Ma}$. 


\section{3) DSDP Hole 217}

\section{A) Nannofossil Abundance Patterns}

The number of taxa per sample recorded in the upper Maestrichtian chalk in Hole 217 varies between 27 and 44 (Figure 33). Below 455.19 mbsf ( $68.56 \mathrm{Ma}$ ) between 35 and 43 taxa per sample were recorded; in the interval of high sample resolution between 455.19 and $450.49 \mathrm{mbsf}$ ( 68.56 and $68.27 \mathrm{Ma}$ ) species richness was highly variable, with values on average lower than below, fluctuating around 35 taxa. The lowest species richness was recorded at 426.70 mbsf ( 66.76 Ma; 27 taxa); above this level species richness increased again and values as high as in the lowest part of the section (between $~ 35-40$ taxa per sample) were recorded immediately below the K/P boundary.

While the counts were made the preservation in each sample was noted, and there was no indication of systematic poorer preservation in the samples that displayed reduced species richness (compare "Preservation" among samples in Appendix II: Table 217). Therefore the trend of decreasing species richness between 492.32 and $426.70 \mathrm{mbsf}(\sim 71-66.76 \mathrm{Ma})$ and the ensuing increase in the uppermost $5.5 \mathrm{~m}$ of the Maestrichtian is considered to be a genuine signal rather than an artifact of preservation. Below I discuss the abundance patterns of selected taxa in order to examine which taxa disappear from the assemblages below 426.7 mbsf ( 66.76 Ma), and which taxa first occurred at this level or became more abundant causing the increased species richnesses just below the $\mathrm{K} / \mathrm{P}$ boundary.

Micula staurophora is among the most abundant taxa constituting $\sim 10 \%$ to $25 \%$ (average $15 \%$ ) of the entire Maestrichtian assemblage with peak abundances exceeding $30 \%$ (Figure 34). No long term trend of increasing or decreasing abundance was recorded. Because of the high abundance of $\underline{M}$. staurophora the percentages of all other nannofossil taxa were calculated exclusive of $\underline{M}$. staurophora. As in the other sections this procedure was chosen so that smaller abundance changes in comparatively rare taxa would not be suppressed.

\section{a) Taxa decreasing in relative abundance:}

Ahmuellerella octoradiata constitutes several percent of the assemblage in the lower part of the section (below $469.06 \mathrm{mbsf}$; $69.4 \mathrm{Ma}$; Figure 35a), its 


\section{Taxon Richness}

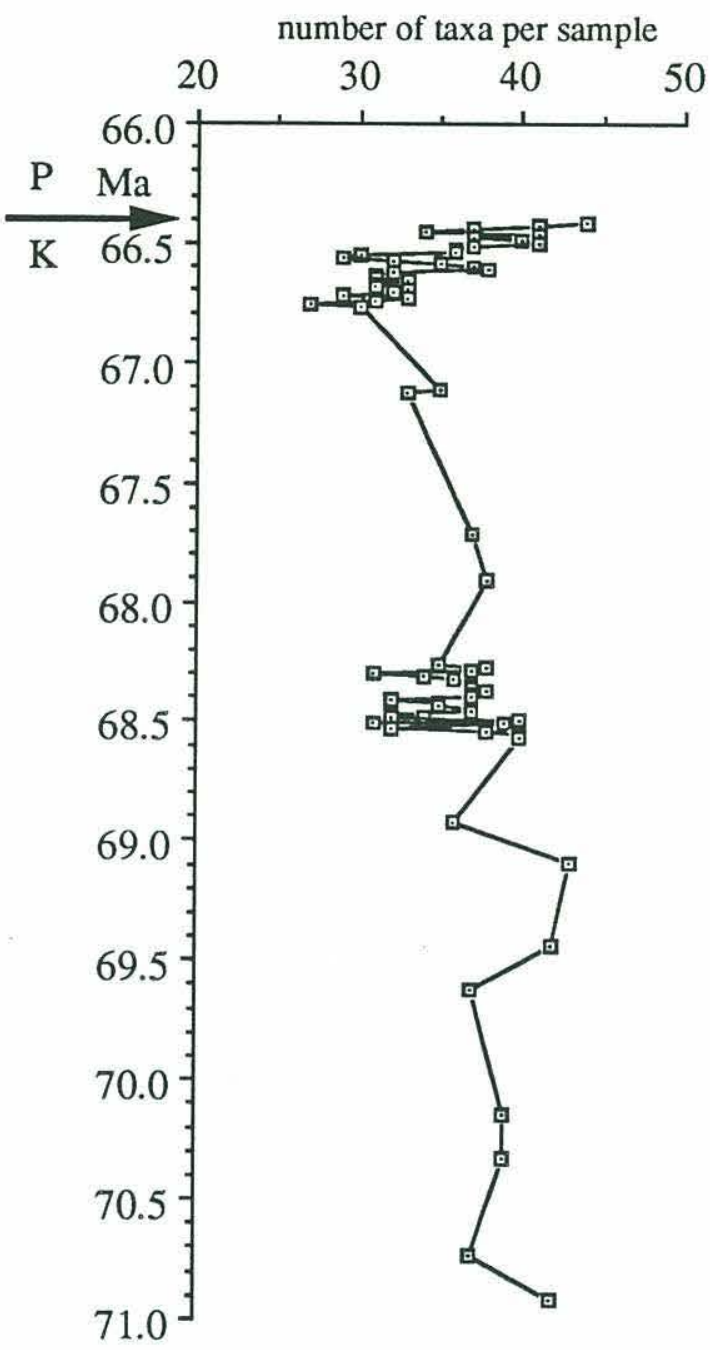

Figure 33: Species Richness (number of taxa per sample) plotted against age. The decrease between about $71 \mathrm{Ma}$ and $67 \mathrm{Ma}$ and the subsequent increase cannot be explained as dissolution artifacts. 


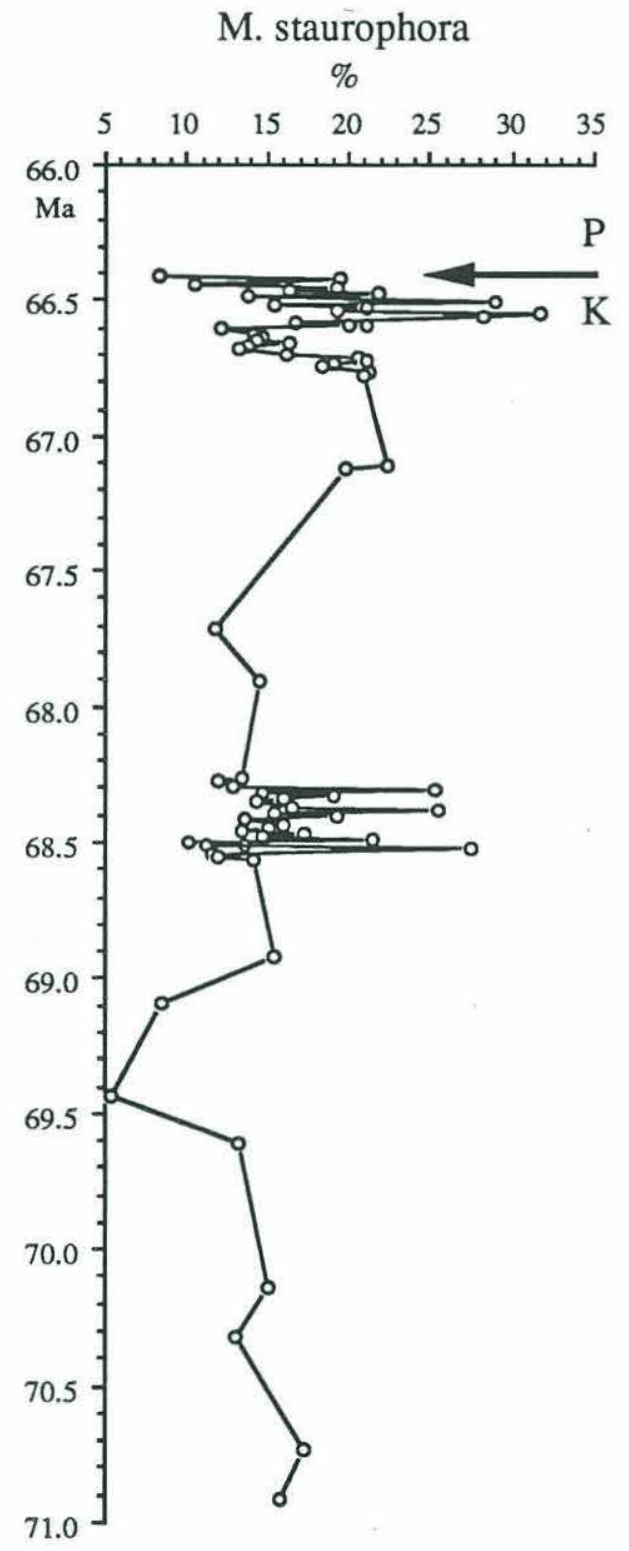

Figure 34: Relative abundance changes (\%) of Micula staurophora during the late Maestrichtian in Hole 217. 

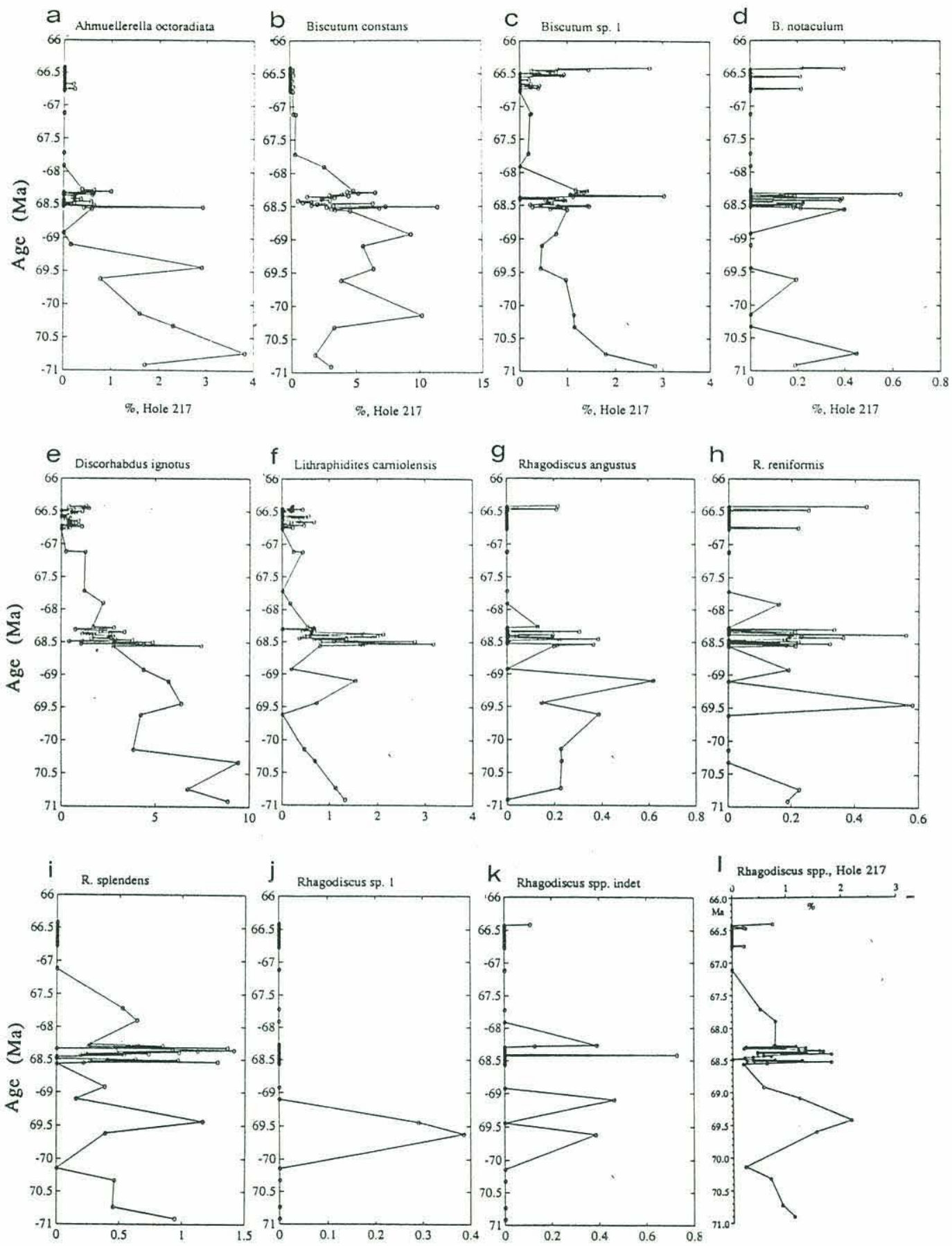

Figure 35: Relative abundance changes (\%) of selected taxa during the late Maestrichtian in Hole 217. (All calculations exclusive of $\underline{M}$. staurophora). 
abundance decreases to $<1 \%$ between 455.19 and 450.49 mbsf ( 68.56-68.27 Ma). It was absent from most counts above 450 mbsf ( 68.27 Ma).

Biscutum constans (Figure $35 \mathrm{~b}$ ) is common to abundant $(5-10 \%)$ below 455.19 mbsf $(\sim 68.56 \mathrm{Ma})$. In the interval of high sample density between 455.19 and 450.49 mbsf ( 68.56-68.27 Ma) $\underline{\text { B }}$ constans initially decreases in abundance from $\sim 5 \%$ to $<2 \%$ (between $455.19-453.30 \mathrm{mbsf}$ ), but then increases again to $\sim 5 \%$ at 451.08 mbsf. It decreases again and is very rare $(<1 \%)$ above $444.8 \mathrm{mbsf}$ ( 67.9 Ma).

Biscutum sp. 1 (Figure 35c) decreases in abundance from almost $3 \%$ to $<1 \%$ throughout the lower half of the section (492.32 to $455.19 \mathrm{mbsf}$; $~ 70.9-68.56$ $\mathrm{Ma);} \mathrm{similar} \mathrm{to} \underline{\mathrm{B}}$. constans it increases in abundance between 453.9 and 450.49 mbsf ( 68.48-68.27 Ma). Above 450.49 mbsf $(68.27 \mathrm{Ma})$ it is present in very low abundance $(<<1 \%)$. In contrast to $\underline{B}$. constans, however, Biscutum sp. 1 increases in abundance again immediately below the $\mathrm{K} / \mathrm{P}$ boundary to values $>1 \%$ (between 423.2 and $421.2 \mathrm{mbsf}$; 66.54-66.41 Ma).

Biscutum notaculum is always very rare (exceeding $0.5 \%$ only in one sample; Figure 35d). Below $451.30 \mathrm{mbsf}(\sim 68.3 \mathrm{Ma})$ it was recorded in almost each sample whereas above this level this species is so rare that it was recorded only in very few samples.

Discorhabdus ignotus decreases in abundance throughout the section (Figure 35e): it constitutes almost $10 \%$ of the assemblage below 480.14 mbsf ( 70.14 Ma), but only around $1 \%$ above $432.4 \mathrm{mbsf}(\sim 67.1 \mathrm{Ma})$.

Lithraphidites carniolensis is comparatively rare (in most samples $1 \%$ and less) throughout the section (Figure 35f). Below $450.49 \mathrm{mbsf}(\sim 68.27 \mathrm{Ma}$ ) its abundance fluctuates considerably: peak abundances of $>1 \%$ were recorded in several samples and $>3 \%$ in one sample at 454.59 mbsf. Above 450.49 mbsf $(\sim 68.27 \mathrm{Ma})$ this species is always very rare $(<1 \%)$.

Several species of Rhagodiscus were recorded. Although rare (individual species almost always $<1 \%$, Figures $35, \mathrm{~g}-\mathrm{k}$ ), all species displayed similar abundance patterns: they are more abundant and were more consistently recorded below 441.8 mbsf ( $67.72 \mathrm{Ma})$; above $441.8 \mathrm{mbsf}$ all species are very rare. This trend is especially obvious when the sum of all species of Rhagodiscus is considered (Figure 351).

In the lowermost part of the section (between 492.32 and 480.14 mbsf; 70.9-70.14 Ma) Ceratolithoides sp. cf. $\underline{\text { C. }}$ aculeus is rare $(>2 \%)$; between 480.14 and 471.82 mbsf $(\sim 70.14-69.61)$ it increases abruptly in abundance from $<2 \%$ to 
$\sim 5 \%$ (Figure 36a), remains between $3 \%$ and $5 \%$ up to $432.22 \mathrm{mbsf}(\sim 67.1 \mathrm{Ma})$, decreases precipitously in abundance between 432.22 and 426.9 mbsf ( 67.1$66.77 \mathrm{Ma})$ and is absent or very rare $(<<1 \%)$ above $426.9 \mathrm{mbsf}$. Considerable inter-sample variability was recorded in the interval of very closely spaced samples between 455.19 and 450.49 mbsf ( 68.56-68.27 Ma).

\section{b) Taxa increasing in relative abundance}

Below $\sim 460$ mbsf ( 68.9 Ma) $\underline{C}$ gallicus is recorded only in one sample (Figure 36f). In the closely sampled interval (455.19 - $450.49 \mathrm{mbsf} ; 68.56$ to $68.27 \mathrm{Ma}$ ) this species increases in abundance from $\sim 0.5 \%$ to $\sim 1 \%$ and maintains this abundance throughout the remainder of the section. An exceptionally high abundance of almost $3 \%$ is recorded at 422.6 mbsf $(\sim 66.5 \mathrm{Ma})$. This is $>1 \%$ higher than the abundances in either of its adjacent samples which are comparatively high ( $>\sim 1.5 \%$; Figure 36f). I suspected that the outlier value of $3 \%$ resulted from enrichment through dissolution. Cylindralithus gallicus is not included in the dissolution ranking of Thierstein (1980), but a structurally very similar form, Cylindralithus serratus is ranked as very slightly solution resistant. Cylindralithus gallicus consists of more massive elements than $\underline{C}$. serratus and I assume that it is more solution resistant. In the same sample

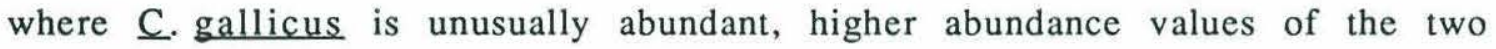
most dissolution resistant taxa in this assemblage, M. staurophora (29\%, vs. $14 \%$ and $16 \%)$ and $\underline{\mathrm{W}}$. barnesae $(27 \%$, vs. $22 \%$ and $20 \%)$ were also recorded than in the adjacent samples. Thus it appears that the relative abundance of $\underline{\mathrm{C}}$. gallicus at 422.6 mbsf is increased by dissolution.

The relative abundance of $\underline{\mathrm{G}}$. $\underline{\text { fessus }}$ is $\sim 2 \%$ below $444.8 \mathrm{mbsf}(\sim 67.9 \mathrm{Ma}$; Figure $36 \mathrm{~g}$ ). Above this level abundance values increases and throughout the uppermost $5.7 \mathrm{~m}$ of the section $(\sim 66.77-66.41 \mathrm{Ma})$ they vary around $4 \%$, fluctuating strongly. Relative abundance values exceeding $6 \%$ were recorded in two samples in the uppermost Maestrichtian, at $422.0 \mathrm{mbsf}$ and at 425.49 mbsf. These elevated values are isolated within the abundance pattern of $\underline{G}$. fessus and do not correspond to unusually high or low values in dissolution resistant taxa. Thus it appears that they cannot be explained as presrvational artifacts; their paleoceanographic significance is not understood at the moment.

Lithraphidites praequadratus is very rare $(<<1 \%)$ below 463.65 mbsf $(69.1$ Ma; Figure 36h). Between 469.06 and $463.65 \mathrm{mbsf}(\sim 69.44-69.1 \mathrm{Ma})$ its 

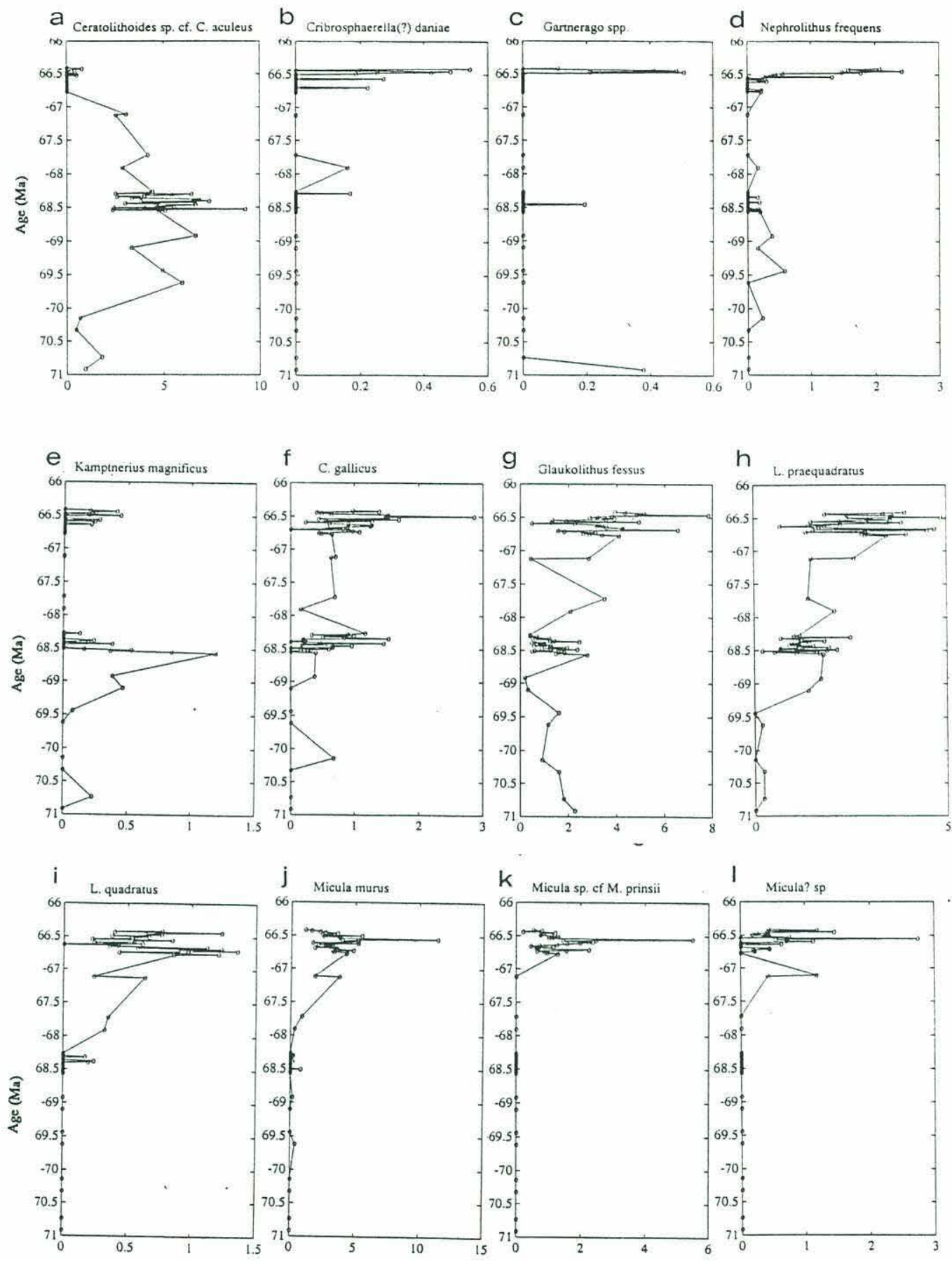

Figure 36: Relative abundance changes (\%) of selected taxa during the late Maestrichtian in Hole 217. (All calculations exclusive of $\mathrm{M}$. staurophora). 
abundance increases sharply from 0 to $\sim 1.5 \%$, remains between $\sim 1$ and $2 \%$ up to 432.4 mbsf ( 67.12 $\mathrm{Ma})$, and then increases again to average values around $3 \%$ (and fairly high inter-sample variability) throughout the remainder of the Maestrichtian.

Lithraphidites quadratus was not recorded below to 452.5 mbsf $(\sim 68.39$ Ma; Figure 36i). Between 452.5 and 426.9 mbsf ( 68.39 - 66.73 Ma) its abundance increases steadily to values around $1 \%$, subsequently decreases to around $0.5 \%$ between 426.9 and $424.9 \mathrm{mbsf}(\sim 66.73-66.65 \mathrm{Ma})$, and increases slightly below the K/P boundary (between 424.9 and $421.2 \mathrm{mbsf}$; $66.65-66.41 \mathrm{Ma}$ ).

Below about $455.19 \mathrm{mbsf}(\sim 68.56 \mathrm{Ma}) \underline{\mathrm{P}}$ stoveri is fairly rare $(<2 \%)$ except in the lowermost two samples where it reaches abundances $>3 \%$ (Figure 37a). Above 455.19 mbsf this species increases steadily in abundance and at 444.8 mbsf ( 67.9 Ma) its abundance is 4\%. Throughout the remainder of the

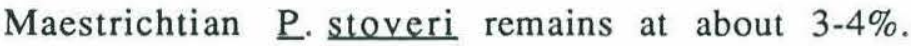

Tranolithus macleodae is rare in most samples $(<0.5 \%$, Figure $37 \mathrm{~b})$, but increased abundance values $(1.5-2 \%)$ are recorded immediately below the $\mathrm{K} / \mathrm{P}$ boundary (422.6 - $421.2 \mathrm{mbsf} ; \sim 66.5-66.41 \mathrm{Ma}$ ).

The relative abundance of Vagalapilla spp. is low $(<0.5 \%)$ throughout most of the section; higher values $(>1 \%)$ are recorded in two samples in the lowest part of the section (489.51 and $483.03 \mathrm{mbsf} ; 70.73-70.32 \mathrm{Ma}$ ) as well as in several samples immediately below the $\mathrm{K} / \mathrm{P}$ boundary $(422.0,421.6,421.2$ mbsf; $~ 66.46,66.44,66.41 \mathrm{Ma}$; Figure 37c).

Cribrosphaerella? daniae, Gartnerago spp., and $\underline{\mathrm{N}}$. frequens are absent or very rare in most samples, but increased in abundance in a few samples immediately below the K/P boundary (422.2 - 421.2 mbsf; $~ 66.48$ - $66.41 \mathrm{Ma}$; Figures 36, b-d). Cribrosphaerella? daniae and Gartnerago spp. increase from virtually $0 \%$ to $\sim 0.5 \%$; Nephrolithus frequens is recorded in most samples in low abundances $(<0.5 \%)$ and increases to $\sim 2 \%$ below the $\mathrm{K} / \mathrm{P}$ boundary. 

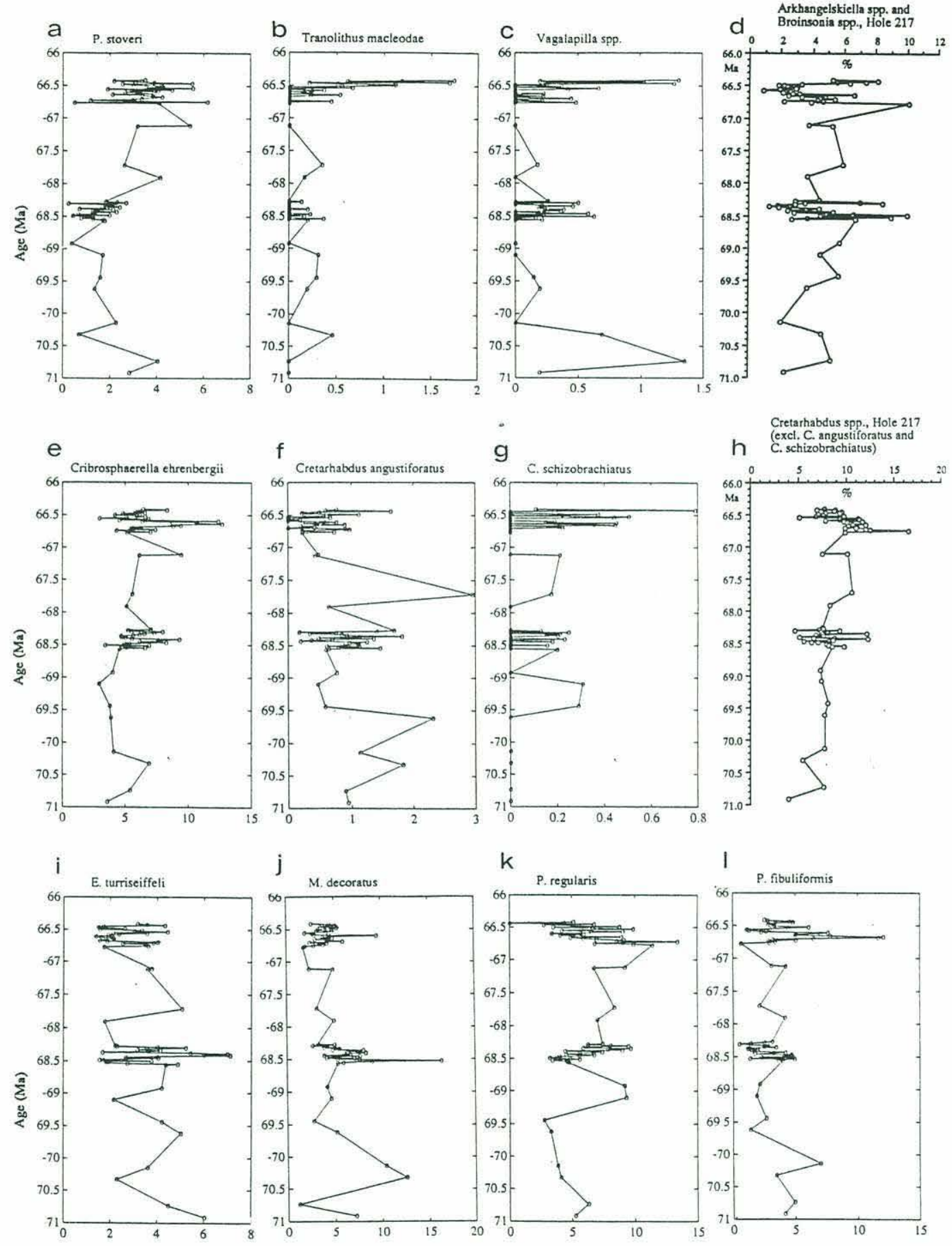

Figure 37: Relative abundance changes (\%) of selected taxa during the late Maestrichtian in Hole 217. (All calculations exclusive of $\underline{M}$. staurophora). 


\section{c) Other Fluctuations}

Arkhangelskiella spp. and Broinsonia spp. have been grouped together because preservational differences between samples made it impossible to distinguish these taxa consistently. Below $455.19 \mathrm{mbsf}(68.56 \mathrm{Ma})$ relative abundance values range from $<2 \%$ to $>6 \%$, with steadily increasing values between 480.14 and $455.19 \mathrm{mbsf}(\sim 70.14$ - $68.56 \mathrm{Ma}$; Figure 37d). The relative abundance fluctuates considerably $(<3 \%$ to $>10 \%$ ) between 455.19 and 453.90 mbsf ( 68.56 - $68.48 \mathrm{Ma})$, decreases to $\sim 2 \%$ at $452.3 \mathrm{mbsf}(68.38 \mathrm{Ma})$ and then increases slowly to $4 \%$ at 450.49 mbsf. This gradual increase is interrupted by two very high abundance values $(\sim 8 \%)$ at 451.08 and $450.90 \mathrm{mbsf}(\sim 68.3$ and $68.29 \mathrm{Ma})$. Between 450.49 and $432.22 \mathrm{mbsf}$ abundance values vary between $\sim 4$ and $6 \%$. One of the highest values $(>10 \%)$ is recorded at $426.9 \mathrm{mbsf}(\sim 66.77 \mathrm{Ma})$. Between 426.7 and 424.9 mbsf ( 66.76 - $66.65 \mathrm{Ma})$ relative abundances vary between $\sim 5$ and $2 \%$; between 424.9 and $422.2 \mathrm{mbsf}(66.65-66.48 \mathrm{Ma})$ they are slightly lower $(\sim 2 \%)$ and display low variability. Increased abundance (6-8\%) is recorded in five samples immediately below the $\mathrm{K} / \mathrm{P}$ boundary $(422.0-421.2$ mbsf; $~ 66.46$ - $66.41 \mathrm{Ma}$ ).

Despite considerable variability between samples (e.g. between 455 and $452 \mathrm{mbsf}$ ) trends are only discernible in the intervals of high sample density. High sample density throughout the Maestrichtian would be required to determine trends in these two taxa.

Cribrosphaerella ehrenbergii is common to abundant in all samples $(\sim>5 \%)$ below 425.49 mbsf ( 66.68 Ma; Figure 37e). Between 425.49 and 424.1 mbsf its relative abundance increases to $\sim 10 \%$; above this interval the abundance decreases again to $5-7 \%$.

Several species of Cretarhabdus were combined because different preservation made it impossible to distinguish them consistently ( $\underline{C}$. conicus, $\underline{C}$. crenulatus, $\boldsymbol{C}$. surirellus, Cretarhabdus spp. indet.). The abundance variations of Cretarhabdus angustiforatus (Figure 37f) and $\underline{\mathrm{C}}$. schizobrachiatus (Figure $37 \mathrm{~g}$ ) were plotted separately since the characteristic optical extinction pattern which results from the attachment of the central structure to the margin allows the unambiguous identification of these two species even when most of the central area is missing. The graph of the combined Cretarhabdus spp.

(Figure 37h) shows an abundance increase throughout the section, from about $5 \%$ at 492.32 mbsf $(\sim 71 \mathrm{Ma})$ to $\sim 10 \%$ at 426.9 mbsf $(\sim 66.77 \mathrm{Ma})$. In the remainder of the section (426.9 - 421.2 mbsf; $66.77-66.41 \mathrm{Ma})$ the relative abundance of 
this taxon decreases from $\sim 10-13 \%$ to $\sim 8 \%$. An isolated abundance peak of almost $17 \%$ was recorded at 426.7 mbsf ( 66.76 Ma). The relative abundance of Cretarhabdus angustiforatus never exceeds $3 \%$ and usually remains below $1 \%$. It decreases from $\sim 1 \%$ to values around $0.5 \%$ between 426.9 and $421.2 \mathrm{mbsf}$ (66.77 -66.41 Ma). Cretarhabdus schizobrachiatus was very rare in all samples (hardly ever exceeding $0.5 \%$; Figure $37 \mathrm{~g}$ ). It was absent from the lowest samples. Throughout its record no abundance changes were recorded. The abundance values of E. turriseiffeli fluctuate between $\sim 2$ and $6 \%$ (Figure 37i). Below $455.19 \mathrm{mbsf}(68.56 \mathrm{Ma})$ the sample density is insufficient to assess whether the recorded abundance fluctuations represent a genuine pattern. In the closely sampled interval between 455.19 and 450.49 mbsf (68.56 and $68.27 \mathrm{Ma}$ ) the abundance of this species lies mostly between $\sim 2$ and $4 \%$. In four samples in the middle of this interval, however, elevated abundances of $\underline{E}$. turriseiffeli $(>5 \%)$ were recorded $(452.89$ - $452.3 \mathrm{mbsf} ; \sim 68.42-68.38 \mathrm{Ma} ; \sim 6 \%$ and more). No clear trend is discernible from the abundance fluctuations between 450.49 and $426.9 \mathrm{mbsf}$ (68.27 and $66.77 \mathrm{Ma}$ ). In the uppermost 5.7 meters of the section increased abundance values were recorded in three intervals: 426.7-425.7 mbsf, 423.6-422.8, and immediately below the K/P boundary (421.6 - $421.2 \mathrm{mbsf} ; 66.76-66.70 \mathrm{Ma}, 66.56-66.51 \mathrm{Ma}$, and $\sim 66.44-66.41$ Ma). In the intervening samples abundance values $\sim 2 \%$ were recorded.

Kamptnerius magnificus was very rare in all samples (usually $<0.5 \%$ ) except for higher abundance values (around 1\%) in two samples at 455.19 and 454.99 mbsf ( 68.56 - $68.55 \mathrm{Ma}$; Figure 36e).

Microrhabdulus decoratus constitutes about $5 \%$ of the assemblage in most samples (Figure 37j). In the lower part of the section high abundance values $(>10 \%)$ were recorded at 483.03 and 480.14 mbsf ( 70.32 and $70.14 \mathrm{Ma})$. These high values may be indicative of a genuine increase of $\underline{M}$. decoratus. Two other samples with comparatively high abundance values were recorded: at 454.59 mbsf this species exceed $15 \%$, and at $424.1 \mathrm{mbsf}(\sim 66.60 \mathrm{Ma})$ it reaches almost $10 \%$. These latter values are isolated outliers with background levels $\sim 5 \%$; the reason for their elevated abundance is not well understood; it may be related to preservation (see discussion below).

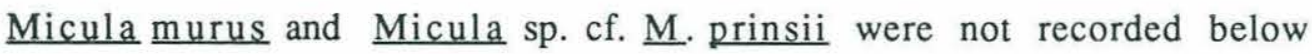
432.4 mbsf (67.12 Ma; Figure 36j); above this level they constitute between $\sim 2$ $8 \%$ of the assemblage. Subtle abundance variations were recorded in the uppermost $5.7 \mathrm{~m}$ of the Maestrichtian where closely spaced samples were 
examined (Figure 36k): relatively high abundance values $(\sim 5-6 \%)$ were recorded between 426.90 and $425.90 \mathrm{mbsf}$, followed by lower abundances ( 3\%) between 425.70 and 424.70 mbsf. Subsequently abundances rise again to $\sim 6-8 \%$ between 424.50 and $423.40 \mathrm{mbsf}$. From there they decrease to $\sim 2 \%$ at the $\mathrm{K} / \mathrm{P}$ boundary.

Parhabdolithus regularis is common in most samples, constituting between about $5-10 \%$ of the assemblages (Figure 37k). Below 463.65 mbsf ( 69.1 Ma) its abundance lies around 5\%, fluctuating only slightly. At 463.65 and at 460.82 mbsf $(\sim 69.1$ - $68.92 \mathrm{Ma})$ it increases in abundance to $\sim 10 \%$ in two samples, but returns to $\sim 5 \%$ at 455.19 mbsf ( $\sim 68.56 \mathrm{Ma})$. Between 455.19 and $426.1 \mathrm{mbsf}$ $(\sim 68.56$ - $66.72 \mathrm{Ma})$ its abundance increases steadily from $\sim 5 \%$ to a maximum values of $>13 \%$. Above this peak abundance values decrease again to $<5 \%$ at the $\mathrm{K} / \mathrm{P}$ boundary. A very similar pattern was recorded for $\underline{\mathrm{P}}$ cretacea (see below).

Placozygus fibuliformis constitutes around $3 \%$ of the assemblage (Figure 371). However, increased values ( $>10 \%$ ) were recorded at some levels in the uppermost Maestrichtian (425.49 and $425.30 \mathrm{mbsf} ; ~ 66.68$ - $66.67 \mathrm{Ma}$ ). Above these maximum values its relative abundance decreases again to values around $3 \%$.

Prediscosphaera cretacea is one of the most abundant taxa, constituting on average $\sim 15 \%$ of the assemblage (Figure 38a). An abundance increase from $<10 \%$ to $\sim 20 \%$ was recorded between 455.19 and 426.9 mbsf $(\sim 68.56-66.77 \mathrm{Ma})$, followed by a decrease to $\sim 12 \%$ between $426.9 \mathrm{mbsf}$ and the K/P boundary.

Relative abundance values of $\underline{\mathrm{P}}$ spinosa never exceed $5 \%$, and lie around $2 \%$ in most samples (Figure 38b). Between 455.19 and 450.49 mbsf ( 68.56 - 68.27 $\mathrm{Ma}$ ) an abundance increase from $\sim 1 \%$ to $\sim 2 \%$ was recorded.

Watznaueria barnesae is one of the most abundant taxa with relative abundance values between $\sim 10-30 \%$ throughout most of the Maestrichtian (Figure 38c). In the lowest samples (492.32 - 480.14 mbsf; $70.91-70.14 \mathrm{Ma}$ ) the relative abundance was conspicuously lower $(\sim 10 \%)$ than above where the abundance fluctuates around $20 \%$. Very high percentages of this species ( $>25$ to almost $30 \%$ ) were recorded in several samples (at 454.30, 453.99, 453.90, $452.30,424.10$, and $423.80 \mathrm{mbsf}$ ). As $\underline{\mathrm{W}}$. barnesae is a very dissolution resistant taxon (Roth and Bowdler, 1981; Thierstein, 1980), these high values could be due to increased dissolution rather than reflect a primary signal (see discussion below). 

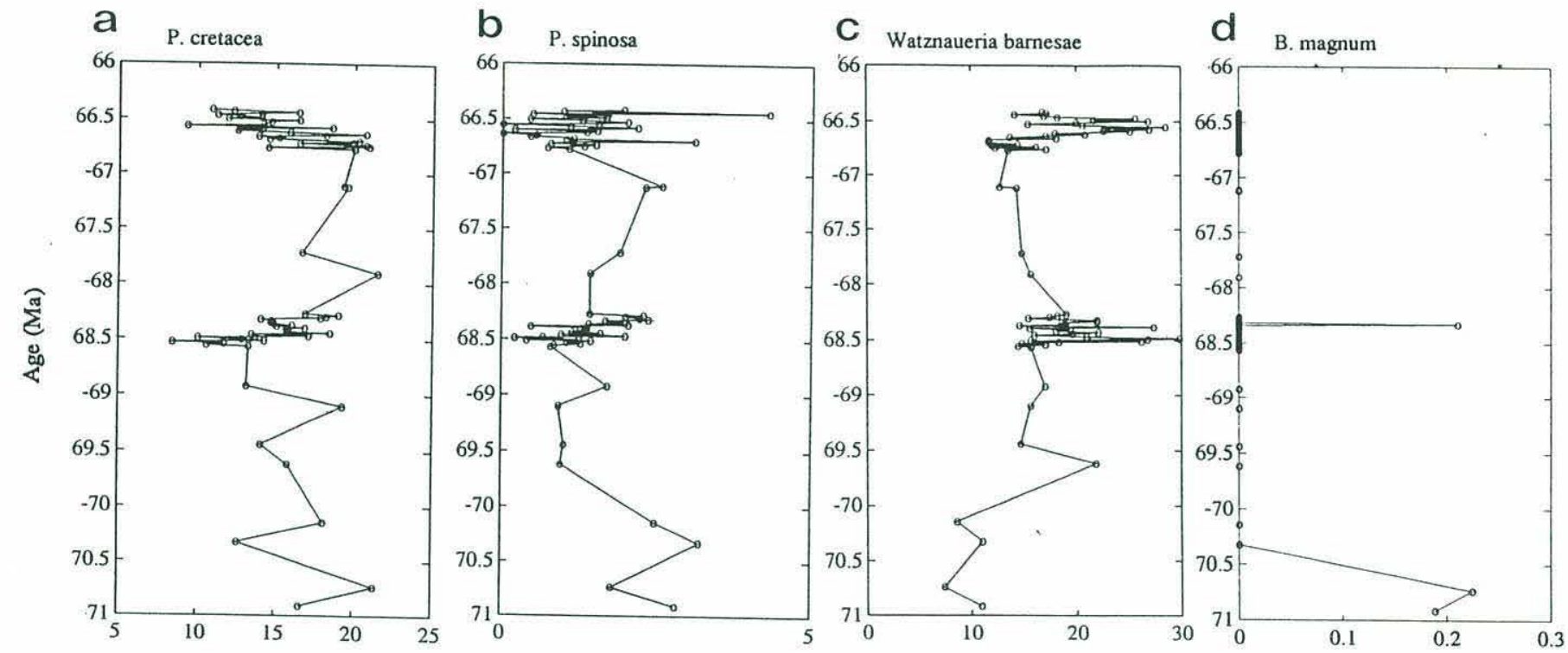

Figure 38: Relative abundance changes (\%) of selected taxa during the late Maestrichtian in Hole 217. (All calculations exclusive of $\underline{M}$. staurophora). 
Biscutum magnum, a species very common in the lower Maestrichtian in high latitudes was observed in three samples in very low abundance (492.32, 489.51, and 451.49 mbsf; 70.92, 70.73, and $\sim 68.33$ Ma; Figure 38d).

\section{B) Assessment of Preservation}

Several dissolution resistant taxa were compared, and only a trend that is apparent in all these taxa should be considered indicative of dissolution. Micula staurophora, $\underline{W}$. barnesae, Arkhangelskiella spp. and Broinsonia spp. were selected as representatives of the dissolution resistant taxa (following Thierstein, 1980). Combined in the group of dissolution susceptible taxa were $\underline{C}$.

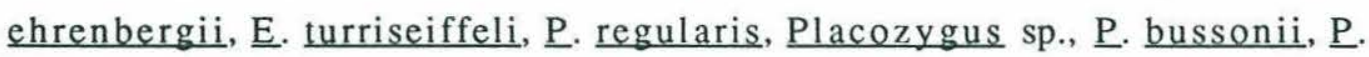
sigmoides, $\underline{P}$. spinosa, and Vagalapilla spp. (following Thierstein, 1980).

No evidence indicative of increased dissolution was observed in the intervals of increased sample spacing (Figure 39). Especially the decrease in species richness between about 68.5 and $66.8 \mathrm{Ma}$ cannot be explained as a consequence of increasing dissolution (compare e.g. the record of the dissolution susceptible taxa, which increase during the same interval: Figure $39 \mathrm{~g}$ ). Unusually high or low values of selected taxa (or groups of taxa) occurred in single samples, but lack of corresponding excursions in other taxa indicated that preservation could not be the explanation in these cases.

Graphs of the interval between $\sim 66.80-66.40$ Ma are presented in Figure 40. The species richness increased from values around 30 taxa per sample during the earlier part of this interval to values around 40 during the last 150 ky of the Maestrichtian (Figure 40a). Similarly, increased abundances during the later part of this interval were observed in the distribution of the absolute as well as the relative abundances of $\underline{M}$. staurophora (Figure 40c, d), and also in the relative abundances of $\underline{\mathrm{W}}$. barnesae (Figure 40e). In contrast, this pattern was not present in the plot of Arkhangelskiella spp. and Broinsonia spp.: these two genera remained at comparatively low abundances throughout most of the latest Maestrichtian and increased in abundance only at about 66.47 Ma (Figure 40f). Virtually no changes between the earlier and the later part of this interval exist in the absolute abundance of calcareous nannofossils

(Figure $40 \mathrm{~b}$ ) as well as in the dissolution susceptible taxa (Figure $40 \mathrm{~g}$ ). Because of the discrepancies between the abundance patterns of different dissolution 

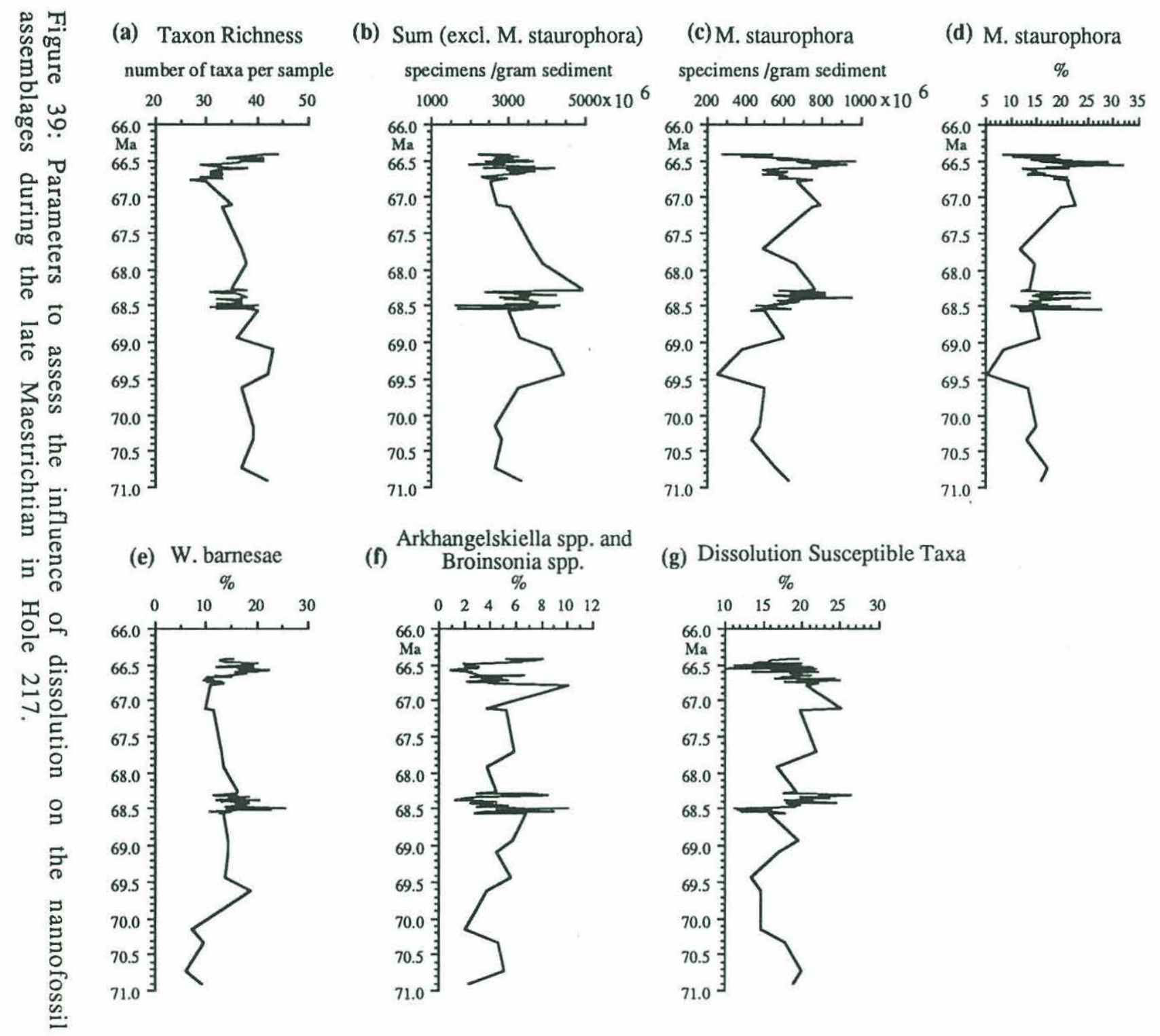

Arkhangelskiella spp. and

(f) Broinsonia spp.

(g) Dissolution Susceptible Taxa

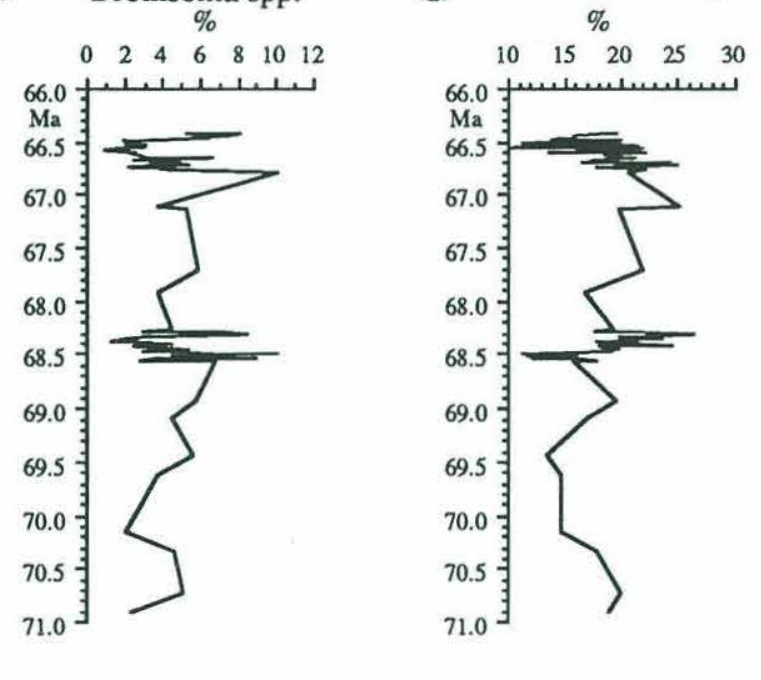




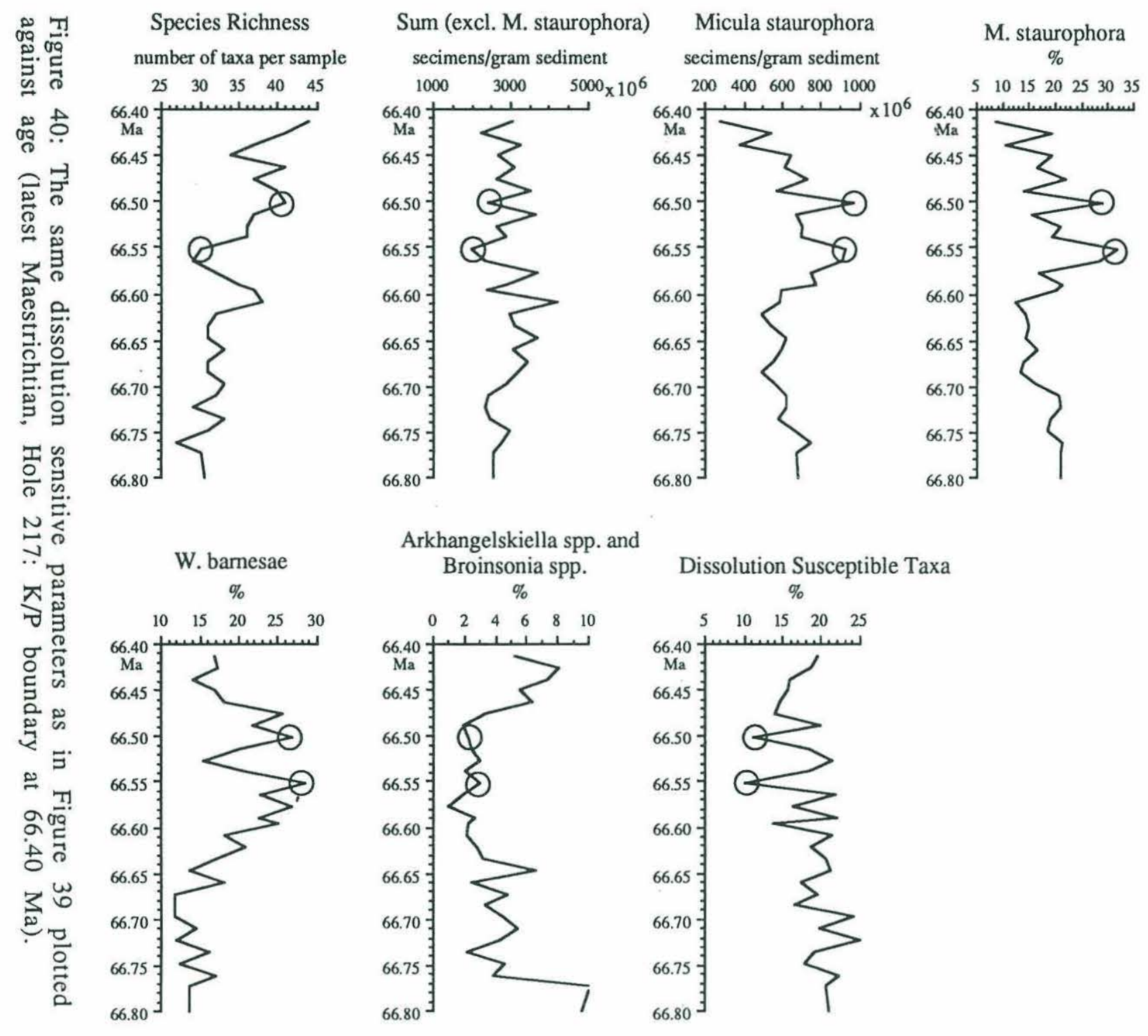


sensitive taxa, dissolution cannot be invoked as an explanation of the observed variations. Therefore the trends during the latest Maestrichtian are considered to be a genuine record of abundance fluctuations in the nannofossil assemblages.

However, in two instances in the uppermost Maestrichtian interval, exceptionally low abundances of dissolution susceptible taxa (Figure 40g) correspond to minimum values of absolute abundances of calcareous nannofossils (Figure 40b) and to peak values of dissolution resistant taxa (Figures 40d, e). The nannofossil distribution in these samples (marked with black circles in Figure 40) was apparently modified by above average dissolution. If this interpretation is correct, it would imply that 1) Arkhangelskiella and Broinsonia are not as dissolution resistant as previously assumed by Thierstein, 1980; and 2) it would indicate that dissolution was not sufficiently severe to eliminate certain taxa, since the species richness in these two samples appears not significantly different from the next higher and lower samples.

The other interval that was investigated at high resolution in Hole 217 was between about 68.6 and $68.2 \mathrm{Ma}$. Long term trends were only discernible in the absolute abundances of $\underline{M}$. staurophora, which increase steadily during this interval, and an almost stepwise increase of the dissolution susceptible taxa from lower values between $10-15 \%$ prior to about $68.47 \mathrm{Ma}$ to increased values (around 20\%) thereafter. Due to lack of correlation with the other dissolution indicators neither of these trends is interpreted as a manifestation of changing preservation. Instead three samples were identified in this interval where the coincidence of unusually high or low values in several of the dissolution indicators suggests that increased dissolution has modified the nannofossil assemblages. These samples are marked with black circles. In none of these samples do all the dissolution indicators agree and it appears that in two of these samples the number of species was reduced.

Except for a few isolated samples where increased dissolution had altered the nannofossil assemblages, the abundance distributions of the calcareous nannofossil taxa seem to reflect genuine abundance changes 


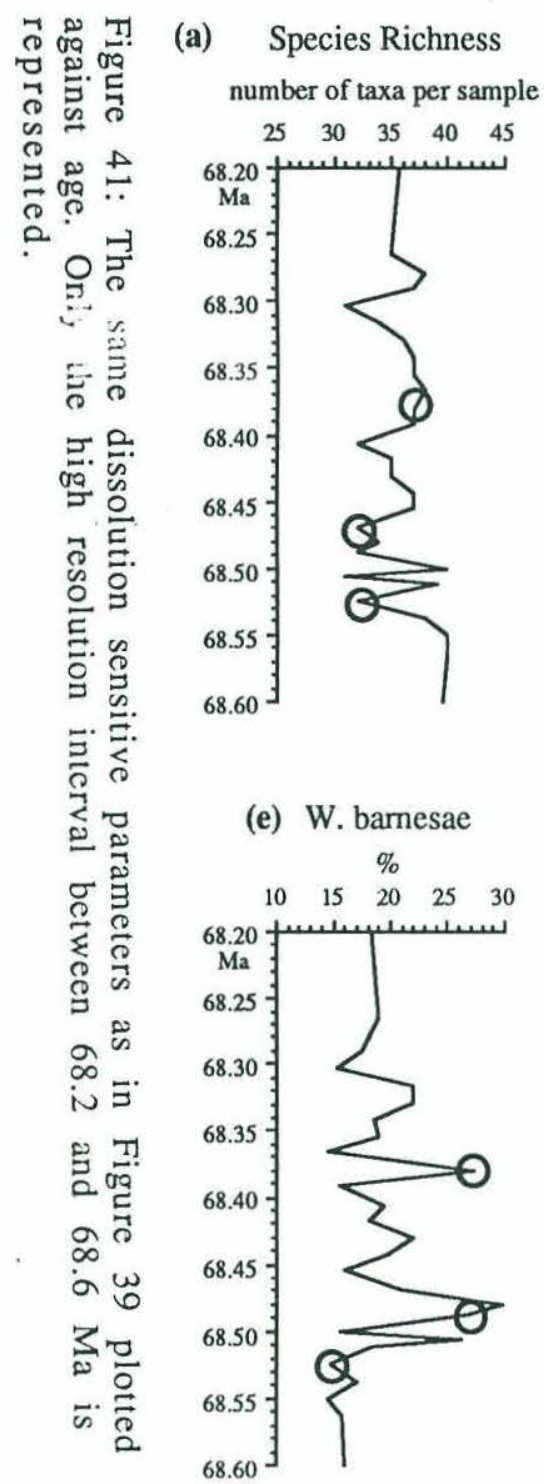

(b) Sum (excl. M. staurophora)

(c) Micula staurophora

(d) M. staurophora

specimens/gram sediment

specimens/gram sediment
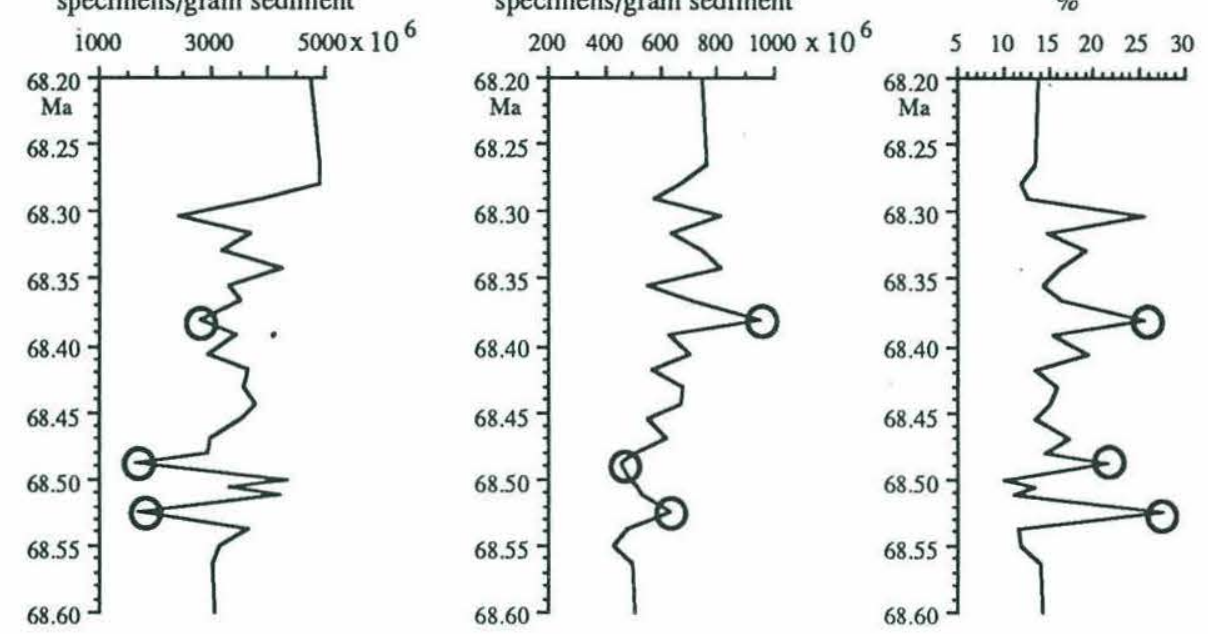

(f) Arkhangelskiella spp. and

Broinsonia spp.

(g) Dissolution Susceptible Taxa

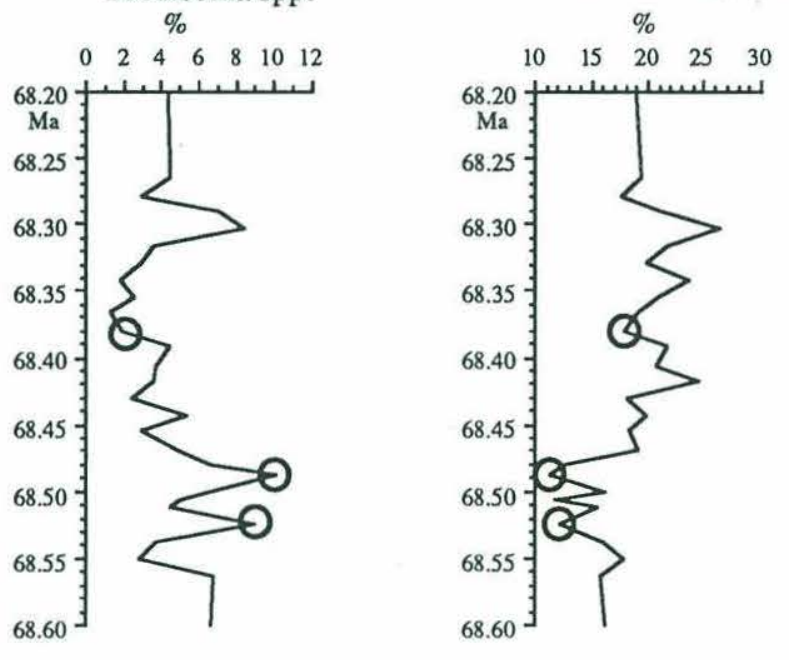




\section{4) DSDP Hole $\mathbf{5 2 8}$}

In DSDP Hole 528 a section $15.33 \mathrm{~m}$ thick, representing the last $800 \mathrm{ky}$ (from about 67.2 to $66.4 \mathrm{Ma}$ ) of the Cretaceous was examined (Sections 528-32-1 to $528-33-4 ; 407.0-422.5 \mathrm{mbsf}$ ). The sediment is conspicuously coloured red and white, the thickness of each color band varies between about 20 and $50 \mathrm{~cm}$ (Shipboard Scientific Party, 1984: p. 390; see also Figure 42a).

Two unrelated questions were addressed in this study: 1) Are there differences in the calcareous nannofossil assemblages between different colored sediment layers? 2) Which abundance trends are discernible in calcareous nannofossil taxa during the last $800 \mathrm{ky}$ of the Maestrichtian at this site?

\section{1a) Differences Between Red and White Sediment}

In the light sediment the carbonate content typically is $>70 \%$ (and up to $90 \%$ ) whereas in the dark red layers it is typically less than $60 \%$ (and may be as low as <50\%; data from Shackleton et al., 1984, and from D'Hondt, unpublished data; Figure 42c). Herbert and D'Hondt (1991) suggested that the alternation of the sediment colors was an expression of precessional cyclicity in the latest Cretaceous. One of the goals of this study was to examine whether differences in nannofossil assemblages exist between the different colored sediment and whether they could be explained as consequences of the precessional cyclicity. Since carbonate dissolution on the seafloor can change nannofossil assemblages considerably due to the preferrential removal of fragile, dissolution susceptible forms and enrichment of more robust, dissolution resistant forms it has to be established first whether dissolution of calcareous nannofossils occurred and may have overprinted original abundance variations. Several samples were taken from each color-band throughout Section 528-32-1 corresponding to sample spacing of about $5 \mathrm{~cm}$ (or about $3 \mathrm{ky}$ ).

Dissolution experiments performed on Cretaceous calcareous nannofossils by Thierstein (1980) allowed him to rank the taxa according to their dissolution resistance. Micula staurophora is by far the most dissolution resistant species in this list. It is also the most abundant taxon encountered in Hole 528 and its relative abundance was recorded with respect to all other taxa. The results from Section 528-32-1 are plotted in Figure 42e. Two intervals of 

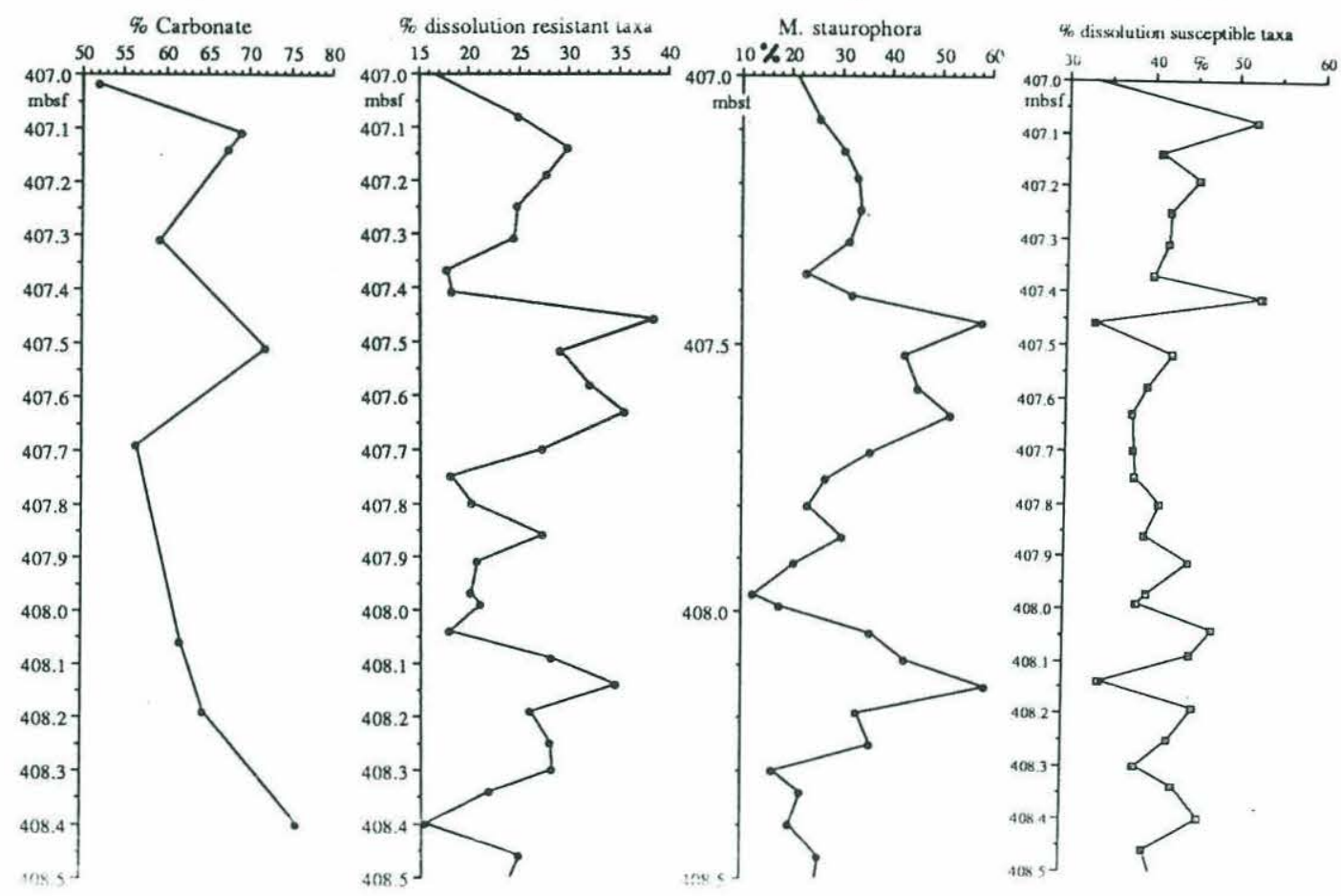

Figure 42: Sediment colors, carbonate contents, and nannofossil dissolution indicators in Section 528-32-1. The position of the Cretaceous/Paleocene (K/P) boundary lies at the very top of this section.

a) Schematic representation of sediment colors: darker shades of grey indicate deeper red sediment colors, ligher shades of grey indicate light-red, light brown or whitish-grey sediment colors. Drawing is based on colors of samples used in this study and on photograph in Shipboard Scientific Party (1984, p. 390). Scale on left hand side indicates $\mathrm{cm}$ level in this section.

b) Age estimates based on age model discussed in chapter "Chronology".

c) Carbonate data from Shackleton et al. (1984) and from D'Hondt (unpublished data).

d) Percentage of dissolution resistant taxa in Section 528-32-1.

e) Abundance of $\mathrm{M}$. staurophora (\%) relative to all other calcareous nannofossil taxa counted in this section. This dissolution resistant species is enriched in samples where other taxa were diagenetically removed.

f) Percentage of dissolution susceptible taxa (for further discussion see text). 
maximum enrichment ( $>50 \%$ of all nannofossils counted) of $\underline{M}$. staurophora are discernible: the first one peaks at about $408.15 \mathrm{mbsf}$, almost exactly coinciding with a dark red layer (Figure 42a). The other interval is really a double peak, one peak at 407.65 mbsf almost coinciding with the second dark red sediment layer in this section, the other one occurred at 407.45 mbsf in fairly light colored sediment. This later peak could be interpreted as an outlier among generally decreasing values of $\underline{\mathrm{M}}$. staurophora (possibly a consequence of the strong bioturbation of the sediment). A comparatively minor increase of the relative abundances of $\underline{M}$. staurophora (from about $20 \%$ to $>30 \%$ ) coincides with the uppermost red layer at about 407.25 mbsf. Due to the imperfect correlation of the abundance peaks of $\underline{M}$. staurophora with the red sediment layers abundance variations of other solution resistant and susceptible taxa were examined.

The inclusion of taxa in the dissolution resistant group was based on results of Thierstein (1980), but slightly modified: All dissolution resistant taxa of Thierstein (1980) were included as far as they were present in the material investigated, except for the persistent and the incoming taxa because they show a genuine (i.e. independent of preservation) abundance increase in the earliest Paleocene (beginning in some forms in the latest Maestrichtian). In addition, Ceratolithoides kamptneri was included, since it is closely related and morphologically similar to Tetralithus aculeus. The following taxa were included among the dissolution resistant forms:

Arkhangelskiella spp. and Broinsonia spp.

Ceratolithoides kamptneri

Cylindralithus spp. (mostly $\underline{\text { C. gallicus) }}$

Kamptnerius magnificus

Lucianorhabdus cayeuxii

Micula spp. (except $\underline{M}$. staurophora)

Watznaueria barnesae

The relative abundances of these taxa were calculated exclusive of $\underline{M}$. staurophora, so that this abundant species did not influence (dampen) their percantages and the sum of their abundances were plotted against depth (Figure 42d). The same peaks are discernible as in $\underline{M}$. staurophora, and again the abundance peaks of the solution resistant taxa are not restricted to the red sediment layers. It is noteworthy in this context that the individual abundance fluctuations of the taxa included in the dissolution resistant group (Figure 43) 


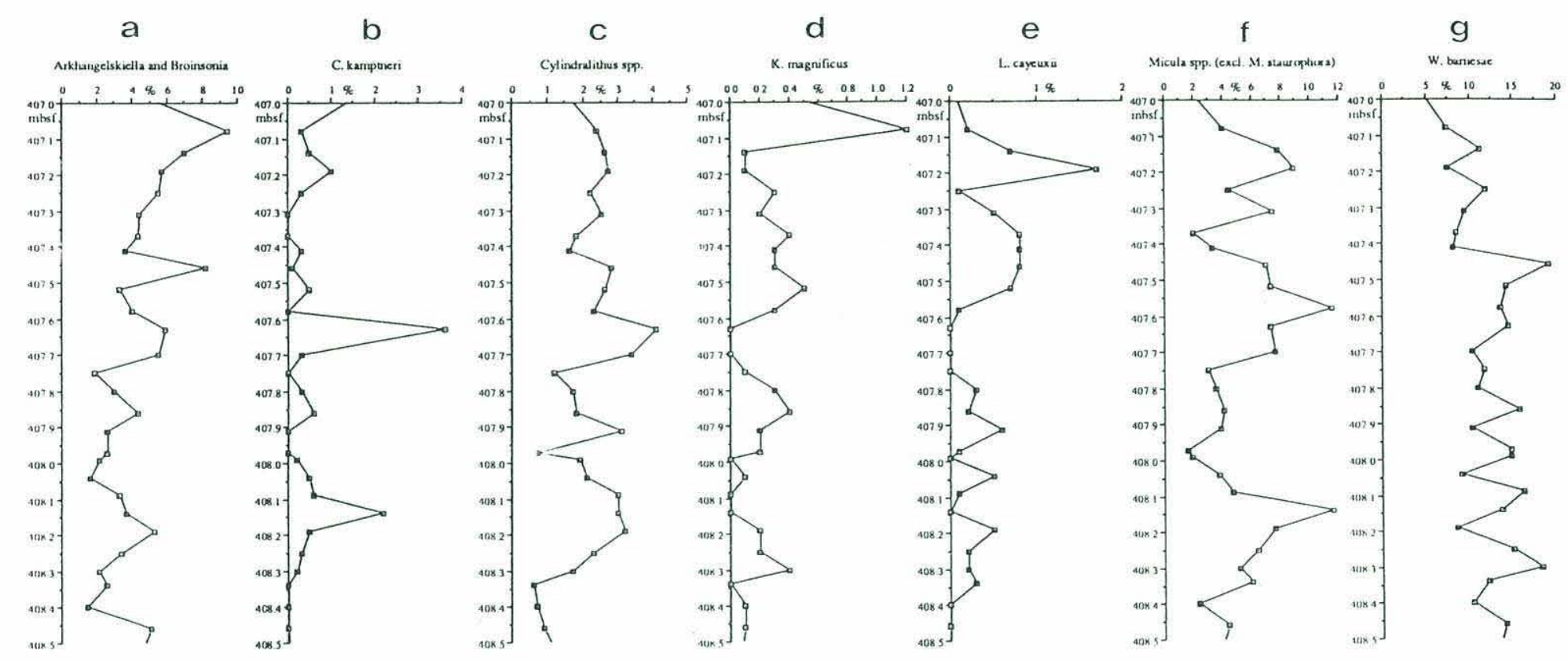

Figure 43: Individual plots of those taxa included in the dissolution resistant group. 
do not all show the same peaks as their combined graph (except Micula spp., Figure 43f). This indicates that each taxon singly cannot be used as a preservational indicator, but when they are all combined their individual fluctuations (i.e species-specific variations) are cancelled out and their common traits (i.e. dissolution resistance) become enhanced.

Particularly dissolution susceptible taxa were identified following Thierstein's (1980) dissolution ranking. Again, persistent taxa (Biscutum spp., Placozygus spp.) were omitted from the dissolution susceptible group which included:

Ahmuellerella ectoradiata and Parhabdolithus regularis

Cribrosphaerella ehrenbergii

Discorhabdus ignotus

Eiffellithus turriseiffeli

Microrhabdulus decoratus

Nephrolithus frequens

Prediscosphaera creatcea

P. spinosa

Vagalpilla spp.

The abundance variations of the dissolution susceptible taxa were plotted in Figure 42f. Hardly any differences between the light and the red sediment layers are noticeable, but two minimum values of the dissolution susceptible group coincide with peak abundances of the dissolution resistant taxa (at about 407.45 and 408.15 mbsf). Apparently dissolution susceptible taxa are not very sensitive preservation indicators but only respond with anomalously low abundances in very strongly dissolved samples.

Abundance variations of the most solution resistant nannofossil taxa indicate that dissolution did affect the nannofossil assemblages. This is corroborated in at least two samples by an abundance decrease of solution susceptible taxa. The poor correlation of the abundance peaks of the solution resistant taxa with the sediment colors may either be due to problems of bioturbation, or may indicate that increased dissolution did also occur during the deposition of the white sediment layers and was not restricted to the red ones. In this case the increased clay content in the red sediment layers cannot be interpreted as residual enrichment due to the dissolution of carbonate but as a consequence of increased clay influx (due to increased wind strength?). 


\section{1b) Nannofossil Fluctuations During the Last $75 \mathrm{ky}$ of the}

\section{Maestrichtian}

The high sample resolution during the last $7.5 \mathrm{~m}$ of the Maestrichtian (one sample every $\sim 5 \mathrm{~cm}$, corresponding to a temporal resolution of about $3 \mathrm{ky}$ ) allowed the identification of very short term fluctuations in some taxa which seemed to be independant of preservational overprint. Relative abundance fluctuations are discussed in the following chapter. Some taxa show peculiar abundance variations throughout Section 528-32-1 (about 66.40 to $66.48 \mathrm{Ma}$ ). Placozygus fibuliformis decreased in abundance during the last $80 \mathrm{ky}$ of the Maestrichtian (Figure 44a). Superimposed on this general trend are shorter fluctuations which do not coincide with the color bands (i.e. preservation). The fact that most of the peaks and troughs are defined by multiple data points and the observation that these fluctuations occur independent of preservational cycles suggest that these abundance variations are genuine. These fluctuations are particularly well developed between about 66.47 and 66.42 $\mathrm{Ma}$ and appear to be cyclical with a period of about 11-14 ky. This is about half of the precessional wavelength and thus may be a response to orbital forcing (D'Hondt, oral communication). This is particularly interesting since this species showed pronounced abundance variations during the latest Maestrichtian in ODP Hole 690C apparently as a response to changing water temperatures $\left(\delta^{18} \mathrm{O}\right)$ or changing nutrient levels $\left(\delta^{13} \mathrm{C}\right)$.

Prediscosphaera stoveri constituted about $5-10 \%$ of the nannofossil assemblage during the last $75 \mathrm{ky}$ of the Maestrichtian (Figure 44b). Like $\underline{\mathrm{P}}$. fibuliformis this species shows short term, cyclical abundance fluctuations with period of $\sim 10 \mathrm{ky}$. The values fluctuate over $\sim 5 \%$, which is much more than in $\underline{P}$. fibuliformis, but they are less regularly spaced. Also the abundance fluctuations of $\underline{D}$. ignotus (Figure 44c) resemble those of $\underline{P}$. fibuliformis between about 66.46 and $66.40 \mathrm{Ma}$ and may contain a cyclical signal of slightly less than $10 \mathrm{ky}$. Since $\underline{\mathrm{D}}$. $\underline{\text { ignotus }}$ was quite rare throughout this interval (mostly $<1.5 \%$ ) it is difficult to assess the reliability of these abundance variations.

Increases in relative abundances during the last $\sim 75 \mathrm{ky}$ of the Maestrichtian were observed in Arkhangelskiella spp. and Broinsonia spp., $\underline{C}$.

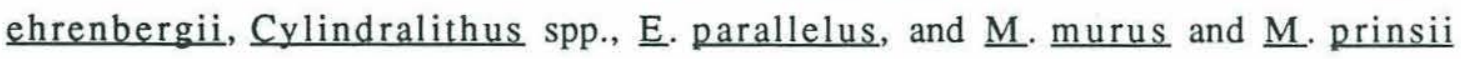



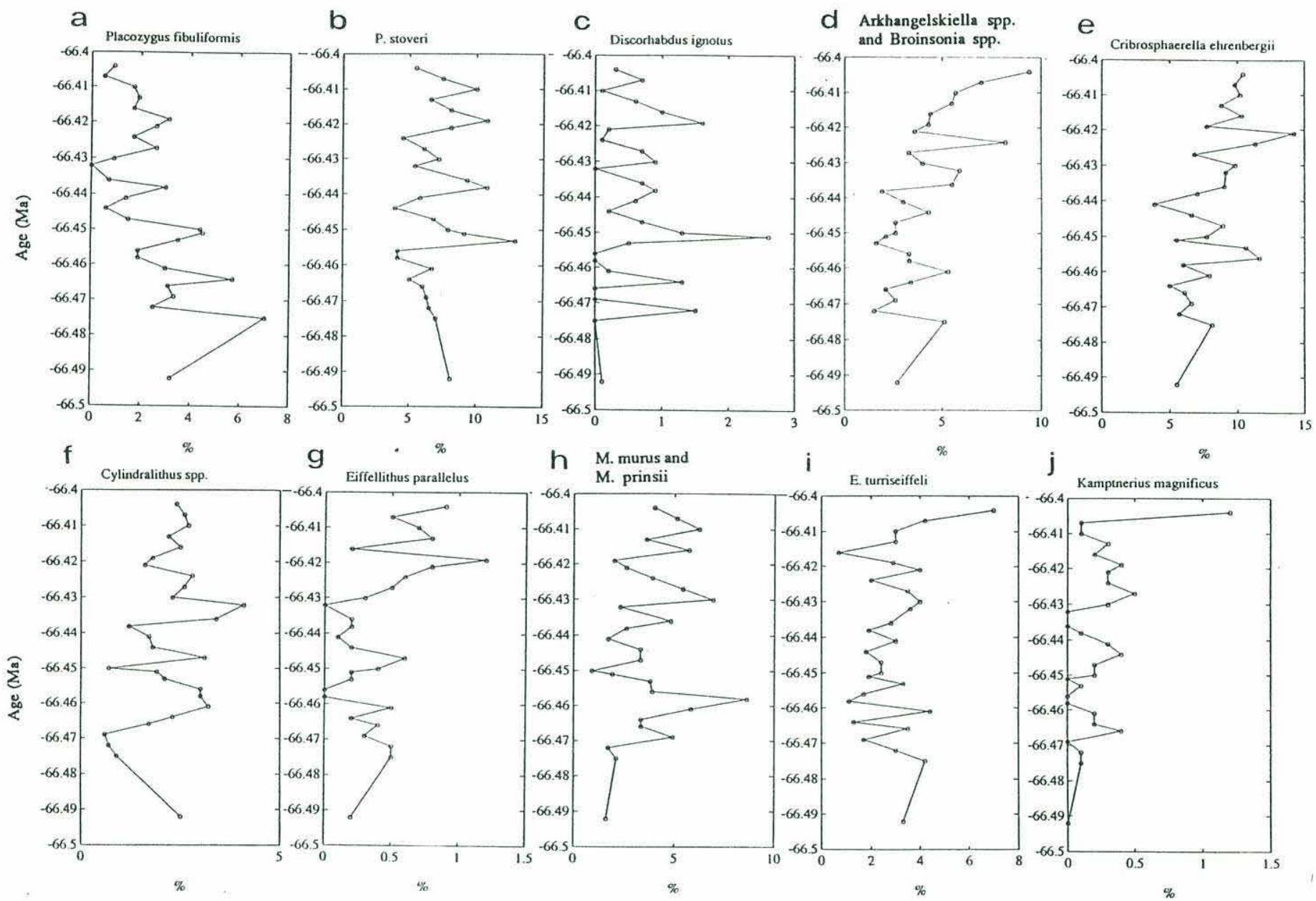

Figure 44: Fluctuations of relative abundances (\%) of calcareous nannofossil taxa during the last $100 \mathrm{ky}$ of the Maestrichtian in Hole 528. The Cretaceous/Paleocene boundary was drawn at $66.4 \mathrm{Ma}$ (after Berggren et al., 1985). 
(Figure 44d-h). Superimposed on the general abundance increase of Eiffellithus parallelus (Figure $44 \mathrm{~g}$ ) are short term variations that varied opposite to the abundance fluctuations of $\underline{M}$. staurophora and of the dissolution resistant taxa which indicates that this species should be considered a dissolution susceptible taxon. The fact that it was not included in the dissolution susceptible group discussed above did not change the results since this species was very rare $(<1 \%)$ in Section $528-32-1$. Thus the abundance increases cannot be explained as preservational artifacts since dissolution susceptible (‥ ehrenbergii, E. parallelus) as well as dissolution resistant (Arkhangelskiella and Broinsonia, $\underline{\text { Cylindralithus, }} \underline{\mathrm{M}}$. $\underline{\text { murus }}$ and $\underline{\mathrm{M}}$. prinsii) taxa show similar patterns. Furthermore, not all dissolution resistant taxa increase in abundance during this time interval.

Eiffellithus turriseiffeli, $\underline{\text { K. magnificus }}$ and $\underline{\text { N. frequens }}$ (Figure $44 i-j$, 45a) displayed rather constant relative abundances during most of the last 100 ky of the Maestrichtian but all three species had increased abundance values immediately preceding the $\mathrm{K} / \mathrm{P}$ boundary. Nephrolithus frequens has another peak of similar magnitude about $20 \mathrm{ky}$ earlier. This common trend cannot be explained as dissolution artifact since $\underline{E}$. turriseiffeli and $\underline{N}$. frequens are more dissolution prone, whereas $\underline{\mathrm{K}}$. $\underline{\mathrm{magnificus}}$ is rather dissolution resistant (based on Thierstein, 1980).

Generally decreasing relative abundances throughout the last $\sim 75 \mathrm{ky}$ of the Maestrichtian were observed in $\underline{A}$. ectoradiata and $\underline{P}$. regularis,

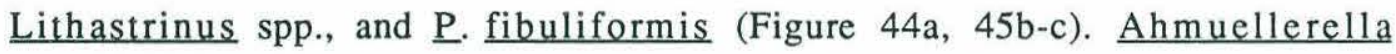
octoradiata and $\underline{\mathrm{P}}$ reglaris show generally lower values in samples where the solution resistant taxa were enriched, indicating that these forms are susceptible to dissolution. This observation supports Thierstein's (1980) ranking. Lithastrinus spp. is comparatively rare $(<2 \%)$; its highest values were recorded in the same sample where $\underline{M}$. staurophora had one of its abundance peaks (at about $66.46 \mathrm{Ma}$ ) which is interpreted here that Lithastrinus spp. are somewhat resistant to dissolution.

Cretarhabdus spp., Cyclagelosphaera spp., G. fessus, and $\underline{T}$. decorus all display increased abundances between about 66.45 and $6.43 \mathrm{Ma}$ (Figure 45d-g). This time interval corresponds roughly to the interval of decreased abundances of the dissolution resistant taxa (particularly with low abundances 

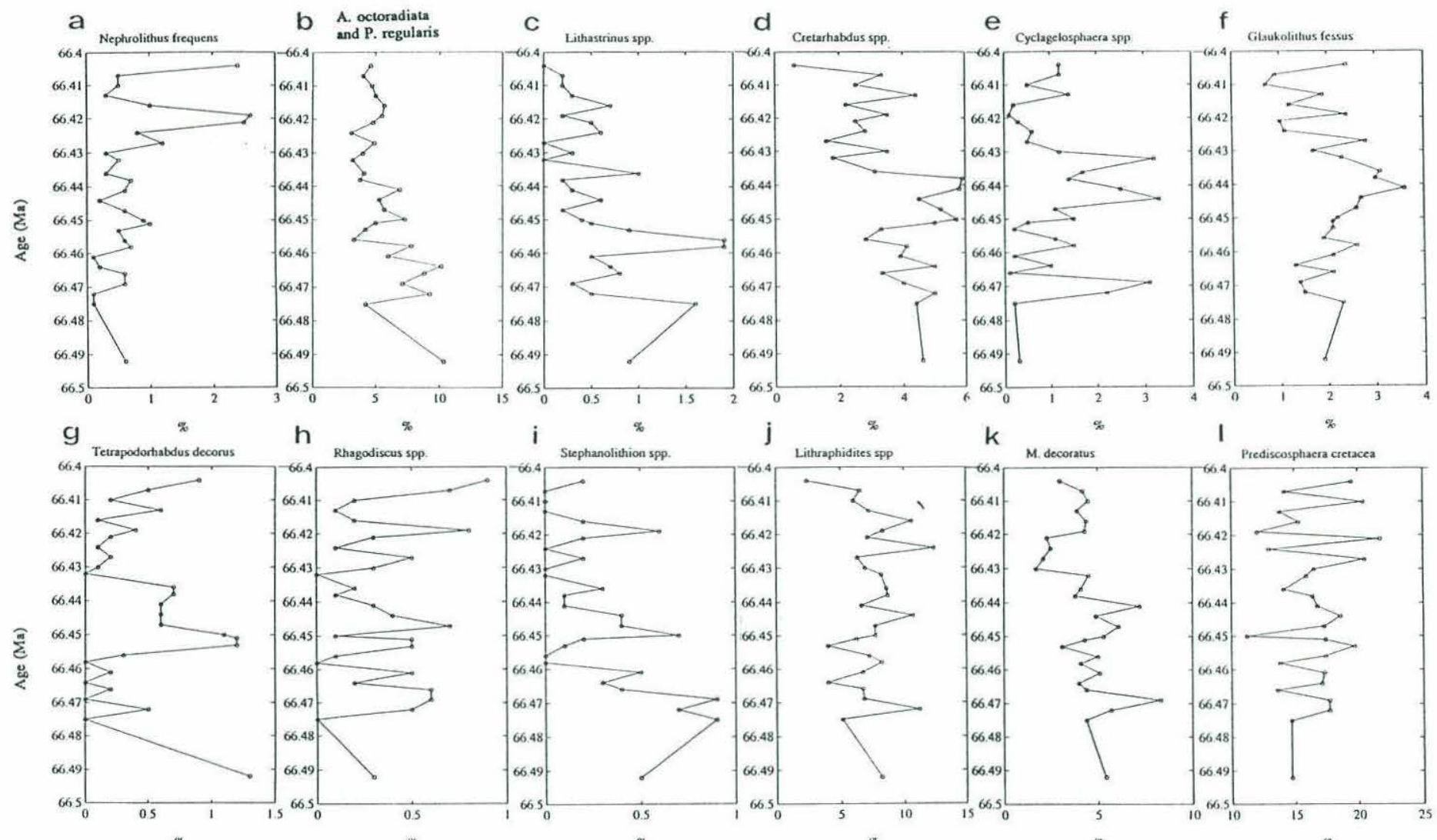

Figure 45: Fluctuations of relative abundances (\%) of calcareous nannofossil taxa during the last $100 \mathrm{ky}$ of the Maestrichtian in Hole 528. The

Cretaceous/Paleocene boundary was drawn at $66.4 \mathrm{Ma}$ (after Berggren et al., 1985). 
of $\underline{M}$. staurophora). This would indicate that these four taxa became relatively more abundant in comparatively well preserved sediment and that they should be considered as dissolution susceptible.

Rhagodiscus spp. and Stephanolithion spp. are very rare during the last $100 \mathrm{ky}$ of the Maestrichtian ( $<1 \%$, Figure $46 \mathrm{~h}-\mathrm{i})$ but both taxa seem to be rather dissolution susceptible as they displayed especially low abundances (or were absent) in the samples from the red sediment layers.

Some of the most abundant taxa in Hole 528 did not show any conspicuous abundance trends during the last $\sim 75 \mathrm{ky}$ of the Maestrichtian. They include Lithraphidites spp., $\underline{\mathrm{M}}$. $\underline{\text { decoratus, }} \underline{\mathrm{P}}$. cretacea, $\underline{\mathrm{P}}$. $\underline{\text { spinosa, }}$, and $\underline{\mathrm{W}}$. barnesae (Figure 46j-1, 47a-b). Microrhabdulus decoratus remained virtually constant with the exception of slightly lower values in the red sediment layers, which agrees with the dissolution ranking of this taxon as comparatively dissolution susceptible by Thierstein (1980). Prediscosphaera $\underline{\text { cretacea }} \underline{\mathrm{P}}$. spinosa, and $\underline{\mathrm{W}}$. barnesae displayed comparatively strong variability between adjacent samples which cannot be explained by different preservation. Except Lithraphidites spp. and $\underline{\mathrm{W}}$. barnesae all taxa mentioned above were included in the dissolution susceptible group discussed above. Their comparatively low variability between red and white layers is apparently the reason for the fact that the dissolution susceptible group do not vary significantly between the red and the white layers. This is in contrast to the dissolution resistant group where the combination of several taxa enhances the weak preservational signals contained in each individual taxon.

\section{2) Nannofossil Variations Between 67.2 and $66.2 \mathrm{Ma}$}

Below Section 528-32-1 samples were taken from the white intervals only since dissolution was less severe and nannofossil preservation accordingly better than in the red layers. The results described below are primarily fluctuations of relative abundances; absolute abundances were included for selected taxa when they showed abundance changes more conspicuously. Four samples were examined from the Core Catcher and from Section 7 of Core 528-31 because it was unclear whether the exact location of the $\mathrm{K} / \mathrm{P}$ boundary was in 528-31-CC or whether it was between Cores 528-31 and 528-32. Ultimately the K/P boundary was placed between Cores 528-31 and 528- 


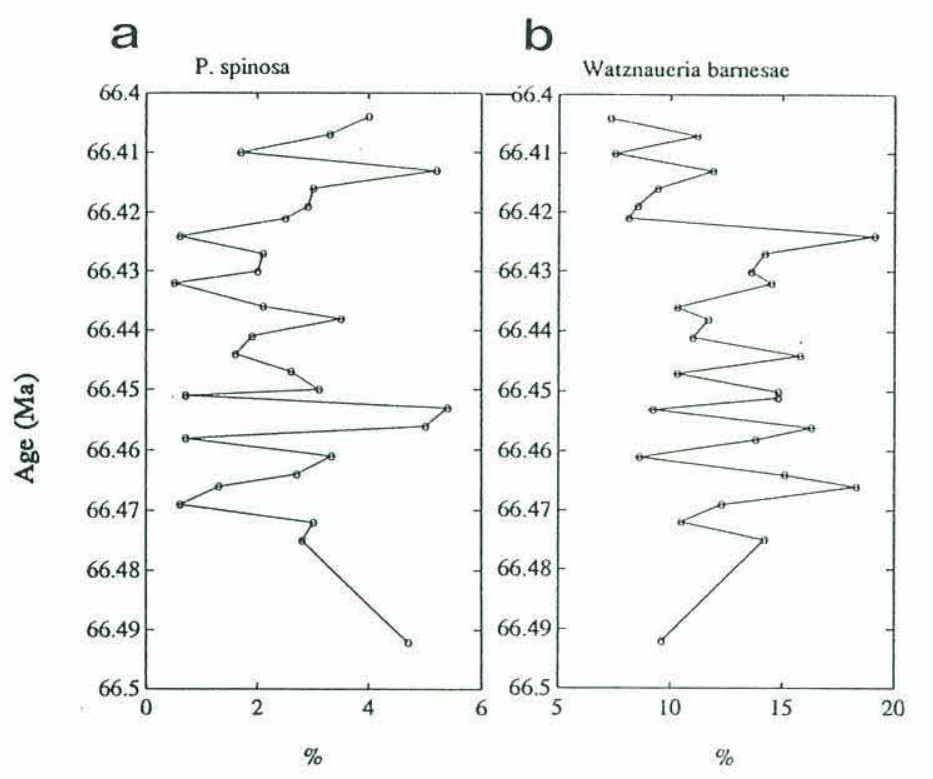

Figure 46: Fluctuations of relative abundances (\%) of calcareous nannofossil taxa during the last $100 \mathrm{ky}$ of the Maestrichtian in Hole 528. The

Cretaceous/Paleocene boundary was drawn at $66.4 \mathrm{Ma}$ (after Berggren et al., 1985). 

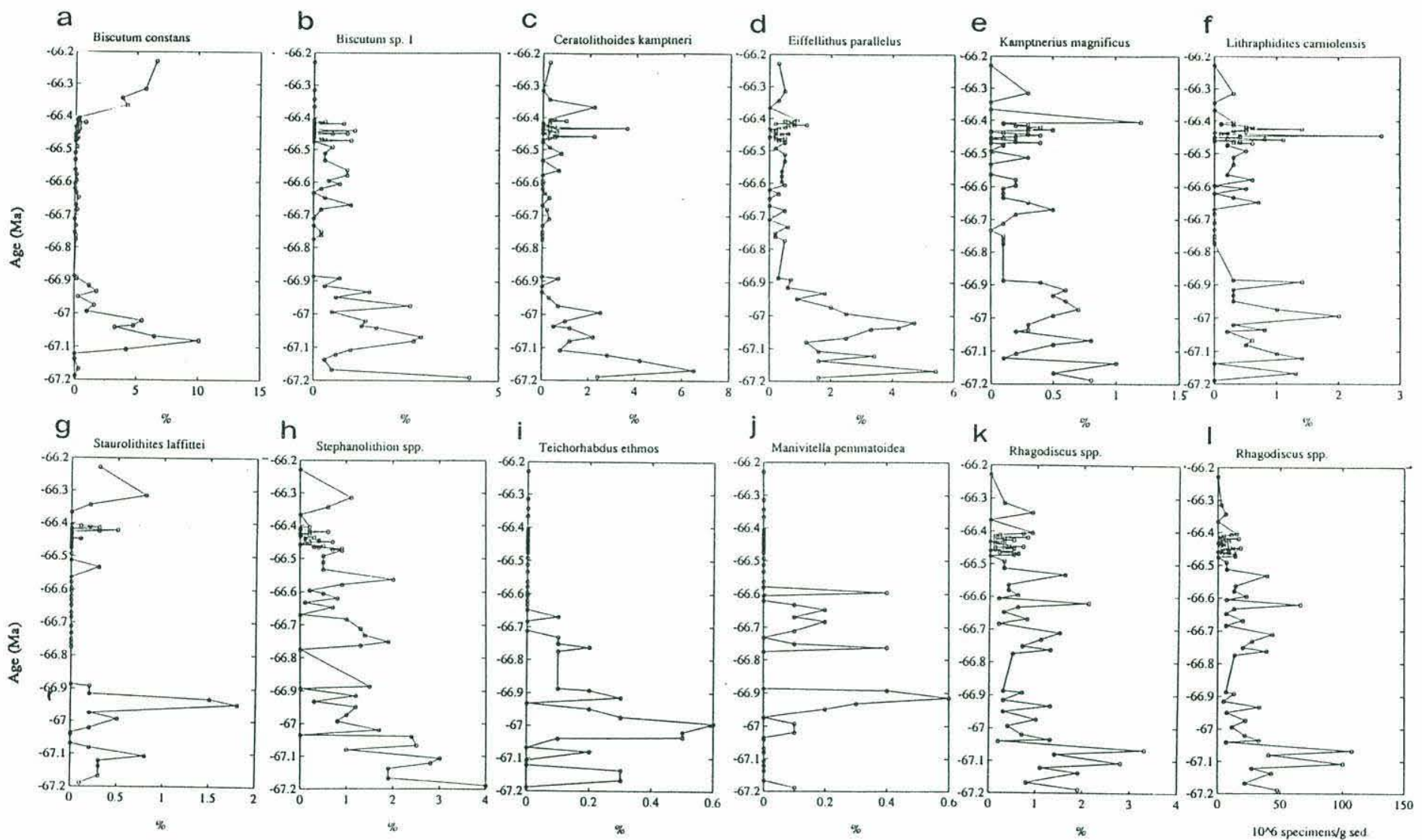

Figure 47: Fluctuations of relative abundances (\%) of calcareous nannofossil taxa during the last $100 \mathrm{ky}$ of the Maestrichtian. The Cretaceous/Paleocene boundary was drawn at $66.4 \mathrm{Ma}$ (after Berggren et al., 1984). 
32, resulting in a Paleocene age for four of the samples investigated (between 66.4 and $66.2 \mathrm{Ma})$.

The assemblage at this mid latitude site is more diverse than it was at high latitude Site 690C. On average 40 taxa per sample were encountered. This is more than in the latest Maestrichtian in Hole $690 \mathrm{C}$ where the number of taxa encountered per sample was only about 20 .

Several taxa displayed higher abundance between about 67.2 and 66.9 Ma. Biscutum constans (Figure 47a) was very rare prior to $\sim 67.1 \mathrm{Ma}$, then it increased very abruptly and reached peak abundances of $>10 \%$ at $67.1 \mathrm{Ma}$; subsequently the abundance of this species decreased again to very low values $(<1 \%)$ at about 66.9 Ma. During the remainder of the Maestrichtian $\underline{B}$. constans was rare but its abundance increased again in the early Danian (66.4 to 66.2 Ma). Very similar is the abundance distribution of Biscutum sp. 1 (Figure 47b).

The abundance distribution of $\underline{C}$. kamptneri resembles that of $\underline{B}$. constans (Figure 47c) as it constituted up to $>6 \%$ of the assemblage between $\sim 67.2$ and $67.1 \mathrm{Ma}$, decreased to very low values $(<1 \%)$ at about $66.9 \mathrm{Ma}$ and stayed very low for the remainder of the Maestrichtian. Eiffellithus parallelus displayed the same abundance variations (Figure 48d): between about 67.2 and 66.9 $\mathrm{Ma}$ its abundance was highest (up to $>4 \%$ ); it had decreased to values $<1 \%$ by $66.9 \mathrm{Ma}$ and remained at these low abundances for the remainder of the Maestrichtian. Kamptnerius magnificus was always rare $(<1.5 \%$, Figure $47 \mathrm{e})$ but its abundances were slightly higher prior to $66.9 \mathrm{Ma}$ than thereafter. The abundance pattern of $\underline{\mathrm{L}}$. $\underline{\text { carniolensis }}$ was similar to that of $\underline{\mathrm{K}}$. magnificus with higher abundance prior to $\sim 66.9 \mathrm{Ma}$ (Figure 47f). Staurolithites laffittei was a comparatively rare component (always $<2 \%$, Figure $47 \mathrm{~g}$ ), but it was recorded in almost all samples prior to $66.9 \mathrm{Ma}$. After that its abundance became so rare that it was encountered only sporadically in the counts. Stephanolithion spp. decreased in abundance from $>2 \%$ prior to about 67 Ma to values between $1-2 \%$ thereafter. Teichorhabdus ethmos was extremely rare in all samples investigated $(<1 \%)$; it was recorded in most samples prior to about $66.65 \mathrm{Ma}$, but not in any younger sample. Also $\underline{\mathrm{M}}$. pemmatoidea is very rare $(<0.6 \%$, Figure $47 \mathrm{j}$ ), but more frequent in the lower part of the section than in the upper part. The relative and the absolute frequencies of species of Rhagodiscus (Figure $47 \mathrm{k}$, 1) revealed that these species displayed an abundance peak around 67.1 
$\mathrm{Ma}$, whereafter they were encountered rarely (usually $<1 \%$ ) up to the $\mathrm{K} / \mathrm{P}$ boundary.

The taxa illustrated in Figure 48 are those whose abundance decreased steadily during the last $800 \mathrm{ky}$ of the Maestrichtian. The trend was very

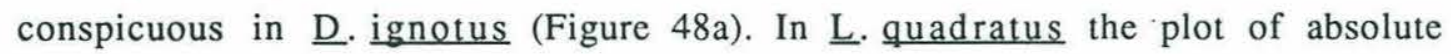
frequency (Figure 48c) showed the decrease more clearly than the relative frequencies (Figure 48b); the same was true for $\underline{\mathrm{N}}$ frequens (Figure 48d, e) which was quite rare in most samples $(<1 \%)$ in Hole 528.

All taxa whose abundance patterns were illustrated on Figure 49 had lower abundances in the earlier part of the section than in the later part. Whereas this trend is not very pronounced in $\underline{\mathrm{A}}$. octoradiata and $\underline{\mathrm{P}}$ regularis, it is fairly obvious in the other taxa. Cretarhabdus spp. displayed maximum values at about $66.9 \mathrm{Ma}$ and declined in abundance until the $\mathrm{K} / \mathrm{P}$ boundary. In G. fessus increased values were observed between $\sim 67$ and $66.6 \mathrm{Ma}$ (in relative and in absolute abundances, Figure 49c, d), a decline occurred during the last $200 \mathrm{ky}$ of the Maestrichtian. The patterns was slightly different in $\underline{\mathbf{M}}$. decoratus which reached peak values only later, at $\sim 66.6$ to $66.5 \mathrm{Ma}$; also in this species a decline occurred during the last $100 \mathrm{ky}$ of the Maestrichtian. Micula murus and $\underline{M}$. prinsii were combined due to the difficulty of consistent differentiation. Although present throughout the entire interval investigated both forms were too rare to be registered between about 67.2 and $67.05 \mathrm{Ma}$ (Figure $49 \mathrm{~g}$ ). Between $\sim 67.05$ and 66.9 Ma these species increased to about 2-3\% and maintain this abundance until about $66.5 \mathrm{Ma}$. Values increased to $\sim 5 \%$ during the last $100 \mathrm{ky}$ of the Maestrichtian. Tranolithus macleodae was virtually absent from the assemblages prior to about $67 \mathrm{Ma}$; thereafter it was recorded in almost all samples in strongly fluctuating abundances (between 0.1 and $3 \%$, Figure 49h). Cylindralithus spp. (Figure 49i) also displayed lower abundances between about 67.2 and $66.9 \mathrm{Ma}$ than thereafter.

The taxa on Figure 50 displayed isolated abundance peaks. Arkhangelskiella and Broinsonia displayed two abundance peaks, at $\sim 67 \mathrm{Ma}$ and at $66.7 \mathrm{Ma}$ (Figure $50 \mathrm{a}, \mathrm{b}$ ). The relative abundances of $\underline{\mathrm{C}}$. ehrenbergii do not fluctuate very much (Figure 50c) but in the absolute abundances the variability is more pronounced (Figure 50d): abundance peaks are apparent at 67.1 Ma, around $66.8 \mathrm{Ma}$, and at about $66.6 \mathrm{Ma}$. Also E. trabeculatus showed increased abundances at $\sim 67 \mathrm{Ma}$ and at $66.6 \mathrm{Ma}$. Clearly enhanced relative abundances are present in Lithastrinus spp. at $67 \mathrm{Ma}$ (Figure 50f). Watznaueria 

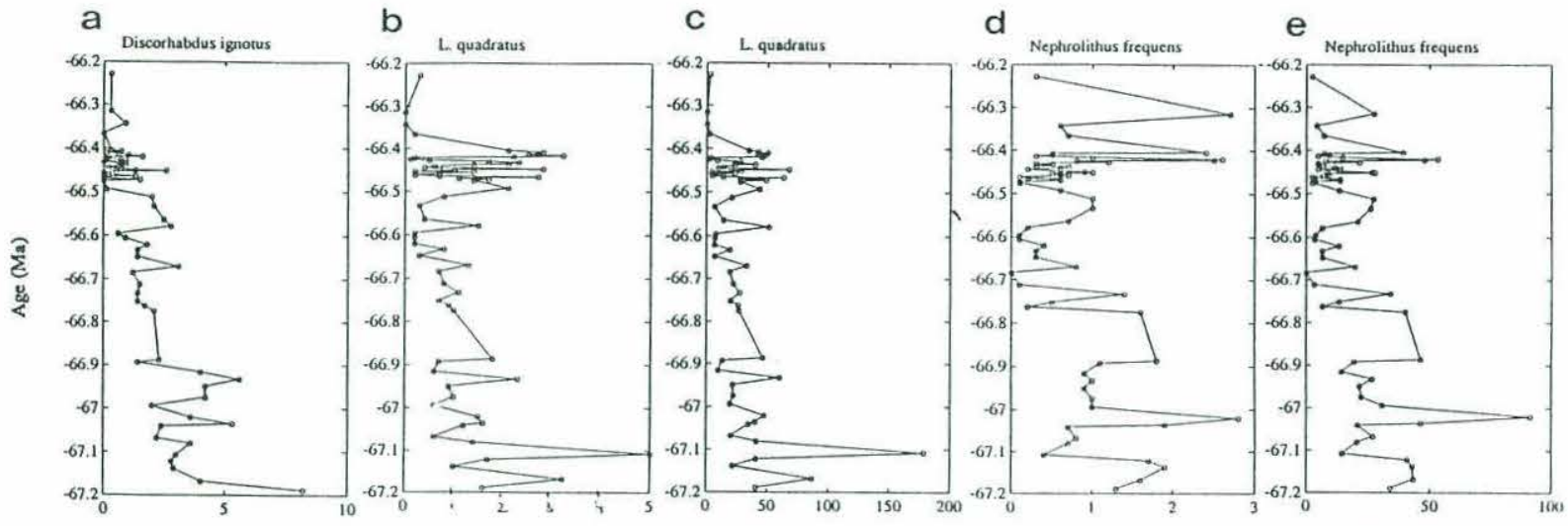

1006 specinenss/g sed

$\%$

1006 specimensys sed

Figure 48: Abundance fluctuations of calcareous nannofossil taxa between 67.2 and 66.2 $\mathrm{Ma}$ in DSDP Hole 528 (Sections 528-31-7 to 528-33-4). The

Cretaceous/Paleocene boundary was placed at 66.4 Ma (after Berggren et al., 1985). The abundances are either expressed as relative abundances (\%) or as absolute abundances ( $10^{6} \mathrm{x}$ number of specimens per gram sediment). 

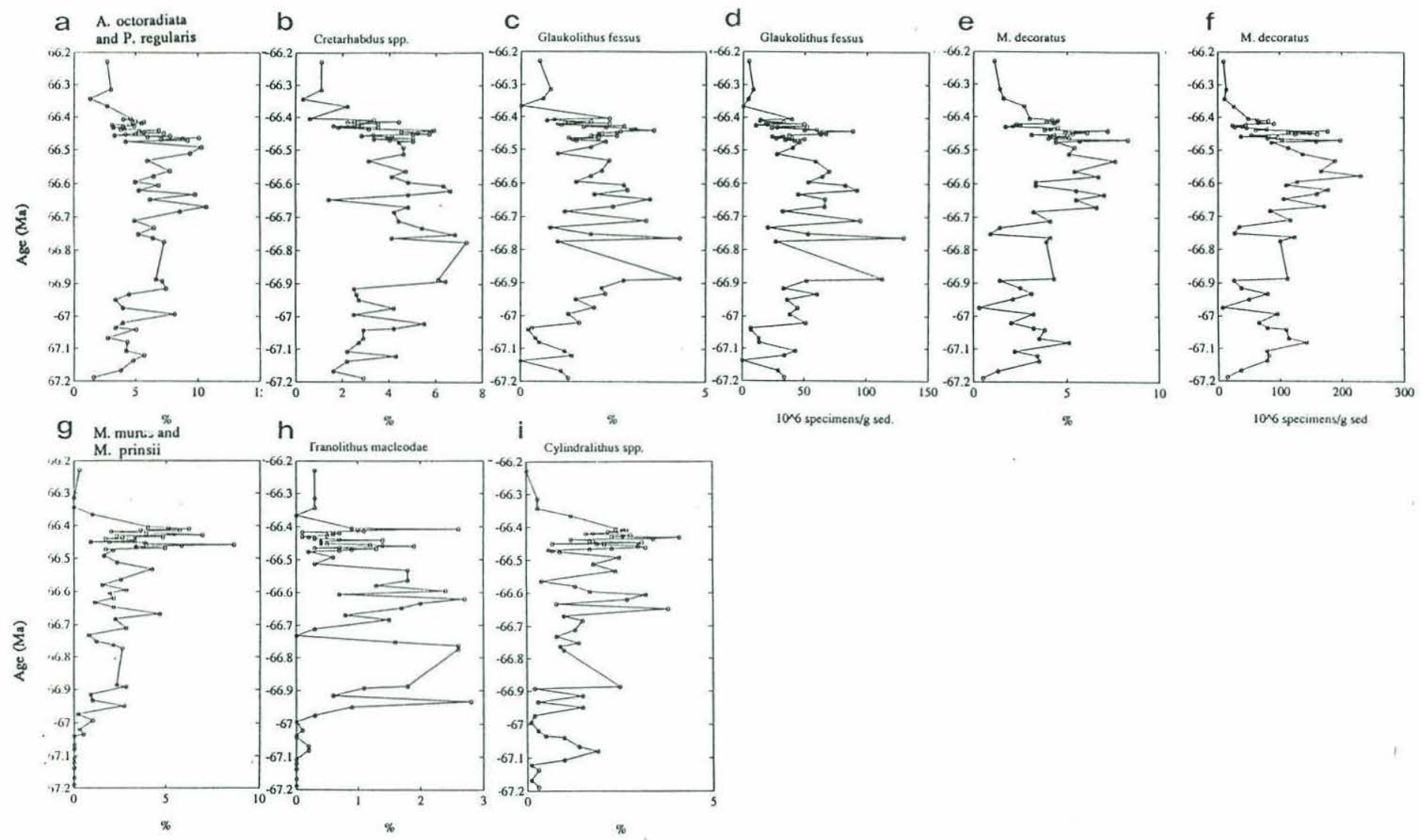

1006 specimens/8 sed

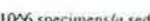

Figure 49: Abundance fluctuations of calcareous nannofossil taxa between 67.2 and 66.2 $\mathrm{Ma}$ in DSDP Hole 528 (Sections 528-31-7 to 528-33-4). The

Cretaceous/Paleocene boundary was placed at 66.4 Ma (after Berggren et al., 1985). The abundances are either expressed as relative abundances (\%) or as absolute abundances $\left(10^{6} \mathrm{x}\right.$ number of specimens per gram sediment). 

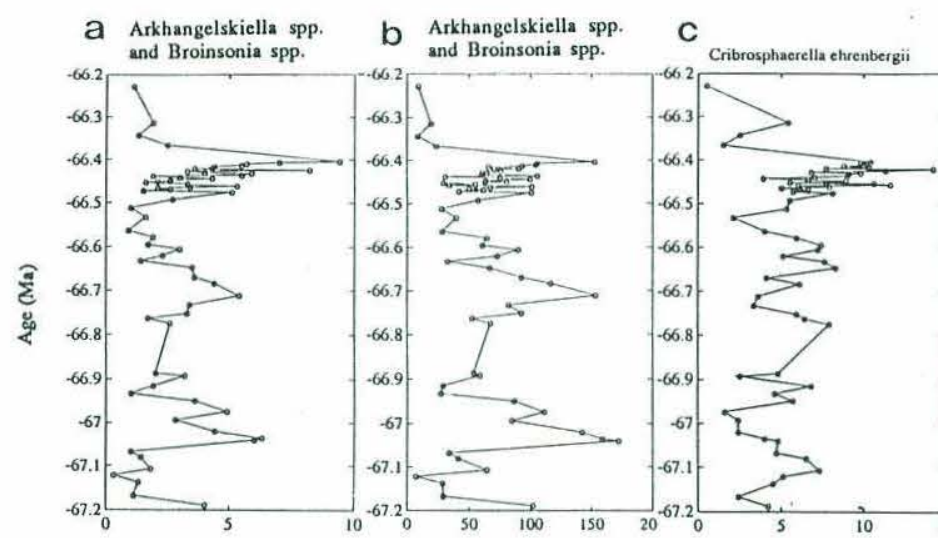

d Cribrosphacectla etrenbergii

e Eubeculatus

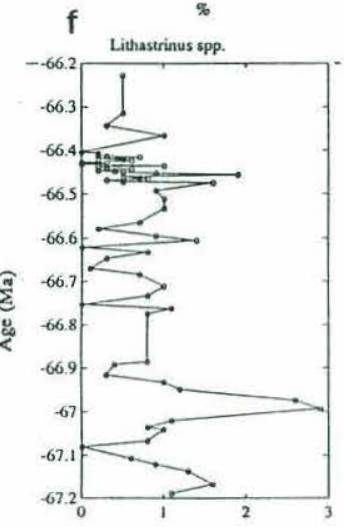

g 1006 specimens/g sed.

\%
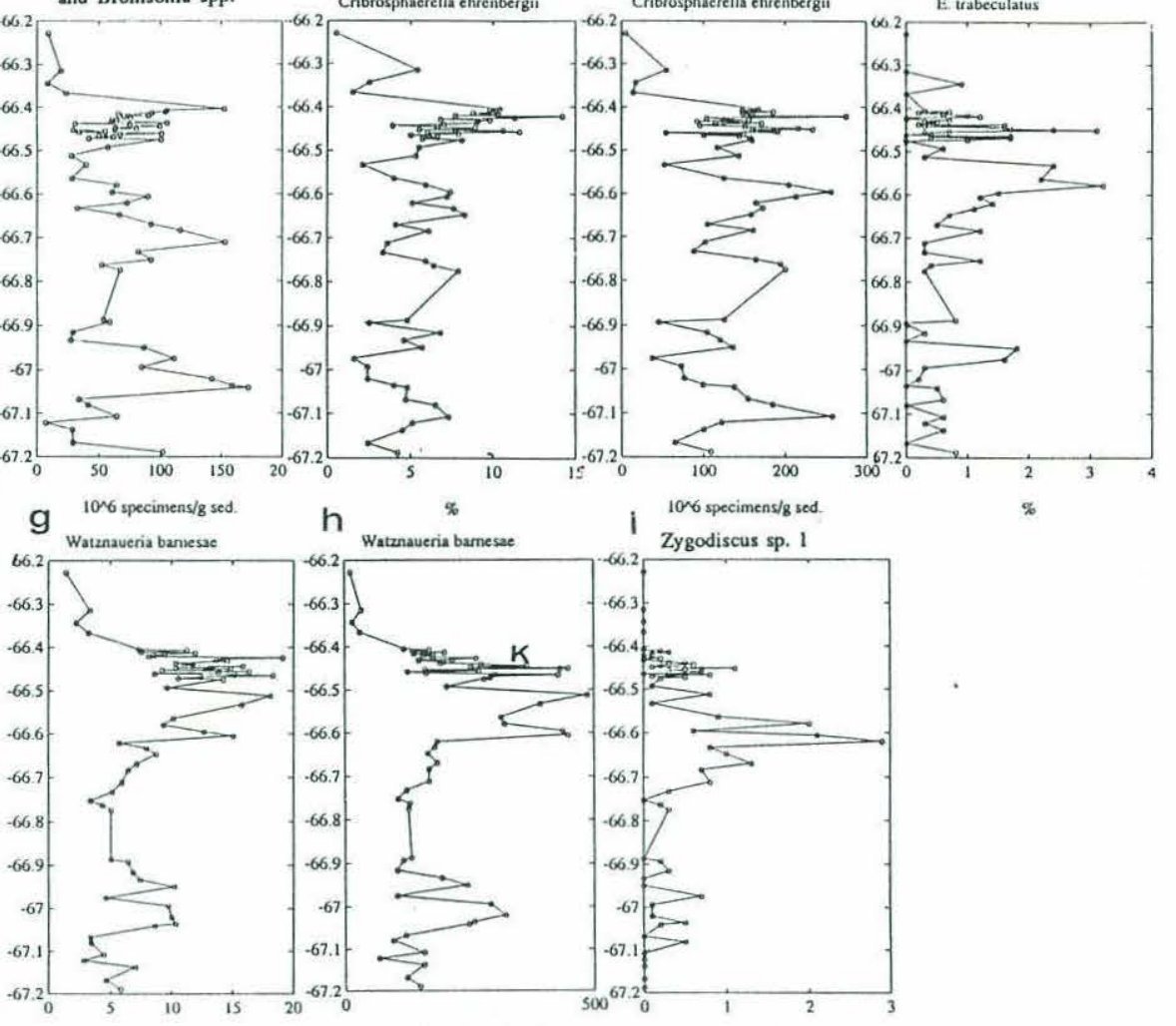

1006 specimens/8 sed.

Figure 50: Abundance fluctuations of calcareous nannofossil taxa between 67.2 and 66.2 $\mathrm{Ma}$ in DSDP Hole 528 (Sections 528-31-7 to 528-33-4). The

Cretaceous/Paleocene boundary was placed at $66.4 \mathrm{Ma}$ (after Berggren et al. 1985). The abundances are either expressed as relative abundances (\%) or as absolute abundances $\left(10^{6} \times\right.$ number of specimens per gram sediment). 
barnesae was one of the most abundant species in Hole 528: abundance peaks are conspicuous at $\sim 67 \mathrm{Ma}$ and between $\sim 66.6$ and $66.5 \mathrm{Ma}$ (Figure $50 \mathrm{~g}, \mathrm{~h}$ ). Zygodiscus sp. 1 showed a conspicuous abundance peak at $66.6 \mathrm{Ma}$ (Figure 50i). In the relative abundance plot of $\underline{\mathrm{P}}$ fibuliformis (Figure 51a) several abundance peaks were registered: 67.2, 66.9, 66.75, 66.6 and 66.5 Ma. Since a tentative cyclicity of about 11-14 ky was identified in this species in the high resolution study, these abundance peaks were possibly a consequence of aliasing (especially as their amplitude is comparable to the amplitude of the 11-14 ky cycles). In the absolute abundance plot (Figure 51b) only three (and possibly four) abundance peaks remained: at $67.2 \mathrm{Ma}$, at $66.75 \mathrm{Ma}$, and at 66.6 Ma (and possibly a minor peak around $66.5 \mathrm{Ma}$ ). The fact that the amplitude of the peaks at 67.2 and at $66.6 \mathrm{Ma}$ is considerably higher than the amplitude of the high frequency cycles makes aliasing as the cause of these peaks unlikely (but not impossible). I conclude therefore that the abundance peaks at 67.2 , at 66.75 and at $66.6 \mathrm{Ma}$ are genuine features. Prediscosphaera stoveri was one of the most abundant species-in Hole 528. Its abundances decreased abruptly at $\sim 66.7 \mathrm{Ma}$ to about half their previous values (Figure 51c, d). Tetrapodorhabdus decorus showed a fairly pronounced abundance peak at 66.6 Ma. Eiffellithus turriseiffeli and L. praequadratus (Figure 52h-k) displayed considerable variability in their abundance records, but on average they hardly changed during the last $800 \mathrm{ky}$ of the Maestrichtian.

The persistent and the incoming taxa are plotted in Figure 52a-h. The fact that Thoracosphaera was virtually absent during the Maestrichtian, but very abundant during the Paleocene (Figure 52g) indicates that bioturbation although very conspicuous and ubiquitous in the sediment - did not cause extensive reworking of calcareous nannofossils downsection.

Prediscosphaera cretacea did not show any conspicuous abundance excursions in the interval studied (Figure 53a, b). A steady decline was registered in the absolute abundance plot of this species during the last $100 \mathrm{ky}$ of the Maestrichtian (Figure 53b). The abundance distribution of $\underline{p}$. spinosa was similar to that of $\underline{P}$. cretacea, but the abundance decline in this species started already 200 ky prior to the K/P boundary (Figure $53 \mathrm{c}$, d). The percentage of unidentifiable calcareous nannofossils remained fairly constant throughout the section (Figure 53e). The comparatively constant relative abundances of $\underline{M}$. staurophora between 67.2 and $66.5 \mathrm{Ma}$ indicated that the preservation of calcareous nannofossils varied within fairly narrow limits. 

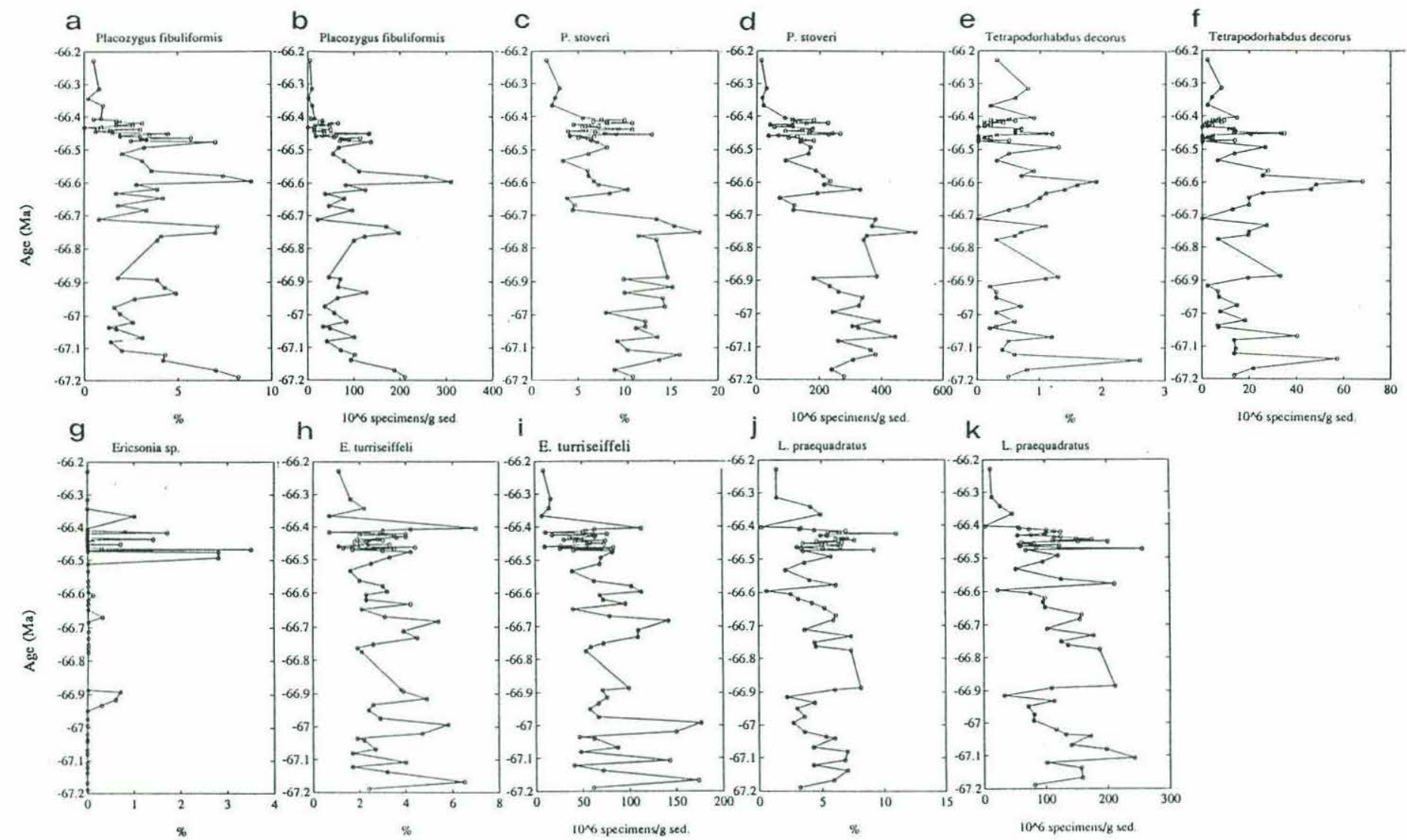

$10 \% 6$ specimens/8 sed

Figure 51: Abundance fluctuations of calcareous nannofossil taxa between 67.2 and 66.2 $\mathrm{Ma}$ in DSDP Hole 528 (Sections 528-31-7 to 528-33-4). The

Cretaceous/Paleocene boundary was placed at $66.4 \mathrm{Ma}$ (after Berggren et al.,

1985). The abundances are either expressed as relative abundances (\%) or as absolute abundances $\left(10^{6} \times\right.$ number of specimens per gram sediment). 

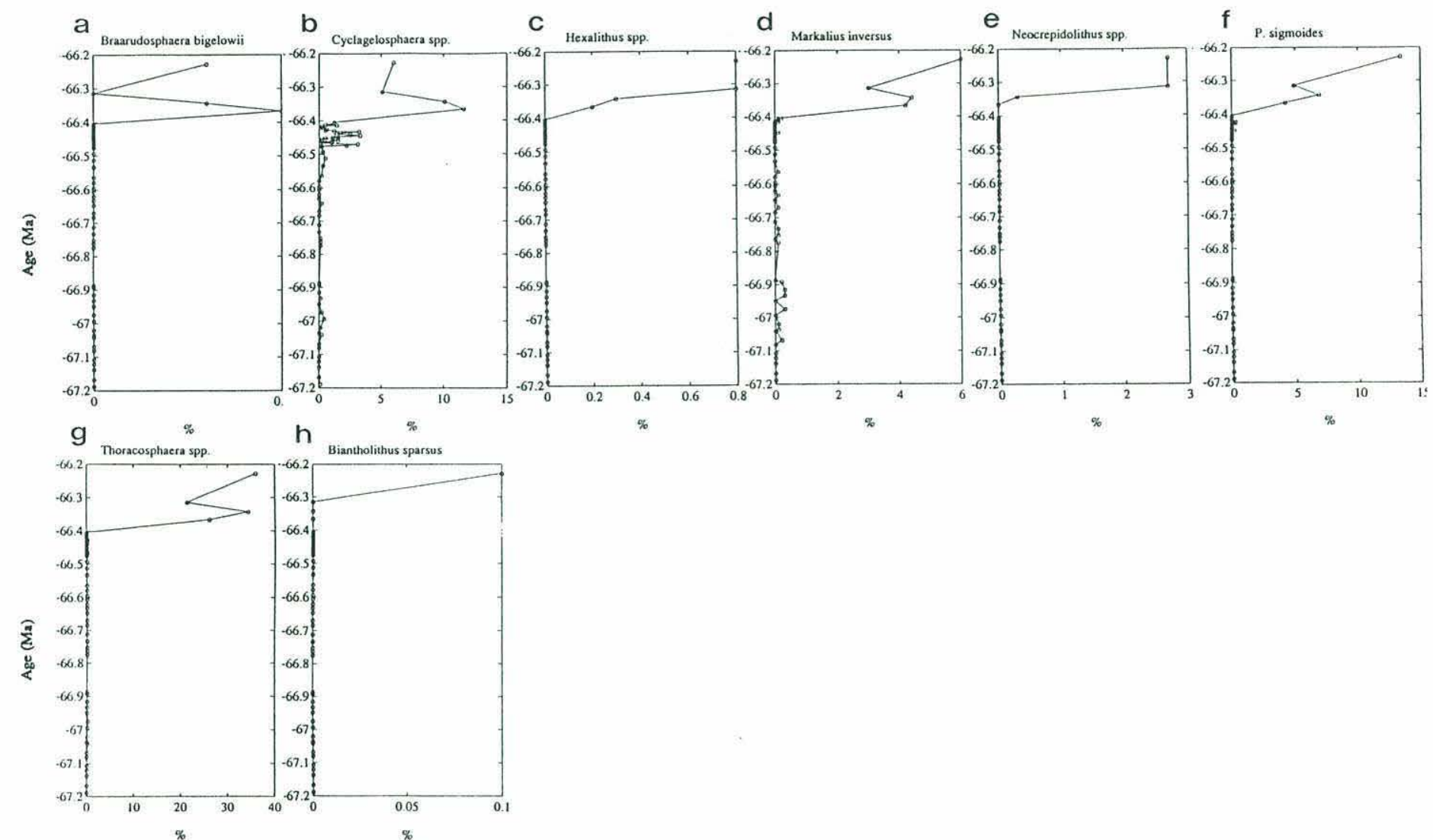

Figure 52: Abundance fluctuations of calcareous nannofossil taxa between 67.2 and 66.2 $\mathrm{Ma}$ in DSDP Hole 528 (Sections 528-31-7 to 528-33-4). The

Cretaceous/Paleocene boundary was placed at $66.4 \mathrm{Ma}$ (after Berggren et al., 1985). The abundances are either expressed as relative abundances (\%) or as absolute abundances $\left(10^{6} \mathrm{x}\right.$ number of specimens per gram sediment). 

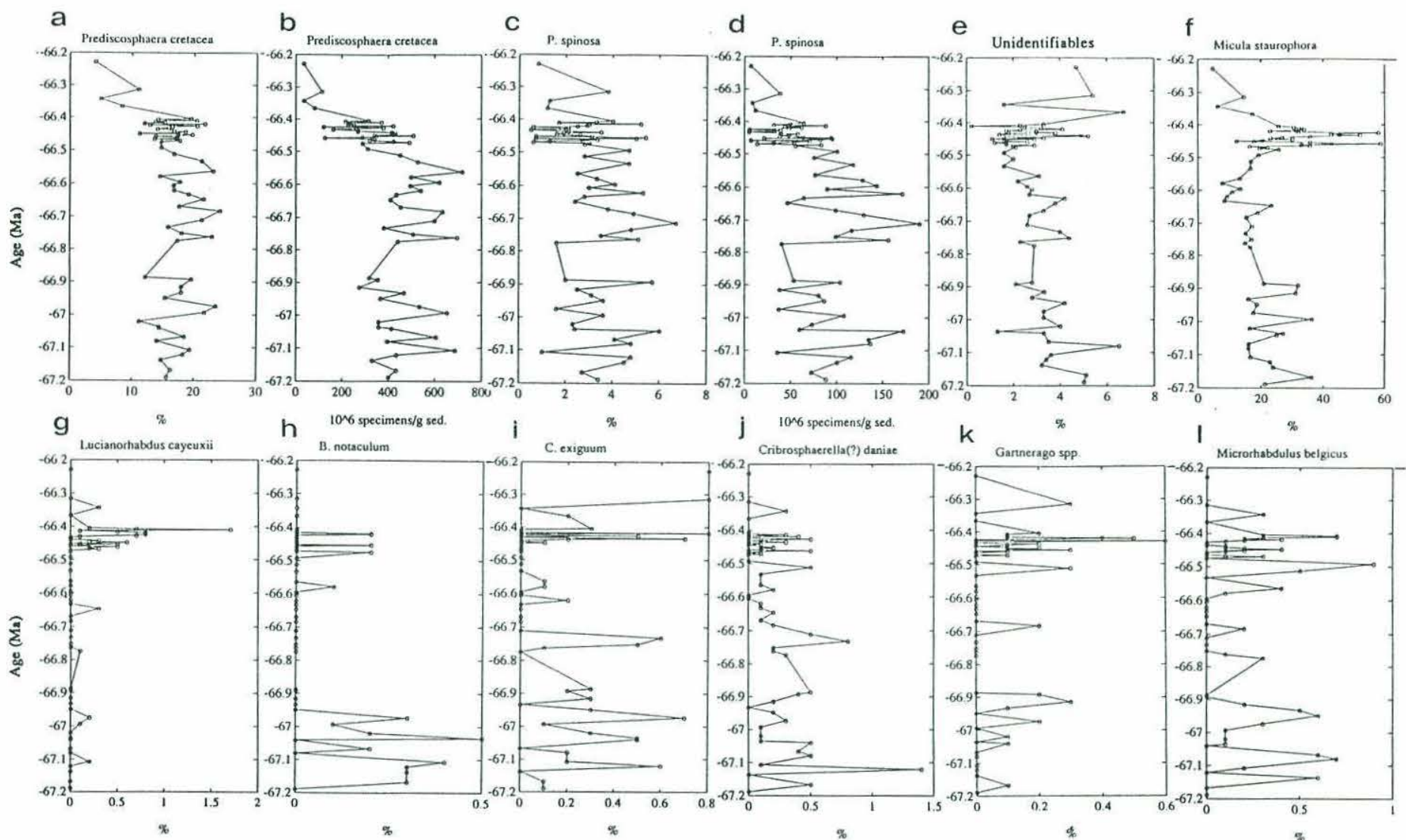

Figure 53: Abundance fluctuations of calcareous nannofossil taxa between 67.2 and 66.2 $\mathrm{Ma}$ in DSDP Hole 528 (Sections 528-31-7 to 528-33-4). The Cretaceous/Paleocene boundary was placed at $66.4 \mathrm{Ma}$ (after Berggren et al., 1985). The abundances are either expressed as relative abundances (\%) or as absolute abundances $\left(10^{6} \times\right.$ number of specimens per gram sediment). 


\section{5) Millers Ferry Section (Borehole 226), Alabama}

The counts were performed on smear slides during an early stage of this study. The preservation between samples in this hole varies strongly with the lithology: in some of the clay rich samples it was excellent, while it was poor when the sand content was high.

Cribrosphaerella ehrenbergii (Figure 54a) increased in abundance throughout the section (from $\sim 5 \%$ to $\sim 20 \%$ ). A high intraspecific variability was recorded in this species: elliptical, parallel sided, triangular, and round morphotypes were observed. The intraspecific variability did not change appreciably throughout the section.

Prediscosphaera stoveri (Figure 54b) decreased during the last $\sim 250 \mathrm{ky}$ of the Maestrichtian from $\sim 15-20 \%$ to $\sim 5 \%$. An abundance peak of similar magnitude of this species was also recorded by Jiang and Gartner (1986) in the Brazos River Section.

The abundance of Prediscosphaera spinosa (Figure 54c) was very low prior to $\sim 66.57(<1 \%)$, it increased to almost $2 \%$ between $\sim 66.57$ and 66.52 , and became very rare thereafter. Only in two samples at $\sim 66.42$ and $\sim 66.4 \mathrm{Ma}$ were higher values $(\sim 2 \%)$ recorded again.

The abundance pattern of $\underline{C}$. exiguum (Figure 54d) was similar to that of P. spinosa. This species occurred more abundantly $(\sim>2 \%)$ between $\sim 66.57$ and $66.50 \mathrm{Ma}$, and very rarely $(<1 \%)$ before and after this abundance peak. A similar abundance pattern was recorded for the species of Cretarhabdus (Figure $54 \mathrm{e}$ ): peak values occurred at $\sim 66.55 \mathrm{Ma}(\sim 3 \%)$, with a gradual increase before and a gradual decrease afterwards.

Species of Thoracosphaera (Figure 54f) increased abruptly in abundance at $\sim 66.5 \mathrm{Ma}$ (from $\sim 2 \%$ to $\sim 4 \%$ ).

Watznaueria barnesae and $\underline{M}$. staurophora (Figure $54 \mathrm{~g}, \mathrm{~h}$ ) were the most abundant taxa $(10-30 \%)$ at this site. A gradual increase in the abundance of $\underline{\mathrm{W}}$. barnesae occurred between $\sim 66.65 \mathrm{Ma}$ and $\sim 66.45 \mathrm{Ma}$. After $66.45 \mathrm{Ma}$ the abundance of this species dropped abruptly from $>20 \%$ to $<10 \%$. Micula staurophora did not display any gradual abundance changes during the last $\sim 250$ ky of the Maestrichtian but remained fairly constantly at $\sim 10-15 \%$. Isolated abundance peaks were recorded in isolated samples and are interpreted as a preservational artifact (see below). 


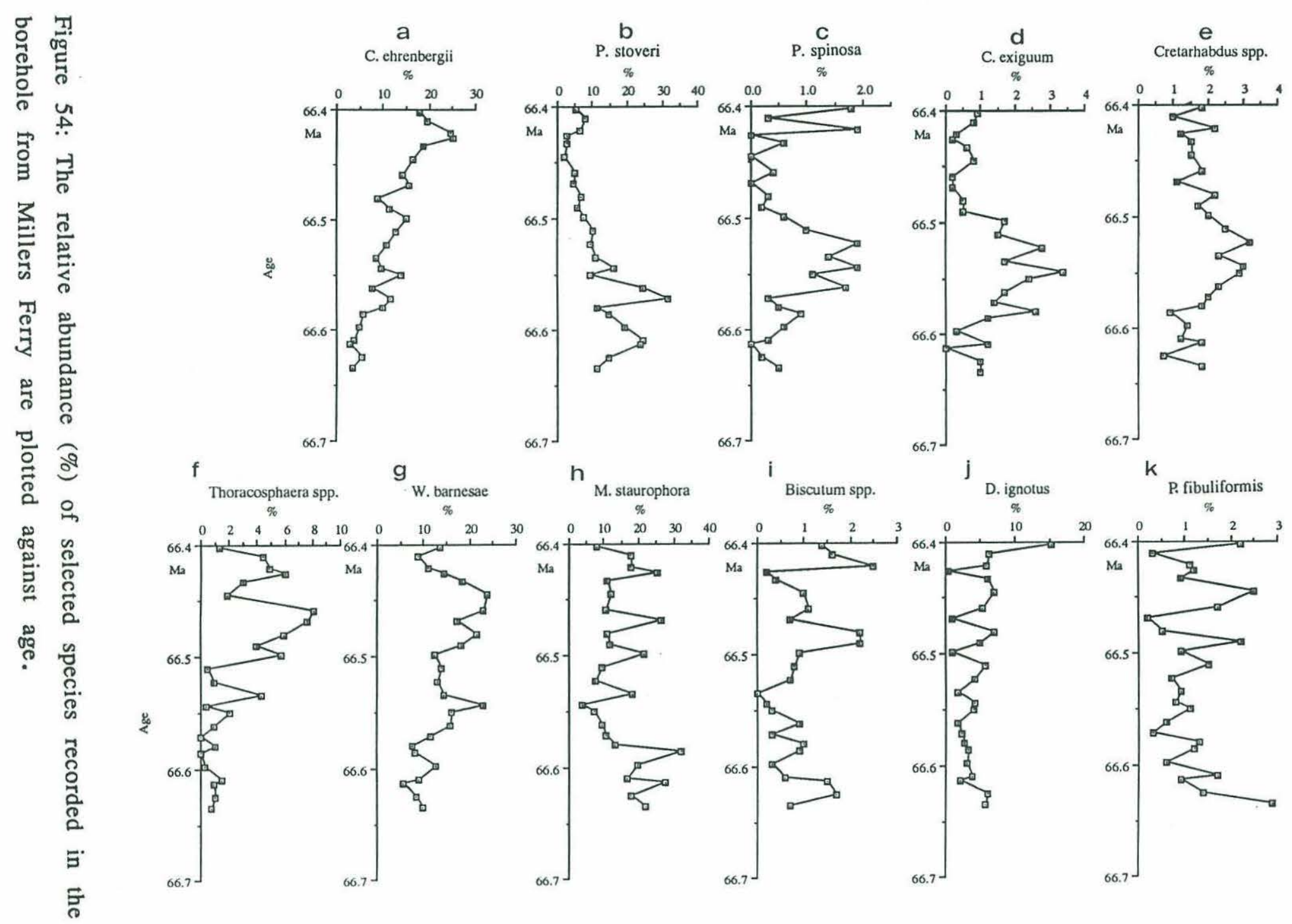


The abundance of species of Biscutum (Figure 54i) remained around $1 \%$ in most samples. Only in three samples did this taxon exceed $2 \%$.

Discorhabdus ignotus (Figure 54j) is common in the Millers Ferry Section ( $\sim 5 \%$ in most samples). In some samples the abundance of this species is conspicuously lower than in the adjacent samples (almost 0\%) and is interpreted as a preservational artifact. An outstanding high abundance $(\sim 15 \%)$ of $\underline{\mathrm{D}}$. ignotus was recorded in one sample at $\sim 66.402 \mathrm{Ma}$.

The abundance of $\underline{\mathrm{P}}$ fibuliformis (Figure 54k) fluctuated between $\sim 0.2$ and $2 \%$ during the last $\sim 250 \mathrm{ky}$ of the Maestrichtian. Elevated abundance values $(\sim 2 \%)$ are concentrated between $\sim 66.5$ and $\sim 66.45 \mathrm{Ma}$, but no conspicuous abundance peaks were recorded.

The most abundant taxa and sample preservation

The isolated abundance peaks of $\underline{M}$. staurophora were recorded in samples where visual inspection revealed that the preservation was poor. Therefore these abundance peaks are considered to be preservational artifacts. Similarly, the isolated abundance decreases of $\underline{D}$. ignotus were recorded in the same samples as the abundance peaks of $\underline{M}$. staurophora and are therefore considered to be preservational artifacts as well. These patterns agree well with the solution ranking of Thierstein (1981). On the other hand, it is surprising that none of the other taxa described above show the same trends. This indicates that $\underline{M}$. staurophora and $\underline{D}$. $\underline{\text { ignotus }}$ are much more sensitive dissolution indicators than the other taxa. 


\section{CHAPTER 5 DISCUSSION}

The abundance patterns described above can be grouped into (i) evolutionary (i.e. extinctions, originations) and (ii) biogeographic changes (migrations, increase and decrease of abundances). They are discussed below in latitudinal order, proceeding from high southern latitudes to mid- and low latitudes.

\section{1) Maestrichtian Evolutionary and Biogeographic Events in High Latitudes}

\section{(A) Evolutionary Changes}

\section{(a) Extinctions}

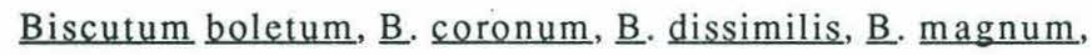
Misceomarginatus spp., Monomarginatus spp., N. watkinsii, ․․ corystus, $\underline{0}$. magnus, $\underline{P}$ obscurus, $\underline{P}$ firthii, and Reinhardtites spp., became extinct during the early and early late Maestrichtian (e.g. Pospichal and Wise, 1990; Watkins, 1992; Bralower and Siesser, 1992; this study). My data show that these twelve taxa represent about a third of all taxa present $(\sim 35-40)$, but constitute only $20-25 \%$ of the assemblages. From the chronology derived for Hole 690C the extinctions occurred within a short stratigraphic interval from $\sim 72.4 \mathrm{Ma}$ to $\sim 70.4 \mathrm{Ma}$ (Figure 55). Many of these taxa were restricted to the southern hemisphere. Only $\underline{B}$. coronum, $\underline{B}$. dissimilis, $\underline{B}$. magnum, Monomarginatus quaternarius, $\underline{\text { O. magnus }}$ and Reinhardtites spp. are also known from northern high latitudes (e.g. in Japan: Okada et al., 1987; in England and northern Germany: Burnett, 1990; in England: Black, 1972; in Poland: Deflandre, 1959).

\section{(b) Originations}

In high latitudes Nephrolithus frequens is the only taxon that originated during the Maestrichtian (between $\sim 71.2$ and $70.4 \mathrm{Ma}$ in Hole $690 \mathrm{C}$ ) and was one of the most abundant taxa in high latitudes (20-40\%; Figure 18a; Table 6). During the late Maestrichtian this species occurred in progressively lower latitudes (Pospichal and Wise, 1990a; see also Chapter 3, Biohorizons) 


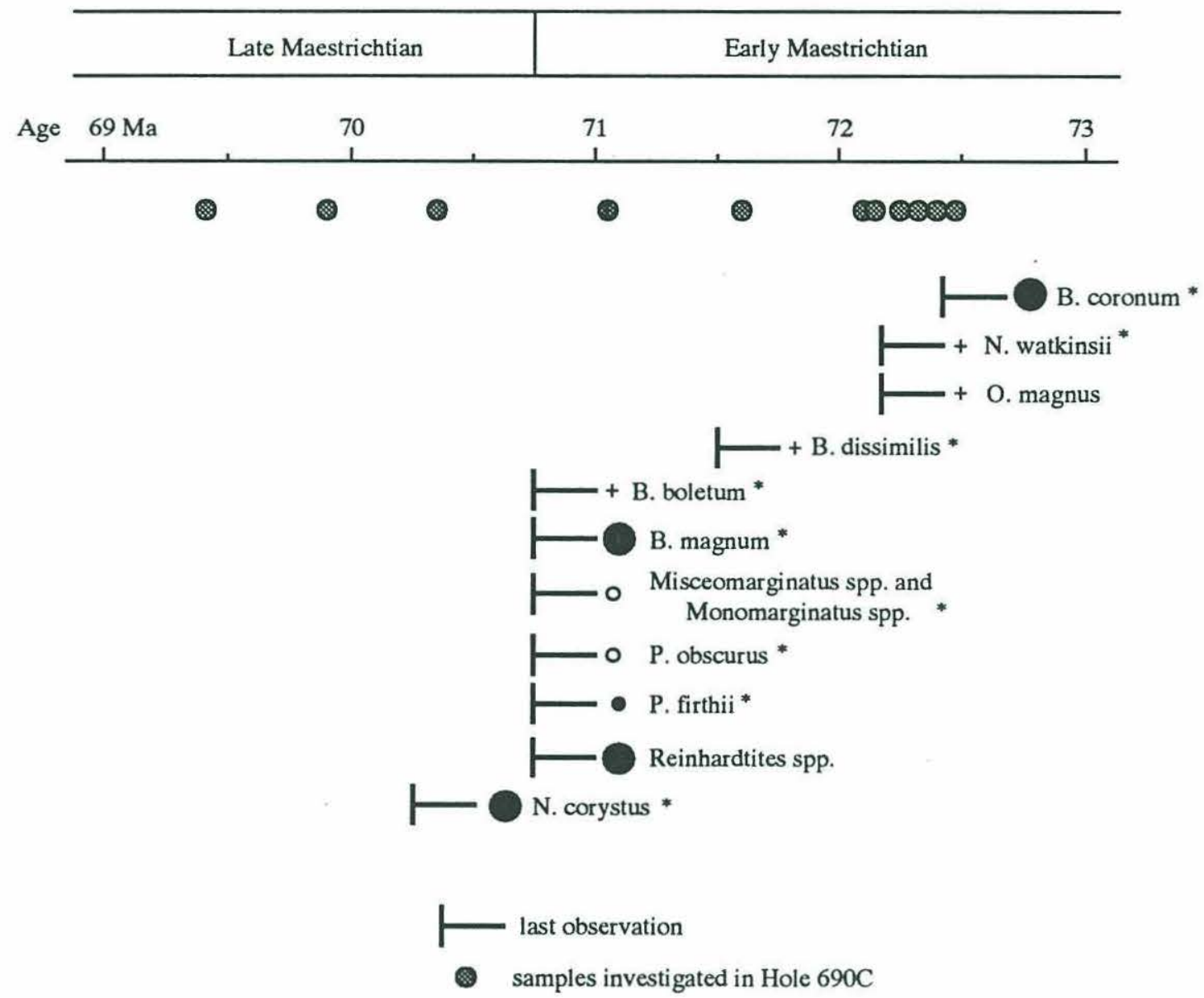

The symbols next to the taxon indicates its maximum abundance:

$\begin{aligned} \square & >20 \% \\ & >10 \%-20 \% \\ & >5 \%-10 \% \\ \circ & >2 \%-5 \% \\ + & <2 \%\end{aligned}$

Figure 55: Sequence of extinctions around the early/late Maestrichtian boundary in high southern latitudes (ODP Hole 690C). All taxa marked with an asterisk $(*)$ are considered to by austral taxa (see text). 


\begin{tabular}{|c|c|c|c|c|c|c|c|}
\hline & \multirow{2}{*}{\multicolumn{2}{|c|}{$\frac{\text { high lat }}{690 \mathrm{C}}$}} & \multicolumn{3}{|c|}{ mid (southem) latitudes } & \multirow{3}{*}{$\begin{array}{l}\text { low/mid N. lat. } \\
\text { Millers } \\
\text { Ferry }\end{array}$} & \\
\hline & & & $761 \mathrm{~B}$ & 578 & 217 & & \\
\hline & $\begin{array}{c}75-71 \\
\mathrm{Ma}\end{array}$ & $\begin{array}{l}71 \mathrm{Ma} \\
. \mathrm{K} / \mathrm{P}\end{array}$ & $761 \mathrm{C}$ & 528 & 217 & & \\
\hline $\begin{array}{l}\text { A snyderi } \\
\text { A. octoradiata }\end{array}$ & $\dot{0}$ & $\dot{0}$ & + & + & $\dot{0}$ & + & \\
\hline 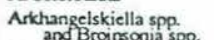 & 0 & 0 & - & - & 8 & 0 & \\
\hline B. sparsus & . & + & . & $-(+)$ & . & . & \\
\hline B. boletum & + & . & - & - & . & . & \\
\hline B. constans & - & - & - & 0 & 0 & + & \\
\hline B. coronum & + & . & . & . & . & : & \\
\hline B. dissimilis & + & . & . & - & . & . & \\
\hline B. magnum & 0 & . & . & . & + & + & \\
\hline B. nocaculum & $\square$ & 0 & + & + & + & + & \\
\hline Biscurum sp. 1 & $\overline{0}$ & - & - & 0 & o & o & \\
\hline Bisaxum sp. 2 & 0 & - & . & - & . & . & \\
\hline B. bigclowii & . & . & - & - & - & + & \\
\hline C. bartata & + & + & + & - & . & . & \\
\hline Ceratolithoides spp. & . & . & ? & - & - & + & \\
\hline C. amphipons & + & - & . & + & + & ० & \\
\hline$C_{- \text {garrisonii }}$ & 0 & - & . & . & . & + & \\
\hline Chiastceygus sp 1 & + & . & + & + & + & + & \\
\hline C. exiguum & . & . & + & + & . & 0 & \\
\hline C. completum & . & - & + & + & + & . & \\
\hline C. angustiforatus & . & - & 0 & 0 & 0 & . & \\
\hline C. conicus & . & + & + & + & + & 0 & \\
\hline C. crenulatus & . & + & + & 0 & 0 & + & \\
\hline C. schizobrachiatus & . & . & + & + & + & . & \\
\hline C. surirellus & + & + & + & 0 & + & . & \\
\hline Cretartabdus sp. 1 & + & . & + & - & . & + & \\
\hline Crecarthabdus spp. & - & - & ? & - & 0 & 0 & \\
\hline C.? daniac & + & - & + & + & + & + & \\
\hline C. etrenbergii & 0 & - & - & ○ & ○ & 口 & \\
\hline Cruciplacolithus spp. & . & + & . & + & - & . & \\
\hline Cyclagelosphacra spp. & + & + & $+(\square)$ & 0 & + & + & \\
\hline C. biarcus & . & - & + & - & 0 & . & \\
\hline C. gallicus & . & - & 0 & 0 & 0 & + & \\
\hline C. serratus & . & - & o & + & + & n.d. & \\
\hline Cylindralithus sp. 1 & . & . & + & . & + & n.d. & \\
\hline Cylindralithus spp. indel. & . & + & . & - & + & - & \\
\hline D. ignorus & + & + & P & - & - & 0 & \\
\hline E eximius & . & . & . & - & + & : & \\
\hline E parallelus & . & . & 0 & - & + & + & \\
\hline E. traboculatus & + & + & + & 0 & + & $\circ$ & \\
\hline E turriseiffelii & - & o & 0 & $\bullet$ & - & $\bullet$ & \\
\hline Ericsonia sp. & . & - & 0 & 0 & + & ad & \\
\hline Gartnerago spp. & 0 & 0 & + & + & + & add & \\
\hline G. fessus & 0 & $\bullet$ & - & 0 & - & . & \\
\hline Hornibrookina spp. & . & + & . & - & . & - & \\
\hline K. magnificus & - & $\square$ & + & + & + & + & \\
\hline Lapideacassis spp. & + & . & + & . & - & . & $>20 \%$ \\
\hline Lithastrinus spp. & . & - & + & 0 & o & n.d. & \\
\hline L camiolensis & + & - & + & 0 & $\bullet$ & + & $>10 \%-20 \%$ \\
\hline L grossopectinatus & - & - & + & + & + & + & - $>5 \%-10 \%$ \\
\hline L. kennectii & : & : & + & $\stackrel{+}{\circ}$ & + & i & 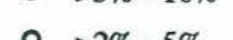 \\
\hline $\begin{array}{l}\text { L procquadratus } \\
\text { L quadratus }\end{array}$ & : & . & : & 0 & $\begin{array}{l}0 \\
+\end{array}$ & $\begin{array}{l}0 \\
0\end{array}$ & $0>2 \%-5 \%$ \\
\hline Litraphidites? sp. 1 & . & 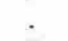 & + & - & + & n.d. & $+<2 \%$ \\
\hline L_cayeuxi & 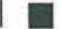 & ? & & + & + & & \\
\hline
\end{tabular}

Table 6: Schematic representation of the abundance of taxa recorded at different sites in this study. (n.d. - taxon not differentiated at time of counting: presence or absence cannot be confirmed) 


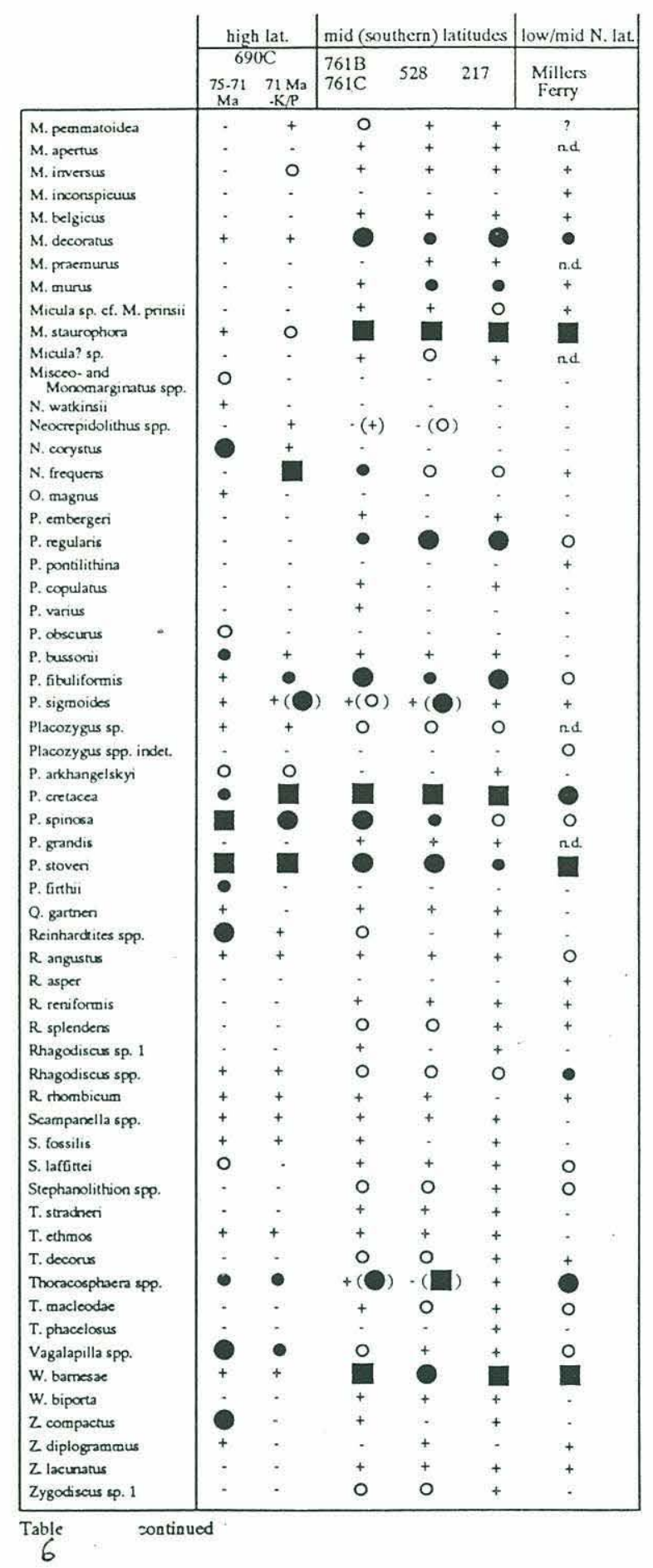


indicating either (i) that high latitude surface water conditions extended into lower latitudes in the late Maestrichtian or (ii) that the ecological tolerance of this species increased to include low latitude conditions (see below).

\section{(B) Biogeographic changes}

\section{(a) Emigrations}

In addition to the twelve species that became extinct, twelve more taxa (Biscutum constans, $\underline{\text { B }}$ notaculum, Biscutum sp. 1, ‥ garrisonii, $\underline{\text { C. amphipons, }}$

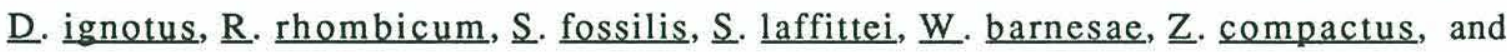
Z. diplogrammus) disappeared from high latitudes (or became extremely rare) during the Maestrichtian (Figure 56) but persisted into or throughout the late Maestrichtian at mid- and low latitudes (compare with range charts in e.g. Pospichal and Wise, 1990; Resiwati, 1991; Bralower and Siesser, 1992; this study). All of these taxa were fairly rare during the early Maestrichtian $(<5 \%$, Table 6) except for $\underline{B}$. constans and $\underline{B}$. notaculum which reached peak abundances of almost $10 \%$ and almost $40 \%$, respectively (Table 6). Most of these disappearances (and abundance decreases) occurred during the same time interval ( 72.4 to $\sim 70.4 \mathrm{Ma}$ ) as the extinctions mentioned above.

\section{(b) Abundance Changes}

Decreasing abundance: Ahmuellerella octoradiata, $\underline{P}$. spinosa and $\underline{P}$. arkhangelskyi decreased in abundance during the early and early late Maestrichtian ( 74-69 Ma; Figure 57a, b). Prediscosphaera arkhangelskyi was virtually absent after $\sim 68.5 \mathrm{Ma}$ whereas $\underline{\mathrm{A}}$. octoradiata and $\underline{\mathrm{P}}$. spinosa increased in abundance again after $\sim 68 \mathrm{Ma}$ (Figure 57a, b). Thoracosphaera spp. decreased gradually throughout the entire Maestrichtian (Figure 57d). Also Vagalapilla spp. decreased in abundance between the earliest and the latest Maestrichtian but between $\sim 72-67 \mathrm{Ma}$ its abundance remained virtually constant (Figure 57e). These taxa (except for Thoracosphaera spp.) were more abundant in high latitudes than in mid- or low latitudes.

Increasing abundance: Cribrosphaerella? daniae and $\underline{N}$. frequens increased abruptly in abundance between $\sim 71.1-70 \mathrm{Ma}$ (Figure $58 \mathrm{a}, \mathrm{b}$ ).

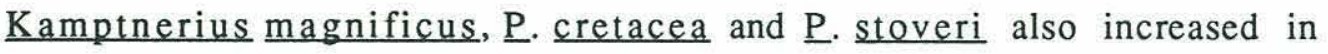
abundance, but more gradually (Figure $58 \mathrm{c}, \mathrm{d}, \mathrm{e})$. Glaukolithus fessus displayed a fairly sudden abundance increase around $69 \mathrm{Ma}$ (Figure 59a) 


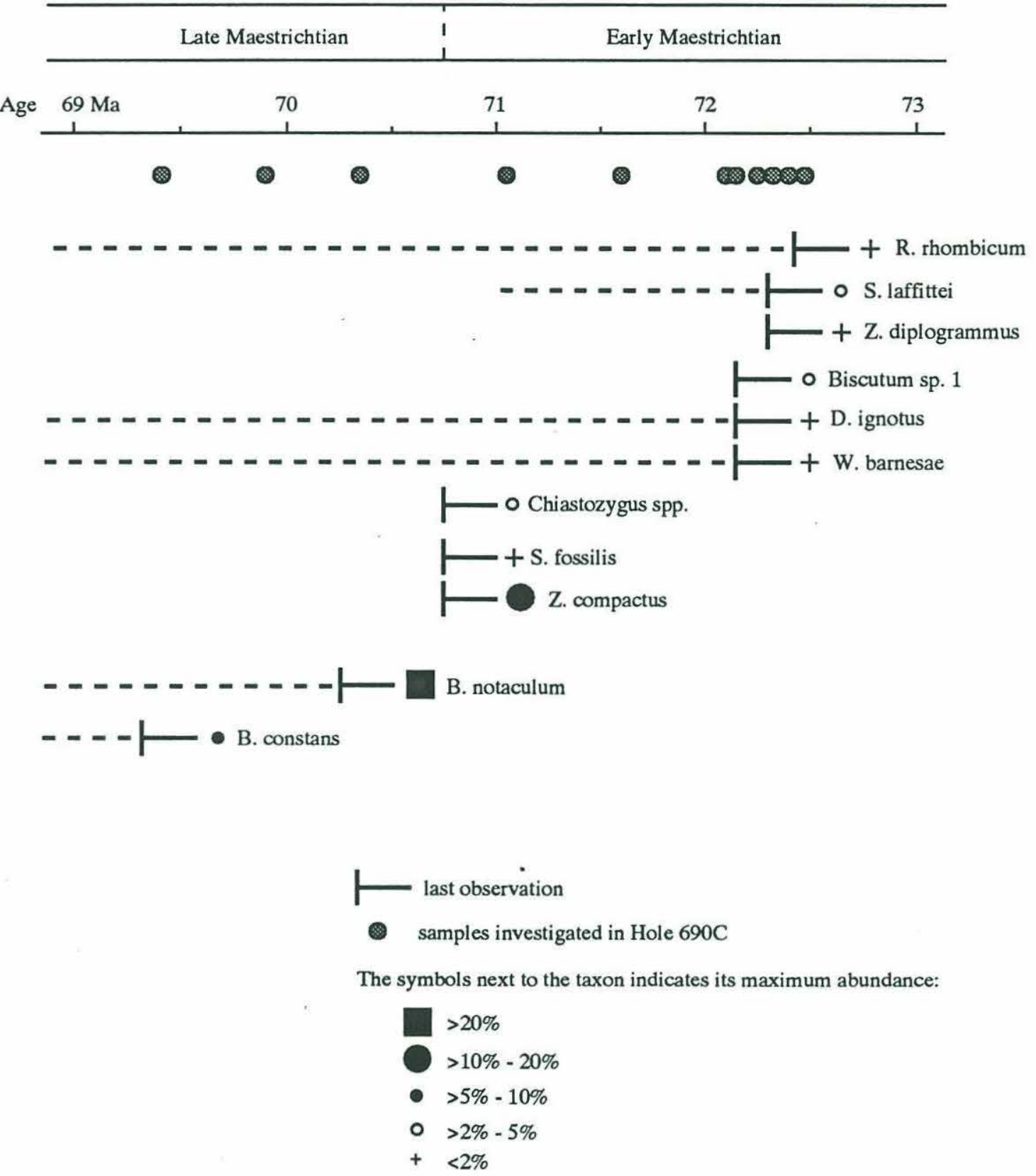

Figure 56: Sequence of regional disappearances of taxa around the early/late Maestrichtian boundary in high southern latitudes (ODP Hole 690C). The dashed lines indicate that some of these taxa were recorded very rarely in at least one sample in the upper Maestrichtian. 

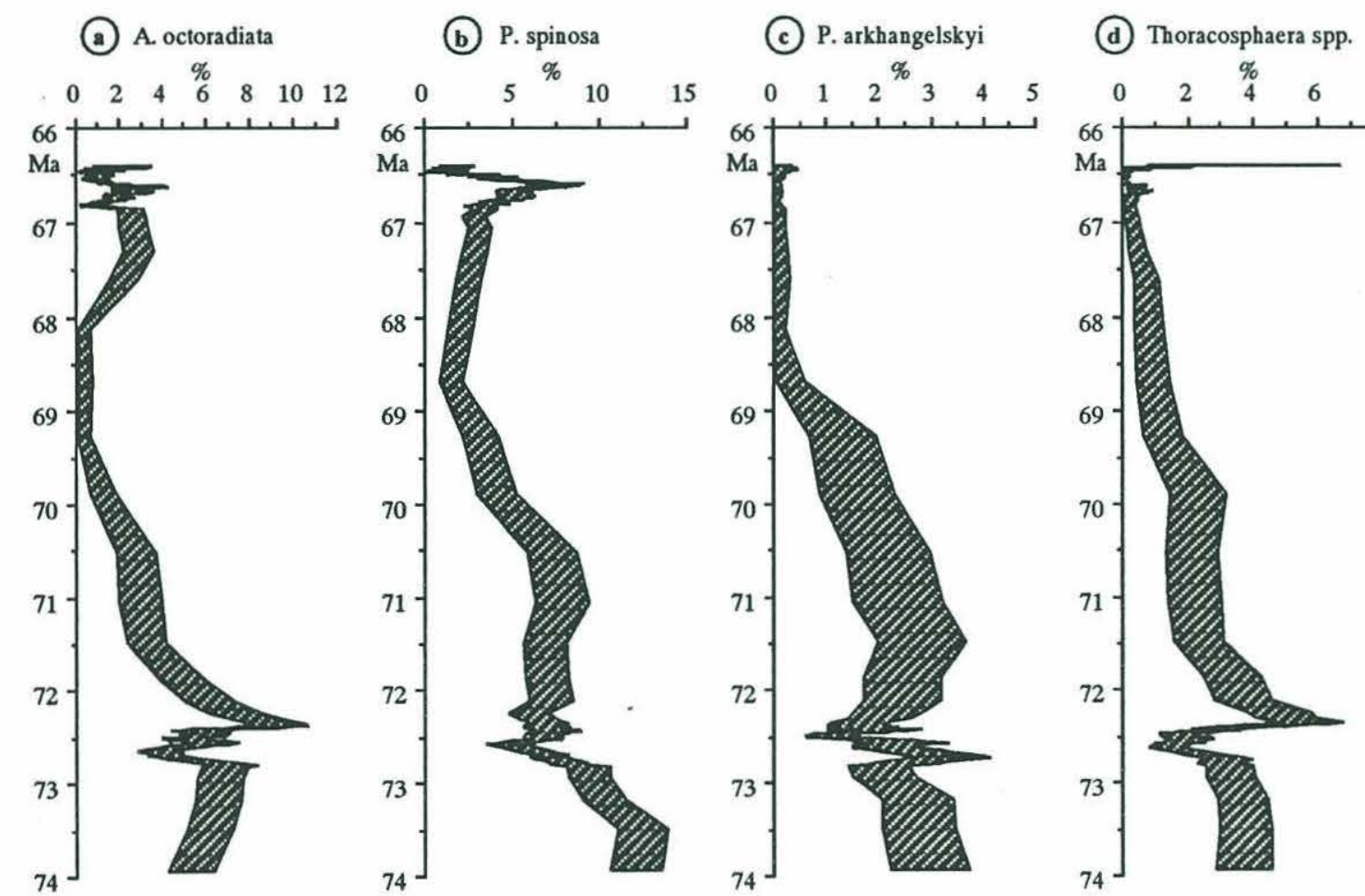

(e) Vagalapilla spp.
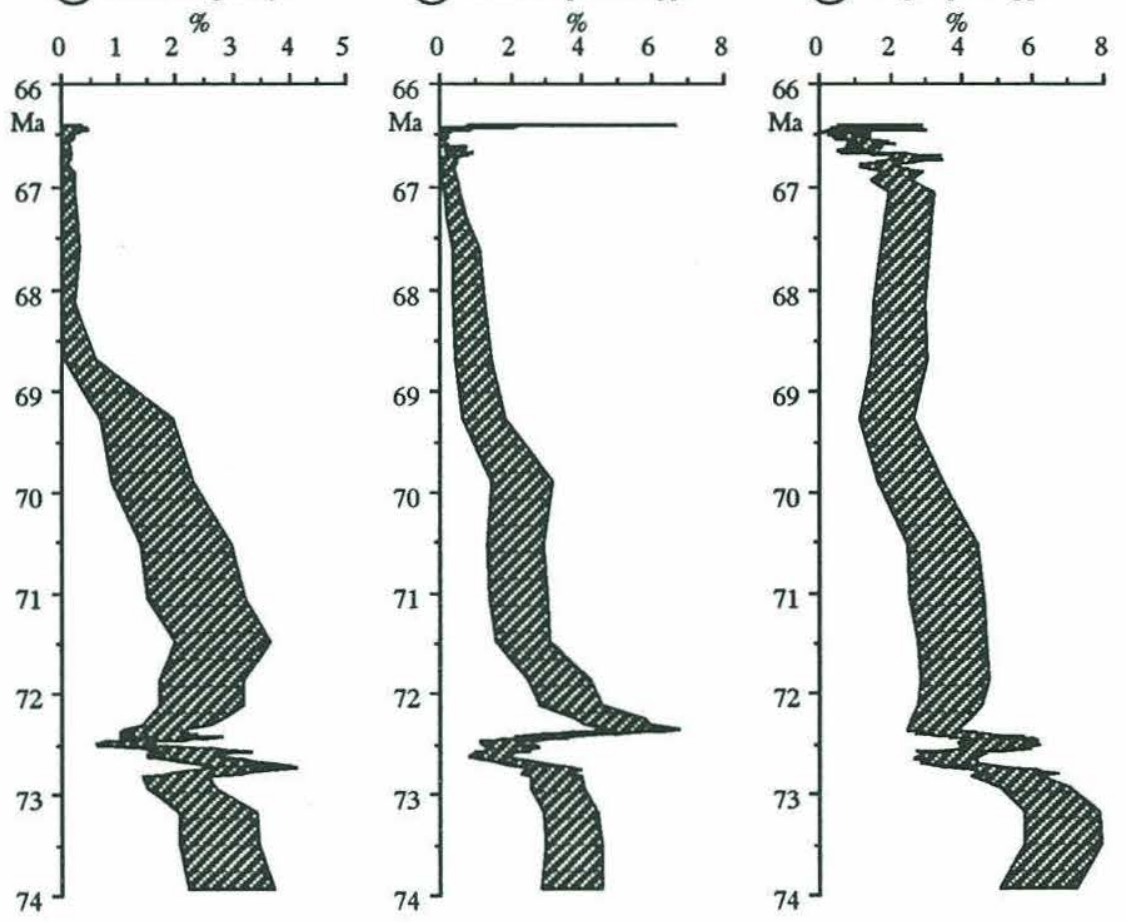

Figure 57: Calcareous nannoplankton taxa that decrease in abundance throughout the Maestrichtian in high southern latitudes (ODP Hole 690C).

Note: A five point running average was calculated from the raw data.

The shaded band indicates the $95 \%$ confidence interval. The

Cretaceous/Paleocene boundary lies at $66.4 \mathrm{Ma}$. 


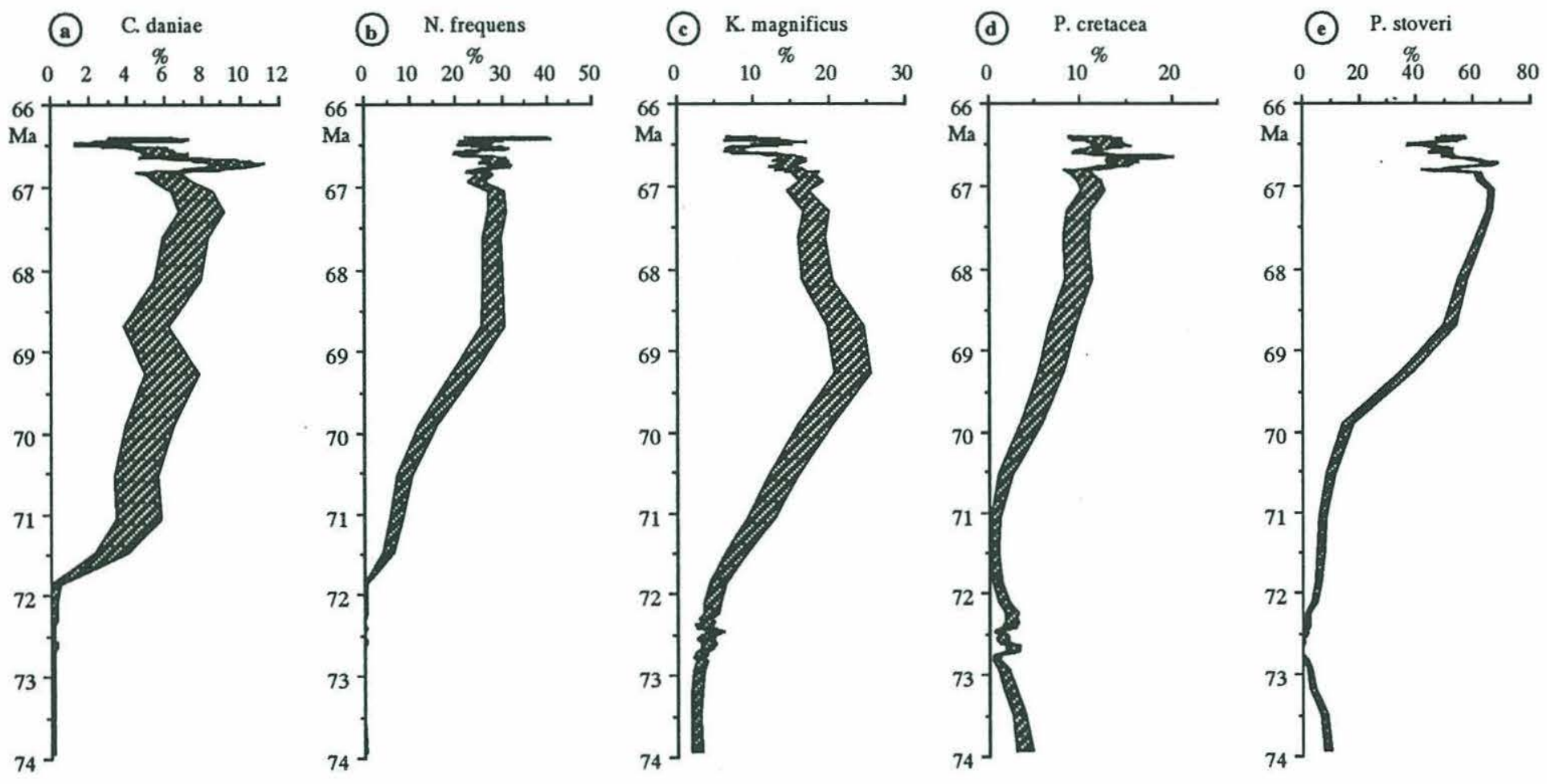

Figure 58: Calcareous nannoplankton taxa that increase in abundance throughout the Maestrichtian in high southern latitudes (ODP Hole 690C). See note in caption of Figure 57. 


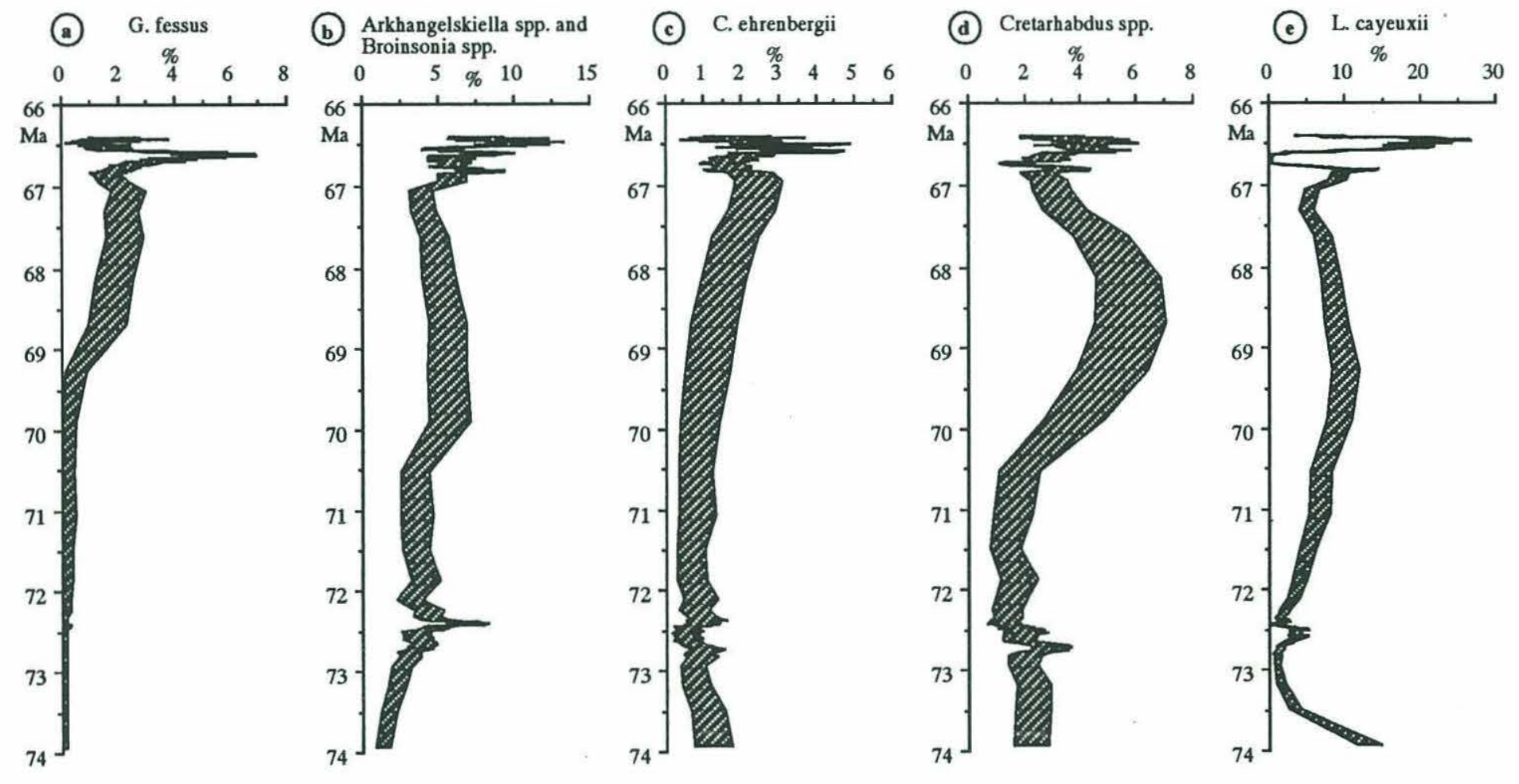

Figure 59: Calcareous nannoplankton taxa that increase in abundance throughout the Maestrichtian in high southern latitudes (ODP Hole 690C). See note in caption of Figure 57. 
whereas Arkhangelskiella spp. and Broinsonia spp, $\underline{C}$. ehrenbergii,

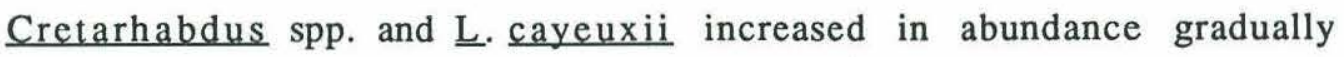
throughout the Maestrichtian (Figure 59b, c, d, e). These taxa dominated the late Maestrichtian nannoplankton assemblages.

In southern high latitudes conspicuous changes of the nannoplankton associations occurred close to the early/late Maestrichtian boundary ( 71 Ma): (i) About one third of all taxa (corresponding to $\sim 20 \%$ of the specimens) became extinct within two million years (between $\sim 72.4$ and $\sim 70.4 \mathrm{Ma}$ ).

(ii) Another third of all taxa (corresponding to $\sim 40 \%$ of all specimens) disappeared from high southern latitudes (or became extremely rare) but persisted in mid- and low latitudes to the K/P boundary $(66.4 \mathrm{Ma})$.

(iii) Most of the dominant nannoplankton species in the late Maestrichtian were rare during the early Maestrichtian.

(iv) Only one species ( $\underline{N}$. frequens) originated during the Maestrichtian (between 71.2 and $70.4 \mathrm{Ma}$ ) in high southern latitudes.

\section{2) Maestrichtian Evolutionary and Biogeographic Events in Mid/Low Latitudes}

\section{(A) Evolutionary Changes}

\section{(a) Extinctions}

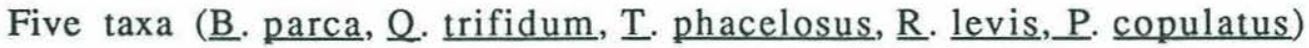
became extinct during the early Maestrichtian in mid- and low latitudes and have been used for stratigraphic purposes (e.g. Bukry, 1973; Sissingh, 1977; Roth, 1978; Perch-Nielsen, 1979a, 1983; Bralower and Siesser, 1992). Because only upper Maestrichtian sediments were investigated from mid- and low latitude sites, it is not possible to evaluate the severity of the early Maestrichtian extinctions or to compare them with those in high latitudes. No extinctions were observed in mid- and low latitudes during the late Maestrichtian (after $71 \mathrm{Ma}$ ). 


\section{(b) Originations}

Three taxa (Lithraphidites quadratus, Micula murus, and $\underline{\text { M.prinsii) }}$ originated during the late Maestrichtian and have been used for stratigraphic purposes (e.g. Cepek and Hay, 1969; Bukry, 1973; Perch-Nielsen, 1979). Their first occurrences are at $\sim 69.0 \mathrm{Ma}, \sim 67.6 \mathrm{Ma}$ and $\sim 66.6 \mathrm{Ma}$, respectively (see Chapter 3, Biohorizons). Micula murus reached abundances of $>5 \%$ in some

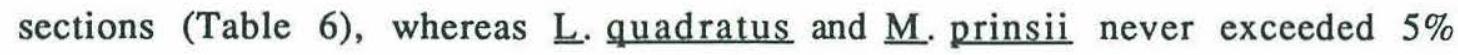
(Table 6).

\section{(B) Biogeographic Changes and Abundance Changes}

Worsley (1974) reported that $\underline{L}$. cayeuxii was restricted to the early Maestrichtian in tropical latitudes, but was still present in the late Maestrichtian in high latitudes.

Wind (1979a) examined Campanian and Maestrichtian nannoplankton abundance changes in the southern hemisphere (in mid- to high southern latitudes of the Atlantic and Indian Oceans). He documented primarily nannoplankton provincialism and indicated that a sharp boundary across the Falkland Plateau separated the high latitude taxa from the mid- latitude nannoplankton community (with abundant $\underline{\mathrm{B}}$. constans and $\underline{\mathrm{M}}$. staurophora). $\mathrm{He}$ also documented an abundance increase of $\underline{\mathrm{W}}$. barnesae and Cyclagelosphaera spp. from mid- to low latitudes. Wind (1979a) did not report abundance changes of individual species through time. Instead he examined changes in the dominance of assemblages (groups of taxa with similar latitudinal preferences) and changes of ratios of certain nannoplankton taxa ( $\underline{B}$. magnum and $\underline{B}$. coronum vs. $\underline{B}$. constans; $\underline{M}$. staurophora vs. $\underline{\text { W. barnesae }}$ and Cyclagelosphaera spp.). Due to this grouping the abundance changes of individual taxa cannot be derived from the trends he reported. Comparison with his raw data, however, revealed some of the same trends recognized in this study (see below).

Only one study has attempted to investigate Maestrichtian nannoplankton biogeographic patterns on a global scale (Thierstein, 1981). The subsequent dearth of similar studies may be due, in part, to Thierstein's conclusion that no nannoplankton biogeographic or abundance changes occurred during the latest Cretaceous. Thierstein (1981) confirmed the results of previous authors (e.g. Worsley and Martini, 1970; Worsley, 1974; Thierstein, 1976; Wind, 1979a) that latitudinally defined, nannoplankton 
paleoprovincialism was strongly developed during the latest Cretaceous. Wise (1988) interpreted this provincialism as a function of surface water temperatures.

Doeven (1983) investigated nannoplankton abundance patterns during the Campanian and Maestrichtian in the northwest Atlantic Ocean (Canadian Atlantic margin). He performed abundance counts on 29 samples from nine drillholes, and as a consequence the chronologic resolution is quite low (usually one sample per nannofossil zone). He reported only the abundance variations of the most abundant taxa (at least $>=2 \%$ in one sample) but worked primarily at the generic level. He noted a pronounced abundance increase in A. cymbiformis from Campanian to Maestrichtian, a concurrent decrease of $\underline{\mathrm{W}}$. barnesae, and a frequency decrease of Biscutum spp. during the Maestrichtian. He considered these changes genuine, because preservation did not change significantly between samples and he interpreted them as reflecting a temperature decrease. No abundance changes of $\underline{M}$. staurophora and $\underline{\mathrm{W}}$. barnesae were observed in this study, possibly due to the fact that only the late Maestrichtian was investigated (i.e. the abundance changes in these two taxa were not recorded because they occurred earlier).

In my study no change in the biogeographic distribution of any taxon during the late Maestrichtian has been observed (i.e. neither immigrations nor emigrations of taxa). A few taxa show abundance changes through the late Maestrichtian at all sites:

Ahmuellerella octoradiata was more abundant in high than in low latitudes during the Maestrichtian (Figure 60) which agrees with its classification as a high latitude taxon (e.g. Thierstein, 1981). At all sites its abundance decreased during the Maestrichtian and this speices virtually disappeared from the records between $\sim 68.5$ and $68 \mathrm{Ma}$ at mid-latitudes in the Indian Ocean (Hole 217 and $761 \mathrm{~B}$, respectively).

Biscutum constans reached peak abundances of $\sim 6-8 \%$ at all sites, it decreased in abundance in all sections during the Maestrichtian (Figure 61). This decrease occurred at different times at different sites ( 70-68 Ma in Hole 690C; $\sim 67-66.7 \mathrm{Ma}$ in Hole 761B; $\sim 68-67 \mathrm{Ma}$ in Hole 217 ; $\sim 67.1$ - $66.9 \mathrm{Ma}$ in Hole 528). 


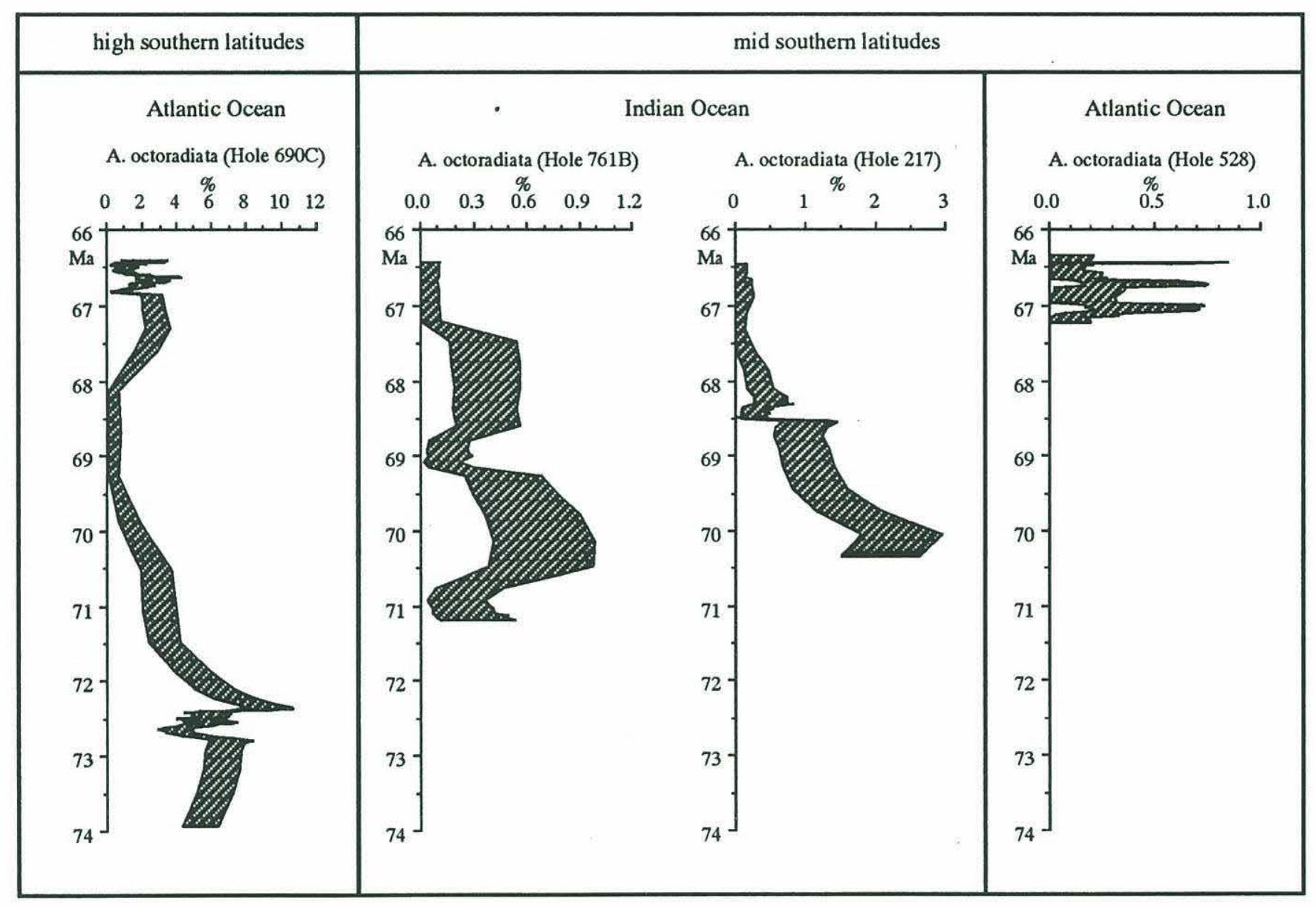

Figure 60: Comparison of abundance variations of Ahmuellerella octoradiata during the Maestrichtian between latitudes and Ocean Basins. See note in caption of Figure 57. 


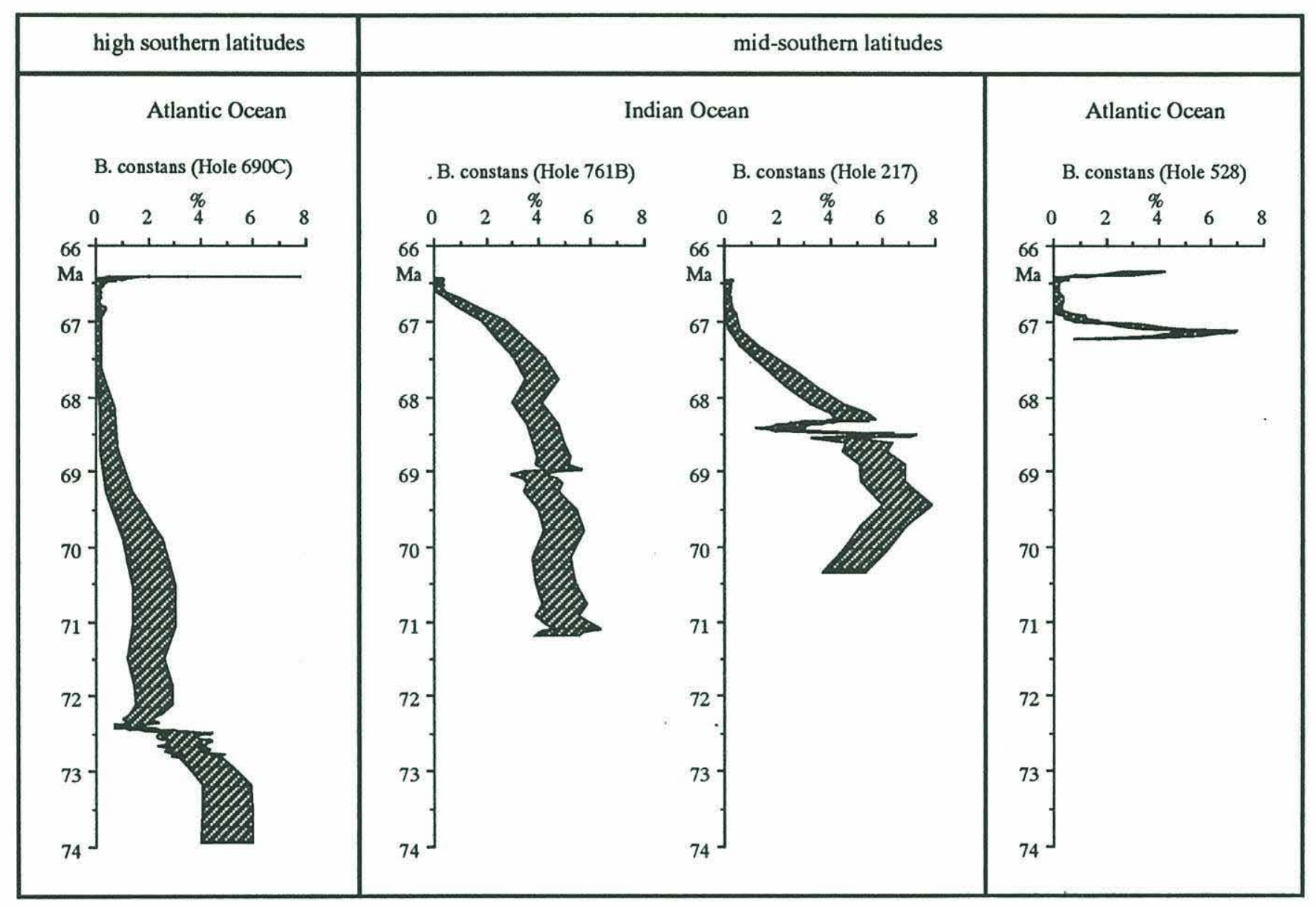

Figure 61: Comparison of abundance variations of Biscutum constans during the Maestrichtian between latitudes and Ocean Basins. See note in caption of Figure 57. 


\section{(3) Maestrichtian Nannoplankton Biogeography: Arguments} against worldwide stable ecological conditions in the surface ocean during the latest Cretaceous.

\section{(A) The Austral Taxa}

\section{(a) Which are the "austral" taxa?}

Resiwati (1991) suggested the term "austral" to refer to late Campanian and early Maestrichtian taxa that were restricted to high southern latitudes. This definition is considered to be too restrictive: several taxa (e.g. N $\underline{\text { corystus) }}$ that are characteristic of high southern latitudes extended into the late Maestrichtian. Others (e.g. B. coronum, ‥ dissimilis, $\underline{B}$. magnum, $\underline{\text { ma }}$. quaternarius) occurred also in the northern hemisphere. I propose to extend the definition of the term "austral" to include taxa that were restricted to or particularly abundant in high southern latitudes from late Campanian to early late Maestrichtian. As a preliminary approach in this study the term austral taxa includes the following: Biscutum boletum, B. coronum, B. dissimilis, $\underline{B}$. magnum, Misceomarginatus pleniporus, Monomarginatus pectinatus, $M$. quaternarius, Neocrepidolithus watkinsii, Nephrolithus corystus, Phanulithus obscurus, and Psyktosphaera firthii. Several new species of holococcoliths (Okkolithus australis, Orastrum asarotum, Phanulithus additus, $\underline{\mathrm{Pharus}}$ simulacrum) were described by Wind and Wise (in Wise and Wind, 1977) from the same material in which many of the above listed austral taxa were first described. Due to their holococcolithic structure these forms are fairly susceptible to dissolution (Wind and Wise, 1978) which may explain why they are only very rarely reported from other austral sites. It is possible that (some of) these species share the stratigraphic and geographic distribution of the austral taxa and should be included in the austral assemblage. On the other hand, their absence may be due to ecologic exclusion since it has been suggested (Perch-Nielsen, 1985) that holococcoliths may be indicative of shallow water depths. A study of recent holococcolith species indicated that holococcolith species are most abundant under oligotrophic conditions (Kleijne, 1991). Despite its high abundance in the early Maestrichtian at high latitudes $\underline{B}$. notaculum is not included in the austral assemblage because this 
species also occurred in the late Maestrichtian at mid-latitudes (e.g. Holes 761B, 528, and 217, as well as Millers Ferry Section; Table 6).

In order to speculate about the causes of the extinctions of the austral taxa it is necessary to explore their paleoecological preferences. Their paleogeographic distribution is used below to infer these preferences.

\section{(b) Paleogeographic distribution of austral taxa}

Austral calcareous nannoplankton species have been reported extensively from the southern Atlantic and southern Indian Ocean (Table 7; Figure 62), but no reports of austral taxa from the southern Pacific Ocean could be located. No early Maestrichtian sediments have been recovered in the South Pacific, except maybe in DSDP Hole 208, where the exact age of the sediment is unclear. None of the ODP Legs in the extratropical South Pacific (Legs 133 and 135) recovered Cretaceous sediments. Five DSDP Legs (Legs 21, 28, 29, 35, and 90) took place in extratropical latitudes in the South Pacific Ocean. Only in one DSDP Hole (Hole 208, Lord Howe Rise, southwestern Pacific Ocean, Leg 21) were sediments recovered that are older than the $\underline{\mathrm{N}}$. frequens Zone (? $\underline{\mathrm{L}}$. quadratus Zone sensu Bukry, [1973a] which extends from the early to the early late Maestrichtian; Bukry, 1973b) and older than the A. mayaroensis Zone (Webb, 1973). Huber (1992b) studied the planktonic foraminifera in Hole 208 and concluded that the age of the Maestrichtian sediments was late early and early late Maestrichtian. Only the more abundant nannofossil taxa were listed (Edwards, 1973; Bukry, 1973b) and Bukry (1973) commented on the high latitude aspect of the assemblage which contained common $\underline{A}$. cymbiformis, $\underline{L}$. cayeuxii, and $\underline{\mathrm{K}}$. magnificus, while $\underline{\mathrm{W}}$. barnesae was absent (Bukry, 1973b). It is possible that austral nannofossil taxa are present in very low abundances in Hole 208.

In the North Sea region where Campanian and Maestrichtian calcareous nannoplankton assemblages have been thoroughly investigated, only few austral taxa occur. Biscutum dissimilis, $\underline{B}$. magnum, and $\underline{M}$. quaternarius have been reported from England and northern Germany (e.g. Burnett, 1990). Their first and last occurrences were used for a stratigraphic subdivision of the Campanian (Burnett, 1990). Burnett (1990) did not indicate the abundance of these three taxa, nor did she supply a species list to indicate whether any other austral taxa were observed. It appears that most of the austral taxa, if present, were much rarer in the northern hemisphere than in the southern. I 
Table 7: List of sites where austral nannofossil taxa were reported. The sites are arranged in geographic order, from the western South Atlantic Ocean to the eastern Indian Ocean.

Site

DSDP Hole 327A

DSDP Hole 511

ODP Hole $700 \mathrm{~B}$

ODP Holes 689B, 690C

DSDP Hole 249

ODP Hole 738C

ODP Holes 747A, 748C, 750A

ODP Holes 752B, 754A

ODP Holes $762 \mathrm{C}$

DSDP Hole 217

ODP Hole $758 \mathrm{~A}$
Location

Falkland Plateau

Falkland Plateau

East Georgia Basin

Maud Rise

Mozambique Plateau

Kerguelen Plateau

Kerguelen Plateau

Broken Ridge

Exmouth Plateau

Ninetyeast Ridge $\left(8^{\circ} \mathrm{N}\right)$ Wind, 1979

Ninetyeast Ridge $\left(5^{\circ} \mathrm{N}\right)$ Resiwati, 1991
Wise and Wind, 1977

Wise, 1983

Crux, 1991

Pospichal and Wise, 1990

Wind, 1979

Wei and Thierstein, 1991

Watkins, 1992

Resiwati, 1991

Bralower and Siesser, 1992 


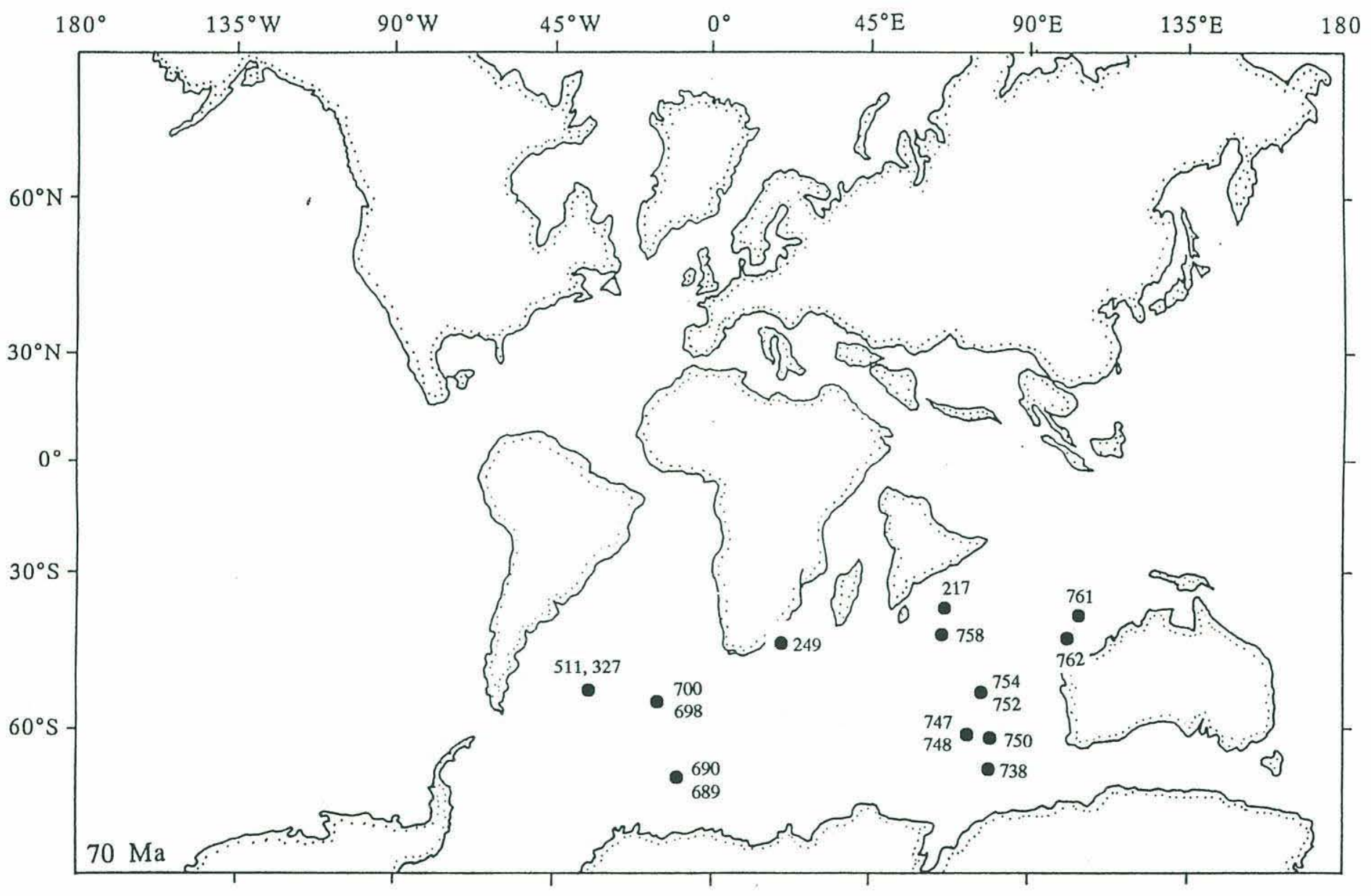

Figure 62: DSDP and ODP sites where austral taxa were recorded.

Paleocontinental reconstruction after Coffin et al. (1992). 
encountered a single specimen of $\underline{B}$. $\underline{\text { magnum }}$ in the upper Maestrichtian ( $\underline{M}$. prinsii Zone) of the Millers Ferry section (paleolatitude $\sim 30^{\circ} \mathrm{N}$ ). Biscutum dissimilis disappeared earlier in the northern hemisphere (late Campanian, Burnett, 1990) than in high southern latitudes (early Maestrichtian, this study). Crux (1991) indicates that the last occurrence of B. magnum was apparently synchronous in high latitudes in both hemispheres (in Chron C31R). Biscutum coronum was reported from upper Campanian sediments in Japan (Okada et al., 1987) where this species was commonly present (1-10\% of the assemblage: Okada et al., 1987).

It appears that most austral calcareous nannoplankton taxa were restricted to the southern Atlantic and southern Indian Ocean during the late Campanian and early Maestrichtian. Some exceptions to this rule have been reported above and future investigations will possibly record other austral taxa from regions where they are still unknown (such as the southern Pacific Ocean).

(c) Why did austral calcareous nannoplankton species become extinct?

The paleogeographic restriction of the austral taxa and the cause of their disappearance are not fully understood. Apparently (i) the extinctions did not occur simultaneously among the austral taxa (although they were concentrated close to the end of the B. magnum Biochron; Figure 65) and (ii) at the same time numerous additional taxa disappeared from Hole 690C or became extremely rare.

In order to explain the pronounced changes that were observed in the Maestrichtian nannofossil assemblages in Hole 690C it is necessary to examine whether and in which way other organisms experienced changes around the early/late Maestrichtian boundary, and to integrate results from stable isotope investigations (planktonic foraminifera: Huber, 1990; benthic foraminifera: Thomas, 1990; stable isotopes: Barrera and Huber, 1990; Stott and Kennett, 1990).

\section{Additional evidence}

Planktonic Foraminifera: Planktonic foraminifera are excellently to well preserved in Maestrichtian sediments in Hole 690C. The slight changes in the proportion of benthic foraminifera throughout the Maestrichtian correlates with excellent preservation during most of the early Maestrichtian 
and good preservation during the earliest and the late Maestrichtian (Barrera and Huber, 1990; Huber, 1990). The austral nature of the assemblage is documented by the presence of five species that were restricted to high latitudes (Archaeoglobigerina australis. A. mateola, Globigerinelloides impensus, Hedbergella sliteri, Rugotruncana circumnodifer; Huber, 1990), by low diversity (compared to tropical and subtropical assemblages), and by the absence or rareness of typical tropical taxa. The diversity of the planktonic assemblage was low during the early early Maestrichtian (around 10 species); it increased in the late early Maestrichtian to $\sim 12-14$ species and remained at that level during the late Maestrichtian (Huber, 1990). The diversity increased due to the first occurrences of five taxa (Globotruncana subcircumnodifer, $\underline{G}$. bulloides, Globotruncanella petaloidea, Globigerinelloides subcarinatus, Globotruncanella citae, Pseudotextularia elegans; Huber, 1990, 1992b) which were known from lower latitudes where their first occurrences are (in some cases considerably) older than on Maud Rise. The poleward migrations of species typical of lower latitudes could be interpreted as warming pulses of surface waters at high latitudes. However, evidence from stable isotopes does not support such an interpretation (Huber, 1990). Paleoceanographic factors other than temperature, such as changes in nutrient supply, salinity, vertical stratification and/or surface water turbidity must be invoked to explain the planktonic foraminiferal patterns (Huber, 1990). Huber (1992a) and Huber and Watkins (1992) suggested that the poleward expansions of low latitude species may have been due to increased stratification of surface waters. Stable isotope records, however, do not seem to support this contention (see below).

Benthic Foraminifera: Benthic foraminiferal assemblages changed moderately between the early and the late Maestrichtian and the changes are sufficient to allow recognition of two assemblages (Thomas, 1990): assemblage 8 ranged throughout the early Maestrichtian and was replaced by assemblage 7 in the early late Maestrichtian (at $\sim 69.4 \mathrm{Ma}$; boundary between subchrons $31 \mathrm{R}$ and $31 \mathrm{~N}$; Thomas, 1990). The differences between these assemblages were small compared to faunal changes at other times (Thomas, 1990) and the changes occurred gradually rather than abruptly. The differences between assemblages 8 and 7 include a slight increase in diversity, a decrease of the percentage of epifaunal species (from 52 to $43 \%$ ) and an increase of infaunal and cylindrical species (from 43 to 51\%; Thomas, 1990). In addition, the 
proportion of benthic to planktonic foraminifera increases at the boundary between assemblages 8 and 7; this increase may reflect decreasing preservation of planktonic foraminifera in the late Maestrichtian (see above, and compare e.g. Huber, 1990; Barrera and Huber, 1990). Variations in relative abundances of infaunal and epifaunal species in recent assemblages reflect variations in the availability of organic carbon to the bottom-dwelling fauna (Corliss and Chen, 1988). Thus the increase of infaunal species may be used to argue for increased productivity in surface waters (Thomas, 1990) or low oxygen content in the bottom water (see Thomas [1990] for a more detailed discussion). Thomas (1990) noted that neither of these arguments was supported by sedimentologic (Robert and Maillot, 1990) or stable isotope evidence (Barrera and Huber, 1990).

Stable isotopes: Barrera and Huber (1990) measured stable isotopes from planktonic and benthic foraminifera as well as from bulk sediment to investigate paleoenvironmental changes at high southern latitudes during the Maestrichtian.

The general trend of oxygen isotope values of planktonic and benthic foraminifera is an increase throughout the Maestrichtian (except for a short negative excursion at the very top of the Maestrichtian; Figure 63a). This indicates a longterm temperature decrease. The increase of $\delta^{18} \mathrm{O}$ values is not gradual but rather proceeds in a stepwise manner with steps at $\sim 73.5 \mathrm{Ma}$ and at about 71.0 Ma. The record of the benthic species Gavelinella beccariiformis shows both steps whereas only the earlier increase is evident in the $\delta^{18} \mathrm{O}$ record of Globigerinelloides multispinatus. The second increase (at $71.0 \mathrm{Ma}$ ) is less apparent in G. multispinatus (only about $0.2 \%$ ). In constrast, the increase at $\sim 73 \mathrm{Ma}$ is not observed in the record of the planktonic species Archaeoglobigerina australis: its $\delta^{18} \mathrm{O}$ values remained roughly constant (average $-0.3 \%$ ) up to about $71 \mathrm{Ma}$, where an abrupt increase of about $0.5 \%$ occurred and subsequently a gradual increase to values similar to those of the benthic species.

The $\delta^{13} \mathrm{C}$ records of benthic and planktonic species vary roughly in parallel, with a constant offset of about $1 \%$ (Figure 63b). A gradual $\delta^{13} \mathrm{C}$ decrease occurred during the early Maestrichtian (from about 74.5 to $71.5 \mathrm{Ma}$ ); it culminated in a spike of very light $\delta^{13} \mathrm{C}$ values at $\sim 71 \mathrm{Ma}$. Carbon isotope ratios quickly rebounded from this negative excursion and around $70.2 \mathrm{Ma}$ the 

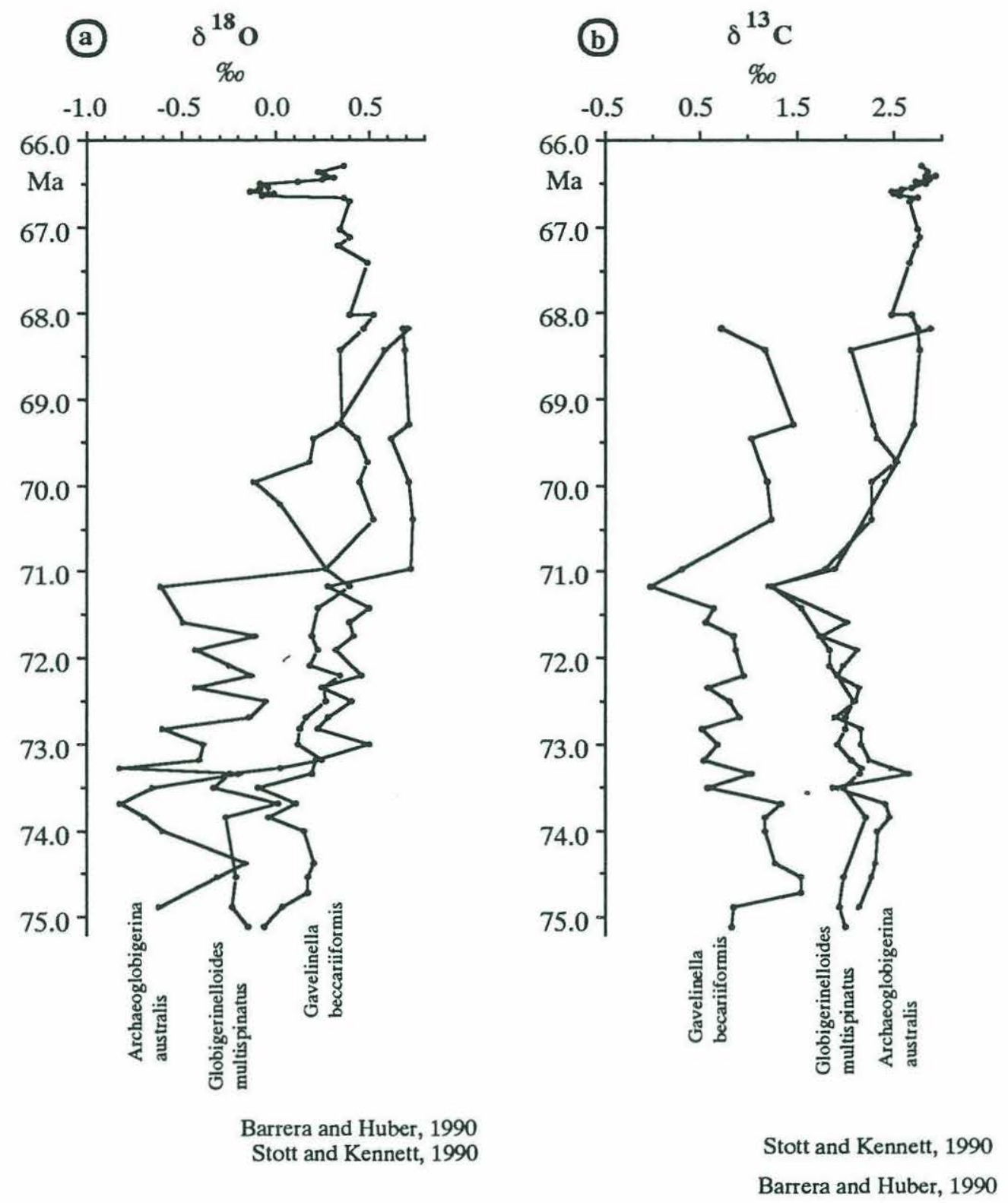

Figure 63: Stable isotope records from Maestrichtian sediments in southern high latitudes (ODP Hole 690C). Data from Barrera and Huber (1990) and Stott and Kennett (1990). 
values were higher than during the early Maestrichtian. For the late Maestrichtian the benthic $\delta^{13} \mathrm{C}$ record shows roughly constant values, while the planktonic record shows an increase that continued up to $\sim 67.5 \mathrm{Ma}$ (as recorded by Barrera and Huber, 1990).

Barrera and Huber (1990) discussed in detail the reliability of the stable isotope data from different foraminiferal species. They concluded that the isotopic values of $\underline{A}$. australis and of $\underline{G}$. beccariiformis reflect changes, respectively, in surface and bottom waters. They argued that $G$. multispinatus lived very close to the surface (based on observations from Seymour Island, Antarctica, where G. multispinatus was recorded abundantly in shallow water sediments; Huber, 1988) and that its $\delta^{13} \mathrm{C}$ record reflects surface water conditions, but that its $\delta^{18} \mathrm{O}$ record was modified by vital effects.

I would suggest, however, that the carbon and oxygen isotope data from Hole $690 \mathrm{C}$ indicate that $\underline{\mathrm{G}}$. multispinatus lived in deeper waters than $\underline{A}$. australis, except for an inversion of their respective $\delta^{18} \mathrm{O}$ and $\delta^{13} \mathrm{C}$ values between about 70 and $68.5 \mathrm{Ma}$. The oxygen isotope data indicate a cooling event at about 73.5 Ma that affected bottom waters and (possibly) the deeper thermocline. This cooling event did not affect surface waters (as recorded by A. australis). It should also be noted that a second cooling pulse occurred at about $71 \mathrm{Ma}$, which affected bottom and surface waters; the temperature decrease in surface waters was much more severe than that of bottom waters. This pronounced cooling of surface waters at $71 \mathrm{Ma}$ coincides with the conspicuous diversity decrease among calcareous nannofossils observed at ODP Site 690 .

The longterm shifts in both the benthic and the planktonic $\delta^{13} \mathrm{C}$ data indicate changing carbon reservoirs, possibly reflecting changing paleocirculation patterns (e.g. better mixing of water masses of the southern high latitudes with the rest of the world's oceans).

A pronounced but brief negative excursion in the $\delta^{13} \mathrm{C}$ record was documented in Hole 690C (Barrera and Huber, 1990): it began at the C32N/C31R boundary in the late early Maestrichtian (top of the $\underline{G}$. havanensis Zone, top of the $\underline{B}$. magnum Zone, $\sim 71.2 \mathrm{Ma}$ according to the age model herein; Figure 57). Its duration is difficult to assess due to incomplete core recovery, but it was probably no longer than $\sim 0.8 \mathrm{~m} . \mathrm{y}$. (and could have been shorter, depending on the age estimated for the core catcher of Core 113-690C-18). The spike to 
lighter $\delta^{13} \mathrm{C}$ values at $\sim 71 \mathrm{Ma}$ occurred at the same time as the cooling event of the entire water column (as expressed by the $\delta^{18} \mathrm{O}$ record) but a causal relation of these two trends is not apparent.

It is unlikely that this decline reflects decreased productivity (Berger and Vincent, 1986) because surface to deep water carbon isotope gradients remained unchanged (Barrera and Huber, 1990). Instead the negative $\delta^{13} \mathrm{C}$ spike could have resulted from decreased storage of organic carbon in shallow shelf areas due to a sea level fall at the early/late Maestrichtian boundary (Haq et al., 1987). Barrera and Huber (1990) interpreted the ensuing increase in the $\delta^{13} \mathrm{C}$ record as a consequence of the subsequent sea-level rise (via increased organic carbon burial on continental shelves).

If the negative carbon isotope spike is due to a global sea level fall, it should be a global feature. Only two sufficiently detailed Maestrichtian carbon isotope records are available for comparison (Figure 64). Mount et al. (1986) reported a negative carbon isotope excursion (Figure 64a) in the lowermost upper Maestrichtian (base of the A. mayaroensis Zone according to Herm, 1963; no paleomagnetic data available) from the Sopelana section in northern Spain. Also at Gubbio (Italy) the lowest $\delta^{13} \mathrm{C}$ values in the Maestrichtian (Corfield et al., 1991; Figure 64b) occur in the mid-Maestrichtian ( 71.5 Ma) shortly before the beginning of Magnetozone C31 (paleomagnetic data of Alvarez et al., 1977).

This suggests that the negative carbon isotope excursion may indeed be a global feature reflecting the sea level fall at the early/late Maestrichtian boundary. The carbon isotope data do not indicate a productivity increase (as suggested by benthic foraminiferal changes), since the offset between planktonic and benthic species remained constant throughout the record.

Summary: Numerous nannoplankton taxa disappear from high southern latitudes around the early/late Maestrichtian boundary ( 71 Ma). Planktonic and benthic foraminifera suggest paleoceanographic changes during the Maestrichtian, but in these latter groups the changes are less pronounced than in the calcareous nannoplankton. No evidence is available to speculate about the influence of salinity changes on changes in calcareous nannoplankton. In the following the evidence for changes of temperature, nutrients, turbidity, and stratification of surface waters as causes for the observed biospheric changes will be briefly discussed. 

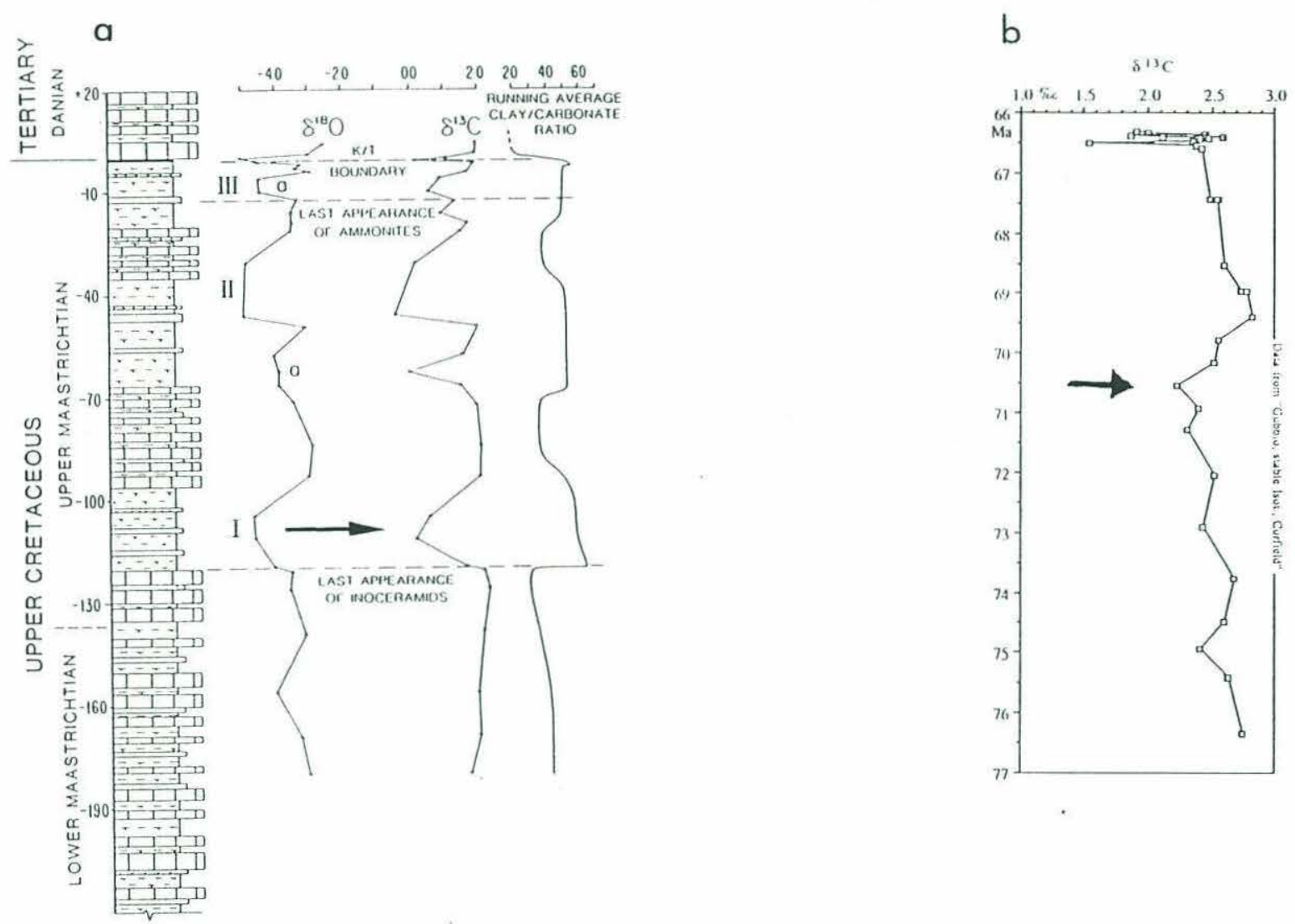

Figure 64: Stable carbon isotope records from the Maestrichtian in two low latitude sections. (a) Zumaya, northern Spain (data from Mount et al., 1986). (b) Gubbio, Italy (data from Corfield et al., 1991): The arrows marks the low $\delta^{13} \mathrm{C}$ values that are thought to reflect the global sea level drop at the early/late Maestrichtian boundary. 
Temperature: Huber (1990) pointed out that a discrepancy existed if the immigration of tropical planktonic taxa into high latitudes during the late Maestrichtian were interpreted as a warming signal, since the stable isotope record indicates cooling. Instead he suggested a solution to this dilemma by proposing that an oceanic front separated the austral realm from mid-latitudes during the late Campanian and early Maestrichtian (Huber, 1992a). He speculated that this oceanic front vanished at the early/late Maestrichtian boundary and that austral surface waters became more stratified. However, a decrease in the interspecific $\delta^{18} \mathrm{O}$ gradient among planktonic foraminifera at the early/late Maestrichtian boundary (Barrera and Huber, 1990) seems to contradict this speculation (see below).

Several nannoplankton species disappeared from (or became very rare in) high latitudes around the early/late Maestrichtian boundary but persisted until the end of the Maestrichtian in mid- and low latitudes (as discussed above). This is interpreted here as a response to cooling in high latitudes as indicated by the oxygen isotope record. In contrast, the group of austral taxa became extinct at about the same time. I would suggest that the extinctions of the austral taxa were not a consequence of decreasing water temperature, because if they were temperature sensitive they would have migrated into lower latitudes. Instead I propose that the extinctions of the austral taxa were a consequence of changes in nutrient availability, stratification of the photic zone, turbidity or salinity changes brought about by circulation changes caused by a sea level fall.

A higher percentage of terrigenous components in early Maestrichtian sediments (compare Figure 6 in the chapter on Chronology) may indicate higher turbidity during this time and some changes among the calcareous plankton may be due to this fact. Comparison with other high latitude sites is needed to indicate whether mid-Maestrichtian changes correlate everywhere with sedimentologic changes.

A change in the stratification of surface waters from early to late Maestrichtian at high southern latitudes is inferred from the stable oxygen isotope record. If the $\delta^{18} \mathrm{O}$ record of $\underline{\mathrm{G}}$. multispinatus is considered to reflect conditions in deeper surface waters and that of $\underline{A}$. australis to reflect those in shallow surface waters, it seems that the temperature differences within the mixed layer were larger during the late early Maestrichtian than during the 
early late Maestrichtian (Figure 63a). A higher temperature gradient in surface waters during the early Maestrichtian may indicate that the thermocline was shallower than during late Maestrichtian. This may imply that the stratification of surface waters decreased from the early to the late Maestrichtian. A decrease in the stratification of surface waters would have facilitated the advection of nutrients into the photic zone, and I would suggest that it was increased surface water fertility that caused the extinction of the austral taxa. This argument is consistent with investigations of recent calcareous nannoplankton: it has been documented that coccolithophorids dominate the phytoplankton under oligotrophic conditions (Smayda, 1980) and that nannoplankton diversity is higher in the oligotrophic open ocean than in eutrophic marginal seas (Okada and Honjo, 1975).

A decrease of surface water stratification is in contrast to the argument of Huber and Watkins (1992) who interpreted the migration of tropical planktonic foraminiferal species to high southern latitudes during the late Maestrichtian as a reflection of increased surface water stratification during the late Maestrichtian.

The following observations are summarized:

(i) Eleven taxa are considered as "austral taxa". All of them were restricted to, or particularly abundant in, high southern latitudes, and all of them became extinct between $\sim 72.4$ and $\sim 70.4$ Ma (most of the extinctions were concentrated between 71.1 and $70.4 \mathrm{Ma}$ ).

(ii) The austral taxa constituted about one third of all taxa present in southern high latitudes, and $\sim 20 \%$ of the assemblage.

(iii) I suggest that the extinctions of most of the austral taxa were a consequence of increased nutrient availability and decreased surface water stratification. The extinctions coincide with a $\delta^{13} \mathrm{C}$ excursion that probably reflects a sea level fall.

(B) Nannoplankton Response to Environmental Perturbations During the Last 500 ky of the Cretaceous

a) High latitude evidence

The following discussion relies mostly on nannofossil and stable isotope data from ODP Hole 690C because no other record of comparable resolution or duration is available. 
At high southern latitudes the following nannoplankton trends occurred during the last $500 \mathrm{ky}$ of the Cretaceous (Figure 65): Between $\sim 66.70$ and 66.57 Ma Placozygus fibuliformis (Figure 65a) was more abundant in the nannoplankton association than either before or afterward. This species reached peak abundances of $\sim 5-6 \%$. An almost exactly opposite abundance pattern was recorded for the species Lucianorhabdus cayeuxii and Micula staurophora (Figure $65 \mathrm{~b}, \mathrm{c}$ ). Both taxa were present prior to $\sim 66.76 \mathrm{Ma}$, disappeared almost completely between $\sim 66.76$ and $66.62 \mathrm{Ma}$, and were present again between $66.62 \mathrm{Ma}$ and $66.4 \mathrm{Ma}$.

A fairly detailed stable isotope record from the uppermost Maestrichtian in Hole 690C was presented by Stott and Kennett (1990). Direct comparison of this record with the nannoplankton abundance patterns is difficult because the resolution of the stable isotope study is much coarser than that of the nannoplankton abundance records in this study. In addition, the stable isotope changes measured on different foraminiferal species or on the fine fraction are not exactly synchronous. The highest resolution was achieved in the stable isotope record of the planktonic foraminifera Globigerinelloides multispinatus and this record was used for comparison with the nannoplankton abundance changes in the following discussion (Figure 65d, e).

A fairly abrupt decrease in $\delta^{18} \mathrm{O}$ values $(\sim 0.5 \%)$ occurred at $\sim 66.65 \mathrm{Ma}$, values remained low until $\sim 66.50 \mathrm{Ma}$, and then increased again abruptly (by $\sim 0.5 \%$; compare Figure $65 \mathrm{~d}$ ). This brief negative excursion was observed in planktonic as well as in benthic foraminferal species and was interpreted by Stott and Kennett (1990) as a warming pulse of $\sim 2^{\circ} \mathrm{C}$. Alternatively, this $\delta^{18} \mathrm{O}$ excursion could indicate a brief episode of decreased salinity. A $\delta^{18} \mathrm{O}$ decrease of $0.5 \%$ corresponds to a salinity decrease of $\sim 1.7 \%$ according to Craig (1966), and $\sim 0.8 \%$ according to Craig and Gordon (1965). Palynomorph evidence from Seymour Island (off the Antarctic Peninsula) suggests a brief warming interval in the latest Maestrichtian (Askin, 1989). The oxygen isotope excursion is interpreted here as a brief warming pulse rather than a salinity decrease. A warming pulse during the latest Maestrichtian (at the base of Magnetochron 29) was also reported from the North American interior based 


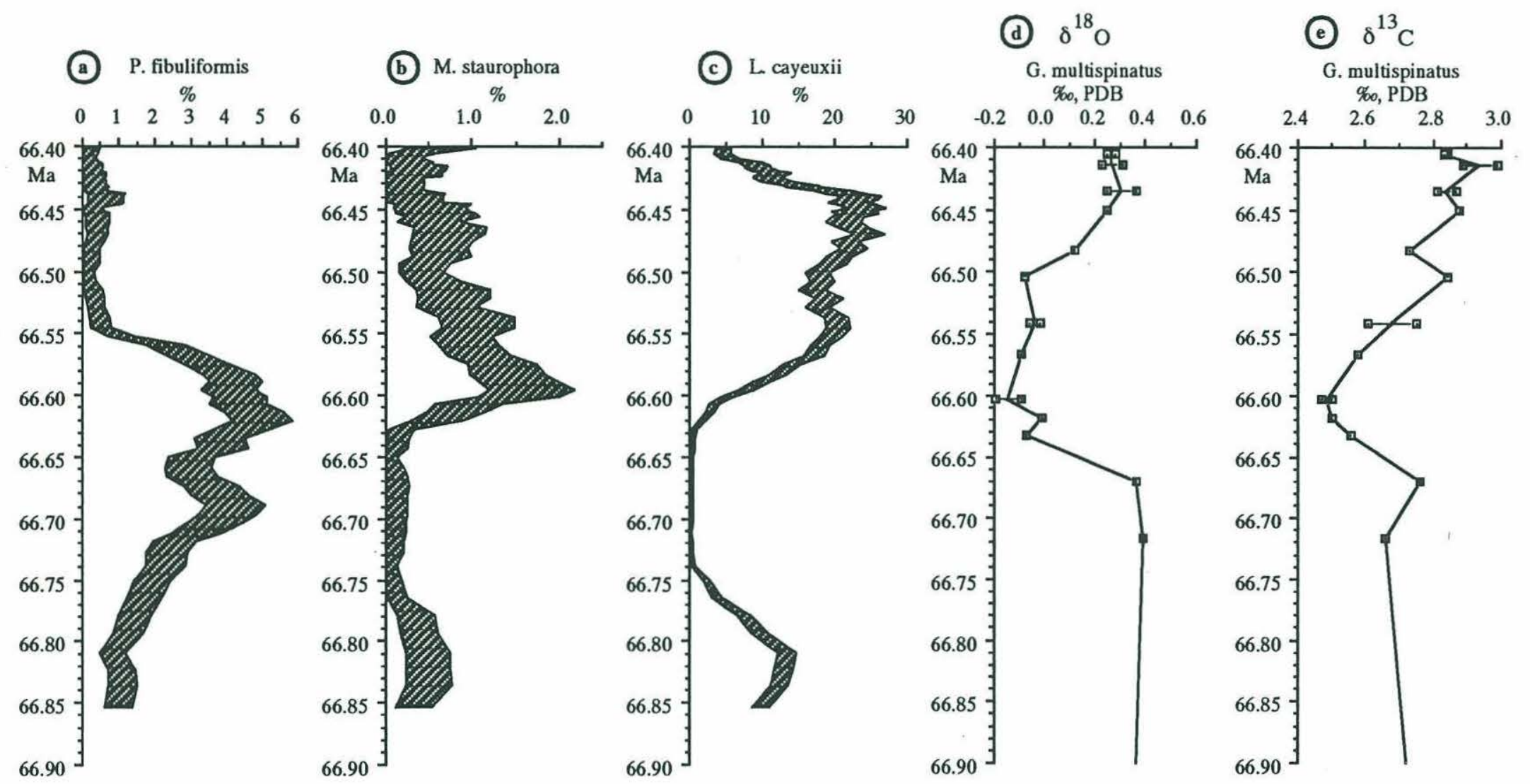

Figure 65: Abundance variations in three calcareous nannoplankton taxa

(Placozygus fibuliformis, Micula staurophora, Lucianorhabdus cayeuxii) and stable isotope records from southern high latitudes (ODP Hole 690C). The relative abundance of the nannoplankton taxa wer calculated under exclusion of Prediscosphaera stoveri. A running five point average was calculated and the shaded band represents the approximate 95\% confidence interval (after Mosiman, 1965). Stable isotope data from Stott and Kennett, 1990). 
on plant fossils (Johnson, 1992). This may indicate that the warming pulse in the latest Maestrichtian was not restricted to high southern latitudes.

The $\delta^{13} \mathrm{C}$ record of $\mathrm{G}$. multispinatus shows increasing values between $\sim 66.6$ and $66.4 \mathrm{Ma}$ but the $\delta^{13} \mathrm{C}$ record of $\underline{\mathrm{A}}$. mayaroensis decreased during the same interval; this latter record is discarded in this discussion because of very few data points. Stott and Kennett (1990) reported that the $\delta^{13} \mathrm{C}$ increase prior to the K/P boundary in Hole $690 \mathrm{C}$ was part of a global pattern reflecting a redistribution of carbon between different reservoirs. Zachos et al. (1989) suggested that the positive $\delta^{13} \mathrm{C}$ excursion prior to the $\mathrm{K} / \mathrm{P}$ boundary in the equatorial Pacific (Site 577) may have been caused by changes in circulation.

The increased abundances of $\underline{\mathrm{P}}$. fibuliformis and its abrupt decline between $\sim 66.60$ and $66.55 \mathrm{Ma}$ does not correlate with any of the observed stable isotope changes (Figure 65a). A similar lack of correlation of calcareous nannoplankton abundance patterns and stable isotope variations was also reported in the late Miocene of the North Atlantic (Beaufort and Aubry, 1990) and in the Miocene of the southern Indian Ocean (Beaufort and Aubry, 1992). Placozygus fibuliformis was observed more abundantly in mid- and low latitudes (this study), but it is unresolved whether this biogeographic pattern reflects temperature preferences.

Lucianorhabdus cayeuxii (Figure 65b) was present between $\sim 66.85$ and $66.75 \mathrm{Ma}$, it was absent between $\sim 66.74$ and $66.62 \mathrm{Ma}$. This species started to increase in abundance at $\sim 66.62 \mathrm{Ma}$, reached maximum values $(\sim 20 \%)$ at $\sim 66.55$ $\mathrm{Ma}$, remained at these high values $66.43 \mathrm{Ma}$, and decreased in abundance to comparatively low values $(<5 \%)$ between 66.43 and $66.40 \mathrm{Ma}$. Insufficient stable isotope data points are available to elucidate the interval between 66.85 and $66.76 \mathrm{Ma}$ (Figure $65 \mathrm{~d}$, e). The beginning of the abundance increase of $\underline{\mathrm{L}}$. cayeuxii started as soon as the warming pulse was fully established (based on the $\delta^{18} \mathrm{O}$ record of $\underline{\mathrm{G}}$. multispinatus). No decline in the abundance of $\underline{\mathrm{L}}$. cayeuxii is observed between $\sim 66.5$ and $66.45 \mathrm{Ma}$ when the $\delta^{18} \mathrm{O}$ record of $\underline{\mathrm{G}}$. multispinatus indicated that surface water temperatures cooled again. An abundance decrease of $\underline{L}$. cayeuxii was recorded only when temperatures had dropped to the same values as before the warming pulse (between $\sim 66.45$ and $66.40 \mathrm{Ma} ; \delta^{18} \mathrm{O}$ record of $\underline{\mathrm{G}}$. multispinatus). These patterns may indicate that $\underline{\mathrm{L}}$. 
cayeuxii thrived during the maximum of the warming pulse and also during its decline, but that it decreased in abundance when temperatures fell below a certain threshold value. The implied temperature sensitivity of $\underline{L}$. cayeuxii is not reflected by any abundance changes during the incipient phase of the warming pulse (between $\sim 66.76$ and $66.62 \mathrm{Ma}$ ), when the change in water temperature was almost the mirror image of that recorded between $\sim 66.5$ and 66.45 Ma. A similar, non-linear correlation of $\underline{L}$. cayeuxii with temperature is also apparent from previously published abundance patterns of this species: due to its abundance peak in high latitudes Lucianorhabdus cayeuxii is considered a high latitude taxon possibly indicative of cooler surface waters (Thierstein, 1981) but Worsley (1974) pointed out that in high latitudes this species was present during the entire Maestrichtian, while in low latitudes it occurred only during the early Maestrichtian. My data indicate that this taxon did not disappear completely from mid- and low latitudes, since it was recorded very rarely in all mid- and low latitude sections (Table 6). Worsley (1974) did not report ex́actly at what time $\underline{\mathrm{L}}$. cayeuxii disappeared from (or became very rare in) low latitudes, but my data suggest that its disappearance/abundance decrease must have occurred prior to $\sim 71 \mathrm{Ma}$. The reason for the disappearance of $\underline{L}$. cayeuxii from low latitudes is unclear, because low latitude surface waters cooled during the Maestrichtian (e.g. Douglas and Savin, 1975) and should have become more hospitable for a high latitude dweller. I conclude that $\underline{L}$. cayeuxii cannot be considered a temperature indicator exclusively.

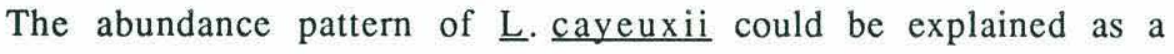
consequence of circulation changes (and nutrient availability?) as expressed by the changes in the $\delta^{13} \mathrm{C}$ record because the beginning abundance increase of $\underline{\mathrm{L}}$. cayeuxii at $\sim 66.61 \mathrm{Ma}$ coincides with the increase in the $\delta^{13} \mathrm{C}$ of $\underline{\mathrm{G}}$. multispinatus (Figure $65 \mathrm{~b}, \mathrm{e}$ ). However, no changes in the $\delta^{13} \mathrm{C}$ record are discernible while $\underline{L}$. cayeuxii decreased in abundance (between $\sim 66.45$ and $66.40 \mathrm{Ma})$.

Micula staurophora increased sharply in abundance at $\sim 66.62 \mathrm{Ma}$ (Figure 65c), reached peak abundances of almost $2 \%$ at $66.60 \mathrm{Ma}$ and gradually decreased in abundance to $<0.5 \%$ between 66.60 and 66.40 Ma. The peak abundance at $66.60 \mathrm{Ma}$ coincided exactly with the beginning of the warming pulse indicated by the $\delta^{18} \mathrm{O}$ record. It is possible that the increased abundance values of $\underline{\mathrm{M}}$. staurophora at $66.60 \mathrm{Ma}$ were caused by increased water 
temperatures. The interpretation of $\underline{M}$. staurophora as a temperature sensitive taxon is in agreement with its latitudinal distribution during the Maestrichtian (Wind, 1979a; Thierstein, 1981) and has been proposed previously (Doeven, 1983). However, the decrease in abundance of $\underline{M}$. staurophora between 66.60 and $66.50 \mathrm{Ma}$, when oxygen isotope data still indicated high surface water temperatures remains unexplained. It is possible that changes in the circulation pattern (suggested by the $\delta^{13} \mathrm{C}$ record; Figure $65 \mathrm{e})$ led to the establishment of deleterious environmental conditions for $\underline{M}$. staurophora.

From the stable isotope results and the nannofossil patterns in the uppermost Maestrichtian in Hole 690C the following conclusions can be reached:

(i) Stable isotope data of higher resolution are required to determine unambiguously the timing of the oxygen and carbon isotope changes.

(ii) The negative $\delta^{18} \mathrm{O}$ excursion between $\sim 66.60$ and $66.40 \mathrm{Ma}$ is interpreted as a warming pulse of $\sim 2^{\circ} \mathrm{C}$ and not as a low-salinity signal, because it affected the entire water column and independent evidence from plant fossils also suggests a short period of elevated temperatures.

(iii) The abundance changes of most calcareous nannoplankton taxa do not correlate with the $\delta^{18} \mathrm{O}$ variations ("warming pulse").

(iv) The abundance increase of $\underline{M}$. staurophora may be a consequence of increased surface water temperatures; its decrease during times of elevated surface water temperatures is not satisfactorily understood. It is possible that changes in ocean circulation as indicated by the $\delta^{13} \mathrm{C}$ record led to environmental changes that were deleterious for this species.

(v) The elevated abundances of $\underline{L}$. cayeuxii between $\sim 66.62$ and $\sim 66.45$ can be interpreted as a consequence of increased nutrient availability. It is possible that the abundance decrease of $\underline{L}$. cayeuxii between $\sim 66.45$ and $66.40 \mathrm{Ma}$ reflects cooler surface waters.

(vi) The abundance changes of $\underline{\mathrm{P}}$. fibuliformis, especially the abrupt decrease between 66.60 and $66.55 \mathrm{Ma}$ does not correlate with variations in the stable isotope records suggesting that this species did not respond linearly to changes recorded by the stable isotopes (e.g. temperature changes, nutrient availability, etc). 


\section{(b) Mid-latitude trends}

Changes in abundance of selected nannoplankton species were observed to occur in mid-latitudes but the species which displayed the most pronounced changes were different in the Atlantic and the Indian Ocean. In the mid-latitude Atlantic Ocean (Hole 528) the abundance changes of selected taxa occurred around 67.0 Ma (Figure 66). Biscutum constans, $\underline{\text { C. kamptneri }}$, and E. parallelus (Figure 66a, b, c) decreased significantly in abundance at that time, whereas T. macleodae (Figure 66d) increased. Zygodiscus sp. 1 (Figure 66e) also fluctuated significantly in abundance; this species reached an abundance peak between $\sim 66.70$ and $66.60 \mathrm{Ma}$. No sufficiently detailed stable isotope records are available to compare with the nannoplankton abundance changes. Biscutum constans has been interpreted as a fertility indicator (Roth and Bowdler, 1981) and it is possible that its decrease in abundance between $\sim 67.1$ and $67.0 \mathrm{Ma}$ reflects a reduction in nutrient availability at that time. If this is the case, then the abundance changes of $\underline{C}$. kamptneri, E. parallelus and I. macleodae may also result from decreased nutrient availability. However, these conclusions are tentative until more detailed stable isotope records are available. No detailed nannoplankton records from the same time interval ( 67 $\mathrm{Ma}$ ) are available for comparison from the other sections studied. The cause for the abundance increase of $\underline{Z y g o d i s c u s} \mathrm{sp.} 1$ remains unclear at the moment.

In the sections investigated in the mid-latitude Indian Ocean (Holes 761B and 217) similar taxa display abundance variations: in both holes $\underline{N}$. frequens, C. daniae, and Vagalapilla spp. increase in abundance during the last $\sim 100 \mathrm{ky}$ of the Maestrichtian (Figures 67 and 68). These three taxa are well known for their abundance maxima in high latitudes (e.g. Thierstein, 1981). There is some evidence (see discussion below) that $\underline{N}$. frequens is indicative of cooler water temperatures and it is suggested that the abundance increase of this species in the mid-latitude Indian Ocean indicates cooling of surface waters during the last $\sim 100 \mathrm{ky}$ of the Maestrichtian. The concomitant abundance increase of two other high latitude taxa ( $\underline{C}$. daniae and Vagalapilla spp.) seems to support this argument.

An abundance decrease of $\underline{P}$ fibuliformis was recorded in both Indian Ocean sites after $\sim 66.65 \mathrm{Ma}$, but whereas this decrease occurs gradually ( 66.65$66.40 \mathrm{Ma}$ ) in Hole $761 \mathrm{~B}$ (Figure $67 \mathrm{~d}$ ) it is fairly abrupt ( 66.65-66.60 Ma) in 


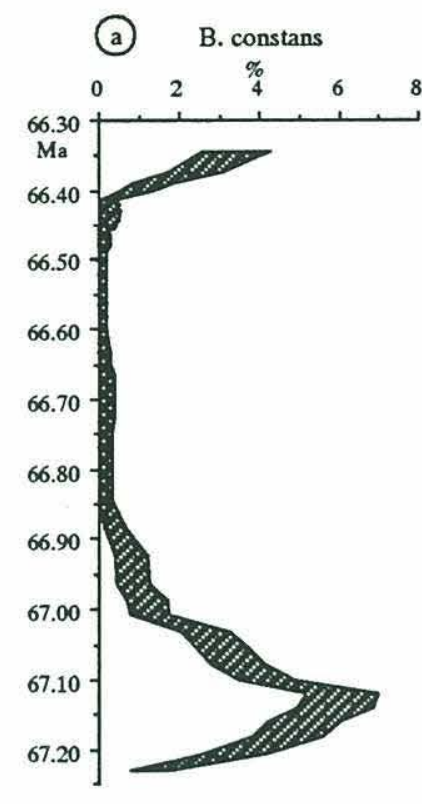

(b) C. kamptneri

(c) E. parallelus
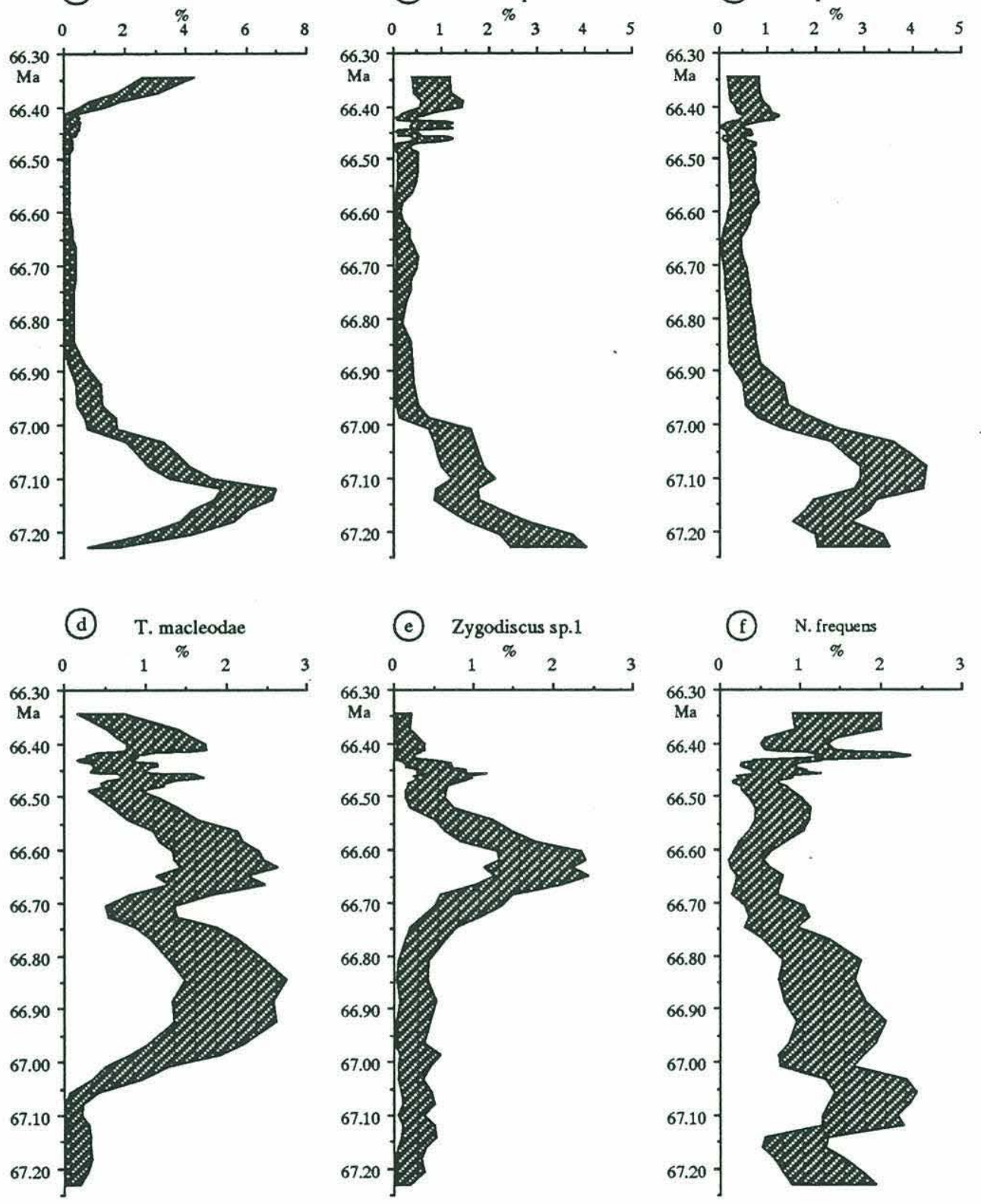

Figure 66: Abundance variations of selected calcareous nannoplankton taxa in mid-latitudes in the Atlantic Ocean (DSDP Hole 528). A running five point average was calculated on the data and the shaded band represents the $95 \%$ confidence interval. The Cretaceous/Paleocene boundary lies at $66.4 \mathrm{Ma}$. 

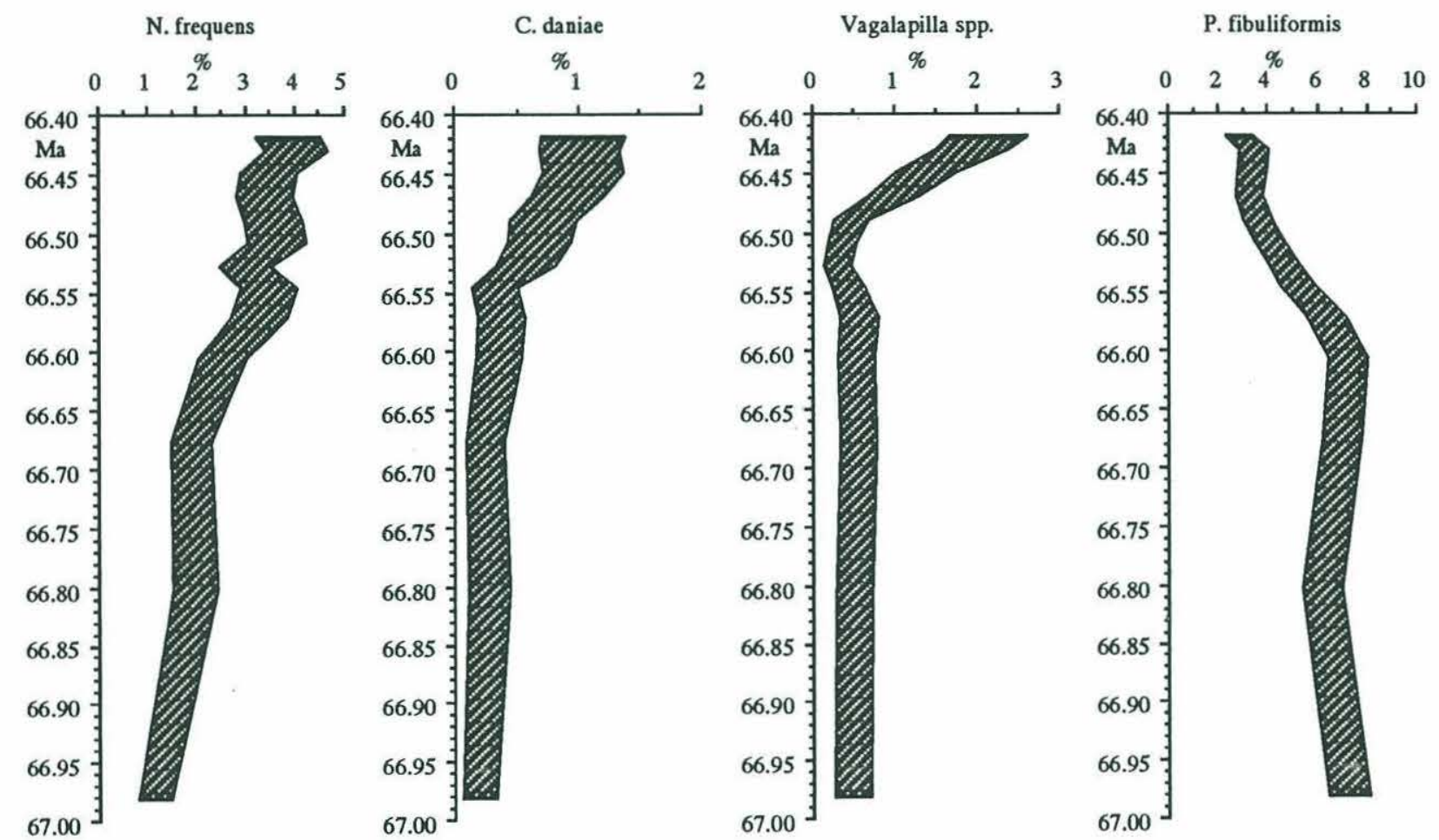

Figure 67: Abundance variations of selected calcareous nannoplankton taxa in mid-latitudes in the Indian Ocean (ODP Hole 761B). The Cretaccous/Paleocene boundary lies at $66.4 \mathrm{Ma}$. See note in caption of Figure 57. 

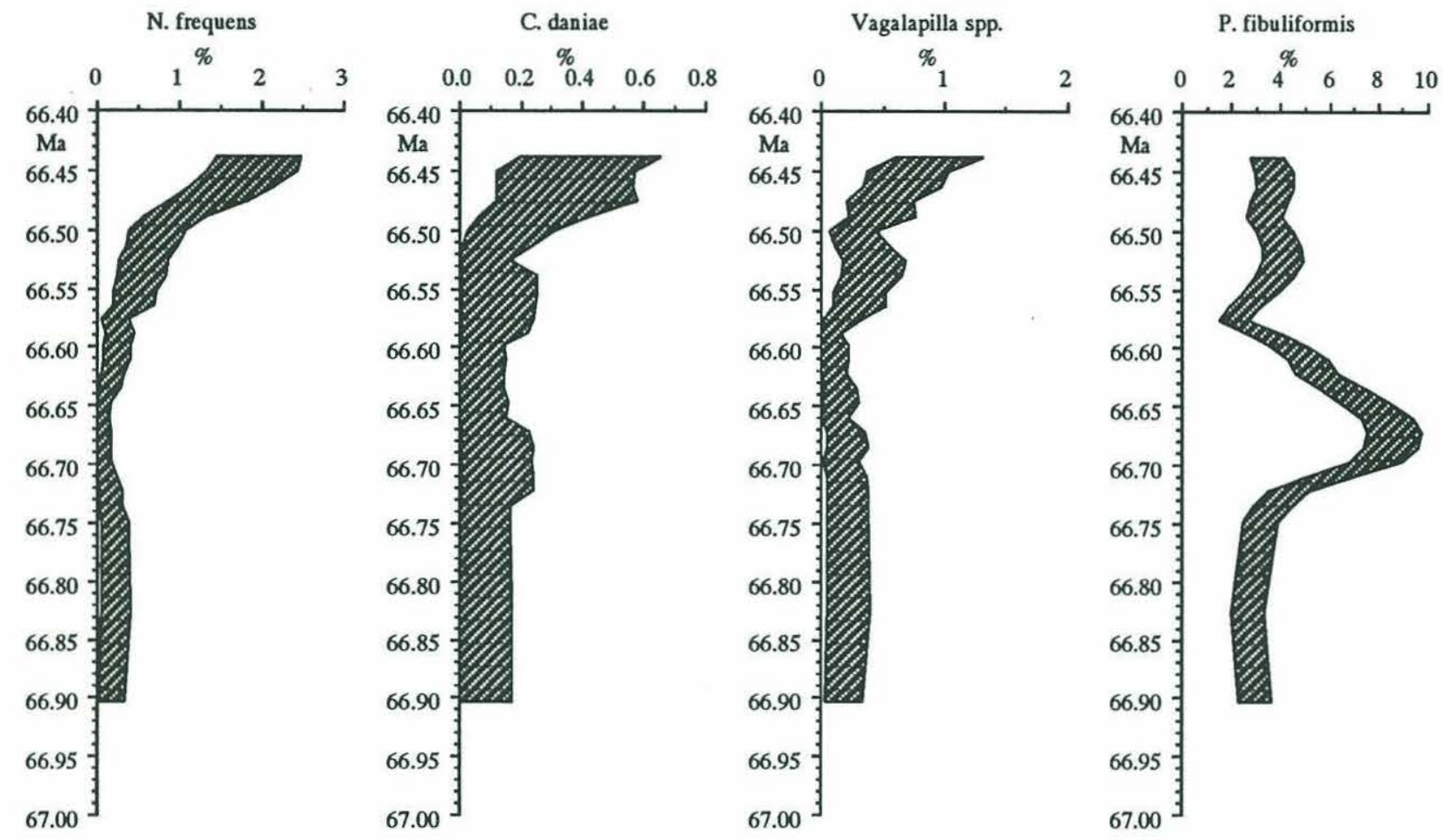

Figure 68: Abundance variations of selected calcareous nannoplankton taxa in mid-latitudes in the Indian Ocean (ODP Hole 217). The Cretaceous/Paleocene boundary lies at $66.4 \mathrm{Ma}$. See note in caption of Figure 57. 
Hole 217 (Figure 68d). In fact the abundance pattern of $\underline{P}$. fibuliformis in Hole 217 is similar to that observed in high southern latitudes (Hole 690C, Figure $65 a)$; it also occurred virtually at the same time at these two sites. No comparable abundance fluctuations of this species were observed in the midlatitude Atlantic Ocean.

The fact that different nannoplankton species displayed significant abundance fluctuations during the last $\sim 500-800 \mathrm{ky}$ of the Maestrichtian is interpreted here as a consequence of different environmental changes (possibly reflecting different water masses) in the high southern Atlantic Ocean, the mid-latitude Atlantic Ocean and the mid-latitude Indian Ocean. No species displayed comparable abundance variations during the latest Maestrichtian in the different ocean basins covered here. The similarity of the abundance record of $\underline{\mathrm{P}}$. fibuliformis between the high southern Atlantic Ocean and the mid-latitude Indian Ocean is considered an exception.

In contrast to the heterogeneous short term ( $500-800 \mathrm{ky})$ abundance fluctuations, some species showed similar long term (throughout the entire Maestrichtian) abundance trends in all ocean basins. These trends are discussed below.

\section{(C) Paleoenvironmental Significance of Selected Nannoplankton} Species.

\section{(a) Previous Studies}

Geographic abundance gradients of Mesozoic nannoplankton species have been interpreted as a consequence of environmental differences. Latitudinal abundance gradients were most often explained as an expression of temperature preference (e.g. Thierstein, 1976; Thierstein, 1981; Wise, 1983). The other environmental parameters invoked were nutrient availability (e.g. Roth and Bowdler, 1981) and water depth (e.g. Thierstein, 1976).

Roth and Bowdler (1981) investigated mid-Cretaceous nannoplankton abundance patterns and observed abundance differences of numerous taxa between continental margin and oceanic associations. In neritic nannoplankton associations they observed comparatively rapid fluctuations of species abundances and monospecific horizons (which they explained as "blooms" of certain taxa during increased nutrient availability). These authors 
explained the nannoplankton patterns in the neritic sites as a consequence of high nutrient availability near continental margins and denoted those taxa that were more abundant in neritic sections (․․ constans, $\underline{Z}$. erectus, $\underline{Z}$. elegans, $\underline{Z}$. diplogrammus, Corollithion sp.) as high fertility indicators. Based on inverse reasoning Roth and Bowdler (1981) identified nannoplankton species that they considered low fertility indicators ( $\underline{W}$. barnesae, $\underline{R}$. splendens, $\underline{R}$. asper, possibly L. carniolensis). Roth and Krumbach(1986) expanded the data set of Roth and Bowdler (1981) and applied more sophisticated statistical analyses, confirming the previous findings. In order to exclude poorly preserved samples from their data Roth and Bowdler (1981) and Roth and Krumbach (1986) discarded samples in which the solution resistant species $\underline{W}$ barnesae constituted $>40 \%$ of the nannofossil assemblage.

Watkins (1989) examined calcareous nannofossil assemblages from Cenomanian-Turonian rhythmically bedded pelagic carbonates of the Western Interior (Greenhorn Limestone). He compared assemblages from chalks with those from interbedded marlstones and concluded that significant differences existed in the abundances of some taxa as well as in diversity and species richness. The biogeographic abundance patterns of $\underline{Z}$. erectus, Biscutum constans, and Zeugrhabdotus elegans were correlated with each other and occurred more frequently in the marls than in the chalks. Opposite abundance

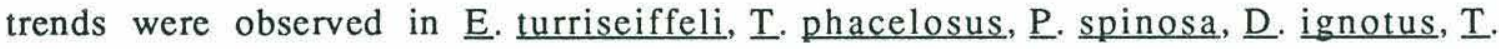
stradneri, and $\underline{L}$. carniolensis. In interpreting these abundance trends Watkins (1989) followed Roth and Bowdler (1981) and Roth and Krumbach (1986) considering the first group of taxa as high fertility indicators and the second as low fertility indicators. Watkins (1989) did not observe a correlation of $\underline{\mathrm{W}}$. barnesae with any other taxa (nor with lithology). In addition, Watkins (1989) observed that nannoplankton diversity (as expressed by the Shannon diversity index) was higher in assemblages in which the low fertility taxa dominated.

Premoli Silva et al. (1989) investigated organic carbon rich sediments of the Aptian-Albian Fucoid Marls in central Italy. Factor analyses performed on calcareous nannofossil assemblages showed that Biscutum constans, Discorhabdus ignotus and Zygodiscus spp. loaded high on the same factor. From comparison with the results of Roth and Bowdler (1981) and Roth and Krumbach (1986) they concluded that these three taxa were indicative of high fertility in areas of vigorous upwelling. Similarly, they interpreted 
Rhagodiscus asper and Lithraphidites carniolensis as indicators of moderate fertility and warmer waters.

Erba et al. (1992) investigated calcareous nannofossil assemblages from the Albian Gault Clay Formation (southern England). Preservation of the calcareous nannofossils was good and she indicated that the abundance variations observed were not a consequence of differential dissolution. This was further supported by the fact that $\underline{W}$. barnesae was never excessively abundant $(<\sim 25 \%$ in all samples). The abundance variations of $\underline{W}$. barnesae and B. constans were inversely correlated in agreement with the results of Roth and Bowdler (1981). Consequently, Erba et al. (1992) interpreted these species as low and high fertility indicators, respectively.

All of the taxa interpreted as fertility indicators in studies of midCretaceous nannoplankton were latitudinally restricted to mid and low latitudes during the Maestrichtian and some of them exhibited very conspicuous abundance changes during this time.

\section{(b) Biscutum constans}

Abundance decrease: An abundance decrease of this species has been observed in all sections investigated (Figure 69). It began in the early Maestrichtian in high latitudes and during the late Maestrichtian in midsouthern latitudes (Figure 69). A comparison with published data (Wind, 1979a; Thierstein, 1981; Doeven, 1983) also revealed decreasing abundances of $\underline{B}$. constans throughout the Maestrichtian.

Geographic distribution of the abundance decrease: An investigation of the count data of Wind (1979a: table 6) reveals that the abundance decrease of $\underline{B}$. constans occurred in several sections. In DSDP Hole 217 (Wind, 1979a) it occurred at exactly the same level where it was found in this study: $>6 \%$ at and below Section $217-21-1 ;<1 \%$ at and above Section 217-191 ; in this study the decrease was observed between Sections 217-19-4 and 21719-2. In DSDP Hole 216 a decrease at the same level (compare Wind, 1979a: figure 14, p. 110) was observed by Wind (1979a) although only two samples document this trend there. In DSDP Hole 249 an abundance decrease of $\underline{B}$. constans (from $>15 \%$ in most samples to $<10 \%$ ) was recorded in the lower Maestrichtian (compare Wind, 1979a: figure 14, p. 110). In DSDP Hole 357 an abundance decrease of $\underline{B}$. constans is apparent from Wind's (1979a) data; its exact level is difficult to delineate due to a coring gap across which the 


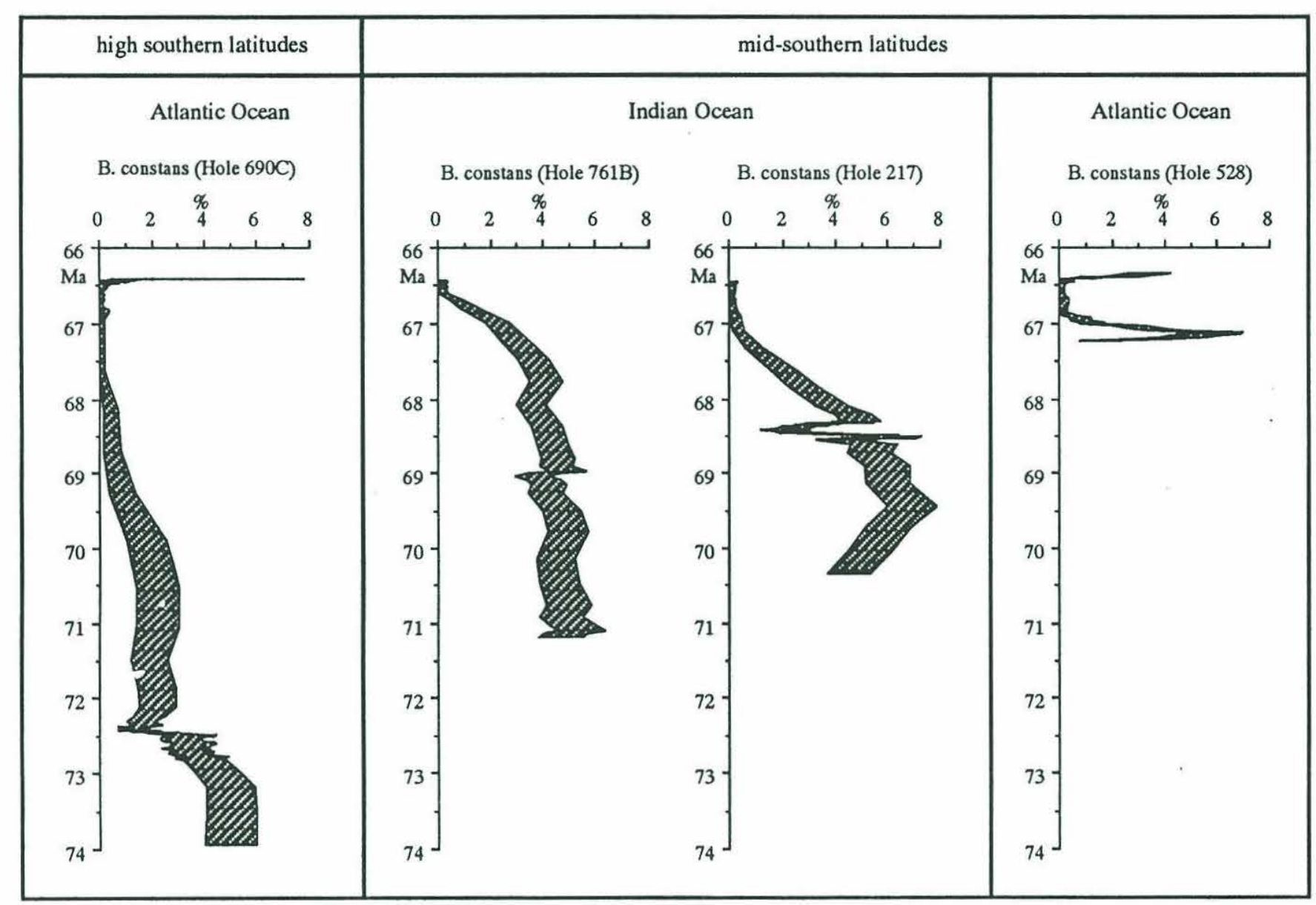

Figure 69: Comparison of the abundance variations of Biscutum constans in different latitudes and different ocean basins during the Maestrichtian. This species decreased in abundance in all holes, but the timing and abruptness of the dcreases were different in all sections investigated. The $\mathrm{K} / \mathrm{P}$ boundary lies at 66.4 Ma. Biscutum constans is a persistent species (i.e. survives the extinctions at the $\mathrm{K} / \mathrm{P}$ boundary ) and abruptly increased in abundance in the earliest Paleocene in Holes 690C and 528. No Paleocene samples were examined in Holes $761 \mathrm{~B}$ and 217. 
abundance change was recorded but it occurred near the boundary between $\underline{Q}$. trifidum Zone and A. cymbiformis Zones (lower Maestrichtian; Perch-Nielsen, 1977; DSDP Vol. 39). In DSDP Hole 10 (central North Atlantic) the decrease of $\underline{B}$. constans (from $\sim 4 \%$ to $<1 \%$ ) occurs at the base of the L. quadratus Zone (Data of Wind, 1979a).

An abundance decrease of $\underline{B}$. constans is not apparent from Thierstein's (1981) study. In DSDP Hole 356 (South Atlantic), DSDP Hole 384 (North Atlantic), and in the low latitude shelf section at Braggs, Alabama, $\underline{B}$. constans was recorded but did not change in abundance throughout the Maestrichtian (Thierstein, 1981). This species was not recorded from DSDP Hole 47.2 (tropical Pacific).

Doeven (1983) documented an abundance decrease of Biscutum spp. during the Maestrichtian, but it is not clear which species he observed, and his sample resolution is very low (see above).

The observations above indicate that although the abundance decrease of $\underline{B}$. constans during the Maestrichtian was not restricted to the southern hemisphere, it did not occur worldwide. They also support my observation that this decrease did not occur simultaneously at different latitudes (Figure 69).

Biscutum constans has been interpreted alternatively as high fertility indicator (e.g. Roth and Bowdler, 1981) and as temperature indicator due to its highest abundances in high mid-latitudes (Wind, 1979a). My investigations showed that the abundance of $\underline{B}$. constans decreased in high southern latitudes throughout the Maestrichtian. During the same time interval a cooling trend is indicated by the oxygen isotope record. This may be interpreted as a causal relation, indicating that $\underline{B}$. constans decreased because surface waters became too cool and supporting Wind's (1979a) suggestion that this species is a (warm) temperature indicator.

At the same time there is evidence for increased surface water fertility during the late Maestrichtian (see discussion above) and the fact that $\underline{B}$. constans did not increase in abundance seems to contradict its interpretation as a high fertility indicator (Roth and Bowdler, 1981). It is possible that abundance changes of this species reflect fertility changes as long as surface water temperatures remain within certain boundaries, but that this species disappears independent of nutrient availability if surface water temperatures exceed its ecological tolerance. It is suggested here that the abundance 
decrease of $\underline{B}$. constans in high southern latitudes was a consequence of cooling beyond the ecologic tolerances of this species, but that its decrease in mid-latitude sections could be due to decreasing nutrient availability.

\section{(c) Discorhabdus ignotus}

Decreasing abundances of $\underline{D}$. ignotus in the late Maestrichtian were observed in two mid latitude sections (Holes 217 and 528) in this study but an increase in the epicontinental section at Millers Ferry is also observed. Like B. constans this species has also been interpreted as high fertility indicator (see above). Its abundance decrease supports the possibility of decreasing nutrient availability during the late Maestrichtian in mid latitudes.

In the Millers Ferry Section this species gradually increased in abundance between $\sim 66.60$ and $66.42 \mathrm{Ma}$ (from $\sim 3 \%$ to $\sim 5 \%$ ). At $\sim 66.41 \mathrm{Ma}$ it increased almost threefold in abundance (from $\sim 5 \%$ to $\sim 15 \%$ ). Since there is a hiatus at the $\mathrm{K} / \mathrm{P}$ boundary, the true extent of this excursion is unknown.

\section{(d) Nephrolithus frequens and other high latitude taxa}

Nephrolithus frequens is more abundant in high than in mid- and low latitudes (e.g. Thierstein, 1981; Figure 70) and its abundance increased during the Maestrichtian in high southern latitudes in parallel with the temperature decrease indicated by the oxygen isotope record. This may indicate that $\underline{\mathrm{N}}$. frequens is indicative of comparatively cool surface water temperatures (e.g. Thierstein, 1981; Pospichal and Wise, 1990). The equatorward spread of the first appearance of $\underline{\mathrm{N}}$. frequens during the Maestrichtian (Figure 71) is has usually been interpreted as reflecting progressive cooling of surface waters. On the other hand, no abundance decrease was observed at high southern latitudes during the warming pulse between $266.65-66.50 \mathrm{Ma}$ (Figure 72) suggesting that $\underline{N}$. frequens is not a very sensitive temperature indicator and/or that abundance fluctuations of this taxon reflects changes in water mass structure or surface water fertility in addition to cooler temperatures.

The abundance increase of $\underline{\mathrm{N}}$. frequens during the last $\sim 100 \mathrm{ky}$ of the Maestrichtian at mid-latitudes in the Atlantic and Indian Oceans (Figure 70) possibly reflects decreasing surface water temperatures at these sites at the end of the Maestrichtian. Together with $\underline{N}$. frequens, two other high latitude taxa also increased significantly in abundance during the last $\sim 100 \mathrm{ky}$ of the Maestrichtian in the mid-latitude Indian Ocean: $\underline{C}$ daniae and Vagalapilla spp. 


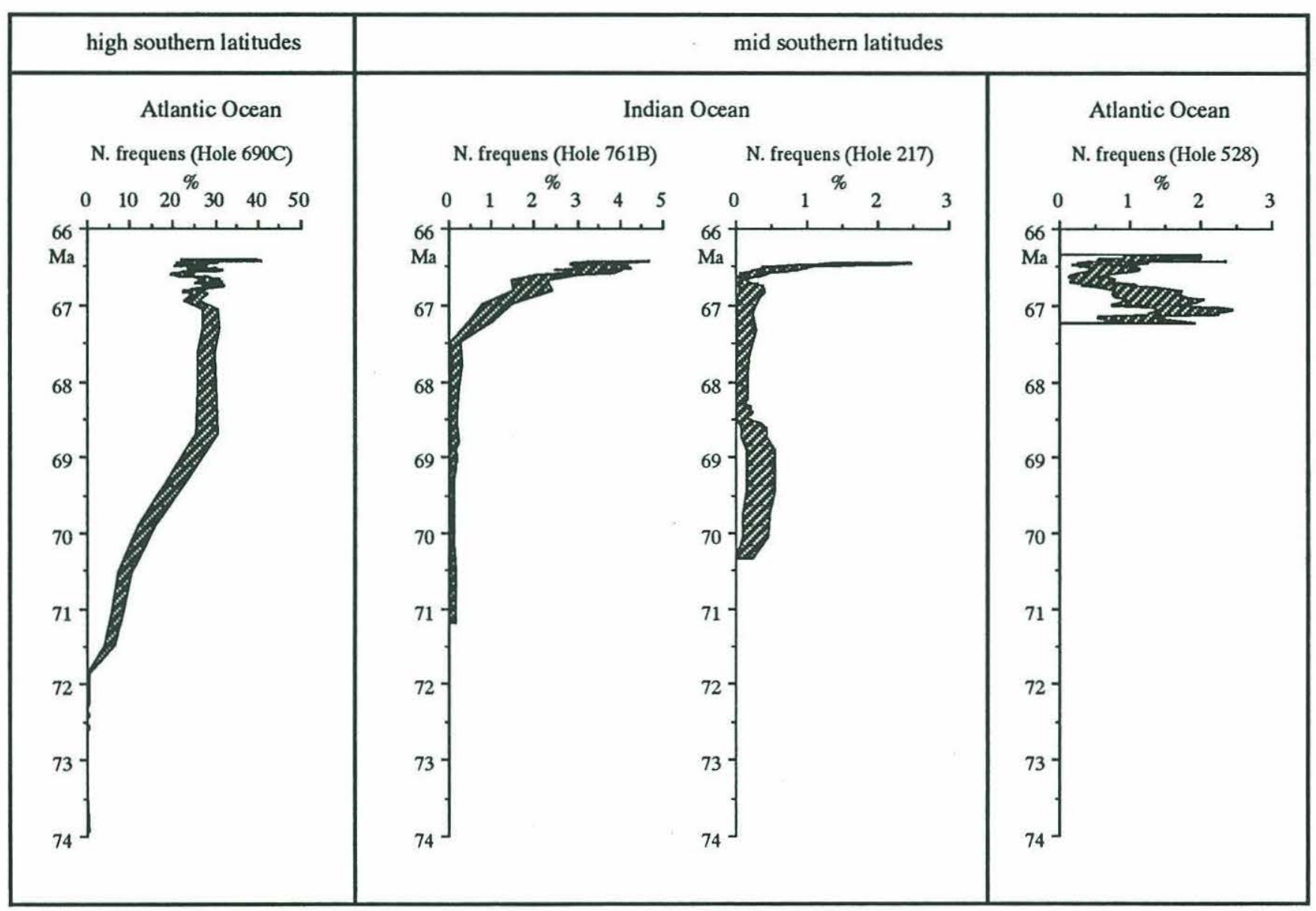

Figure 70: Comparison of the abundance variations of Nephrolithus frequens in different latitudes and different ocean basins during the Maestrichtian. This species increased in abundance much earlier in high southern latitudes than in the mid-latitude Indian Ocean. 


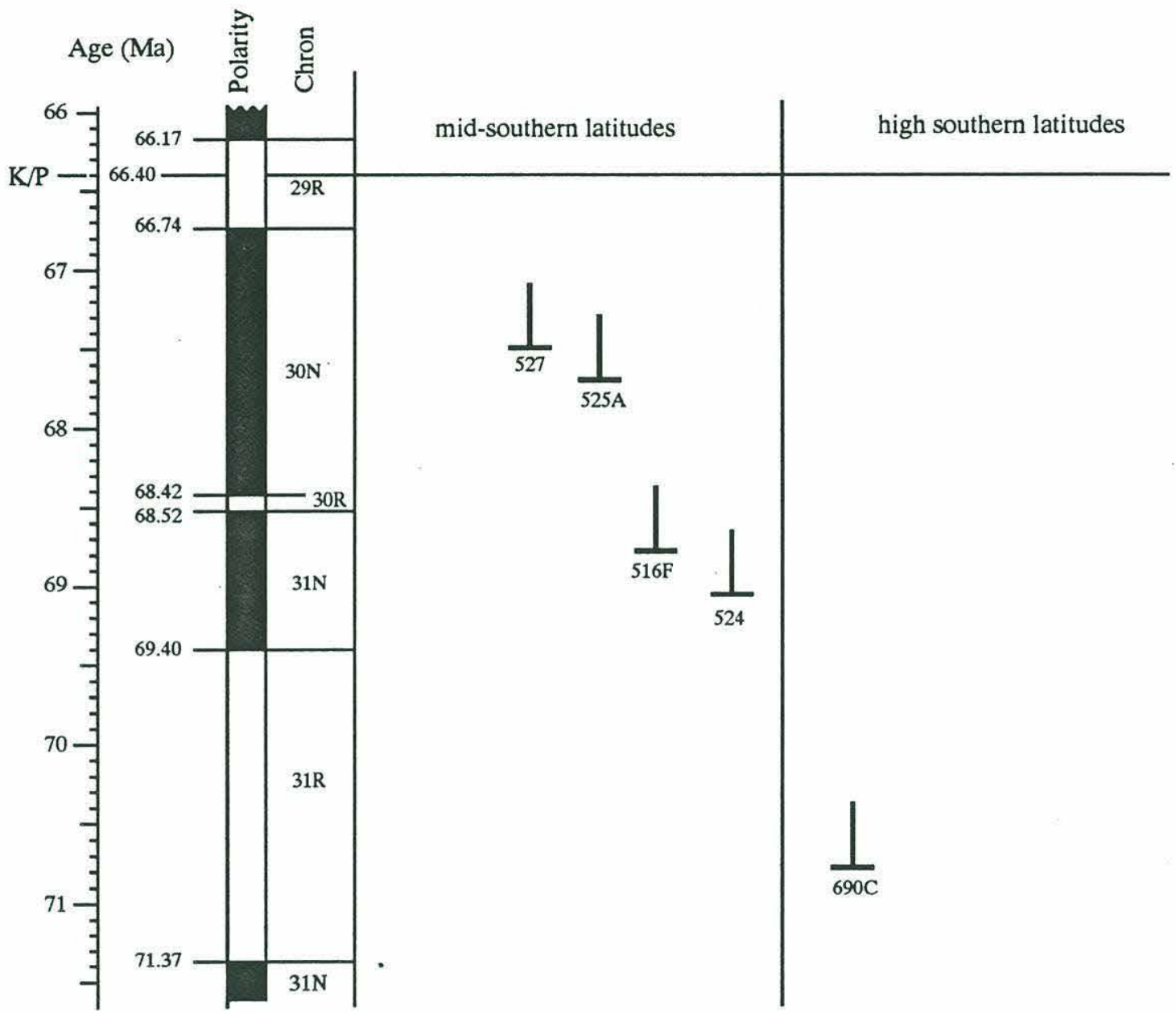

Figure 71: Comparison of the first appearances of Nephrolithus frequens compiled from DSDP- and ODP-Holes where magnetostratigraphic control is available. 


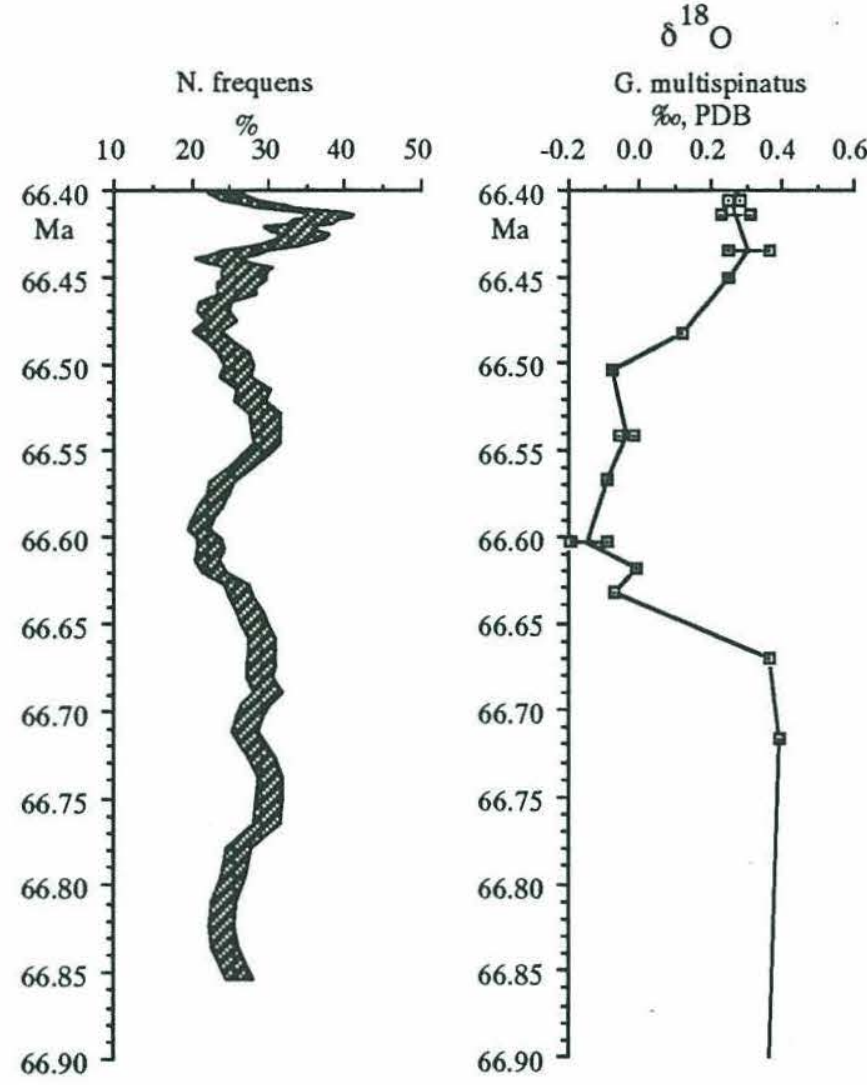

Figure 72: Abundance fluctuations of Nephrolithus frequens and the $\delta^{18} \mathrm{O}$ record during the last $\sim 500 \mathrm{ky}$ of the Maestrichtian (66.9-66.4 Ma). The negative shift of the oxygen isotope values between $\sim 66.65$ and $66.50 \mathrm{Ma}$ is interpreted as a warming pulse. No abundance decrease of the cool water indcator $\underline{\mathrm{N}}$. frequens is apparent during the warming pulse suggesting that this species is not a very sensitive temperature indicator and/or that its abundance fluctuations are not only reflecting temperature changes. Stable isotope data from Stott and Kennett (1990). The relative abundance of $\underline{N}$. $\underline{\text { frequens }}$ was calculated exclusive of $\underline{P}$. stoveri. 
(Figures 67 and 68). Cribrosphaerella daniae increased in abundance in high southern latitudes throughout the Maestrichtian (in parallel with decreasing surface water temperatures); therefore its abundance increase in the latest Maestrichtian in the mid-latitude Indian Ocean may also suggest decreasing surface water temperatures. In contrast, Vagalapilla spp. decreased in ab ndance during the Maestrichtian suggesting that this high latitude taxon does not respond primarily (or exclusively) to changing surface water temperatures.

\section{(f) Ahmuellerella octoradiata}

This species was more abundant in high than in low latitudes during the Maestrichtian (e.g. Thierstein, 1981; this study; Table 6; Figure 73), which was sometimes interpreted as a preference for cooler waters. On the other hand, $\underline{A}$. ectoradiata decreased in abundance during the Maestrichtian in high and midlatitudes (this study, Figure 73) when stable isotope records indicated global cooling and when most other high latitude taxa increased in abundance. The explanation for this abundance change is not obvious but is possibly related to fertility changes. Furthermore the abundance decrease through the Maestrichtian reinforces the warning that species with abundance peaks in high latitudes cannot automatically be interpreted as cool water indicators (e.g. Vagalapilla spp., see previous paragraph).

\section{4) Implications of High Resolution Biogeographic Studies}

Very closely spaced samples permitted a temporal resolution better than $5 \mathrm{ky}$ for the last $60 \mathrm{ky}$ of the Maestrichtian (represented by $\sim 2.7 \mathrm{~m}$ ) in Hole $690 \mathrm{C}$ and during the last $75 \mathrm{ky}$ (represented by $\sim 7.5 \mathrm{~m}$ ) in Hole 528 .

Surprisingly high intersample variability was recorded in virtually all taxa in both holes. The sample spacing in Hole $690 \mathrm{C}$ was $\sim 3-5 \mathrm{~cm}$ and only minor abundance variability of individual nannoplankton taxa between samples had been expected, because (i) lithology (e.g carbonate content) and color are uniform (compare lithologic description in Chapter BIOCHRONOLOGY), and (ii) indications for intensive bioturbation are ubiquitous in the sediment (presumably obliterating any original short term abundance variations through sediment homogenization). The reason for the high intersample variability is not known. In most taxa this variability seems to be random and not cyclical (except maybe for $\underline{C}$. ehrenbergii; compare Chapter RESULTS, HOLE 


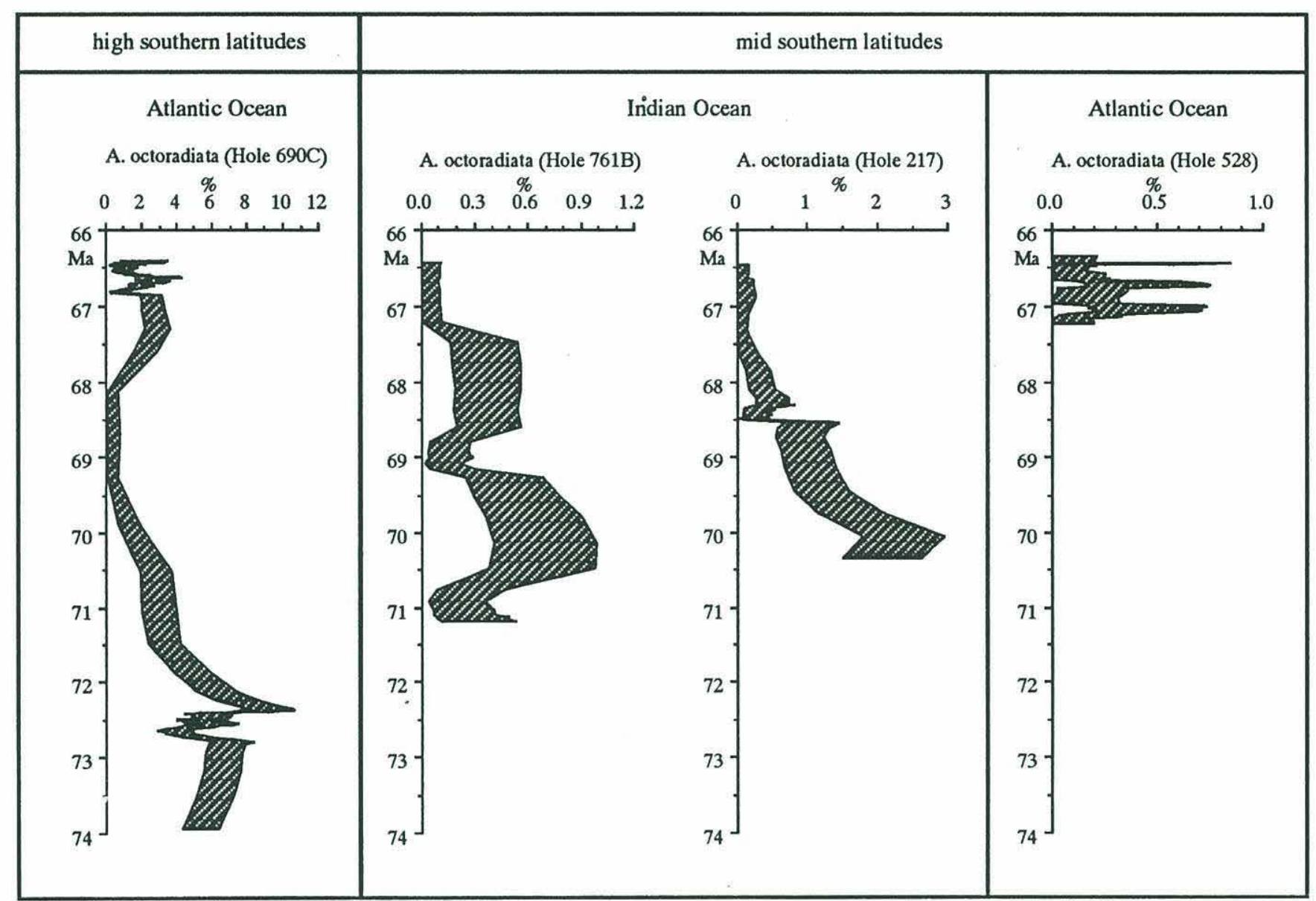

Figure 73: Comparison of the abundance variations of Ahmuellerella octoradiata at different latitudes and ocean basins. This species reached its highest abundances in high southern latitudes. Its abundance decreased throughout the Maestrichtian in all holes investigated when water temperatues decreased globally. Ahmuellerella octoradiata is therefore not interpreted as a cool water indicator, but possibly reflects changes in nutrient availability. 
690C) but time series analyses will have to be used to decipher any genuine cyclicity.

Similar results of high intersample variability between closely spaced samples were obtained in Hole 528, where cyclical abundance variations were possibly recorded in $\underline{P}$. fibuliformis and $\underline{P}$. stoveri (but again, time series analyses will bé necessary to evaluate these trends).

The high variability of nannoplankton species abundances between adjacent samples demonstrates the need of closely spaced samples to characterize genuine abundance trends. The abundance fluctuation of $\underline{P}$. fibuliformis between $\sim 66.85$ and $66.4 \mathrm{Ma}$ in Hole $690 \mathrm{C}$ (Figure 65a) is also apparent in the range chart of Pospichal and Wise (1990: table 2), but this interval is only covered by five samples and therefore the significance of these abundance changes was not recognized.

Similarly, in many cases it is impossible to interpret confidently the abundance fluctuations recorded in widely spaced samples (i.e. one sample every $\sim 3 \mathrm{~m}$ ) in Holes $690 \mathrm{C}, 761 \mathrm{~B}$, and 217 and only the most general trends can be derived.

High inter-sample variability was not restricted to the late Maestrichtian interval, but occurred in all time slices investigated. In order to recognize the statistically significant trends underlying this high variability a moving five-point average was calculated and is reported in the figures in this chapter.

\section{5) IMPLICATIONS FOR CALCAREOUS NANNOPLANKTON EXTINCTIONS}

\section{AT THE K/P BOUNDARY}

My detailed investigations of abundance changes of calcareous nannoplankton taxa do not indicate a gradual loss of species nor stepwise extinctions during the last $\sim 500 \mathrm{ky}$ of the Cretaceous. The nannofossil data thus do not support sequential turnover and stepwise extinctions of planktonic foraminifera reported from several sections (El Kef, Tunisia: Keller, 1988; Brazos River, Texas: Keller, 1989). Conspicuous abundance changes of few taxa were demonstrated during this time interval ( 67-66.4 Ma) which are believed to reflect environmental perturbations, but no extinctions could be demonstrated to occur at the same time. There is no evidence in my data that 
the environmental perturbations inferred from fluctuations of stable isotopes and selected nannoplankton taxa imposed a stress on the calcareous nannoplankton rendering them particularly vulnerable to extinction: relative abundances of most taxa did not change systematically during the last $\sim 500 \mathrm{ky}$ of the Cretaceous.

The abundance fluctuations recorded during the last $\sim 500 \mathrm{ky}$ of the Maestrichtian are not unusual compared to abundance fluctuations recorded in intervals of high sample density earlier in the Maestrichtian (compare e.g. the abundance fluctuations of $\underline{B}$. constans between $\sim 68.6-68.3 \mathrm{Ma}$ in Hole 217 with those between $\sim 67.2-66.4 \mathrm{Ma}$ in Hole 528; Figure 69c, d). This implies that environmental perturbations were not restricted to the last $\sim 500 \mathrm{ky}$ of the Cretaceous, but characterized the entire Maestrichtian. Judging from the nannoplankton results it would be expected that high-resolution stable isotope records during earlier parts of the Maestrichtian should document environmental perturbations similar to those during the latest Maestrichtian ( 67-66.4 Ma).

There is no evidence in my data that calcareous nannoplankton associations in high latitudes were affected by environmental stress to a greater degree than in low latitudes during the last $\sim 500 \mathrm{ky}$ of the Maestrichtian. This contradicts the predictions of Stanley (1984) who argued that global cooling was the cause for the extinctions at the K/P boundary.

\section{6) SUMMARY}

Investigations of evolutionary and biogeographic patterns in Maestrichtian calcareous nannoplankton yield the following results.

1) Major differences in the early and the late Maestrichtian nannoplankton associations existed in high southern latitudes. Over $50 \%$ of all taxa became either extinct or restricted in their geographic distribution to mid- and low latitudes. Most of the extinctions and emigrations occurred in the late early and early late Maestrichtian (between $\sim 71.4$ and $\sim 70.4 \mathrm{Ma}$ ). During this time interval less pronounced assemblage changes were also recorded in planktonic and benthic foraminifera. 
2) Oxygen isotope records of planktonic and benthic foraminifera indicate progressive cooling of water masses during the entire Maestrichtian in high southern latitudes with a cooling pulse at $\sim 71 \mathrm{Ma}$ (early part of Chron $31 \mathrm{R}$ ). A (possibly global) brief negative carbon isotope excursion occurred at $\sim 71 \mathrm{Ma}$ and may be a consequence of the sea-level fall in the mid-Maestrichtian.

3) Many of the nannoplankton taxa that became extinct between 72.4 and 70.4 Ma were restricted to or most abundant in high southern latitudes in the Atlantic and Indian Ocean (austral taxa). It would appear that they became extinct as a consequence of increases in nutrient availability, reduction in the stratification of the photic zone, or changes in salinity, caused by changes in surface circulation as a consequence of a sea level fall.

The emigrations of numerous taxa from high latitudes is interpreted as a response to progressive cooling in high latitudes.

4) In high southern latitudes an abundance increase of Micula staurophora coincided with the beginning of a warming pulse indicating that abundance changes of this species may be due to temperature fluctuations. Previously, abundance fluctuations of this highly solution resistant species have mostly been interpreted as an indicator of preservation.

5) Significant abundance fluctuations were recorded in several other nannoplankton taxa during the last $\sim 500-800 \mathrm{ky}$ of the Maestrichtian. Abundance fluctuations of similar magnitude were also recorded in the early and early late Maestrichtian, indicating that environmental perturbations were not restricted to the latest Maestrichtian.

6) A conspicuous feature of the calcareous nannoplankton assemblage is the lack of abundance changes in numerous high-latitude taxa (i.e. taxa that are most abundant in high latitudes and rare or absent from low latitudes) during a warming pulse of $\sim 2^{\circ} \mathrm{C}$. This may indicate that high-latitude taxa have wide temperature tolerances or that their abundance fluctuations are not exclusively due to temperature changes.

7) Abundance changes in two taxa are of particular interest. An abundance decrease of $\underline{B}$. constans was recorded in all sections studied. It occurred 
diachronously in different sections and is attributed to local decreases in surface water fertility.

Ahmuellerella ectoradiata was more abundant in high than in low latitudes during the Maestrichtian but decreased in abundance throughout the Maestrichtian in all latitudes when stable isotope records indicated progressive cooling of surface waters. This indicates that the higher abundance of $\underline{\text { A. ectoradiata }}$ in high latitudes does not reflect its preference for colder surface waters. This observation indicates that high latitude taxa should not automatically be interpreted as indicative of lower water temperatures.

8) No stepwise extinctions and no gradual loss of species were recorded among the calcareous nannoplankton during the last $\sim 500 \mathrm{ky}$ of the Cretaceous. 


\section{CHAPTER 6 SYNOPSIS}

The following discussion summarizes the major findings of this study and highlights correlations between the biogeographic evolution of the marine calcareous plankton during the Maestrichtian and major oceanographic and climatic events. These events are graphically summarized in Figures 74 and 75.

Maestrichtian calcareous nannoplankton are characterized by pronounced latitudinal provincialism: numerous species display abundance gradients across latitudes and/or are endemic to high or low latitude regions (e.g. Wind, 1979a; Thierstein, 1981; this study). This study shows that a significant turnover occurred in the late early and early late Maestrichtian (between $\sim 72.4$ and $70.4 \mathrm{Ma}$ ) when about one third of all taxa in high southern latitudes became extinct (including all taxa endemic to the austral realm. During the same time interval another third disappeared regionally (Figure 74.2) restricting their geographic distribution to mid and low latitudes where they persisted until the end of the Cretaceous (66.4 Ma).

Ahmuellerella octoradiata and Nephrolithus frequens are both more abundant in high than in low latitudes and it has been implied (Thierstein, 1981) that high latitude taxa preferred colder water temperatures. These two species, however, have opposite abundance trends during the Maestrichtian (Figure 74). When stable isotope evidence suggests gradual global cooling of surface waters, the abundance of $\underline{A}$. octoradiata decreased whereas that of $\underline{N}$. frequens increased, suggesting that $\underline{N}$. frequens may have preferred lower temperatures and that $\underline{A}$. octoradiata was insensitive to the cooling. In addition, the first occurrence of $\underline{\mathrm{N}}$ frequens appears to be diachronous, occurring progressively later (calibrated against paleomagnetic stratigraphy) in midand low than in high latitudes, in agreement with the hypothesis that this species migrated equatorward in response to decreasing surface water temperatures (Pospichal and Wise, 1990).

Biscutum constans also decreased in abundance throughout the Maestrichtian (Figure 74). This abundance decrease occurred earlier in high than in low latitudes. According to Roth and Bowdler (1981) $\underline{B}$. constans is a fertility indicator. Its abundance decrease during the Maestrichtian would suggest that nutrient availability decreased during the latest Cretaceous. 
However, stable isotope records from high southern latitudes may be interpreted as a decrease in the stratification of surface waters, thus facilitating mixing of nutrients into the photic zone. The conflict in the interpretation of the abundance decrease of $\underline{B}$. $\underline{\text { constans }}$ and the stable isotope record cannot be resolved with the data available, but it is likely that the abundance distribution of $\underline{B}$. constans is not simply a fertility signal. Its distribution may also be influenced by temperature changes.

Pronounced provincialism during the late Campanian and early Maestrichtian was also reported for planktonic foraminifera (e.g. Huber, 1992) when austral, transitional, and tethyan assemblages were differentiated. The austral planktonic foraminiferal assemblages were characterized by low diversity, taxa endemic to high southern latitudes, and the absence or extreme rarity of keeled forms. During the late early and late Maestrichtian the differences between the austral, transitional, and tethyan foraminiferal assemblages became less pronounced partly due to the geographic expansion of low latitude, keeled species into high southern latitudes (see Figure 74).

Two Maestrichtian assemblages of benthic foraminifera can be distinguished in high southern latitudes (Thomas, 1990; Figure 74) but the differences between the assemblages are small compared to faunal changes at other times (Thomas, 1990). At $\sim 69.4 \mathrm{Ma}$ (magnetochron $31 \mathrm{R} / 31 \mathrm{~N}$ boundary) species diversity increased slightly, and the proportion of infaunal and cylindrical species increased at the expense of epifaunal species. The causes of the changes in the benthic foraminifera assemblages (changes in the availability of organic carbon due to productivity changes in surface waters or changes in the oxygen content of bottom waters) are not clear, since neither the stable isotope records nor the other microfossil groups exhibit coeval changes.

Stable isotope records indicate global cooling of surface and bottom waters as well as circulation changes. Oxygen isotope data from planktonic and benthic foraminifera from low (Saito and van Donk, 1974; Douglas and Savin, 1975; see summary in Savin, 1977) and high latitudes (Barrera et al., 1987; Barrera and Huber, 1990) indicate that surface and bottom water temperatures decreased throughout the Maestrichtian (see Figure 74). In high southern 
Figure 74: Oceanographic and climatic events in the Maestrichtian as evidenced by calcareous nannoplankton, foraminifera, stable isotopes and seismic stratigraphy. Compiled from the following sources: (1) Kent and Gradstein (1985); Berggren et al. (1985); (2) this study; (3) Huber (1992a); (4) Thomas (1990); (5) Barrera and Huber (1990); Stott and Kennett (1990); Saito and van Donk (1974); Douglas and Savin (1975); (6) Barrera and Huber (1990); Corfield et al. (1991); Mount et al. (1986); (7) Vail et al. (1977); Bond (1978); Hancock and Kauffman (1979); Haq et al. (1987). 


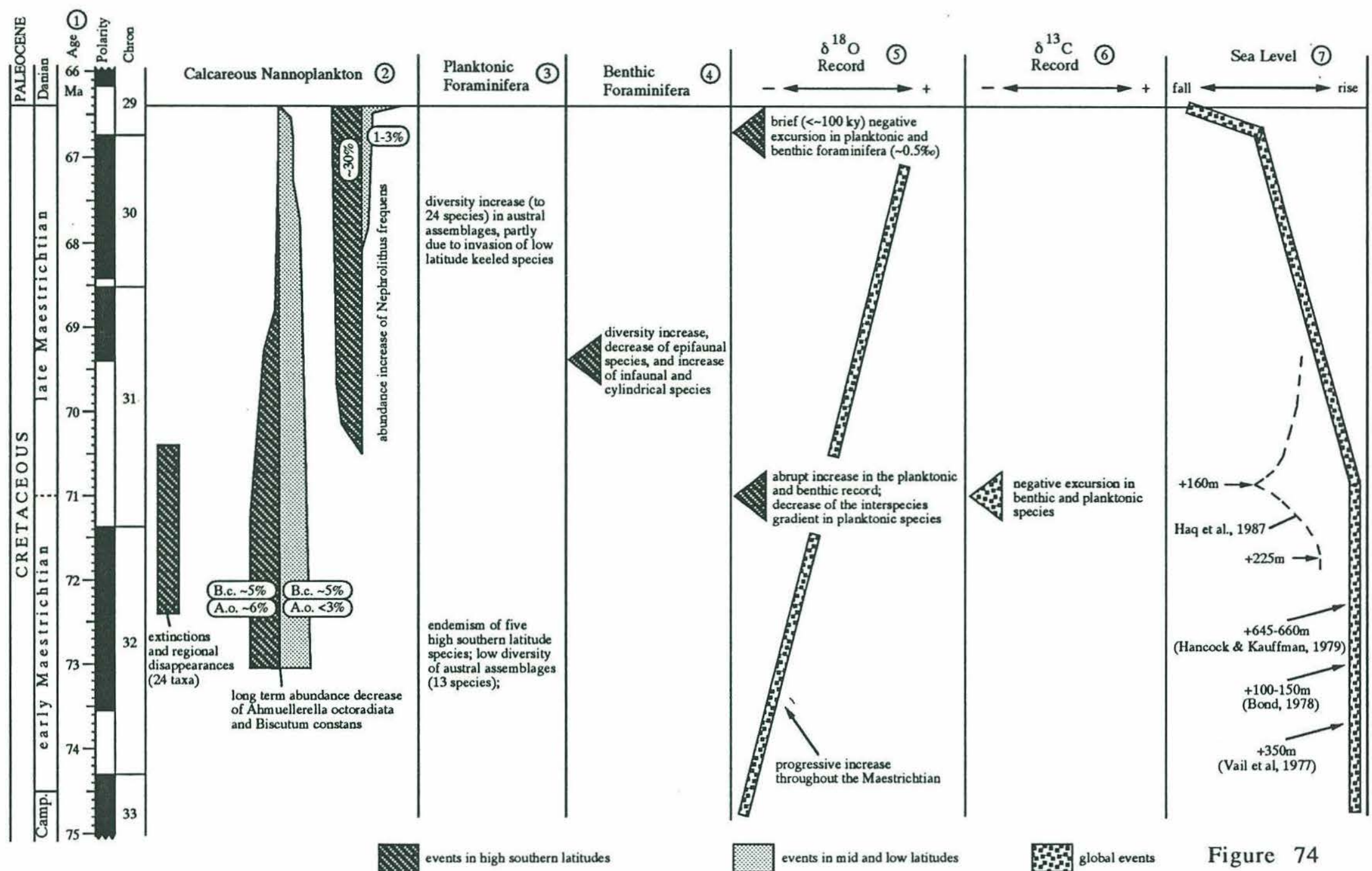


latitudes an abrupt cooling pulse was recorded at the early/late Maestrichtian boundary. I proposed that the temperature decrease of high latitude surface waters was the cause for the regional disappearance of twelve nannoplankton species and genera during the late early and early late Maestrichtian; these taxa persisted until the end of the Cretaceous in lower latitudes where surface water temperatures were warmer.

At the same time as the cooling pulse, the oxygen isotope gradient between planktonic species decreased implying decreased surface water stratification in the late Maestrichtian. This decrease of surface water stratification would have facilitated the mixing of nutrients into surface waters. Studies of recent nannoplankton have shown that coccolithophorid diversity is higher under oligotrophic than under eutrophic conditions (Kilham and Kilham, 1980). I propose that decreasing stratification of surface waters and increased nutrient concentrations in the photic zone resulted in the extinction of twelve taxa in high southern latitudes.

A negative excursion in the carbon isotope record was recorded at the early/late Maestrichtian boundary ( 71 Ma; earliest part of magnetochron $31 \mathrm{R}$ ) in high southern latitudes. This excursion was recorded in planktonic as well as in benthic foraminfera indicating that it affected the entire water column. A similar negative carbon isotope excursion was also observed in two tropical sections indicating a global phenomenon. This excursion may have resulted from an exchange of carbon reservoirs, possibly as a consequence of ocean circulation changes and/or a sea-level fall.

A sea level fall at the early/late Maestrichtian boundary has been suggested by several authors (e.g. Hancock and Kauffman, 1979; Haq et al., 1987), but opinions differ about its abruptness and amplitude. Hancock and Kauffman (1979) reported that the sea level during the late Campanian and early Maestrichtian was about 645-660 $\mathrm{m}$ higher than today, and that it fell during the late Maestrichtian (dotted bar in Figure 74.7). Haq et al. (1987) indicated a fairly abrupt and comparatively brief sea-level fall at the early/late Maestrichtian boundary (from $\sim 225 \mathrm{~m}$ to $\sim 160 \mathrm{~m}$ above present sea level) followed by a return to a high sea level stand during the late Maestrichtian (dashed line in Figure 74.7). Vail et al. (1977) reported that the sea-level in the latest Cretaceous was 300-350 m above present sea level. These authors did not report any details on Cretaceous sea-level changes because these results had not been released for publication (Vail et al., 1977). Bond 
(1978) argued that the sea-level during the late Campanian and early Maestrichtian was only $\sim 100-150 \mathrm{~m}$ higher than today; he suggested that higher estimates derived from North America and Africa were exagerated due to uplift of these continents since the latest Cretaceous.

During the last $\sim 800$ ky of the Maestrichtian pronounced abundance changes occurred in calcareous nannoplankton in all sections investigated. The abundance changes in the mid-latitude Indian Ocean Sites (Site 217 and 761) affected the same species and occurred at approximately the same time; in contrast, the abundance patterns at the other sites strongly differ from those at Sites 217 and 761 and they occurred at different times. This indicates that environmental perturbations occurred in all ocean basins, but apparently were of different nature and timing. It is concluded that the mid-latitude South Atlantic Ocean, the mid-latitude Indian Ocean, and the high-latitude Southern Ocean were occupied by different water masses with different environmental characteristics.

At southern high latitudes stable isotope records from planktonic and benthic foraminifera (Stott and Kennett, 1990) indicate environmental perturbations (warming pulse or low-salinity pulse; ocean circulation changes) but none of the nannoplankton abundance changes exactly correlate with the stable isotope changes.

The planktonic foraminifer Pseudotextularia elegans first appeared in high southern latitudes in the latest Maestrichtian (at $\sim 66.5 \mathrm{Ma}$ on Maud Rise: Huber, 1990; Huber, 1992b). This is much younger than the first appearance datum of this species in low latitudes (late Campanian; see Huber and Watkins, 1992: fig. 16). Huber and Watkins (1992) interpreted the poleward migration of P. elegans in the latest Maestrichtian as a consequence of a brief $(\sim<100 \mathrm{ky})$ warming pulse indicated by a negative excursion in the oxygen isotope records at that time on Maud Rise.

During the same general time Courtillot (1990) placed three major eruption events of the Deccan Trap volcanism. The temporal constraints on these eruption pulses are derived from the paleomagnetic data and are only approximate but they suggest that the bulk of the eruptions occurred during the last $\sim 500 \mathrm{ky}$ of the Cretaceous (Courtillot, 1990). It has been suggested that the eruptions of the Deccan Traps caused environmental (acid rain) and climatic perturbations which leading to the biospheric turnover across the 
Figure 75: Oceanographic and climatic events during the last $800 \mathrm{ky}$ of the Cretaceous based on evidence from calcareous nannoplankton, planktonic foraminifera, stable isotopes, volcanism, seismic stratigraphy, and fossil plant records. Compiled from the following sources: (1) (1) Kent and Gradstein (1985); Berggren et al. (1985); (2) this study; (3) Huber (1990, 1992a); (4) and (5) Stott and Kennett (1990); (6) Courtillot (1990); (7) Vail et al. (1977), Haq et al. (1987), Brinkhuis and Zachariasse (1988). 


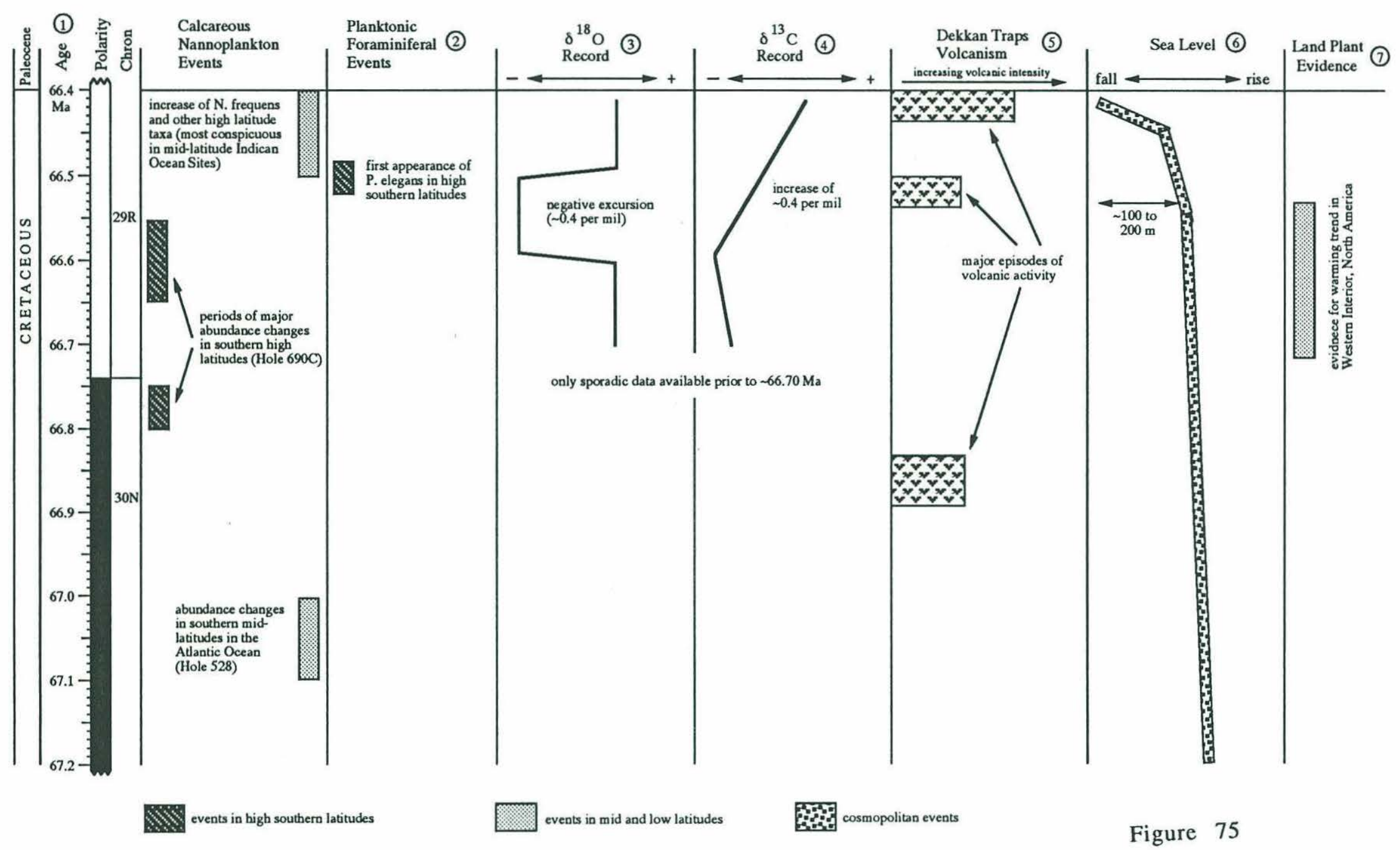


K/P boundary (Officer et al., 1987). However, no gradual or stepwise extinctions of calcareous nannoplankton during the postulated eruption pulses in the latest Maestrichtian could be documented in this study. At the Cretaceous/Paleocene boundary the sea-level fell $\sim 200 \mathrm{~m}$ according to Vail et al. (1977), and $\sim 100 \mathrm{~m}$ according to Haq et al. (1987). Brinkhuis and Zachariasse (1988) reported changes in dinoflagellate associations, number of sporomorphs and changing amounts of land derived organic matter from the El Haria section (Tunisia) and regarded them as indicative of rapidly falling sea level during the last $17 \mathrm{ky}$ of the Cretaceous.

Physiognomic and taxonomic changes of land plant macrofossils from the interior of North America indicate a warming trend beginning at the base of Magnetochron 29 (Johnson, 1992). The correlation of this warming trend with the warming pulse deduced from the oxygen isotope record in high southern latitudes remains tentative at present. 


\section{LITERATURE}

Alvarez, L. W., Alvarez, W., Asaro, F., and Michel, H. V., 1980. Extraterrestrial Cause for the Cretaceous-Tertiary Extinction. Science, 208, 1095-1108.

Alvarez, W., 1986. Toward A Theory of Impact Crisis. Eos, 67, 649-658.

Alvarez, W., Arthur, M. A., Fischer, A. G., Lowrie, W., Napoleone, G., Premoli Silva, I., and Roggenthen, W. M., 1977. Upper Cretaceous-Paleocene magnetic stratigraphy at Gubbio, Italy, V. Type section for the Late Cretaceous-Paleocene geomagnetic reversal time scale. Geol. Soc. Am. Bull., $\underline{88}, 367-389$.

Askin, R. A., 1989. Endemism and heterochroneity in the Late Cretaceous (Campanian) to Paleocene palynofloras of Seymour Island, Antarctica: Implications for origins, dispersal and palaeoclimates of southern floras. In Orignis and Evolution of the Antarcitc Biota, Spec. Publ. Geol. Soc. London, 147, 107-119.

Aubry, M.-P., 1988. Phylogeny of the Cenozoic calcareous nannoplankton genus Helicosphaera. Paleobiology, 14(1), 64-80.

Barrera, E., Huber, B. T., Savin, S. M., and Webb, P.-N., 1987. Antarctic marine temperatures: late Campanian through early Paleocene. Paleoceanography, $\underline{2(1)}, 21-47$.

Barrera, E., and Huber, B. T., 1990. Evolution of Antarctic waters during the Maestrichtian: foraminifer oxygen and carbon isotope ratios, Leg 113. In

Barker, P. F., Kennett, J. P., et al., Proc. ODP. Sci, Results, 113: College Station, TX (Ocean Drilling Program), 813-827.

Barron, E. J., Thompson, S. L., and Schneider, S. H., 1981. An Ice-Free Cretaceous? Results from Climate Model Simulations. Science, 212, 501-509.

Beaufort, L. E., 1991: Adaptation of the random settling method for quantitative studies of calcareous nannofossils. Micropaleontology, 37, 415-418.

Beaufort, L. E., and Aubry, M.-P., 1990. Fluctuations in the composition of late Miocene calcareous nannofossil assemblages as a response to orbital forcing. Paleoceanography, 5(6), 845-865.

Beaufort, L. E., and Aubry, M.-P., 1992. Paleoceanographic implications of a $17-$ m.y.-long record of high-latitude Miocene calcareous nannoplankton fluctuations. In Wise, S. W., Jr., Schlich, R., et al., 1992. Proc. ODP, Sci. Results, 120: College Station, TX (Ocean Drilling Program), 539-549.

Berggren, W. A., Kent, D. V., and Flynn, J. J., 1985. Jurassic to Paleogene: Part 2 Paleogene geochronolgy and chronostratigraphy. In Snelling, N. J., (ed), The Chronology of the Geological Record, Memoir No 10, Geological Society, Blackwell Scientific Publications, Oxford, 141-195. 
Black, M., 1972. British Lower Cretaceous coccoliths. I. Gault Clay. Part 2. Paleontological Society Monographs. The Paleontological Society, London. 49112 , plates $17-33$.

Blackman, R. B., and Tukey, J. W., 1958. The measurement of power spectra. New York, Dover Publishers, 190 pp.

Boersma, A., 1984a. Cretaceous-Tertiary planktonic foraminfers from the southeastern Atlantic, Walvis Ridge area, Deep Sea Drilling Project Leg 74. In Moore, T. C., Jr., Rabinowitz, P. D., et al., Init. Repts. DSDP, 74: Washington (U.S. Govt. Printing Office), 501-523.

Boersma, A., 1984b. Campanian through Paleocene paleotemperature and carbon isotope sequence and the Cretaceous-Tertiary boundary in the Atlantic Ocean. In: Berggren, W. A. and Van Couvering, J. A. (eds). Catastrophies and Earth History, Princeton University Press, Princeton, 247 - 277.

Borella, P. E., 1984. Sedimentology, petrology, and cyclic sedimentation patterns, Walvis Ridge Transect, Leg 74, Deep Sea Drilling Project. In Moore, T. C., Jr., Rabinowitz, P. D., et al., Init. Repts. DSDP, 74: Washington (U.S. Govt. Printing Office), 645-662.

Bralower, T. J., and Siesser, W. G., 1992. Cretaceous calcareous nannofossil biostratigraphy of Sites 761, 762, and 763, Exmouth and Wombat Plateaus, Northwest Australia. In von Rad, U., Haq, B. U., et al., 1992. Proc. ODP, Sci. Results, 122: College Station, TX (Ocean Drilling Program), 529-556.

Bramlette, M. N., and Martini, E., 1964. The great change in calcareous nannoplankton fossils between the Maestrichtian and the Danian. Micropaleontology, 10(3), 291-322.

Brass, G. W., Southam, J. R., and Peterson, W. H., 1982. Warm saline bottom water in the ancient ocean. Nature, 296, 620-623.

Brinkhuis H., and Zachariasse, W. J., 1988. Dinoflagellate cysts, sea level changes and planktonic foraminifers across the Cretaceous-Tertiary boundary at El Haria, northwest Tunisia. Marine Micropaleontology, 13, 153-191.

Bromley, R. G., 1979. Chalk and bryozoan limestone: facies, sediments and

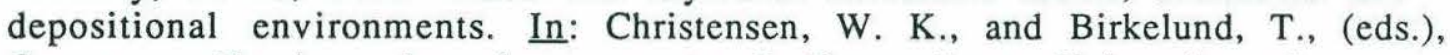
Cretaceous-Tertiary boundary events, I. Proceedings, University of

Copenhagen, 16-32.

Bukry, D. 1969. Upper Cretaceous coccoliths from Texas and Europe. University of Kansas $\mathrm{Pa}$ 'eontological Contributions, Art. 51, 1-79, 40 pls.

Bukry, D., and Bramlette, M. N., 1970. Coccolith age determinations Leg 3, Deep Sea Drilling Project. In Maxwell, A. E., et al., Init. Repts. DSDP, 3: Washington (U.S. Govt. Printing Office), 589-611. 
Bukry, D., 1973. Low-latitude coccolith biostratigraphic zonation. In Edgar, N. T., Saunders, J. B., et al., Init. Repts. DSDP, 15: Washington (U.S. Govt. Printing Office), 685-703.

Bukry, D., 1974. Coccolith and silicoflagellate stratigraphy, eastern Indian Ocean, Deep Sea Drilling Project, Leg 22. In von der Borch, C. C., Sclater, J. G., et al., Init. Repts. DSDP, 22: Washington (U.S. Govt. Printing Office), 601-607.

Cepek, P., and Hay, W. W., 1969. Calcareous nannoplankton and biostratigraphic subdivision of the Upper Cretaceous. Transactions - Gulf Coast Assoc. Geological Societies, 19, 323-336.

Channell, J. E. T., and Dobson, J. P., 1989. Magnetic stratigraphy and magnetic mineralogy at the Cretaceous-Tertiary boundary section, Braggs, Alabama. Palaeogeography, Palaeoclimatology, Palaeoecology, 69, 267-277.

Chave, A. D., 1984. Lower Paleocene-Upper Cretaceous magnetostratigraphy, Sites 525, 527, 528, and 529, Deep Sea Drilling Project Leg 74. In Moore, T. C., Jr., Rabinowitz, P. D., et al., Init. Repts. DSDP, 74: Washington (U.S. Govt. Printing Office), 525-531.

Chepstow-Lusty, A., Backman, J. and Shackleton, N. J., 1989. Comparison of upper Pliocene Discoaster abundance variations from North Atlantic Sites 552, 607, 658, 659, and 662: further evidence for marine plankton responding to orbital forcing. In Ruddiman, W., Sarnthein, M., et al., Proc. ODP, Sci. Results, 108: College Station, TX (Ocean Drilling Program), 121-141.

Christensen, W. K., 1976. Palaeobiogeography of Late Cretaceous belemnites of

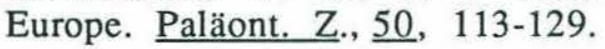

Christensen, W. K., and Birkelund, T.,(eds), 1979. Cretaceous - Tertiary boundary events. Symposium. Part II. Proceedings. University of Copenhagen. 262 pp.

Ciesielski, P. F., Sliter, W. V., Wind, F. H., and Wise, S. W., Jr., 1977.

Paleoenvironmental analysis and correlation of a Cretaceous Islas Orcadas core from the Falkland Plateau, southwest Atlantic. Marine Micropaleontology, $\underline{2}$, 27-34.

Clemens, W. A., Archibald, J. D., and Hickey, L. J., 1981. Out with a whimper not a bang. Paleobiology, Z(3), 293-298.

Clauser, S., 1987. Evolution de la composition isotopique de l'oxygène des carbonates durant le Campanien-Maastrichtien. Données préliminaires issues de la séric de Bidart (Pyrénés-Atlantiques). C. N. Acad. Sc. Paris, 304, Série 2 (11), 579-584.

Cobban, W. A., and Scott, G. R., 1972: Stratigraphy and ammonite fauna of the Graneros Shale and Greenhorn Limestone near Pueblo, Colorado. U. S. Geol. Surv. Prof. Paper, 645, 1-108. 
Coffin, M. F., Gahagan, L. M., Lawver, L. A., Lee., T.-Y., and Rosencrantz, E., 1992. Atlas of Mesozoic/Cenozoic reconstructions (200 Ma to Present Day), PLATES Progress Report No. 1-0192, Univesity of Texas Institute for Geophysics Technical Report No. 122, 49 pp.

Copeland, C. W., and Mancini, E. A., 1986. Cretaceous-TErtiary boundary southeast of Braggs, Lowndes County, Alabama. In: T. L. Neathery (ed), Southeastern Section of the Geological Society of America, Centennial Field Guide, ㅈ, 369-372.

Corfield, R. M., Cartlidge, J. E., Premoli-Silva, I., and Housley, R. A., 1991. Oxygen and carbon isotope stratigraphy of the Palaeogene and Cretaceous limestones in the Bottacione Gorge and the Contessa Highway sections, Umbria, Italy. Terra Nova, $\underline{3}, 414-422$.

Courtillot, V., 1990. Deccan volcanism at the Cretaceous-Tertiary boundary: past climatic crises as a key to the future? Palaeogeography, Palaeoclimatology, Palaeoecology (Global and Planetary Change section), 189, 291-299.

Courtillot, V., Besse, J., Vandamme, D., Montigny, R., Jaeger, J. J., and Cappetta, H., 1986. Deccan flood basalts at the Cretaceous-Tertiary boundary? Earth and Planetary Science Letters, $\underline{80}$, 361-374.

Craig, H., 1966. Isotopic composition and origin of the Red Sea and Salton Sea geothermal brines. Science, 154, 1544-1548.

Craig, H., and Gordon, 1965. Deuterium and oxygen-18 variations in the ocean and the marine atmosphere. In: Stable Isotopes in Oceanographic Studies and Paleotemperatures. Spoleto, July 26-27, 1965. Consiglio Nazionale delle Richerche, Laboratorio di Geologia Nucleare, Pisa, 1-22.

Crux, J. A., 1991. Calcareous nannofossils recovered by Leg 114 in the subantarctic South Atlantic Ocean. In Ciesielski, P. F., Kristofferson, Y., et al., 1991. Proc. ODP, Sci. Results, 114: College Station TX (Ocean Drilling Program), $155-177$.

Deflandre, G., 1959. Sur les nannofossiles calcaires et leur systématique. Extr. de la Rev. de Micropaléont., $\underline{2}$, 127-152.

Doeven, P. H., 1983. Cretaceous nannofossil stratigraphy and paleoecology of the Canadian Atlantic margin. Canadian Geological Survey Bulletin, 356, 1-70.

Douglas, R. G., and Savin, S. M., 1971. Isotopic analyses of planktonic foraminifera from the Cenozoic of the Norhtwestern Pacific, Leg 6. In A. G. Fischer, and others (Ed.), Init. Repts. DSDP (pp. 1123-1127). Washington, D. C.: U.S. Govt. Printing Office.

Douglas, R. G., and Savin, S. M., 1973. Oxygen and carbon isotope analyses of Cretaceous and Tertiary foraminifera from the central North Pacific. In E. L. Winterer, J. I. Ewing, and others (Ed.), Init. Repts. DSDP (pp. 591-605).

Washington, D. C.: U.S. Govt. Printing Office. 
Douglas, R. G., and Savin, S. M., 1975. Oxygen and carbon isotope analyses of Tertiary and Cretaceous microfossils from Shatsky Rise and other sites in the North Pacific Ocean. In R. L. Larson Moberly, R. et al. (Ed.), Init. Repts. DSDP (pp. 509-520). Washington: U.S. Government Printing Office.

Erba, E., Castradori, D., Guasti, G., Ripepe, M., 1992. Calcareous nannofossils and Milankovitch cycles: the example of the Albian Gault Clay Formation (southern England). Palaeogeogr.. Palaeoclimatol.. Palaeoecol., 23, 47-69.

Firstbrook, P. L., Funnell, B. M., Hurley, A. M., and Smith, A. G., 1979. Paleoceanic reconstructions 160-0 Ma. University of California, Scripps Institute of Oceanography, $41 \mathrm{pp}$.

Fütterer, D. K., 1990. Distribution of calcareous dinoflagellates at the Cretaceous-Tertiary boundary of Queen Maud Rise, Eastern Weddell Sea, Antarctica (ODP Leg 113). In Barker, P. F., Kennett, J. P., et al.,Proc. ODP, Sci. Results. 113: College Station, TX (Ocean Drilling Program), 533-548.

Galbrun, B., 1992. Magnetostratigraphy of Upper Cretaceous and lower Tertiary sediments, 761 and 762, Exmouth Plateau, norhtwest Australia. In von Rad, U., Haq, B. U., et al., 1992. Proc. ODP, Sci. Results, 122: College Station, TX (Ocean Drilling Program), 699-716.

Gartner, S., Jr., 1974. Nannofossil Biostratigraphy, Leg 22, Deep Sea Drilling Project. In von der Borch, C. C., Sclater, J. G., et al., Init. Repts. DSDP, 22: Washington (U.S. Govt. Printing Office), 577-599.

Hallam, A., and Perch-Nielsen, K., 1990. The biotic record of events in the marine realm at the end of the Cretaceous: calcareous, siliceous and organicwalled microfossils and macroinvertebrates. Tectonophysics, 171, 347-357.

Hamilton, N., 1990. Mesozoic magnetostratigraphy of Maud Rise, Antarctica. In Barker, P. F., Kennett, J. P., et al.,Proc. ODP, Sci. Results, 113: College Station, TX (Ocean Drilling Program), 255-260.

Hamilton, N., Suzyumov, A. E., and Shirshov, P. P., 1983. Late Cretaceous magnetostratigraphy of Site 516, Rio Grande Rise, southwestern Atlantic Ocean, Deep Sea Drilling Project, Leg 72. In Barker, P. F., Carlson, R. L., and Johnson, D. A. Init. Repts. DSDP, 72: Washington (U.S. Govt. Printing Office), 723-730.

Haq, B. U., Hardenbol, J., and Vail, P., 1987. Chronology of fluctuating sea levels since the Triassic. Science, 235, 1156-1167.

Herbert, T. D., and D'Hondt, S. L., 1990. Precessional climate cyclicity in Late Cretaceous-Early Tertiary marine sediments: a high resolution chronometer of Cretaceous-Tertiary boundary events. Earth and Planetary Science Letters, 99 , 263-275.

Hildebrand, A. R., Penfield, G. T., Kring, D. A., Pilkington, M., Carmago Z., A., Jacobsen, S. B., and Boynton, W. V., 1991. Chicxulub Crater: A possible Cretaceous/Tertiary boundary impact crater on the Yucatán Peninsula, Mexico. Geology, 19, 867-871. 
Hsü, K. J., 1980. Terrestrial catastrophe caused by cometary impact at the end of Cretaceous. Nature, 285, 201-203.

Hsü, K. J., He, Q., McKenzie, J. A., Weissert, H., Perch-Nielsen, K., Oberhänsli, H., Kelts, K., LaBrecque, J., Tauxe, L., Krähenbühl, U., Percival., S. F., Jr., Wright, R., Karpoff, A. M., Petersen, N., Tucker, P., Poore, R. Z., Gombos, A. M., Pisciotto, K., Carman, M. F., Jr., and Schreiber, E, 1982. Mass Mortality and Its Environmental and Evolutionary Consequences. Science, 216, 249-256.

Huber, B. T., 1990. Maestrichtian planktonic foraminifer biostratigraphy of the Maud Rise (Weddell Sea, Antarctica): ODP Leg 113 Holes 689B and 690C. In Barker, P. F., Kennett, J. P., et al., Proc. ODP. Sci. Results, 113: College Station, TX (Ocean Drilling Program), 489-513.

Huber, B. T., 1992a. Paleobiogeography of Campanian-Maestrichtian foraminifera in the southern high latitudes. Palaeogeography. Palaeoclimatology, Palaeoecology, 22, 325-360.

Huber, B. T., 1992b. Upper Cretaceous planktic foraminiferal biozonation for the Austral Realm. Marine Micropaleontology, 20, 107-128.

Huber, B. T., and Watkins, D. K., 1992. Biogeography of CampanianMaastrichtian calcareous plankton in the region of the Southern Ocean: Paleogeographic and paleoclimatic implications. Antarcic Research Series, $\underline{56}$, 31-60.

Hutchison, J. H. and Archibald, J. D., 1986. Diversity fo turtles across the Cretaceous/Tertiary boundary in northeastern Montana. Paleogeography Paleoclimatology, Paleoecology, 55, 1-22.

Jiang, M. J., and Gartner, S., 1986. Calcareous nannofossil succession across the Cretaceous/Tertiary boundary in east-central Texas. Micropaleontology, 32, 232-255.

Johnson, K. R., 1992. Foliar Physiognomy of Maastrichtian leaf floras from the northern Great Plains: implications for paleoclimate. Abstracts, SEPM 1992 Theme Meeting, Ft. Collins, Colorado, 36.

Johnson, K. R., and Hickey, L. J., 1990. Megafloral change across the Cretaceous/Tertiary boundary in the norhtern Great Plains and Rocky Mountains, U.S.A. GSA Spec. Paper, 247, 433-444.

Katz, M. E., and Miller, K. G., 1991. Early Paleogene benthic foraminferal assembalges and stable isotopes in the Southern Ocean. In Ciesielski, P. F., Kristofferson, Y., et al., 1991. Proc. ODP. Sci. Results, 114: College Station TX (Ocean Drilling Program), 481-512.

Kauffman, E. G., 1984. The fabric of Cretaceous marine extinctions. In Berggren, W. A., and Van Couvering, J. A. (eds.), Catastrophies and Earth History, 151-246, Princeton University Press. 
Keller, G., 1988. Extinction, Survivorship and Evolution of Planktic

Foraminfera across the Cretacesou/Tertiary Boundary at El Kef, Tunisia. Mar. Micropaleontol., 13, 239-263.

Keller, G., 1989. Extended Cretaceous/Tertiary boundary extinctions and delayed population change in planktonic foraminifera from Brazos River, Texas. Paleoceanography, 4 , 287-332.

Kent, D. V., and Gradstein, F. M., 1985. A Cretaceous and Jurassic geochronology. Geological Society of America Bulletin, 26, 1419-1427.

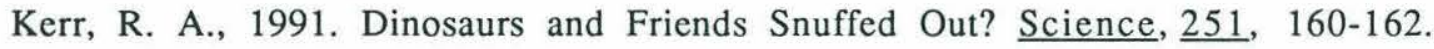

Kilham, P., and Kilham, S. S., 1980. The evolutionary ecology of phytoplankton. In Morris, I., (ed.), The Physiological Ecology of Phytoplankton. Los Angeles (University of California Press), 571-597.

Kitchell, J. A., Clark, D. L., and Gombos, A. M., 1986. Biological Selectivity of Extinction: A Link Between Background and Mass Extinction. Palaios, 1, 504511.

Kleijne, A., 1991. Holococcolithophorids from the Indian Ocean, Red Sea, Mediterranean Sea and North Atlantic Ocean. Mar. Micropaleontol, 17, 1-76.

Ledbetter, M. T., and Ellwood, B. B., 1976. Selection of sample intervals in deepsea sedimentary cores. Geology, 4, 303-304.

Liu, Chengjie, 1992. Uppermost Cretaceous - lower Paleocene stratigraphy and turnover of planktonic foraminifera across the Cretaceous-Paleogene boundary. Dissertation, State University of New Jersey, New Brunswick Rutgers.

Loeblich, Jr., A. R., and Tappan, H., 1957. Correlation of the Gulf and Atlantic Coastal Plain Paleocene and Lower Eocene formations by means of planktonic Foraminifera. I. Paleontology, 31, 1109-1137.

Luterbacher, H. P., and Premoli Silva, I., 1964. Biostratigrafia del limite Cretaceo-Terziario nell'Appennino centrale. Rivista Italiana di Paleontologia e Stratigrafia, $70,67-128$.

MacLeod, N., and Keller, G., 1991. Hiatus distributions and mass extinctions at the Cretaceous/Tertiary boundary. Geology, 19, 497-501.

Mancini, E. A., Tew, B. H., and Smith, C. C., 1989. Cretaceous-Tertiary contact, Mississippi and Alabama. Journal of Foraminiferal Research, 19(2), 93-104.

Manivit, H., 1984. Paleogene and Upper Cretaceous calcareous nannofossils from Deep Sea Drilling Project Leg 74. In Moore, T. C., Jr., Rabinowitz, P. D., et al., Init. Repts. DSDP, 74: Washington (U.S. Govt. Printing Office), 475-499. 
Margolis, S. V., Kroopnick, P. M., and Goodney, D. E., 1977. Cenozoic and late Mesozoic paleoceanographic and paleoglacial history recorded in circumAntarctic deep-sea sediments. Marine Geology, 25, 131-147.

McGowran, B., 1974. Foraminifera. In von der Borch, C. C., Sclater, J. G., et al., Init. Repts. DSDP, 22: Washington (U.S. Govt. Printing Office), 609-627.

Michel, H. V., Asaro, F., Alvarez, W., and Alvarez, L. W., 1985. Elemental profile of iridium and other elements near the Cretaceous/Tertiary boundary in Hole 577B. In Heath, G. R., Burckle, L. H., et al., Init. Repts. DSDP, 86: Washington (U.S. Govt. Printing Office), 533-538.

Michel, H. V., Asaro, F., Alvarez, W., and Alvarez, L. W., 1990. Geochemical studies of the Cretaceous-Tertiary boundary in ODP Holes 689B and 690C. In Barker, P. F., Kennett, J. P., et al.,Proc. ODP, Sci. Results, 113: College Station, TX (Ocean Drilling Program), 159-168.

Miller, K. G., and Fairbanks, R. G., 1987. Tertiary oxygen synthesis, sea level history, and continental margin erosion. Paleoceanography, $2,1-19$.

Monechi, S., 1985. Campanian to Pleistocene calcareous nannofossil stratigraphy from the northwest Pacific Ocean, Deep Sea Drilling Project Leg 86. In Heath, G. R., Burckle, L. H., et al., Init. Repts. DSDP, 86: Washington (U.S. Govt. Printing Office), 301-336.

Monechi, S., and Thierstein, H. R., 1985. Late Cretaceous - Eocene nannofossil and magnetostratigraphic correlations near Gubbio, Italy. Mar. Micropaleontol., 2, 419-440.

Mosimann, J. E., 1965. Statistical methods for the pollen analyst: Multinomial and negative mulitnomial techniques. In Kummel, B., and Raup, D., (eds.), Handbook of Paleontological Techniques. W. H. Freeman, San Francisco, California, 636-673.

Mount, J. F., Margolis, S. V., Showers, W., Ward, P., Doehne, E., 1986. Carbon and Oxygen Isotope Stratigraphy of the Upper Maestrichtian, Zumaya, Spain: A Record of Oceanographic and Biologic Changes a the End of the Cretaceous Period. Palaios, 1 , 87-92.

Nederbragt, A. J., 1990. Biostratigraphy and paleoceanographic potential of the Cretaceous planktonic foraminiera Heterohelicidae. (Ph. D. Thesis). Centrale Huisdrukkerij Vrije Univ., Amsterdam.

Noël, D., 1970. Coccolithes Crétacés. Centre National de la Recherche Scientifique, Paris, 129 pp., 48 pls.

Officer, C. B., Hallam, A., Drake, C. L. and Devine, J. D., 1987. Late Cietaceous and paroxysmal Cretaceous/Tertiary extinctions. Nature, 326, 143-149.

Okada, H., and Honjo, S., 1975. Distribution of Coccolithophores in Marginal Seas along the Western Pacific Ocean and in the Red Sea. Mar. Biology, 31, 271-285. 
Okada, H., Yamada, M., and Matsuoka, H., 1987. Calcareous nannofossils and biostratigraphy of the Upper Cretaceous and lower Paleogene Nemuro Group, eastern Hokkaido, Japan. J. Geol. Soc. Japan, 93(5), 329-348.

Olsson, R. K., Liu, C., Aubry, M.-P., Ehrendorfer, T., 1992. A biostratigraphically continuous Cretaceous/Paleogene section at Millers Ferry, Alabama: support for a bolide impact. GSA Abstr. w. Prgm., Annual Meeting, Cincinnati, Ohio, A28.

Parrish, J. T., and Spicer, R. A., 1988. Late Cretaceous terrestrial vegetation: A near-polar temperature curve. Geology, 16, 22-25.

Perch-Nielsen, K., 1968. Der Feinbau und die Klassifikation der Coccolithen aus dem Maastrichtien von Dänemark. Kongelige Danske Videnskabernes Selskab, Biologiske Skrifter, $16(1), 1-96,32$ pls.

Perch-Nielsen, K., 1983. Recognition of Cretaceous stage boundaries by means of calcareous nannofossils. In T. Birkelund, et al. (eds), Symposium on

Cretaceous Stage Boundaries, Copenhagen, Abstracts, 152-156.

Perch-Nielsen, K., McKenzie, J. A., and He, Q., 1982: Biostratigraphy and isotope stratigraphy and the 'catastrophic' extinction of calcareous nannoplankton at the Cretaceous/Tertiary boundary. Spec. Pap. geol Soc. Amer., 190, 353-371.

Percival, S. F., Jr., 1984. Late Cretaceous to Pleistocene calcareous nannofossils from the South Atlantic, Deep Sea Drilling Project Leg 73. In Hsü, K. J., LaBrecque, J. L., et al., Init. Repts. DSDP, 73: Washington (U.S. Govt. Printing Office), 391-424.

Percival, S. F., and Fischer, A. G., 1977. Changes in calcareous nannoplankton in the Cretaceous-Tertiary biotic crisis at Zumaya, Spain. Evol. Theory, 2, 1-35.

Pessagno, E. A., Jr., and Michael, F. Y., 1974. Mesozoic foraminifera, Leg 22, Site 217. In von der Borch, C. C., Sclater, J. G., et al., Init. Repts. DSDP, 22:

Washington (U.S. Govt. Printing Office), 629-634.

Pospichal, J. J., 1991. Calcareous nannofossils across Cretaceous/Tertiary boundary at Site 752, eastern Indian Ocean. In Weissel, J., Peirce, J., Taylor, E., Alt, J., et al., 1991. Proc. ODP. Sci. Results, 121: College Station, TX (Ocean Drilling Program), 395-410.

Pospichal, J. J., and Wise, S. W., Jr., 1990a. Maestrichtian calcareous nannofossil biostratigraphy of Maud Rise ODP Leg 113 Sites 689 and 690, Weddell Sea. In Barker, P. F., Kennett, J. P., et al.,Proc. ODP. Sci. Results, 113: College Station, TX (Ocean Drilling Program), 465-487.

Pospichal, J. J., and Wise, S. W., Jr., 1990b. Calcareous nannofossils across the K/T boundary, ODP Hole 690C, Maud Rise, Weddell Sea. In Barker, P. F., Kennett, J. P., et al.,Proc. ODP, Sci. Results, 113: College Station, TX (Ocean Drilling Program), 515-532. 
Pospichal, J. J., Wise, S. W., Jr., Asaro, F., and Hamilton, N., 1990. The effects of bioturbation across a biostratigraphically complete high southern latitude Cretaceous/Tertiary boundary. In Sharpton, V. L., and Ward, P. D. (eds.), Global Catastrophes in Earth History: An Interdisciplinary Conference on Impacts Volcanism, and Mass Mortality. GSA Spec. Paper 247, 497-507.

Pospichal, J. J., and Bralower, T. J., 1992. Calcareous nannofossils across the Cretaceous/Tertiary boundary, Site 761 , northwest Australian margin. In von Rad, U., Haq, B. U., et al., Proc. ODP, Sci. Results; 122: College Station, TX (Ocean Drilling Program), 735-751.

Premoli Silva, I., Erba, E., Tornaghi, M. E., 1989. Paleoenvironmental signals and changes in surface fertility in mid Cretaceous Corg-rich pelagic facies of the Fucoid Marls (central Italy). Geobios, Special Vol. 11, 225-236.

Raup, D. M., and Sepkoski, J. J., Jr., 1984. Periodicity of extinctions in the geologic past. Proc. Natl. Acad. Sci. USA, 81, 801-805.

Resiwati, P., 1991. Upper Cretaceous calcareous nannofossils from Broken Ridge and Ninetyeast Ridge, Indian Ocean. In Weissel, J., Peirce, J., Taylor, E., Alt, J., et al., 1991. Proc. ODP, Sci. Results, 121: College Station, TX (Ocean Drilling Program), 141-170.

Robert, C, and Maillot, H.,1990. Paleoenvironments in the Weddell Sea area and Antarctic climates, as deduced from clay mineral associations and geochemical data, ODP leg 113. In Barker, P. F., Kennett, J. P., et al.,Proc. ODP, Sci. Results, 113: College Station, TX (Ocean Drilling Program), 51-70.

Rocchia, R., Boclet, D., Bonté, P., Froget, L., Galbrun, B., Jéhanno, C., and Robin, E., 1992. Iridium and other element distributions, mineralogy, and magnetostratigraphy near the Cretaceous/Tertiary boundary in Hole $761 \mathrm{C}$. In von Rad, U., Haq, B. U., et al., Proc. ODP, Sci. Results, 122: College Station, TX (Ocean Drilling Program), 753-762.

Romein, A. J. T., 1979. Lineages in early Paleogene calcareous nannoplankton. Utrecht Micropaleontol, Bull., 22, 1-231.

Roth, P. H., and Bowdler, J. L., 1981. Middle Cretaceous calcareous nannoplankton biogeography and oceanography of the Atlantic Ocean. SEPM Special Publication, 32, 517-546.

Roth, P. H., and Krumbach, K. R., 1986. Middle Cretaceous calcareous nannofossil biogeography and preservation in the Atlantic and Indian Oceans: implications for paleoceanography. Mar. Micropaleontol., $\underline{10}$, 235-266.

Royer, J.-Y., Peirce, J. W., and Weissel, J. K., 1991. Tectonic constraints on the hotspot formation of Ninetyeast Ridge. In Weissel, J., Peirce, J., Taylor, E., Alt, J., et al., 1991. Proc. ODP. Sci. Results, 121: College Station, TX (Ocean Drilling Program), 763-776.

Russell, D. A., 1977. The biotic crisis at the end of the Cretaceous Period. Syllogeus, 12, 11-23. 
Saltzman, E. S., and Barron, E. J., 1982. Deep circulation in the Late Cretaceous: oxygen isotope paleotamperatures from Inoceramus remains in D.S.D.P. cores. Palaeogeography. Palaeoclimatology. Palaeoecology, 40, 167-181.

Savin, S. M. 1977. The history of the earth's surface temperature during the past 100 millio years. Ann. Earth Sci. Rev., 5, 319-355.

Saito, T., and Van Donk, J., 1974. Oxygen and carbon isotope measurements of Late Cretaceous and Early Tertiary foraminifera. Micropaleontology, 20(2), 152-177.

Shackleton, N. J., and Boersma, A., 1984. Oxygen and carbon isotope data from Leg 74 foraminifers. In Moore, T. C, Jr., Rabinowitz, P. D., et al., Init. Repts. DSDP, 74: Washington (U.S. Govt. Printing Office), 599-612.

Shipboard Scientific Party, 1974. Site 217. In von der Borch, C. C., Sclater, J. G., et al., Init. Repts. DSDP, 22: Washington (U.S. Govt. Printing Office), 267-324.

Shipboard Scientific Party, 1977. Site 327. In Barker, P. F., Dalziel, I. W. D., et al., Init. Repts. DSDP, 36: Washington (U.S. Govt. Printing Office), 27-86.

Shipboard Scientific Party, 1983. Site 516: Rio Grande Rise. In Barker, P. F., Carlson, R. L., and Johnson, D. A. Init. Repts. DSDP, 72: Washington (U.S. Govt. Printing Office), 155-338.

Shipboard Scientific Party, 1984. Site 528. In Moore, T. C., Jr., Rabinowitz, P. D., et al., Init. Repts. DSDP, 74: Washington (U.S. Govt. Printing Office), 307-405.

Shipboard Scientific Party, 1988. Site 690. In Barker, P. F., Kennett, J. P., et al., Proc. ODP. Init. Repts., 113: College Station, TX (Ocean Drilling Program).

Shipboard Scientific Party, 1990. Site 761. In Haq, B. U., von Rad, U., O'Connell, S., et al., Proc. ODP, Init. Repts., 122: College STation, TX (Ocean Drilling Program), 161-211.

Signor, P. W., III, and Lipps, J. H., 1982. Sampling bias, gradual extinction patterns, and catastrophes in the fossil record. GSA Special Paper, 190, 291-296.

Sissingh, W., 1977. Biostratigraphy of Cretaceous calcareous nannoplankton. Geologie en Mijnbouw, 56(1), 37-65.

Smayda, T. J., 1980. Phytoplankton species succession. In Morris, I. (ed), The physiological ecology of phytoplankton. Studies in Ecology, I, 493-570.

Smit, J., 1990. Meteorite impact, extinctions and the Cretaceous-Tertiary Boundary. Geologie en Mijnbouw, 69, 187-204.

Smith, A. G., Hurley, A. M., and Briden, J. C., 1981. Phanerozoic paleocontinental world maps. Cambridge University Press, Cambridge, 102 pp. 
Smith, C. C., and Poore, R. Z., 1984. Upper Maestrichtian and Paleocene planktonic foraminiferal biostratigraphy of the northern Cape Basin, Deep Sea Drilling Project Hole 524. In Hsü, K. J., LaBrecque, J. L., et al., Init. Repts. DSDP, 73: Washington (U.S. Govt. Printing Office), 449-457.

Stanley, S. M., 1984. Temperature and biotic crises in the marine realm. Geology, 12, 205-208.

Stott, L. D., and Kennett, J. P., 1990a. Antarctic Paleogene planktonic foraminifer biostratigraphy: ODP Leg 113, Sites 698 and 690. In Barker, P. F., Kennett, J. P., et al., Proc. ODP, Sci. Results, 113: College Station, TX (Ocean Drilling Program), 549-569.

Stott, L. D., and Kennett, J. P., 1990b. The paleoceanographic and paleoclimatic signature of the Cretaceous/Paleogene boundary in the Antarctic: stable isotopic results from ODP leg 113. In Barker, P. F., Kennett, J. P., et al., Proc. ODP, Sci. Results, 113: College Station, TX (Ocean Drilling Program), 829-848.

Tauxe, L., Tucker, P., Petersen, N. P., LaBrecque, J. L., 1984. Magnetostratigraphy of Leg 73 sediments. In Hsü, K. J., LaBrecque, J. L., et al., Init. Repts. DSDP, 73: Washington (U.S. Govt. Printing Office), 609-621.

Thierstein, H. R., 1976. Mesozoic calcareous nannoplankton biostratigraphy of marine sediments. Mar. Micropaleontol., 1, 325-362.

Thierstein, H. R., 1980. Selective dissolution of late Cretaceous and earliest Tertiary calcareous nannofossils: experimental evidence. Cretaceous Research, $\underline{2}, 165-176$.

Thierstein, H. R., 1981. Late Cretaceous nannoplankton and the change at the Cretaceous-Tertiary boundary. SEPM Special Publication, 32, 355-394.

Thierstein, H. R., 1982. Terminal Cretaceous plankton extinctions: A critical assessment. GSA Special Paper, 190, 385-399.

Thomas, E., 1990. Late Cretaceous through Neogene deep-sea benthic foraminifers (Maud Rise, Weddell Sea, Antarctica). In Barker, P. F., Kennett, J. P., et al.,Proc. ODP, Sci. Results, 113: College Station, TX (Ocean Drilling Program), 571-594.

Van Valen, L., and Sloan, Robert E., 1977. Ecology and the extinction of the dinosaurs. Evol. Theory, 2, 37-64.

Watkins, D. K., 1989. Nannoplankton productivity fluctuations and rhythmically-bedded pelagic carbonates of the Greenhorn Limestone (Upper Cretaceous). Palaeogeography, Palaeoclimatology, Palaeoecology, 74, 75-86.

Watkins, D. K., 1992. Upper Cretaceous nannofossils from Leg 120, Kerguelen Plateau, Southern Ocean. In Wise, S. W., Jr., Schlich, R., et al., 1992. Proc. ODP. Sci. Results, 120: College Station, TX (Ocean Drilling Program), 343-370. 
Wei, W., and Thierstein, H. R., 1991. Upper Cretaceous and Cenozoic calcareous nannofossils of the Kerguelen Plateau (southern Indian Ocean) and Prydz Bay (East Antarctica). In Barron, J., Larsen, B., et al., 1991. Proc. ODP, Sci. Results, 119: College Station, TX (Ocean Drilling Program), 467-493.

Weiss, W., 1983. Upper Cretaceous planktonic foraminiferal biostratigraphy from the Rio Grande Rise: Site 516 of Leg 72, Deep Sea Drilling Project. In Barker, P. F., Carlson, R. L., and Johnson, D. A. Init. Repts. DSDP, 72: Washington (U.S. Govt. Printing Office), 715-721.

Wiedmann, J., 1964. Le Crétacé supérieur de l'Espagne et du Portugal et ses Céphalopodes. Estud. Geol., 20, 107-148.

Wind, F. H., 1979a. Late Campanian and Maestrichtian calcareous nannoplankton biogeography and high-latitude biostratigraphy. Ph. D. Thesis. Florida State University, Tallahassee, 333 pp.

Wind, F. H., 1979b. Maestrichtian-Campanian Nannofloral Provinces of the Southern Atlantic and Indian Oceans. In Talwani, M., Hay, W., and Ryan, W. B. F. (eds.), Deep Drilling Results in the Atlantic Ocean: Continental Margins and Paleoenvironment. AGU, Washington D. C., 123-137.

Wind, F. H., and Wise, S. W., 1983. Correlation of upper Campanian-lower Maestrichtian calcareous nannofossil assemblages in drill and piston cores from the Falkland Plateau, southwest Atlantic Ocean. In Ludwig, W. J., Krasheninnikov, V., et al., Init. Repts. DSDP, 71: Washington (U.S. Govt. Printing Office), 551-563.

Wise, S. W., Jr., 1983. Mesozoic and Cenozoic calcareous nannofossils recovered by Deep Sea Drilling Project Leg 71 in the Falkland Plateau region, southwest Atlantic Ocean. In Ludwig, W. J., Krasheninnikov, V., et al., Init. Repts. DSDP, 71: Washington (U.S. Govt. Printing Office), 481-550.

Wise, S. W., Jr., 1988. Mesozoic-Cenozoic history of calcareous nannofossils in the region of the Southern Ocean. Palaeogeogr.. Palaeoclimatol., Palaeoecol., 67, 157-179.

Wise, S. W., Jr., and Wind, F. H., 1977. Mesozoic and Cenozoic calcareous nannofossils recovered by DSDP Leg 36 drilling on the Falkland Plateau, southwest Atlantic sector of the Southern Ocean. In Barker, P. F., Dalziel, I. W. D., et al., Init. Repts. DSDP, 36: Washington (U.S. Govt. Printing Office), 269-491. -

Wonders, A. A. H., 1992. Cretaceous planktonic foraminiferal biostratigraphy, Leg 122, Exmouth Plateau, Australia. In von Rad, U., Haq, B. U., et al., 1992. Proc. ODP, Sci. Results, 122: College Station, TX (Ocean Drilling Program), 587-599.

Worsley, T., 1974. The Cretaceous-Tertiary boundary event in the ocean. SEPM Special Publication, 20, 94-125.

Worsley, T., and Martini, E., 1970. Late Maestrichtian Nannoplankton Provinces. Nature, 225, 1242-1243. 
Zachos, J. C., and Arthur, M. A., 1986. Paleoceanography of the Cretaceous/Tertiary boundary event: inferences. from stable isotopic and other data. Paleoceanography, 1(1), 5-26.

Zachos, J. C., Arthur, M. A., and Dean, W. E., 1989. Geochemical evidence for suppression of pelagic marine productivity at the Cretaceous/Tertiary boundary. Nature, 337, 61-64. 


\section{APPENDIX I TAXONOMY}

Different levels of taxonomic identificatation were possible depending on preservation. In the data tables (Appendix II) the highest taxonomic resolution achieved is given for each sample: in well preserved samples most taxa could be identified at the species level, whereas in many moderately to poorly preserved samples only generic identification was possible in certain taxa. When identification at the species level could not be maintained in all samples it was necessary to group species at the generic level for comparison between samples and between sections. The following is a list of the species identified in this study; included are discussions of the grouping of taxa for inter-sample comparison.

Ahmuellerella ectoradiata (Gorka, 1957) Reinhardt (1964)

Angulofenestrellithus snyderi Bukry (1969)

Arkhangelskiella cymbiformis Vekshina (1959)

A. specillata Vekshina (1959): In poorly preserved samples it was not always possible to differentiate between $\underline{A}$. cymbiformis and $\underline{A}$. specillata because the pores in the central area were covered due to recrystallization. (see also comments under Broinsonia enormis).

Biantholithus sparsus Bramlette and Martini, 1964

Biscutum Black in Black and Barnes, 1959

B. boletum Wind and Wise in Wise and Wind (1977)

B. constans (Gorka, 1957) Black, 1967: In this study $\underline{\text { B. constans }}$ and $\underline{\text { B. }}$.

castrorum are considered synonymous. According to Perch-Nielsen (1968) B. constans has priority over B. testudinarium Black (1959) which is a younger synonym. Biscutum constans and $\underline{B}$. castrorum are considered synonyms (following Noël, 1970), although some researchers indicate that these may be indeed two distinct genera, based on coccolith size and number of marginal elements (Perch-Nielsen, 1968) or on coccolith size and the construction of the central area (Romein, 1979). According to Romein (1979) the elements of the proximal shield extend into and close the central area in $\underline{B}$. castrorum, whereas in $\underline{B}$. constans the central area is filled with granular elements which are clearly separate from the shield elements. The light microscope expression of 
these two types of construction is not demonstrated satifactorily: in $\underline{B}$. castrorum the entire central area is birefringent (Romein, 1979; pl. 9, fig. 1), but no light microscope picture was supplied of $\underline{B}$. constans. Pospichal (1991; pl. 2, fig. 1-2 and pl. 3, fig. 3) gave light microscope illustrations of both species: the central area of $\underline{B}$. castrorum is completely bright in cross-polarized light, whereas only a narrow birefringent ring lines the central area in $\underline{B}$. constans. No electron microscope pictures of the proximal sides of these two forms were provided so that the the correspondence of the light-microscope pictures to the ultra structure as described by Romein (1979) is still unproven. In my investigations both of the forms illustrated by Pospichal (1991) as $\underline{B}$. castrorum and as $\underline{B}$. constans were encountered; both were recorded as $\underline{B}$. constans because I interpreted the forms with a birefringent ring in the central area as incomplete (broken) specimens of those with a completely birefringent area.

B. coronum Wind and Wise in Wise and Wind (1977): The species illustrated by Bralower and Siesser (1992: pl. 1, figs. 23, 24) is not included with $\underline{B}$. coronum in this study, but would probably by classified as $\underline{B}$. constans. B. dissimilis Wind and Wise in Wise and Wind (1977)

B. magnum Wind and Wise in Wise and Wind (1977)

Biscutum sp. cf. B. magnum: This species is very similar to $\underline{B}$. magnum except that its margin is much narrower than typical specimens of this species.

B. notaculum Wind and Wise in Wise and Wind (1977)

Biscutum sp. 1 (Pospichal and Bralower; 1992; pl.3, fig. 1-2): This taxon is common in all sections studied. It is smaller than other species of this genus observed in this investigation (with the exception of $\underline{B}$. notaculum). In normal light a ring of high relief surrounds the central area; this ring is bright in cross polarized light. Biscutum sp. 1 differs from $\underline{B}$. constans in having a fairly narrow margin (the diameter of the central area is bigger than the width of the margin).

Biscutum sp. 2 This species is characterized by a narrow margin and a cross like (?) structure spanning the central opening. It was only observed in Hole 690C.

Braarudosphaera bigelowii (Gran and Braarud, 1935) Deflandre, 1947 
Broinsonia Bukry, 1969: This genus differs from Arkhangelskiella in the presence of a second, outer, narrow marginal cycle on the distal side (Bukry, 1969). This cycle is clearly visible only in well preserved material. In moderately and poorly preserved material the outer marginal cycle cannot be distinguished in most cases. Bralower and Siesser (1992) used the presence/absence of pores as well as the extinction pattern of the central area to distinguish between Arkhangelskiella and Broinsonia. This practice is not adopted here since observations in well preserved material (where Broinsonia can be recognized based on the outer marginal cycle) indicate that both of these characteristics are very variable and do not allow consistent differentiation between the genera.

Broinsonia bevieri Bukry, 1969

Broinsonia enormis (Shumenko, 1969) Manivit (1971): In size and in ratio of margin to central area this species is very similar to Arkhangelskiella cymbiformis. In many cases it was impossible to determine whether the margin consisted of one or of two cycles; $\underline{A}$. cymbiformis and $\underline{\text { cy. enormis }}$ were then recorded as one taxon.

Broinsonia parca (Stradner, 1963) Bukry, 1969: Because of the small size of the central area this species could be identified consistently.

Centosphaera barbata Wind and Wise in Wise and Wind, 1977

Ceratolithoides aculeus (Stradner, 1961) Prins and Sissingh in .Sissingh, 1977

C. kamptneri Bramlette and Martini, 1964

Ceratolithoides sp. 1: This form has broad, parallel arms that touch each other in many specimens. It is not clear whether these forms are recrystallized specimens of $\underline{C}$. kamptneri or of $\underline{C}$. aculeus, or whether they represent a separate taxon.

\section{Chiastozygus Gartner, 1968}

C. amphipons (Bramlette and Martini, 1964) Gartner, 1968: This species has a fairly wide margin which does not display sharp extinction lines in cross-polarized light. The central $X$ consists of arms that are as wide as the margin; under cross-polarized light the arms are divided lengthwise.

C. garrisonii Bukry, 1969: A small square is visible at the central juncture of the arms; it is interpreted as the base of a central stem which in most cases is not preserved. 
Chiastozygus sp. 1: This taxon is characterized by a narrow margin (compared

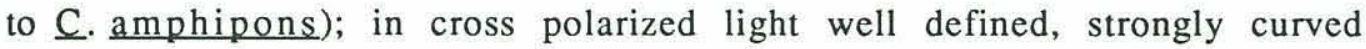
extinction lines occur in the margin. The central crossbars do not intersect at one point, but rather form a distorted $\mathrm{H}$. This species differs from $\underline{C}$. amphipons in having a narrower margin, in the extinction pattern of the margin, and in the fact that in $\underline{C}$. amphipons the central crossbars form a perfect $X$. This form differs from $\underline{C}$.garrisonii in lacking an opening at the intersection point of the crossbars.

Corollithion? completum Perch-Nielsen, 1973

Corollithion exiguum Stradner, 1961

Cretarhabdus Bramlette and Martini, 1964: The distinction between $\underline{C}$. conicus,

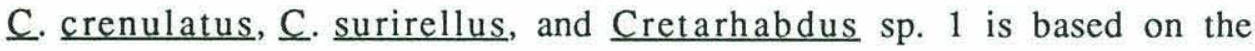
construction of the central area. Species identification was thus not possible when the central area was incompletely preserved. On the other hand, identification of $\underline{C}$. angustiforatus and of $\underline{C}$. schizobrachiatus was still possible when most of the central area was missing: the points where the central arms were connected to the margin were still recognizable. Species identification was possible because of the characteristic number (eight in $\underline{C}$. angustiforatus) and position (groups of three in $\mathrm{C}$. schizobrachiatus) of these points on the margin. Thus, the forms included in this group are mostly $\underline{C}$. conicus, $\underline{C}$. crenulatus, $\underline{C}$. surirellus and Cretarhabdus sp. 1. Because distinction between these species was so dependent on preservation, these four species and Cretarhabdus spp. were added and treated as one taxon for plotting purposes.

Cretarhabdus angustiforatus (Black, 1971) Bukry, 1973: A species of Cretarhabdus with eight radial arms in the central area: four longer arms are aligned with the ellipse; the other four arms are somwhat shorter and lie at an angle of about $45^{\circ}$ to the ellipse axes.

C. conicus Bramlette and Martini, 1964: Included in this species are forms with more than one row of central perforations (as explicitly stated by Bukry, 1969), i.e. the central area appears to be covered by a porous grid. Cretarhabdus conicus may have a central cross aligned with the ellipse axes.

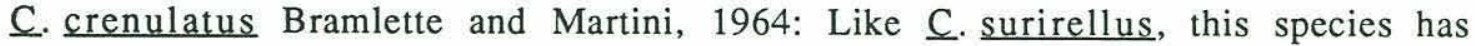
only one row of openings in the central area, i.e. its central area 
appears to be spanned by short buttresses/rods. The relative size of the central area was used to distinguish $\underline{C}$. crenulatus from $\underline{C}$. surirellus. In

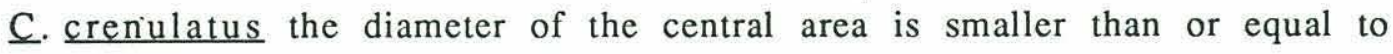
the width of the margin (measured along the short ellipse axis). In $\underline{C}$. surirellus the diameter of the central area is larger than the width of the margin.

C. schizobrachiatus (Gartner, 1968) Bukry, 1969

C. surirellus (Deflandre, 1964), Reinhardt, 1970: see comments under $\underline{\text { C. }}$ crenulatus

Cretarhabdus sp. 1: This species is characterized by numerous pores in the central area (similar to the central area of $\underline{\mathrm{C}}$. ehrenbergii), but with a margin typical of Cretarhabdus. It was observed in the Millers Ferry section, in Hole 690C and in Hole 761C.

Cribrosphaerella? daniae Perch-Nielsen, 1973

Cribrosphaerella ehrenbergii (Arkhangelskii, 1912) Deflandre in Piveteau, 1952: Included in this species are elliptical, triangular, as well as almost circular morphotypes.

Cruciplacolithus Hay and Mohler in Hay et al, 1967: Rare representatives of this genus have been observed in the uppermost Maestrichtian samples in Hole $690 \mathrm{C}$ where they are considered to be contamination due to bioturbation.

Cyclagelosphaera alta Perch-Nielsen, 1979a

C. margerelii Noel, 1965

C. reinhardtii (Perch-Nielsen, 1968) Romein, 1977

Cyclagelosphaera sp. 1: In size and extinction pattern this species is similar to C. margerelii but in brightfield 4 or 5 ridges are visible radiating from the center of the coccolith and extending about halfway to its periphery.

Cylindralithus Bramlette and Martini, 1964

C. biarcus Bukry, 1969

C. gallicus (Stradner, 1963) Bramlette and Martini, 1964: Round and elliptical morphotypes were observed.

C. Serratus Bramlette and Martini, 1964: Included in this species are all specimens that have a narrow margin in comparison to $\underline{C}$. gallicus.

Cylindralithus sp. 1: This form consists of wide, thick, numerous, strongly overlapping elements. It is distinguished from $\underline{\mathrm{C}}$.gallicus by having 
more numerous elements, from $\underline{C}$. serratus by being thicker. In cross polarized light this forms is highly birefringent, blue and orange interference colors are characteristic. Monechi (1985, pl. 2, figs. 6, 10A, 10B) illustrated this form as Cylindralithus sp.

Discorhabdus ignotus (Gorka, 1957) Perch-Nielsen, 1968

Eiffellithus parallelus Perch-Nielsen, 1973

E. trabeculatus (Gorka, 1957) Reinhardt and Gorka (1967)

E. turriseiffeli (Deflandre in Deflandre and Fert, 1954) Reinhardt (1965): The size variation within this species is considerable, but continuous.

Ericsonia Black, 1964

Ericsonia sp.: Included in this taxon are cirular forms with a large central opening with white to light yellow interference colors.

Gartnerago Bukry, 1969

Gartnerage spp.: Thierstein (1974) used the number and arrangement of pores in the central area to distinguish between $\underline{G}$ segmentatus, $\underline{\text { s. obliquum, }}$ and $\underline{G}$. segmentatum, but he reports that the pores get easily obliterated as a consequence of recrystallization. This observation is corroborated in this study. As a consequence it was not possible here to differentiate between different species.

Glaukolithus fessus (Stover, 1966) Perch-Nielsen, 1968

Hexalithus Gardet, 1955: Forms with six and with eight rays were observed.

Hornibrookina Edwards, 1973

Kamptnerius magnificus Deflandre, 1959: Included in this species are also the perforated forms (K. punctatus) that were occasionally encountered.

Lapideacassis Black, 1971 spp indet: Due to fragmentation rigorous and consistent species identification was impossible in this genus.

Lithastrinus Stradner, 1962

Lithastrinus spp.: I have assigned to this genus small circular forms that usually have high interference colors (orange-red).

Lithraphidites carniolensis Deflandre, 1963

L. grossopectinatus Bukry, 1969

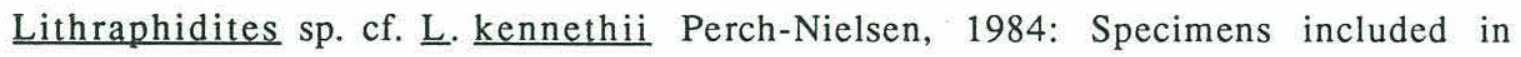
this taxon are almost as wide as they are long, resembling $\underline{L}$. quadratus that has been reduced to about half its length without changing the width.

L. praequadratus Roth, 1978 
L. quadratus (Bramlette and Martini, 1964) Roth, 1978

Lithraphidites (?) sp. 1: This form is tentatively assigned to Lithraphidites.

Under the light-microscope it consists of two parallel rods which overlap for about one third of their length. The overlapping portions

are somewhat thicker than the parts that form the two tips of this form.

Lucianorhabdus cayeuxii Deflandre (1959): Acuturris scotus is also included in

this taxon. Both taxa occurred mostly as fragments which made

consistent species identification impossible.

Manivitella pemmatoidea (Deflandre ex Manivit, 1965) Thierstein, 1971

Markalius apertus Perch-Nielsen, 1979

M. inversus (Deflandre in Deflandre and Fert, 1954) Bramlette and Martini, 1964

Microrhabdulus decoratus Deflandre, 1959

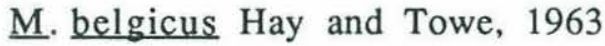

Micula murus (Martini, 1961) Bukry 1973

M. praemurus (Bukry, 1973) Stradner and Steinmetz, 1984

Micula sp. cf. M. prinsii Perch-Nielsen, 1979: Micula prinsii s. str. is characterized by curved arms with a delicate, terminal bifurcation that tends to recrystallize and overgrow. Specimens with long, curved arms were observed, but the characteristic bifurcation at the tips of the arms was absent. In some cases the tips of the arms were thickened and of higher birefringence than the remainder of the nannofossil, possibly due to recrystallization of the delicate terminal bifurcation.

M. staurophora (Gardet, 1955) Stradner, 1963

Micula? sp.: Pospichal and Bralower (1992, pl. 4, figs. 7, 8) illustrate this species: the fact that it consists of four crystals and its extinction pattern suggest that it belongs to the genus Micula. The triangular outline of this form is unusual for Micula. It was encountered only at mid and low latitudes, its stratigraphic range is the uppermost Maestrichtian (approximately the M. murus Zone).

Misceomarginatus Wind and Wise in Wise and Wind, 1977

Misceomarginatus pleniporus Wind and Wise in Wise and Wind, 1977: Species identification of Misceomarginatus and of Monomarginatus was not consistently possible due to susceptibility of these species to dissolution and recrystallization. For plotting purposes species from both genera were added together. 
Monomarginatus Wind and Wise in Wise and Wind, 1977

Monomarginatus pectinatus Wind and Wise in Wise and Wind, 1977

M. quaternarius Wind and Wise in Wise and Wind, 1977

Neocrepidolithus Romein, 1979 spp indet.: Included here are all species of

Neocrepidolithus that were encountered in the immediate vicinity of

the K/P boundary (e.g. $\underline{N}$. crassus, $\underline{N}$. cruciatus, etc). Never included is $\underline{N}$. watkinsii.

Neocrepidolithus watkinsii Pospichal and Wise, 1990

Nephrolithus frequens Gorka, 1957: Frequently specimens were observed with

a highly birefringent crystal in the center of the distal side of the coccolith. It is possible that this bright spot was caused by a piece of calcite debris lying on top of the nannofossils; this is improbable considering that the "bright spot" occurred consistently in the center of the central area. Alternatively, the "bright spot" could be the expression of a genuine structural feature, like a knob or short stem, similar to the stems observed in $\underline{\mathrm{N}}$. corystus. Watkins (1992: pl. 4, fig. 1) has indeed illustrated $\underline{\mathrm{N}}$. frequens with a short stem in material from the Kerguelen Plateau.

N. corystus Wind, 1983

Octocyclus magnus Black, 1972

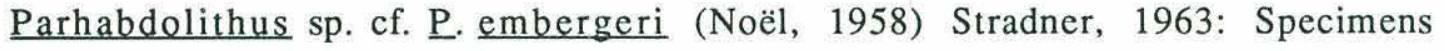
included in this taxon differ from $\underline{P}$. embergeri in lacking a clear bipartition of the transverse bar, which is usually massive and diamond shaped. The specimens are virtually always very recrystallized, with high relief, outline of individual elements never discernible, and high interference colors (red, blue). The openings in the central area are often completely closed due to overgrowth.

Parhabdolithus regularis (Gorka, 1957) Bukry, 1969

Pervilithus varius Crux, 1981: This species occurs very rarely in the upper Maestrichtian (․․ frequens Zone) in Hole 690C and upper Maestrichtian M. murus Zone in Hole 217. This extends the range originally assigned to this species (Santonian to Campanian; Crux, 1981) into the upper Maestrichtian.

Petrarhabdus copulatus (Deflandre, 1959) Wind and Wise in Wise (1983): Phanulithus obscurus (Deflandre, 1959) Wind and Wise in Wise and Wind (1977) 
Placozygus fibuliformis (Reinhardt, 1964) Hoffmann, 1970

P. bussonii Perch-Nielsen, 1968

P. sigmoides (Bramlette and Sullivan, 1961) Romein, 1979

Placozygus sp: This species was illustrated by Pospichal and Bralower (1992, pl. 4, figs 11-12) as Zygodiscus sp. The basal plate and the flange (sensu Aubry, 1988) of this form are usually present, the transverse bar in virtually all cases absent. The basal plate is quite narrow. The flange is always well developed and consists of strongly overlapping, distally flaring elements. The sutures in this cycle are easily discernible under the light micsroscope (bright field). In many forms it appears as if an additional cycle is present in the central area, adjacent to the basal plate and the flange, usually extending all the way around. The provenance of this cycle is unclear: it may either correspond to the blocky elements at the junction of transverse bar and basal plate in $\underline{\mathrm{P}}$ sigmoides, or may be an artifact of recrystallization and overgrowth of the basal plate extending into the central opening. The size of this species is quite variable; it is fairly common in the Maestrichtian at middle and low latitudes.

Prediscosphaera arkhangelskyi (Reinhardt, 1965) Perch-Nielsen, 1984

P. cretacea (Arkhangelsky, 1912) Gartner, 1968: Considerable size variation is conspicuous within this species. It did not appear, however, that distinct size classes justify the separation of subspecies, or morphotypes. A quantitative study may be necessary to investigate this isssue. Round morphotypes of Prediscosphaera were included in this species.

P. grandis Perch-Nielsen, 1979

P. spinosa (Bramlette and Martini, 1964) Gartner, 1968

P. stoveri (Perch-Nielsen, 1968) Shafik and Stradner, 1971

Prinsius tenuiculum (Okada and Thierstein, 1979) Perch-Nielsen, 1984

Psyktosphaera firthii Pospichal and Wise, 1990: The perforate inner central area of this species is elliptical and has a granulate appearance in cross polarized light. Some specimens were encountered in which the perforate part of the central area was extremely narrow.

Quadrum gartneri Prins and Perch-Nielsen in Manivit et al, 1977

Q. trifidum (Stradner in Stradner and Papp, 1961) Prins and Perch-Nielsen in

Manivit et al, 1977

Reinhardtites aff. anthophorus Prins and Sissingh in Sissingh, 1977 
R. levis Prins and Sissingh in Sissingh, 1977

Rhagodiscus Reinhardt, 1967

Rhagodiscus angustus (Stradner, 1963) Reinhardt, 1971

R. reniformis Perch-Nielsen, 1973

R. splendens (Deflandre, 1953) Verbeek, 1977

Rhagodiscus sp. 1: This species is characterized by an extremely narrow central area.

Rhombolithion rhombicum (Stradner and Adamiker, 1966) Black, 1973

Rucinolithus hayi Stover, 1966

Scampanella Forchheimer and Stradner, 1973

S. asymmetrica Perch-Nielsen, 1977

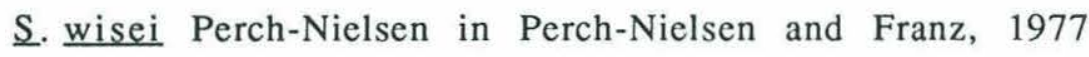

Scapholithus fossilis Deflandre in Deflandre and Fert, 1954

Staurolithites laffittei Caratini, 1963

Stephanolithion Deflandre, 1939 spp indet.: Different species of this genus are recognized based on the number of central spokes and peripheral knobs. In less than well preserved material the central spokes are unrecognizable and the knobs on the outside of the nannofossil are partly dissolved. The consistent recognition of species was therefore impossible.

Tegumentum stradneri Thierstein in Roth and Thierstein, 1972

Teichorhabdus ethmos Wind and Wise in Wise and Wind, 1977

Tetrapodorhabdus decorus (Deflandre in Deflandre and Fert, 1954) Wind and

Wise in Wise and Wind, 1977

Thoracosphaera Kamptner, 1927 spp: included are I. operculata, T. saxea

Tranolithus macleodae (Bukry, 1969) Perch-Nielsen, 1984: includes T. minimus

Tranolithus phacelosus Stover, 1966

Vagalapilla Bukry, 1969

Watznaueria barnesae (Black in Black and Barnes, 1959) Perch-Nielsen, 1968

W. biporta Bukry, 1969

Zygodiscus compactus Bukry, 1969

Z. diplogrammus (Deflandre in Deflandre and Fert, 1954) Gartner, 1968

Z. lacunatus Gartner, 1968

Zygodiscus sp. 1: This is a small form of Zygodiscus? with a cross aligned with the ellipse axes spanning the central opening. Under the light 
microscope a small dark spot at the intersection of the cross arms is a very distinct feature. 


\section{APPENDIX II}

\section{DATA}

The counting results are listed in the following tables. The following abbreviations are used:

Preservation: $\quad$ G - good

M - modẹrate

$\mathrm{P}$ - poor

PP- very poor

$\begin{array}{ll}\text { Abundance: } & \text { A - abundant } \\ & \text { C - common } \\ & \text { R - rare }\end{array}$

Carbonate content: n.d. - not determined

An asterisk $\left(^{*}\right)$ or a ' $\mathrm{P}$ ' in the data tables indicates that this taxon was observed at this level during the additional scanning after the counts were performed. 


\begin{tabular}{|c|c|c|c|c|c|c|c|c|c|}
\hline Sample Number & 1 & 2 & 3 & 4 & 5 & 6 & 7 & 8 & 9 \\
\hline ODP Hole $690 \mathrm{C}$ & $690 \mathrm{C}$ & $690 \mathrm{C}$ & $690 \mathrm{C}$ & $690 \mathrm{C}$ & $690 \mathrm{C}$ & $690 \mathrm{C}$ & $690 \mathrm{C}$ & $690 \mathrm{C}$ & $690 \mathrm{C}$ \\
\hline Core - Section & $15-4$ & $15-4$ & $15-4$ & $15-4$ & $15-4$ & $15-4$ & $15-4$ & $15-4$ & $15-4$ \\
\hline $\mathrm{cm}$ - level & 38 & 41 & 43.5 & 47 & 50 & 53 & $56.5 w$ & $56.5 \mathrm{~b}$ & 60.5 \\
\hline Depth (mbsf) & 247.78 & 247.81 & 247.835 & 247.87 & 247.9 & 247.93 & 247.965 & 247.965 & 248.005 \\
\hline Sedimentation rate (m/m.y.) & 1.04 & 13.2 & 13.2 & 13.2 & 13.2 & 13.2 & 13.2 & 13.2 & 13.2 \\
\hline Age (Ma) & 66.390 & 66.402 & 66.403 & 66.406 & 66.408 & 66.411 & 66.413 & 66.413 & 66.416 \\
\hline Preservation (G, M, P) & M-P & M & M & M & M & M & M-P & M & M \\
\hline Abundance $(A, C, R)$ & C-A & A & A & A & A & A & A & C-A & A \\
\hline Fields counted & 153.9 & 99.2 & 34 & 174 & 33 & 32 & 18 & 28 & 67 \\
\hline Sediment used for slide (mg) & 20.1 & 19.5 & 19.9 & 19.1 & 19.7 & 18.4 & 19.1 & 13.8 & 19.9 \\
\hline Carbonate content (wt-\%) & 49.8 & 48.2 & 51.5 & 56.2 & 67.9 & 79.5 & 81.8 & & 83.1 \\
\hline Beaker Constant & 3.0 & 3.0 & 3.0 & 3.0 & 3.0 & 3.0 & 3.0 & 3.0 & 3.0 \\
\hline Ahmuellerella octoradiata (and P. regularis) & . & 1 & 4 & 8 & 4 & 4 & 8 & 3 & 6 \\
\hline Arkhangelskiella cymbiformis & 35 & 11 & 12 & 43 & 16 & 19 & 5 & 9 & 30 \\
\hline A. cymbiformis/specillata & . & . & · & . & . & · & $\cdot$ & . & . \\
\hline A. specillata & . & . & . & $\cdot$ & . & . & . & . & . \\
\hline Biantholithus sparsus & . & $\mathrm{P}$ & . & $\mathbf{P}$ & $\mathrm{P}$ & . & . & . & . \\
\hline Biscutum boletum & . & . & . & . & . & . & . & . & . \\
\hline B. constans & 45 & 16 & 5 & 25 & 6 & P & . & 1 & 2 \\
\hline B. coronum & . & . & . & . & . & . & . & . & . \\
\hline B. dissimilis & . & . & . & . & . & . & . & . & . \\
\hline B. magnum & . & . & . & . & . & . & . & . & . \\
\hline B. notaculum & . & . & . & . & . & . & . & . & . \\
\hline Biscutum sp. 1 & . & . & . & . & . & . & . & . & . \\
\hline Biscutum sp. 2 & . & . & . & . & . & . & . & . & · \\
\hline Broinsonia sp. cf. B. bevieri & . & . & . & . & . & - & . & . & . \\
\hline Broinsonia spp. & . & . & . & - & - & . & · & . & . \\
\hline Centosphaera barbata & . & . & . & . & . & . & . & . & . \\
\hline Chiastozygus amphipons & . & . & . & . & - & . & . & . & . \\
\hline C. garrisonii & . & . & . & . & . & . & . & . & . \\
\hline Chiastozygus sp. 1 & . & . & . & . & . & . & . & . & . \\
\hline Cretarhabdus conicus & . & . & . & . & 1 & . & . & . & . \\
\hline C. crenulatus & . & . & . & . & . & . & . & . & . \\
\hline C. surirellus & . & . & . & . & . & . & . & . & . \\
\hline Cretarhabdus sp. 1 & . & . & . & . & . & . & . & . & . \\
\hline Cretarhabdus spp. & 12 & 7 & 3 & 20 & 5 & 4 & 3 & 5 & 10 \\
\hline Cribrosphaerella (?) daniae & 7 & 10 & 9 & 26 & 7 & 5 & 16 & 9 & 14 \\
\hline Cribrosphaerella ehrenbergii & 5 & 2 & 2 & 12 & 2 & 3 & 5 & 3 & 6 \\
\hline Cruciplacolithus spp. & . & . & . & . & . & . & . & . & . \\
\hline Cyclagelosphaera spp. & . & . & . & . & $\cdot$ & · & . & . & . \\
\hline Cylindralithus spp. & . & . & . & . & - & . & . & . & . \\
\hline Discorhabdus ignotus & . & . & . & . & - & . & . & . & . \\
\hline Eiffellithus trabeculatus & . & . & . & . & . & . & . & . & : \\
\hline E. turriseiffeli & 1 & P & 1 & 3 & 2 & P & 3 & 1 & 6 \\
\hline Gartnerago spp. & 1 & . & 1 & 2 & 1 & 1 & 1 & . & 3 \\
\hline Glaukolithus fessus & 3 & 2 & 4 & 9 & 4 & 1 & 5 & 1 & 8 \\
\hline Homibrookina spp. & 3 & . & . & . & $\mathbf{P}$ & 1 & . & . & . \\
\hline Kamptnerius magnificus & 40 & 13 & 15 & 40 & 21 & 18 & 10 & 14 & 27 \\
\hline Lapideacassis spp. & . & . & . & . & . & . & . & . & . \\
\hline Lithraphidites camiolensis & . & . & . & . & . & . & . & . & . \\
\hline Lucianorhabdus cayeuxii & 23 & 6 & 2 & 26 & 10 & 12 & 15 & 8 & 38 \\
\hline Markalius inversus & 5 & 4 & 3 & 13 & P & 2 & . & 1 & 1 \\
\hline Microrhabdulus decoratus & . & . & . & . & . & . & . & . & . \\
\hline Micula staurophora & 6 & 1 & . & 1 & . & . & . & . & 1 \\
\hline Misceomarginatus pleniporus & . & . & . & . & . & . & . & . & . \\
\hline Misceomarginatus sp. & . & . & . & . & . & . & . & · & . \\
\hline Monomarginatus pectinatus & . & . & . & . & . & . & . & . & . \\
\hline M. quaternarius & . & . & . & . & . & . & . & . & . \\
\hline Monomarginatus sp. & . & . & . & . & . & . & . & . & . \\
\hline Misceomarginatus/Monomarginatus sp. & . & . & . & . & . & . & . & . & . \\
\hline Neocrepidolithus watkinsii & . & . & . & . & . & $\cdot$ & . & . & . \\
\hline Neocrepidolithus spp. & 18 & 5 & 2 & 12 & 2 & P & . & 1 & . \\
\hline Nephrolithus corystus & . & . & . & . & . & . & . & . & . \\
\hline N. frequens & 79 & 33 & 42 & 156 & 51 & 51 & 79 & 58 & 137 \\
\hline Octocyclus magnus & . & . & . & . & . & . & . & . & . \\
\hline Phanulithus obscurus & , & . & . & . & . & . & . & . & . \\
\hline
\end{tabular}




\begin{tabular}{|c|c|c|c|c|c|c|c|c|c|}
\hline Sample Number & 1 & 2 & 3 & 4 & 5 & 6 & 7 & 8 & 9 \\
\hline ODP Hole 690C & $690 \mathrm{C}$ & $690 \mathrm{C}$ & $690 \mathrm{C}$ & $690 \mathrm{C}$ & $690 \mathrm{C}$ & $690 \mathrm{C}$ & $690 \mathrm{C}$ & $690 \mathrm{C}$ & $690 \mathrm{C}$ \\
\hline Core - Section & $15-4$ & $15-4$ & $15-4$ & $15-4$ & $15-4$ & $15-4$ & $15-4$ & $15-4$ & $15-4$ \\
\hline $\mathrm{cm}$ - level & 38 & 41 & 43.5 & 47 & 50 & 53 & $56.5 w$ & $56.5 \mathrm{~b}$ & 60.5 \\
\hline Depth (mbsf) & 247.78 & 247.81 & 247.835 & 247.87 & 247.9 & 247.93 & 247.965 & 247.965 & 248.005 \\
\hline Placozygus bussonii & . & . & . & . & . & . & . & . & . \\
\hline P. fibuliformis & 1 & $\mathrm{P}$ & . & . & $\mathrm{P}$ & . & . & . & . \\
\hline P. sigmoides & 52 & 19 & 9 & 80 & 5 & 1 & 1 & 16 & 5 \\
\hline Placozygus sp. & . & . & . & . & . & . & . & . & . \\
\hline Prediscosphaera arkhangelskyi & . & . & . & . & . & . & . & . & . \\
\hline P. cretacea & 36 & 20 & 29 & 65 & 19 & 18 & 19 & 18 & 35 \\
\hline P. spinosa & . & 2 & 2 & 14 & 1 & $\mathrm{P}$ & 6 & 4 & 4 \\
\hline Psyktosphaera firthii & . & . & . & . & . & . & . & . & . \\
\hline Quadrum gartneri & . & . & . & . & . & . & . & . & . \\
\hline Reinhardtites spp. & . & . & . & . & . & . & . & . & . \\
\hline Rhagodiscus angustus & . & . & . & . & . & . & . & . & . \\
\hline Rhagodiscus spp. & . & . & . & . & . & . & . & . & . \\
\hline Rhombolithion rhombicum & . & . & . & . & . & . & . & . & . \\
\hline Scampanella asymmetrica & . & . & . & . & . & . & . & . & . \\
\hline S. wisei & . & . & . & . & . & . & . & . & . \\
\hline Scampanella spp. & . & $P$ & . & . & . & . & . & . & . \\
\hline Scapholithus fossilis & & . & . & . & . & . & . & . & . \\
\hline Staurolithites laffittei & . & . & . & . & . & . & . & . & . \\
\hline Teichorhabdus ethmos & . & . & . & . & . & . & . & . & . \\
\hline Thoracosphaera spp. & 5 & 16 & 3 & 44 & 3 & 3 & 1 & 4 & 3 \\
\hline Vagalapilla spp. & . & 1 & 1 & 8 & 3 & 2 & 4 & 3 & 8 \\
\hline Watznaueria bamesae & . & . & . & . & 1 & . & . & . & . \\
\hline Zygodiscus compactus & . & . & . & . & . & . & . & . & . \\
\hline Z. diplogrammus & . & . & . & . & . & . & . & . & . \\
\hline Unidentifiable & 6 & 5 & 4 & 18 & 5 & 5 & 5 & 3 & 9 \\
\hline Total (exclusive of P. stoveri): & 383 & 174 & 153 & 625 & 169 & 150 & 186 & 162 & 353 \\
\hline Prediscosphaera stoveri & 366 & 148 & 190 & 187 & 192 & 199 & 169 & 178 & 518 \\
\hline Total of P. stoveri - count(s) & 750 & 322 & 343 & 345 & 361 & 351 & 355 & 340 & 871 \\
\hline P. stoveri, fields & 153.9 & 99.2 & 34 & 42 & 33 & 32 & 18 & 28 & 67 \\
\hline
\end{tabular}




\begin{tabular}{|c|c|c|c|c|c|c|c|c|c|c|c|c|}
\hline Sample Number & 10 & 11 & 12 & 13 & 14 & 15 & 16 & 17 & 18 & 19 & 20 & 21 \\
\hline Hole & $690 \mathrm{C}$ & $690 \mathrm{C}$ & $690 \mathrm{C}$ & $690 \mathrm{C}$ & $690 \mathrm{C}$ & $690 \mathrm{C}$ & $690 \mathrm{C}$ & $690 \mathrm{C}$ & $690 \mathrm{C}$ & $690 \mathrm{C}$ & $690 \mathrm{C}$ & $690 \mathrm{C}$ \\
\hline Core - Section & $15-4$ & $15-4$ & $15-4$ & $15-4$ & $15-4$ & $15-4$ & $15-4$ & $15-4$ & $15-4$ & $15-4$ & $15-4$ & $15-4$ \\
\hline $\mathrm{cm}$ - level & 62 & 64 & 67 & 70 & 73 & 76 & 79 & 82.5 & 85 & 88 & 92 & 95 \\
\hline Depth (mbsf) & 248.02 & 248.04 & 248.07 & 248.1 & 248.13 & 248.16 & 248.19 & 248.225 & 248.25 & 248.28 & 248.32 & 248.35 \\
\hline Sed. rate (m/m.y.) & 13.2 & 13.2 & 13.2 & 13.2 & 13.2 & 13.2 & 13.2 & 13.2 & 13.2 & 13.2 & 13.2 & 13.2 \\
\hline Age (Ma) & 66.417 & 66.419 & 66.421 & 66.423 & 66.426 & 66.428 & 66.430 & 66.433 & 66.435 & 66.437 & 66.440 & 66.442 \\
\hline Pres. (G, M, P) & M & M & M & M & M-G & M & M-G & PP & P-M & M & M-P & M-G \\
\hline Abund. (A, C, R) & A & A & A & A & A & A & A & C & $C-R$ & A & A-C & A-C \\
\hline Fields counted & 22 & 25 & 23 & 25 & 24 & 21 & 19 & 49 & 46 & 19 & 42 & 34 \\
\hline mg sediment & 20.4 & 19.7 & 21.6 & 19.5 & 22.1 & 20.4 & 19.2 & 19.8 & 18.4 & 19.7 & 19.4 & 18.9 \\
\hline Carbonate (wt-\%) & 83.7 & 83.3 & 81.3 & 87.5 & 82.3 & 86.1 & 85 & 83.8 & 79.8 & 84.4 & 87 & 88.9 \\
\hline Beaker Constant & 3.0 & 3.0 & 3.0 & 3.0 & 3.0 & 3.0 & 3.0 & 3.0 & 3.0 & 3.0 & 3.0 & 3.0 \\
\hline A. octoradiata & 1 & 2 & 6 & 4 & . & 5 & 2 & . & 1 & 2 & 2 & 3 \\
\hline A.cymbiformis & 15 & 19 & 16 & 18 & 20 & 10 & 7 & 17 & 21 & 8 & 18 & 9 \\
\hline A. cymbif./specill. & . & . & . & . & . & . & . & - & . & . & . & . \\
\hline A. specillata & . & . & . & . & . & . & . & . & . & . & . & . \\
\hline B. sparsus & . & . & . & . & . & . & . & . & . & . & . & . \\
\hline B. boletum & . & . & . & . & . & . & . & . & . & . & . & . \\
\hline B. constans & 2 & . & 2 & . & . & 1 & . & 1 & $\mathrm{P}$ & . & 2 & . \\
\hline B. coronum & . & . & . & . & . & . & . & . & . & . & . & . \\
\hline B. dissimilis & . & . & . & . & . & . & . & . & . & . & . & . \\
\hline B. magnum & . & . & . & . & . & . & . & . & . & . & . & . \\
\hline B. notaculum & . & . & . & . & . & & 1 & . & . & . & . & . \\
\hline Biscutum sp. 1 & . & . & . & . & . & . & . & . & . & . & . & · \\
\hline Biscutum sp. 2 & . & . & - & . & . & . & - & . & . & . & . & . \\
\hline B. cf bevieri & . & - & & . & . & . & . & . & . & . & . & . \\
\hline Broinsonia spp. & . & . & . & . & . & . & - & . & . & . & . & . \\
\hline C. barbata & . & - & . & . & . & . & - & . & - & . & . & . \\
\hline C. amphipons & . & . & . & . & . & . & . & . & . & . & - & . \\
\hline C. garrisonii & . & . & . & . & - & . & . & . & . & . & . & . \\
\hline Chiastozygus sp. 1 & . & . & . & . & . & . & . & . & . & . & . & . \\
\hline C. conicus & . & . & 1 & . & . & . & . & . & . & . & . & . \\
\hline C. crenulatus & . & . & . & . & . & . & . & . & . & . & . & . \\
\hline C. surirellus & . & . & . & . & . & . & . & . & . & . & . & . \\
\hline Cretarhabdus sp. 1 & . & . & . & . & . & . & . & . & . & . & . & . \\
\hline Cretarhabdus spp. & 6 & 6 & 2 & 15 & 2 & 5 & 2 & 4 & 12 & 5 & 5 & 7 \\
\hline C. daniae & 12 & 6 & 16 & 7 & 7 & 6 & 9 & 6 & 7 & 16 & 9 & 5 \\
\hline C. ehrenbergii & 1 & 1 & 5 & 1 & 2 & 5 & 9 & 4 & 1 & 2 & . & 1 \\
\hline Cruciplacolithus spp. & . & . & . & . & . & . & . & . & $\mathrm{P}$ & . & . & . \\
\hline Cyclagelosph. spp. & . & . & . & . & . & . & . & . & . & . & . & . \\
\hline Cylindralithus spp. & . & . & . & . & . & . & . & . & . & . & . & . \\
\hline D. ignotus & . & . & 1 & . & . & . & . & . & . & . & . & . \\
\hline E. trabeculatus & . & . & . & . & . & . & . & . & . & . & . & . \\
\hline E. turriseiffeli & 1 & 1 & 4 & 6 & . & 5 & 3 & . & 1 & 6 & 2 & 4 \\
\hline Gartnerago spp. & . & 1 & 2 & 3 & 3 & . & 2 & . & 1 & $\mathbf{P}$ & 2 & 4 \\
\hline G. fessus & 1 & 2 & 9 & 4 & 1 & 6 & 2 & 1 & $\mathbf{P}$ & 6 & 1 & . \\
\hline Homibrookina spp. & 1 & . & . & . & . & . & . & 1 & P & . & . & . \\
\hline K. magnificus & 23 & 6 & 18 & 20 & 25 & 16 & 17 & 19 & 21 & 25 & 12 & 11 \\
\hline Lapideacassis spp. & . & . & . & . & . & . & . & . & . & . & . & . \\
\hline L. camiolensis & . & . & . & . & . & . & . & . & . & . & . & . \\
\hline L. cayeuxii & 17 & 14 & 19 & 21 & 29 & 9 & 19 & 21 & 49 & 37 & 39 & 28 \\
\hline M. inversus & 1 & . & . & . & 1 & . & . & 1 & 3 & . & . & . \\
\hline M. decoratus & . & . & 1 & . & . & . & . & . & . & . & 1 & . \\
\hline M. staurophora & . & 1 & . & . & . & . & . & . & . & . & . & 1 \\
\hline M. pleniporus & , & . & . & . & . & . & . & . & . & . & . & . \\
\hline Misceomarg. sp. & . & . & . & . & . & . & . & . & . & . & . & . \\
\hline M. pectinatus & . & . & . & . & . & . & . & . & . & . & . & . \\
\hline M. quaternarius & . & . & . & . & . & . & . & . & . & . & . & . \\
\hline Monomarg. sp. & . & . & . & . & . & . & . & . & . & . & . & . \\
\hline Misceo/Monomg sp. & . & - & . & . & . & . & . & . & . & . & . & . \\
\hline N. watkinsii & . & . & . & . & . & . & . & . & . & . & . & . \\
\hline Neocrepidol. spp. & 1 & . & . & . & . & . & . & . & 1 & . & 1 & . \\
\hline N. corystus & . & . & . & . & . & . & . & . & . & . & . & . \\
\hline N. frequens & 65 & 40 & 70 & 59 & 45 & 73 & 66 & 43 & 41 & 42 & 33 & 46 \\
\hline O. magnus & . & . & . & . & . & . & . & . & . & . & . & . \\
\hline P. obscurus & . & . & . & . & . & . & . & . & . & . & . & . \\
\hline
\end{tabular}




\begin{tabular}{|c|c|c|c|c|c|c|c|c|c|c|c|c|}
\hline Sample Number & 10 & 11 & 12 & 13 & 14 & 15 & 16 & 17 & 18 & 19 & 20 & 21 \\
\hline Hole & $690 \mathrm{C}$ & $690 \mathrm{C}$ & $690 \mathrm{C}$ & $690 \mathrm{C}$ & $690 \mathrm{C}$ & $690 \mathrm{C}$ & $690 \mathrm{C}$ & $690 \mathrm{C}$ & $690 \mathrm{C}$ & $690 \mathrm{C}$ & $690 \mathrm{C}$ & $690 \mathrm{C}$ \\
\hline Core - Section & $15-4$ & $15-4$ & $15-4$ & $15-4$ & $15-4$ & $15-4$ & $15-4$ & $15-4$ & $15-4$ & $15-4$ & $15-4$ & $15-4$ \\
\hline $\mathrm{cm}$ - level & 62 & 64 & 67 & 70 & 73 & 76 & 79 & 82.5 & 85 & 88 & 92 & 95 \\
\hline Depth (mbsf) & 248.02 & 248.04 & 248.07 & 248.1 & 248.13 & 248.16 & 248.19 & 248.225 & 248.25 & 248.28 & 248.32 & 248.35 \\
\hline P. bussonii & . & . & . & . & . & . & . & . & . & · & · & - \\
\hline P. fibuliformis & 1 & . & . & . & . & 1 & . & . & . & $\mathbf{P}$ & . & 3 \\
\hline P. sigmoides & . & . & . & . & . & . & . & . & 3 & . & . & . \\
\hline Placozygus sp. & . & - & . & · & . & . & . & - & . & . & . & . \\
\hline P. arkhangelskyi & . & . & . & . & . & . & . & . & . & $\dot{0}$ & $\therefore$ & $\dot{0}$ \\
\hline P. cretacea & 20 & 26 & 23 & 21 & 17 & 19 & 26 & 14 & 19 & 24 & 17 & 17 \\
\hline P. spinosa & 1 & 1 & 3 & 2 & 1 & 6 & 2 & . & 2 & 4 & . & 2 \\
\hline P. firthii & . & . & · & - & - & . & . & - & . & . & . & . \\
\hline Q. gartneri & . & . & . & . & . & . & . & . & . & . & . & . \\
\hline Reinhardtites spp. & . & . & . & . & . & . & . & . & . & . & . & . \\
\hline $\mathrm{R}$. angustus & . & . & - & . & . & . & . & . & . & . & . & . \\
\hline Rhagodiscus spp. & . & . & . & - & . & . & . & - & . & . & . & . \\
\hline R. rhombicum & . & . & . & . & . & . & . & . & . & . & . & . \\
\hline S. asymmetrica & . & . & . & . & . & . & . & . & . & - & . & . \\
\hline S. wisei & . & . & . & . & . & . & 2 & . & . & . & . & . \\
\hline Scampanella spp. & . & . & . & . & . & . & . & . & . & . & · & · \\
\hline S. fossilis & . & . & . & . & . & . & . & . & . & . & . & . \\
\hline S. laffittei & . & . & . & . & . & . & . & . & . & . & . & . \\
\hline T. ethmos & . & . & . & . & . & . & . & . & . & . & . & . \\
\hline Thoracosph. spp. & 2 & 2 & 2 & . & 1 & 1 & . & . & . & 1 & 1 & . \\
\hline Vagalapilla spp. & 1 & 1 & 1 & 2 & 1 & 4 & 7 & 1 & 2 & 1 & . & 3 \\
\hline W. bamesae & . & . & . & - & . & $\cdot$ & . & . & . & - & . & . \\
\hline Z. compactus & . & . & . & . & . & . & . & . & . & . & . & . \\
\hline Z. diplogrammus & . & . & . & . & . & . & . & . & . & . & . & . \\
\hline Unidentifiable & 1 & 4 & 4 & 4 & 5 & 2 & 1 & 7 & 3 & 5 & 6 & 4 \\
\hline Total (excl. P. stov.) & 173 & 133 & 205 & 187 & 160 & 174 & 177 & 140 & 188 & 184 & 151 & 148 \\
\hline P. stoveri & 175 & 205 & 226 & 189 & 178 & 215 & 148 & 175 & 158 & 160 & 174 & 171 \\
\hline Total (P. stov.count) & 348 & 338 & 431 & 376 & 338 & 389 & 325 & 315 & 346 & 344 & 325 & 319 \\
\hline P. stoveri, fields & 22 & 25 & 23 & 25 & 24 & 21 & 19 & 49 & 46 & 19 & 42 & 34 \\
\hline
\end{tabular}




\begin{tabular}{|c|c|c|c|c|c|c|c|c|c|c|c|c|}
\hline Sample Number & 22 & 23 & 24 & 25 & 26 & 27 & 28 & 29 & 30 & 31 & 32 & 33 \\
\hline Hole & $690 \mathrm{C}$ & $690 \mathrm{C}$ & $690 \mathrm{C}$ & $690 \mathrm{C}$ & $690 \mathrm{C}$ & $690 \mathrm{C}$ & $690 \mathrm{C}$ & $690 \mathrm{C}$ & $690 \mathrm{C}$ & $690 \mathrm{C}$ & $690 \mathrm{C}$ & $690 \mathrm{C}$ \\
\hline Core - Section & $15-4$ & $15-4$ & $15-4$ & $15-4$ & $15-4$ & $15-4$ & $15-4$ & $15-4$ & $15-4$ & $15-4$ & $15-4$ & $15-5$ \\
\hline $\mathrm{cm}$ - level & 98 & $100-101$ & 103-104 & $106-107$ & $110-111$ & $113-114$ & 118 & 121 & 129 & 140 & 149 & 3 \\
\hline Depth (mbsf) & 248.38 & 248.4 & 248.43 & 248.46 & 248.5 & 248.53 & 248.58 & 248.61 & 248.69 & 248.8 & 248.89 & 248.93 \\
\hline Sed. rate (m/m.y.) & 13.2 & 13.2 & 13.2 & 13.2 & 13.2 & 13.2 & 13.2 & 13.2 & 13.2 & 13.2 & 13.2 & 13.2 \\
\hline Age (Ma) & 66.445 & 66.446 & 66.448 & 66.451 & 66.454 & 66.456 & 66.460 & 66.462 & 66.468 & 66.476 & 66.483 & 66.486 \\
\hline Pres. (G, M, P) & $\mathbf{M}$ & M & M-P & M-P & M & M-G & $\mathrm{M}$ & M-P & M-P & PP & PP & M-P \\
\hline Abund. $(A, C, R)$ & $A-C$ & A & A & C-A & C-A & A & A & A & A & R-C & $\mathrm{R}-\mathrm{C}$ & A \\
\hline Fields counted & 47 & 43 & 30 & 47 & 36 & 16 & 34 & 103.7 & 44 & 232.3 & 101 & 113 \\
\hline mg sediment & 20.1 & 19.3 & 20.4 & 18.7 & 19.5 & 19.2 & 18.9 & 19.1 & 18.2 & 18.2 & 20.4 & 20.0 \\
\hline Carbonate (wt- $\%$ ) & 85.9 & 86.9 & 90.2 & 88.3 & 86.2 & 84.9 & 87.7 & 86.2 & 84.8 & 83.2 & 81.8 & 83.8 \\
\hline Beaker Constant & 3.0 & 3.0 & 3.0 & 3.0 & 3.0 & 3.0 & 3.0 & 3.0 & 3.0 & 3.0 & 3.0 & 3.0 \\
\hline A. octoradiata & . & 1 & 5 & 1 & . & 1 & P & 2 & 2 & . & 1 & 9 \\
\hline A.cymbiformis & 24 & 24 & 6 & 13 & 22 & 14 & 13 & 54 & 15 & 63 & 30 & 20 \\
\hline A. cymbif./specill. & . & . & . & . & . & . & . & . & . & . & . & . \\
\hline A. specillata & . & . & . & . & . & . & . & . & . & . & . & . \\
\hline B. sparsus & . & . & . & . & . & . & . & . & . & . & . & . \\
\hline B. boletum & . & . & . & . & . & . & . & . & . & . & . & . \\
\hline B. constans & . & 1 & . & . & . & 1 & P & P & 1 & 1 & . & . \\
\hline B. coronum & . & . & . & . & . & . & . & . & . & . & - & . \\
\hline B. dissimilis & . & . & . & . & . & . & . & . & . & . & . & . \\
\hline B. magnum & . & . & . & . & . & ; & . & . & . & . & $\therefore$ & . \\
\hline B. notaculum & . & . & . & . & · & 1 & . & . & . & . & 1 & . \\
\hline Biscutum sp. 1 & . & . & - & . & $\cdot$ & . & . & . & . & . & . & · \\
\hline Biscutum sp. 2 & - & . & . & . & . & . & . & . & . & . & . & $\cdot$ \\
\hline B. cf bevieri & . & · & . & · & . & . & . & . & . & . & . & $\cdot$ \\
\hline Broinsonia spp. & . & . & · & . & . & . & · & . & . & $\cdot$ & . & · \\
\hline C. barbata & . & . & . & . & . & . & . & . & . & . & . & . \\
\hline C. amphipons & . & . & . & . & . & . & . & . & . & . & . & . \\
\hline C. garrisonii & . & . & . & . & . & . & . & . & . & . & . & . \\
\hline Chiastozygus sp. 1 & . & . & . & . & . & . & . & . & · & . & . & . \\
\hline C. conicus & . & . & . & . & . & . & . & . & . & . & . & . \\
\hline C. crenulatus & . & . & . & . & . & . & . & . & . & . & . & . \\
\hline C. surirellus & . & . & . & . & . & . & . & . & . & . & . & . \\
\hline Cretarhabdus sp. 1 & . & . & . & . & . & . & . & . & . & . & . & . \\
\hline Cretarhabdus spp. & 7 & 9 & 5 & 4 & 12 & 5 & 3 & 23 & 4 & 22 & 7 & 26 \\
\hline C. daniae & 6 & 8 & 12 & 8 & 6 & 10 & 5 & 10 & 3 & 5 & 4 & 17 \\
\hline C. ehrenbergii & 3 & 5 & 3 & 4 & 1 & 5 & 1 & 14 & 3 & 1 & 2 & 22 \\
\hline Cruciplacolithus spp. & . & . & . & . & . & . & . & . & . & . & . & . \\
\hline Cyclagelosph. spp. & . & . & . & . & . & . & . & . & 1 & . & . & . \\
\hline Cylindralithus spp. & . & . & . & . & . & . & . & . & . & . & . & . \\
\hline D. ignotus & . & . & . & . & . & . & . & . & . & . & . & . \\
\hline E. trabeculatus & . & . & . & . & . & . & . & . & . & . & . & . \\
\hline E. turriseiffeli & 2 & . & 1 & 3 & 1 & 3 & P & 1 & . & . & . & 7 \\
\hline Gartnerago spp. & . & 4 & $\mathbf{P}$ & 1 & 4 & 1 & 1 & 3 & 2 & 4 & 1 & 2 \\
\hline G. fessus & 1 & 1 & 8 & . & 1 & 5 & 1 & 2 & . & . & 1 & 17 \\
\hline Homibrookina spp. & . & $\mathrm{P}$ & . & . & . & . & . & . & 1 & $P$ & . & . \\
\hline K. magnificus & 19 & 16 & 10 & 21 & 14 & 20 & 16 & 81 & 30 & 74 & 21 & 37 \\
\hline Lapideacassis spp. & . & . & . & . & . & . & . & . & . & . & . & . \\
\hline L. camiolensis & . & . & . & . & . & . & . & . & . & . & . & . \\
\hline L. cayeuxii & 45 & 46 & 25 & 58 & 53 & 19 & 43 & 85 & 47 & 131 & 63 & 63 \\
\hline M. inversus & . & . & . & . & . & . & . & . & 1 & 1 & . & . \\
\hline M. decoratus & . & . & . & . & . & . & . & . & . & . & . & . \\
\hline M. staurophora & . & . & . & 2 & 1 & . & . & 3 & . & 6 & . & 1 \\
\hline M. pleniporus & . & . & . & . & . & . & . & . & . & . & . & . \\
\hline Misceomarg. sp. & . & . & . & . & . & . & . & . & · & . & . & . \\
\hline M. pectinatus & . & . & . & . & . & . & . & . & . & . & . & . \\
\hline M. quatemarius & . & . & . & . & . & . & . & . & . & . & . & . \\
\hline Monomarg. sp. & . & . & . & . & . & . & . & . & . & . & . & $\cdot$ \\
\hline Misceo/Monomg sp. & . & . & . & . & . & . & . & . & . & . & . & . \\
\hline N. watkinsii & . & . & . & . & . & . & . & . & . & . & . & . \\
\hline Neocrepidol. spp. & . & · & . & - & . & . & . & . & . & . & . & $\cdot$ \\
\hline N. corystus & - & . & $\therefore$ & . & $\therefore$ & - & $\therefore$ & - & . & . & . & . \\
\hline N. frequens & 33 & 54 & 65 & 37 & 57 & 29 & 34 & 148 & 33 & 88 & 35 & 125 \\
\hline O. magnus & . & . & . & . & . & . & . & . & . & . & . & . \\
\hline P. obscurus & . & . & . & . & . & . & . & . & . & . & . & . \\
\hline
\end{tabular}




\begin{tabular}{|c|c|c|c|c|c|c|c|c|c|c|c|c|}
\hline Sample Number & 22 & 23 & 24 & 25 & 26 & 27 & 28 & 29 & 30 & 31 & 32 & 33 \\
\hline Hole & $690 \mathrm{C}$ & $690 \mathrm{C}$ & $690 \mathrm{C}$ & $690 \mathrm{C}$ & $690 \mathrm{C}$ & $690 \mathrm{C}$ & $690 \mathrm{C}$ & $690 \mathrm{C}$ & $690 \mathrm{C}$ & $690 \mathrm{C}$ & $690 \mathrm{C}$ & $690 \mathrm{C}$ \\
\hline Core - Section & $15-4$ & $15-4$ & $15-4$ & $15-4$ & $15-4$ & $15-4$ & $15-4$ & $15-4$ & $15-4$ & $15-4$ & $15-4$ & $15-5$ \\
\hline $\mathrm{cm}$ - level & 98 & $100-101$ & $103-104$ & $106-107$ & $110-111$ & $113-114$ & 118 & 121 & 129 & 140 & 149 & 3 \\
\hline Depth (mbsf) & 248.38 & 248.4 & 248.43 & 248.46 & 248.5 & 248.53 & 248.58 & 248.61 & 248.69 & 248.8 & 248.89 & 248.93 \\
\hline P. bussonii & . & . & . & . & . & . & . & . & . & . & . & . \\
\hline P. fibuliformis & . & . & P & . & . & P & P & 2 & . & 1 & 1 & $P$ \\
\hline P. sigmoides & . & . & . & . & . & 1 & . & 1 & . & $?$ & . & . \\
\hline Placozygus sp. & . & . & . & . & . & . & . & . & . & . & . & . \\
\hline P. arkhangelskyi & . & . & . & . & . & . & . & . & . & . & . & . \\
\hline P. cretacea & 28 & 17 & 22 & 21 & 24 & 22 & 14 & 68 & 22 & 60 & 21 & 61 \\
\hline P. spinosa & . & 2 & 7 & 2 & . & 2 & P & $\mathbf{P}$ & . & 2 & 2 & 26 \\
\hline P. firthii & . & . & . & . & . & . & . & . & . & . & . & . \\
\hline Q. gartneri & . & . & . & . & . & . & . & . & . & . & . & . \\
\hline Reinhardtites spp. & . & . & . & . & . & . & . & . & . & . & . & . \\
\hline R. angustus & . & . & . & . & . & . & . & . & . & . & . & . \\
\hline Rhagodiscus spp. & . & . & . & . & . & . & . & . & . & . & . & . \\
\hline R. rhombicum & . & . & . & . & . & . & . & . & . & . & . & . \\
\hline S. asymmetrica & . & . & . & . & . & . & . & $\mathbf{P}$ & . & . & . & . \\
\hline S. wisei & . & . & . & . & . & . & . & . & . & . & . & . \\
\hline Scampanella spp. & . & . & . & 1 & . & . & $\mathbf{P}$ & . & . & . & . & . \\
\hline S. fossilis & . & . & & . & . & . & . & . & . & . & . & . \\
\hline S. laffittei & . & . & . & . & . & . & . & . & . & . & . & . \\
\hline T. ethmos & . & . & . & . & . & . & . & . & . & . & . & . \\
\hline Thoracosph. spp. & . & . & . & . & . & . & . & . & . & . & . & . \\
\hline Vagalapilla spp. & $\mathrm{P}$ & 2 & 10 & 2 & . & 1 & P & 2 & . & . & . & 9 \\
\hline W. bamesae & . & . & . & . & . & . & , & . & . & . & . & . \\
\hline Z. compactus & . & . & . & . & . & . & . & . & . & . & . & . \\
\hline Z. diplogrammus & . & . & . & . & . & . & . & . & . & . & . & . \\
\hline Unidentifiable & 3 & 3 & 5 & 8 & 3 & 10 & 4 & 21 & 3 & 13 & 6 & 16 \\
\hline Total (excl. P. stov.) & 171 & 193 & 184 & 186 & 199 & 150 & 135 & 520 & 168 & 472 & 196 & 458 \\
\hline P. stoveri & 186 & 222 & 221 & 200 & 153 & 178 & 189 & 192 & 157 & 134 & 110 & 181 \\
\hline Total (P. stov.count) & 357 & 415 & 405 & 386 & 352 & 328 & 324 & 345 & 325 & 301 & 306 & 312 \\
\hline P. stoveri, fields & 47 & 43 & 30 & 47 & 36 & 16 & 34 & 44 & 44 & 80 & 101 & 34 \\
\hline
\end{tabular}




\begin{tabular}{|c|c|c|c|c|c|c|c|c|c|c|c|c|}
\hline Sample Number & 34 & 35 & 36 & 37 & 38 & 39 & 40 & 41 & 42 & 43 & 44 & 45 \\
\hline Hole & $690 \mathrm{C}$ & $690 \mathrm{C}$ & $690 \mathrm{C}$ & $690 \mathrm{C}$ & $690 \mathrm{C}$ & $690 \mathrm{C}$ & $690 \mathrm{C}$ & $690 \mathrm{C}$ & $690 \mathrm{C}$ & $690 \mathrm{C}$ & $690 \mathrm{C}$ & $690 \mathrm{C}$ \\
\hline Core - Section & $15-5$ & $15-5$ & $15-5$ & $15-5$ & $15-5$ & $15-5$ & $15-5$ & $15-5$ & $15-5$ & $15-5$ & $15-5$ & $15-5$ \\
\hline $\mathrm{cm}$ - level & $11-12.0$ & $22-23$ & 31 & $39-40$ & $49-50$ & $60-61$ & $70-71$ & $79-80$ & $90-91$ & 101 & $110-111$ & 120 \\
\hline Depth (mbsf) & 249.01 & 249.12 & 249.21 & 249.29 & 249.39 & 249.5 & 249.6 & 249.69 & 249.8 & 249.91 & 250 & 250.1 \\
\hline Sed. rate (m/m.y.) & 13.2 & 13.2 & 13.2 & 13.2 & 13.2 & 13.2 & 13.2 & 13.2 & 13.2 & 13.2 & 13.2 & 13.2 \\
\hline Age (Ma) & 66.492 & 66.501 & 66.507 & 66.514 & 66.521 & 66.529 & 66.537 & 66.544 & 66.552 & 66.560 & 66.567 & 66.575 \\
\hline Pres. (G, M, P) & $\mathbf{M}$ & M-G & M-P & M-G & $M-G$ & M-G & $\mathrm{M}$ & M-P & M-P & M & M-P & M-P \\
\hline Abund. (A, C, R) & C & A & $\mathrm{C}$ & A & A & A & A & C-R & $\mathrm{C}$ & A & C-A & A-C \\
\hline Fields counted & 175.2 & 22 & 86.9 & 51.7 & 32 & 30 & 30 & 97.6 & 99.2 & 97.2 & 119.8 & 76.5 \\
\hline mg sediment & 20.7 & 18.9 & 19.4 & 20.0 & 20.6 & 20.2 & 19.9 & 18.4 & 19.5 & 20.5 & 19.4 & 18.9 \\
\hline Carbonate (wt-\%) & 82.4 & 83.6 & 82.3 & 80 & 80.7 & 86.5 & 85.7 & 88.2 & 88.7 & 90 & 88.2 & 81.1 \\
\hline Beaker Constant & 3.0 & 3.0 & 3.0 & 3.0 & 3.0 & 3.0 & 3.0 & 2.7 & 3.0 & 3.0 & 3.0 & 3.0 \\
\hline A. octoradiata & 6 & 2 & 1 & 7 & 2 & 2 & $P$ & 5 & . & 5 & 14 & 10 \\
\hline A.cymbiformis & 83 & 13 & 33 & 28 & 22 & 24 & 19 & 21 & 22 & 30 & 31 & 38 \\
\hline A. cymbif./specill. & . & . & . & . & . & . & . & . & . & . & . & . \\
\hline A. specillata & . & . & . & . & . & . & . & . & . & . & . & . \\
\hline B. sparsus & . & . & . & . & . & . & . & . & . & . & . & . \\
\hline B. boletum & . & . & . & . & . & . & . & . & . & . & . & . \\
\hline B. constans & . & . & . & . & P & . & $\mathbf{P}$ & . & . & . & . & . \\
\hline B. coronum & . & . & . & . & . & . & . & . & . & . & . & . \\
\hline B. dissimilis & . & . & . & . & , & . & . & . & . & . & . & . \\
\hline B. magnum & . & . & . & . & . & . & . & . & . & . & . & . \\
\hline B. notaculum & $?$ & . & . & . & . & . & . & . & . & . & . & . \\
\hline Biscutum sp. 1 & . & . & . & . & . & . & . & . & . & . & . & . \\
\hline Biscutum sp. 2 & . & . & . & . & . & . & . & , & . & . & . & . \\
\hline B. cf bevieri & . & . & . & . & . & . & . & . & . & . & . & . \\
\hline Broinsonia spp. & . & . & . & . & . & . & . & . & . & . & . & . \\
\hline C. barbata & . & . & . & . & . & . & . & . & . & . & . & . \\
\hline C. amphipons & . & . & . & . & . & . & . & . & . & . & . & . \\
\hline C. garrisonii & . & . & . & . & . & . & . & . & . & . & . & . \\
\hline Chiastozygus sp. 1 & . & . & . & . & , & . & . & . & . & . & . & . \\
\hline C. conicus & . & . & . & P & . & . & . & . & . & $\mathbf{P}$ & $\mathbf{P}$ & P \\
\hline C. crenulatus & . & P & . & . & . & . & . & . & . & . & . & . \\
\hline C. surirellus & . & . & . & . & . & . & . & . & . & . & . & . \\
\hline Cretarhabdus sp. 1 & . & . & . & . & . & . & . & . & . & . & . & . \\
\hline Cretarhabdus spp. & 39 & . & 2 & 21 & 7 & 18 & 18 & 19 & 16 & 17 & 40 & 28 \\
\hline C. daniae & 5 & 11 & 6 & 28 & 17 & 18 & 8 & 36 & 22 & 38 & 38 & 30 \\
\hline C. ehrenbergii & 17 & 11 & 4 & 28 & 5 & 6 & 8 & 11 & 7 & 24 & 15 & 25 \\
\hline Cruciplacolithus spp. & . & . & . & . & . & . & . & . & . & . & . & . \\
\hline Cyclagelosph. spp. & . & . & . & . & . & . & . & . & . & . & . & $?$ \\
\hline Cylindralithus spp. & . & . & . & $\mathbf{P}$ & . & . & . & . & . & . & . & . \\
\hline D. ignotus & . & . & . & . & . & . & . & . & . & . & . & . \\
\hline E. trabeculatus & . & . & . & . & . & . & 1 & . & . & . & . & . \\
\hline E. turriseiffeli & P & 5 & . & 4 & 4 & 5 & 2 & 5 & 1 & 5 & 10 & 22 \\
\hline Gartnerago spp. & 2 & . & 3 & 4 & 3 & 13 & 11 & 6 & 2 & 5 & 4 & 3 \\
\hline G. fessus & 1 & 1 & 1 & 17 & 4 & 4 & 1 & 13 & 4 & 11 & 19 & 38 \\
\hline Hornibrookina spp. & . & . & . & . & . & . & . & . & ? & . & . & . \\
\hline K. magnificus & 101 & 16 & 34 & 39 & 35 & 15 & 27 & 45 & 38 & 55 & 30 & 62 \\
\hline Lapideacassis spp. & . & . & . & . & . & . & . & . & . & . & . & . \\
\hline L. camiolensis & . & . & . & . & . & . & . & . & . & . & . & . \\
\hline L. cayeuxii & 132 & 14 & 74 & 77 & 46 & 55 & 72 & 107 & 120 & 120 & 91 & 98 \\
\hline$M$. inversus & . & . & . & . & . & . & . & . & . & P & . & . \\
\hline M. decoratus & 1 & . & . & . & . & . & . & . & . & . & . & . \\
\hline M. staurophora & 3 & 1 & 1 & P & 3 & 5 & 2 & 2 & 7 & 7 & 3 & 8 \\
\hline M. pleniporus & . & . & . & . & . & . & . & . & . & . & . & . \\
\hline Misceomarg. sp. & . & . & . & . & . & . & . & . & . & . & . & . \\
\hline M. pectinatus & . & . & . & . & . & . & . & . & . & . & . & . \\
\hline M. quatemarius & . & . & . & . & . & . & . & . & . & . & . & . \\
\hline Monomarg. sp. & . & . & . & . & . & . & . & . & . & . & . & . \\
\hline Misceo/Monomg sp. & . & . & . & . & . & . & . & . & . & . & . & . \\
\hline N. watkinsii & . & . & . & . & . & . & . & . & . & . & . & . \\
\hline Neocrepidol. spp. & . & . & . & . & . & . & . & . & . & . & . & . \\
\hline N. corystus & . & . & . & . & . & . & . & . & . & . & . & . \\
\hline $\mathrm{N}$. frequens & 141 & 77 & 64 & 124 & 74 & 101 & 98 & 202 & 110 & 178 & 152 & 146 \\
\hline O. magnus & . & . & . & . & . & . & . & . & . & . & . & . \\
\hline P. obscurus & . & . & . & . & . & . & . & . & . & . & . & . \\
\hline
\end{tabular}




\begin{tabular}{|c|c|c|c|c|c|c|c|c|c|c|c|c|}
\hline Sample Number & 34 & 35 & 36 & 37 & 38 & 39 & 40 & 41 & 42 & 43 & 44 & 45 \\
\hline Hole & $690 \mathrm{C}$ & $690 \mathrm{C}$ & $690 \mathrm{C}$ & $690 \mathrm{C}$ & $690 \mathrm{C}$ & $690 \mathrm{C}$ & $690 \mathrm{C}$ & $690 \mathrm{C}$ & $690 \mathrm{C}$ & $690 \mathrm{C}$ & $690 \mathrm{C}$ & $690 \mathrm{C}$ \\
\hline Core - Section & $15-5$ & $15-5$ & $15-5$ & $15-5$ & $15-5$ & $15-5$ & $15-5$ & $15-5$ & $15-5$ & $15-5$ & $15-5$ & $15-5$ \\
\hline $\mathrm{cm}$ - level & $11-12.0$ & $22-23$ & 31 & $39-40$ & $49-50$ & $60-61$ & $70-71$ & $79-80$ & $90-91$ & 101 & $110-111$ & 120 \\
\hline Depth (mbsf) & 249.01 & 249.12 & 249.21 & 249.29 & 249.39 & 249.5 & 249.6 & 249.69 & 249.8 & 249.91 & 250 & 250.1 \\
\hline P. bussonii & . & . & . & - & . & . & . & . & . & . & - & . \\
\hline P. fibuliformis & 1 & . & . & $\mathbf{P}$ & $\mathrm{P}$ & 2 & 1 & 2 & 2 & 3 & 19 & 41 \\
\hline P. sigmoides & . & . & . & $\mathbf{P}$ & 2 & . & P & . & . & 1 & 1 & 1 \\
\hline Placozygus sp. & . & . & . & . & . & . & . & . & . & . & - & - \\
\hline P. arkhangelskyi & . & . & . & . & . & . & . & . & . & . & . & . \\
\hline P. cretacea & 80 & 37 & 27 & 71 & 46 & 42 & 35 & 75 & 63 & 70 & 66 & 58 \\
\hline P. spinosa & 6 & 13 & 2 & 24 & 17 & 12 & 6 & 32 & 7 & 36 & 50 & 49 \\
\hline P. firthii & . & · & • & . & · & . & . & . & · & . & . & . \\
\hline Q. gartneri & . & . & - & . & . & . & . & . & . & . & . & . \\
\hline Reinhardtites spp. & . & . & . & . & . & . & . & . & . & . & . & - \\
\hline R. angustus & . & - & . & . & . & . & . & . & . & . & . & . \\
\hline Rhagodiscus spp. & . & . & . & . & . & . & . & . & . & . & . & . \\
\hline R. hombicum & . & . & . & . & . & . & . & . & . & . & . & . \\
\hline S. asymmetrica & . & . & . & . & . & . & . & . & . & . & . & . \\
\hline S. wisei & : & . & . & $\mathbf{P}$ & . & . & . & . & . & P & . & P \\
\hline Scampanella spp. & P & . & . & $\mathbf{P}$ & P & . & P & 1 & . & . & 1 & . \\
\hline S. fossilis & . & . & . & . & . & . & - & . & . & . & - & $\cdot$ \\
\hline S. laffittei & . & . & . & . & . & . & . & . & . & . & . & . \\
\hline T. ethmos & . & . & . & . & . & . & . & . & . & . & . & . \\
\hline Thoracosph. spp. & . & . & . & . & . & . & . & . & . & . & . & . \\
\hline Vagalapilla spp. & 1 & 3 & . & 6 & 2 & 3 & 2 & 7 & . & 6 & 23 & 8 \\
\hline W. bamesae & . & - & $\cdot$ & · & - & · & - & . & · & . & - & · \\
\hline Z. compactus & . & . & . & . & . & . & . & . & . & . & . & . \\
\hline Z. diplogrammus & . & . & . & . & . & . & . & . & . & . & . & . \\
\hline Unidentifiable & 15 & 3 & 4 & 10 & 5 & 4 & 4 & 20 & 11 & 13 & 22 & 11 \\
\hline Total (excl. P. stov.) & 634 & 207 & 256 & 488 & 294 & 329 & 315 & 609 & 432 & 624 & 629 & 676 \\
\hline P. stoveri & 297 & 172 & 145 & 166 & 188 & 314 & 269 & 189 & 151 & 176 & 220 & 254 \\
\hline Total (P. stov.count) & 931 & 379 & 401 & 318 & 482 & 646 & 585 & 352 & 310 & 341 & 433 & 495 \\
\hline P. stoveri, fields & 101.4 & 22 & 86.9 & 17 & 32 & 30 & 30 & 30 & 43 & 30 & 32 & 30 \\
\hline
\end{tabular}




\begin{tabular}{|c|c|c|c|c|c|c|c|c|c|c|c|c|}
\hline Sample Number & 46 & 47 & 48 & 49 & 50 & 51 & 52 & 53 & 54 & 55 & 56 & 57 \\
\hline Hole & $690 \mathrm{C}$ & $690 \mathrm{C}$ & $690 \mathrm{C}$ & $690 \mathrm{C}$ & $690 \mathrm{C}$ & $690 \mathrm{C}$ & $690 \mathrm{C}$ & $690 \mathrm{C}$ & $690 \mathrm{C}$ & $690 \mathrm{C}$ & $690 \mathrm{C}$ & $690 \mathrm{C}$ \\
\hline Core - Section & $15-5$ & $15-5$ & $15-5$ & $15-6$ & $15-6$ & $15-6$ & $15-6$ & $15-6$ & $15-6$ & $15-6$ & $15-6$ & $15-6$ \\
\hline $\mathrm{cm}$ - level & $130-131$ & $140-141$ & 150 & 4. -5 & 10 & 20 & $30-31$ & $40-41$ & $50-51$ & $59-60$ & 70 & 80 \\
\hline Depth (mbsf) & 250.2 & 250.3 & 250.4 & 250.44 & 250.5 & 250.6 & 250.7 & 250.8 & 250.9 & 250.99 & 251.1 & 251.2 \\
\hline Sed. rate (m/m.y.) & 13.2 & 13.2 & 13.2 & 13.2 & 13.2 & 13.2 & 13.2 & 13.2 & 13.2 & 13.2 & 13.2 & 13.2 \\
\hline Age (Ma) & 66.582 & 66.590 & 66.598 & 66.601 & 66.605 & 66.613 & 66.620 & 66.628 & 66.635 & 66.642 & 66.651 & 66.658 \\
\hline Pres. (G, M, P) & M & M-P & M & M-P & P & M-G & G & M-G & M & M & M & M-G \\
\hline Abund. (A, C, R) & A & A-C & A & A & C-A & A & A & A & A & A & A & A \\
\hline Fields counted & 43.2 & 84 & 27 & 61.6 & 100 & 52.8 & 30 & 55.5 & 40.1 & 64.7 & 43.6 & 30 \\
\hline mg sediment & 20.5 & 18.5 & 20.3 & 19.9 & 19.6 & 18.9 & 19.6 & 18.5 & 19.3 & 20.1 & 17.1 & 20.0 \\
\hline Carbonate (wt-\%) & 77.2 & 77.6 & 78.6 & 79.3 & 78.2 & 78.4 & 78.1 & 79 & 76.8 & 73.8 & 75.5 & 76.4 \\
\hline Beaker Constant & 2.7 & 3.0 & 3.0 & 3.0 & 3.0 & 2.7 & 3.0 & 3.0 & 3.0 & 2.7 & 3.0 & 3.0 \\
\hline A. octoradiata & 5 & 9 & 4 & 23 & 13 & 19 & 13 & 23 & 23 & 11 & 10 & 11 \\
\hline A.cymbiformis & 53 & 36 & 15 & 48 & 84 & 36 & 29 & 24 & 20 & 31 & 40 & 24 \\
\hline A. cymbif./specill. & . & . & . & . & . & . & · & · & . & . & . & . \\
\hline A. specillata & . & . & . & . & . & . & . & . & . & . & . & . \\
\hline B. sparsus & . & . & . & . & . & . & . & . & . & . & . & . \\
\hline B. boletum & . & . & . & . & . & . & . & . & . & . & . & . \\
\hline B. constans & . & . & . & . & . & . & P & . & $?$ & . & . & . \\
\hline B. coronum & . & . & . & . & . & . & . & . & . & . & . & . \\
\hline B. dissimilis & . & . & . & . & . & . & . & . & . & . & . & . \\
\hline B. magnum & . & . & . & . & . & . & . & . & . & . & . & . \\
\hline B. notaculum & . & . & . & . & . & . & . & . & . & . & . & . \\
\hline Biscutum sp. 1 & . & . & & . & . & . & . & . & . & . & . & . \\
\hline Biscutum sp. 2 & . & . & . & . & . & . & . & . & . & . & . & . \\
\hline B. cf bevieri & . & . & . & . & . & . & . & $\cdot$ & . & . & . & . \\
\hline Broinsonia spp. & . & . & . & . & . & . & . & . & . & . & . & . \\
\hline C. barbata & . & $\cdot$ & . & . & . & . & . & $\cdot$ & . & . & . & . \\
\hline C. amphipons & . & . & . & . & . & . & . & $\cdot$ & $\cdot$ & . & $\cdot$ & . \\
\hline C. garrisonii & . & . & . & . & . & . & . & . & . & . & . & $\cdot$ \\
\hline Chiastozygus sp. 1 & . & : & . & $\dot{ }$ & . & . & $\cdot$ & . & . & $\cdot$ & . & $\cdot$ \\
\hline C. conicus & . & $\mathbf{P}$ & . & P & . & . & . & $\cdot$ & $?$ & · & . & $\cdot$ \\
\hline C. crenulatus & . & . & . & - & . & . & . & $\cdot$ & · & · & $\cdot$ & . \\
\hline C. surirellus & . & . & . & . & . & . & · & . & . & . & $\cdot$ & · \\
\hline Cretarhabdus sp. 1 & . & . & . & . & . & . & . & . & . & . & $\therefore$ & $\dot{8}$ \\
\hline Cretarhabdus spp. & 21 & 40 & 9 & 23 & 23 & 16 & 12 & 11 & 16 & 25 & 15 & 9 \\
\hline C. daniae & 38 & 37 & 16 & 34 & 25 & 43 & 30 & 32 & 27 & 31 & 38 & 22 \\
\hline C. ehrenbergii & 20 & 31 & 17 & 18 & 12 & 9 & 10 & 7 & 19 & 15 & 6 & 9 \\
\hline Cruciplacolithus spp. & . & . & . & . & . & . & . & $?$ & . & . & $\cdot$ & . \\
\hline Cyclagelosph. spp. & . & . & . & 2 & . & . & . & . & . & . & . & . \\
\hline Cylindralithus spp. & . & . & . & . & . & . & . & . & . & . & · & . \\
\hline D. ignotus & . & . & . & 1 & 1 & . & . & . & . & . & . & . \\
\hline E. trabeculatus & . & . & . & . & . & . & . & . & . & . & . & . \\
\hline E. turriseiffeli & 17 & 13 & 9 & 24 & 7 & 7 & 3 & 5 & 5 & 4 & 3 & 4 \\
\hline Gartnerago spp. & 7 & 3 & 2 & 3 & 3 & 9 & 3 & 5 & 3 & 5 & 6 & 5 \\
\hline G. fessus & 18 & 30 & 12 & 42 & 20 & 41 & 16 & 35 & 38 & 25 & 18 & 20 \\
\hline Homibrookina spp. & . & . & . & . & . & . & . & . & . & . & . & . \\
\hline K. magnificus & 47 & 41 & 19 & 49 & 68 & 72 & 44 & 76 & 72 & 109 & 76 & 74 \\
\hline Lapideacassis spp. & . & . & . & . & . & . & . & . & . & . & . & . \\
\hline L. camiolensis & . & . & . & . & $\therefore$ & . & . & . & $?$ & . & . & . \\
\hline L. cayeuxii & 75 & 54 & 13 & 34 & 25 & 5 & 1 & 4 & 3 & 1 & 2 & 1 \\
\hline M. inversus & . & . & . & 1 & . & 1 & . & . & 2 & . & : & . \\
\hline M. decoratus & 1 & . & 1 & . & . & . & 1 & . & . & . & 1 & . \\
\hline M. staurophora & 5 & 17 & 4 & 6 & 10 & 1 & . & 2 & . & . & . & $\cdot$ \\
\hline M. pleniporus & . & . & . & . & . & . & . & . & . & . & , & $\cdot$ \\
\hline Misceomarg. sp. & . & . & . & . & . & . & . & · & $\cdot$ & . & . & $\cdot$ \\
\hline M. pectinatus & . & - & . & - & . & . & . & . & · & $\cdot$ & . & . \\
\hline M. quaternarius & . & . & . & . & . & . & . & · & $\cdot$ & $\cdot$ & · & . \\
\hline Monomarg. sp. & . & . & . & . & . & . & · & . & $\cdot$ & . & . & $\cdot$ \\
\hline Misceo/Monomg sp. & . & . & . & . & . & . & . & . & $\cdot$ & · & . & $\cdot$ \\
\hline N. watkinsii & . & . & . & . & $\cdot$ & . & . & . & $\cdot$ & $\cdot$ & $\cdot$ & $\cdot$ \\
\hline Neocrepidol. spp. & . & . & . & . & . & . & . & . & . & . & . & . \\
\hline N. corystus & . & . & . & . & . & . & . & . & . & . & . & . \\
\hline N. frequens & 116 & 137 & 67 & 124 & 98 & 156 & 83 & 107 & 128 & 212 & 164 & 141 \\
\hline O. magnus & . & . & . & . & . & . & . & · & . & . & . & . \\
\hline P. obscurus & . & . & . & . & . & . & . & . & . & . & . & . \\
\hline
\end{tabular}




\begin{tabular}{|c|c|c|c|c|c|c|c|c|c|c|c|c|}
\hline Sample Number & 46 & 47 & 48 & 49 & 50 & 51 & 52 & 53 & 54 & 55 & 56 & 57 \\
\hline Hole & $690 \mathrm{C}$ & $690 \mathrm{C}$ & $690 \mathrm{C}$ & $690 \mathrm{C}$ & $690 \mathrm{C}$ & $690 \mathrm{C}$ & $690 \mathrm{C}$ & $690 \mathrm{C}$ & $690 \mathrm{C}$ & $690 \mathrm{C}$ & $690 \mathrm{C}$ & $690 \mathrm{C}$ \\
\hline Core - Section & $15-5$ & $15-5$ & $15-5$ & $15-6$ & $15-6$ & $15-6$ & $15-6$ & $15 \cdot 6$ & $15-6$ & $15-6$ & $15-6$ & $15-6$ \\
\hline $\mathrm{cm}$ - level & $130-131$ & $140-141$ & 150 & 4. -5 & 10 & 20 & $30-31$ & $40-41$ & $50-51$ & $59-60$ & 70 & 80 \\
\hline Depth (mbsf) & 250.2 & 250.3 & 250.4 & 250.44 & 250.5 & 250.6 & 250.7 & 250.8 & 250.9 & 250.99 & 251.1 & 251.2 \\
\hline P. bussonii & . & . & . & . & . & . & . & . & . & . & . & . \\
\hline P. fibuliformis & 19 & 24 & 8 & 23 & 30 & 27 & 12 & 30 & 24 & 22 & 11 & 18 \\
\hline P. sigmoides & . & . & . & . & . & 1 & 1 & 1 & 2 & 1 & 1 & . \\
\hline Placozygus sp. & . & - & - & . & . & . & . & . & . & . & . & . \\
\hline P. arkhangelskyi & . & - & . & . & . & - & . & . & . & . & . & . \\
\hline P. cretacea & 79 & 55 & 34 & 62 & 68 & 47 & 45 & 74 & 86 & 144 & 115 & 84 \\
\hline P. spinosa & 35 & 42 & 26 & 73 & 11 & 45 & 31 & 40 & 40 & 33 & 26 & 17 \\
\hline P. firthii & . & . & . & . & . & . & . & . & . & · & . & . \\
\hline Q. gartneri & . & . & . & . & . & - & . & . & . & . & . & . \\
\hline Reinhardtites spp. & . & . & . & . & . & . & . & . & . & . & . & . \\
\hline $\mathrm{R}$. angustus & . & . & . & . & . & . & . & . & . & . & . & . \\
\hline Rhagodiscus spp. & . & . & . & . & . & : & . & . & - & . & . & . \\
\hline R. thombicum & . & . & . & . & . & 1 & . & . & . & . & . & • \\
\hline S. asymmetrica & . & . & . & . & . & . & . & . & . & . & . & . \\
\hline S. wisei & . & . & . & . & . & . & · & . & - & ; & - & · \\
\hline Scampanella spp. & $\mathrm{P}$ & . & . & . & . & . & . & . & . & 1 & . & . \\
\hline S. fossilis & . & . & . & . & . & . & . & . & . & . & . & . \\
\hline S. laffittei & . & . & . & . & . & . & . & . & . & . & . & . \\
\hline T. ethmos & . & . & . & . & . & . & . & . & . & . & . & . \\
\hline Thoracosph. spp. & . & . & . & 1 & . & 2 & 6 & 2 & . & 1 & 1 & 4 \\
\hline Vagalapilla spp. & 3 & 11 & 1 & 10 & 4 & 5 & 9 & 6 & 7 & 2 & 5 & 3 \\
\hline W. barnesae & . & . & . & . & 1 & . & . & . & . & . & . & . \\
\hline Z. compactus & . & . & . & . & . & . & . & . & . & . & . & . \\
\hline Z. diplogrammus & . & . & . & . & . & . & . & . & . & . & . & . \\
\hline Unidentifiable & 9 & 21 & 12 & 19 & 33 & 19 & 12 & 18 & 20 & 19 & 11 & 11 \\
\hline Total (excl. P. stov.) & 568 & 601 & 269 & 620 & 536 & 562 & 361 & 502 & 535 & 692 & 549 & 457 \\
\hline P. stoveri & 424 & 233 & 139 & 222 & 187 & 314 & 298 & 352 & 413 & 313 & 354 & 428 \\
\hline Total (P. stov.count) & 829 & 474 & 410 & 462 & 329 & 644 & 659 & 602 & 802 & 567 & 715 & 885 \\
\hline P. stoveri, fields & 30 & 30 & 27 & 30 & 35 & 30 & 30 & 30 & 30 & 30 & 30 & 30 \\
\hline
\end{tabular}




\begin{tabular}{|c|c|c|c|c|c|c|c|c|c|c|c|c|}
\hline Sample Number & 58 & 59 & 60 & 61 & 62 & 63 & 64 & 65 & 66 & 67 & 68 & 69 \\
\hline Hole & $690 \mathrm{C}$ & $690 \mathrm{C}$ & $690 \mathrm{C}$ & $690 \mathrm{C}$ & $690 \mathrm{C}$ & $690 \mathrm{C}$ & $690 \mathrm{C}$ & $690 \mathrm{C}$ & $690 \mathrm{C}$ & $690 \mathrm{C}$ & $690 \mathrm{C}$ & $690 \mathrm{C}$ \\
\hline Core - Section & $15-6$ & $15-6$ & $15-6$ & $15-6$ & $15-6$ & $15-6$ & $15-6$ & $15-7$ & $15-7$ & $15-7$ & $15-\mathrm{CC}$ & $15-\mathrm{CC}$ \\
\hline $\mathrm{cm}$ - level & $90-91$ & 101 & $110-111$ & $120-121$ & $130-131$ & $140-141$ & $149-150$ & 10 & $20-21$ & 30 & 8 & $19-20$ \\
\hline Depth (mbsf) & 251.3 & 251.41 & 251.5 & 251.6 & 251.7 & 251.8 & 251.89 & 252 & 252.1 & 252.2 & 252.33 & 252.44 \\
\hline Sed. rate (m/m.y.) & 13.2 & 13.2 & 13.2 & 13.2 & 13.2 & 13.2 & 13.2 & 13.2 & 13.2 & 13.2 & 7.5 & 7.5 \\
\hline Age (Ma) & 66.666 & 66.674 & 66.681 & 66.688 & 66.696 & 66.704 & 66.710 & 66.719 & 66.726 & 66.734 & 66.747 & 66.761 \\
\hline Pres. (G, M, P) & M-G & M-G & M & M & M & $M$ & M-G & M & M & M-P & M & M-G \\
\hline Abund. (A, C, R) & A & A & $A-C$ & A & A & A & A & A & A & C & A & A \\
\hline Fields counted & 30 & 30 & 30 & 30 & 30 & 30 & 30 & 30 & 35.6 & 69.5 & 30 & 39.7 \\
\hline mg sediment & 18.9 & 20.0 & 19.3 & 20.3 & 18.7 & 19.5 & 19.1 & 19.5 & 19.8 & 20.9 & 19.5 & 16.8 \\
\hline Carbonate (wt-\%) & 78 & 83.2 & 83.6 & 80.4 & 82.6 & 84.5 & 85.9 & 86.9 & 86.9 & 89.1 & 87.2 & 88.4 \\
\hline Beaker Constant & 3.0 & 3.0 & 3.0 & 3.0 & 3.0 & 3.0 & 3.0 & 2.7 & 3.0 & 3.0 & 2.7 & 2.7 \\
\hline A. octoradiata & 12 & 14 & 11 & 9 & 17 & 2 & 12 & 3 & 10 & 20 & 14 & 11 \\
\hline A.cymbiformis & 41 & 18 & 22 & 18 & 34 & 21 & 24 & 34 & 43 & 41 & 21 & 29 \\
\hline A. cymbif./specill. & . & . & . & . & . & . & . & . & . & . & . & . \\
\hline A. specillata & . & . & . & . & . & . & . & · & . & . & . & . \\
\hline B. sparsus & . & . & . & . & - & · & · & $\cdot$ & . & · & . & . \\
\hline B. boletum & . & . & . & . & . & . & . & . & . & . & . & . \\
\hline B. constans & . & . & . & . & . & . & . & . & . & . & . & . \\
\hline B. coronum & . & . & . & . & . & . & . & . & . & . & . & . \\
\hline B. dissimilis & . & . & . & . & . & . & . & . & . & . & . & . \\
\hline B. magnum & . & . & . & . & . & . & . & . & . & . & . & . \\
\hline B. notaculum & . & . & . & . & . & . & . & . & . & . & . & . \\
\hline Biscutum sp. 1 & . & . & . & . & . & . & . & . & . & . & . & . \\
\hline Biscutum sp. 2 & . & . & . & $\cdot$ & . & . & . & . & . & . & . & . \\
\hline B. cf bevieri & . & . & . & . & . & . & . & . & . & . & . & - \\
\hline Broinsonia spp. & . & . & . & . & . & . & . & . & - & - & . & · \\
\hline C. barbata & · & . & . & . & . & . & . & . & . & . & . & . \\
\hline C. amphipons & . & . & . & . & . & . & . & . & . & - & - & $\cdot$ \\
\hline C. garrisonii & . & . & . & . & · & . & . & . & . & . & . & . \\
\hline Chiastozygus sp. 1 & . & . & . & . & . & . & : & . & . & . & . & . \\
\hline C. conicus & . & . & . & . & . & . & 1 & . & . & . & 1 & . \\
\hline C. crenulatus & . & . & . & . & . & . & . & . & . & . & $\cdot$ & . \\
\hline C. surirellus & . & . & . & . & . & . & . & . & . & . & . & . \\
\hline Cretarhabdus sp. 1 & . & . & . & . & . & . & . & . & . & . & . & . \\
\hline Cretarhabdus spp. & 14 & 11 & 12 & 7 & 19 & 13 & 15 & 6 & 11 & 3 & 4 & 16 \\
\hline C. daniae & 52 & 32 & 29 & 35 & 44 & 51 & 46 & 42 & 56 & 67 & 55 & 54 \\
\hline C. ehrenbergii & 12 & 5 & 4 & 4 & 13 & 14 & 4 & 3 & 8 & 9 & 10 & 13 \\
\hline Cruciplacolithus spp. & . & . & . & . & . & . & . & . & . & . & . & . \\
\hline Cyclagelosph. spp. & · & . & . & . & . & . & . & . & . & . & . & . \\
\hline Cylindralithus spp. & . & . & . & . & . & . & . & . & . & . & . & . \\
\hline D. ignotus & . & . & . & . & . & . & . & . & . & . & . & . \\
\hline E. trabeculatus & . & . & . & . & . & : & . & . & . & . & . & . \\
\hline E. turriseiffeli & 8 & 3 & 1 & 3 & 3 & 5 & 7 & 20 & 16 & 20 & 5 & 11 \\
\hline Gartnerago spp. & 7 & 1 & 1 & 5 & 4 & 6 & 7 & 5 & 9 & 8 & 9 & 8 \\
\hline G. fessus & 14 & 20 & 12 & 17 & 15 & 13 & 16 & 7 & 17 & 18 & 10 & 10 \\
\hline Homibrookina spp. & . & . & . & . & . & . & . & . & . & . & . & . \\
\hline K. magnificus & 90 & 38 & 60 & 68 & 78 & 64 & 86 & 76 & 75 & 90 & 74 & 94 \\
\hline Lapideacassis spp. & . & . & . & . & . & . & . & . & . & . & . & . \\
\hline L. camiolensis & . & . & . & . & . & . & . & . & . & . & . & . \\
\hline L. cayeuxii & 1 & 1 & 1 & 1 & . & 1 & 1 & . & . & 3 & $\mathrm{P}$ & 5 \\
\hline M. inversus & . & . & . & . & . & . & . & . & . & . & . & . \\
\hline M. decoratus & . & 1 & . & 1 & 1 & . & 1 & 1 & . & . & 1 & . \\
\hline M. staurophora & . & 1 & . & . & . & . & 1 & . & . & . & . & . \\
\hline M. pleniporus & . & . & . & . & . & . & . & . & . & . & . & . \\
\hline Misceomarg. sp. & . & . & . & . & . & . & . & . & . & . & . & . \\
\hline M. pectinatus & . & . & . & . & . & . & . & . & . & . & . & . \\
\hline M. quatemarius & . & . & . & . & . & . & . & . & . & . & . & . \\
\hline Monomarg. sp. & . & . & . & . & . & . & . & . & . & . & . & . \\
\hline Misceo/Monomg sp. & . & . & . & . & . & . & . & . & . & . & . & . \\
\hline N. watkinsii & . & . & . & . & . & . & . & . & . & . & . & . \\
\hline Neocrepidol. spp. & . & . & . & . & . & . & . & . & . & . & . & . \\
\hline N. corystus & . & . & . & . & . & . & . & . & . & . & . & . \\
\hline N. frequens & 125 & 103 & 114 & 121 & 169 & 127 & 102 & 113 & 145 & 224 & 195 & 151 \\
\hline O. magnus & . & . & . & . & . & . & . & . & . & . & $\cdot$ & . \\
\hline P. obscurus & . & . & . & . & . & . & . & . & . & . & . & . \\
\hline
\end{tabular}




\begin{tabular}{|c|c|c|c|c|c|c|c|c|c|c|c|c|}
\hline Sample Number & 58 & 59 & 60 & 61 & 62 & 63 & 64 & 65 & 66 & 67 & 68 & 69 \\
\hline Hole & $690 \mathrm{C}$ & $690 \mathrm{C}$ & $690 \mathrm{C}$ & $690 \mathrm{C}$ & $690 \mathrm{C}$ & $690 \mathrm{C}$ & $690 \mathrm{C}$ & $690 \mathrm{C}$ & $690 \mathrm{C}$ & $690 \mathrm{C}$ & $690 \mathrm{C}$ & $690 \mathrm{C}$ \\
\hline Core - Section & $15-6$ & $15-6$ & $15-6$ & $15-6$ & $15-6$ & $15-6$ & $15-6$ & $15-7$ & $15-7$ & $15-7$ & $15-\mathrm{CC}$ & $15-\mathrm{CC}$ \\
\hline $\mathrm{cm}$ - level & $90-91$ & 101 & $110-111$ & $120-121$ & $130-131$ & $140-141$ & $149-150$ & 10 & $20-21$ & 30 & 8 & $19-20$ \\
\hline Depth (mbsf) & 251.3 & 251.41 & 251.5 & 251.6 & 251.7 & 251.8 & 251.89 & 252 & 252.1 & 252.2 & 252.33 & 252.44 \\
\hline P. bussonii & . & . & . & . & . & . & . & . & . & . & . & . \\
\hline P. fibuliformis & 6 & 16 & 15 & 18 & 27 & 13 & 16 & 9 & 11 & 14 & 11 & 16 \\
\hline P. sigmoides & . & . & . & 1 & . & . & 1 & . & 3 & 4 & . & . \\
\hline Placozygus sp. & . & . & . & . & . & . & . & . & . & . & . & . \\
\hline P. arkhangelskyi & . & . & . & . & . & . & . & . & . & . & . & . \\
\hline P. cretacea & 75 & 64 & 41 & 54 & 88 & 65 & 74 & 52 & 101 & 79 & 94 & 69 \\
\hline P. spinosa & 30 & 25 & 11 & 22 & 28 & 19 & 33 & 20 & 36 & 27 & 29 & 21 \\
\hline P. firthii & . & . & . & . & . & . & . & . & . & . & . & . \\
\hline Q. gartneri & . & . & . & . & . & . & . & . & . & . & . & . \\
\hline Reinhardtites spp. & . & . & . & . & . & . & . & . & . & . & . & . \\
\hline $\mathrm{R}$. angustus & . & . & . & . & . & . & . & . & . & . & . & . \\
\hline Rhagodiscus spp. & . & 1 & . & . & . & . & . & . & . & . & . & . \\
\hline R. rhombicum & . & . & . & . & . & . & . & . & . & . & . & . \\
\hline S. asymmetrica & . & . & . & . & . & . & $?$ & . & . & . & . & . \\
\hline S. wisei & . & . & . & . & . & . & . & . & . & . & . & 1 \\
\hline Scampanella spp. & . & . & . & . & . & . & . & . & . & . & . & \\
\hline S. fossilis & . & . & . & . & . & . & . & . & . & . & . & . \\
\hline S. laffittei & . & . & . & . & . & . & . & . & . & . & . & . \\
\hline T. ethmos & . & . & . & . & . & . & P & . & . & . & . & . \\
\hline Thoracosph. spp. & . & . & 3 & 4 & 2 & . & 1 & 1 & 2 & . & 2 & . \\
\hline Vagalapilla spp. & 4 & 7 & 3 & 9 & 17 & 9 & 15 & 14 & 9 & 22 & 17 & 6 \\
\hline W. bamesae & . & . & . & . & . & . & . & . & . & . & . & . \\
\hline Z. compactus & . & . & . & . & . & . & . & . & . & . & . & . \\
\hline Z. diplogrammus & . & . & . & . & . & . & . & . & . & . & . & . \\
\hline Unidentifiable & 9 & 9 & 11 & 11 & 12 & 8 & 10 & 8 & 9 & 16 & 7 & 23 \\
\hline Total (excl. P. stov.) & 500 & 370 & 351 & 408 & 571 & 431 & 473 & 414 & 561 & 665 & 559 & 538 \\
\hline P. stoveri & 495 & 574 & 557 & 614 & 810 & 691 & 758 & 817 & 1084 & 841 & 889 & 606 \\
\hline Total (P. stov.count) & 995 & 944 & 908 & 1022 & 1381 & 1122 & 1231 & 1231 & 1535 & 1072 & 1448 & 1014 \\
\hline P. stoveri, fields & 30 & 30 & 30 & 30 & 30 & 30 & 30 & 30 & 30 & 30 & 30 & 30 \\
\hline
\end{tabular}




\begin{tabular}{lcccccccccccc} 
Sample Number & 70 & 71 & 72 & 73 & 74 & 75 & 76 & 77 & 78 & 79 & 80 & 81 \\
Hole & $690 \mathrm{C}$ & $690 \mathrm{C}$ & $690 \mathrm{C}$ & $690 \mathrm{C}$ & $690 \mathrm{C}$ & $690 \mathrm{C}$ & $690 \mathrm{C}$ & $690 \mathrm{C}$ & $690 \mathrm{C}$ & $690 \mathrm{C}$ & $690 \mathrm{C}$ & $690 \mathrm{C}$ \\
Core - Section & $16-1$ & $16-1$ & $16-1$ & $16-1$ & $16-1$ & $16-1$ & $16-1$ & $16-1$ & $16-3$ & $16-4$ & $17-1$ & $17-3$ \\
Cm - level & $9 .-10$ & $21-22$ & $30-31$ & $40-41$ & $50-51$ & $59-60$ & 70 & $100-101$ & $20-21$ & 80 & $31-32$ & $29-30$ \\
Depth (mbsf) & 252.59 & 252.71 & 252.8 & 252.9 & 253 & 253.09 & 253.2 & 253.5 & 255.7 & 257.8 & 262.11 & 265.09 \\
Sed. rate (m/m.y.) & 7.5 & 7.5 & 7.5 & 7.5 & 7.5 & 7.5 & 7.5 & 7.5 & 7.5 & 7.5 & 7.5 & 7.5 \\
Age (Ma) & 66.781 & 66.797 & 66.809 & 66.823 & 66.836 & 66.848 & 66.863 & 66.902 & 67.195 & 67.475 & 68.049 & 68.446 \\
Pres. (G, M, P) & M-P & P & M-P & M-P & PP & M-P & M-G & M & M & M & M-P & M-P \\
Abund. (A, C, R) & A & R & R-C & A & RR & A & A & A & A & A & A-C & C \\
Fields counted & 64.2 & 61.6 & 273.2 & 49.3 & 142.8 & 52.4 & 30 & 30 & 15.8 & 20.2 & 59.7 & 64.1 \\
mg sediment & 19.8 & 18.2 & 19.3 & 20.8 & 21.0 & 20.7 & 18.3 & 19.3 & 19.9 & 20.8 & 19.6 & 21.2 \\
Carbonate (wt- $\%$ ) & 87.4 & 88.3 & 88.3 & 91.6 & 91.1 & 93.2 & 88.2 & 91.4 & 92.1 & 87.1 & 88.2 & 89.7 \\
Beaker Constant & 2.7 & 3.0 & 2.7 & 2.7 & 3.0 & 2.7 & 3.0 & 3.0 & 2.7 & 2.7 & 2.7 & 2.7 \\
\hline A. octoradiata & 6 & 5 &. & 4 &. & 3 & 19 & 34 & 1 & 2 & 1 & 1 \\
A.cymbiformis & 33 & 28 & 85 & 23 & 54 & 33 & 22 & 11 & 10 & 8 & 26 & 25
\end{tabular}

iformis

A. cymbif./specill.

A. specillata

B. sparsus

B. boletum

B. constans

B. coronum

B. dissimilis

B. magnum

B. notaculum

Biscutum sp. 1

Biscutum sp. 2

B. cf bevieri

Broinsonia spp.

C. barbata

C. amphipons

C. garrisonii

Chiastozygus sp. 1

C. conicus

C. crenulatus

C. surirellus

Cretarhabdus sp. 1

Cretarhabdus spp.

C. daniae

C. ehrenbergii

Cruciplacolithus spp.

Cyclagelosph. spp.

Cylindralithus spp.

D. ignotus

E. trabeculatus

E. turriseiffeli

Gartnerago spp.

$\mathrm{G}$. fessus

Hornibrookina spp.

K. magnificus

Lapideacassis spp.

L. camiolensis

L. cayeuxii

$M$. inversus

M. decoratus

M. staurophora

M. pleniporus

Misceomarg. sp.

M. pectinatus

M. quatemarius

Monomarg. sp.

Misceo/Monomg sp.

N. watkinsii

Neocrepidol. spp.

N. corystus

N. frequens

O. magnus

P. obscurus 


\begin{tabular}{|c|c|c|c|c|c|c|c|c|c|c|c|c|}
\hline Sample Number & 70 & 71 & 72 & 73 & 74 & 75 & 76 & 77 & 78 & 79 & 80 & 81 \\
\hline Hole & $690 \mathrm{C}$ & $690 \mathrm{C}$ & $690 \mathrm{C}$ & $690 \mathrm{C}$ & $690 \mathrm{C}$ & $690 \mathrm{C}$ & $690 \mathrm{C}$ & $690 \mathrm{C}$ & $690 \mathrm{C}$ & $690 \mathrm{C}$ & $690 \mathrm{C}$ & $690 \mathrm{C}$ \\
\hline Core-Section & $16-1$ & $16-1$ & $16-1$ & $16-1$ & $16-1$ & $16-1$ & $16-1$ & $16-1$ & $16-3$ & $16-4$ & $17-1$ & $17-3$ \\
\hline $\mathrm{cm}$ - level & 9.-10 & $21-22$ & $30-31$ & $40-41$ & $50-51$ & $59-60$ & 70 & $100-101$ & $20-21$ & 80 & $31-32$ & $29-30$ \\
\hline Depth (mbsf) & 252.59 & 252.71 & 252.8 & 252.9 & 253 & 253.09 & 253.2 & 253.5 & 255.7 & 257.8 & 262.11 & 265.09 \\
\hline P. bussonii & . & . & . & . & . & . & . & . & . & . & 1 & . \\
\hline P. fibuliformis & 3 & 4 & 4 & 6 & 3 & 10 & 4 & . & 4 & 2 & 6 & 3 \\
\hline P. sigmoides & 6 & . & 1 & . & . & . & . & . & . & . & . & . \\
\hline Placozygus sp. & . & . & . & . & . & . & . & . & . & . & . & 1 \\
\hline P. arkhangelskyi & . & . & . & . & . & . & . & 1 & . & . & . & . \\
\hline P. cretacea & 75 & 69 & 35 & 53 & 11 & 92 & 59 & 30 & 53 & 23 & 30 & 28 \\
\hline P. spinosa & 29 & 24 & 3 & 37 & 1 & 19 & 14 & 21 & 13 & 10 & 5 & 1 \\
\hline P. firthii & . & . & . & . & . & . & . & . & . & . & . & . \\
\hline Q. gartneri & . & . & . & . & . & . & . & . & . & . & . & . \\
\hline Reinhardtites spp. & . & . & . & . & . & . & . & . & . & . & 1 & . \\
\hline $\mathrm{R}$. angustus & . & . & . & . & . & . & . & 1 & . & . & . & . \\
\hline Rhagodiscus spp. & . & . & . & . & . & . & . & . & . & 1 & . & . \\
\hline R. rhombicum & . & . & . & . & . & . & . & . & . & . & . & . \\
\hline S. asymmetrica & . & . & . & . & . & . & . & . & . & . & . & . \\
\hline S. wisei & . & . & . & . & . & . & . & . & . & . & . & . \\
\hline Scampanella spp. & . & . & . & . & . & . & 1 & 1 & . & . & . & . \\
\hline S. fossilis & . & . & . & . & . & . & . & . & . & . & . & . \\
\hline S. laffittei & . & . & . & . & . & & . & . & . & . & . & . \\
\hline T. ethmos & . & . & . & ? & . & . & $P$ & . & $\mathbf{P}$ & 1 & . & 1 \\
\hline Thoracosph. spp. & 3 & 1 & . & 1 & . & 2 & . & 1 & . & . & . & 1 \\
\hline Vagalapilla spp. & 6 & 13 & 2 & 20 & 1 & 16 & 9 & 11 & 8 & 14 & 7 & 2 \\
\hline W. bamesae & . & . & . & . & . & . & . & . & . & . & . & . \\
\hline Z. compactus & . & . & . & . & . & . & . & . & . & . & . & . \\
\hline Z. diplogrammus & . & . & . & . & . & . & . & . & . & . & . & . \\
\hline Unidentifiable & 17 & 34 & 15 & 10 & 19 & 16 & 20 & 10 & 15 & 5 & 6 & 2 \\
\hline Total (excl. P. stov.) & 600 & 547 & 512 & 564 & 402 & 596 & 477 & 409 & 357 & 411 & 345 & 245 \\
\hline P. stoveri & 293 & 308 & 281 & 437 & 79 & 588 & 1004 & 1066 & 622 & 677 & 461 & 111 \\
\hline Total (P. stov.count) & 631 & 544 & 793 & 780 & 481 & 932 & 1482 & 1476 & 979 & 1088 & 806 & 356 \\
\hline P. stoveri, fields & 30 & 30 & 273.2 & 30 & 142.8 & 30 & 30 & 30 & 15.8 & 20.2 & 59.7 & 64.1 \\
\hline
\end{tabular}




\begin{tabular}{|c|c|c|c|c|c|c|c|c|c|c|c|c|}
\hline Sample Number & 82 & 83 & 84 & 85 & 86 & 87 & 88 & 89 & 90 & 91 & 92 & 93 \\
\hline Hole & $690 \mathrm{C}$ & $690 \mathrm{C}$ & $690 \mathrm{C}$ & $690 \mathrm{C}$ & $690 \mathrm{C}$ & $690 \mathrm{C}$ & $690 \mathrm{C}$ & $690 \mathrm{C}$ & $690 \mathrm{C}$ & $690 \mathrm{C}$ & $690 \mathrm{C}$ & $690 \mathrm{C}$ \\
\hline Core-Section & $18-1$ & $18-3$ & $18-5$ & $19-1$ & $19-3$ & $19-6$ & $19-7$ & $20-1$ & $20-1$ & $20-1$ & $20-1$ & $20-2$ \\
\hline $\mathrm{cm}$ - level & $107-108$ & 106 & 54 & 107 & 137 & $110-111$ & $20-21$ & $68-69$ & 130 & 136 & 145 & $4 .-5$ \\
\hline Depth (mbsf) & 272.47 & 275.46 & 277.94 & 282.17 & 285.47 & 289.7 & 290.3 & 291.48 & 292.1 & 292.16 & 292.25 & 292.34 \\
\hline Sed. rate (m/m.y.) & 5.7 & 5.7 & 5.7 & 5.7 & 8.9 & 8.9 & 8.9 & 8.9 & 8.9 & 8.9 & 8.9 & 8.9 \\
\hline Age (Ma) & 69.439 & 69.968 & 70.407 & 71.156 & 71.604 & 72.080 & 72.147 & 72.280 & 72.350 & 72.357 & 72.367 & 72.377 \\
\hline Pres. (G, M, P) & P-M & PP & M-P & M & M & PP & $\mathrm{M}$ & M & M-G & M-G & $M-G$ & M-G \\
\hline Abund. (A, C, R) & $C-R$ & C & A-C & $\mathrm{C}$ & A & $\mathbf{R}$ & A & A & A & A & A & A \\
\hline Fields counted & 65.9 & 24.6 & 40 & 54.9 & 20.2 & 23.7 & 20.6 & 23.3 & 29 & 35.1 & 59.7 & 36.4 \\
\hline mg sediment & 21.0 & 21.1 & 21.2 & 20.5 & 20.4 & 20.4 & 20.3 & 20.8 & 21.1 & 20.0 & 19.7 & 20.1 \\
\hline Carbonate (wt-\%) & 89.9 & 81.3 & 76.3 & 62.7 & 61.5 & 83.1 & 76.3 & 47.8 & 53.1 & 52.2 & 54.3 & 55.3 \\
\hline Beaker Constant & 2.7 & 2.7 & 2.7 & 2.7 & 2.7 & 2.7 & 2.7 & 2.7 & 2.7 & 2.7 & 2.7 & 2.7 \\
\hline A. octoradiata & 1 & . & . & 26 & 36 & . & 25 & 42 & 58 & 64 & 53 & 51 \\
\hline A.cymbiformis & 7 & 2 & 2 & . & . & 4 & . & . & . & 19 & 12 & 7 \\
\hline A. cymbif./specill. & . & . & . & . & . & . & . & 1 & 6 & . & . & . \\
\hline A. specillata & . & . & . & . & . & . & . & . & . & 4 & 1 & 2 \\
\hline B. sparsus & . & . & . & . & . & . & . & . & . & . & . & . \\
\hline B. boletum & . & . & . & 2 & 1 & . & 1 & . & . & . & . & . \\
\hline B. constans & 4 & . & 4 & 10 & 8 & 2 & 3 & 10 & 13 & 3 & 2 & 10 \\
\hline B. coronum & . & . & . & . & . & . & . & . & . & . & . & . \\
\hline B. dissimilis & . & . & . & . & 3 & . & 2 & 1 & 1 & . & . & 2 \\
\hline B. magnum & . & . & . & 12 & 45 & 5 & 37 & 31 & 21 & 25 & 13 & 29 \\
\hline B. notaculum & . & . & 10 & 50 & 42 & 7 & 40 & 54 & 50 & 51 & 75 & 66 \\
\hline Biscutum sp. 1 & . & . & . & . & . & . & 3 & . & 1 & . & 1 & 2 \\
\hline Biscutum sp. 2 & . & . & . & 2 & 1 & 1 & 3 & 3 & . & . & . & . \\
\hline B. cf bevieri & . & . & . & . & . & . & 5 & 5 & 3 & 4 & 3 & 16 \\
\hline Broinsonia spp. & . & . & . & 27 & 4 & 1 & 8 & 9 & 6 & . & . & . \\
\hline C. barbata & 1 & . & 2 & 6 & 3 & . & . & 4 & 10 & 10 & 11 & 1 \\
\hline C. amphipons & . & . & . & $?$ & ? & 1 & 1 & . & . & . & 1 & . \\
\hline C. garrisonii & . & . & . & 3 & 3 & . & 7 & 6 & 4 & 6 & 3 & 7 \\
\hline Chiastozygus sp. 1 & . & . & . & . & . & . & 2 & . & . & . & . & 1 \\
\hline C. conicus & . & . & . & . & 1 & . & 1 & 2 & 2 & 3 & . & 4 \\
\hline C. crenulatus & . & . & . & . & . & . & . & . & . & . & . & . \\
\hline C. surirellus & . & . & . & 6 & 2 & . & 1 & 2 & . & . & 4 & 1 \\
\hline Cretarhabdus sp. 1 & . & . & . & . & 1 & . & 1 & 1 & 1 & . & . & . \\
\hline Cretarhabdus spp. & 4 & 3 & . & 3 & 1 & . & 1 & 4 & 3 & . & 1 & . \\
\hline C. daniae & 3 & 7 & 44 & 1 & . & . & 1 & . & . & . & . & . \\
\hline C. ehrenbergii & . & . & . & 3 & 5 & . & . & 1 & 8 & 2 & 6 & 3 \\
\hline Cruciplacolithus spp. & . & . & . & . & . & . & . & . & . & . & . & . \\
\hline Cyclagelosph. spp. & . & . & . & . & . & . & . & 1 & . & . & . & 1 \\
\hline Cylindralithus spp. & . & . & . & . & . & . & . & . & . & . & . & . \\
\hline D. ignotus & . & . & . & 1 & . & . & . & . & . & 1 & . & . \\
\hline E. trabeculatus & . & . & . & . & . & . & . & . & . & . & . & . \\
\hline E. turriseiffeli & . & 1 & 16 & 6 & 16 & 1 & 31 & 15 & 21 & 23 & 15 & 14 \\
\hline Gartnerago spp. & . & $\mathrm{P}$ & 10 & 5 & 8 & . & 3 & 2 & 12 & 8 & 7 & 5 \\
\hline G. fessus & 1 & . & . & . & . & 1 & . & . & . & . & . & . \\
\hline Homibrookina spp. & . & . & . & . & . & . & . & . & . & . & . & . \\
\hline K. magnificus & 54 & 21 & 63 & 27 & 12 & 6 & 9 & 29 & 22 & 10 & 6 & 20 \\
\hline Lapideacassis spp. & . & . & . & : & . & . & . & . & . & . & . & . \\
\hline L. camiolensis & . & . & . & 1 & . & . & . & . & . & . & . & . \\
\hline L. cayeuxii & 15 & 24 & 17 & 10 & 21 & 5 & 24 & 1 & 1 & 4 & 7 & 9 \\
\hline M. inversus & . & . & . & . & . & · & . & . & · & · & . & . \\
\hline M. decoratus & . & . & . & . & . & . & . & . & . & . & . & . \\
\hline M. staurophora & 1 & . & . & 3 & . & . & . & . & . & . & 1 & 1 \\
\hline M. pleniporus & . & . & . & . & 1 & . & . & 1 & 4 & . & . & . \\
\hline Misceomarg. sp. & . & . & . & . & . & . & . & . & . & . & . & . \\
\hline M. pectinatus & . & . & . & . & . & . & . & 1 & 1 & 1 & . & 3 \\
\hline M. quaternarius & . & . & . & 7 & 7 & . & 10 & 2 & 2 & . & 5 & 4 \\
\hline Monomarg. sp. & . & . & . & . & . & . & . & . & . & . & . & . \\
\hline Misceo/Monomg sp. & . & . & . & . & . & . & . & 1 & . & . & . & . \\
\hline N. watkinsii & . & . & . & . & . & . & . & . & 2 & 3 & . & 2 \\
\hline Neocrepidol. spp. & . & . & . & . & . & . & . & . & . & . & . & . \\
\hline N. corystus & . & . & 4 & 14 & 27 & 2 & 47 & 50 & 39 & 36 & 33 & 34 \\
\hline N. frequens & 29 & 5 & 75 & . & . & . & . & . & . & . & . & . \\
\hline O. magnus & . & . & . & . & . & . & 5 & 1 & . & . & 1 & 1 \\
\hline P. obscurus & . & . & . & 3 & 7 & 2 & 11 & 1 & 3 & 2 & 2 & 3 \\
\hline
\end{tabular}




\begin{tabular}{|c|c|c|c|c|c|c|c|c|c|c|c|c|}
\hline Sample Number & 82 & 83 & 84 & 85 & 86 & 87 & 88 & 89 & 90 & 91 & 92 & 93 \\
\hline Hole & $690 \mathrm{C}$ & $690 \mathrm{C}$ & $690 \mathrm{C}$ & $690 \mathrm{C}$ & $690 \mathrm{C}$ & $690 \mathrm{C}$ & $690 \mathrm{C}$ & $690 \mathrm{C}$ & $690 \mathrm{C}$ & $690 \mathrm{C}$ & $690 \mathrm{C}$ & $690 \mathrm{C}$ \\
\hline Core - Section & $18-1$ & $18-3$ & $18-5$ & $19-1$ & $19-3$ & $19-6$ & $19-7$ & $20-1$ & $20-1$ & $20-1$ & $20-1$ & $20-2$ \\
\hline $\mathrm{cm}$ - level & $107-108$ & 106 & 54 & 107 & 137 & $110-111$ & $20-21$ & $68-69$ & 130 & 136 & 145 & $4 .-5$ \\
\hline Depth (mbsf) & 272.47 & 275.46 & 277.94 & 282.17 & 285.47 & 289.7 & 290.3 & 291.48 & 292.1 & 292.16 & 292.25 & 292.34 \\
\hline P. bussonii &. & . &. & 1 & . & 3 & 2 & 1 & 1 & . & . & . \\
\hline P. fibuliformis & . & . & 5 & 4 & . & . & . & . & . & 2 & 2 & 3 \\
\hline P. sigmoides & . & . & . & . & 1 & . & . & 1 & 4 & 1 & 1 & . \\
\hline Placozygus sp. & . & . & . & . & . & . & 1 & . & . & . & . & . \\
\hline P. arkhangelskyi & . & 2 & 11 & 3 & 10 & . & 17 & 7 & 6 & 6 & 4 & 9 \\
\hline P. cretacea & 14 & 2 & . & 4 & 1 & . & 3 & 5 & 18 & 15 & 6 & 7 \\
\hline P. spinosa & 1 & 1 & 27 & 15 & 47 & . & 13 & 34 & 28 & 26 & 32 & 30 \\
\hline P. firthii & . & . & . & 5 & 38 & . & 19 & 15 & 18 & 12 & 8 & 12 \\
\hline Q. gartneri & . & . & . & . & . & . & . & . & . & . & . & . \\
\hline Reinhardtites spp. & . & . & . & 18 & 6 & 2 & 4 & 20 & 38 & 28 & 39 & 16 \\
\hline $\mathrm{R}$. angustus & . & . & . & . & . & . & . & . & 7 & . & . & . \\
\hline Rhagodiscus spp. & . & . & . & . & . & . & . & . & . & . & . & . \\
\hline R. rhombicum & . & . & . & . & . & . & 2 & 1 & $P$ & . & . & 1 \\
\hline S. asymmetrica & . & . & . & . & . & . & . & . & . & . & . & . \\
\hline S. wisei & . & . & . & . & . & . & . & . & . & . & . & . \\
\hline Scampanella spp. & . & . & 1 & . & . & . & . & . & . & . & . & . \\
\hline S. fossilis & . & . & 4 & . & 1 & . & 3 & 1 & 2 & 7 & 1 & 2 \\
\hline S. laffittei & . & . & . & 1 & . & . & . & . & . & . & 1 & 4 \\
\hline T. ethmos & 1 & . & ? & . & . & . & 1 & . & P & 1 & . & . \\
\hline Thoracosph. spp. & . & . & 1 & 12 & 3 & . & 10 & 17 & 15 & 16 & 9 & 27 \\
\hline Vagalapilla spp. & 2 & 1 & 8 & 14 & 17 & . & 16 & 12 & 16 & 14 & 9 & 15 \\
\hline W. barnesae & . & . & . & . & . & . & . & 1 & 1 & 2 & . & 2 \\
\hline Z. compactus & . & . & . & 12 & . & 6 & 8 & . & . & . & . & . \\
\hline Z. diplogrammus & . & . & . & . & . & . & . & . & . & . & . & . \\
\hline Unidentifiable & 5 & 1 & 12 & 16 & 14 & . & 31 & 9 & 9 & 26 & 7 & 22 \\
\hline Total (excl. P. stov.) & 143 & 70 & 316 & 333 & 393 & 49 & 412 & 405 & 457 & 435 & 382 & 449 \\
\hline P. stoveri & 53 & . & 17 & 26 & 43 & 1 & 13 & 3 & 12 & 7 & 5 & 9 \\
\hline Total (P. stov.count) & 196 & 70 & 333 & 359 & 436 & 50 & 425 & 408 & 468 & 442 & 387 & 458 \\
\hline P. stoveri, fields & 65.9 & 24.6 & 40 & 54.9 & 20.2 & 23.7 & 20.6 & 23.3 & 29 & 35.1 & 59.7 & 36.4 \\
\hline
\end{tabular}




\begin{tabular}{|c|c|c|c|c|c|c|c|c|c|c|c|c|}
\hline Sample Number & 94 & 95 & 96 & 97 & 98 & 99 & 100 & 101 & 102 & 103 & 104 & 105 \\
\hline Hole & $690 \mathrm{C}$ & $690 \mathrm{C}$ & $690 \mathrm{C}$ & $690 \mathrm{C}$ & $690 \mathrm{C}$ & $690 \mathrm{C}$ & $690 \mathrm{C}$ & $690 \mathrm{C}$ & $690 \mathrm{C}$ & $690 \mathrm{C}$ & $690 \mathrm{C}$ & $690 \mathrm{C}$ \\
\hline Core - Section & $20-2$ & $20-2$ & $20-2$ & $20-2$ & $20-2$ & $20-2$ & $20-2$ & $20-2$ & $20-2$ & $20-2$ & $20-2$ & $20-2$ \\
\hline $\mathrm{cm}$ - level & $10 .-11$ & $19-20$ & $29-30$ & $38-39$ & $47-48$ & $51-52$ & 61.1 & $70-71$ & 80 & 90 & 100 & $110-111$ \\
\hline Depth (mbsf) & 292.4 & 292.49 & 292.59 & 292.68 & 292.77 & 292.81 & 292.91 & 293 & 293.1 & 293.2 & 293.3 & 293.4 \\
\hline Sed. rate (m/m.y.) & 8.9 & 8.9 & 8.9 & 8.9 & 8.9 & 8.9 & 8.9 & 8.9 & 8.9 & 8.9 & 8.9 & 8.9 \\
\hline Age (Ma) & 72.383 & 72.394 & 72.405 & 72.415 & 72.425 & 72.430 & 72.441 & 72.451 & 72.462 & 72.473 & 72.485 & 72.496 \\
\hline Pres. (G, M, P) & M-G & M & $M-G$ & $\mathrm{M}$ & M-G & G & M-G & M & M & M-P & M-P & M-G \\
\hline Abund. (A, C, R) & C-A & A & A & A & C & A & A & A & A & C & C-R & A \\
\hline Fields counted & 70.7 & 52.7 & 20 & 41 & 73.3 & 20.2 & 22 & 17.6 & 22 & 45.7 & 56.2 & 12.7 \\
\hline mg sediment & 18.3 & 18.5 & 18.6 & 18.0 & 17.1 & 21.1 & 19.0 & 21.8 & 20.4 & 20.4 & 21.0 & 20.0 \\
\hline Carbonate (wt-\%) & 55.9 & 53.3 & 56.7 & 52.9 & 52.7 & 50.4 & 58.2 & 60.3 & 62.5 & 70.1 & 70.5 & 68.7 \\
\hline Beaker Constant & 2.7 & 2.7 & 2.7 & 2.7 & 2.7 & 2.7 & 2.7 & 2.7 & 2.7 & 2.7 & 2.7 & 2.7 \\
\hline A. octoradiata & 29 & 32 & 12 & 18 & 34 & 31 & 41 & 50 & 38 & 33 & 30 & 26 \\
\hline A.cymbiformis & 23 & 17 & 9 & 11 & 11 & 8 & 8 & 11 & 9 & 6 & 4 & 1 \\
\hline A. cymbif./specill. & . & . & . & . & . & . & . & . & . & . & 2 & . \\
\hline A. specillata & . & . & $\mathrm{P}$ & 1 & 1 & 5 & 2 & 4 & 2 & . & 2 & $?$ \\
\hline B. sparsus & . & . & . & . & . & . & . & . & . & . & . & . \\
\hline B. boletum & 2 & . & . & . & . & . & . & . & . & . & . & . \\
\hline B. constans & 1 & 6 & 3 & 3 & 6 & 10 & 6 & 10 & 14 & 11 & 14 & 16 \\
\hline B. coronum & . & . & $\mathbf{P}$ & . & 1 & . & . & . & . & . & . & $\mathbf{P}$ \\
\hline B. dissimilis & . & 1 & . & . & . & 2 & 1 & 4 & 1 & 1 & . & 4 \\
\hline B. magnum & 29 & 29 & 13 & 22 & 16 & 27 & 24 & 22 & 33 & 39 & 21 & 28 \\
\hline B. notaculum & 67 & 58 & 23 & 56 & 97 & 45 & 77 & 69 & 77 & 84 & 96 & 66 \\
\hline Biscutum sp. 1 & . & 1 & . & . & . & 2 & . & 3 & . & . & & . \\
\hline Biscutum sp. 2 & . & 2 & . & . & . & 3 & 2 & 8 & 2 & 1 & . & 2 \\
\hline B. cf bevieri & 10 & 15 & 11 & 9 & . & 7 & 10 & 8 & 8 & 2 & 5 & 5 \\
\hline Broinsonia spp. & . & . & . & . & . & . & . & . & 5 & 1 & 5 & 5 \\
\hline C. barbata & 3 & 4 & 1 & 5 & 2 & 1 & 2 & 3 & 1 & 1 & . & 1 \\
\hline C. amphipons & . & . & P & 2 & . & 1 & . & 1 & . & . & 1 & . \\
\hline C. garrisonii & 1 & P & 6 & 1 & 3 & 4 & 10 & 3 & 8 & 1 & . & 10 \\
\hline Chiastozygus sp. 1 & . & . & . & . & . & 1 & 2 & 1 & 2 & . & . & . \\
\hline C. conicus & 1 & . & . & . & . & 2 & $\mathrm{P}$ & . & 1 & 1 & . & . \\
\hline C. crenulatus & . & . & . & . & . & . & . & . & . & . & . & . \\
\hline C. surirellus & 3 & 3 & 1 & 2 & 2 & 3 & 3 & 4 & 2 & 1 & 5 & 1 \\
\hline Cretarhabdus sp. 1 & . & . & . & . & . & . & 3 & 2 & 4 & 1 & . & P \\
\hline Cretarhabdus spp. & 3 & . & 1 & 1 & 2 & 1 & 1 & 1 & . & 3 & 3 & . \\
\hline C. daniae & . & . & . & . & . & . & . & . & . & . & . & . \\
\hline C. ehrenbergii & 4 & 2 & 2 & 6 & 1 & 3 & 2 & 2 & . & 3 & 3 & 1 \\
\hline Cruciplacolithus spp. & . & . & . & . & . & . & . & . & . & . & . & . \\
\hline Cyclagelosph. spp. & . & . & . & . & . & . & . & . & . & . & . & . \\
\hline Cylindralithus spp. & . & . & . & . & . & . & . & . & . & . & . & . \\
\hline D. ignotus & . & . & . & . & . & . & 1 & . & . & . & . & . \\
\hline E. trabeculatus & . & . & . & . & 1 & . & . & . & $\cdot$ & . & . & . \\
\hline E. turriseiffeli & 14 & 23 & 10 & 15 & 6 & 18 & 16 & 21 & 17 & 3 & 4 & 12 \\
\hline Gartnerago spp. & 8 & 12 & 1 & 2 & 8 & 4 & 10 & 15 & 20 & 8 & 8 & 12 \\
\hline G. fessus & . & . & . & 1 & . & . & . & . & . & . & . & . \\
\hline Homibrookina spp. & . & . & . & . & . & . & . & . & . & . & . & . \\
\hline K. magnificus & 14 & 15 & 10 & 12 & 11 & 24 & 20 & 20 & 25 & 19 & 10 & 21 \\
\hline Lapideacassis spp. & . & . & . & . & . & 1 & . & 1 & . & . & . & . \\
\hline L. camiolensis & . & . & . & 1 & . & . & . & . & $\therefore$ & $\therefore$ & . & $\cdot$ \\
\hline L. cayeuxii & 9 & 9 & 5 & P & 1 & 1 & 2 & 5 & 13 & 19 & 15 & 13 \\
\hline M. inversus & . & . & . & . & . & . & . & . & . & . & . & . \\
\hline M. decoratus & . & . & . & . & . & . & . & . & . & . & . & . \\
\hline M. staurophora & . & . & 1 & 2 & . & . & . & . & . & . & 2 & 2 \\
\hline M. pleniporus & . & . & 1 & . & . & . & . & 1 & 1 & 1 & 1 & . \\
\hline Misceomarg. sp. & . & . & . & . & . & . & . & . & . & . & . & . \\
\hline M. pectinatus & 1 & . & . & . & . & . & 2 & . & . & . & 1 & . \\
\hline M. quaternarius & 3 & 7 & 2 & 3 & 6 & . & 3 & 2 & 5 & 3 & 2 & 4 \\
\hline Monomarg. sp. & . & . & . & . & . & . & . & . & . & . & . & . \\
\hline Misceo/Monomg sp. & . & . & . & . & . & . & . & . & . & . & . & . \\
\hline N. watkinsii & . & 1 & 1 & . & 6 & 2 & . & 4 & 1 & 2 & 2 & P \\
\hline Neocrepidol. spp. & . & . & . & . & . & . & . & . & . & . & . & . \\
\hline N. corystus & 36 & 36 & 23 & 43 & 37 & 42 & 34 & 51 & 23 & 25 & 28 & 22 \\
\hline N. frequens & . & . & . & . & . & . & . & . & . & . & . & . \\
\hline O. magnus & . & 1 & . & P & . & . & . & 1 & . & . & . & . \\
\hline P. obscurus & . & . & 1 & 1 & 1 & 2 & 3 & 2 & 2 & 5 & 3 & 3 \\
\hline
\end{tabular}




\begin{tabular}{|c|c|c|c|c|c|c|c|c|c|c|c|c|}
\hline Sample Number & 94 & 95 & 96 & 97 & 98 & 99 & 100 & 101 & 102 & 103 & 104 & 105 \\
\hline Hole & $690 \mathrm{C}$ & $690 \mathrm{C}$ & $690 \mathrm{C}$ & $690 \mathrm{C}$ & $690 \mathrm{C}$ & $690 \mathrm{C}$ & $690 \mathrm{C}$ & $690 \mathrm{C}$ & $690 \mathrm{C}$ & $690 \mathrm{C}$ & $690 \mathrm{C}$ & $690 \mathrm{C}$ \\
\hline Core-Section & $20-2$ & $20-2$ & $20-2$ & $20-2$ & $20-2$ & $20-2$ & $20-2$ & $20-2$ & $20-2$ & $20-2$ & $20-2$ & $20-2$ \\
\hline $\mathrm{cm}$ - level & 10.-11 & $19-20$ & $29-30$ & $38-39$ & 47.48 & $51-52$ & 61.1 & $70-71$ & 80 & 90 & 100 & $110-111$ \\
\hline Depth (mbsf) & 292.4 & 292.49 & 292.59 & 292.68 & 292.77 & 292.81 & 292.91 & 293 & 293.1 & 293.2 & 293.3 & 293.4 \\
\hline P. bussonii & . & . & . & . & . & . & . & . & . & . & . & $\mathrm{P}$ \\
\hline P. fibuliformis & 1 & . & . & 1 & 1 & 1 & 2 & 4 & 1 & 1 & 1 & . \\
\hline P. sigmoides & 2 & 3 & 2 & 2 & 2 & . & . & 1 & 3 & 1 & . & 2 \\
\hline Placozygus sp. & . & 1 & . & . & . & . & . & . & . & 1 & 3 & . \\
\hline P. arkhangelskyi & 7 & 4 & 7 & 5 & 3 & 11 & 11 & 6 & 3 & 1 & 2 & 8 \\
\hline P. cretacea & 7 & 11 & 4 & 11 & 6 & 7 & 4 & 2 & 4 & 4 & 4 & 3 \\
\hline P. spinosa & 26 & 22 & 15 & 39 & 22 & 29 & 31 & 34 & 32 & 21 & 22 & 24 \\
\hline P. firthii & 13 & 10 & 9 & 15 & 8 & 18 & 10 & 10 & 18 & 7 & 7 & 13 \\
\hline Q. gartneri & . & . & . & . & . & . & . & . & . & 2 & . & . \\
\hline Reinhardtites spp. & 24 & 32 & 10 & 23 & 22 & 19 & 17 & 9 & 9 & 6 & 9 & 10 \\
\hline $\mathrm{R}$. angustus & . & 1 & . & . & . & . & 1 & 2 & . & . & . & 1 \\
\hline Rhagodiscus spp. & . & . & . & . & . & . & . & . & . & . & . & . \\
\hline R. rhombicum & 1 & . & 1 & 1 & . & 2 & . & 1 & 1 & . & 1 & 3 \\
\hline S. asymmetrica & . & . & . & . & . & . & . & . & . & 1 & . & $\mathrm{P}$ \\
\hline S. wisei & . & . & . & . & . & . & . & . & . & . & . & . \\
\hline Scampanella spp. & . & . & P & . & & . & . & . & . & . & . & . \\
\hline S. fossilis & 1 & . & 1 & 2 & 3 & 2 & 7 & 5 & 3 & . & . & 6 \\
\hline S. laffittei & 2 & 3 & . & 3 & 3 & 3 & 6 & 5 & 5 & 3 & 3 & 4 \\
\hline T. ethmos & . & . & P & P & $\mathrm{P}$ & 2 & 1 & . & . & . & . & . \\
\hline Thoracosph. spp. & 9 & 9 & 2 & 9 & 9 & 11 & 9 & 6 & 7 & 3 & 2 & 9 \\
\hline Vagalapilla spp. & 13 & 22 & 6 & 13 & 20 & 23 & 21 & 14 & 26 & 23 & 21 & 12 \\
\hline W. bamesae & 3 & . & . & 2 & 1 & 1 & 2 & . & 2 & . & . & . \\
\hline Z. compactus & . & . & . & . & 1 & . & . & 2 & . & 9 & 13 & 1 \\
\hline Z. diplogrammus & . & . & P & 1 & . & . & . & . & . & . & . & $P$ \\
\hline Unidentifiable & 24 & 10 & 17 & 26 & 13 & 13 & 13 & 15 & 19 & 6 & 17 & 20 \\
\hline Total (excl. P. stov.) & 394 & 402 & 211 & 370 & 367 & 392 & 420 & 445 & 447 & 363 & 372 & 371 \\
\hline P. stoveri & 9 & 6 & . & 6 & 4 & 13 & 2 & 4 & 2 & 10 & 2 & . \\
\hline Total (P. stov.count) & 403 & 408 & 211 & 376 & 371 & 405 & 422 & 449 & 449 & 373 & 374 & 371 \\
\hline P. stoveri, fields & 70.7 & 52.7 & 20 & 41 & 73.3 & 20.2 & 22 & 17.6 & 22 & 45.7 & 56.2 & 12.7 \\
\hline
\end{tabular}




\begin{tabular}{|c|c|c|c|c|c|c|c|c|c|c|c|c|}
\hline Sample Number & 106 & 107 & 108 & 109 & 110 & 111 & 112 & 113 & 114 & 115 & 116 & 117 \\
\hline Hole & $690 \mathrm{C}$ & $690 \mathrm{C}$ & $690 \mathrm{C}$ & $690 \mathrm{C}$ & $690 \mathrm{C}$ & $690 \mathrm{C}$ & $690 \mathrm{C}$ & $690 \mathrm{C}$ & $690 \mathrm{C}$ & $690 \mathrm{C}$ & $690 \mathrm{C}$ & $690 \mathrm{C}$ \\
\hline Core - Section & $20-2$ & $20-2$ & $20-2$ & $20-2$ & $20-3$ & $20-3$ & $20-3$ & $20-3$ & $20-3$ & $20-3$ & $20-3$ & $20-3$ \\
\hline $\mathrm{cm}$ - level & 120 & $129-130$ & $140-141$ & 149 & 10.1 & 30.1 & 52 & 70 & $90-91$ & $107-108$ & 130 & 150 \\
\hline Depth (mbsf) & 293.5 & 293.59 & 293.7 & 293.79 & 293.9 & 294.1 & 294.32 & 294.5 & 294.7 & 294.87 & 295.1 & 295.3 \\
\hline Sed. rate (m/m.y.) & 8.9 & 8.9 & 8.9 & 8.9 & 8.9 & 8.9 & 8.9 & 8.9 & 8.9 & 8.9 & 8.9 & 8.9 \\
\hline Age (Ma) & 72.507 & 72.517 & 72.530 & 72.540 & 72.552 & 72.575 & 72.599 & 72.620 & 72.642 & 72.661 & 72.687 & 72.710 \\
\hline Pres. (G, M, P) & M-G & M-P & M & M-P & M & M & P-M & PP & M & M & M & $\mathrm{M}$ \\
\hline Abund. (A, C, R) & A & A-C & A & A-C & A & A & A & A & A & A & A & A \\
\hline Fields counted & 20.6 & 29.9 & 14.5 & 19.8 & 21.1 & 30.7 & 26.3 & 58.8 & 21.1 & 22.4 & 20.2 & 20.6 \\
\hline mg sediment & 21.6 & 20.4 & 20.7 & 21.0 & 20.0 & 20.7 & 19.8 & 19.7 & 20.6 & 21.2 & 19.5 & 20.6 \\
\hline Carbonate (wt-\%) & 65.5 & 65.3 & 65.2 & 63.3 & 62.3 & 63.3 & 75 & 77.4 & 69.5 & 65 & 62.8 & 61.6 \\
\hline Beaker Constant & 2.7 & 2.7 & 2.7 & 2.7 & 2.7 & 2.7 & 2.7 & 2.7 & 2.7 & 2.7 & 2.7 & 2.7 \\
\hline A. octoradiata & 32 & 43 & 38 & 38 & 43 & 36 & 22 & 25 & 23 & 32 & 34 & 47 \\
\hline A.cymbiformis & 4 & 2 & 5 & 6 & 4 & . & 8 & 13 & 3 & 4 & 4 & . \\
\hline A. cymbif./specill. & . & 1 & 2 & 1 & 3 & . & . & . & . & 3 & 3 & 4 \\
\hline A. specillata & 2 & . & 1 & 1 & . & . & . & 1 & 1 & . & . & 1 \\
\hline B. sparsus & . & . & . & . & . & . & . & . & . & . & . & . \\
\hline B. boletum & . & . & . & . & . & . & 1 & 4 & 2 & 8 & 5 & 3 \\
\hline B. constans & 14 & 11 & 7 & 9 & 18 & 13 & 13 & 11 & 13 & 18 & 17 & 7 \\
\hline B. coronum & $\mathbf{P}$ & . & . & . & . & . & 1 & . & . & 1 & 1 & 1 \\
\hline B. dissimilis & 2 & 1 & 1 & 1 & 1 & . & . & 3 & 1 & 1 & 2 & 4 \\
\hline B. magnum & 30 & 25 & 22 & 11 & 32 & 28 & 25 & 22 & 31 & 38 & 43 & 44 \\
\hline B. notaculum & 61 & 112 & 75 & 119 & 81 & 116 & 96 & 138 & 102 & 86 & 72 & 71 \\
\hline Biscutum sp. 1 & . & . & . & . & . & . & . & 1 & . & 8 & 4 & . \\
\hline Biscutum sp. 2 & . & . & 2 & . & . & 2 & . & . & . & 5 & . & 1 \\
\hline B. cf bevieri & 5 & 4 & 5 & 6 & 5 & 2 & 5 & 3 & 3 & 12 & 5 & 7 \\
\hline Broinsonia spp. & 4 & 3 & 3 & 1 & 5 & 5 & . & 2 & 2 & 8 & 7 & 2 \\
\hline C. barbata & 6 & 3 & 2 & 1 & 2 & 2 & 2 & 3 & . & 5 & 7 & 7 \\
\hline C. amphipons & 1 & . & . & . & . & . & . & & . & . & . & 1 \\
\hline C. garrisonii & 7 & 3 & 9 & 3 & 4 & . & 3 & 1 & 4 & 4 & 7 & 6 \\
\hline Chiastozygus sp. 1 & 1 & . & 1 & . & 3 & . & . & . & 2 & 2 & 1 & 1 \\
\hline C. conicus & 1 & . & 1 & . & 1 & . & . & . & . & . & . & . \\
\hline C. crenulatus & . & . & . & . & . & . & . & . & . & . & . & . \\
\hline C. surirellus & 7 & 6 & 1 & 1 & 6 & 5 & 3 & 1 & 1 & 7 & 7 & 9 \\
\hline Cretarhabdus sp. 1 & 3 & . & . & 1 & 2 & 1 & . & . & 2 & 3 & 1 & 5 \\
\hline Cretarhabdus spp. & 5 & 2 & 2 & 2 & 1 & 2 & 5 & 1 & 2 & 1 & 4 & 9 \\
\hline C. daniae & . & . & . & . & . & . & 1 & . & . & . & . & . \\
\hline C. ehrenbergii & 3 & 1 & 1 & . & 5 & 1 & 2 & 1 & 2 & 1 & 6 & 4 \\
\hline Cruciplacolithus spp. & . & . & . & . & . & . & . & . & . & . & . & . \\
\hline Cyclagelosph. spp. & . & . & . & . & . & . & . & . & . & . & . & . \\
\hline Cylindralithus spp. & . & . & . & . & . & . & . & . & . & . & . & . \\
\hline D. ignotus & . & . & . & . & . & . & . & . & . & . & . & . \\
\hline E. trabeculatus & . & . & . & . & . & . & . & 1 & . & . & . & . \\
\hline E. turriseiffeli & 13 & 14 & 18 & 10 & 4 & 8 & 15 & 6 & 7 & 7 & 9 & 10 \\
\hline Gartnerago spp. & 19 & 10 & 13 & 6 & 13 & 6 & 10 & 4 & 12 & 7 & 7 & 6 \\
\hline G. fessus & . & . & . & . & . & . & . & . & . & . & . & . \\
\hline Homibrookina spp. & . & . & . & . & . & . & . & . & . & . & . & . \\
\hline K. magnificus & 19 & 12 & 13 & 15 & 11 & 15 & 14 & 19 & 18 & 19 & 13 & 19 \\
\hline Lapideacassis spp. & . & . & . & . & . & . & . & . & . & 1 & . & . \\
\hline L. camiolensis & . & . & . & . & . & . & . & . & . & . & . & . \\
\hline L. cayeuxii & 19 & 18 & 2 & 12 & 17 & 17 & 9 & 23 & 9 & 8 & 6 & 5 \\
\hline M. inversus & . & . & . & . & . & . & . & . & . & . & . & . \\
\hline M. decoratus & . & . & $?$ & . & . & . & . & . & . & . & . & . \\
\hline M. staurophora & . & 1 & . & . & 1 & . & 1 & . & . & 2 & 4 & . \\
\hline M. pleniporus & . & . & . & . & . & . & . & . & . & . & 1 & . \\
\hline Misceomarg. sp. & . & . & . & . & . & . & . & . & . & . & . & . \\
\hline M. pectinatus & . & . & . & . & . & . & . & . & . & . & . & . \\
\hline M. quaternarius & 1 & . & 3 & 5 & 3 & 1 & 2 & 2 & . & 2 & 6 & 9 \\
\hline Monomarg. sp. & . & . & . & . & . & . & . & . & 1 & . & . & . \\
\hline Misceo/Monomg sp. & . & . & . & . & . & . & . & . & . & . & . & . \\
\hline N. watkinsii & . & 1 & 2 & . & 1 & . & 2 & 1 & . & . & 2 & 1 \\
\hline Neocrepidol. spp. & . & . & . & . & . & . & . & $:$ & . & . & . & . \\
\hline N. corystus & 25 & 22 & 31 & 19 & 18 & 22 & 27 & 21 & 39 & 39 & 44 & 30 \\
\hline N. frequens & . & . & . & . & . & . & . & . & . & . & . & . \\
\hline O. magnus & . & . & . & . & . & . & . & . & . & . & . & . \\
\hline P. obscurus & 5 & 5 & 6 & 10 & 6 & 7 & 4 & 10 & 5 & 7 & 9 & 3 \\
\hline
\end{tabular}




\begin{tabular}{|c|c|c|c|c|c|c|c|c|c|c|c|c|}
\hline Sample Number & 106 & 107 & 108 & 109 & 110 & 111 & 112 & 113 & 114 & 115 & 116 & 117 \\
\hline Hole & $690 \mathrm{C}$ & $690 \mathrm{C}$ & $690 \mathrm{C}$ & $690 \mathrm{C}$ & $690 \mathrm{C}$ & $690 \mathrm{C}$ & $690 \mathrm{C}$ & $690 \mathrm{C}$ & $690 \mathrm{C}$ & $690 \mathrm{C}$ & $690 \mathrm{C}$ & $690 \mathrm{C}$ \\
\hline Core - Section & $20-2$ & $20-2$ & $20-2$ & $20-2$ & $20-3$ & $20-3$ & $20-3$ & $20-3$ & $20-3$ & $20-3$ & $20-3$ & $20-3$ \\
\hline $\mathrm{cm}$ - level & 120 & $129-130$ & $140-141$ & 149 & 10.1 & 30.1 & 52 & 70 & $90-91$ & $107-108$ & 130 & 150 \\
\hline Depth (mbsf) & 293.5 & 293.59 & 293.7 & 293.79 & 293.9 & 294.1 & 294.32 & 294.5 & 294.7 & 294.87 & 295.1 & 295.3 \\
\hline P. bussonii & . & . & . & . & 1 & . & . & . & 1 & 2 & 2 & 2 \\
\hline P. fibuliformis & . & . & 3 & . & 2 & . & 1 & . & . & . & 2 & 1 \\
\hline P. sigmoides & . & 2 & 2 & . & 1 & 5 & 2 & . & . & . & . & . \\
\hline Placozygus sp. & 3 & 1 & . & . & . & 1 & 1 & 1 & 1 & 1 & . & . \\
\hline P. arkhangelskyi & 5 & 3 & 6 & 12 & 12 & 8 & 10 & 1 & 9 & 13 & 20 & 15 \\
\hline P. cretacea & 7 & 8 & 4 & 5 & 6 & 1 & 12 & . & 7 & 14 & 22 & 10 \\
\hline P. spinosa & 33 & 30 & 24 & 18 & 14 & 17 & 19 & 12 & 34 & 31 & 35 & 32 \\
\hline P. firthii & 15 & 16 & 14 & 16 & 11 & 10 & 11 & 4 & 10 & 30 & 26 & 8 \\
\hline Q. gartneri & . & . & . & . & . & . & . & . & . & . & . & . \\
\hline Reinhardtites spp. & 7 & 11 & 12 & 9 & 4 & 5 & 6 & 8 & 9 & 6 & 12 & 5 \\
\hline R. angustus & . & . & . & . & . & . & . & . & . & 1 & 1 & . \\
\hline Rhagodiscus spp. & . & . & . & . & . & . & . & . & . & . & . & . \\
\hline R. rhombicum & 6 & 1 & 2 & 1 & 1 & 1 & 3 & . & 6 & 2 & 2 & 6 \\
\hline S. asymmetrica & . & . & . & . & . & . & . & . & . & . & . & . \\
\hline S. wisei & . & . & . & . & . & . & . & . & . & . & . & . \\
\hline Scampanella spp. & . & . & . & . & . & . & . & . & $\mathbf{P}$ & . & . & . \\
\hline S. fossilis & 3 & 3 & . & 5 & . & . & 3 & . & 1 & 2 & 7 & 5 \\
\hline S. laffittei & 5 & 6 & 5 & 2 & 2 & 1 & 2 & 1 & 5 & 1 & 5 & 3 \\
\hline T. ethmos & $\mathbf{p}$ & . & . & $\mathbf{P}$ & . & . & . & 1 & . & $\mathrm{P}$ & . & 2 \\
\hline Thoracosph. spp. & 5 & 4 & 8 & 3 & 8 & 2 & 5 & 1 & 3 & 3 & 6 & 9 \\
\hline Vagalapilla spp. & 20 & 21 & 28 & 14 & 14 & 17 & 7 & 13 & 21 & 15 & 16 & 15 \\
\hline W. bamesae & . & . & . & 1 & . & . & . & 1 & . & . & 1 & 1 \\
\hline Z. compactus & . & . & . & . & . & . & . & . & . & . & . & . \\
\hline Z. diplogrammus & . & : & & 1 & . & . & 1 & . & $\therefore$ & . & $\therefore$ & . \\
\hline Unidentifiable & 7 & 16 & 6 & 8 & 21 & 10 & 22 & 14 & 21 & 22 & 22 & 15 \\
\hline Total (excl. P. stov.) & 405 & 422 & 380 & 373 & 387 & 367 & 376 & 374 & 413 & 482 & 510 & 446 \\
\hline P. stoveri & 12 & 1 & . & . & . & 1 & . & . & 1 & . & . & . \\
\hline Total (P. stov.count) & 417 & 423 & 380 & 373 & 387 & 368 & 376 & 374 & 414 & 482 & 510 & 446 \\
\hline P. stoveri, fields & 20.6 & 29.9 & 14.5 & 19.8 & 21.1 & 30.7 & 26.3 & 58.8 & 21.1 & 22.4 & 20.2 & 20.6 \\
\hline
\end{tabular}




\begin{tabular}{|c|c|c|c|c|c|c|c|c|c|c|c|}
\hline Sample Number & 118 & 119 & 120 & 121 & 122 & 123 & 124 & 125 & 126 & 127 & 128 \\
\hline Hole & $690 \mathrm{C}$ & $690 \mathrm{C}$ & $690 \mathrm{C}$ & $690 \mathrm{C}$ & $690 \mathrm{C}$ & $690 \mathrm{C}$ & $690 \mathrm{C}$ & $690 \mathrm{C}$ & $690 \mathrm{C}$ & $690 \mathrm{C}$ & $690 \mathrm{C}$ \\
\hline Core - Section & $20-4$ & $20-4$ & $20-4$ & $20-4$ & $20-4$ & $20-4$ & $20-4$ & $21-1$ & $21-4$ & $22-1$ & $22-4$ \\
\hline $\mathrm{cm}$ - level & 8.-9 & 31 & 50 & $70-71$ & $89-90$ & 109 & $115-116$ & $123-124$ & 121 & $46-47$ & $119-120$ \\
\hline Depth (mbsf) & 295.38 & 295.61 & 295.8 & 296 & 296.19 & 296.39 & 296.45 & 301.63 & 306.11 & 310.56 & 315.79 \\
\hline Sed. rate (m/m.y.) & 8.9 & 8.9 & 8.9 & 8.9 & 8.9 & 8.9 & 8.9 & 8.9 & 8.9 & 8.9 & 8.9 \\
\hline Age (Ma) & 72.719 & 72.745 & 72.766 & 72.788 & 72.810 & 72.832 & 72.839 & 73.422 & 73.925 & 74.425 & 75.013 \\
\hline Pres. (G, M, P) & M-P & M & M-G & $\mathrm{M}$ & $\mathrm{M}$ & M & $\mathrm{M}$ & G-M & M-P & M-P & P-M \\
\hline Abund. $(A, C, R)$ & A & A & A & A & A & A & A & A & A & C & C \\
\hline Fields counted & 26.3 & 20.2 & 19.3 & 20.2 & 21.1 & 34.2 & 21.1 & 25.5 & 30.7 & 55.3 & 47.4 \\
\hline mg sediment & 20.0 & 20.4 & 20.4 & 21.5 & 20.0 & 20.6 & 19.9 & 19.8 & 21.0 & 20.8 & 21.3 \\
\hline Carbonate (wt-\%) & 60.8 & 56.2 & 56.5 & 56.1 & 53.8 & 58 & 59.4 & 52.5 & 46.7 & 43.8 & 55 \\
\hline Beaker Constant & 2.7 & 2.7 & 2.7 & 2.7 & 2.7 & 2.7 & 2.7 & 2.7 & 2.7 & 2.7 & \\
\hline A. octoradiata & 30 & 52 & 47 & 52 & 52 & 52 & 32 & 65 & 65 & 17 & . \\
\hline A.cymbiformis & . & . & . & . & . & . & . & . & . & . & 3 \\
\hline A. cymbif./specill. & 3 & 2 & 3 & . & 2 & 1 & 1 & . & 1 & 1 & 1 \\
\hline A. specillata & 1 & . & 1 & . & . & 1 & 1 & . & . & . & . \\
\hline B. sparsus & . & . & . & . & . & . & . & . & . & . & . \\
\hline B. boletum & 5 & 3 & 5 & 3 & 1 & 1 & . & 4 & . & . & . \\
\hline B. constans & 24 & 17 & 9 & 21 & 18 & 12 & 23 & 20 & 34 & 11 & 4 \\
\hline B. coronum & . & . & . & . & . & . & . & . & $\mathbf{P}$ & . & 1 \\
\hline B. dissimilis & . & . & 1 & 2 & . & 1 & 2 & . & . & 2 & . \\
\hline B. magnum & 28 & 30 & 26 & 19 & 20 & 26 & 19 & 2 & 7 & 22 & . \\
\hline B. notaculum & 102 & 76 & 51 & 51 & 58 & 92 & 58 & 100 & 11 & 4 & 6 \\
\hline Biscutum sp. 1 & 1 & . & 3 & 1 & 1 & 2 & 1 & . & 2 & 3 & 6 \\
\hline Biscutum sp. 2 & 1 & . & 3 & 2 & 2 & 2 & . & 2 & . & . & . \\
\hline B. cf bevieri & 8 & 8 & 5 & 6 & 5 & 10 & 5 & 3 & . & . & . \\
\hline Broinsonia spp. & 2 & 5 & 6 & 2 & 3 & 2 & 5 & 2 & : & : & . \\
\hline C. barbata & 6 & 5 & 3 & 6 & 2 & 2 & 6 & 3 & 5 & 3 & . \\
\hline C. amphipons & . & . & . & . & . & 1 & . & . & . & . & . \\
\hline C. garrisonii & 10 & 4 & 9 & 5 & 11 & 6 & 3 & 25 & 3 & 1 & 2 \\
\hline Chiastozygus sp. 1 & 1 & . & . & 2 & . & 1 & 1 & 4 & 1 & . & . \\
\hline C. conicus & . & . & 1 & 1 & 9 & 2 & 1 & . & . & . & . \\
\hline C. crenulatus & . & . & . & . & . & . & . & . & . & . & . \\
\hline C. surirellus & 8 & 3 & 2 & 5 & . & 1 & . & 1 & 7 & 4 & $\mathbf{P}$ \\
\hline Cretarhabdus sp. 1 & . & 2 & . & 1 & 1 & . & 2 & 6 & 4 & . & . \\
\hline Cretarhabdus spp. & 5 & 4 & 5 & 3 & 1 & 4 & 2 & 1 & 7 & 3 & 2 \\
\hline C. daniae & . & . & . & . & . & . & . & . & . & . & . \\
\hline C. ehrenbergii & 5 & 4 & 5 & 3 & 1 & 4 & 6 & . & 5 & 6 & 5 \\
\hline Cruciplacolithus spp. & . & . & . & . & . & . & . & . & . & . & . \\
\hline Cyclagelosph. spp. & . & . & . & . & . & . & . & . & . & 1 & . \\
\hline Cylindralithus spp. & . & . & . & . & . & . & . & . & . & . & . \\
\hline D. ignotus & . & . & 1 & . & 1 & 2 & 1 & . & 1 & 1 & . \\
\hline E. trabeculatus & . & . & . & . & . & . & . & . & . & . & . \\
\hline E. turriseiffeli & 11 & 14 & 8 & 7 & 14 & 6 & 11 & 10 & 18 & 8 & 1 \\
\hline Gartnerago spp. & 4 & 3 & 6 & 5 & 4 & 4 & 5 & 8 & 4 & 1 & . \\
\hline G. fessus & . & . & . & . & . & . & . & . & . & . & . \\
\hline Homibrookina spp. & . & . & . & . & . & . & . & . & . & . & . \\
\hline K. magnificus & 11 & 16 & 13 & 14 & 9 & 12 & 20 & 7 & 7 & 3 & 12 \\
\hline Lapideacassis spp. & . & . & . & . & . & . & . & . & 1 & . & . \\
\hline L. camiolensis & . & . & . & . & . & . & . & . & . & . & . \\
\hline L. cayeuxii & 10 & 3 & 5 & 5 & 2 & 4 & 9 & 2 & 15 & 39 & 185 \\
\hline M. inversus & . & . & . & . & . & . & . & . & . & . & . \\
\hline M. decoratus & . & . & . & . & . & . & . & . & . & . & . \\
\hline M. staurophora & . & . & 1 & . & 1 & 1 & 1 & . & . & 4 & . \\
\hline M. pleniporus & . & . & . & 9 & . & . & . & 3 & . & . & . \\
\hline Misceomarg. sp. & . & . & . & . & . & . & . & . & . & . & 2 \\
\hline M. pectinatus & 1 & . & . & . & . & . & . & 2 & . & . & . \\
\hline M. quatemarius & 1 & 3 & 5 & 3 & 5 & 3 & 6 & . & . & . & . \\
\hline Monomarg. sp. & . & . & . & . & . & . & . & . & . & 1 & . \\
\hline Misceo/Monomg sp. & . & . & . & . & . & . & . & 1 & . & 1 & . \\
\hline N. watkinsii & 3 & 3 & . & 3 & . & 1 & 1 & 2 & . & . & 2 \\
\hline Neocrepidol. spp. & . & . & . & . & . & . & . & . & . & . & . \\
\hline N. corystus & 32 & 40 & 48 & 41 & 31 & 30 & 30 & 33 & 8 & . & . \\
\hline N. frequens & - & . & . & . & . & . & . & . & . & . & . \\
\hline O. magnus & . & . & 1 & . & . & . & . & 1 & 1 & . & . \\
\hline P. obscurus & 2 & 2 & 4 & 4 & 2 & 1 & 9 & 1 & . & 1 & . \\
\hline
\end{tabular}




\begin{tabular}{|c|c|c|c|c|c|c|c|c|c|c|c|}
\hline Sample Number & 118 & 119 & 120 & 121 & 122 & 123 & 124 & 125 & 126 & 127 & 128 \\
\hline Hole & $690 \mathrm{C}$ & $690 \mathrm{C}$ & $690 \mathrm{C}$ & $690 \mathrm{C}$ & $690 \mathrm{C}$ & $690 \mathrm{C}$ & $690 \mathrm{C}$ & $690 \mathrm{C}$ & $690 \mathrm{C}$ & $690 \mathrm{C}$ & $690 \mathrm{C}$ \\
\hline Core - Section & $20-4$ & $20-4$ & $20-4$ & $20-4$ & $20-4$ & $20-4$ & $20-4$ & $21-1$ & $21-4$ & $22-1$ & $22-4$ \\
\hline $\mathrm{cm}$ - level & $8 .-9$ & 31 & 50 & $70-71$ & $89-90$ & 109 & $115-116$ & $123-124$ & 121 & $46-47$ & $119-120$ \\
\hline Depth (mbsf) & 295.38 & 295.61 & 295.8 & 296 & 296.19 & 296.39 & 296.45 & 301.63 & 306.11 & 310.56 & 315.79 \\
\hline P. bussonii & 8 & 6 & 4 & 1 & 4 & . & 2 & 3 & 2 & 3 & . \\
\hline P. fibuliformis & . & . & 1 & 3 & 2 & 1 & 2 & . & 3 & 3 & 3 \\
\hline P. sigmoides & . & . & . & . & . & 1 & . & 2 & 4 & . & . \\
\hline Placozygus sp. & . & 2 & 5 & . & 2 & 1 & 2 & 1 & 1 & . & . \\
\hline P. arkhangelskyi & 10 & 17 & 14 & 8 & 7 & 7 & 5 & 18 & 21 & 4 & 7 \\
\hline P. cretacea & 7 & 3 & 1 & 1 & 5 & 5 & 2 & 20 & 15 & 22 & 12 \\
\hline P. spinosa & 32 & 33 & 33 & 45 & 35 & 35 & 51 & 41 & 64 & 66 & 8 \\
\hline P. firthii & 14 & 15 & 20 & 27 & 37 & 38 & 36 & . & . & . & . \\
\hline Q. gartneri & . & . & . & . & . & . & . & $\therefore$ & i & . & . \\
\hline Reinhardtites spp. & 8 & 5 & 5 & 9 & 7 & 12 & 6 & 18 & 17 & . & . \\
\hline R. angustus & . & . & . & . & . & . & . & . & . & . & · \\
\hline Rhagodiscus spp. & . & . & . & . & . & . & . & . & . & . & . \\
\hline R. hombicum & . & 8 & 3 & 2 & 1 & . & 2 & . & . & . & . \\
\hline S. asymmetrica & . & . & . & . & . & . & . & . & . & . & $\cdot$ \\
\hline S. wisei & . & . & . & . & . & . & . & . & . & . & . \\
\hline Scampanella spp. & . & . & . & . & . & . & . & . & . & . & . \\
\hline S. fossilis & 1 & 4 & 2 & 3 & 2 & 1 & . & 6 & 2 & . & . \\
\hline S. laffittei & 12 & 8 & 7 & 4 & 5 & 13 & 3 & 2 & ; & . & . \\
\hline T. ethmos & . & . & . & . & . & . & . & . & 1 & . & . \\
\hline Thoracosph. spp. & 5 & 7 & 13 & 10 & 9 & 7 & 10 & 17 & 19 & 5 & 2 \\
\hline Vagalapilla spp. & 15 & 30 & 22 & 32 & 18 & 23 & 15 & 44 & 48 & 9 & . \\
\hline W. bamesae & 3 & 5 & 2 & 1 & . & . & 3 & . & . & 1 & . \\
\hline Z compactus & . & . & . & 1 & . & . & & . & 7 & 1 & 4 \\
\hline Z. diplogrammus & . & . & . & 1 & . & 1 & 2 & . & . & . & . \\
\hline Unidentifiable & 19 & 24 & 19 & 16 & 18 & 8 & 13 & 12 & 15 & 10 & 11 \\
\hline Total (excl. P. stov.) & 449 & 466 & 428 & 440 & 408 & 440 & 415 & 492 & 426 & 261 & 279 \\
\hline P. stoveri & . & . & . & . & 5 & 8 & 15 & 21 & 31 & 93 & 16 \\
\hline Total (P. stov.count) & 449 & 466 & 428 & 440 & 413 & 448 & 430 & 513 & 457 & 354 & 295 \\
\hline P. stoveri, fields & 26.3 & 20.2 & 19.3 & 20.2 & 21.1 & 34.2 & 21.1 & 25.5 & 30.7 & 55.3 & 47.4 \\
\hline
\end{tabular}




$\begin{array}{lcccccccccc} & 1 & 2 & 3 & 4 & 5 & 6 & 7 & 8 & 9 & 10 \\ \text { ODP Hole 761 B } & 761 \mathrm{~B} & 761 \mathrm{~B} & 761 \mathrm{~B} & 761 \mathrm{~B} & 761 \mathrm{~B} & 761 \mathrm{~B} & 761 \mathrm{~B} & 761 \mathrm{~B} & 761 \mathrm{~B} & 761 \mathrm{~B} \\ \text { Core-Section } & 21-4 & 21-4 & 21-4 & 21-5 & 21-5 & 21-5 & 21-5 & 21-5 & 21-6 & 21-6 \\ \text { cm-level } & 130 & 140 & 145 & 10 & 45 & 80 & 115 & 150 & 11 & 45 \\ \text { Depth (mbsf) } & 176.00 & 176.10 & 176.15 & 176.30 & 176.65 & 177.00 & 177.35 & 177.70 & 177.81 & 178.15 \\ \text { Age (Ma) } & 66.403 & 66.409 & 66.412 & 66.422 & 66.445 & 66.468 & 66.491 & 66.514 & 66.521 & 66.543 \\ \text { Sedimentation Rate (m/m.y.) } & 15.32 & 15.32 & 15.32 & 15.32 & 15.32 & 15.32 & 15.32 & 15.32 & 15.32 & 15.32 \\ \text { Carbonate content (weight-\%) } & 82.7 & \text { n.d. } & 86.7 & 89.3 & \text { n.d. } & \text { n.d. } & \text { n.d. } & \text { n.d. } & 90 & \text { n.d. } \\ \text { Preservation } & \mathrm{M} & \mathrm{M} & \mathrm{M} & \mathrm{M} & \mathrm{M} & \mathrm{M} & \mathrm{M} & \mathrm{M} & \mathrm{M} & \mathrm{M} \\ \text { Abundance } & \mathrm{A} & \mathrm{A} & \mathrm{A} & \mathrm{A} & \mathrm{A} & \mathrm{A} & \mathrm{A} & \mathrm{A} & \mathrm{A} & \mathrm{A} \\ \text { Fields counted } & 20 & 20 & 20 & 20 & 20 & 20 & 20 & 20 & 20 & 20 \\ \text { mg sediment used } & 20.7 & 20.8 & 20.9 & 21 & 20.8 & 20.6 & 20.4 & 20.9 & 20.3 & 20.8\end{array}$

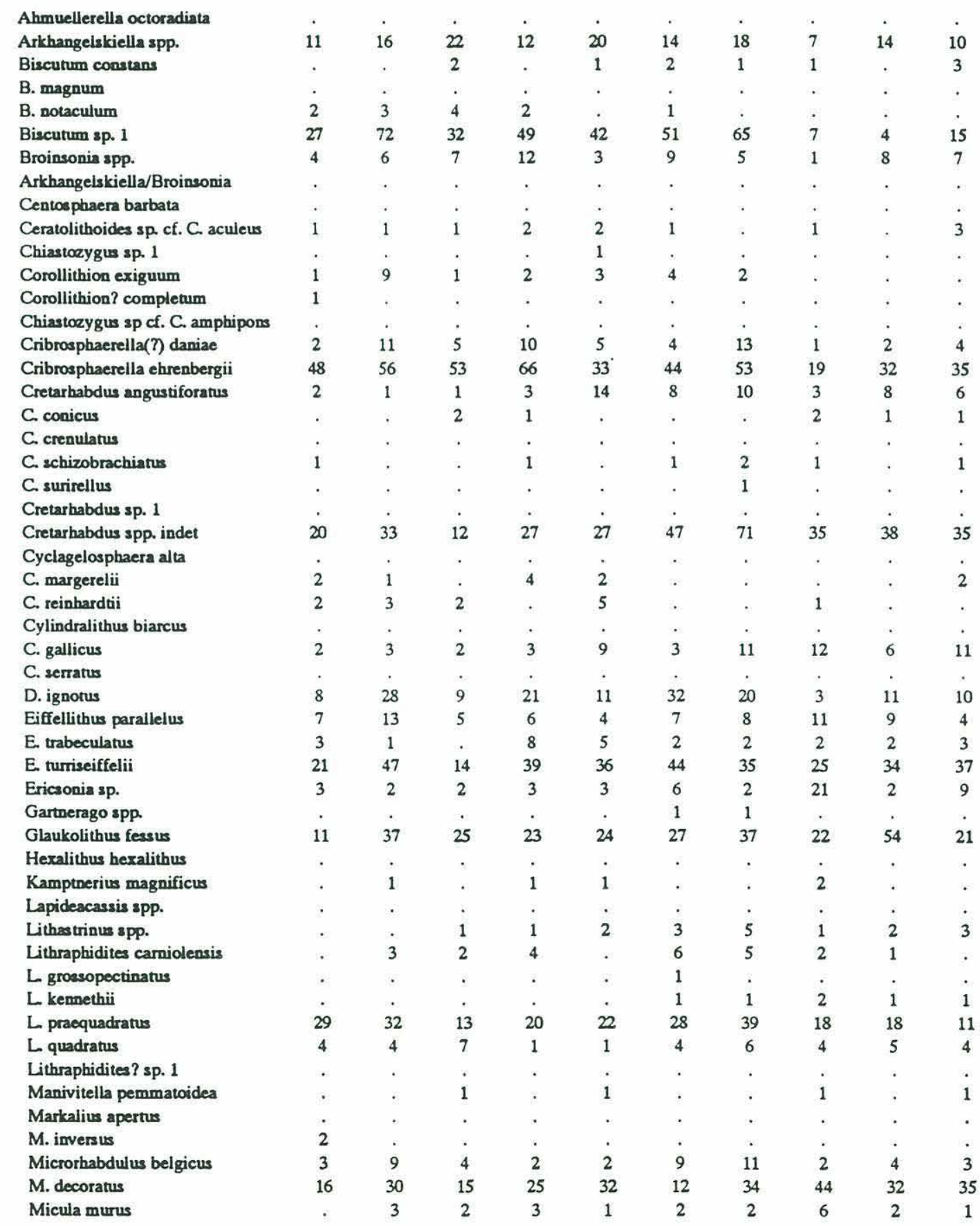




\begin{tabular}{|c|c|c|c|c|c|c|c|c|c|c|}
\hline & 1 & 2 & 3 & 4 & 5 & 6 & 7 & 8 & 9 & 10 \\
\hline ODP Hole 761 B & $761 \mathrm{~B}$ & $761 \mathrm{~B}$ & $761 \mathrm{~B}$ & $761 \mathrm{~B}$ & $761 \mathrm{~B}$ & $761 \mathrm{~B}$ & $761 \mathrm{~B}$ & $761 \mathrm{~B}$ & $761 \mathrm{~B}$ & $761 \mathrm{~B}$ \\
\hline Core-Section & $21-4$ & $21-4$ & $21-4$ & $21-5$ & 21.5 & $21-5$ & $21-5$ & 21.5 & $21-6$ & $21-6$ \\
\hline cm-level & 130 & 140 & 145 & 10 & 45 & 80 & 115 & 150 & 11 & 45 \\
\hline Depth (mbst) & 176.00 & 176.10 & 176.15 & 176.30 & 176.65 & 177.00 & 177.35 & 177.70 & 177.81 & 178.15 \\
\hline Micula? sp. & 5 & 1 & 3 & 4 & . & 5 & 1 & 2 & . & 1 \\
\hline Neocrepidolithus spp & . & . & . & . & . & . & . & . & . & . \\
\hline Nephrolithus frequens & 11 & 38 & 20 & 40 & 19 & 30 & 19 & 20 & 44 & 24 \\
\hline Parhabdolithus regularis & 13 & 14 & 11 & 12 & 9 & 24 & 31 & 19 & 37 & 17 \\
\hline Parhabdolithus sp. cf P. embergeri & . & . & . & . & . & 1 & . & 1 & . & 1 \\
\hline Petrarhabdus copulatus & - & . & : & $\cdot$ & . & · & . & · & . & . \\
\hline Placozygus bussonii & . & 1 & 1 & . & - & . & . & . & . & . \\
\hline Placozygus fibuliformis & 12 & 28 & 15 & 19 & 19 & 45 & 26 & 13 & 31 & 39 \\
\hline P. aigmoides & . & . & . & $\therefore$ & $\therefore$ & : & : & $\dot{0}$ & . & . \\
\hline Placozygus sp. & 10 & 16 & 9 & 19 & 12 & 3 & 5 & 3 & 1 & 1 \\
\hline Prediscosphaera arkhangelskyi & . & . & . & . & . & . & . & . & . & . \\
\hline P. cretacea & 94 & 117 & 104 & 112 & 128 & 110 & 141 & 151 & 84 & 145 \\
\hline P. grandis & 4 & 3 & 2 & 1 & 2 & $\therefore$ & 3 & . & 1 & 7 \\
\hline P. spinosa & 22 & 43 & 20 & 13 & 22 & 56 & 40 & 9 & 46 & 18 \\
\hline P. stoveri & 15 & 26 & 17 & 16 & 14 & 51 & 52 & 27 & 46 & 57 \\
\hline Quadrum gartneri & . & . & . & . & . & . & . & 1 & . & . \\
\hline Reinhardtites levis & . & . & . & . & . & . & : & . & . & . \\
\hline Rhagodiscus angustus & 1 & 2 & 3 & . & 1 & . & 2 & . & . & . \\
\hline R. reniformis & 3 & 5 & 3 & 4 & . & 1 & 5 & 1 & . & . \\
\hline R. splendens & 2 & . & 1 & 4 & 1 & 1 & 2 & 2 & . & . \\
\hline Rhagodiscus sp. 1 & . & . & . & . & · & · & $\cdot$ & · & . & · \\
\hline Rhagodiscus spp. indet. & . & $\therefore$ & . & : & · & · & · & · & . & $\cdot$ \\
\hline Rhombolithion rhombicum & . & 2 & . & 1 & . & . & . & . & . & . \\
\hline Scampanella spp. & . & . & . & . & . & $\cdot$ & . & . & . & . \\
\hline Scapholithus fossilis & . & . & . & . & . & . & . & . & . & . \\
\hline Staurolithites laffittei & . & . & . & . & . & . & . & . & . & . \\
\hline Stephanolithion spp. & 2 & 11 & 1 & 8 & 9 & 10 & 9 & 5 & 8 & 2 \\
\hline Tegumentum stradneri & . & . & . & . & . & . & . & . & . & 1 \\
\hline Teichorhabdus ethmos & . & . & . & . & . & . & . & . & . & . \\
\hline Tetrapodorhabdus decorus & 3 & 10 & 2 & 5 & . & 16 & 7 & 6 & 6 & 4 \\
\hline Thoracosphaera spp. & . & . & . & . & . & . & . & 2 & . & . \\
\hline Tranolithus macleodae & . & 1 & 1 & 1 & 1 & 3 & 3 & 3 & 2 & 2 \\
\hline T. phacelosus & . & . & . & . & : & . & . & . & . & . \\
\hline Vagalapilla spp. & 9 & 19 & 16 & 21 & 5 & 8 & . & 2 & 1 & 1 \\
\hline Watznaueria barnesae & 51 & 78 & 105 & 110 & 56 & 73 & 108 & 151 & 70 & 70 \\
\hline W. biporta & . & . & . & 1 & . & . & . & . & . & . \\
\hline Zygodiscus compactus & . & . & . & . & . & . & . & . & . & . \\
\hline Zygodiscus lacunatus & . & . & . & . & 1 & . & 2 & 1 & 2 & . \\
\hline Zygodiscus sp. 1 & 15 & 14 & 16 & 10 & 7 & . & 3 & . & 16 & 1 \\
\hline Unidentifiables & 7 & 8 & 8 & 2 & 5 & 10 & 10 & 10 & 12 & 8 \\
\hline Sum (excl. M. staurophora) & 819 & 1180.1 & 928.15 & 944.3 & 849.65 & 1084 & 1228.35 & 1021.7 & 894.81 & 908.15 \\
\hline Micula staurophora & 77 & 62 & 66 & 89 & 76 & 58 & 59 & 113 & 111 & 106 \\
\hline Sum of M. staurophora counts & 896 & 1242.1 & 994.15 & 1033.3 & 925.65 & 1142 & 1287.35 & 1134.7 & 1005.81 & 1014.15 \\
\hline Fields of M. staurophora counts & 20 & 20 & 20 & 20 & 20 & 20 & 20 & 20 & 20 & 20 \\
\hline
\end{tabular}




$\begin{array}{lccccccccccc} & 11 & 12 & 13 & 14 & 15 & 16 & 17 & 18 & 19 & 20 & 21 \\ \text { ODP Hole 761B } & 761 \mathrm{~B} & 761 \mathrm{~B} & 761 \mathrm{~B} & 761 \mathrm{~B} & 761 \mathrm{~B} & 761 \mathrm{~B} & 761 \mathrm{~B} & 761 \mathrm{~B} & 761 \mathrm{~B} & 761 \mathrm{~B} & 761 \mathrm{~B} \\ \text { Core-Section } & 21-6 & 21-6 & 21-\mathrm{CC} & 22-1 & 22-2 & 22-3 & 22-4 & 22-5 & 22-6 & 23-1 & 23-2 \\ \text { cm-level } & 80 & 101 & 31-32 & 80 & 80 & 80 & 79 & 70 & 56-57 & 70 & 72 \\ \text { Depth (mbsf) } & 178.50 & 178.71 & 179.70 & 180.50 & 182.00 & 183.50 & 184.99 & 186.40 & 187.76 & 189.90 & 191.42 \\ \text { Age (Ma) } & 66.566 & 66.580 & 66.644 & 66.696 & 66.900 & 67.190 & 67.477 & 67.750 & 68.012 & 68.425 & 68.719 \\ \text { Sed. Rate (m/m.y.) } & 15.32 & 15.32 & 15.32 & 15.32 & 5.18 & 5.18 & 5.18 & 5.18 & 5.18 & 5.18 & 5.18 \\ \text { WL.-\% Carbonate } & \text { n.d. } & \text { n.d. } & \text { n.d. } & 88.4 & \text { n.d. } & 86.5 & \text { n.d. } & 88.5 & \text { n.d. } & 91 & \text { n.d. } \\ \text { Preservation } & \mathrm{M} & \mathrm{M} & \mathrm{M} & \mathrm{M} & \mathrm{M} & \mathrm{M} & \mathrm{M} & \mathrm{M} & \mathrm{M} & \mathrm{M} & \mathrm{M} \\ \text { Abundance } & \mathrm{A} & \mathrm{A} & \mathrm{A} & \mathrm{A} & \mathrm{A} & \mathrm{A} & \mathrm{A} & \mathrm{A} & \mathrm{A} & \mathrm{A} & \mathrm{A} \\ \text { Fields counted } & 20 & 20 & 20 & 20 & 20 & 20 & 20 & 20 & 20 & 20 & 20 \\ \text { mg sediment used } & 21 & 19.5 & 19.9 & 19.5 & 19.8 & 20.8 & 20.7 & 20.1 & 19.1 & 19.6 & 20.2\end{array}$

\begin{tabular}{|c|c|c|c|c|c|c|c|c|c|c|c|}
\hline A. octoradiata & . & . & . & . & . & . & . & . & 10 & 1 & 2 \\
\hline Arkhangeiskiella spp. & 17 & 9 & 20 & 7 & 4 & 10 & 1 & . & 27 & 16 & 23 \\
\hline Biscutum constans & . & . & 3 & 1 & 19 & 20 & 34 & 24 & 24 & 41 & 14 \\
\hline B. magnum & . & . & . & . & . & . & . & . & . & . & . \\
\hline B. notaculum & . & . & 1 & . & 1 & . & 2 & 2 & . & . & . \\
\hline Biscutum sp. 1 & 21 & 25 & 19 & 71 & 26 & 10 & 8 & 8 & 3 & 8 & 6 \\
\hline Broinsonia spp. & 7 & 7 & 6 & 2 & . & 1 & . & . & 4 & 1 & 1 \\
\hline Arkhang./Broinsonia & - & . & . & $\cdot$ & . & . & . & . & . & $\cdot$ & . \\
\hline Centosphaera barbata & . & . & . & . & - & . & . & . & . & & . \\
\hline C. cf aculeus & 2 & 1 & 2 & . & 6 & 8 & 22 & 6 & 8 & 18 & 11 \\
\hline Chiastozygus sp. 1 & . & 1 & 4 & . & 5 & . & . & $\cdot$ & . & . & 1 \\
\hline Corollithion exiguum & . & 1 & . & . & . & . & . & . & . & $\cdot$ & $\cdot$ \\
\hline C.? completum & . & . & . & . & $\cdot$ & $\cdot$ & · & · & $\cdot$ & . & . \\
\hline C. cf amphipons & . & . & . & . & . & . & . & . & . & . & $\therefore$ \\
\hline C.(?) daniae & . & 3 & 3 & 2 & $\dot{.}$ & . & $\cdot$ & . & . & . & 1 \\
\hline C. ebrenbergii & 30 & 32 & 37 & 43 & 55 & 30 & 38 & 34 & 20 & 31 & 20 \\
\hline C. angustiforatus & 14 & 7 & 6 & 6 & 4 & 5 & 3 & 9 & 10 & 4 & 4 \\
\hline C. conicus & 1 & 3 & . & 1 & 1 & : & $\dot{0}$ & 2 & . & 1 & 1 \\
\hline C. crenulatus & . & . & . & . & 1 & 1 & 7 & . & . & . & . \\
\hline C. schizobrachiatus & . & . & . & : & 2 & . & 2 & 2 & . & 2 & 2 \\
\hline C. surirellus & . & . & · & 1 & . & . & . & . & . & . & . \\
\hline Cretarhabdus sp. 1 & $\therefore$ & . & . & . & . & . & . & . & . & . & . \\
\hline Cretarhabdus spp. indet & 75 & 30 & 29 & 41 & 61 & 39 & 34 & 41 & 62 & 65 & 49 \\
\hline C. alta & . & . & : & : & . & . & : & . & . & . & . \\
\hline C. margerelii & . & 4 & 4 & 4 & 4 & 5 & 3 & 1 & 3 & 4 & 4 \\
\hline C. reinhardtii & 1 & . & 1 & $\cdot$ & . & . & 2 & 2 & 4 & . & 3 \\
\hline C. biarcus & . & . & . & : & . & $\therefore$ & : & - & . & : & . \\
\hline C. gallicus & 11 & 14 & 11 & 10 & . & 5 & 1 & . & 2 & 2 & 4 \\
\hline C. serratus & $\therefore$ & . & $\therefore$ & $\dot{0}$ & . & $\therefore$ & $\therefore$ & . & $\therefore$ & $\therefore$ & i \\
\hline D. ignotus & 13 & 29 & 22 & 29 & 18 & 14 & 15 & 17 & 23 & 31 & 75 \\
\hline E. parallelus & 6 & 8 & 4 & 6 & 9 & 12 & 6 & 6 & 19 & 30 & 26 \\
\hline E. trabeculatus & 4 & 9 & 2 & 1 & 5 & . & 3 & 2 & 13 & 6 & 7 \\
\hline E. turriseiffelii & 43 & 21 & 15 & 19 & 27 & 10 & 14 & 23 & 26 & 26 & 21 \\
\hline Ericsonia sp. & 5 & 2 & 4 & 2 & 1 & 1 & 8 & 8 & 8 & 17 & 4 \\
\hline Gartnerago spp. & . & . & . & 2 & . & - & . & . & . & . & . \\
\hline G. fessus & 26 & 26 & 39 & 42 & 12 & 7 & 8 & 6 & 21 & 45 & 42 \\
\hline H. hexalithus & $\dot{0}$ & : & · & . & · & · & $\cdot$ & $\cdot$ & · & $\cdot$ & $\cdot$ \\
\hline K. magnificus & 2 & 1 & . & . & . & . & . & . & . & . & . \\
\hline Lapideacassis spp. & $\cdot$ & : & $\cdot$ & ; & $\cdot$ & ; & : & $\cdot$ & : & : & 1 \\
\hline Lithas trinus spp. & . & 5 & . & 6 & 4 & 1 & 1 & . & 1 & 1 & . \\
\hline L carniolensis & . & 2 & 1 & 4 & 3 & . & 6 & 6 & 2 & 2 & . \\
\hline L groseopectinatus & . & 1 & . & . & : & $\cdot$ & $\cdot$ & $\cdot$ & . & . & $\cdot$ \\
\hline L kennethii & . & . & - & . & 1 & $\therefore$ & . & . & . & . & . \\
\hline L praequadratus & 25 & 23 & 8 & 24 & 44 & 17 & 45 & 11 & 18 & 21 & 29 \\
\hline L quadratus & 3 & 3 & 2 & 4 & 9 & $\cdot$ & 7 & 1 & 3 & $\cdot$ & 4 \\
\hline Lithraphidites? sp. 1 & . & . & . & . & $\dot{0}$ & $\cdot$ & $\cdot$ & $\dot{s}$ & . & $\cdot$ & $\cdot$ \\
\hline M. pemmatoidea & . & . & . & : & 3 & $\cdot$ & $\cdot$ & 2 & 1 & $\cdot$ & $\cdot$ \\
\hline M. apertus & . & . & : & 1 & . & : & . & $\cdot$ & . & $\cdot$ & $\cdot$ \\
\hline M. inversus & . & $\dot{0}$ & 1 & $\dot{s}$ & $\dot{s}$ & 1 & $\cdot$ & : & . & $\cdot$ & $\cdot$ \\
\hline M. belgicus & 4 & 5 & 2 & 7 & 2 & 1 & 1 & 5 & 2 & 1 & 1 \\
\hline M. decoratus & 53 & 31 & 28 & 37 & 16 & 18 & 9 & 19 & 16 & 13 & 21 \\
\hline Micula murus & 4 & 2 & 9 & 1 & . & . & . & . & . & . & . \\
\hline
\end{tabular}




$\begin{array}{lccccccccccc} & 11 & 12 & 13 & 14 & 15 & 16 & 17 & 18 & 19 & 20 & 21 \\ \text { ODP Hole 761B } & 761 \mathrm{~B} & 761 \mathrm{~B} & 761 \mathrm{~B} & 761 \mathrm{~B} & 761 \mathrm{~B} & 761 \mathrm{~B} & 761 \mathrm{~B} & 761 \mathrm{~B} & 761 \mathrm{~B} & 761 \mathrm{~B} & 761 \mathrm{~B} \\ \text { Core-Section } & 21-6 & 21-6 & 21-\mathrm{CC} & 22-1 & 22-2 & 22-3 & 22-4 & 22-5 & 22-6 & 23-1 & 23-2 \\ \text { cm-level } & 80 & 101 & 31-32 & 80 & 80 & 80 & 79 & 70 & 56-57 & 70 & 72 \\ \text { Depth (mbsf) } & 178.50 & 178.71 & 179.70 & 180.50 & 182.00 & 183.50 & 184.99 & 186.40 & 187.76 & 189.90 & 191.42\end{array}$

\begin{tabular}{|c|c|c|c|c|c|c|c|c|c|c|c|}
\hline Micula? sp. & 1 & 2 & 3 & . & . & 1 & . & . & . & . & . \\
\hline Neocrepidolithus spp. & . & . & . & . & . & . & . & . & . & . & . \\
\hline N. frequens & 6 & 30 & 14 & 21 & 1 & 2 & . & . & . & 3 & . \\
\hline P. regularis & 40 & 20 & 14 & 24 & 26 & 6 & 24 & 22 & 43 & 70 & 48 \\
\hline P. cf embergeri & . & . & . & . & . & . & . & . & 1 & . & 1 \\
\hline P. copulatus & . & . & . & . & . & . & . & . & . & . & . \\
\hline P. bussonii & . & . & . . & . & . & . & . & . & 1 & . & . \\
\hline P. fibuliformis & 68 & 37 & 56 & 76 & 35 & 15 & 72 & 51 & 57 & 49 & 43 \\
\hline P. sigmoides & . & . & . & . & . & . & . & . & 1 & . & . \\
\hline Placozygus sp. & 2 & 1 & 2 & 7 & 6 & 4 & 4 & 4 & 13 & 4 & 6 \\
\hline P. arkhangelskyi & $\cdot$ & . & . & . & . & . & . & . & . & . & . \\
\hline P. cretacea & 160 & 142 & 127 & 186 & 174 & 124 & 166 & 185 & 152 & 175 & 212 \\
\hline P. grandis & 3 & . & . & 2 & 1 & 2 & . & . & . & . & 1 \\
\hline P. spinosa & 11 & 24 & 23 & 25 & 29 & 16 & 25 & 23 & 28 & 41 & 47 \\
\hline P. stoveri & 46 & 39 & 31 & 69 & 55 & 19 & 29 & 73 & 66 & 65 & 57 \\
\hline Q. gartneri & . & . & . & . & . & . & . & . & . & . & 1 \\
\hline R. levis & . & . & . & . & . & . & . & . & . & . & . \\
\hline$R$. angustus & . & . & . & 1 & . & . & . & . & . & 1 & 1 \\
\hline R. reniformis & . & 1 & 1 & 3 & 3 & 3 & . & 1 & . & 4 & 1 \\
\hline R. splendens & 1 & 1 & . & 1 & 4 & 1 & 4 & 3 & 5 & 3 & 6 \\
\hline Rhagodiscus sp. 1 & . & . & . & . & . & . & . & . & . & . & . \\
\hline Rhagodiscus spp. indet. & . & . & . & . & . & . & . & . & . & . & . \\
\hline R. rhombicum & . & . & . & . & . & . & . & . & . & 1 & . \\
\hline Scampanella spp. & . & . & . & . & . & . & . & . & . & . & . \\
\hline S. fossilis & . & . & . & . & . & . & . & . & . & 1 & 1 \\
\hline S. laffittei & . & . & . & . & . & . & . & . & . & . & . \\
\hline Stephanolithion spp. & 5 & 11 & 1 & 7 & 11 & 1 & 11 & 14 & 18 & 9 & 4 \\
\hline T. stradneri & . & . & . & . & . & . & . & . & . & . & . \\
\hline T. ethmos & . & . & . & . & . & . & . & . & 1 & . & . \\
\hline T. decorus & 7 & 13 & 8 & 7 & 3 & 8 & 2 & 6 & 6 & 13 & 8 \\
\hline Thoracosphaera spp. & . & . & . & . & 1 & . & . & . & . & 1 & 1 \\
\hline T. macleodae & 1 & 2 & 9 & . & 2 & 2 & 3 & 3 & 5 & 17 & 6 \\
\hline T. phacelosus & . & . & . & . & . & . & . & . & . & . & . \\
\hline Vagalapilla spp. & 6 & 4 & 7 & 1 & 2 & 2 & 3 & . & . & . & 1 \\
\hline W. barnesae & 85 & 101 & 124 & 53 & 43 & 31 & 52 & 46 & 39 & 41 & 52 \\
\hline W. biporta & 1 & . & 2 & . & . & $\therefore$ & & . & . & . & . \\
\hline Z. compactus & . & . & . & . & . & . & . & . & . & . & . \\
\hline Z. lacunatus & 3 & . & . & . & . & . & 1 & . & . & . & . \\
\hline Zygodiscus sp. 1 & 5 & 2 & 13 & 7 & 12 & 2 & 9 & 2 & 4 & 1 & 2 \\
\hline Unidentifiables & 10 & 3 & 8 & 11 & 11 & 1 & 11 & 3 & 9 & 12 & 6 \\
\hline Sum (excl. M. stauroph.) & 1097.5 & 1029.71 & 918.7 & 1149.5 & 1039 & 735.5 & 976.99 & 947.4 & 985.76 & 1177.9 & 1166.42 \\
\hline Micula staurophora & 118 & 57 & 77 & 84 & 125 & 85 & 125 & 74 & 90 & 65 & 67 \\
\hline Sum of M. staur. counts & 1215.5 & 1086.71 & 995.7 & 1233.5 & 1164 & 820.5 & 1101.99 & 1021.4 & 1075.76 & 1242.9 & 1233.42 \\
\hline Fields of M. staur. counts & 20 & 20 & 20 & 20 & 20 & 20 & 20 & 20 & 20 & 20 & 20 \\
\hline
\end{tabular}




\begin{tabular}{|c|c|c|c|c|c|c|c|c|c|c|c|}
\hline & 22 & 23 & 24 & 25 & 26 & 27 & 28 & 29 & 30 & 31 & 32 \\
\hline ODP Hole 761B & $761 \mathrm{~B}$ & $761 \mathrm{~B}$ & $761 \mathrm{~B}$ & $761 \mathrm{~B}$ & $761 \mathrm{~B}$ & $761 \mathrm{~B}$ & $761 \mathrm{~B}$ & $761 \mathrm{~B}$ & $761 \mathrm{~B}$ & $761 \mathrm{~B}$ & $761 \mathrm{~B}$ \\
\hline Core-Section & $23-3$ & $23-3$ & $23-3$ & $23-3$ & $23 \cdot 3$ & $23-3$ & $23-3$ & $23-3$ & $23-4$ & $23-5$ & $24-1$ \\
\hline cm-level & 10 & 30 & 50 & 70 & 90 & 110 & 130 & 150 & 70 & 80 & $98-99$ \\
\hline Depth (mbst) & 192.30 & 192.50 & 192.70 & 192.90 & 193.10 & 193.30 & 193.50 & 193.70 & 194.40 & 196.00 & 199.68 \\
\hline Age (Ma) & 68.889 & 68.927 & 68.966 & 69.004 & 69.043 & 69.082 & 69.120 & 69.159 & 69.294 & 69.603 & 70.313 \\
\hline Sed. Rate (m/m.y.) & 5.18 & 5.18 & 5.18 & 5.18 & 5.18 & 5.18 & 5.18 & 5.18 & 5.18 & 5.18 & 5.18 \\
\hline Wt-\% Carbonate & 89.9 & n.d. & n.d. & n.d. & n.d. & 89 & n.d. & n.d. & n.d. & n.d. & 83.5 \\
\hline Preservation & M & M & M & M & M & M & M & M & M & M & M \\
\hline Abundance & A & A & A & A & A & A & A & A & A & A & A \\
\hline Fields counted & 20 & 20 & 20 & 20 & 20 & 20 & 20 & 20 & 20 & 20 & 20 \\
\hline mg rediment used & 19.8 & 20.5 & 20.1 & 18.9 & 20.5 & 20 & 20.1 & 20 & 20 & 18.9 & 19.1 \\
\hline A. octoradiata & . & 1 & 1 & . & 2 & . & . & . & 2 & 12 & 2 \\
\hline Arkhangeiskiella spp. & 8 & 5 & 4 & 6 & 3 & 6 & 7 & 2 & 17 & 10 & 41 \\
\hline Biscutum constans & 65 & 35 & 36 & 25 & 22 & 22 & 14 & 47 & 36 & 19 & 40 \\
\hline B. magnum & . & . & . & . & . & . & . & . & . & . & . \\
\hline B. notaculum & 1 & 1 & . & 1 & 2 & . & . & . & . & 1 & . \\
\hline Biscutum sp. 1 & 11 & 16 & 16 & 5 & 22 & 19 & 26 & 21 & 17 & 5 & 2 \\
\hline Broinsonia spp. & 2 & . & 1 & 1 & . & 1 & 2 & . & . & . & . \\
\hline Arkhang./Broinsonia & . & . & . & . & . & . & . & . & . & . & . \\
\hline Centos phaera barbata & . & . & 1 & . & 1 & . & . & - & . & - & . \\
\hline C. cf aculeus & 14 & 8 & 17 & 8 & 14 & 9 & 10 & 18 & 11 & 17 & 15 \\
\hline Chiastozygus sp. 1 & . & - & 2 & . & . & . & . & 2 & . & - & 1 \\
\hline Corollithion exiguum & . & . & . & . & - & . & . & . & 1 & 1 & . \\
\hline C. 2 completum & . & 1 & . & . & . & . & . & . & . & . & . \\
\hline C. cf amphipons & . & . & . & . & . & . & . & . & . & . & . \\
\hline C.(?) daniae & . & . & 2 & . & . & - & . & . & . & . & . \\
\hline C. ebrenbergii & 33 & 30 & 46 & 22 & 29 & 22 & 24 & 35 & 30 & 23 & 32 \\
\hline C. angustiforatus & 1 & 6 & 1 & 1 & 1 & 2 & 3 & 1 & 13 & . & 6 \\
\hline C. conicus & 1 & . & 1 & . & 1 & . & 2 & 2 & 1 & 1 & 3 \\
\hline C. crenulatus & . & . & . & . & . & . & . & . & . & . & . \\
\hline C. schizobrachiatus & 1 & 1 & 1 & 1 & 2 & 1 & . & . & . & . & 3 \\
\hline C. surirellus & . & · & . & . & · & . & . & . & . & . & . \\
\hline Cretarhabdus sp. 1 & . & . & . & . & . & . & . & . & . & . & . \\
\hline Cretarhabdus spp. indet & 24 & 38 & 35 & 38 & 36 & 38 & 30 & 21 & 63 & 31 & 31 \\
\hline C. alta & . & : & . & . & . & . & : & : & . & . & . \\
\hline C. margerelii & . & 2 & 3 & 1 & 1 & 2 & 2 & 2 & 11 & 1 & . \\
\hline C. reinhardtii & . & . & . & . & 2 & . & . & 1 & . & 2 & 1 \\
\hline C. biarcus & . & . & . & . & : & . & . & : & · & . & 1 \\
\hline C. gallicus & 5 & 2 & 8 & 1 & 3 & 7 & 2 & 2 & . & . & 2 \\
\hline C. serratus & . & . & . & . & 1 & . & . & . & . & . & . \\
\hline D. ignotus & 46 & 22 & 38 & 32 & 21 & 19 & 18 & 24 & 45 & 87 & 21 \\
\hline E. parallelus & 23 & 14 & 6 & 16 & 13 & 20 & 13 & 5 & 14 & 6 & 8 \\
\hline E trabeculatus & 2 & 4 & 4 & 3 & 6 & 3 & 4 & . & 5 & 4 & . \\
\hline E. turriseiffelii & 17 & 21 & 5 & 8 & 18 & 9 & 18 & 15 & 22 & 25 & 18 \\
\hline Ericsonia sp. & 2 & . & . & 6 & 3 & . & 2 & 3 & 9 & 3 & 3 \\
\hline Gartnerago spp. & . & . & . & . & . & . & . & . & . & . & . \\
\hline G. fessus & 36 & 40 & 16 & 15 & 21 & 28 & 79 & 61 & 6 & 5 & 12 \\
\hline H. hexalithus & . & . & . & . & . & . & . & . & . & . & . \\
\hline K. magnificus & . & . & . & . & . & . & . & 1 & . & . & . \\
\hline Lapideacassis spp. & . & . & . & . & . & . & . & . & . & . & . \\
\hline Lithastrinus spp. & . & . & 3 & 3 & 1 & . & 5 & 1 & 1 & . & . \\
\hline L carniolensis & 3 & . & . & 2 & 1 & . & 2 & 4 & 3 & 1 & 8 \\
\hline L groseopectinatus & : & . & . & . & . & . & . & . & . & . & . \\
\hline L. kennethii & 1 & . & . & . & . & . & . & . & . & . & . \\
\hline L praequadratus & 14 & 40 & 18 & 18 & 18 & 17 & 14 & 23 & 1 & . & . \\
\hline L quadratus & 2 & 1 & 3 & . & . & . & . & 1 & . & . & . \\
\hline Lithraphidites? sp. 1 & . & . & . & 2 & 1 & 1 & 3 & . & . & . & . \\
\hline M. pemmatoidea & . & 2 & 8 & 2 & 3 & . & 1 & 1 & 1 & 2 & 1 \\
\hline M. apertus & . & . & . & . & . & . & : & . & . & . & . \\
\hline M. inversus & . & . & . & . & . & . & 1 & . & . & . & . \\
\hline M. belgicus & 1 & 5 & . & 3 & 2 & 4 & . & . & . & 1 & . \\
\hline M. decoratus & 24 & 23 & 12 & 18 & 16 & 31 & 6 & 9 & 47 & 84 & 21 \\
\hline Micula murus & . & . & . & . & . & . & . & . & . & . & . \\
\hline
\end{tabular}




$\begin{array}{lccccccccccc} & 22 & 23 & 24 & 25 & 26 & 27 & 28 & 29 & 30 & 31 & 32 \\ \text { ODP Hole 761B } & 761 \mathrm{~B} & 761 \mathrm{~B} & 761 \mathrm{~B} & 761 \mathrm{~B} & 761 \mathrm{~B} & 761 \mathrm{~B} & 761 \mathrm{~B} & 761 \mathrm{~B} & 761 \mathrm{~B} & 761 \mathrm{~B} & 761 \mathrm{~B} \\ \text { Core-Section } & 23-3 & 23-3 & 23-3 & 23-3 & 23-3 & 23-3 & 23-3 & 23-3 & 23-4 & 23-5 & 24-1 \\ \text { cm-level } & 10 & 30 & 50 & 70 & 90 & 110 & 130 & 150 & 70 & 80 & 98-99 \\ \text { Depth (mbst) } & 192.30 & 192.50 & 192.70 & 192.90 & 193.10 & 193.30 & 193.50 & 193.70 & 194.40 & 196.00 & 199.68\end{array}$

Micula? sp.

Neocrepidolithus spp.

$\mathrm{N}$. frequens

P. regularis

P. cf embergeri

P. copulatus

P. bussonii

P. fibuliformis

P. sigmoides

Placozygus sp.

P. arkhangeiskyi

P. cretacea

P. grandis

P. spinosa

P. stoveri

Q. gartmeri

R. levis

$R$. angustus

$R$. reniformis

R. splendens

Rhagodiscus sp. 1

Rhagodiscus spp. indet.

R. thombicum

Scampanella spp.

S. fossilis

S. laffittei

Stephanolithion spp.

T. stradneri

T. ethmos

T. decorus

Thoracosphaera spp.

T. macleodae

T. phacelosus

Vagalapilla spp.

W. barnesae

W. biporta

Z. compactus

$Z$ lacunatus

Zygodiscus sp. 1

Unidentifiables

Sum (excl. M. stauroph.)

Micula staumopor

Sum of M. staur counts

Fields of M. staur. counts

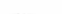

.

\begin{abstract}
.
\end{abstract}




\begin{tabular}{|c|c|c|c|c|c|c|c|c|c|c|}
\hline & 33 & 34 & 35 & 36 & 37 & 38 & 39 & 40 & 41 & 42 \\
\hline ODP Hole 761B & $761 \mathrm{~B}$ & $761 \mathrm{~B}$ & $761 \mathrm{~B}$ & $761 \mathrm{~B}$ & $761 \mathrm{~B}$ & $761 \mathrm{~B}$ & $761 \mathrm{~B}$ & $761 \mathrm{~B}$ & $761 \mathrm{~B}$ & $761 \mathrm{~B}$ \\
\hline Core-Section & $24-2$ & $24-3$ & $24-4$ & $24-4$ & $24-4$ & $24-4$ & $24-4$ & $24-4$ & $24-4$ & $24-4$ \\
\hline cm-level & 80 & 80 & 10 & $31-32$ & $49-50$ & 70 & 80 & 90 & 110 & 130 \\
\hline Depth (mbsf) & 201.00 & 202.50 & 203.30 & 203.51 & 203.69 & 203.90 & 204.00 & 204.10 & 204.30 & 204.50 \\
\hline Age (Ma) & 70.568 & 70.858 & 71.012 & 71.053 & 71.087 & 71.128 & 71.147 & 71.167 & 71.205 & 71.244 \\
\hline Sed. Rate (m/m.y.) & 5.18 & 5.18 & 5.18 & 5.18 & 5.18 & 5.18 & 5.18 & 5.18 & 5.18 & 5.18 \\
\hline Wt-\% Carbonate & 81.8 & 88.3 & n.d. & 87.4 & n.d. & n.d. & 88.1 & n.d. & n.d. & 90 \\
\hline Preservation & M & $M$ & M & $M$ & $M$ & $M$ & M & $M$ & $M$ & $M$ \\
\hline Abundance & A & A & A & A & A & A & A & A & A & A \\
\hline Fields counted & 30 & 20 & 30 & 30 & 30 & 20 & 20 & 30 & 20 & 20 \\
\hline mg sediment used & 20.5 & 18.7 & 20.7 & 20.3 & 20.4 & 19.9 & 19.2 & 19.7 & 20.3 & 20.1 \\
\hline A. octoradiata & 2 & 1 & . & . & . & 3 & 1 & 1 & . & 1 \\
\hline Arkhangelskiella spp. & 31 & 19 & 34 & 41 & 30 & 12 & 19 & 12 & 4 & 3 \\
\hline Biscutum constans & 11 & 25 & 31 & 16 & 29 & 25 & 30 & 17 & 17 & 24 \\
\hline B. magnum & . & . & . & . & . & . & . & . & . & . \\
\hline B. notaculum & 2 & 1 & . & . & 1 & . & . & . & . & . \\
\hline Biscutum sp. 1 & . & 2 & 1 & 9 & 1 & 17 & 17 & 1 & 6 & 3 \\
\hline Broinsonia spp. & 3 & 2 & . & . & . & . & 1 & . & . & . \\
\hline Arkhang./Broinsonia & . & . & . & . & . & . & . & . & . & . \\
\hline Centosphaera barbata & . & . & . & . & . & . & . & . & . & . \\
\hline C. cf aculeus & 51 & 13 & 33 & 26 & 12 & 7 & 12 & 15 & 15 & 23 \\
\hline Chiastozygus sp. 1 & . & . & . & . & . & . & . & . & . & . \\
\hline Corollithion exiguum & . & . & . & . & . & . & . & . & . & . \\
\hline C.? completum & . & . & . & . & . & . & . & . & . & . \\
\hline C. cf amphipons & . & . & . & . & . & . & . & . & . & . \\
\hline C.(?) daniae & . & 1 & . & . & . & . & . & . & . & . \\
\hline C. ehrenbergii & 45 & 34 & 54 & 64 & 56 & 45 & 25 & 34 & 48 & 33 \\
\hline C. angustiforatus & 10 & 19 & 14 & 2 & 14 & 11 & 8 & 13 & 8 & 7 \\
\hline C. conicus & 5 & 1 & 4 & 1 & 3 & 3 & 2 & 3 & 5 & . \\
\hline C. crenulatus & . & . & . & . & . & . & . & . & . & . \\
\hline C. schizobrachiatus & . & . & . & 2 & . & . & . & . & . & . \\
\hline C. surirellus & . & . & . & . & . & . & . & . & . & . \\
\hline Cretarhabdus sp. 1 & . & . & . & . & . & . & . & . & . & . \\
\hline Cretarhabdus spp. indet & 56 & 29 & 54 & 37 & 30 & 20 & 35 & 13 & 33 & 15 \\
\hline C. alta & . & . & . & . & . & . & . & . & . & . \\
\hline C. margerelii & 1 & 1 & 1 & 1 & 4 & . & 6 & 1 & 3 & 1 \\
\hline C. reinhardtii & 1 & 2 & 2 & . & 2 & 1 & 1 & . & . & . \\
\hline C. biarcus & . & . & . & . & . & . & . & . & . & . \\
\hline C. gallicus & . & . & 1 & . & 4 & 1 & . & . & . & . \\
\hline C. serratus & 3 & 7 & 3 & 4 & 2 & 2 & 9 & 11 & 4 & 13 \\
\hline D. ignotus & 12 & 15 & 4 & 14 & 11 & 42 & 11 & 8 & 16 & 7 \\
\hline E. parallelus & 2 & 3 & 4 & 7 & . & 6 & 3 & 1 & 2 & 5 \\
\hline E. trabeculatus & . & . & . & . & . & 6 & 1 & 1 & 1 & . \\
\hline E. turriseiffelii & 10 & 21 & 6 & 8 & 9 & 12 & 23 & 10 & 26 & 18 \\
\hline Ericsonia sp. & 14 & 2 & 7 & . & 2 & 4 & 6 & 12 & 6 & 5 \\
\hline Gartnerago spp. & . & . & . & . & . & . & . & . & . & . \\
\hline G. fessus & . & 12 & 6 & 4 & 3 & 7 & 4 & 1 & 2 & 2 \\
\hline H. hexalithus & . & . & . & . & . & . & . & . & . & . \\
\hline K. magnificus & . & . & . & . & . & . & . & 1 & . & . \\
\hline Lapideacassis spp. & 1 & . & . & . & . & . & . & . & . & . \\
\hline Lithas trinus spp. & . & 1 & 2 & 4 & 4 & . & . & . & 1 & 4 \\
\hline L carniolensis & 4 & 5 & 5 & 7 & 3 & . & 4 & . & 1 & . \\
\hline L grossopectinatus & . & . & . & . & . & . & . & . & . & . \\
\hline L. kennethii & . & . & . & . & . & . & . & . & . & . \\
\hline L praequadratus & . & . & . & . & . & . & . & . & . & . \\
\hline L quadratus & . & . & . & . & . & . & . & . & . & . \\
\hline Lithraphidites? sp. 1 & . & . & . & . & . & . & . & . & . & . \\
\hline M. pemmatoidea & 4 & 1 & 3 & 5 & 6 & 2 & 3 & 8 & 4 & 4 \\
\hline M. apertus & . & . & . & . & . & . & . & . & . & . \\
\hline M. inversus & 1 & . & 1 & . & . & . & . & . & . & . \\
\hline M. belgicus & 2 & . & 2 & 1 & . & 2 & 1 & . & 1 & . \\
\hline M. decoratus & 24 & 37 & 16 & 8 & 18 & 11 & 16 & 9 & 27 & 15 \\
\hline Micula murus & . & . & . & . & . & . & . & . & . & . \\
\hline
\end{tabular}




$\begin{array}{lcccccccccc} & 33 & 34 & 35 & 36 & 37 & 38 & 39 & 40 & 41 & 42 \\ \text { ODP Hole 761B } & 761 \mathrm{~B} & 761 \mathrm{~B} & 761 \mathrm{~B} & 761 \mathrm{~B} & 761 \mathrm{~B} & 761 \mathrm{~B} & 761 \mathrm{~B} & 761 \mathrm{~B} & 761 \mathrm{~B} & 761 \mathrm{~B} \\ \text { Core-Section } & 24-2 & 24-3 & 24-4 & 24-4 & 24-4 & 24-4 & 24-4 & 24-4 & 24-4 & 24-4 \\ \text { cm-level } & 80 & 80 & 10 & 31-32 & 49-50 & 70 & 80 & 90 & 110 & 130 \\ \text { Depth (mbsf) } & 201.00 & 202.50 & 203.30 & 203.51 & 203.69 & 203.90 & 204.00 & 204.10 & 204.30 & 204.50\end{array}$

Micula? sp.

Neocrepidolithus spp.

N. frequens

P. regularis

P. cf embergeri

P. copulatus

P. bussonii

P. fibuliformis

P. sigmoides

Placozygus sp.

P. arkhangelskyi

P. cretacea

P. grandis

P. spinosa

P. stoveri

Q. garmeri

R. levis

$R$. angustus

R. reniformis

$R$. splendens

Rhagodiscus sp. 1

$R$ hagodiscus spp. indet.

R. rhombicum

Scampanella spp.

S. fossilis

S. laffittei

Stephanolithion spp.

T. stradneri

T. ethmos

$T$. decorus

Thoracosphaera spp.

T. macieodae

$T$. phacelosus

Vagalapilla spp.

W. barnesae

W. biporta

Z. compactus

Z. lacunatus

Zygodiscus sp. 1

Unidentifiables

Sum (excl. M. stauroph.)

Micula staurophora

Sum of M. staur. counts

Fields of M. staur. counts

. 


\begin{tabular}{|c|c|c|c|c|c|c|c|c|c|c|}
\hline & 1 & 2 & 3 & 4 & 5 & 6 & 7 & 8 & 9 & 10 \\
\hline ODP Hole 761C & $761 C$ & $761 C$ & $761 C$ & $761 C$ & $761 \mathrm{C}$ & $761 \mathrm{C}$ & $761 \mathrm{C}$ & $761 \mathrm{C}$ & $761 \mathrm{C}$ & $761 \mathrm{C}$ \\
\hline Core-Section & $3 .-3$ & $3 .-3$ & $3 .-3$ & $3 .-3$ & $3 .-3$ & $3 .-3$ & 3.-4 & $3 .-4$ & $3 .-4$ & $3 .-4$ \\
\hline cm-level & 66 & 75 & 83 & 102 & 120 & 138-139 & 9 & 44 & 75 & $110-111$ \\
\hline Depth (mbsf) & 172.38 & 172.47 & 172.55 & 172.74 & 172.92 & 173.1 & 173.31 & 173.66 & 173.97 & 174.32 \\
\hline Age (Ma) & 66.344 & 66.4 & 66.405 & 66.418 & 66.429 & 66.441 & 66.455 & 66.478 & 66.498 & 66.521 \\
\hline Sedimentation Rate (m/m.y.) & 1.61 & 15.32 & 15.32 & 15.32 & 15.32 & 15.32 & 15.32 & 15.32 & 15.32 & 15.32 \\
\hline \% Carbonate (ex: Rocchia et al) & 71.6 & 86 & 86.7 & 91.1 & 91.1 & 90.5 & 90.15 & 89.75 & 90.4 & 90.95 \\
\hline Preservation & $\mathrm{P}$ & M & M-P & $M \cdot P$ & M & M & M & M & M & M-P \\
\hline Abundance & C-R & A & A & A & A & A & A & A & A & A \\
\hline Fields counted & 26 & 20 & 20 & 20 & 20 & 20 & 20 & 20 & 20 & 20 \\
\hline mg sediment used & 21.2 & 19.9 & 18.2 & 20.3 & 19.8 & 19.6 & 20 & 20.3 & 19.5 & 19.5 \\
\hline Arkhangelskiella spp. & . & 6 & 9 & 14 & 9 & 14 & 22 & 5 & 13 & 12 \\
\hline Biscutum constans & 3 & 2 & 1 & . & 2 & . & 2 & 2 & 2 & 2 \\
\hline B. notaculum & 1 & 4 & 2 & 1 & 2 & 1 & 1 & 2 & . & . \\
\hline Biscutum sp. 1 & . & 21 & 36 & 55 & 37 & 55 & 71 & 57 & 40 & 39 \\
\hline Broinsonia spp. & 1 & 6 & 9 & 6 & 3 & 9 & 16 & 10 & 8 & 12 \\
\hline Centosphaera barbata & . & . & . & . & . & 1 & . & . & 1 & . \\
\hline Ceratolithoides sp. cf C. aculeus & . & . & . & 1 & ? $?$ & . & 1 & 1 & 4 & . \\
\hline Chiastozygus sp. 1 & . & 2 & 2 & . & 1 & 1 & . & . & . & . \\
\hline Corollithion exiguum & . & 4 & 2 & 2 & 6 & 6 & 4 & 5 & 1 & 4 \\
\hline Cribrosphaerella(?) daniae & . & 7 & 4 & 5 & 4 & 9 & 8 & 6 & 4 & 2 \\
\hline Cribrosphaerella ehrenbergii & 5 & 44 & 57 & 43 & 42 & 41 & 34 & 31 & 39 & 46 \\
\hline Cretarhabdus angustiforatus & . & 1 & 1 & 1 & 12 & 8 & 8 & 12 & 2 & 5 \\
\hline C. conicus & . & 1 & 1 & 2 & . & . & . & 1 & 1 & . \\
\hline C. crenulatus & . & . & . & 1 & 1 & . & . & . & . & . \\
\hline C. schizobrachiatus & . & 2 & 1 & . & . & 1 & . & 1 & 2 & 2 \\
\hline C. surirellus & . & . & . & . & 1 & . & . & . & . & . \\
\hline Cretarhabdus sp. 1 & . & . & . & . & . & . & . & . & . & . \\
\hline Cretarhabdus spp. indet & 1 & 28 & 28 & 43 & 38 & 38 & 44 & 46 & 46 & 35 \\
\hline Cyclagelosphaera alta & 1 & . & 1 & . & . & . & $\dot{5}$ & . & . & : \\
\hline C. margerelii & 58 & 4 & 2 & 1 & . & 1 & 2 & . & . & 1 \\
\hline C. reinhardtii & . & . & . & 1 & . & . & . & . & 2 & 2 \\
\hline Cylindralithus gallicus & . & 3 & . & 3 & 5 & 2 & 2. & 3 & 2 & 3 \\
\hline C. serratus & . & . & . & 1 & 1 & . & . & . & . & . \\
\hline Cylindralithus sp. 1 & . & . & . & . & . & . & . & 1 & . & . \\
\hline Discorhabdus ignotus & . & 20 & 14 & 28 & 8 & 14 & 15 & 13 & 14 & 18 \\
\hline Eiffellithus parallelus & . & 11 & 5 & 6 & 5 & 7 & 5 & 11 & 7 & 8 \\
\hline E. trabeculatus & . & . & 2 & 7 & 1 & 2 & 5 & 6 & 3 & 2 \\
\hline E. turriseiffelii & 3 & 32 & 16 & 40 & 38 & 56 & 32 & 25 & 20 & 22 \\
\hline Ericsonia sp. & . & 1 & 2 & . & . & 2 & 1 & 5 & 6 & 4 \\
\hline Gartnerago spp. & . & . & . & 1 & . & . & . & . & . & . \\
\hline Glaukolithus fessus & 2 & 12 & 12 & 21 & 15 & 25 & 37 & 38 & 25 & 31 \\
\hline Hexalithus hexalithus & 1 & . & . & . & . & . & . & . & . & . \\
\hline Kamptnerius magnificus & . & . & 2 & . & 2 & 4 & 3 & . & . & 1 \\
\hline Lithastrinus sp. & . & . & . & 2 & . & 2 & 1 & . & 4 & 4 \\
\hline Lithraphidites carniolensis & . & 4 & 4 & . & 1 & 1 & 3 & 2 & 4 & 2 \\
\hline L kennethii & . & . & . & . & . & . & . & . & 1 & . \\
\hline L praequadratus & 1 & 16 & 20 & 15 & 17 & 10 & 26 & 33 & 32 & 28 \\
\hline L quadratus & 2 & 18 & 5 & 4 & 4 & 6 & 7 & 13 & 5 & 10 \\
\hline Lucianorhabdus cayeuxii & . & 1 & . & . & . & . & 1 & 2 & . & . \\
\hline Manivitella pemmatoidea & . & . & . & 1 & . & . & . & . & . & . \\
\hline Markalius apertus & . & . & . & . & . & . & . & . & . & . \\
\hline M. inversus & 23 & 6 & . & . & . & 1 & . & 1 & . & . \\
\hline Microrhabdulus belgicus & . & 3 & 5 & 5 & 2 & 12 & 6 & 2 & 8 & 7 \\
\hline M. decoratus & 3 & 22 & 19 & 29 & 24 & 30 & 34 & 32 & 36 & 39 \\
\hline Micula murus & . & . & 2 & 2 & 1 & 2 & . & 2 & . & 2 \\
\hline Micula sp. cf M. prinsii & . & . & . & 1 & . & . & . & . & . & . \\
\hline Micula? sp. & . & 1 & 4 & 3 & 3 & . & 4 & . & 2 & . \\
\hline Neocrepidolithus spp. & 2 & . & . & . & . & . & . & . & . & . \\
\hline Nephrolithus frequens & . & 24 & 22 & 43 & 27 & 39 & 27 & 28 & 15 & 37 \\
\hline Parhabdolithus embergeri & . & 1 & . & . & 1 & . & . & . & 2 & 1 \\
\hline P. regularis & . & 27 & 17 & 15 & 16 & 22 & 11 & 35 & 21 & 27 \\
\hline Pervilithus varius & . & . & . & . & . & . & . & . & . & . \\
\hline
\end{tabular}




$\begin{array}{lcccccccccc} & 1 & 2 & 3 & 4 & 5 & 6 & 7 & 8 & 9 & 10 \\ \text { ODP Hole 761C } & 761 \mathrm{C} & 761 \mathrm{C} & 761 \mathrm{C} & 761 \mathrm{C} & 761 \mathrm{C} & 761 \mathrm{C} & 761 \mathrm{C} & 761 \mathrm{C} & 761 \mathrm{C} & 761 \mathrm{C} \\ \text { Core-Section } & 3 .-3 & 3 .-3 & 3 .-3 & 3 .-3 & 3 .-3 & 3 .-3 & 3 .-4 & 3 .-4 & 3 .-4 & 3 .-4 \\ \text { cm-level } & 66 & 75 & 83 & 102 & 120 & 138-139 & 9 & 44 & 75 & 110-111 \\ \text { Depth (mbsf) } & 172.38 & 172.47 & 172.55 & 172.74 & 172.92 & 173.1 & 173.31 & 173.66 & 173.97 & 174.32\end{array}$

\begin{tabular}{|c|c|c|c|c|c|c|c|c|c|c|}
\hline Placozygus bussonii & . & 3 & 1 & . & . & . & 1 & 1 & . & . \\
\hline P. fibuliformis & 1 & 9 & 13 & 17 & 25 & 24 & 22 & 28 & 16 & 28 \\
\hline P. sigmoides & 5 & 1 & . & . & . & . & . & . & . & . \\
\hline Placozygus sp. & . & 3 & 6 & 10 & 19 & 4 & 12 & 2 & . & 2 \\
\hline Prediscosphaera cretscea & 7 & 98 & 74 & 112 & 137 & 110 & 124 & 112 & 103 & 98 \\
\hline P. grandis & . & 2 & . & 2 & 1 & 3 & 1 & 1 & 3 & 2 \\
\hline P. spinosa & . & 33 & 24 & 22 & 23 & 21 & 9 & 28 & 28 & 8 \\
\hline P. stoveri & 1 & 31 & 15 & 20 & 18 & 33 & 20 & 37 & 39 & 57 \\
\hline Quadrum gartneri & . & . & . & . & . & . & . & . & 1 & . \\
\hline Rhagodiscus angustus & . & 1 & 1 & 1 & 1 & . & 2 & 3 & . & . \\
\hline Rhagodiscus reniformis & . & 2 & 2 & 1 & 5 & 5 & 7 & 6 & 5 & 3 \\
\hline Rhagodiscus splendens & . & 6 & 1 & 5 & 1 & 2 & 2 & 5 & 1 & . \\
\hline Rhombolithion rhombicum & . & . & . & 3 & . & 2 & . & . & 3 & . \\
\hline Scampanelia spp. & . & . & . & . & . & . & . & . & . & . \\
\hline Staurolithites laffittei & . & . & . & . & 1 & . & : & : & . & . \\
\hline Stephanolithion spp. & . & 12 & 2 & 9 & 7 & 8 & 5 & 8 & 6 & 6 \\
\hline Tegumentum stradneri & . & . & . & . & . & : & : & . & . & . \\
\hline Tetrapodorhabdus decorus & . & 6 & 5 & 7 & 2 & 3 & 5 & 15 & 9 & 6 \\
\hline Thoracosphaera operculata & 20 & 3 & 1 & . & . & . & . & 1 & . & . \\
\hline Tranolithus minimus & . & 1 & . & $\therefore$ & 2 & 2 & 1 & 9 & 2 & 6 \\
\hline Vagalapilla spp. & . & 11 & 8 & 12 & 19 & 9 & 11 & 5 & 3 & 4 \\
\hline Watznaueria barnesae & 10 & 21 & 69 & 92 & 51 & 60 & 42 & 56 & 87 & 74 \\
\hline W. biporta & . & . & . & . & . & . & . & . & . & . \\
\hline Zygodiscus compactus & . & . & . & . & . & . & . & . & . & 7 \\
\hline Z. lacunatus & . & . & . & . & . & 10 & . & . & . & 2 \\
\hline Zygodiscus sp. 1 & 1 & 9 & 14 & 9 & 7 & . & 2 & 2 & 5 & . \\
\hline Unidentifiable & 5 & 6 & 7 & 8 & 3 & 5 & 9 & 2 & 4 & 6 \\
\hline SUM (excl. M. staurophora) & 152 & 586 & 543 & 725 & 648 & 718 & 699 & 750 & 683 & 711 \\
\hline M. staurophora & 7 & 75 & 65 & 80 & 65 & 84 & 66 & 64 & 66 & 86 \\
\hline Sum of M. staurophora counts & 159 & 661 & 608 & 805 & 713 & 802 & 765 & 814 & 749 & 797 \\
\hline Fields of M. staurophora counts & 26 & 20 & 20 & 20 & 20 & 20 & 20 & 20 & 20 & 20 \\
\hline
\end{tabular}




\begin{tabular}{|c|c|c|c|c|c|c|c|c|c|}
\hline & 11 & 12 & 13 & 14 & 15 & 16 & 17 & 18 & 19 \\
\hline ODP Hole 761C & $761 C$ & $761 C$ & $761 C$ & $761 C$ & $761 \mathrm{C}$ & $761 \mathrm{C}$ & $761 \mathrm{C}$ & $761 C$ & $761 C$ \\
\hline Core-Section & $3 .-4$ & $3 .-5$ & $3 .-5$ & $3 .-5$ & $3 . .5$ & $3 .-6$ & $3 .-6$ & 3.-6 & $3 .-6$ \\
\hline $\mathrm{cm}$-level & 145 & 30 & 65 & 100 & 136 & 20 & 55 & 91.5 & 125 \\
\hline Depth (mbsf) & 174.67 & 175.02 & 175.37 & 175.72 & 176.08 & 176.42 & 176.77 & 177.13 & 177.47 \\
\hline Age (Ma) & 66.544 & 66.566 & 66.589 & 66.612 & 66.636 & 66.658 & 66.681 & 66.704 & 66.726 \\
\hline Sedimentation Rate (m/m.y.) & 15.32 & 15.32 & 15.32 & 15.32 & 15.32 & 15.32 & 15.32 & 15.32 & 15.32 \\
\hline \% Carbonate (ex: Rocchia et al) & 91.6 & 92.4 & 91.8 & 90.7 & 89.95 & 89.6 & 89.4 & 89.2 & 89.2 \\
\hline Preservation & M-P & M-P & M-P & M-P & M-P & M-P & M-P & M-P & M-P \\
\hline Abundance & A & A & A & A & A & A & A & A & A \\
\hline Fields counted & 20 & 20 & 20 & 20 & 20 & 20 & 20 & 20 & 20 \\
\hline mg sediment used & 21 & 20.9 & 20.4 & 20.9 & 21 & 21 & 20.9 & 20.8 & 20.9 \\
\hline Arkhangelskiella spp. & 11 & 7 & 16 & 8 & 14 & 13 & 17 & 16 & 7 \\
\hline Biscutum constans & 2 & 2 & . & 4 & 1 & . & 3 & 6 & . \\
\hline B. notaculum & 1 & . & . & 1 & . & 1 & 1 & 1 & 1 \\
\hline Biscutum sp. 1 & 23 & 12 & 3 & 3 & 35 & 37 & 26 & 15 & 48 \\
\hline Broinsonia spp. & 8 & 5 & 5 & 4 & 11 & 16 & 12 & 7 & 3 \\
\hline Centosphaera barbata & . & . & . & . & : & : & . & . & . \\
\hline Ceratolithoides sp. cf C. aculeus & 1 & . & . & 3 & 2 & 5 & 4 & 4 & 3 \\
\hline Chiastozygus sp. 1 & . & . & . & . & . & 1 & . & . & . \\
\hline Corollithion exiguum & 1 & . & . & . & . & 1 & . & . & . \\
\hline Cribrosphaerella(?) daniae & 4 & . & . & . & . & . & 1 & . & 8 \\
\hline Cribrosphaerella ehrenbergii & 33 & 38 & 42 & 39 & 32 & 39 & 41 & 45 & 54 \\
\hline Cretarhabdus angustiforatus & 4 & 1 & 14 & 4 & 9 & 12 & 11 & 3 & 6 \\
\hline C. conicus & 2 & . & . & . & 3 & 1 & . & . & 1 \\
\hline C. crenulatus & . & . & . & . & . & . & . & . & . \\
\hline C. schizobrachiatus & . & 1 & . & 1 & 3 & 4 & . & . & . \\
\hline C. surirellus & . & . & . & . & . & . & . & . & . \\
\hline Cretarhabdus sp. 1 & . & 1 & . & . & . & . & . & . & . \\
\hline Cretarhabdus spp. indet & 43 & 27 & 47 & 39 & 52 & 50 & 48 & 28 & 45 \\
\hline Cyclagelosphaera alta & . & . & . & . & . & . & . & . & . \\
\hline C. margerelii & 2 & . & . & . & 2 & . & . & 3 & 1 \\
\hline C. reinhardtii & 2 & . & . & . & 1 & . & . & . & . \\
\hline Cylindralithus gallicus & 6 & 5 & 14 & 5 & 5 & 12 & 7 & 12 & 3 \\
\hline C. serratus & . & . & 2 & . & . & . & . & . & . \\
\hline Cylindralithus sp. 1 & . & . & . & . & . & . & . & . & . \\
\hline Discorbabdus ignotus & 15 & 2 & 5 & 6 & 7 & 11 & 15 & 13 & 30 \\
\hline Eiffellithus parallelus & 6 & 4 & 2 & 1 & 8 & 7 & 3 & . & 3 \\
\hline E. trabeculatus & 10 & 3 & 3 & 2 & 7 & 7 & 3 & 4 & 5 \\
\hline E. turriseiffelii & 29 & 22 & 25 & 24 & 45 & 31 & 18 & 16 & 19 \\
\hline Ericsonia sp. & 13 & 8 & . & 2 & 4 & 7 & 3 & 4 & 1 \\
\hline Gartnerago spp. & . & . & . & . & . & . & . & . & . \\
\hline Glaukolithus fessus & 40 & 21 & 22 & 33 & 33 & 43 & 29 & 24 & 27 \\
\hline Hexalithus hexalithus & . & . & . & . & . & . & . & . & . \\
\hline Kamptnerius magnificus & . & . & . & . & . & 1 & . & 2 & 1 \\
\hline Lithastrinus sp. & 6 & 6 & 4 & 4 & 4 & 4 & 1 & 5 & 6 \\
\hline Lithraphidites carniolensis & 4 & 1 & . & . & . & 2 & . & . & . \\
\hline L kennethii & 1 & . & 1 & . & 2 & . & . & . & . \\
\hline L praequadratus & 24 & 17 & 20 & 30 & 24 & 29 & 11 & 14 & 17 \\
\hline L quadratus & 7 & 4 & 14 & 1 & 4 & 9 & 4 & 5 & 9 \\
\hline Lucianorhabdus cayeuxii & . & . & . & . & . & . & . & . & . \\
\hline Manivitella pemmatoidea & . & . & . & . & . & . & 1 & . & . \\
\hline Markalius apertus & . & . & . & . & . & . & . & . & 2 \\
\hline M. inversus & . & . & . & . & . & 1 & 1 & 1 & . \\
\hline Microrhabdulus belgicus & 6 & 2 & 8 & . & 4 & . & 2 & 5 & 10 \\
\hline M. decoratus & 50 & 57 & 59 & 53 & 53 & 48 & 20 & 18 & 31 \\
\hline Micula murus & 1 & . & 2 & 4 & 2 & 5 & 5 & 3 & . \\
\hline Micula sp. cf M. prinsii & 1 & . & . & . & . & . & . & 1 & . \\
\hline Micula? sp. & 2 & 1 & 1 & 2 & 1 & 2 & 1 & 1 & . \\
\hline Neocrepidolithus spp. & . & . & . & . & . & . & . & . & . \\
\hline Nephrolithus frequens & 27 & 13 & 5 & 15 & 22 & 22 & 16 & 2 & 14 \\
\hline Parhabdolithus embergeri & 3 & . & . & . & 1 & . & . & . & . \\
\hline P. regularis & 20 & 20 & 25 & 34 & 33 & 35 & 9 & 14 & 25 \\
\hline Pervilithus varius & 1 & . & . & . & . & . & . & . & . \\
\hline
\end{tabular}




\begin{tabular}{|c|c|c|c|c|c|c|c|c|c|}
\hline & 11 & 12 & 13 & 14 & 15 & 16 & 17 & 18 & 19 \\
\hline ODP Hole $761 \mathrm{C}$ & $761 \mathrm{C}$ & $761 \mathrm{C}$ & $761 C$ & $761 \mathrm{C}$ & $761 \mathrm{C}$ & $761 \mathrm{C}$ & $761 C$ & $761 \mathrm{C}$ & $761 \mathrm{C}$ \\
\hline Core-Section & $3 .-4$ & $3 .-5$ & $3 .-5$ & $3 .-5$ & $3 .-5$ & $3 .-6$ & 3.-6 & $3 .-6$ & $3 .-6$ \\
\hline cm-level & 145 & 30 & 65 & 100 & 136 & 20 & 55 & 91.5 & 125 \\
\hline Depth (mbsf) & 174.67 & 175.02 & 175.37 & 175.72 & 176.08 & 176.42 & 176.77 & 177.13 & 177.47 \\
\hline Placozygus bussonii & 1 & 1 & . & 1 & . & . & . & 2 & . \\
\hline P. fibuliformis & 26 & 15 & 57 & 32 & 43 & 40 & 48 & 28 & 56 \\
\hline P. sigmoides & . & . & . & . & . & . & 1 & 1 & . \\
\hline Placozygus sp. & 2 & . & . & 6 & 2 & 2 & 2 & 1 & 2 \\
\hline Prediscosphaera cretacea & 140 & 91 & 94 & 108 & 148 & 185 & 150 & 129 & 146 \\
\hline P. grandis & 2 & 1 & 4 & 8 & 2 & 3 & 5 & 3 & . \\
\hline P. spinosa & 27 & 23 & 18 & 31 & 40 & 14 & 22 & 14 & 26 \\
\hline P. stoveri & 27 & 33 & 33 & 44 & 37 & 49 & 27 & 32 & 59 \\
\hline Quadrum garineri & . & 1 & . & . & . & . & . & . & - \\
\hline Rhagodiscus angustus & . & . & . & . & . & . & . & . & . \\
\hline Rhagodiscus reniformis & 4 & 3 & . & . & 1 & . & 1 & 1 & 2 \\
\hline Rhagodiscus splendens & , & 3 & 1 & 3 & 2 & 2 & 2 & . & . \\
\hline Rhombolithion rhombicum & . & . & . & . & . & $\cdot$ & . & . & . \\
\hline Scampanella spp. & . & . & . & . & . & . & . & 1 & - \\
\hline Staurolithites laffittei & . & . & . & . & . & . & . & . & . \\
\hline Stephanolithion spp. & 8 & 3 & 1 & 1 & 2 & 13 & 2 & 2 & 3 \\
\hline Tegumentum stradneri & . & . & . & . & 1 & . & . & . & . \\
\hline Tetrapodorhabdus decorus & 15 & 8 & 5 & 3 & 9 & 16 & 6 & 6 & 7 \\
\hline Thoracosphaera operculata & . & 1 & . & . & . & . & . & . & . \\
\hline Tranolithus minimus & 6 & 5 & 2 & 3 & 1 & 1 & 7 & . & 2 \\
\hline Vagaiapilla spp. & 3 & 1 & 2 & . & 2 & 8 & 3 & 3 & 2 \\
\hline Watznaueria barnesae & 67 & 75 & 106 & 96 & 67 & 114 & 106 & 119 & 57 \\
\hline W. biporta & 1 & . & . & . & . & . & . & . & . \\
\hline Zygodiscus compactus & . & . & . & . & . & . & . & · & · \\
\hline Z. lacunatus & 3 & . & . & . & . & . & . & . & . \\
\hline Zygodiscus sp. 1 & 19 & 3 & 22 & 10 & 2 & 3 & 1 & . & 7 \\
\hline Unidentifiable & 6 & 1 & 4 & 4 & 11 & 7 & 7 & 5 & 8 \\
\hline SUM (excl. M. staurophora) & 760 & 547 & 684 & 668 & 783 & 906 & 696 & 614 & 749 \\
\hline M. staurophora & 103 & 115 & 125 & 124 & 130 & 87 & 107 & 85 & 84 \\
\hline Sum of M. staurophora counts & 863 & 662 & 809 & 792 & 913 & 993 & 803 & 699 & 833 \\
\hline Fields of M. staurophora counts & 20 & 20 & 20 & 20 & 20 & 20 & 20 & 20 & 20 \\
\hline
\end{tabular}




DSDP Hole 217
Core-Section
cm-level
Depth (mbst)
Age (Ma)
Sedimentation Rate (m/m.y.)
Carbonate content (weight-\%)
Preservation
Abundance
Fields counted
mg sediment used

$\begin{array}{cccccccccc}1 & 2 & 3 & 4 & 5 & 6 & 7 & 8 & 9 & 10 \\ 217 & 217 & 217 & 217 & 217 & 217 & 217 & 217 & 217 & 217 \\ 17-1 & 17-1 & 17-1 & 17-1 & 17-1 & 17-1 & 17-1 & 17-2 & 17-2 & 17-2 \\ 20-21 & 40-41 & 60-61 & 80-81 & 100-101 & 120-121 & 140-141 & 10 .-11 & 30-31 & 50-51 \\ 421.20 & 421.40 & 421.60 & 421.80 & 422.00 & 422.20 & 422.40 & 422.60 & 422.80 & 423.00 \\ 66.413 & 66.425 & 66.438 & 66.451 & 66.463 & 66.476 & 66.489 & 66.501 & 66.514 & 66.527 \\ 15.81 & 15.81 & 15.81 & 15.81 & 15.81 & 15.81 & 15.81 & 15.81 & 15.81 & 15.81 \\ 91.5 & 90.2 & \text { n.d. } & \text { n.d. } & \text { n.d. } & \text { n.d. } & \text { n.d. } & \text { n.d. } & \text { n.d. } & \text { n.d } \\ \text { M } & \text { M } & \text { M } & \text { M } & \text { M } & \text { M } & \text { M } & \text { M } & \text { M } & \text { M } \\ \text { A } & \text { A-C } & \text { A } & \text { A } & \text { A } & \text { A } & \text { A } & \text { A } & \text { A } & \text { A } \\ 40.0 & 30.0 & 20.0 & 20.0 & 20.0 & 20.0 & 20.0 & 25.0 & 20.0 & 20.0 \\ 20.5 & 20.3 & 20.2 & 20.9 & 20.6 & 20.4 & 20.6 & 20.6 & 20.0 & 20.5\end{array}$

\begin{tabular}{|c|c|c|c|c|c|c|c|c|c|c|}
\hline Ahmuellerella octoradiata & . & . & . & . & . & . & . & . & . & . \\
\hline Arkhangelskiella spp. & 16 & 20 & 18 & 14 & 18 & 5 & 6 & 2 & 1 & 2 \\
\hline Biscutum constans & . & . & 1 & . & 1 & . & . & . & . & 1 \\
\hline B. magnum & . & . & . & . & . & . & . & . & . & . \\
\hline B. notaculum & 2 & 2 & . & . & . & . & . & . & . & . \\
\hline Biscutum sp. 1 & 25 & 4 & 7 & 1 & 3 & 3 & 2 & . & 5 & 1 \\
\hline Broinsonia spp. & 31 & 21 & 18 & 9 & 12 & 8 & 4 & 8 & 12 & 10 \\
\hline Arkhangeiskiella/Broinsonia & 1 & . & . & . & . & . & . & . & . & . \\
\hline Ceratolithoides sp. cf. C. aculeus & . & 4 & 2 & 1 & . & . & . & 2 & $\cdot$ & 2 \\
\hline Chiastozygus sp. 1 & 1 & . & . & . & . & . & : & . & : & . \\
\hline Corollithion completum & . & . & . & . & . & . & 1 & . & 1 & . \\
\hline Chiastozygus sp. cf. C. amphipons & 2 & . & . & $\therefore$ & : & : & : & . & . & . \\
\hline Cribrosphaerella(?) daniae & 5 & 1 & . & 2 & 2 & 1 & 1 & . & . & . \\
\hline Cribrosphaerella ehrenbergii & 59 & 42 & 30 & 24 & 31 & 19 & 33 & 19 & 32 & 26 \\
\hline Cretarhabdus angustiforatus & 7 & 3 & 8 & 2 & 1 & 1 & 6 & 3 & 3 & . \\
\hline C. conicus & 2 & 1 & 1 & . & 1 & 3 & $\dot{2}$ & 1 & 2 & . \\
\hline C. crenulatus & . & . & 4 & 1 & . & 1 & 3 & 3 & 4 & $\dot{x}$ \\
\hline C. schizobrachiatus & 1 & 4 & 1 & . & . & : & 2 & 1 & . & 2 \\
\hline C. surirellus & 8 & 3 & 1 & 1 & 2 & 1 & . & . & · & . \\
\hline Cretarhabdus spp. indet & 61 & 31 & 37 & 34 & 42 & 32 & 39 & 28 & 35 & 27 \\
\hline Cyclagelosphaera alta & . & . & . & . & . & . & . & . & : & . \\
\hline C. reinhardtii & . & . & 1 & . & . & . & . & . & 1 & . \\
\hline Cylindralithus biarcus & . & . & . & . & . & . & . & . & . & . \\
\hline C. gallicus & 9 & 7 & 2 & 2 & 3 & 6 & 8 & 13 & 8 & 6 \\
\hline C. serratus & . & . & . & . & . & · & · & 1 & · & . \\
\hline Cylindralithus sp. 1 & . & . & . & . & $\cdot$ & . & . & . & . & . \\
\hline Cylindralithus spp. indet. & . & . & . & ; & $\cdot$ & $\cdot$ & . & . & . & . \\
\hline Discorhabdus ignotus & 12 & 2 & 6 & 6 & 3 & 1 & · & 5 & 3 & 3 \\
\hline Eiffellithus eximius & . & . & . & . & 1 & · & : & . & . & . \\
\hline E. parailelus & 5 & & 1 & . & 1 & · & 1 & & & 2 \\
\hline E. trabeculatus & 3 & 1 & . & . & . & $\dot{5}$ & $\cdot$ & : & 1 & . \\
\hline E. turriseiffelii & 29 & 18 & 21 & 7 & 7 & 7 & 14 & 7 & 20 & 12 \\
\hline Ericsonia sp. & 10 & 8 & 2 & 2 & 4 & 4 & 8 & 9 & 7 & 2 \\
\hline Gartnerago spp. & 1 & . & 2 & 2 & 1 & 2 & $\therefore$ & . & $\dot{x}$ & . \\
\hline Glaukolithus fessus & 36 & 22 & 25 & 20 & 37 & 15 & 17 & 13 & 21 & 14 \\
\hline Kamptnerius magnificus & . & 1 & 2 & 1 & 1 & . & 1 & 2 & $\cdot$ & . \\
\hline Lithastrinus spp. & 29 & 15 & 3 & 5 & 7 & 11 & 8 & 16 & 13 & 7 \\
\hline Lithraphidites carniolensis & 2 & 1 & 1 & . & 2 & . & 1 & 1 & $\cdot$ & . \\
\hline L grossopectinatus & . & . & . & 1 & . & . & : & . & . & . \\
\hline L. kennethii & . & . & . & . & . & . & 2 & 1 & . & 2 \\
\hline L praequadratus & 36 & 17 & 9 & 10 & 17 & 14 & 26 & 11 & 16 & 14 \\
\hline L quadratus & 7 & 2 & 6 & 3 & 3 & 3 & 2 & 3 & 3 & 2 \\
\hline Lithraphidites(?) sp. 1 & $\cdot$ & . & . & . & . & · & . & . & . & . \\
\hline Lucianorhabdus cayeuxii & $\cdot$ & . & · & · & $\cdot$ & · & $\cdot$ & . & - & . \\
\hline Manivitella pemmatoidea & $\cdot$ & . & . & . & . & . & . & . & . & 1 \\
\hline Markalius apertus & . & . & . & . & . & $\cdot$ & $\cdot$ & . & . & . \\
\hline M. inversus & : & . & $\cdot$ & . & $\cdot$ & $\cdot$ & . & . & . & . \\
\hline Microrhabdulus belgicus & 1 & . & . & . & . & . & . & . & . & . \\
\hline M. decoratus & 24 & 23 & 25 & 17 & 17 & 21 & 26 & 17 & 17 & 19 \\
\hline Micula praemurus & . & . & . & . & . & . & . & . & . & . \\
\hline Micula murus & 10 & 8 & 11 & 11 & 17 & 12 & 13 & 25 & 14 & 15 \\
\hline Micula sp. cf M. prinsii & 5 & 4 & 1 & 5 & 4 & 3 & 4 & 5 & 7 & 4 \\
\hline
\end{tabular}


DSDP Hole 217

Core-Section

$\mathrm{cm}$-level

Depth (mbsf)

Micula? sp

Nephrolithus frequens

Parhabdolithus embergeri

P. regularis

Petrarhabdus copulatus

Placozygus bussoni

P. fibuliformis

P. sigmoides

Placozygus sp.

Prediscosphaera arkhangelskyi

P. cretacea

P. spinosa

P. grandis

P. stoveri

Quadrum gartneri

Reinhardtites sp aff. $R$. anthophorus

Reinhardtites levis

Rhagodiscus angustus

R. reniformis

R. splendens

Rhagodiscus sp. 1

Rhagodiscus spp. indet

Scampanella spp.

Scapholithus fossilis

Staurolitites laffittei

Stephanolithion spp.

Tegumentum stradner

Teichorhabdus ethmos

Tetrapodorhabdus decorus

Thoracosphaera spp.

Tranolithus macleodae

T. phacelosus

Vagalapilla spp.

Watznaueria barnesae

W. biporta

Zygodiscus compactus

Z. lacunatus

Zygodiscus sp. 1

Unidentifiable

Sum (excl. M. staurophora)

Micula staurophora

Sum of M. staurophora counts

Fields of M. staurophora counts

$\begin{array}{cccccccccc}1 & 2 & 3 & 4 & 5 & 6 & 7 & 8 & 9 & 10 \\ 217 & 217 & 217 & 217 & 217 & 217 & 217 & 217 & 217 & 217 \\ 17-1 & 17-1 & 17-1 & 17-1 & 17-1 & 17-1 & 17-1 & 17-2 & 17-2 & 17-2 \\ 20-21 & 40-41 & 60-61 & 80-81 & 100-101 & 120-121 & 140-141 & 10 .-11 & 30-31 & 50-51 \\ 421.20 & 421.40 & 421.60 & 421.80 & 422.00 & 422.20 & 422.40 & 422.60 & 422.80 & 423.00\end{array}$

$\begin{array}{cccccccccc}4 & 6 & 2 & 6 & 2 & 1 & 1 & 2 & 2 & 3 \\ 19 & 8 & 9 & 10 & 7 & 7 & 3 & 2 & 2 & 1 \\ . & . & 1 & . & 1 & . & . & . & . & 1 \\ 47 & 22 & . & 28 & 13 & 20 & 47 & 16 & 36 & 39 \\ . & . & . & . & . & . & . & . & . & . \\ 4 & . & . & . & . & 3 & 1 & 1 & . & . \\ 23 & 14 & 22 & 20 & 16 & 11 & 16 & 15 & 20 & 24 \\ . & . & . & . & . & . & . & . & . & . \\ 10 & 6 & . & 3 & 4 & 1 & 3 & 5 & 2 & . \\ . & . & . & . & . & . & . & . & . & . \\ 100 & 62 & 80 & 58 & 53 & 50 & 75 & 54 & 89 & 58 \\ 18 & 5 & 21 & 2 & 8 & 4 & 9 & 2 & 7 & 8 \\ . & 1 & . & . & 1 & 1 & . & . & 2 & . \\ 32 & 11 & 15 & 16 & 26 & 10 & 16 & 19 & 23 & 14\end{array}$




$\begin{array}{lccccccccccc} & 11 & 12 & 13 & 14 & 15 & 16 & 17 & 18 & 19 & 20 & 21 \\ \text { DSDP Hole 217 } & 217 & 217 & 217 & 217 & 217 & 217 & 217 & 217 & 217 & 217 & 217 \\ \text { Core-Section } & 17-2 & 17-2 & 17-2 & 17-2 & 17-2 & 17-3 & 17-3 & 17-3 & 17-3 & 17-3 & 17-3 \\ \text { cm-level } & 70-71 & 90-91 & 110-111 & 130-131 & 149-150 & 10 .-11 & 30-31 & 50-51 & 70-71 & 90-91 & 110-111 \\ \text { Depth (mbst) } & 423.20 & 423.40 & 423.60 & 423.80 & 423.99 & 424.10 & 424.30 & 424.50 & 424.70 & 424.90 & 425.10 \\ \text { Age (Ma) } & 66.539 & 66.552 & 66.564 & 66.577 & 66.589 & 66.596 & 66.609 & 66.621 & 66.634 & 66.647 & 66.659 \\ \text { Sed. Rate (m/m.y.) } & 15.81 & 15.81 & 15.81 & 15.81 & 15.81 & 15.81 & 15.81 & 15.81 & 15.81 & 15.81 & 15.81 \\ \text { Carbonate (wt-\%) } & \text { n.d. } & \text { n.d. } & \text { n.d. } & \text { n.d. } & \text { n.d. } & \text { n.d. } & \text { n.d. } & \text { n.d. } & \text { n.d. } & \text { n.d. } & \text { n.d. } \\ \text { Preservation } & \mathrm{M} & \mathrm{M} & \mathrm{M} & \mathrm{M} & \mathrm{M} & \mathrm{M} & \mathrm{M} & \mathrm{M} & \mathrm{M} & \mathrm{M} & \mathrm{M} \\ \text { Abundance } & \mathrm{A} & \mathrm{A} & \mathrm{A} & \mathrm{A} & \mathrm{A} & \mathrm{A} & \mathrm{AA} & \mathrm{A} & \mathrm{A} & \text { AA } & \text { A } \\ \text { Fields counted } & 20.0 & 30.0 & 20.0 & 20.0 & 20.0 & 30.0 & 20.0 & 20.0 & 20.0 & 20.0 & 20.0 \\ \text { mg sediment used } & 21.1 & 21.5 & 21.4 & 20.1 & 19.7 & 20.5 & 21.2 & 20.3 & 20.6 & 20.6 & 20.0\end{array}$

A. octoradiata

Arkhangelskiella spp.

B. magnum

B. notaculum

Biscutum sp. 1

Broinsonia spp.

Arkhang./Broinsonia

C. cf aculeus

Chiastozygus sp. 1

C. completum

C. cf. amphipons

C.(?) daniae

C. ehrenbergii

C. angustiforatus

C. conicus

C. crenulatus

C. schizobrachiatus

C. surirellus

Cretarhabdus spp. indet.

C. alta

C. reinhardtii

C. biarcus

C. gallicus

C. serratus

Cylindralithus sp. 1

Cylindralithus spp. indet.

D. ignotus

E. eximius

E. parallelus

E. trabeculatus

E. turriseiffelii

Ericsonia sp.

Gartnerago spp.

G. fessus

K. magnificus

Lithastrinus spp.

L carniolensis

L grossopectinatus

L. kennethii

L praequadratus

L quadratus

Lithraphidites(?) sp. 1

L cayeuxii

M. pemmatoidea

M. apertus

M. inversus

M. belgicus

M. decoratus

M. praemurus

M. murus

M. cf prinsii

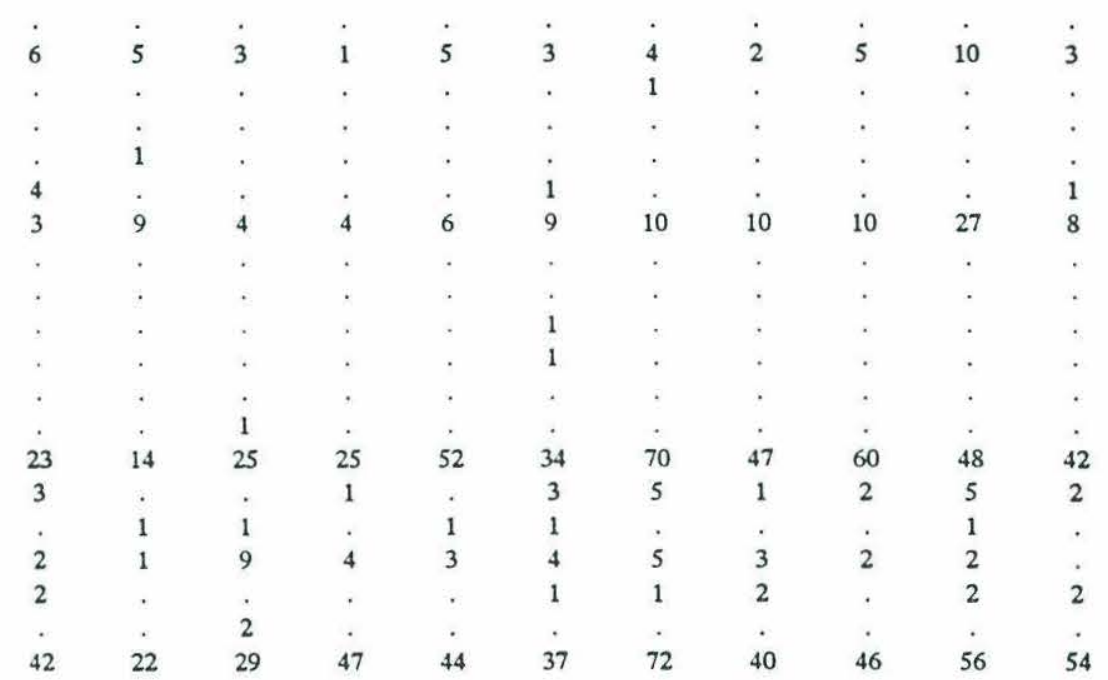




$\begin{array}{lccccccccccc} & 11 & 12 & 13 & 14 & 15 & 16 & 17 & 18 & 19 & 20 & 21 \\ \text { DSDP Hole 217 } & 217 & 217 & 217 & 217 & 217 & 217 & 217 & 217 & 217 & 217 & 217 \\ \text { Core-Section } & 17-2 & 17-2 & 17-2 & 17-2 & 17-2 & 17-3 & 17-3 & 17-3 & 17-3 & 17-3 & 17-3 \\ \text { cm-level } & 70-71 & 90-91 & 110-111 & 130-131 & 149-150 & 10 .-11 & 30-31 & 50-51 & 70-71 & 90-91 & 110-111 \\ \text { Depth (mbst) } & 423.20 & 423.40 & 423.60 & 423.80 & 423.99 & 424.10 & 424.30 & 424.50 & 424.70 & 424.90 & 425.10\end{array}$

\begin{tabular}{|c|c|c|c|c|c|c|c|c|c|c|c|}
\hline Micula? sp & . & 4 & 2 & 4 & 3 & 6 & . & . & 3 & . & . \\
\hline N. frequens & 6 & . & 1 & . & 1 & 1 & 2 & . & . & . & $\cdot$ \\
\hline P. embergeri & 1 & $\therefore$ & . & . & . & . & . & . & $\therefore$ & . & . \\
\hline P. regularis & 26 & 20 & 33 & 36 & 24 & 20 & 39 & 18 & 24 & 50 & 22 \\
\hline P. copulatus & . & . & . & . & . & $\dot{2}$ & $\dot{s}$ & · & : & : & : \\
\hline P. bussoni & 1 & . & , $\cdot$ & : & . & 2 & 2 & $\dot{2}$ & 1 & 1 & 2 \\
\hline P. fibuliformis & 20 & 14 & 4 & 7 & 11 & 12 & 50 & 31 & 24 & 28 & 35 \\
\hline P. sigmoides & . & . & $\therefore$ & . & . & . & . & . & . & $\therefore$ & . \\
\hline Placozygus ap. & 3 & 2 & 5 & 3 & 3 & 5 & 10 & 3 & 2 & 5 & 1 \\
\hline P. arkhangelskyi & . & . & . & . & . & . & . & . & . & . & . \\
\hline P. cretacea & 65 & 67 & 34 & 102 & 53 & 75 & 82 & 70 & 98 & 102 & 62 \\
\hline P. spinosa & 7 & . & 4 & 12 & 6 & 1 & 10 & 6 & . & 3 & 2 \\
\hline P. grandis & . & 2 & . & 5 & 3 & 6 & . & 1 & 1 & 2 & 4 \\
\hline P. stoveri & 25 & 9 & 17 & 16 & 17 & 14 & 21 & 17 & 10 & 21 & 17 \\
\hline Q. gartneri & . & . & 1 & . & . & . & . & 2 & . & . & . \\
\hline R. aff. anthophorus & . & . & . & . & - & . & . & . & . & . & . \\
\hline R. levis & . & . & . & . & 1 & . & . & . & . & . & - \\
\hline R. angustus & . & - & - & . & - & - & . & $\cdot$ & . & . & . \\
\hline R. reniformis & . & - & - & - & . & - & . & . & - & . & . \\
\hline R. splendens & . & . & . & . & . & - & . & . & - & - & . \\
\hline Rhagodiscus sp. 1 & . & . & . & . & . & . & - & . & . & . & . \\
\hline Rhagodiscus spp. indet & . & . & . & . & . & . & . & . & . & . & . \\
\hline Scampanella spp. & . & . & . & . & . & . & . & . & . & . & . \\
\hline S. fossilis & . & . & . & . & . & . & . & . & - & - & . \\
\hline S. laffittei & . & . & . & . & . & . & . & . & . & . & . \\
\hline Stephanolithion spp. & . & . & . & . & . & . & . & . & . & . & $\cdot$ \\
\hline T. stradneri & . & . & . & 1 & . & . & . & 1 & . & . & . \\
\hline T. ethmos & - & : & $\therefore$ & . & - & - & . & - & - & . & . \\
\hline T. decorus & 6 & 1 & 3 & 4 & 1 & . & 4 & 1 & 1 & . & 1 \\
\hline Thoracosphaera spp. & 1 & . & . & . & 1 & 1 & 4 & 1 & . & . & - \\
\hline T. macleodae & 3 & . & . & 2 & 1 & . & 1 & 1 & . & 3 & 1 \\
\hline T. phacelosus & . & . & . & . & . & . & . & . & . & . & . \\
\hline Vagalapilla spp. & 3 & 2 & . & - & - & . & . & 1 & . & . & 1 \\
\hline W. barnesae & 93 & 135 & 83 & 148 & 95 & 134 & 118 & 92 & 81 & 77 & 81 \\
\hline W. biporta & . & . & . & 1 & 1 & . & . & . & 1 & . & . \\
\hline Z. compactus & : & $\dot{0}$ & . & : & . & . & : & : & . & . & . \\
\hline Z. lacunatus & 3 & 2 & . & 3 & 1 & . & 1 & 1 & . & . & . \\
\hline Zygodiscus sp. 1 & - & . & 3 & 3 & 2 & 1 & 6 & . & 3 & 1 & 3 \\
\hline Unidentifiable & 5 & 3 & 2 & 4 & 2 & 6 & 9 & 5 & 5 & 11 & 6 \\
\hline Sum (excl. M. staur.) & 452 & 415 & 366 & 550 & 421 & 534 & 656 & 442 & 474 & 562 & 448 \\
\hline Micula staurophora & 108 & 221 & 144 & 111 & 113 & 134 & 91 & 73 & 82 & 94 & 88 \\
\hline Sum of M. staur. counts & 560 & 636 & 510 & 661 & 534 & 668 & 747 & 515 & 556 & 656 & 536 \\
\hline Fields of M. staur. counts & 20.0 & 30.0 & 20.0 & 20.0 & 20.0 & 30.0 & 20.0 & 20.0 & 20.0 & 20.0 & 20.0 \\
\hline
\end{tabular}




$\begin{array}{lccccccccccc} & 22 & 23 & 24 & 25 & 26 & 27 & 28 & 29 & 30 & 31 & 32 \\ \text { DSDP Hole 217 } & 217 & 217 & 217 & 217 & 217 & 217 & 217 & 217 & 217 & 217 & 217 \\ \text { Core-Section } & 17-3 & 17-3 & 17-4 & 17-4 & 17-4 & 17-4 & 17-4 & 17-4 & 17-4 & 18-2 & 18-2 \\ \text { cm-level } & 130-131 & 149-150 & 20-21 & 40-41 & 60-61 & 80-81 & 100-101 & 120-121 & 140-141 & 22 & 40-42 \\ \text { Depth (mbsf) } & 425.30 & 425.49 & 425.70 & 425.90 & 426.10 & 426.30 & 426.50 & 426.70 & 426.90 & 432.22 & 432.40 \\ \text { Age (Ma) } & 66.672 & 66.684 & 66.697 & 66.710 & 66.723 & 66.735 & 66.748 & 66.761 & 66.773 & 67.110 & 67.121 \\ \text { Sed. Rate (m/m.y.) } & 15.81 & 15.81 & 15.81 & 15.81 & 15.81 & 15.81 & 15.81 & 15.81 & 15.81 & 15.81 & 15.81 \\ \text { Carbonate (wt-\%) } & \text { n.d. } & \text { n.d. } & \text { n.d. } & \text { n.d. } & \text { n.d. } & \text { n.d. } & \text { nd. } & \text { n.d. } & \text { n.d. } & \text { n.d. } & \text { n.d. } \\ \text { Preservation } & \text { M } & \text { M } & \text { M } & \text { M } & \text { M } & \text { M } & \text { M } & \text { M } & \text { M } & \text { M } & \text { M } \\ \text { Abundance } & \text { A } & \text { A } & \text { A } & \text { A-C } & \text { C-A } & \text { A-C } & \text { A-C } & \text { A } & \text { A } & \text { A } & \text { A } \\ \text { Fields counted } & 20.0 & 20.0 & 20.0 & 25.0 & 30.0 & 25.0 & 20.0 & 20.0 & 25.0 & 20.0 & 20.0 \\ \text { mg sediment used } & 20.7 & 20.8 & 21.1 & 20.1 & 20.2 & 20.4 & 20.8 & 20.3 & 19.8 & 21.1 & 21.2\end{array}$

A. octoradiata

Arkhangeiskiella spp.

Biscutum constans

B. magnum

B. notaculum

Biscutum ap. 1

Broinsonia spp.

Arkhang./Broinsonia

C. cf aculeus

Chiastoeygus sp. 1

C. completum

C. cf. amphipons

C.(?) daniae

C. ehrenbergii

C. angustiforatus

C. conicus

C. crenulatus

C. schizobrachiatus

C. surirellus

Cretarhabdus spp. indet.

C. alta

C. reinhardtii

C. biarcus

C. gallicus

C. serratus

Cylindralithus sp. 1

Cylindralithus spp. indet.

D. ignotus

E. eximius

E parallelus

E. trabeculatus

E. turriseiffelii

Ericsonia sp.

Gartnerago spp.

G. fessus

K. magnificus

Lithastrinus spp.

L carniolensis

L grossopectinatus

L. kennethii

L praequadratus

L quadratus

Lithraphidites(?) sp. 1

L cayeurii

M. pemmatoidea

M. apertus

$M$. inversus

M. belgicus

M. decoratus

M. praemurus

M. murus

M. cf prinsii

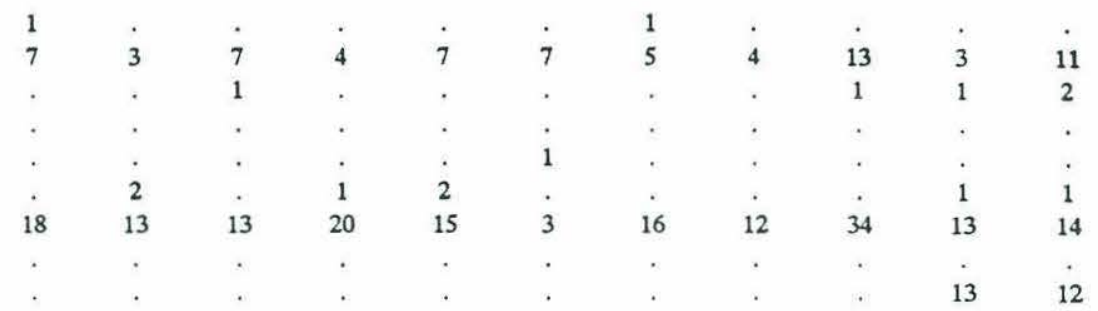




$\begin{array}{lccccccccccc} & 22 & 23 & 24 & 25 & 26 & 27 & 28 & 29 & 30 & 31 & 32 \\ \text { DSDP Hole 217 } & 217 & 217 & 217 & 217 & 217 & 217 & 217 & 217 & 217 & 217 & 217 \\ \text { Core-Section } & 17-3 & 17-3 & 17-4 & 17-4 & 17-4 & 17-4 & 17-4 & 17-4 & 17-4 & 18-2 & 18-2 \\ \text { cm-level } & 130-131 & 149-150 & 20-21 & 40-41 & 60-61 & 80-81 & 100-101 & 120-121 & 140-141 & 22 & 40-42 \\ \text { Depth (mbsf) } & 425.30 & 425.49 & 425.70 & 425.90 & 426.10 & 426.30 & 426.50 & 426.70 & 426.90 & 432.22 & 432.40\end{array}$

\begin{tabular}{|c|c|c|c|c|c|c|c|c|c|c|c|}
\hline Micula? sp & . & . & 2 & 2 & 1 & 1 & 1 & . & : & 5 & 2 \\
\hline N. frequens. & . & . & . & . & . & 1 & 1 & $\cdot$ & 1 & . & $\cdot$ \\
\hline P. embergeri & . & . & . & . & . & . & . & . & . & . & . \\
\hline P. regularis & 31 & 34 & 41 & 38 & 69 & 42 & 31 & 41 & 53 & 39 & 32 \\
\hline P. copulatus & . & . & . & . & . & . & . & . & . & . & . \\
\hline P. bussoni & 4 & 1 & . & . & . & . & . & . & 1 & . & . \\
\hline P. fibuliformis & 63 & 57 & . 29 & 14 & 26 & 13 & 17 & 12 & 3 & 13 & 20 \\
\hline P. sigmoides & . & . & 2 & . & . & . & . & 1 & . & . & . \\
\hline Placozygus sp. & 7 & 5 & 4 & 3 & 5 & 2 & 4 & 1 & 5 & 1 & 5 \\
\hline P. arkhangelskyi & . & . & . & . & . & . & . & . & . & . & . \\
\hline P. cretacea & 79 & 71 & 91 & 88 & 85 & 96 & 95 & 60 & 93 & 82 & 93 \\
\hline P. spinosa & 6 & 5 & 14 & 5 & 4 & 7 & 6 & 3 & 5 & 11 & 11 \\
\hline P. grandis & 2 & 2 & 1 & 3 & 1 & 1 & 2 & . & . & 1 & . \\
\hline P. stoveri & 22 & 19 & 15 & 13 & 6 & 14 & 28 & 2 & 19 & 23 & 15 \\
\hline Q. gartneri & . & 1 & . & . & . & . & 1 & . & 1 & . & $\cdot$ \\
\hline R. aff. anthophorus & . & . & · & · & . & . & . & . & . & . & . \\
\hline R. levis & . & . & . & . & . & . & . & . & . & . & $\cdot$ \\
\hline R. angustus & . & . & . & . & · & . & : & $\cdot$ & . & . & . \\
\hline R. reniformis & . & . & . & . & . & . & 1 & · & . & . & . \\
\hline R. splendens & . & . & . & . & . & . & · & $\cdot$ & . & . & . \\
\hline Rhagodiscus sp. 1 & . & . & . & . & $\cdot$ & $\cdot$ & . & $\cdot$ & . & . & . \\
\hline Rhagodiscus spp. indet & . & . & . & . & $\cdot$ & $\cdot$ & . & · & . & . & $\cdot$ \\
\hline Scampanella spp. & . & . & . & . & . & . & . & . & . & . & $\cdot$ \\
\hline S. fossilis & . & . & . & . & · & . & · & $\cdot$ & . & . & $\cdot$ \\
\hline S. laffittei & . & . & . & . & . & : & $\cdot$ & $\cdot$ & . & : & . \\
\hline Stephanolithion spp. & 1 & . & . & $\cdot$ & . & 1 & . & . & . & 1 & 2 \\
\hline T. stradneri & . & . & . & : & · & 1 & . & . & . & . & . \\
\hline T. ethmos & . & . & . & 1 & 1 & . & : & · & . & . & . \\
\hline T. decorus & 3 & . & 3 & . & 2 & 1 & 3 & 1 & . & 4 & 4 \\
\hline Thoracosphaera spp. & . & . & . & . & . & . & . & . & . & . & . \\
\hline T. macleodae & . & . & . & . & . & . & 2 & . & . & . & . \\
\hline T. phacelosus & . & . & . & . & . & . & . & $\dot{5}$ & $\cdot$ & . & $\cdot$ \\
\hline Vagalapilla spp. & . & . & 2 & . & · & 1 & . & 2 & . & . & . \\
\hline W. barnesae & 61 & 57 & 53 & 64 & 62 & 75 & 56 & 71 & 63 & 54 & 68 \\
\hline W. biporta & . & 1 & . & . & . & - & · & . & 1 & 1 & . \\
\hline Z. compactus & . & . & . & . & . & . & . & . & . & . & . \\
\hline Z. lacunatus & . & . & 1 & . & . & . & . & 1 & . & 1 & 3 \\
\hline Zygodiscus sp. 1 & 1 & 7 & 1 & 2 & 1 & . & . & . & 1 & 1 & . \\
\hline Unidentifiable & 11 & 8 & 8 & 6 & 8 & 18 & 6 & 7 & 6 & 10 & 5 \\
\hline Sum (excl. M. staur.) & 522 & 489 & 450 & 444 & 516 & 464 & 455 & 415 & 466 & 425 & 475 \\
\hline Micula staurophora & 84 & 75 & 87 & 115 & 138 & 109 & 102 & 112 & 123 & 123 & 117 \\
\hline Sum of M. staur. counts & 606 & 564 & 537 & 559 & 654 & 573 & 557 & 527 & 589 & 548 & 592 \\
\hline Fields of M. staur. counts & 20.0 & 20.0 & 20.0 & 25.0 & 30.0 & 25.0 & 20.0 & 20.0 & 25.0 & 20.0 & 20.0 \\
\hline
\end{tabular}




$\begin{array}{lccccccccccc} & 33 & 34 & 35 & 36 & 37 & 38 & 39 & 40 & 41 & 42 & 43 \\ \text { DSDP Hole 217 } & 217 & 217 & 217 & 217 & 217 & 217 & 217 & 217 & 217 & 217 & 217 \\ \text { Core-Section } & 19-2 & 19-4 & 20-1 & 20-1 & 20-1 & 20-2 & 20-2 & 20-2 & 20-2 & 20-2 & 20-2 \\ \text { cm-level } & 30 & 30 & 99-100 & 120-121 & 140-141 & 8 .-9 & 30 & 49-50 & 70-71 & 90 & 109-110 \\ \text { Depth (mbst) } & 441.80 & 444.80 & 450.49 & 450.70 & 450.90 & 451.08 & 451.30 & 451.49 & 451.70 & 451.90 & 452.09 \\ \text { Age (Ma) } & 67.716 & 67.905 & 68.265 & 68.279 & 68.291 & 68.303 & 68.317 & 68.329 & 68.342 & 68.354 & 68.366 \\ \text { Sed. Rate (m/m.y.) } & 15.81 & 15.81 & 15.81 & 15.81 & 15.81 & 15.81 & 15.81 & 15.81 & 15.81 & 15.81 & 15.81 \\ \text { Carbonate (wt-\%) } & 85.6 & \text { n.d. } & \text { n.d. } & \text { n.d. } & \text { n. } & \text { n.d. } & \text { n.d. } & \text { n.d. } & \text { n.d. } & \text { n.d. } & \text { n.d. } \\ \text { Preservation } & \mathrm{M} & \mathrm{M} & \mathrm{M} & \mathrm{M} & \mathrm{M} & \mathrm{M} & \mathrm{M} & \mathrm{M} & \mathrm{M} & \mathrm{M} & \mathrm{M} \\ \text { Abundance } & \mathrm{A} & \mathrm{A} & \mathrm{A} & \mathrm{A} & \mathrm{A} & \mathrm{A} & \mathrm{A} & \mathrm{A} & \mathrm{A} & \mathrm{A} & \mathrm{A} \\ \text { Fields counted } & 20.0 & 20.0 & 20.0 & 20.0 & 20.0 & 22.0 & 20.0 & 20.0 & 20.0 & 20.0 & 20.0 \\ \text { mg sediment used } & 21.3 & 21.7 & 21.2 & 21.5 & 20.7 & 20.6 & 21.7 & 20.2 & 20.8 & 20.4 & 20.5\end{array}$

\begin{tabular}{|c|c|c|c|c|c|c|c|c|c|c|c|}
\hline A. octoradiata & . & . & 3 & 5 & 2 & 4 & . & 3 & . & 3 & . \\
\hline Arkhangeiskiella spp. & 5 & 9 & 21 & 8 & 30 & 25 & 8 & 6 & 6 & 10 & 4 \\
\hline Biscutum constans & 2 & 16 & 37 & 34 & 39 & 21 & 23 & 14 & 29 & 6 & 20 \\
\hline B. magnum & . & . & . & . & . & . & . & 1 & . & . & . \\
\hline B. notaculum & . & . & . & . & . & . & . & 3 & 1 & . & 1 \\
\hline Biscutum sp. 1 & 1 & . & 9 & 11 & 8 & 5 & 7 & 5 & 7 & 15 & 6 \\
\hline Broinsonia spp. & 29 & 14 & 13 & 15 & 12 & 9 & 13 & 8 & 6 & 3 & 3 \\
\hline Arkhang./Broinsonia & $\cdot$ & . & . & . & . & $\cdot$ & $\dot{x}$ & $\cdot$ & · & . & . \\
\hline C. cf aculeus & 24 & 18 & 34 & 33 & 15 & 26 & 32 & 19 & 17 & 19 & 20 \\
\hline Chiastozygus sp. 1 & . & . & . & . & . & . & . & . & 1 & . & . \\
\hline C. completum & 1 & . & . & . & . & . & . & . & . & . & . \\
\hline C. cf. amphipons & . & . & . & . & . & . & . & · & . & . & . \\
\hline C.(7) daniae & . & 1 & . & . & 1 & . & · & $\cdot$ & . & . & . \\
\hline C. ehrenbergii & 32 & 32 & 54 & 41 & 33 & 32 & 43 & 31 & 40 & 28 & 25 \\
\hline C. angustiforatus & 17 & 4 & 13 & 11 & 1 & 3 & 2 & 4 & 6 & 9 & 6 \\
\hline C. conicus & . & 2 & 2 & 1 & 2 & . & 2 & . & . & 1 & 1 \\
\hline C. crenulatus & . & . & 1 & 2 & . & . & . & 3 & . & . & 1 \\
\hline C. schizobrachiatus & 1 & . & . & 1 & . & 1 & $\cdot$ & 1 & 1 & 1 & . \\
\hline C. surirellus & . & . & . & . & . & . & . & . & . & . & . \\
\hline Cretarhabdus spp. indet. & 61 & 50 & 55 & 57 & 41 & 19 & 53 & 32 & 53 & 36 & 63 \\
\hline C. alta & . & . & . & . & 1 & . & $\cdot$ & . & $\cdot$ & . & . \\
\hline C. reinhardtii & . & . & 3 & 2 & . & . & 1 & 2 & 1 & 2 & 2 \\
\hline C. biarcus & . & . & . & . & . & . & . & . & . & . & . \\
\hline C. gallicus & 4 & 1 & 9 & 7 & 2 & 4 & 3 & 4 & 10 & 1 & 1 \\
\hline C. serratus & . & . & . & . & . & . & 2 & . & . & . & . \\
\hline Cylindralithus sp. 1 & . & . & . & . & . & 1 & . & . & . & 1 & . \\
\hline Cylindralithus spp. indet. & . & . & . & . & . & . & . & . & . & . & . \\
\hline D. ignotus & 7 & 14 & 13 & 22 & 14 & 3 & 8 & 10 & 22 & 13 & 6 \\
\hline E. eximius & . & . & . & . & . & . & . & . & . & . & . \\
\hline E. parallelus & 5 & 2 & 4 & . & 6 & 1 & . & 3 & 4 & 2 & 3 \\
\hline E trabeculatus & . & 1 & . & 2 & . & . & . & . & . & . & 1 \\
\hline E. turriseiffelii & 29 & 11 & 17 & 18 & 24 & 21 & 21 & 15 & 27 & 18 & 9 \\
\hline Ericsonia sp. & 4 & 5 & 7 & 4 & 2 & 2 & 5 & 2 & 6 & . & 2 \\
\hline Gartnerago spp. & . & . & . & . & . & . & . & . & . & . & . \\
\hline G. fessus & 20 & 13 & 3 & 3 & 4 & 2 & 7 & 3 & 8 & 7 & 13 \\
\hline K. magnificus & . & . & . & 1 & . & . & . & . & . & . & . \\
\hline Lithastrinus spp. & 5 & 8 & 12 & 10 & 3 & 1 & 8 & 16 & 6 & 5 & 6 \\
\hline L carniolensis & . & 1 & 4 & 5 & 4 & . & 4 & 2 & 4 & 3 & 9 \\
\hline L grossopectinatus & . & . & . & . & . & . & . & . & . & . & . \\
\hline L kennethii & . & 2 & . & 1 & : & $\therefore$ & . & . & . & . & . \\
\hline L praequadratus & 8 & 13 & 9 & 8 & 7 & 10 & 4 & 5 & 8 & 9 & 6 \\
\hline $\mathrm{L}$ quadratus & 2 & 2 & . & . & . & . & 1 & . & . & . & . \\
\hline Lithraphidites(?) sp. 1 & . & 4 & . & . & . & . & . & . & . & $\cdot$ & . \\
\hline L cayeuxii & . & . & . & . & . & . & . & . & . & . & . \\
\hline M. pemmatoidea & 1 & . & . & . & . & . & 1 & . & 1 & 1 & 1 \\
\hline M. apertus & . & . & . & . & . & . & . & . & . & . & . \\
\hline M. inversus & . & P & . & . & . & . & . & $\cdot$ & . & . & . \\
\hline M. beigicus & . & 1 & . & . & . & . & . & . & . & . & 1 \\
\hline M. decoratus & 18 & 31 & 25 & 39 & 16 & 17 & 23 & 24 & 36 & 24 & 43 \\
\hline M. praemurus & . & . & . & . & . & . & $\cdot$ & . & 1 & . & 2 \\
\hline M. murus & . & . & . & . & . & . & . & $\cdot$ & $\cdot$ & . & . \\
\hline M. cf prinsii & . & . & . & . & $\cdot$ & . & $\cdot$ & $\cdot$ & $\cdot$ & $\cdot$ & . \\
\hline
\end{tabular}




$\begin{array}{lccccccccccc} & 33 & 34 & 35 & 36 & 37 & 38 & 39 & 40 & 41 & 42 & 43 \\ \text { DSDP Hole 217 } & 217 & 217 & 217 & 217 & 217 & 217 & 217 & 217 & 217 & 217 & 217 \\ \text { Core-Section } & 19-2 & 19-4 & 20-1 & 20-1 & 20-1 & 20-2 & 20-2 & 20-2 & 20-2 & 20-2 & 20-2 \\ \text { cm-level } & 30 & 30 & 99-100 & 120-121 & 140-141 & 8 .-9 & 30 & 49-50 & 70-71 & 90 & 109-110 \\ \text { Depth (mbsf) } & 441.80 & 444.80 & 450.49 & 450.70 & 450.90 & 451.08 & 451.30 & 451.49 & 451.70 & 451.90 & 452.09\end{array}$

\begin{tabular}{|c|c|c|c|c|c|c|c|c|c|c|c|}
\hline Micula? sp & . & . & . & . & . & . & . & . & . & . & . \\
\hline N. frequens & . & 1 & . & . & . & . & . & . & 1 & . & . \\
\hline P. embergeri & 2 & . & 1 & 1 & . & . & . & 1 & . & 1 & 1 \\
\hline P. regularis & 48 & 44 & 57 & 49 & 48 & 38 & 37 & 28 & 63 & 39 & 48 \\
\hline P. copulatus & . & . & . & . & . & . & . & . & 1 & . & . \\
\hline P. buseoni & 2 & 4 & . & 2 & . & . & 4 & . & . & 2 & . \\
\hline P. fibuliformis & 12 & 26 & ' 24 & 19 & 8 & 2 & 8 & 13 & 16 & 17 & 6 \\
\hline P. sigmoides & . & . & . & 1 & . & . & . & . & . & . & . \\
\hline Placozygus sp. & 3 & 5 & 8 & 9 & 6 & 6 & 9 & 11 & 8 & 9 & 9 \\
\hline P. arkhangelskyi & . & . & . & . & . & . & . & . & . & . & . \\
\hline P. cretacea & 96 & 135 & 130 & 149 & 109 & 72 & 83 & 70 & 96 & 74 & 86 \\
\hline P. spinosa & 11 & 9 & 11 & 18 & 12 & 9 & 14 & 8 & 13 & 7 & 11 \\
\hline P. grandis & 1 & 1 & . & . & . & . & . & . & . & 1 & . \\
\hline P. stoveri & 15 & 26 & 14 & 18 & 16 & 1 & 13 & 10 & 11 & 12 & 10 \\
\hline Q. garmeri & . & . & . & . & . & . & . & . & . & . & . \\
\hline R. aff. anthophorus & . & . & . & . & . & . & . & . & . & . & . \\
\hline R. levis & . & . & 1 & . & 1 & . & . & . & . & . & 1 \\
\hline R. angustus & . & . & 1 & . & . & . & . & . & 2 & . & . \\
\hline R. reniformis & . & 1 & . & . & 2 & . & . & 1 & . & 1 & 3 \\
\hline R. splendens & 3 & 4 & 2 & 5 & 5 & 1 & 8 & . & 6 & 7 & 6 \\
\hline Rhagodiscus sp. 1 & . & . & . & . & . & . & . & . & . & . & . \\
\hline Rhagodiscus spp. indet & . & . & 3 & 1 & . & . & . & . & . & . & . \\
\hline Scampanella spp. & . & . & . & . & 1 & . & . & . & . & . & . \\
\hline S. fossilis & . & . & . & . & . & . & . & . & . & . & . \\
\hline S. laffittei & . & . & . & . & . & . & . & . & . & . & . \\
\hline Stephanolithion spp. & . & 2 & 1 & 4 & 2 & . & 1 & 2 & 3 & 1 & 2 \\
\hline T. stradneri & . & . & . & . & . & . & . & . & . & . & . \\
\hline T. ethmos & . & . & . & . & 1 & 1 & . & . & . & . & . \\
\hline T. decorus & 7 & 8 & 6 & 11 & 5 & . & 3 & 2 & 7 & 5 & 4 \\
\hline Thoracosphaera spp. & . & . & 2 & . & 1 & . & 1 & . & . & . & 1 \\
\hline T. macleodae & 2 & 1 & . & 1 & . & . & . & . & . & . & . \\
\hline T. phacelosus & . & . & . & . & . & . & . & . & . & . & . \\
\hline Vagalapilla spp. & 1 & . & 2 & . & 3 & . & . & 1 & 3 & 1 & 1 \\
\hline W. barnesae & 85 & 98 & 146 & 142 & 104 & 62 & 129 & 104 & 121 & 94 & 78 \\
\hline W. biporta & . & . & 2 & . & . & . & . & . & . & . & . \\
\hline Z compactus & . & . & . & . & . & . & . & . & . & & . \\
\hline Z. lacunatus & 1 & . & . & 2 & . & 1 & . & 1 & . & . & . \\
\hline Zygodiscus sp. 1 & . & . & . & . & 1 & . & . & . & . & 1 & . \\
\hline Unidentifiable & 5 & 6 & 11 & 11 & 6 & 2 & 8 & 7 & 2 & 8 & 14 \\
\hline Sum (excl. M. staur.) & 575 & 628 & 770 & 784 & 598 & 403 & 590 & 475 & 654 & 497 & 536 \\
\hline Micula staurophora & 82 & 108 & 120 & 107 & 88 & 138 & 103 & 112 & 125 & 83 & 106 \\
\hline Sum of M. staur. counts & 652 & 734 & 890 & 891 & 686 & 540 & 692 & 587 & 779 & 580 & 642 \\
\hline Fields of M. staur. counts & 20.0 & 20.0 & 20.0 & 20.0 & 20.0 & 22.0 & 20.0 & 20.0 & 20.0 & 20.0 & 20.0 \\
\hline
\end{tabular}




\begin{tabular}{|c|c|c|c|c|c|c|c|c|c|c|c|}
\hline & 44 & 45 & 46 & 47 & 48 & 49 & 50 & 51 & 52 & 53 & 54 \\
\hline DSDP Hole 217 & 217 & 217 & 217 & 217 & 217 & 217 & 217 & 217 & 217 & 217 & 217 \\
\hline Core-Section & $20-2$ & $20-2$ & $20-3$ & $20-3$ & $20-3$ & $20-3$ & $20-3$ & $20-3$ & $20-3$ & $20-3$ & $20-4$ \\
\hline cm-level & 130 & 150 & 21.22 & $39-40$ & $60-61$ & $80-81$ & $99-100$ & 120 & $140-141$ & $149-150$ & $20-21$ \\
\hline Depth (mbsf) & 45230 & 452.50 & 452.71 & 452.89 & 453.10 & 453.30 & 453.49 & 453.70 & 453.90 & 453.99 & 454.20 \\
\hline Age (Ma) & 68.380 & 68.392 & 68.406 & 68.417 & 68.430 & 68.443 & 68.455 & 68.468 & 68.481 & 68.487 & 68.500 \\
\hline Sed. Rate (m/m.y.) & 15.81 & 15.81 & 15.81 & 15.81 & 15.81 & 15.81 & 15.81 & 15.81 & 15.81 & 15.81 & 15.81 \\
\hline Carbonate (wt-\%) & n.d. & n.d. & n.d. & n.d. & n.d. & n.d. & n.d. & n.d. & nd. & n.d. & n.d. \\
\hline Preservation & M-P & M & M & M & M & M & M & M & M & $M-P$ & $\mathrm{M}$ \\
\hline Abundance & A & A & A & A & A & A & A & A & A & A & A \\
\hline Fields counted & 20.0 & 20.0 & 20.0 & 20.0 & 20.0 & 20.0 & 20.0 & 20.0 & 20.0 & 38.0 & 20.0 \\
\hline mg rediment used & 20.6 & 20.3 & 20.1 & 20.4 & 20.0 & 20.1 & 20.0 & 20.6 & 20.9 & 20.1 & 20.0 \\
\hline A. octoradiata & 1 & 1 & 1 & 2 & . & . & 3 & . & 1 & . & 1 \\
\hline Arkhangeiskiella spp. & 5 & 20 & 10 & 13 & 9 & 18 & 12 & 18 & 21 & 39 & 26 \\
\hline Biscutum constans & 10 & 12 & 13 & 3 & 8 & 5 & 33 & 9 & 7 & 17 & 47 \\
\hline B. magnum & . & . & . & . & . & . & . & . & . & . & . \\
\hline B. notaculum & . & 2 & . & . & 2 & . & . & 1 & 1 & . & 1 \\
\hline Biscutum sp. 1 & . & 4 & . & 5 & 5 & 3 & 3 & 3 & 2 & 1 & 9 \\
\hline Broinsonia spp. & 3 & 3 & 6 & 7 & 4 & 12 & 3 & 4 & 9 & 8 & 16 \\
\hline Arkhang./Broinsonia & . & . & . & . & . & . & . & . & . & . & . \\
\hline C. cf aculeus & 29 & 34 & 32 & 21 & 35 & 17 & 24 & 30 & 21 & 26 & 30 \\
\hline Chiastozygus sp. 1 & . & & . & . & . & . & : & . & . & . & . \\
\hline C. completum & . & . & . & . & . & . & 1 & . & . & . & . \\
\hline C. cf. amphipons & . & . & . & . & . & . & . & . & . & . & . \\
\hline C. $($ ?) daniae & . & . & . & . & . & . & . & . & . & . & . \\
\hline C. ehrenbergii & 20 & 26 & 24 & 51 & 40 & 44 & 32 & 37 & 24 & 23 & 33 \\
\hline C. angustiforatus & 2 & 7 & 3 & 2 & 1 & 7 & 5 & 5 & 5 & 4 & 6 \\
\hline C. conicus & 2 & 4 & . & 2 & 1 & 1 & . & . & 1 & 1 & 2 \\
\hline C. crenulatus & 1 & . & . & . & 1 & 1 & 1 & 1 & . & 2 & . \\
\hline C. schizobrachiatus & . & . & 1 & . & . & 1 & . & . & . & . & 1 \\
\hline C. surirellus & . & . & . & . & . & . & . & . & 1 & . & . \\
\hline Cretarhabdus spp. indet. & 26 & 35 & 22 & 46 & 33 & 67 & 44 & 24 & 35 & 27 & 43 \\
\hline C. alta & . & . & 1 & . & . & . & . & . & . & 3 & . \\
\hline C. reinhardtii & 1 & 1 & 2 & 2 & 1 & . & 2 & . & 1 & 1 & . \\
\hline C. biarcus & . & . & . & . & . & . & . & . & . & . & . \\
\hline C. gallicus & 1 & . & 2 & 8 & 1 & 1 & 5 & 3 & 3 & . & 1 \\
\hline C. serratus & . & . & . & . & . & . & . & . & . & . & . \\
\hline Cylindralithus sp. 1 & 2 & . & . & 1 & . & 1 & . & . & . & 1 & . \\
\hline Cylindralithus spp. indet. & . & . & . & . & . & . & . & . & . & . & . \\
\hline D. ignotus & 6 & 9 & 12 & 14 & 14 & 9 & 15 & 17 & 5 & 2 & 31 \\
\hline E. eximius & . & . & . & . & . & . & . & . & . & . & . \\
\hline E. parallelus & . & . & 2 & 3 & . & . & 1 & 1 & 1 & 1 & 2 \\
\hline E. trabeculatus & . & 2 & . & . & 2 & 2 & . & . & 1 & . & 1 \\
\hline E. turriseiffelii & 23 & 36 & 26 & 39 & 21 & 15 & 21 & 12 & 7 & 8 & 24 \\
\hline Ericsonia sp. & 4 & . & . & . & 4 & 11 & 3 & 1 & 4 & . & 1 \\
\hline Gartnerago spp. & . & . & . & . & . & . & 1 & . & . & . & . \\
\hline G. fessus & 2 & 5 & 3 & 7 & 3 & 7 & 10 & 4 & 8 & 11 & 8 \\
\hline K. magnificus & 1 & 1 & . & . & 2 & . & . & . . & . & . & . \\
\hline Lithas trinus spp. & 6 & 6 & 10 & 2 & 7 & 1 & 5 & 8 & 2 & 5 & 6 \\
\hline L carniolensis & 9 & 3 & 2 & 11 & 10 & 2 & 7 & 3 & 7 & 13 & 7 \\
\hline L grossopectinatus & . & . & . & . & . & . & . & . & . & . & . \\
\hline L kennethii & . & . & . & . & . & . & . & . & . & . & . \\
\hline L praequadratus & 6 & 5 & 5 & 5 & 8 & 6 & 10 & 3 & 3 & 10 & 12 \\
\hline L quadratus & 1 & 1 & . & . & . & . & . & . & . & . & . \\
\hline Lithraphidites(?) sp. 1 & . & . & . & . & . & . & $\cdot$ & . & . & . & $\cdot$ \\
\hline L cayeuxii & . & . & . & . & : & : & . & . & . & . & $\cdot$ \\
\hline M. pemmatoidea & . & 1 & . & . & 1 & 1 & . & . & . & · & $\cdot$ \\
\hline M. apertus & . & . & . & . & . & . & . & . & . & . & $\cdot$ \\
\hline M. inversus & . & $P$ & 1 & . & . & . & . & . & . & . & $\cdot$ \\
\hline M. belgicus & . & . & . & . & . & 1 & . & . & . & . & . \\
\hline M. decoratus & 27 & 39 & 36 & 33 & 35 & 22 & 40 & 22 & 19 & 33 & 34 \\
\hline M. praemurus & . & 1 & 1 & . & 1 & 2 & . & 1 & . & . & . \\
\hline M. murus & . & . & . & . & . & . & . & . & . & . & . \\
\hline M. cf prinsii & . & . & . & . & . & . & . & . & . & . & . \\
\hline
\end{tabular}




$\begin{array}{lccccccccccc} & 44 & 45 & 46 & 47 & 48 & 49 & 50 & 51 & 52 & 53 & 54 \\ \text { DSDP Hole 217 } & 217 & 217 & 217 & 217 & 217 & 217 & 217 & 217 & 217 & 217 & 217 \\ \text { Core-Section } & 20-2 & 20-2 & 20-3 & 20-3 & 20-3 & 20-3 & 20-3 & 20-3 & 20-3 & 20-3 & 20-4 \\ \text { cm-level } & 130 & 150 & 21-22 & 39-40 & 60-61 & 80-81 & 99-100 & 120 & 140-141 & 149-150 & 20-21 \\ \text { Depth (mbsf) } & 452.30 & 452.50 & 452.71 & 452.89 & 453.10 & 453.30 & 453.49 & 453.70 & 453.90 & 453.99 & 454.20\end{array}$

\begin{tabular}{|c|c|c|c|c|c|c|c|c|c|c|c|}
\hline Micula? sp & . & . & . & . & . & . & . & . & . & . & . \\
\hline N. frequens & . & . & . & 1 & . & . & . & . & . & . & . \\
\hline P. embergeri & 1 & 2 & . & . & 1 & 1 & 1 & . & . & . & 1 \\
\hline P. regularis & 19 & 38 & 29 & 31 & 24 & 38 & 29 & 18 & 17 & 15 & 31 \\
\hline P. copulatus & 1 & . & . & . & . & . & . & . & . & . & 1 \\
\hline P. bussoni & . & . & . & 1 & . & . & . & . & . & . & . \\
\hline P. fibuliformis & 5 & 10 & 7 & 8 & 22 & 18 & 9 & 21 & 21 & 19 & 28 \\
\hline P. sigmoides & . & . & . & . & 1 & . & . & . & . & . & 1 \\
\hline Placozygus sp. & 11 & 3 & 4 & 3 & 3 & 5 & 5 & 10 & 5 & 6 & 3 \\
\hline P. arkhangelskyi & . & . & . & . & . & . & . & . & . & . & . \\
\hline P. cretacea & 64 & 87 & 68 & 87 & 83 & 104 & 70 & 77 & 62 & 47 & 82 \\
\hline P. spinosa & 2 & 7 & 6 & 7 & 6 & 9 & 5 & 9 & 3 & 1 & 8 \\
\hline P. grandis & 1 & 2 & . & . & . & . & . & . & . & . & . \\
\hline P. stoveri & 3 & 11 & 6 & 7 & 12 & 7 & 7 & 3 & 9 & 2 & 8 \\
\hline Q. gartneri & 1 & . & . & 1 & . & . & . & . & . & . & . \\
\hline R. aff. anthophorus & . & . & . & . & . & · & . & . & . & . & . \\
\hline R. levis & . & . & 2 & . & 1 & & . & : & . & . & 1 \\
\hline R. angustus & . & 1 & . & . & 1 & . & 2 & 1 & . & . & . \\
\hline R. reniformis & . & 1 & 1 & 2 & 1 & 1 & . & . & 1 & . & 1 \\
\hline R. splendens & 2 & 5 & 1 & 4 & 1 & 3 & . & . & . & . & 4 \\
\hline Rhagodiscus sp. 1 & . & . & . & . & . & . & . & . & . & . & . \\
\hline Rhagodiscus spp. indet & . & . & . & 4 & . & . & . & . & . & . & . \\
\hline Scampanella spp. & . & . & . & . & . & . & . & . & . & . & . \\
\hline S. fossilis & . & . & . & . & . & . & . & . & . & . & . \\
\hline S. laffittei & . & . & . & . & . & . & . & . & . & 1 & . \\
\hline Stephanolithion spp. & . & . & . & 1 & . & 1 & 2 & 1 & 1 & 1 & 6 \\
\hline T. stradneri & . & . & . & . & . & 1 & . & . & . & 1 & . \\
\hline T. ethmos & . & . & . & . & . & . & . & . & - & - & . \\
\hline T. decorus & 2 & 1 & 5 & 3 & . & 2 & 7 & & 2 & 1 & 2 \\
\hline Thoracosphaera spp. & 1 & . & . & . & 1 & . & 3 & . & . & , & 2 \\
\hline T. macleodae & . & 1 & . & . & . & . & . & 1 & . & . & 1 \\
\hline T. phacelosus & . & . & . & . & . & . & . & 1 & . & . & 1 \\
\hline Vagalapilla spp. & 1 & 2 & 1 & 2 & . & 1 & 3 & . & 1 & . & 4 \\
\hline W. barnesae & 116 & 80 & 84 & 99 & 116 & 110 & 83 & 94 & 135 & 125 & 100 \\
\hline W. biporta & . & , & . & . & . & . & 3 & 2 & . & 2 & . \\
\hline Z. compactus & . & & . & . & . & . & . & . & . & . & . \\
\hline Z. lacunatus & 1 & . & . & 3 & . & 3 & . & . & 2 & 4 & . \\
\hline Zygodiscus sp. 1 & . & - & . & . & . & - & 1 & . & . & 1 & . \\
\hline Unidentifiable & 6 & 6 & 5 & 9 & 5 & 2 & 9 & 5 & 5 & 6 & 13 \\
\hline Sum (excl. M. staur.) & 425 & 516 & 434 & 550 & 527 & 563 & 520 & 450 & 453 & 468 & 640 \\
\hline Micula staurophora & 145 & 95 & 104 & 86 & 100 & 100 & 81 & 94 & 78 & 128 & 72 \\
\hline Sum of M. staur. counts & 570 & 610 & 538 & 636 & 627 & 663 & 601 & 544 & 531 & 596 & 712 \\
\hline Fields of M. staur. counts & 20.0 & 20.0 & 20.0 & 20.0 & 20.0 & 20.0 & 20.0 & 20.0 & 20.0 & 38.0 & 20.0 \\
\hline
\end{tabular}




$\begin{array}{lccccccccccc} & 55 & 56 & 57 & 58 & 59 & 60 & 61 & 62 & 63 & 64 & 65 \\ \text { DSDP Hole 217 } & 217 & 217 & 217 & 217 & 217 & 217 & 217 & 217 & 217 & 217 & 217 \\ \text { Core-Section } & 20-4 & 20-4 & 20-4 & 20-4 & 20-4 & 20-4 & 21-2 & 21-4 & 22-1 & 22-3 & 23-2 \\ \text { cm-level } & 30 & 39-40 & 59-60 & 80-81 & 99-100 & 119-120 & 32-34 & 15-17 & 56-57 & 32-33 & 64-65 \\ \text { Depth (mbst) } & 454.30 & 454.39 & 454.59 & 454.80 & 454.99 & 455.19 & 460.82 & 463.65 & 469.06 & 471.82 & 480.14 \\ \text { Age (Ma) } & 68.506 & 68.512 & 68.525 & 68.538 & 68.550 & 68.563 & 68.919 & 69.098 & 69.440 & 69.614 & 70.141 \\ \text { Sed. Rate (m/m.y.) } & 15.81 & 15.81 & 15.81 & 15.81 & 15.81 & 15.81 & 15.81 & 15.81 & 15.81 & 15.81 & 15.81 \\ \text { Carbonate (wt-\%) } & \text { n.d. } & \text { n.d. } & \text { n.d. } & \text { n.d. } & \text { n.d. } & \text { n.d. } & \text { n.d. } & \text { n.d. } & \text { n.d. } & \text { n.d. } & \text { n.d. } \\ \text { Preservation } & \mathrm{M} & \mathrm{M} & \mathrm{M}-\mathrm{P} & \mathrm{M} & \mathrm{M} & \mathrm{M} & \mathrm{M} & \mathrm{M} & \mathrm{M} & \mathrm{M}-\mathrm{P} & \mathrm{M} \\ \text { Abundance } & \mathrm{A} & \mathrm{A} & \mathrm{A}-\mathrm{C} & \mathrm{A} & \mathrm{A} & \mathrm{A} & \mathrm{A} & \mathrm{A}-\mathrm{A} A & \mathrm{~A} & \mathrm{~A} & \text { A } \\ \text { Fields counted } & 20.0 & 20.0 & 30.0 & 20.0 & 20.0 & 22.0 & 20.0 & 20.0 & 20.0 & 20.0 & 21.0 \\ \text { mg rediment used } & 20.5 & 20.0 & 20.4 & 20.3 & 20.3 & 20.6 & 21.5 & 21.2 & 20.9 & 21.4 & 21.4\end{array}$

A. octoradiat $\begin{array}{llllllllllll}\text { Arkhangelskiella spp. } & 8 & 23 & 26 & 18 & 5 & 24 & 20 & 10 & 28 & 15 & 8\end{array}$ $\begin{array}{llllllllllll}\text { Biscutum constans } & 57 & 17 & 26 & 17 & 16 & 23 & 49 & 36 & 44 & 20 & 45\end{array}$

B. magnum

B. notaculum

Biscutum sp. 1

Broinsonia spp.

Arkhang./Broinsonia

C. cf aculeus

Chiastozygus sp. 1

C. completum

C. cf. amphipons

C.(?) daniae

C. ehrenbergii

C. angustiforatus

C. conicus

C. crenulatus

C. schizobrachiatus

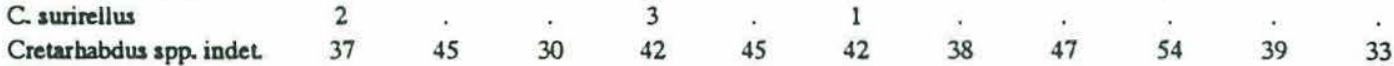

C. alta

C. reinhardtii

C. biarcus

C. gallicus

C. serratus

Cylindralithus sp. 1

Cylindralithus spp. indet.

D. ignotus

E. eximius

E. parallelus

E. trabeculatus

E turriseiffelii

Ericsonia sp.

Gartnerago spp.

G. fessus

K. magnificus

Lithastrinus spp.

L. carniolensis

L grossopectinatus

L. kennethii

L praequadratus

L quadratus

Lithraphidites(?) sp. 1

L. cayeuxii

M. pemmatoidea

M. apertus

M. inversus

M. belgicus

M. decoratus

M. praemurus

M. murus

M. cf prinsii 


$\begin{array}{lccccccccccc} & 55 & 56 & 57 & 58 & 59 & 60 & 61 & 62 & 63 & 64 & 65 \\ \text { DSDP Hole 217 } & 217 & 217 & 217 & 217 & 217 & 217 & 217 & 217 & 217 & 217 & 217 \\ \text { Core-Section } & 20-4 & 20-4 & 20-4 & 20-4 & 20-4 & 20-4 & 21-2 & 21-4 & 22-1 & 22-3 & 23-2 \\ \text { cm-level } & 30 & 39-40 & 59-60 & 80-81 & 99-100 & 119-120 & 32-34 & 15-17 & 56-57 & 32-33 & 64-65 \\ \text { Depth (mbsf) } & 454.30 & 454.39 & 454.59 & 454.80 & 454.99 & 455.19 & 460.82 & 463.65 & 469.06 & 471.82 & 480.14\end{array}$

Micula? sp

$\mathrm{N}$. frequens

P. embergeri

P. regularis

P. copulatus

P. bussoni

P. fibuliformis

P. sigmoides

Placozygus sp.

P. arkhangetsikyi

P. cretacea

P. spinosa

P. grandis

P. stoveri

Q. gartmeri

R. aff. anthophorus

R. levis

$R$. angustus

$R$. reniformis

R. splendens

Rhagodiscus sp. 1

Rhagodiscus spp. indet

Scampanella spp.

S. fossilis

S. laffittei

Stephanolithion spp.

T. stradneri

T. ethmos

T. decorus

Thoracosphaera spp.

T. macieodae

T. phacelosus

Vagalapilla spp.

W. barnesae

W. biporta

Z. compactus

Z. lacunatus

Zygodiscus sp. 1

Unidentifiable

Sum (excl. M. staur.)

Micula staurophora

Sum of M. staur. counts

.

Fields of M. staur. counts

is

$25 \quad 13$

. 22

i1 $\quad \begin{gathered}2 \\ .\end{gathered}$

i 5 i

$66 \quad 89 \quad 32$

$\begin{array}{llllllll}i & . & i & 2 & i & 4 & . & 1 \\ . & 1 & . & . & . & . & . & .\end{array}$

$\begin{array}{llllllll}25 & 22 & 24 & 48 & 60 & 19 & 19 & 17\end{array}$

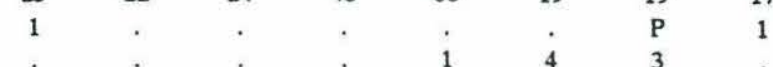

$\begin{array}{llllllll}27 & 17 & 20 & 11 & 12 & 18 & 7 & 31\end{array}$

$\begin{array}{llllllll}64 & 50 & 67 & 69 & 125 & 97 & 82 & 80\end{array}$

$\begin{array}{lll}7 & 4 & 4\end{array}$

$\begin{array}{llll}7 & 8 & 2 \\ 9 & 9\end{array}$ 


$\begin{array}{lccc} & 66 & 67 & 68 \\ \text { DSDP Hole 217 } & 217 & 217 & 217 \\ \text { Core-Section } & 23-4 & 24-2 & 24-4 \\ \text { cm-level } & 53-54 & 51-53 & 32-33 \\ \text { Depth (mbst) } & 483.03 & 489.51 & 492.32 \\ \text { Age (Ma) } & 70.323 & 70.733 & 70.911 \\ \text { Sed. Rate (m/m.y.) } & 15.81 & 15.81 & 15.81 \\ \text { Carbonate (wt-\%) } & \text { n.d. } & \text { n.d. } & 86.7 \\ \text { Preservation } & \text { M } & \text { M-P } & \text { M-P } \\ \text { Abundance } & \text { A } & \text { A } & \text { A } \\ \text { Fields counted } & 20.0 & 21.0 & 20.0 \\ \text { mg sediment used } & 20.9 & 21.6 & 21.5\end{array}$

\begin{tabular}{|c|c|c|c|}
\hline A. octoradiata & 10 & 17 & 9 \\
\hline Arkhangelskiella spp. & 15 & 16 & 10 \\
\hline Biscutum constans & 16 & 8 & 16 \\
\hline B. magnum & . & 1 & 1 \\
\hline B. notaculum & . & 2 & 1 \\
\hline Biscutum sp. 1 & 5 & 8 & 15 \\
\hline Broinsonia spp. & 5 & 7 & 2 \\
\hline Arkhang./Broinsonia & . & . & . \\
\hline C. cf aculeus & 2 & 8 & 5 \\
\hline Chiastozygus sp. 1 & . & , & . \\
\hline C. completum & . & . & . \\
\hline C. cf. amphipons & . & . & . \\
\hline C.(?) daniae & . & . & . \\
\hline C. ehrenbergii & 30 & 24 & 19 \\
\hline C. angustiforatus & 8 & 4 & 5 \\
\hline C. conicus & . & 3 & 1 \\
\hline C. crenulatus & . & . & . \\
\hline C. schizobrachiatus & . & . & . \\
\hline C. surirellus & . & . & . \\
\hline Cretarhabdus spp. indet & 24 & 31 & 20 \\
\hline C. alta & . & 1 & . \\
\hline C. reinhardtii & 1 & . & 1 \\
\hline C. biarcus & 7 & 3 & . \\
\hline C. gallicus & . & . & . \\
\hline C. serratus & 1 & . & . \\
\hline Cylindralithus sp. 1 & 1 & . & . \\
\hline Cylindralithus spp. indet. & 1 & 4 & . \\
\hline D. ignotus & 41 & 30 & 47 \\
\hline E. eximius & . & . & . \\
\hline E. parallelus & 1 & 1 & 3 \\
\hline E trabeculatus & 2 & . & 2 \\
\hline E. turriseiffelii & 10 & 20 & 32 \\
\hline Ericsonia sp. & 2 & . & 1 \\
\hline Gartnerago spp. & . & . & 2 \\
\hline G. fessus & 7 & 8 & 12 \\
\hline K. magnificus & . & 1 & . \\
\hline Lithas trinus spp. & 9 & 5 & 5 \\
\hline L carniolensis & 3 & 5 & 7 \\
\hline L grossopectinatus & . & . & . \\
\hline L. kennethii & . & . & . \\
\hline L praequadratus & 1 & 1 & . \\
\hline $\mathrm{L}$ quadratus & $\cdot$ & . & . \\
\hline Lithraphidites(?) sp. 1 & . & . & . \\
\hline L cayeuxii & . & . & . \\
\hline M. pemmatoidea & . & . & . \\
\hline M. apertus & . & . & . \\
\hline M. inversus & . & . & . \\
\hline M. belgicus & . & . & . \\
\hline M. decoratus & 55 & 5 & 38 \\
\hline M. praemurus & . & . & . \\
\hline M. murus & . & . & . \\
\hline M. cf prinsii & . & . & . \\
\hline
\end{tabular}




\begin{tabular}{|c|c|c|c|}
\hline & 66 & 67 & 68 \\
\hline DSDP Hole 217 & 217 & 217 & 217 \\
\hline Core-Section & $23-4$ & $24-2$ & $24-4$ \\
\hline cm-level & $53-54$ & $51-53$ & $32-33$ \\
\hline Depth (mbst) & 483.03 & 489.51 & 492.32 \\
\hline Micula? sp & . & . & . \\
\hline N. frequens & . & . & . \\
\hline P. embergeri & . & . & . \\
\hline P. regularis & 18 & 28 & 28 \\
\hline P. copulatus & . & . & 1 \\
\hline P. bussoni & . & . & 1 \\
\hline P. fibuliformis & 15 & 22 & ' 22 \\
\hline P. sigmoides & . & . & . \\
\hline Placozygus sp. & 3 & 3 & 4 \\
\hline P. arkhangelskyi & . & 1 & . \\
\hline P. cretacea & 55 & 95 & 88 \\
\hline P. spinosa & 14 & 8 & 15 \\
\hline P. grandis & 2 & 3 & 4 \\
\hline P. stoveri & 3 & 18 & 15 \\
\hline Q. garmeri & . & . & . \\
\hline R. aff. anthophorus & . & . & 4 \\
\hline R. levis & . & . & 4 \\
\hline R. angustus & 1 & 1 & . \\
\hline R. reniformis & . & 1 & 1 \\
\hline R. splendens & 2 & 2 & 5 \\
\hline Rhagodiscus sp. 1 & . & . & . \\
\hline Rhagodiscus spp. indet & . & . & . \\
\hline Scampanella spp. & . & . & . \\
\hline S. fossilis & . & . & . \\
\hline S. laffittei & . & . & . \\
\hline Stephanolithion spp. & . & . & . \\
\hline T. stradneri & . & . & . \\
\hline T. ethmos & . & . & 1 \\
\hline T. decorus & 4 & 1 & 6 \\
\hline Thoracosphaera spp. & . & . & . \\
\hline T. macleodae & 2 & . & . \\
\hline T. phacelosus & . & 1 & 2 \\
\hline Vagalapilla spp. & 3 & 6 & 1 \\
\hline W. barnesae & 48 & 33 & 58 \\
\hline W. biporta & 1 & . & . \\
\hline Z. compactus & 1 & 3 & 6 \\
\hline Z. lacunatus & 1 & . & 1 \\
\hline Zygodiscus sp. 1 & . & . & 2 \\
\hline Unidentifiable & 7 & 7 & 8 \\
\hline Sum (excl. M. staur.) & 437 & 446 & 531 \\
\hline Micula staurophora & 66 & 93 & 100 \\
\hline Sum of M. staur. counts & 503 & 539 & 631 \\
\hline Fields of M. staur. counts & 20.0 & 21.0 & 20.0 \\
\hline
\end{tabular}




\begin{tabular}{|c|c|c|c|c|c|c|c|c|c|c|c|c|c|c|c|c|c|c|c|c|c|c|}
\hline & 1 & 2 & 3 & 4 & 5 & 6 & 7 & 8 & 9 & 10 & 11 & 12 & 13 & 14 & 15 & 16 & 17 & 18 & 19 & 20 & 21 & 22 \\
\hline DSDP Hole 528 & 528 & 528 & 528 & 528 & 528 & 528 & 528 & 528 & 523 & 528 & 528 & 528 & 528 & 528 & 528 & 528 & 528 & 528 & 528 & 528 & 528 & 528 \\
\hline Core-Section & 31.7 & $31-c c$ & $31-\mathrm{cc}$ & $31-\mathrm{cc}$ & $32-1$ & $32-1$ & 32.1 & $32-1$ & $32-1$ & 32.1 & $32-1$ & 32.1 & $32-1$ & $32-1$ & 32.1 & $32-1$ & $32-1$ & $32-1$ & $32-1$ & $32-1$ & $32-1$ & $32-1$ \\
\hline $\mathrm{cm}$-level & $58-59$ & 5.6 & 10 & 14 & 8 & 14 & 19 & 25 & 31 & 37 & 41 & $46-47$ & 52.53 & 58.59 & $63-64$ & $70-71$ & $75-76$ & $80-81$ & $86-87$ & 91.92 & 97.98 & 99.100 \\
\hline Depth (mbsf) & 406.70 & 406.85 & 406.90 & 406.94 & 407.08 & 407.14 & 407.19 & 407.25 & 407.31 & 40737 & 407.41 & 407.46 & 407.52 & 407.58 & 407.63 & 407.70 & 407.75 & 407.80 & 407.86 & 407.91 & 407.97 & 407.99 \\
\hline Age (Ma) & 66.262 & 66.331 & 66.354 & 66.372 & 66.404 & 66.408 & 66.410 & 66.413 & 66.417 & 66.420 & 66.422 & 66.425 & 66.428 & 66.431 & 66.434 & 66.438 & 66.440 & 66.443 & 66.446 & 66.449 & 66.452 & 66.453 \\
\hline Sedimentation Rate (m/m.y.) & 2.17 & 2.17 & 2.17 & 2.17 & 18.53 & 18.53 & 18.53 & 18.53 & 18.53 & 18.53 & 18.53 & 18.53 & 18.53 & 18.53 & 18.53 & 18.53 & 18.53 & 18.53 & 18.53 & 18.53 & 18.53 & 18.53 \\
\hline Carbonate Content (welght- $\%$ ) & 626 & 70.5 & 72.1 & 47.6 & 67.9 & 63.8 & 60.9 & 59.0 & 64.9 & 2.9 & 74.8 & 75.3 & 68.6 & 59.1 & 56.1 & 50.7 & 57.8 & 70.9 & 79.1 & 82.8 & 83.6 & 71.7 \\
\hline Preservation & $\mathrm{P}$ & M.P & $\mathrm{P}$ & $\mathbf{P}$ & M & $M \cdot G$ & M & M & $M-G$ & M & M & M.P & $P$ & M.P & $\mathrm{P}$ & $\mathrm{P}-\mathrm{M}$ & $\mathrm{P}$ & $M-P$ & $\mathrm{P}$ & P-M & M & $\mathrm{M}$ \\
\hline Abundance & c & $\mathrm{c}$ & $C_{R}$ & $\mathrm{~A}-\mathrm{C}$ & A & A & $\mathrm{A}$ & A & A & A & A & A & A & $\mathrm{A}$ & $\mathrm{CA}$ & A & A & A & A & $\mathrm{A}$ & A & A \\
\hline Fleids counted & 60.0 & 48.4 & 67.8 & 59.0 & 30.0 & 38.0 & 30.0 & 30.0 & 36.0 & 35.0 & 44.0 & 53.9 & 30.0 & 30.0 & 30.0 & 20.0 & 35.0 & 20.0 & 30.0 & 30.0 & 20.0 & 20.0 \\
\hline mg sediment used & 20.1 & 20.3 & 18.9 & 19.5 & 18.3 & 20.2 & 19.9 & 19.4 & 20.6 & 18.8 & 19.2 & 19.3 & 20.9 & 19.7 & 19.5 & 20.5 & 20.2 & 19.8 & 19.0 & 20.0 & 20.2 & 19.4 \\
\hline Ahmuellerella octoradiata & . & . & . & & . & & . & $?$ & & . & . & . & 3 & . & & . & 4 & . & . & 1 & . & \\
\hline Arkhangelskiella spp. & 4 & 7 & 4 & 10 & 31 & 30 & 23 & 20 & 18 & 22 & 22 & 29 & 14 & 14 & 13 & 16 & 8 & 11 & 21 & 14 & 12 & 9 \\
\hline Arkhangelskiella/Brolnsonla & $0^{\circ}$ & . & . & . & . & . & . & . & . & & . & & . & & . & . & . & . & . & . & . & . \\
\hline Biantholithus sparsus & - & . & . & . & . & . & . & . & . & . & . & . & : & : & . & . & : & . & . & . & : & : \\
\hline Biscutum constans & 24 & 21 & 12 & 17 & 1 & 1 & - & 1 & 1 & 4 & 2 & 1 & - & - & . & 1 & - & 1 & - & 1 & - & 1 \\
\hline B. notaculum & . & . & . & . & . & . & . & . & . & 1 & 1 & . & . & & . & . & . & . & . & . & . & . \\
\hline Biscutum sp. 1 & . & . & . & . & . & . & . & 1 & . & 4 & . & . & . & . & . & . & . & 4 & . & . & 4 & 2 \\
\hline Braarudosphaera bigelowit & 1 & . & 1 & 2 & . & . & . & . & . & . & . & . & . & . & . & . & . & . & . & . & . & . \\
\hline Broinsonia spp. & . & . & . & . & . & . & . & . & . & . & . & . & . & . & . & . & . & . & . & . & . & . \\
\hline Calculites obscurus & . & . & 12 & . & . & . & . & . & . & . & . & . & . & . & $0^{\prime}$ & . & . & . & . & . & . & . \\
\hline Ceratolithoides kamptneri & 1 & . & 1 & 9 & 1 & 2 & 4 & 1 & . & . & 2 & - & 2 & . & 8 & 1 & . & 1 & 3 & . & . & 1 \\
\hline Chiastozygus amphipons & - & 5 & 1 & . & . & . & . & . & . & . & . & . & . & : & . & . & . & : & . & : & & \\
\hline Chlastozygus sp. 1 & 2 & . & . & . & . & . & . & . & 1 & - & $i$ & . & - & - & . & . & . & - & . & - & - & 1 \\
\hline Corollithlon completum & . & . & . & : & : & . & . & - & . & i & . & . & : & . & . & . & : & . & . & : & . & . \\
\hline C. exiguum & 3 & 3 & . & 1 & 1 & . & . & . & . & 4 & . & . & 2 & . & . & 2 & 1 & . & . & & . & . \\
\hline Cretarhabdus angustiforatus & 1 & 3 & 1 & 3 & 2 & 7 & . & 1 & 1 & 4 & 3 & 3 & 1 & 1 & 1 & 2 & 6 & 5 & 7 & 7 & 7 & 1 \\
\hline C. conicus & . & . & - & . & - & 4 & 1 & 2 & - & 1 & . & 1 & 1 & - & . & . & - & . & 1 & 2 & . & . \\
\hline C. crenulatus & 1 & . & - & 1 & . & 1 & 4 & 1 & 2 & 3 & 1 & $i$ & : & 1 & . & 6 & 3 & 3 & s & 1 & . & 1 \\
\hline C. schizobrachlatus & . & . & . & . & . & . & - & - & - & - & . & . & - & - & . & . & 1 & 1 & - & 2 & 2 & - \\
\hline C. surirellus & . & . & . & . & . & . & . & . & . & 1 & . & . & . & . & . & - & $i$ & 2 & - & 4 & 7 & 7 \\
\hline Cretarhabdus spp. & 2 & i & . & s & . & 4 & s & 12 & 6 & 9 & i1 & s & s & io & 3 & 1 & 14 & 10 & 9 & 12 & 10 & 12 \\
\hline Cribrosphaerella(?) daniae & & & $i$ & & & & & 1 & & 2 & & & 2 & • & . & $i$ & & - & . & - & 1 & : \\
\hline Cribrosphaerella ehrenbergil & 2 & 20 & 8 & 6 & 34 & 42 & 41 & 32 & 42 & 39 & 86 & 40 & 29 & 34 & 20 & 26 & 30 & 14 & 32 & 48 & 35 & 23 \\
\hline Cruciplacolithus spp. & . & . & . & . & . & . & . & . & . & . & . & ? & . & . & . & . & . & . & . & . & . & . \\
\hline Cyclagelopshaera alta & & & & $\dot{7}$ & ; & ; & 2 & & i & 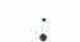 & 2 & 2 & , & ; & 7 & 5 & ; & 0 & $\therefore$ & $\dot{0}$ & $\dot{7}$ & , \\
\hline Cyclagelosphaera reinhardtil & 22 & 19 & 32 & 47 & 4 & 5 & 2 & $\begin{array}{l}5 \\
8\end{array}$ & 1 & : & 2 & 2 & 2 & 4 & $?$ & 5 & 6 & 9 & 16 & 6 & 7 & 2 \\
\hline & . & 1 & 1 & 5 & 8 & 11 & 11 & 8 & 10 & 9 & $\begin{array}{l}10 \\
.\end{array}$ & 10 & 11 & 8 & 9 & $\begin{array}{l}10 \\
.\end{array}$ & 5 & 6 & 9 & 17 & $\begin{array}{l}2 \\
1\end{array}$ & 8 \\
\hline $\begin{array}{l}\text { C. serratus } \\
\text { Discorhabdus ignotus }\end{array}$ & $i$ & i & 3 & : & i & $\dot{3}$ & 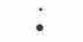 & $\dot{2}$ & 4 & 8 & $i$ & : & 3 & 3 & . & $\dot{2}$ & $i$ & $\dot{2}$ & i & 4 & 6 & i1 \\
\hline Eiffellithus parallelus & 1 & 2 & 1 & . & 3 & 2 & 3 & 3 & 1 & 6 & s & 2 & 2 & 1 & . & : & 1 & : & $i$ & 3 & 2 & 1 \\
\hline E. trabeculatus & . & . & 3 & . & 1 & 3 & 1 & 2 & 4 & 6 & 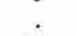 & . & 3 & $i$ & $i$ & - & 7 & 1 & 8 & 9 & 11 & 13 \\
\hline E. turriseiffell & 4 & 6 & 7 & 3 & 23 & 18 & 12 & 11 & 3 & 15 & 24 & 7 & 15 & 14 & 8 & 8 & 8 & 11 & 9 & 13 & 11 & 8 \\
\hline Ericsonla sp. & . & . & . & 4 & & . & . & 3 & 7 & . & . & . & . & ? & . & 4 & . & - & . & & & 3 \\
\hline Gartnerago spp. & 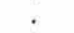 & 1 & . & . & - & - & : & : & : & 2 & 3 & . & . & 2 & . & . & $i$ & - & . & : & : & 1 \\
\hline Glaukolithus fessus & 2 & 3 & 2 & . & 8 & 4 & 3 & 7 & 5 & 12 & 6 & 4 & 12 & 6 & 5 & 9 & 13 & 13 & 13 & 14 & 10 & 9 \\
\hline Hexalithus spp. & 3 & 3 & 1 & 1 & . & . & . & . & . & . & . & " & 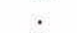 & 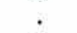 & . & . & . & 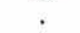 & . & . & . & . \\
\hline Kamptnerlus magnificus & . & 1 & . & . & 4 & - & - & 1 & 1 & 2 & 2 & 1 & 2 & 1 & . & . & - & 1 & 2 & 1 & 1 & 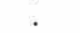 \\
\hline Lithastrinus spp. & 2 & 2 & 1 & 4 & . & 1 & 1 & 1 & 3 & 1 & 3 & 2 & . & 1 & . & 3 & 1 & 1 & 3 & 1 & 2 & 2 \\
\hline
\end{tabular}


Sample-Depth (mbsi)

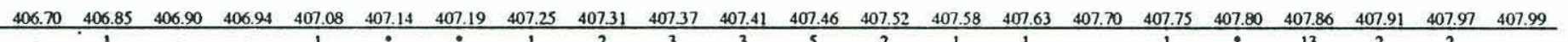

Lithraphidites carniolensis

L grossopectinatus

L praequadratus

Lithraph. sp. of L. kennethil

Luclanorhabdus cayeuxll

Manlvitella pemmatoldea

Markallus apertus

Markalius inversus

Microrhabdulus belgicus

M. decoratus

M. murus/prins

M. prinsil

M. swastlke
Micula? sp.

Neocrepidolithus spp.

Nephrolithus frequens

Placozygus fibuliformis

P. bussoni

P. sigmoides

Podorhabdus regular

Prediscosphaera cretacea

P. grandis

P. spinosa

Prinsius tenuiculum

Quadrum gartnerl

Relnhardtites levis

Rhagodiscus spp.

Rhombolithlon rhomblcum Rucinollthus hayl

Scampanella asymmetrica Scampanella spp.

Staurolithites laffitte

Stephanolithion spp.

Tegumentum stradnerl

Teichorhabdus ethmos

Tetrapodorhabdus decor

Thoracosphaera spp.
Tranolithus macleodae

Tranolithus macleod

Vagalapilla spp.
Watznaueria barnesae

Watznaueria

W. biporta
Zygodiscus lacunatus

Zygodiscus sp.1

Zygolithus diplogrammus Und

M. staurophora

M. staurophora - Fields

Micula staurophora

Sum of $M$. stauroph. count

\begin{tabular}{|c|c|c|c|c|c|c|c|c|c|c|c|c|c|c|c|c|c|c|c|c|c|}
\hline$\therefore$ & $\therefore$ & 1 & . & : & . & . & . & . & . & . & . & . & . & . & . & . & . & . & . & . & \\
\hline 5 & 5 & 13 & 20 & $\dot{0}$ & 16 & 13 & 16 & 28 & 28 & 39 & 39 & 23 & 17 & 12 & 19 & 30 & 22 & 37 & 25 & 30 & 22 \\
\hline 1 & . & . & 1 & 7 & 12 & 11 & 9 & 13 & 11 & 1 & $\bullet$ & 2 & 6 & 5 & 6 & 6 & 2 & 2 & 15 & 3 & 4 \\
\hline : & $\vdots$ & $i$ & $\dot{i}$ & : & 3 & 7 & : & 2 & $i$ & ; & $\dot{3}$ & 3 & : & $\dot{.}$ & $i$ & : & $\dot{1}_{1}$ & $i$ & 3 & $\vdots$ & $\therefore$ \\
\hline . & ; & $\cdot$ & $\cdot$ & $\cdot$ & . & $\cdot$ & . & $\cdot$ & $\cdot$ & . & . & . & $\cdot$ & . & . & . & . & . & $\cdot$ & . & . \\
\hline$n$ & 2 & i & 17 & : & : & : & . & : & . & . & $\cdot$ & $\cdot$ & $\dot{n}$ & $\cdot$ & . & . & . & . & : & - & . \\
\hline 2 & 11 & 14 & 17 & 1 & 3 & 3 & $i$ & 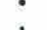 & : & . & . & . & ? & $\cdot$ & . & . & . & . & • & . & . \\
\hline i & ; & 1 & $\dot{u}$ & 10 & 18 & 18 & $\begin{array}{c}1 \\
14\end{array}$ & 1 & 2 & 1 & 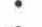 & - & : & $\therefore$ & $\therefore$ & ${ }^{\circ}$ & $\dot{ }$ & 1 & 2 & $\bullet$ & 1 \\
\hline 4 & 5 & 5 & . & 13 & 22 & 25 & $\begin{array}{l}14 \\
10\end{array}$ & 18 & 22 & 14 & 9 & 9 & 6 & 10 & 12 & 16 & 26 & 24 & 33 & 24 & 18 \\
\hline & & & & & & - & $\begin{array}{l}10 \\
3\end{array}$ & 22 & 10 & 16 & 14 & 20 & 19 & 3 & 7 & 5 & 6 & 11 & 18 & 4 & 8 \\
\hline & & & & & & & 3 & 1 & . & . & : & 2 & 2 & 2 & 4 & 6 & - & 5 & . & $\bullet$ & • \\
\hline 1 & $\vdots$ & $?$ & $\begin{array}{l}4 \\
.\end{array}$ & ? & $:$ & ; & $\cdot$ & $\cdot$ & & . & $?$ & 1 & 3 & $\cdot$ & 3 & ; & $\cdot$ & $\cdot$ & $\cdot$ & $\cdot$ & . \\
\hline$:$ & $\cdot$ & $\dot{.}$ & $\dot{.}$ & $\dot{.}$ & 11 & 10 & 3 & $i$ & $\cdot$ & : & $\therefore$ & : & 1 & $\therefore$ & : & 1 & i & $\dot{4}$ & $\dot{3}$ & j & $\cdot$ \\
\hline 10 & 10 & 1 & . & . & . & . & . & . & 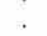 & . & . & . & 15 & . & . & 1 & . & . & . & . & : \\
\hline 1 & 10 & 2 & 3 & 8 & 2 & 2 & 1 & 4 & 13 & 15 & 3 & 5 & 1 & 1 & 1 & 3 & 2 & 1 & 3 & 4 & 4 \\
\hline 2 & 3 & $\bullet$ & 4 & 3 & 2 & 7 & 7 & 7 & 16 & 16 & 6 & 11 & 3 & . & 2 & 13 & 5 & 3 & 8 & 20 & 19 \\
\hline : & & $\dot{\sim}$ & $\therefore$ & . & $\cdot$ & $\cdot$ & $\bullet$ & $\cdot$ & 2 & : & . & 1 & • & . & . & 1 & • & • & • & 1 & 1 \\
\hline 49 & 18 & 22 & 17 & $i$ & $\dot{z}$ & : & i & i & ; & 2 & 1 & 1 & . & ; & : & : & i & $?$ & 1 & ; & : \\
\hline$\therefore$ & $\begin{array}{c}2 \\
11\end{array}$ & $\begin{array}{l}1 \\
4\end{array}$ & i1 & 15 & 17 & 19 & 18 & 23 & 27 & 29 & $\therefore$ & $\begin{array}{r}2 \\
18\end{array}$ & 14 & 7 & 12 & 12 & $\begin{array}{l}4 \\
25\end{array}$ & 2 & 1 & 2 & i \\
\hline $\begin{array}{l}10 \\
15\end{array}$ & 41 & 16 & 34 & 64 & 61 & 82 & 50 & 62 & 61 & $\begin{array}{l}29 \\
132\end{array}$ & 11 & $\begin{array}{l}18 \\
88\end{array}$ & 57 & 35 & 41 & 70 & 61 & $\begin{array}{l}26 \\
91\end{array}$ & 30 & $\begin{array}{l}33 \\
51\end{array}$ & $\begin{array}{l}21 \\
73\end{array}$ \\
\hline 1 & . & . & 2 & 1 & • & • & • & $\bullet$ & 1 & 1 & $\begin{array}{l}40 \\
.\end{array}$ & $\begin{array}{c}\infty \\
1\end{array}$ & • & 1 & . & • & 1 & 1 & $?^{94}$ & 1 & . \\
\hline 3 & 14 & 4 & 5 & 13 & 14 & 7 & 19 & 12 & 15 & 15 & 2 & 9 & 7 & 1 & 6 & 15 & 7 & 8 & 14 & 14 & 3 \\
\hline 6 & 11 & 8 & 9 & 18 & 32 & 40 & 24 & 33 & 55 & 49 & 16 & 26 & 25 & 12 & 27 & 46 & 21 & 19 & 37 & 36 & 38 \\
\hline 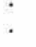 & $i$ & : & $i$ & $i$ & $i$ & i & $\therefore$ & i. & i. & $i$ & : & i. & : & : & : & : & : & $i$ & . & $\dot{v}$ & $i$ \\
\hline . & ; & ; & $\cdot$ & i & i & $\therefore$ & : & : & : & : & : & ; & : & . & : & 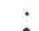 & : & : & . & $\therefore$ & $\dot{\theta}^{\circ}$ \\
\hline . & 1 & 3 & $\cdot$ & 3 & 3 & 1 & 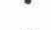 & 1 & 4 & 2 & 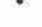 & 2 & 1 & . & 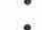 & : & 1 & 2 & 4 & 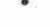 & 2 \\
\hline . & 1 & $\cdot$ & $\cdot$ & ${ }^{\circ}$ & . & $\cdot$ & . & : & $\cdot$ & $\cdot$ & . & $\bullet$ & $\cdot$ & . & $\bullet$ & 1 & $\cdot$ & 1 & ${ }^{\circ}$ & . & . \\
\hline$\cdot$ & $\cdot$ & 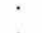 & $\cdot$ & i & i & $\cdot$ & $\cdot$ & . & $\cdot$ & $\cdot$ & $\cdot$ & $\cdot$ & $\cdot$ & $\cdot$ & $\cdot$ & $\cdot$ & $\cdot$ & $\cdot$ & $\cdot$ & : & $\cdot$ \\
\hline$:$ & $\vdots$ & $\cdot$ & $\vdots$ & $\therefore$ & : & 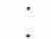 & $\vdots$ & : & 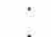 & : & 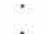 & : & $i$ & : & . & : & $\cdot$ & $\cdot$ & $\cdot$ & 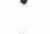 & . \\
\hline 1 & 3 & • & . & . & • & 1 & 1 & . & . & 3 & 1 & . & . & . & . & . & . & . & : & . & $\vdots$ \\
\hline . & 4 & 2 & . & $\bullet$ & . & $\cdot$ & $\cdot$ & 1 & 3 & 1 & . & 1 & . & . & 1 & • & • & 2 & 2 & 3 & 1 \\
\hline : & $\vdots$ & $\dot{.}$ & : & $\vdots$ & $\vdots$ & : & $\therefore$ & : & $\dot{.}$ & i & : & : & $\dot{.}$ & 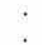 & 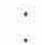 & $\stackrel{\circ}{\circ}$ & 1 & - & 1 & • & ${ }^{\circ}$ \\
\hline 1 & 3 & 2 & 1 & 3 & 2 & 1 & 2 & • & 2 & 1 & • & 1 & • & . & 2 & 3 & 2 & 3 & 3 & $j$ & 5 \\
\hline 131 & 79 & 109 & 106 & . & . & . & . & . & . & . & • & 1 & . & & . & - & & - & - & & \\
\hline 1 & 1 & 1 & : & 3 & 11 & 4 & 4 & • & 3 & 4 & 2 & 2 & ${ }^{\circ}$ & ${ }^{\circ}$ & 1 & 3 & 5 & 2 & 2 & 2 & 2 \\
\hline 1 & 1 & 2 & 1 & 3 & $\therefore$ & 1 & 5 & 2 & 3 & 4 & $\therefore$ & 2 & 1 & 1 & 2 & 1 & $\dot{0}$ & $\dot{x}$ & 1 & 2 & $\dot{0}$ \\
\hline 5 & 12 & 7 & 13 & 24 & 48 & 30 & 43 & 38 & 43 & 49 & 68 & 61 & 47 & 32 & 30 & 50 & 40 & $\pi$ & 56 & 67 & 62 \\
\hline${ }^{\circ}$ & $\cdot$ & $\cdot$ & . & : & . & ; & ; & $\dot{0}$ & • & $\cdot$ & : & ; & : & 1 & $\vdots$ & . & : & : & : & : & 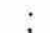 \\
\hline - & $\cdot$ & $\cdot$ & . & 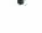 & . & 1 & 1 & : & : & $\cdot$ & 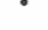 & 2 & $\bullet$ & 1 & ${ }^{\bullet}$ & $\dot{0}$ & ; & : & : & $:$ & 1 \\
\hline$\cdot$ & i & : & . & s. & $\cdot$ & 1 & 1 & 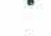 & 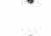 & $\cdot$ & $\cdot$ & 1 & $\cdot$ & $\cdot$ & 1 & 2 & 2 & 1 & • & 5 & 3 \\
\hline 17 & 20 & 5 & 27 & 11 & 10 & 1 & 9 & 13 & 21 & 14 & 6 & 13 & 13 & 4 & 4 & 21 & 19 & $\dot{8}$ & 18 & ; & 12 \\
\hline 363 & 369 & 316 & 406 & 325 & 426 & 398 & 359 & 401 & 506 & 607 & 351 & 427 & 341 & 20 & 286 & 421 & 356 & 486 & 536 & 448 & 417 \\
\hline 60 & 48 & 68 & 59 & 30 & 38 & 30 & 30 & 36 & 35 & 30 & 54 & 30 & 30 & 30 & 20 & 35 & 20 & 30 & 30 & 20 & 20 \\
\hline 18 & 63 & 21 & 85 & 113 & 188 & 198 & 185 & 185 & 151 & 189 & 488 & 317 & 287 & 238 & 161 & 155 & 109 & 209 & 139 & 63 & 90 \\
\hline 381 & 432 & 337 & 491 & 438 & 614 & 596 & 544 & 586 & 657 & 593 & 839 & 744 & 628 & 458 & 447 & 576 & 465 & 695 & 675 & 511 & 507 \\
\hline
\end{tabular}




\begin{tabular}{|c|c|c|c|c|c|c|c|c|c|c|c|c|c|c|c|c|c|c|c|c|c|c|}
\hline & 23 & 24 & 25 & 26 & 27 & 28 & 29 & 30 & 31 & 32 & 33 & 34 & 35 & 36 & 37 & 38 & 39 & 40 & 41 & 42 & 43 & 44 \\
\hline DSDP Hole 528 & 528 & 528 & 528 & 528 & 528 & 528 & 528 & 528 & 528 & 528 & 528 & 528 & 528 & 528 & 528 & 528 & 528 & 528 & 528 & 528 & 528 & 528 \\
\hline Core-Section & $32-1$ & 32.1 & $32-1$ & $32-1$ & $32-1$ & $32-1$ & $32-1$ & $32-1$ & $32-1$ & $32-2$ & $32-2$ & $32-2$ & $32-3$ & $32-3$ & $32-3$ & 32.3 & 32.3 & $32-4$ & $32-4$ & $32-4$ & $32-4$ & $32-5$ \\
\hline $\mathrm{cm}$-level & $104-105$ & 109110 & $114-115$ & $119-120$ & $125-126$ & $130-131$ & 134.135 & $140-141$ & $146-147$ & 2930 & $68-69$ & 108.109 & $18-19$ & 49.50 & $81-82$ & $101-102$ & $131-132$ & $4 .-5$ & 34.35 & 77.78 & $103-104$ & $9 .-10$ \\
\hline Depth (mbsf) & 408.04 & 408.09 & 408.14 & 408.19 & 408.25 & 408.30 & 408.34 & 408.40 & 408.46 & 408.79 & 409.18 & 409.58 & 410.18 & 410.49 & 410.81 & 411.01 & 41131 & 411.54 & 411.84 & 412.27 & 41253 & 413.09 \\
\hline Age $(\mathrm{Ma})$ & 66.456 & 66.459 & 66.462 & 66.464 & 66.467 & 66.470 & 66.472 & 66.476 & 66.479 & 66.497 & 66518 & 66.539 & 66.572 & 66.588 & 66.606 & 66.616 & 66.633 & 66.645 & 66.661 & 66.684 & 66.698 & 66.729 \\
\hline Sedimentation Rate ( $m / m . y)$. & 1853 & 18.53 & 18.53 & 18.53 & 18.53 & 18.53 & 18.53 & 18.53 & 18.53 & 18.53 & 18.53 & 18.53 & 18.53 & 1853 & 18.53 & 18.53 & 18.53 & 18.53 & 1853 & 18.53 & 18.53 & 18.53 \\
\hline Carbonate Content (weight-\%) & 62.1 & 60.4 & 61.8 & 65.1 & 2.6 & 78.6 & 78.3 & 79.7 & 66.4 & 83.1 & 81.8 & 86.9 & 85.9 & a.d. & a.d. & o.d. & ad. & a.d. & a.d. & ad. & n.d. & 80.8 \\
\hline Preservation & $\mathbf{P}$ & P & $\mathbf{P}$ & M-P & M & P-M & M & M & P.M & M-P & M & M-G & M & M & M & M-P & M & M & $M-P$ & M & M & M \\
\hline Abundance & A & A & A & A & A & A & A & A & A & A & A & A & A & A & A & A & A & A & A & A & $\mathbf{A}$ & A \\
\hline Fields counted & 30.0 & 30.0 & 40.0 & 30.0 & 20.0 & 30.0 & 20.0 & 20.0 & 300 & 40.0 & 20.0 & 20.0 & 20.0 & 20.0 & 20.0 & 20.0 & 20.0 & 20.0 & 20.0 & 20.0 & 20.0 & 20.0 \\
\hline mg sediment used & 21.8 & 19.8 & 20.0 & 20.5 & 20.2 & 20.0 & 19.8 & 19.5 & 19.7 & 20.2 & 19.7 & 20.7 & 19.4 & 21.1 & 17.9 & 19.6 & 20.5 & 21.1 & 20.4 & 20.5 & 20.9 & 18.5 \\
\hline Ahmuellerella octoradiata & & & & & & & & & & & & & & & 1 & & & & & & 5 & 1 \\
\hline Arkhangelsklella spp. & 7 & 12 & 10 & 23 & 10 & 11 & 9 & 6 & 22 & 17 & 4 & 6 & 4 & 10 & s & 13 & ii & 3 & 1 & 3 & 1 & 4 \\
\hline Arkhangelsklella/Broinsonla & . & . & . & . & . & & . & . & . & & . & . & . & . & 2 & . & . & . & . & . & . & . \\
\hline Biantholithus sparsus & . & . & . & . & . & : & : & : & . & : & . & . & . & : & . & . & . & . & . & . & . & . \\
\hline Biscutum constans & . & . & . & . & . & 1 & - & - & : & - & . & . & . & : & - & . & . & - & 1 & - & 1 & . \\
\hline B. notaculum & 1 & . & . & . & . & . & . & . & 1 & . & . & . & . & - & . & . & . & . & . & . & . & . \\
\hline Biscutum sp. 1 & . & . & . & . & . & 1 & 1 & 4 & . & 3 & 1 & 1 & 4 & 5 & 2 & 3 & 1 & . & 1 & 4 & 1 & . \\
\hline Braarudosphaera bigelowil & . & . & . & . & . & . & . & . & . & . & . & . & . & . & . & . & . & . & . & . & . & . \\
\hline Broinsonia spp. & . & . & . & . & . & . & . & . & . & . & . & . & . & . & 1 & . & . & 2 & 9 & 11 & 17 & 17 \\
\hline Calculites obscurus & . & . & . & . & . & . & . & . & . & . & . & . & . & . & . & . & . & $\ldots$ & . & . & . & . \\
\hline Ceratolithoides kamptneri & 2 & 2 & 6 & 2 & i & i & . & . & . & 2 & 3 & . & 3 & . & . & . & . & : & $i$ & . & $i$ & $i$ \\
\hline Chlastozygus amphipons & . & . & . & . & . & . & . & . & . & . & . & . & . & . & . & . & . & . & . & . & . & . \\
\hline Chlastozygus sp. 1 & . & . & . & . & - & . & . & . & . & - & . & . & 1 & . & 5 & 1 & . & . & . & . & . & . \\
\hline Corollithlon completum & . & . & . & . & . & . & . & . & . & . & . & . & . & . & . & - & . & . & . & . & . & . \\
\hline C. exiguum & 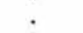 & . & . & : & & . & . & . & . & . & . & . & • & • & . & . & i & 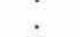 & & 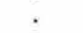 & & . \\
\hline Cretarhabdus angustiforatus & 2 & 4 & 3 & 5 & 3 & 4 & 4 & 1 & 4 & 3 & 5 & 9 & 5 & 4 & 1 & - & 6 & s & - & - & 1 & \\
\hline C. conicus & . & . & . & . & - & - & - & - & 1 & . & - & - & . & - & - & - & 1 & . & - & . & . & - \\
\hline C. crenulatus & . & - & i & i & . & - & . & 1 & . & 4 & . & . & : & 2 & 2 & 1 & 3 & : & . & $\mathrm{i}$ & : & 1 \\
\hline c. schizobrachiatus & $i$ & - & . & $i$ & : & - & 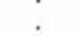 & $i$ & . & - & : & : & 1 & : & : & : & 2 & $i$ & . & $i$ & . & i \\
\hline C. surirellus & i & $?$ & 1 & $i$ & 2 & 2 & 2 & 2 & . & 4 & 2 & 3 & 10 & 4 & 3 & 9 & 3 & 3 & $i$ & 4 & $i$ & 3 \\
\hline Crotarhabdus spp. & 10 & 6 & 6 & 9 & 10 & 13 & 8 & 15 & 14 & 18 & 11 & . & 5 & 12 & 16 & 17 & 17 & 8 & 3 & 13 & is & 11 \\
\hline Cribrosphaerella(?) daniae & 1 & - & . & 2 & . & • & & - & & . & 2 & : & - & 1 & & & $\because$ & - & - & ? & 1 & 2 \\
\hline Cribrosphaerella ehrenbergll & 45 & 42 & 16 & 34 & 15 & 32 & 23 & 23 & 35 & 35 & 21 & 8 & 18 & 32 & 34 & 31 & 25 & 27 & 24 & 16 & 25 & 14 \\
\hline Cruciplacolithus spp. & . & . & . & . & . & . & . & . & $0^{\circ}$ & . & . & . & . & . & . & . & . & . & . & . & . & . \\
\hline Cyclagelopshaera alta & . & . & . & . & $0^{\circ}$ & . & . & . & 1 & . & & . & . & . & . & . & . & . & . & . & . & . \\
\hline Cyclagelosphaera reinhardtil & 1 & 4 & 4 & 1 & 3 & - & 11 & 9 & - & 2 & 2 & 1 & 1 & $\therefore$ & : & $\therefore$ & $\therefore$ & : & - & : & : & : \\
\hline Cylindralithus gallicus & 9 & 11 & 8 & 13 & 7 & 9 & 2 & 3 & 4 & 16 & 7 & 9 & 2 & 7 & 8 & 14 & 13 & 3 & 11 & 4 & 6 & $s$ \\
\hline C. serratus & 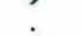 & . & . & 1 & . & . & : & . & . & . & . & . & . & . & . & . & & & . & . & . & . \\
\hline Discorhabdus Ignotus & 2 & . & . & 1 & 4 & . & . & 6 & . & - & 8 & 8 & 11 & 15 & 3 & 4 & 9 & 5 & 4 & 12 & 5 & 6 \\
\hline Eiffellithus parallelus & 1 & . & . & 2 & - & 2 & $i$ & 2 & 2 & 1 & 2 & 2 & 2 & 2 & 2 & 2 & . & 1 & . & . & 2 & . \\
\hline E. trabeculatus & 3 & $i$ & $i$ & . & 5 & 2 & 6 & 4 & 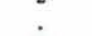 & 4 & 1 & 9 & 10 & 17 & 7 & 5 & i & 4 & $i$ & $i$ & 5 & $i$ \\
\hline E. turrlseiffell & 14 & 6 & 3 & 19 & 4 & 18 & 6 & 12 & 18 & 21 & 10 & 6 & 9 & 16 & 15 & 10 & 11 & 15 & 6 & 12 & 22 & 15 \\
\hline Ericsonia sp. & . & . & . & . & 1 & 18 & . & . & 12 & 18 & . & . & . & . & . & - & . & . & . & 1 & . & . \\
\hline Gartnerago spp. & - & 1 & . & - & . & & . & - & . & & 1 & . & . & . & . & . & . & . & . & . & 1 & . \\
\hline Glaukollthus fessus & 9 & 7 & 7 & 9 & 4 & 11 & s & 6 & 10 & 12 & 4 & 9 & 10 & 10 & 7 & 12 & 14 & 7 & 10 & 10 & 5 & 13 \\
\hline Hexallithus spp. & : & . & . & ; & : & ; & . & : & : & . & ; & . & . & ; & ; & : & : & $:$ & ; & ; & ; & : \\
\hline $\begin{array}{l}\text { Kamptnerlus magnificus } \\
\text { Uthastrinus spp. }\end{array}$ & $\dot{4}$ & ; & ; & $\begin{array}{l}1 \\
2\end{array}$ & $\dot{2}$ & $\begin{array}{l}2 \\
4\end{array}$ & i & $\dot{2}$ & $\dot{i}$ & i & 1 & i & i & $\begin{array}{l}1 \\
1\end{array}$ & $\begin{array}{l}1 \\
4\end{array}$ & $\dot{6}$ & $\bullet$ & $\dot{3}$ & $\begin{array}{l}1 \\
1\end{array}$ & $?$ & $\frac{1}{3}$ & i \\
\hline
\end{tabular}


Sample-Depth (mbsi

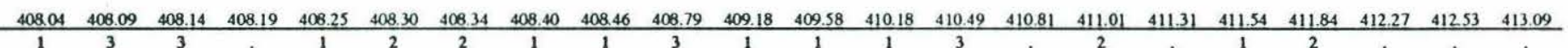
Lithraphidites carnlolensis

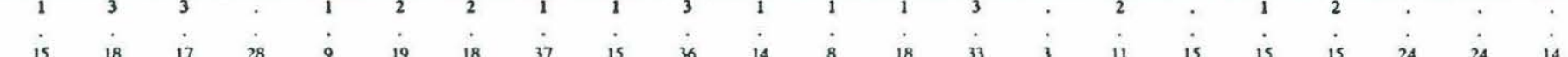

Lreoguadinatus

L. quadratus

Lithraph. sp. of. L. kennethil

Luclanorhabdus cayeux\|I

Manlvitella pemmatolde日

Markalius apertus

Markalius Inversus

Microrhabdulus belgicus

M. decoratus

Micula murus
M. murus/prinsi

M. prinsil

M. swastika

Neocrepidolithus spp.

Nephrolithus frequens

Placozygus fibuliformis

P. bussoni

P. sigmoides

Placozygus sp.

Podorhabdus regularis

Prediscosphaera cretace

P. grandis
P. spinosa

P. spinosa

Prinslus tenuiculum

Quadrum gartneri

Reinhardtites

Rhagodiscus spp.

Ahombollthlon rhomblcum

Rucinolithus hayl

Scampanella asymmetrica Scampanella spp.

Staurolithites laffittel

Stephanolithion spp.

Tegumentum stradneri

Teichorhabdus ethmos

Tetrapodorhabdus decorus

Thoracospheera spp.

Tranolithus macleodae

Vagalapilla spp.

Watznaueria barnesae

W. biporta

Zygodiscus lacunatus

Zygodlscus sp. 1

Zygollthus diplogrammus Unidentifiable

Sum (excl. M. staurophora)

M. staurophora - Fields

Micula staurophora
Sum of M. stauroph. count

\begin{tabular}{|c|c|c|c|c|c|c|c|c|c|c|c|c|c|c|c|c|c|}
\hline 15 & 18 & 17 & 28 & 9 & 19 & 18 & 37 & 15 & 36 & 14 & 8 & 18 & 33 & 3 & 11 & is & 1 \\
\hline 1 & 5 & 2 & 1 & 2 & 14 & 4 & 7 & 6 & 13 & 3 & 1 & 2 & 8 & 1 & 1 & 1 & 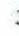 \\
\hline 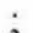 & : & . & i & : & ; & : & $\bullet$ & . & . & . & . & . & . & . & . & . & \\
\hline . & . & : & . & . & . & $\begin{array}{l}1 \\
.\end{array}$ & $\vdots$ & $\vdots$ & : & $\therefore$ & $\vdots$ & $\vdots$ & : & i & : & : & \\
\hline . & $\cdot$ & . & . & • & & . & . & . & . & . & . & . & 1 & • & . & . & \\
\hline : & $\cdot$ & . & . & . & : & : & : & . & • & . & . & • & 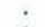 & . & . & . & \\
\hline & & $\therefore$ & & in & $\dot{n}$ & 1 & $\dot{0}$ & in & 6 & 2 & $\dot{0}$ & 2 & $\dot{ }$ & & & & \\
\hline 13 & 18 & 11 & 22 & 12 & 23 & 29 & 23 & 19 & 34 & 20 & 29 & 24 & 36 & 17 & 16 & 27 & 2 \\
\hline 10 & 12 & 14 & 19 & 7 & 18 & 13 & 6 & 9 & 10 & 8 & 11 & 9 & 8 & 10 & 7 & 8 & \\
\hline 6 & 2 & 7 & 6 & 4 & 1 & 4 & 1 & $?$ & . & 1 & 5 & 2 & . & 3 & 1 & 2 & \\
\hline . & . & 2 & . & . & . & $\cdot$ & . & . & . & . & . & $\cdot$ & . & . & . & . & \\
\hline : & 3 & 8 & 8 & 8 & 8 & 4 & 3 & io & 2 & ; & 4 & $i$ & . & ; & : & $i$ & \\
\hline . & $\therefore$ & 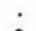 & & 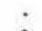 & : & . & . & . & . & . & . & . & . & ${ }^{\circ}$ & . & . & \\
\hline 2 & 2 & 2 & $\bullet$ & $\bullet$ & 3 & 2 & • & • & 4 & 4 & 4 & 3 & 1 & $\bullet$ & • & 2 & \\
\hline 15 & 7 & 5 & 13 & 17 & 16 & 13 & 10 & 30 & 20 & 8 & 12 & 16 & 40 & 41 & 12 & 19 & \\
\hline$\bullet$ & . & . & 1 & 1 & . & . & 1 & • & $\bullet$ & 2 & . & $\cdot$ & 2 & $\bullet$ & . & $\bullet$ & \\
\hline ; & j & . & : & 2 & ${ }_{3}$ & ; & i & i & i & i & ; & i & j & i & : & i & \\
\hline 18 & 12 & 21 & 26 & 30 & 46 & 25 & 37 & 18 & 65 & 37 & 23 & 35 & 35 & 22 & 30 & 26 & 3 \\
\hline 84 & 63 & 37 & 75 & 51 & 71 & 62 & 71 & 63 & 93 & 66 & 81 & 103 & 78 & 82 & $n$ & 82 & \\
\hline • & 1 & . & 1 & & • & 2 & • & 1 & • & • & 3 & 1 & • & 1 & 1 & 1 & \\
\hline 23 & 18 & 2 & 16 & 8 & 7 & 2 & 12 & 12 & 30 & 11 & 18 & 11 & 20 & 19 & 13 & 26 & \\
\hline 55 & 15 & 11 & 29 & 15 & 31 & 22 & 26 & 30 & 51 & 24 & 14 & 27 & 33 & 31 & 31 & 50 & \\
\hline
\end{tabular}




\begin{tabular}{|c|c|c|c|c|c|c|c|c|c|c|c|c|c|c|c|c|c|c|c|c|c|}
\hline & 45 & 46 & 47 & 48 & 49 & so & 51 & 52 & 53 & 54 & 55 & 56 & 57 & 58 & 59 & 60 & 61 & 62 & 63 & 64 & 65 \\
\hline DSDP Hole 528 & 528 & 528 & 528 & 528 & 528 & 528 & 528 & 528 & 528 & 528 & 528 & 528 & 528 & 528 & 528 & 528 & 528 & 528 & 528 & 528 & 528 \\
\hline Core-Section & $32-5$ & $32-5$ & $32-5$ & 32.5 & $32 . \mathrm{CC}$ & $33-1$ & $33-1$ & $33-1$ & $33-1$ & $33-2$ & $33-2$ & $33-2$ & $33-2$ & $33-3$ & $33-3$ & $33-3$ & $33-3$ & $33-4$ & $33-4$ & $33-4$ & $33-4$ \\
\hline $\mathrm{cm}$-level & 49.50 & $86-87$ & $108-109$ & 132-133 & $9 .-10$ & $12 .-13$ & 58.59 & $91-92$ & $124-125$ & $23-23$ & $59-60$ & $112-113$ & $143-144$ & $1 .-2$ & $55-56$ & $80-81$ & 132.133 & 10.-11 & $41-42$ & $101-102$ & $141-142$ \\
\hline Depth (mbsf) & 413.49 & 413.86 & 414.08 & 414.32 & 416.50 & 416.62 & 417.08 & 417.41 & 417.74 & 418.23 & 418.59 & 419.12 & 419.43 & 419.51 & 420.05 & 420.30 & 420.82 & 421.10 & 421.41 & 422.01 & 42241 \\
\hline Age $(\mathrm{Ma})$ & 66.751 & 66.773 & 66.786 & 66.801 & 66.930 & 66.938 & 66.965 & 66.985 & 67.004 & 67.033 & ๑.055 & 67.086 & 67.105 & 67.110 & 67.142 & 67.157 & 67.188 & 67.204 & 67.223 & 67.258 & 67.282 \\
\hline Sedimentation Rate (m/m.y.) & 16.80 & 16.80 & 16.80 & 16.80 & 16.80 & 16.80 & 16.80 & 16.80 & 16.80 & 16.80 & 16.80 & 16.80 & 16.80 & 16.80 & 16.80 & 16.80 & 16.80 & 16.80 & 16.80 & 16.80 & 16.80 \\
\hline Carbonate Content (welght-\%) & n.d. & a.d. & n.d. & n.d. & a.d. & n.d. & ad. & n.d. & a.d. & 78.2 & a.d. & ad. & o.d. & 72.2 & ad. & a.d. & ad & 79.7 & n.d. & ad. & 62.0 \\
\hline Preservation & $M$ & M & M & M & $\mathrm{M}$ & $\mathrm{M}$ & M & M & $M-G$ & M & M & M & $M-G$ & M & M & M & M & M & M & M & M \\
\hline Abundance & A & A & A & A & A & A & A & A & A & A & A & A & A & A & A & A & A & A & A & A & A \\
\hline Fields counted & 20.0 & 20.0 & 20.0 & 20.0 & 20.0 & 20.0 & 30.0 & 20.0 & 20.0 & 20.0 & 40.0 & 40.0 & 20.0 & 20.0 & 20.0 & 20.0 & 20.0 & 20.0 & 20.0 & 20.0 & 20.0 \\
\hline mg sediment used & 19.8 & 20.5 & 20.8 & 20.2 & 20.4 & 20.9 & 19.0 & 20.2 & 18.8 & 18.2 & 17.6 & 18.5 & 20.4 & 19.6 & 20.1 & 19.8 & 18.9 & 19.9 & 18.9 & 18.7 & 19.9 \\
\hline Ahmuellerella octoradiata & $\bullet$ & 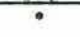 & . & . & 1 & . & $?$ & . & . & 5 & 3 & - & 2 & . & . & . & . & . & . & . & . \\
\hline Arkhangelskiella spp. & 5 & 6 & - & . & 1 & 3 & 1 & 4 & 2 & 3 & 10 & 12 & 12 & 8 & 2 & 2 & 3 & - & 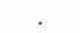 & . & \\
\hline Arkhangelsklella/Broinsonia & . & & . & & & & & . & 3 & 9 & 9 & 26 & 11 & 15 & 3 & 4 & 6 & 1 & 4 & 4 & is \\
\hline Bianthollthus sparsus & . & . & . & . & . & . & . & . & . & . & . & . & & & . & . & . & . & . & . & . \\
\hline Biscutum constans & - & . & - & - & . & - & 4 & 7 & 1 & s & 8 & 48 & 18 & 14 & 32 & 42 & 21 & . & : & $i$ & : \\
\hline B. notaculum & . & . & . & . & . & . & . & . & . & 1 & - & 2 & 2 & & 1 & . & 2 & 1 & 1 & $i$ & \\
\hline Biscutum sp. 1 & . & 1 & 1 & . & . & 2 & 1 & 6 & 2 & 8 & 4 & 12 & 5 & 7 & 14 & 11 & 5 & 2 & $i$ & 2 & 16 \\
\hline Braarudosphaera bigelowli & . & . & . & . & . & . & . & . & . & . & . & . & . & . & & . & . & . & . & . & . \\
\hline Broinsonla spp. & 7 & 8 & 8 & 10 & 7 & 6 & 5 & . & 7 & 3 & 3 & 1 & 1 & 2 & . & . & . & . & . & . & . \\
\hline Calculites obscurus & . & . & . & . & . & . & . & . & . & ; & $\dot{x}$ & i & ; & : & $\therefore$ & : & i & $\therefore$ & $\therefore$ & $\therefore$ & $\therefore$ \\
\hline Ceratolitholdes kamptneri & . & . & . & . & . & 2 & . & . & 1 & 2 & 20 & 9 & 2 & 5 & 11 & 5 & 4 & 10 & 13 & 24 & \\
\hline Chiastozygus amphipons & . & . & . & . & . & . & : & : & . & . & : & ; & ; & . & . & . & . & . & . & . & $\cdot$ \\
\hline $\begin{array}{l}\text { Chiastozygus sp. } 1 \\
\text { Corollithion completum }\end{array}$ & : & : & . & : & : & : & : & $\dot{.}$ & : & : & 1 & 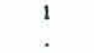 & ? & : & : & : & : & : & : & : & : \\
\hline C. exiguum & 2 & 2 & - & . & 1 & - & 1 & . & 1 & 2 & 1 & 3 & 2 & 2 & . & 1 & 1 & 2 & . & $:$ & : \\
\hline Cretarhabdus angustiforatus & 1 & : & - & 5 & $i$ & 1 & . & i & : & : & 3 & . & . & 1 & 1 & . & 1 & 3 & . & . & . \\
\hline C. conicus & - & 1 & 1 & - & 1 & $i$ & $i$ & : & - & - & $i$ & i & 1 & $i$ & 3 & . & . & . & 1 & . & - \\
\hline C. crenulatus & $v^{\circ}$ & - & - & 1 & . & . & - & . & 1 & . & - & 1 & . & . & . & . & . & . & . & : & : \\
\hline C. schizobrachiatus & 2 & - & 1 & - & 1 & 5 & - & - & - & - & 1 & - & 1 & 1 & 2 & 2 & 1 & - & . & - & 2 \\
\hline C. surirellus & 4 & 9 & s & 5 & $i$ & 1 & 2 & 2 & 4 & s & 2 & 1 & . & & & . & & 1 & . & & \\
\hline Cretarhabdus spp. & 12 & 19 & 12 & 17 & 20 & 10 & s & 7 & 4 & 8 & 13 & 45 & 14 & 9 & 8 & 9 & 9 & i1 & 6 & 6 & 9 \\
\hline Cribrosphaerella(?) danlae & 3 & 1 & 1 & 1 & 2 & 1 & - & . & - & 1 & : & 1 & : & 2 & 2 & 2 & : & 5 & . & 2 & . \\
\hline Cribrosphaerella ehrenbergll & 13 & 25 & 30 & 30 & 19 & 7 & 22 & 18 & 19 & 5 & 19 & 21 & 15 & 20 & 23 & 27 & 36 & 18 & 14 & 9 & 16 \\
\hline Cruciplacolithus spp. & . & . & . & . & . & . & . & . & . & . & : & . & . & . & . & . & . & . & . & . & . \\
\hline Cyclagelopshaera alta & . & . & : & : & . & . & . & . & . & : & - & 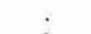 & . & . & . & . & . & . & . & . & : \\
\hline Cyclagelosphaera reinhardtil & . & - & - & - & . & . & . & - & . & - & 3 & - & . & 1 & . & . & : & : & : & . & • \\
\hline Cylindralithus gallicus & 3 & 6 & 4 & 4 & 10 & - & $s$ & 1 & 5 & - & $\cdot$ & 3 & 2 & 4 & 6 & 8 & s & • & 1 & $\cdot$ & 1 \\
\hline C. serratus & ; & $\dot{6}$ & 8 & 8 & ; & ; & $\therefore$ & $\dot{20}$ & $\dot{14}$ & 13 & is & $\dot{32}$ & $\dot{20}$ & io & 1 & is & is & in & ; & is & ;1 \\
\hline $\begin{array}{l}\text { Discorhabdus ignotus } \\
\text { Eiffellithus parallelus }\end{array}$ & $\begin{array}{l}5 \\
2\end{array}$ & $\begin{array}{l}6 \\
1\end{array}$ & $\begin{array}{l}8 \\
1\end{array}$ & $\begin{array}{l}8 \\
2\end{array}$ & $\begin{array}{l}9 \\
1\end{array}$ & $\begin{array}{l}4 \\
2\end{array}$ & $\begin{array}{l}13 \\
2\end{array}$ & $\frac{22}{7}$ & $\begin{array}{c}14 \\
3\end{array}$ & $\begin{array}{c}13 \\
6\end{array}$ & $\begin{array}{l}16 \\
20\end{array}$ & $\begin{array}{l}32 \\
41\end{array}$ & $\begin{array}{l}20 \\
16\end{array}$ & $\begin{array}{l}10 \\
14\end{array}$ & $\begin{array}{l}11 \\
12\end{array}$ & $\begin{array}{c}15 \\
5\end{array}$ & $\begin{array}{l}15 \\
8\end{array}$ & $\begin{array}{l}10 \\
12\end{array}$ & $\begin{array}{l}9 \\
5\end{array}$ & $\begin{array}{l}15 \\
20\end{array}$ & $\begin{array}{c}31 \\
6\end{array}$ \\
\hline $\begin{array}{l}\text { Eiffellithus parallelus } \\
\text { E. trabeculatus }\end{array}$ & $i$ & 5 & 2 & $i$ & 3 & . & 1 & & 6 & 5 & 2 & 2 & . & 2 & 3 & . & 3 & 1 & 2 & & 3 \\
\hline E. turriseiffell & 16 & 11 & 9 & 8 & 15 & i1 & 16 & 10 & 8 & 9 & 46 & 41 & 7 & 9 & 13 & 7 & 20 & 6 & 10 & 24 & 9 \\
\hline Ericsonla sp. & . & . & . & . & . & 2 & 2 & 1 & . & . & . & . & . & . & . & . & . & . & . & . & . \\
\hline Gartnerago spp. & $0^{\circ}$ & & . & . & . & - & 1 & - & 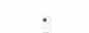 & - & . & - & . & - & : & . & . & . & . & : & \\
\hline Glaukolithus fessus & 3 & 8 & 20 & 4 & 17 & 8 & 7 & 9 & 5 & 6 & 10 & 14 & 1 & 1 & 2 & 2 & 6 & 5 & . & 4 & 5 \\
\hline Hexalithus spp. & - & $:$ & : & : & $\therefore$ & 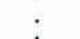 & $\therefore$ & 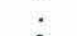 & : & : & : & $\therefore$ & . & : & : & : & : & : & ; & 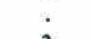 & \\
\hline Kamptnerius magnificus & i & $\cdot$ & $\dot{5}$ & $\dot{3}$ & $\dot{3}$ & 1 & 2 & 2 & 2 & 2 & 4 & 3 & 1 & 1 & 4 & 2 & 1 & $\dot{3}$ & 3 & 2 & 3 \\
\hline Lithastrinus spp. & 3 & . & & & 3 & 1 & 1 & 4 & 4 & 8 & 23 & 10 & 3 & 4 & 4 & . & 3 & 3 & 4 & 6 & \\
\hline
\end{tabular}


Sample-Depth (mbsf)

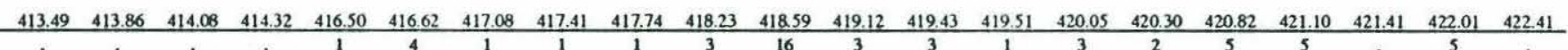

Lithraphidites carn

L grossopectinatus

L. quadratus

Lthraph. sp. ct. L. kennethi

Luclanorhabdus cayeuxil

Manivitella pemmatoldea

Markallus apertus
Markallus inversus

Microrhabdulus belgicus

M. decoratus

Micula murus

M. murus/prins
M. prinsil

M. swastlka

Micula? sp.

Neocrepidolithus spp.

Nephrolithus frequens

bussoni

P. bussoni

P. sigmoides

Podorhabdus regularis

Prediscosphaera cretacea

P. grandis
P. spinosa

P. stoveri

Prinslus tenuiculum

Quadrum gartneri

Reinhardtites levis

Rhagodiscus spp.

Rhombolithlon rhombicum

Rucinolithus hay

Scampanella asymmetrica

Scampanella spp.

Staurolithites laffittel

Stephanolithion spp.

egumentum stradnerl

Tetrapodostus dis

Thoracos

Thoraclospha

Vagalapilla spp.

Watznaueria barnesae

W. biporta

Zygodiscus lacunatus

Zygodiscus sp.1

Zygolithus diplogrammus Unidentiflable

Sum (excl. M. staurophora) M. staurophora - Fields

Micula staurophora

Sum of M. stauroph. count

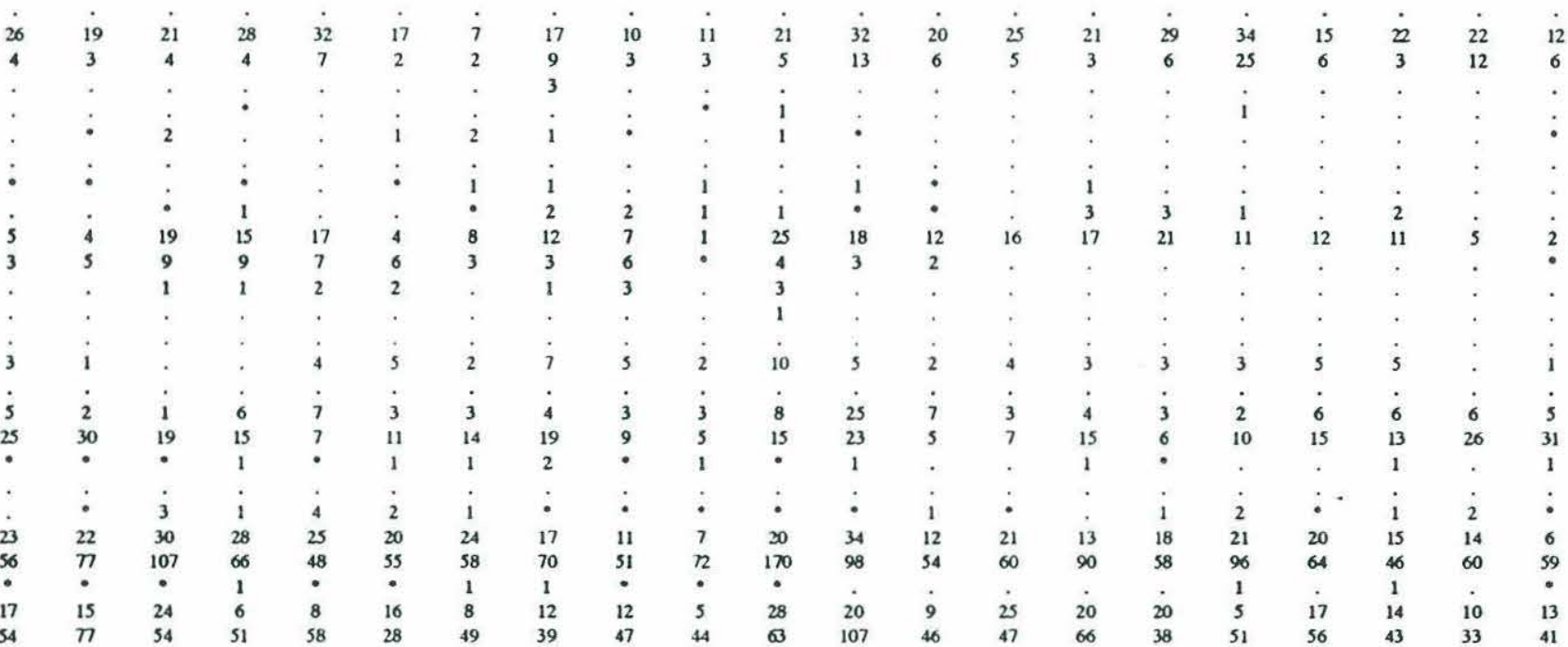




\begin{tabular}{|c|c|c|c|c|c|c|c|c|c|c|c|}
\hline \multicolumn{12}{|l|}{ Millers Ferry } \\
\hline Sample Number & 99 & 96 & 92 & 91 & 87 & 83 & 81 & 78 & 75 & 71 & 69 \\
\hline cm below/above $K / P$ boundary & .234 & -225 & -213 & -210 & -198 & -186 & -180 & -171 & -162 & -150 & -144 \\
\hline Preservation & G & $\mathrm{M}$ & M-P & M-G & M-G & $\mathrm{P}$ & G & P-M & $M-G$ & M-G & $M-G$ \\
\hline number of fields counted & 90 & 42 & 40 & 30 & 26 & 57 & 33 & 40 & 24 & 37 & 28 \\
\hline Angul ofenestrellithus snyderi & 1 & . & . & . & . & . & . & . & . & 1 & . \\
\hline Arkhangeskiella and Broinsonia spp. & 66 & 8 & 39 & 17 & 14 & 12 & 47 & 11 & 10 & 20 & 13 \\
\hline Biscutum constans & . & 2 & 3 & 1 & . & 1 & 1 & . & . & . & . \\
\hline B. magnum & - & . & . & . & . & . & . & . & . & . & . \\
\hline B. notaculum & . & 1 & . & . & . & . & . & . & 1 & . & . \\
\hline Biscutum sp. 1 & 8 & 4 & 2 & 1 & 1 & 2 & 3 & 1 & 2 & 1 & 1 \\
\hline Braarudosphaera bigelowii & . & : & . & . & . & . & . & 1 & . & . & 1 \\
\hline Ceratolithina kamptneri & 6 & 3 & . & . & . & . & . & . & . & . & . \\
\hline Chiastozygus amphipons & 10 & 2. & 3 & 5 & 7 & 5 & 6 & 9 & 8 & 6 & 20 \\
\hline C. garrisonii & . & . & . & 4 & . & 3 & 6 & 2 & . & . & 1 \\
\hline Chiastozygus sp. 1 & 2 & . & . & . & 3 & 1 & 2 & . & 2 & . & 1 \\
\hline Corollithion exiguum & 11 & 4 & . & 4 & 1 & 4 & 10 & 5 & 6 & 9 & 18 \\
\hline Cretarhabdus conicus & 18 & . & . & 1 & 1 & . & 2 & 2 & 7 & 5 & 8 \\
\hline C. crenulatus & 2 & . & . & . & . & . & . & . & . & . & . \\
\hline Cretarhabdus sp. 1 & - & . & . & . & . & . & - & . & . & . & . \\
\hline Cretarhabdus spp. indet. & . & 3 & 6 & 3 & 4 & 3 & 5 & 5 & 1 & 6 & 8 \\
\hline Cribrosphaerella? daniac & . & . & . & . & . & . & . & . & . & . & 2 \\
\hline C. ehrenbergil & 39 & 22 & 9 & 13 & 17 & 20 & 38 & 41 & 27 & 52 & 51 \\
\hline Cyclageiosphaera spp. & 1 & . & . & & . & . & . & . & . & . & 1 \\
\hline Cylindralithus spp. & 1 & 1 & . & & . & . & 2 & & 1 & 3 & 3 \\
\hline Discorhabdus ignouus & 63 & 25 & 7 & 13 & 11 & 11 & 10 & 8 & 6 & 15 & 22 \\
\hline Eiffellithus parallelus & 13 & 4 & 3 & 4 & 1 & 1 & 6 & 6 & 2 & 3 & 2 \\
\hline E. trabeculatus & 36 & 13 & 4 & 5 & 4 & 2 & 6 & . & 1 & 6 & 2 \\
\hline E. turriseiffelii & 47 & 15 & 13 & 16 & 15 & 12 & 26 & 13 & 10 & 17 & 16 \\
\hline Kamptnerius magnificus & 4 & . & . & 1 & . & . & . & . & . & . & . \\
\hline Lithraphidites camiolensis & 11 & 4 & 4 & . & . & . & 1 & & . & 1 & 1 \\
\hline L. grossopecunatus & 8 & 1 & . & 1 & 1 & . & . & 1 & 1 & 1 & 3 \\
\hline L praequadratus & 22 & 11 & 2 & 5 & 3 & 5 & 11 & 5 & 4 & 3 & 8 \\
\hline L. quadratus & 21 & 4 & . & . & 1 & . & 1 & 1 & 5 & 3 & 1 \\
\hline Lucianorhabdus cayeuxii & 1 & . & . & . & . & . & . & . & . & . & . \\
\hline Manivitella sp. & . & . & 1 & 3 & . & . & 4 & . & . & . & . \\
\hline Markalius inversus & . & . & . & 1 & . & . & . & . & . & . & . \\
\hline Marthasterites inconspicuus & 3 & 2 & . & . & . & . & . & $\dot{0}$ & : & & 1 \\
\hline Microrhabdulus belgicus & 5 & 2 & 1 & 4 & 2 & . & . & 2 & 4 & 1 & 2 \\
\hline M. decoratus & 2 & 2 & 1 & 1 & 4 & 6 & 3 & 6 & 4 & 4 & 7 \\
\hline Micula murus & . & . & . & & $?$ & . & $?$ & . & . & . & . \\
\hline M. prinsii & - & . & : & . & . & . & & . & . & & . \\
\hline Nephrolithus frequens & 2 & 1 & 3 & . & . & . & . & . & & . & . \\
\hline Parhabdolithus regularis & 23 & 11 & 3 & 2 & 2 & 3 & 3 & 5 & 7 & 13 & 10 \\
\hline Percivalia pontilithina & 4 & 3 & & 2 & . & . & 1 & . & . & & 3 \\
\hline Placozygus fibuliformis & 33 & 6 & 3 & 6 & 2 & 4 & 5 & 1 & 2 & 4 & 4 \\
\hline P. sigmoides & . & & & & . & . & & . & . & . & . \\
\hline Placozygus spp. indet. & . & 5 & 6 & 5 & 3 & 5 & 8 & . & 2 & . & 8 \\
\hline Prediscosphaera cretacea & 77 & 25 & 14 & 29 & 29 & 16 & 32 & 17 & 26 & 26 & 44 \\
\hline P. spinosa & 6 & 1 & . & 1 & 2 & 3 & 2 & 1 & 6 & 4 & 10 \\
\hline P. stoven & 125 & 62 & 80 & 84 & 67 & 51 & 43 & 113 & 86 & 36 & 86 \\
\hline Rhagodiscus angustus & 8 & 6 & 2 & 4 & 6 & 5 & 6 & 3 & 12 & 5 & 7 \\
\hline R. asper & . & . & . & : & . & $\dot{0}$ & : & . & . & : & . \\
\hline R. reniformis & 2 & 4 & . & 3 & 1 & 2 & 1 & . & . & 2 & . \\
\hline R. splendens & 5 & 5 & . & 1 & 3 & . & . & . & 3 & 2 & 3 \\
\hline Rhagodiscus spp. indet. & . & 2 & . & . & 1 & 1 & 1 & . & . & 1 & . \\
\hline Rhombolithium thombicum & 5 & 3 & . & 4 & 2 & 2 & . & . & . & 1 & 1 \\
\hline Staurolithites laffittei & 9 & 3 & 3 & 3 & 6 & 2 & 2 & . & 3 & 3 & 3 \\
\hline Stephanolithion app. & 18 & 13 & 5 & 7 & 5 & . & 1 & 3 & 2 & 2 & 16 \\
\hline Tetrapodorhabdus decorus & 5 & 2 & 1 & . & . & . & 1 & 2 & . & . & 2 \\
\hline Thoracosphaera spp. & 9 & 4 & 3 & 5 & 1 & . & 4 & . & 3 & 8 & 2 \\
\hline Tranolithus macieodac & 20 & 10 & . & 1 & 3 & 4 & 5 & 4 & 7 & 2 & 3 \\
\hline Vagalapilla spp. & 34 & 13 & 1 & 2 & 4 & 1 & 8 & 1 & 3 & 1 & 3 \\
\hline Watz, bamesae & 110 & 36 & 19 & 31 & 44 & 28 & 29 & 41 & 56 & 60 & 120 \\
\hline Zygodiscus diplogrammmus & 2 & . & . & . & . & . & . & . & . & , & . \\
\hline $\mathrm{Z}$ lacunatus & . & . & . & . & . & . & . & . & . & . & . \\
\hline Unidentifiable & 11 & 11 & 10 & 9 & 15 & 27 & 10 & 14 & 2 & 27 & 7 \\
\hline Sum (excl. M. staurophora) & 909 & 359 & 251 & 302 & 286 & 242 & 352 & 324 & 322 & 354 & 525 \\
\hline Micula staurophora & 247 & 75 & 92 & 57 & 69 & 111 & 50 & 38 & 33 & 27 & 20 \\
\hline Sum (incl. M. staurophora) & 1156 & 434 & 343 & 359 & 355 & 353 & 402 & 362 & 355 & 381 & 545 \\
\hline
\end{tabular}


Millers Ferry

Sample Number

cm below/above K/P boundary

$\begin{array}{cccccc}66 & 63 & 58 & 54 & 51 & 48 \\ -135 & -123 & -111 & -99 & -90 & -8 \\ \text { P.M } & \text { M-G } & \text { M-G } & \text { P } & \text { M-G } & \text { M }\end{array}$

Preservation

number of fieids counted

$\begin{array}{ccccccc}M-G & M & P & P-M & M & M & -60\end{array}$

Angul ofenestrellithus snyderi

\begin{tabular}{|c|c|c|c|c|c|c|c|c|c|c|}
\hline 40 & 18 & 21 & 55 & 39 & 45 & 91 & 64 & 43 & 36 & 52 \\
\hline . & 1 & . & . & 1 & . & . & . & 1 & . & . \\
\hline 27 & 18 & 12 & 25 & 19 & 9 & 18 & 17 & 24 & 21 & 23 \\
\hline
\end{tabular}

Biscutum constans

B. magnum

B. notaculum

Biscutum sp. 1

Branudosphaera bigelowii

Ceratolithima kamptneri

Chiastozygus amphipons

C. garrisonii

Chiastozygus sp. 1

Corollithion exiguum

Cretarhabdus conicus

C. crenulatus

Cretarhabdus sp. 1

Cretartuabdus spp. indet.

Cribrosphaerella? daniae

C. ehrenbergil

Cyclagelosphaera spp.

Cylindralithus spp.

Discorthabdus ignotus

Eiffellithus parallelus

E trabeculatus

E turriseiffelii

Kampenerius magnificus

Lithraphidites carniolensis

L grossopectumatus

L praequadratus

L. quadratus

Lucianorhabdus cayeuxii

Manivitella sp.

Markalius inversus

Marthastentes inconspicuus

Microrhabdulus belgicus

M. decoratus

Micula murus

M. prinsii

Nephrolithus frequens

Parhabdolithus regularis

Percivalıa pontilithina

Placozygus fibuliformis

P. sigmoides

Placozygus spp. indet.

Prediscos phaera cretacea

P. spinosa

P. stover

Rhagodiscus angustus

R. asper

$R$. reniformis

$R$ splendens

Rhagodiscus spp. indet.

Rhombolithium thombiam

Staurolithites laffittei

Stephanolithion spp.

Tetrapodortabdus decorus

Thoracosphaera spp.

Tranolithus macieodae

Vagalapilla spp.

Watz. barnesae

Zygodiscus diplogrammmus

Z. lacuratus

Unidentifiable

Sum (excl. M. staurophora)

Micula staurophora

Sum (incl. M. staurophora)

12




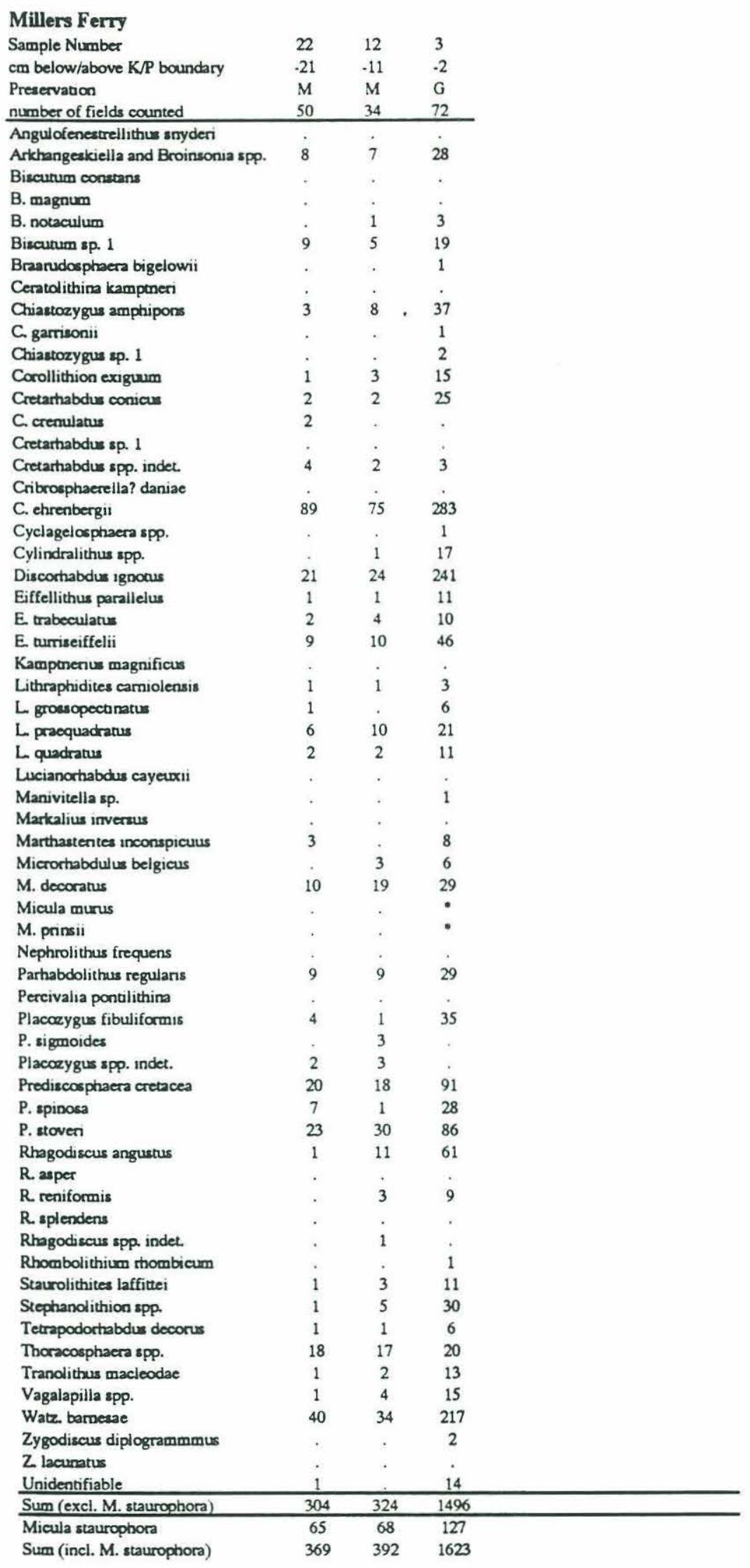




\section{Curriculum Vitae}

Thomas Ehrendorfer

Woods Hole Oceanographic Institution

Department of Geology and Geophysics

Woods Hole, Massachusetts 02543

U.S.A. after 01-March-1993:

University College London

Department of Geological Sciences

Gower Street, London WC1E 6BT

United Kingdom

\section{EDUCATION}

1982-1987: study of earth sciences at the University of Vienna, Austria; major: Geology

since July 1987: graduate student in Woods Hole Oceanographic Institution/Massachusetts Institute of Technology Joint Program in Oceanography, Department of Geology and Geophysics; specialization in micropaleontology (calcareous nannoplankton).

\section{PROFESSIONAL EXPERIENCE}

August 1984: summer job at the Austrian Petroleum Administration (ÖMV), sedimentology laboratory

summer 1985: field mapping for the Austrian Petroleum Administration (ÖMV)

summer 1986: field mapping for the Geological Survey of Austria

\section{HONORS AND AWARDS}

1981: graduated from high scool with distinction, was awarded the 'Golden Needle' for passing every year in high school with distinction

1985, 1986, 1987: received a 'Stipend for the Gifted' from the University of Vienna for outstanding study success

1990: AAPG Grant-in-Aid

1991: grant from the Ocean Ventures Fund at the Woods Hole Oceanographic Institution

1991: Research Grant-in-Aid from the Paleontological Society

1992: Grant-in-Aid of Research from the Sigma Xi Society

\section{PUBLICATIONS}

Ehrendorfer, T., 1988. Zur Geologie der Weyerer Bögen im Gebiet von Großraming an der Enns (O.Ö.). Mitt. Ges. Geol. Bergbaustud. Österr. 34/35, 135-149.

Ehrendorfer, T. W., Lea, D. W., and Boyle, E. A., 1989. Strontium/Calcium Ratios in Benthic Foraminifera at the Miocene/Pliocene Boundary. TERRA abstracts $\underline{1}$ (Abstracts of Third International Conference on Paleo-Oceanography), 65.

Ehrendorfer, T., and Aubry, M.-P., 1992. Calcareous Nannoplankton Changes Across the Cretaceous/Paleocene Boundary in the Southern Indian Ocean (Site 750). In: Wise, S. W., Jr., Schlich, R., et al., 1992. Proc. ODP, Sci. Results, 120: College Station, TX (Ocean Drilling Program), 451-470.

Ehrendorfer, T., 1992. Diversity changes in the calcareous nannoplankton during the Maestrichtian in southern high latitudes (ODP Hole 690C, Maud Rise, Weddell Sea). GSA Annual Meeting, Cincinnati, Abstracts w. Programs, A361.

Ehrendorfer, T., in press. Nephrolithus frequens GORKA and its Morphotypes. Iournal of Paleontology.

Olsson, R. K., Liu, C., Aubry, M.-P., and Ehrendorfer, T., 1992. A biostratigraphically continuous Cretaceous/Paleocene section at Millers Ferry, Alabama: support for a bolide impact. GSA Annual Meeting, Cincinnati, Abstracts w. Programs, A28. 